INSTITUTO DE AGROQUÍMICA Y TECNOLOGÍA DE ALIMENTOS (IATA-CSIC) Grupo de Nuevos Materiales y Nanotecnología
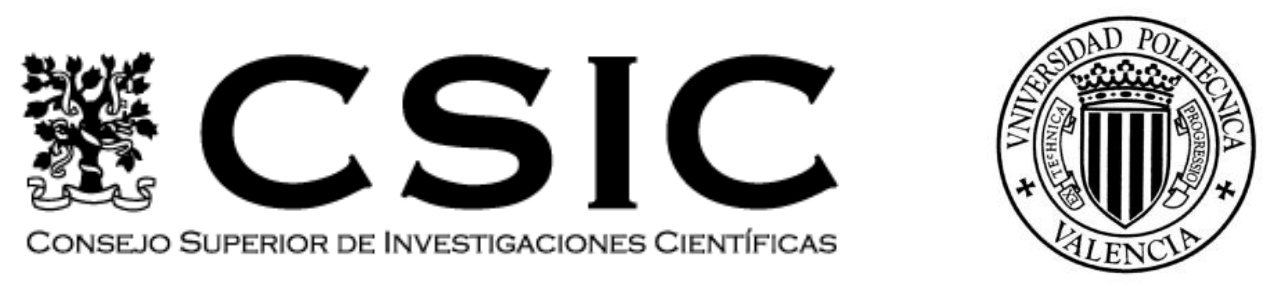

\title{
BACTERIAL CELLULOSE NANOWHISKERS TO \\ ENHANCE THE PROPERTIES OF PLASTICS AND BIOPLASTICS OF INTEREST IN FOOD
}

PACKAGING

\author{
DOCTORAL THESIS \\ Presented by: Marta Martínez Sanz \\ Supervised by: José María Lagarón Cabello \\ Amparo López Rubio
}

Valencia, June 2013 

A groan of tedium escapes me,

Startling the fearful.

Is this a test? It has to 6e,

Otherwise I can't go on.

Draining patience, drain vitality.

This paranoid, paralyzed vampire act's a little old.

But I'm still right here

Giving 6lood, keeping faith

And I'm still right here.

Wait it out,

Gonna wait it out,

Be patient (wait it out).

If there were no rewards to reap,

$\mathcal{N}$ o loving embrace to see me through

This tedious path I've chosen here,

I certainly would've walked away by now.

Gonna wait it out.

If there were no desire to heal

The damaged and broken met along

This tedious path I've chosen here

I certainly would've walked away by now.

And I still may ... I still may.

TOOL, "The Patient"

...A mi padre... 

Tras más de cuatro años de trabajo, ha llegado el momento. No sólo se trata del final de mi tesis, si no tambien del final de una etapa en mi vida. Siempre me pareció que este momento estaba muy lejos y que tardaría en llegar. Pero lo cierto es, que al final del camino, parece que este tiempo ha pasado en un suspiro. De estos años me llevo muchas cosas: he aprendido muchísimo tanto a nivel profesional, como a nivel personal, he tenido la oportunidad de trabajar con gente excepcional y además, me llevo grandes amigos. Llegado este momento, me gustaría dar las gracias a todas las personas que han estado a mi lado y $\sin$ las que esta tesis no habría sido posible.

En primer lugar, me gustaría agradecer a mis directores de tesis, Chema y Amparo, por confiar en mi y darme la oportunidad de haber trabajado con ellos. Gracias a Chema, porque con su alto nivel de exigencia, ha hecho que cada día me superara más y más y que no dudara en perseguir mis metas aunque parecieran muy difíciles. Creo que muy pocos becarios tienen la oportunidad de enfrentarse a tantos retos, con tanta libertad como lo hacemos en este grupo, y por eso estoy tremendamente agradecida. Ampi, sobra decir que no sólo eres una excelente científica, sino que además tienes la paciencia y las ganas para transmitir tus conocimientos y motivar a todo el mundo. Quería darte las gracias porque has sido mi apoyo fundamental en el laboratorio durante estos años y a parte de mi directora de tesis, te has convertido en mi amiga. En cierto modo si yo estoy hoy aquí presentando mi tesis, es gracias a ti, tanto porque me abriste la puerta cuando no sabía qué hacer con mi futuro, como porque me has ayudado a cerrar esta etapa y empezar una nueva en Australia. Podría llenar una página entera con mis agradecimientos para ti... pero sólo te diré que eres MUY GRANDE!

Por supuesto, también me gustaría dar las gracias a todos los que fueron y son mis compañeros de lab, que son "lo más". Para mi, ir a trabajar nunca ha sido un suplicio y esto ha sido gracias a la gente con la que he trabajado (y convivido) durante este tiempo. Recuerdo los inicios de mi tesis, en el lab 106. Richard fue mi "maestro jedi" de la celulosa, que supo transmitirme sus conocimientos y empujarme a iniciar mi tesis con muchísimas ganas e ilusión. Ajo, gracias por tu ayuda, jamás había trabajado con bacterias y sin tu ayuda no podría haber afrontado los inicios de mi tesis. Gracias también por tus consejos y tu apoyo durante estos años. Chicos del 106, Merche (Zipi), Sergi (Chechi/Powder), Lola, Carla... creo que nunca me lo he pasado tan bien trabajando, fue una época de muchas risas y buen rollo en el lab. Gracias a vosotros guardo en mi memoria momentos únicos del inicio de la tesis que jamás olvidaré. Mer, gracias por convertirte en mi amiga, por las risas que nos hemos echado y las conversaciones (tanto en los buenos momentos como en los malos), así como por tu ayuda con la "sepia-celulosa". No puedo decir menos de mis compis del 502, Rocío, Jesús, Pablo, María José, Gloria, Wilson, Paula... porque formamos una piña, nos apoyamos los unos a los otros y aún en los momentos más "chungos" conseguimos verlo todo con una sonrisa. De verdad, sois los mejores, me llevo grandes recuerdos con vosotros. iOS QUIERO MIL! Antonio, a ti no te he puesto porque en realidad me caes mal... jajaja. En serio, gracias por soportarme como tu compi todo este tiempo, sé que a veces soy cansina y me meto mucho contigo, pero ya me conoces (soy un cuatro) y sabes que eso es porque quizás contigo tengo más confianza y te aprecio muchísimo! No sé si podría haber hecho mi tesis sin tus zarandeos diarios. Gracias a todos aquellos que en algún momento han pasado por el lab y que también han dejado su huella: Adriana, María, Begoña, Rafa, Roxane y Noëlle (merci, porque una parte de esta tesis también es vuestra), Marysol (que desde la distancia me ha seguido dando ánimos en los 
momentos más malos) y todos los chicos de prácticas. Gracias también a las chicas de NBM (María, Sabina, Patri) y a la gente de la UJI (en especial a Lluis), tanto por su contribución a esta tesis como por los momentos de risas fuera del trabajo. A los técnicos del SCSIE, en especial MariTere y Pilar, gracias por siempre estar dispuestas a ayudar durante las largas sesiones de SEM y TEM.

También quiero dar las gracias a la gente que tuve la suerte de conocer durante mi estancia en California (Syed, Bill, Cris, Mohamed, Tina, De, Bor-Sen, Wen, Artur...), porque fue un placer trabajar con ellos y porque me ayudaron a sentirme como en mi casa aún estando tan lejos.

Por último, agradecer a todas esas personas que están en mi vida desde hace mucho tiempo y que también han sido para mi, un apoyo fundamental. Beg, Vero, Héctor y Jose, gracias de corazón, porque gracias a vosotros he conseguido sonreir en momentos muy duros, he conseguido relajarme en los días más estresantes y siempre habéis estado ahí. Os quiero! David, que sepas que en este mundo existen muy pocas personas como tú y me siento muy afortunada de haberte conocido. Gracias por tus consejos, porque después de hablar contigo no veo las cosas tan negras... no sé cómo lo haces, pero siempre sabes cómo ayudar a los demás! Gracias también por tu revisión de la tesis, has sido el único fuera del ámbito de trabajo que se ha leído este tocho. Gracias también a mi familia, en especial a mis tíos Pepe, Consu, Boro, Ana y Rosa y a mis primas Ana y Eva, que se han preocupado por mi y han intentado animarme siempre. A mis padres, que son los que más me han sufrido y me han apoyado incondicionalmente. Mamá, gracias por tus ánimos, por siempre estar dispuesta a ayudarme y porque tienes una fuerza extraordinaria que siempre me ha inspirado a perseguir mis metas. Papá, aunque te quejes de que no te hago caso, eres mi ejemplo a seguir, si estoy aquí es gracias a tus consejos y opiniones que, aunque no siempre han sido lo que quería oir, me han hecho crecer como persona. Para mi eres la definición de una persona luchadora, pocos tienen tu fuerza y estoy orgullosa de ti. Juanfran, qué te voy a decir a ti... GRACIAS porque sé que estos años no han sido fáciles, siempre te has esforzado y has conseguido levantarme todas y cada una de las veces que me he caído (que no han sido pocas), has sido capaz de ilusionarme, has sido mi colega número uno, me has hecho reir como nadie y me has ayudado a crecer como persona... en definitiva, gracias por estar conmigo a lo largo de este "epic journey", que ahora vamos a continuar en Australia. 


\begin{abstract}
The present work aims to study the application of cellulose nanowhiskers extracted from bacterial cellulose by acid hydrolysis (BCNW) for the development of polymeric and biopolymeric materials with enhanced properties for their use in food packaging applications.

In first place, the extraction process of BCNW was studied and optimized. An extraction procedure with sulphuric acid, which allowed obtaining nanocrystals with high aspect ratio and crystallinity and, at the same time, high extraction yields, was developed. This extraction procedure also comprises a subsequent neutralization step which was seen to be necessary to guarantee the nanocrystals' thermal stability.
\end{abstract}

The next step consisted in the formulation of nanocomposite materials with improved properties by incorporating $\mathrm{BCNW}$ into different plastic matrices, specifically into ethylene vinyl alcohol copolymer (EVOH), polylactic acid (PLA) and polyhydroxyalkanoates (PHAs). Hybrid EVOH and PLA fibres loaded with BCNW were generated by means of the electrospinning and blow spinning techniques. The incorporation of BCNW in the solutions used to produce fibres significantly modified their properties (viscosity, surface tension and conductivity) and, therefore, the morphology of fibres was affected. Additionally, fibres with antimicrobial properties were generated by incorporating additives and the antimicrobial effect was maximized with the addition of hydrophilic substances. Subsequently, nanocomposites were produced by melt compounding and methods for the pre-incorporation of $\mathrm{BCNW}$ were developed, thus avoiding the agglomeration of BCNW not only in hydrophilic matrices such as EVOH but also in hydrophobic matrices such as PLA. The optimized dispersion of BCNW resulted in improved mechanical and barrier properties for the nanocomposites. Moreover, the surface modification of the nanocrystals by graft copolymerization with poly(glycidyl methacrylate), to enhance the compatibility of BCNW with a hydrophobic matrix as PLA, was studied. Furthermore, the first results obtained in relation to the production of nanobiocomposites synthesized by microorganisms, consisting in PHAs with different valerate contents reinforced with $\mathrm{BCNW}$, are also included.

Finally, high barrier films based on BCNW coated with hydrophobic layers were developed. Coating by fibre deposition through electrospinning followed by homogenization through annealing guaranteed a good adhesion between the different layers, hence protecting the BCNW films from the negative effect of moisture. 



\section{RESUMEN}

El presente trabajo tiene por objetivo estudiar las aplicaciones de los nanocristales o "nanowhiskers" extraídos mediante hidrólisis ácida de celulosa bacteriana (BCNW) para el desarrollo de materiales poliméricos y biopoliméricos con propiedades mejoradas para su uso en aplicaciones de envasado de alimentos.

En primer lugar se estudió y optimizó el proceso de extracción de BCNW. Se desarrolló un procedimiento de extracción con ácido sulfúrico, que permitió obtener nanocristales con elevada relación de aspecto y cristalinidad y al mismo tiempo, un elevado rendimiento de extracción. Este procedimiento comprende una posterior etapa de neutralización que resultó ser necesaria para garantizar la estabilidad térmica de los nanocristales.

El siguiente paso consistió en la formulación de materiales nanocompuestos con propiedades mejoradas incorporando $\mathrm{BCNW}$ en diferentes matrices plásticas, en concreto copolímeros de etileno-alcohol vinílico (EVOH), ácido poliláctico (PLA) y polihidroxialcanoatos (PHAs). Mediante las técnicas de electroestirado y estirado por soplado se generaron fibras híbridas de EVOH y PLA con BCNW. La incorporación de BCNW en las disoluciones empleadas para producir fibras modificó significativamente sus propiedades (viscosidad, tensión superficial y conductividad) y por tanto, la morfología de las fibras se vio afectada. Además, se generaron fibras con propiedades antimicrobianas mediante la incorporación de aditivos, maximizando el efecto antimicrobiano con la adición de sustancias de carácter hidrofílico. Seguidamente, se produjeron nanocompuestos por mezclado en fundido y se desarrollaron técnicas de preincorporación de BCNW para evitar la aglomeración de los mismos no sólo en matrices hidrofílicas como el EVOH, sino también en matrices hidrofóbicas como el PLA. La dispersión óptima de BCNW resultó en una mejora de las propiedades mecánicas y de barrera de los nanocompuestos. También se estudió la modificación de la superficie de los nanocristales mediante copolimerización con poli(glicidil metacrilato) para mejorar la compatibilidad de BCNW con una matriz hidrofóbica como el PLA. Se incluyen además los primeros resultados obtenidos en cuanto a la producción de nanobiocompuestos sintetizados por microorganismos, que consisten en PHAs con diferentes contenidos de hidroxivalerato reforzados con BCNW.

Por último, se desarrollaron películas con propiedades de alta barrera basadas en películas de BCNW recubiertas con capas hidrofóbicas. El recubrimiento mediante la deposición de fibras por electrospinning seguido de homogeneización por calentamiento garantizó una buena adhesión entre las diferentes capas, protegiendo así las películas de BCNW del efecto negativo de la humedad. 



\section{RESUM}

El present treball té per objectiu estudiar les aplicacions dels nanocristals o "nanowhiskers" extrets mitjançant hidròlisi àcida de cel·lulosa bacteriana (BCNW) per al desenvolupament de materials polimèrics i biopolimèrics amb propietats millorades per al seu ús en aplicacions d'envasament d'aliments.

En primer lloc es va estudiar i es va optimitzar el procés d'extracció de BCNW. Es va desenvolupar un procediment d'extracció amb àcid sulfúric que va permetre obtenir nanocristals amb elevada relació d'aspecte i cristal·linitat i al mateix temps, un elevat rendiment d'extracció. Aquest procediment comprèn una etapa posterior de neutralització que va resultar ser necessària per garantir l'estabilitat tèrmica dels nanocristalls.

El següent pas va consistir en la formulació de materials nanocompostos amb propietats millorades incorporant $\mathrm{BCNW}$ en diferents matrius plàstiques, en concret copolímers d'etilèalcohol vinílic (EVOH), àcid polilàctic (PLA) i polihidroxialcanoats (PHAs). Mitjançant les tècniques de electroestiratge ("electrospinning") i estiratge per bufat ("blow spinning") es van generar fibres híbrides de EVOH i PLA amb BCNW. La incorporació de BCNW en les dissolucions emprades per produir fibres va modificar significativament les seues propietats (viscositat, tensió superficial i conductivitat) i per tant, la morfologia de les fibres es va veure afectada. A més, es van generar fibres amb propietats antimicrobianes amb l'addició de substàncies de caràcter hidròfil. Seguidament, es van produir nanocompostos mitjançant barrejat en fos i es van desenvolupar tècniques de pre-incorporació de BCNW per evitar l'aglomeració dels mateixos no només en matrius hidròfiles com el EVOH, sinó també en matrius hidròfobes com el PLA. La dispersió òptima de BCNW va resultar en una millora de les propietats mecàniques i de barrera dels nanocompostos. També es va estudiar la modificació de la superfície dels nanocristals mitjançant copolimerització amb poli(glicidil metacrilat) per millorar la compatibilitat dels BCNW amb una matriu hidròfoba com el PLA. S'inclouen a més els primers resultats obtinguts quant a la producció de nanobiocompostos sintetitzats per microorganismes, que consisteixen en PHAs amb diferents continguts de hidroxivalerat reforçats amb BCNW.

Finalment, es van desenvolupar pel·lícules amb propietats d'alta barrera basades en pel·lícules de BCNW recobertes amb capes hidròfobes. El recobriment mitjançant la deposició de fibres per electroestiratge seguit d'homogeneïtzació per escalfament, va garantir una bona adhesió entre les diferents capes, protegint així les pel·lícules de BCNW de l'efecte negatiu de la humitat. 

I. Introduction............................................................................................................................. 1

1. Polymers in food packaging applications.............................. 1

1.1. Advantages and drawbacks of polymers for food packaging............................................................... 1

1.2. Bio-based (renewable) polymers.............................. 4

2. Nanocomposite polymeric materials........................................ 7

2.1. Electrospinning and solution blow spinning as novel techniques for the production of nanocomposite polymeric materials................ 10

3. Cellulose as a source of crystalline nanofillers............................ 12

3.1. Structural characteristics of cellulose............................... 13

3.2. Bacterial cellulose versus plant cellulose............................ 14

4. Extraction of cellulose nanowhiskers....................................... 15

4.1. Extraction of cellulose nanowhiskers by hydrolysis with sulphuric acid................................................................ 16

5. Nanocomposites containing cellulose nanowhiskers...................... 18

5.1. Surface modification of cellulose nanofillers....................... 19

5.2. Nanocomposites produced by solution casting.................... 21

5.3. Nanocomposites produced by melt compounding................... 23

References................................................................... 26

II. Objectives.......................................................................................... 41

1. General and specific objectives...................................... 41

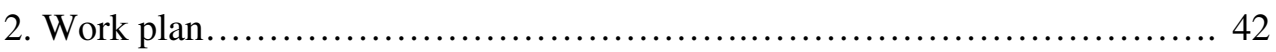

III. Results and discussion............................................................................. 45

1. General introduction to results....................................... 45

-Chapter I. Development of electrospun EVOH fibres reinforced with bacterial cellulose nanowhiskers. Part I: Characterization and method optimization. 
-Chapter II. Development of bacterial cellulose nanowhiskers reinforced EVOH composites by electrospinning.

-Chapter III. Optimization of the nanofabrication by acid hydrolysis of bacterial cellulose nanowhiskers.

-Chapter IV. Nanocomposites of ethylene vinyl alcohol copolymer with thermally resistant cellulose nanowhiskers by melt compounding (I): Morphology and thermal properties. 161

-Chapter V. Nanocomposites of ethylene vinyl alcohol copolymer with thermally resistant cellulose nanowhiskers by melt compounding (II): Water barrier and mechanical properties................................................. 207

-Chapter VI. Dispersing bacterial cellulose nanowhiskers in polylactides via electrohydrodynamic processing. 251

-Chapter VII. Optimization of the dispersion of unmodified bacterial cellulose nanowhiskers into polylactide via melt compounding to significantly enhance barrier and mechanical properties...................................... 293

-Chapter VIII. High-barrier coated bacterial cellulose nanowhiskers films with reduced moisture sensitivity........................................... 347

-Chapter IX. Incorporation of poly(glycidyl methacrylate) grafted bacterial cellulose nanowhiskers in poly(lactic acid) nanocomposites: Improved barrier and mechanical properties.

-Chapter X. Antimicrobial PLA-based nanofibres developed by solution blow spinning....

-Chapter XI. Characterization of polyhydroxyalkanoates synthesized from microbial mixed cultures and of their nanobiocomposites with bacterial cellulose nanowhiskers.

IV. Conclusions. 
I . INTRODUCTION 



\section{POLYMERS IN FOOD PACKAGING APPLICATIONS}

Packaging is nowadays one of the most powerful industrial sectors and it plays an essential role in consumers' everyday life. In particular, food packaging represents $60 \%$ of the European packaging market (according to data provided by Global Packaging Alliance, 2012). Food packages were traditionally intended to be merely containers in which foodstuffs were transported from the place where they were produced to the place of retail or consumption. However, food packages have evolved, mostly during the last few decades, to have new functions and, nowadays, they are considered to be just as important as the packed food product. Amongst the several functions of food packing, the most important ones are the physical and barrier protection, ensuring food quality and safety and information transmission (nutritional information, disposability and recyclability, etc). An ideal package should be strong and light to facilitate handling throughout the distribution chain, cheap enough to make the product competitive and, obviously, safe for the consumer. The extremely demanding markets of the developed countries are permanently asking for novel, sophisticated, ready-to-eat and stable products which retain, to the greatest extent possible, the taste of the fresh product. Furthermore, current trends in the food packaging industry are the development of active or intelligent packaging to extend the shelf life of the product and to monitor its freshness or any other quality-related parameter, as well as the use of "green" packaging materials, which are environmentally friendly.

\subsection{Advantages and drawbacks of polymers for food packaging}

Although materials such as glass, metal and cardboard have been traditionally used in food packaging, the use of plastic materials has been growing continuously and, currently, plastic and paper represent the two major food packaging materials. Plastics or polymeric materials present a clear advantage over 
other conventional packaging materials. Some of their most important advantages include the versatility of their processing methods, the wide variety of materials and compositions available and their interesting cost/performance ratios. Other relevant properties of polymers are their lightness, reduced cost, the possibility of blending/modification and printing and thermo-welding ability. The optical properties of the package can also be adapted to the specific requirements of each product. Transparent packages allow the consumer to see the product, which in most cases produces a good impression. However, in some cases it may be interesting to produce packages which are opaque at a certain wavelength to protect the product from damage caused by light. Thermal and mechanical properties of polymeric materials may be also modified within a certain range, producing from very flexible structures used to manufacture bags and wrappings, to rigid structures which are used for bottles, lids and caps. Moreover, polymeric packages can be produced as part of integrated processes where they are formed, filled and sealed in the same production line, making the process quick and cheap.

It would therefore seem perfectly possible to design a suitable polymeric package for almost every foodstuff. The situation is such that a polymer-based option is available for almost every product and only social and environmental aspects or the cost of the package justify the use of non-polymeric materials. One of the main drawbacks of polymers for food packaging applications is that they are permeable to the transport of low molecular weight compounds, leading to food oxidation by penetration of oxygen, migration of toxic elements from the plastic and scalping of food components of the packaging with the consequent losses in food quality and safety attributes. To overcome these issues, high barrier polymers such as ethylene vinyl alcohol copolymers (EVOH), polyamides (PA) and polyketone (PK) copolymers (aliphatic polyketones) were developed and widely studied during the last decade. In particular, the widely used EVOH copolymers are 
a family of semi-crystalline materials with excellent barrier properties to oxygen and organic compounds along with high chemical resistance and high transparency (Lagaron et al., 2001). The excellent barrier properties of EVOH copolymers derive from their high degree of crystallinity and from the presence of hydroxyl groups in the polymer structure which confer them both high inter- and intramolecular cohesive energy and a low fractional free volume between the polymer chains available for the mass exchange of low molecular weight substances. On the other hand, these hydroxyl groups make these materials highly hydrophilic, so that in high relative humidity conditions, their barrier and mechanical performance is greatly reduced (Iwanami \& Hirai, 1983). Blending of EVOH with less moisture sensitive materials such as amorphous polyamide was suggested as a strategy to improve the barrier performance of these materials even at high relative humidity conditions (Lopez-Rubio \& Lagaron, 2008). Nevertheless, as a result of the strong self-association, EVOH copolymers do not have a good compatibility with other polymers (Coleman et al., 1993). Therefore, EVOH is commonly found as an intermediate layer in co-extruded multilayer structures protected by, at least, two layers of hydrophobic materials such as polyolefins.

Thus, for the packaging of oxygen-sensitive food products, as most commodity plastic packaging materials do not present sufficient barrier to this gas, multilayer structures are normally used. These structures consist of an intermediate high barrier layer, protected by, generally, hydrophobic polymeric layers, such as polyolefins, in which the inner layer must be chemically inert and thermosealable and the outer layer should provide mechanical resistance, a certain barrier to gases and aromas and is normally printable. As an alternative to polymer blending and multilayer systems, the development of nanocomposites represents an efficient technology to produce monolayer materials with improved barrier properties, as it will be further discussed within section 2 (cf. pages 7-12). 
The other major disadvantage of polymers is that conventional plastic materials are synthesized from petroleum resources and their lack of biodegradability and renewability gives rise to severe environmental and economic concerns. Although package stability during the shelf-life of a product is an advantage, this turns into a disadvantage when the packages are rarely reused or recycled and they generate huge volumes of waste. This problem has been attenuated by the development and improvement of recycling systems in many developed countries, but it is believed that it can only be completely solved by the introduction throughout the industry of biodegradable polymers which are obtained from renewable resources. As a result, many efforts have been focused over the last decades to develop and optimize sustainable biodegradable and/or biobased polymeric materials.

\subsection{Bio-based (renewable) polymers}

Biodegradable polymers are defined as materials which are able to undergo decomposition into carbon dioxide, methane, water, inorganic compounds or biomass as a result of being exposed to the enzymatic action of microorganisms (ASTM International, 2010). On the other hand, biopolymers or bio-based polymers are those extracted from renewable resources (for example, starch, cellulose, chitosan, zein, etc), polymerized from renewable monomers (such as poly(lactic acid) (PLA)), or directly synthesized by microorganisms or bacteria (for example, polyhydroxyalkanoates (PHAs) and bacterial cellulose). Although most bio-based polymers are biodegradable, not all the biodegradable polymers are necessarily bio-based; for example, poly(vinyl alcohol) (PVOH) and ethylene vinyl alcohol copolymers $(\mathrm{EVOH})$ are petroleum-based polymers which can biodegrade under certain conditions (Betty Lucy López et al., 1999; Mejía G et al., 2001). Biodegradable polymers represent a possible solution for reducing the amount of 
plastic waste generated by the packaging sector. On the other hand, the use of renewable resources may be interesting from both an environmental and economic point of view as petroleum resources are finite. Amongst the several biopolymers which have been developed and studied during the last years, biopolyesters such as PLA and PHAs have attracted special interest since they present promising properties and they can be processed by conventional processing equipment. These materials are being used in a number of monolayer and also multilayer applications, particularly in the food packaging and biomedical field.

PLA is a biodegradable, aliphatic biopolyester produced from L- and Dlactic acid, which can be derived from fermentation of natural resources such as corn or sugarcane (Auras et al., 2004b; Drumright et al., 2000; Lunt, 1998). It is one of the most widely used and well-studied bio-based polymers, which is already commercially available. PLA has already been used to produce thermoformed trays which may be found in the market for packaging of ready-to-eat meals or salads. It is highly transparent and rigid, with mechanical properties comparable to poly(ethylene terephthalate) (PET) (Auras et al., 2004a). Nevertheless, this material still presents some drawbacks such as low thermal resistance, excessive brittleness, relatively low heat distortion temperature and relatively low barrier to oxygen and water vapour as compared to other benchmark packaging materials such as PET.

PHAs are a family of biopolyesters produced by a wide variety of bacteria as carbon and energy storage materials (Lundgren et al., 1965). Within this range of materials, the homopolymer poly-3-hydroxybutyrate (PHB) has been more extensively studied since it presents mechanical properties similar to those of conventional petroleum-based polymers. In addition, this material possesses a relatively high melting and glass transition temperature (Choi \& Park, 2004; 
Mitomo et al., 1999), as well as great stiffness since it possesses a relatively high crystallinity (Barham et al., 1984). However, this material presents limited applicability due to its excessive brittleness and low thermal stability, which makes it unstable during melt processing. To overcome these issues, PHB has been typically blended with other polymers such as polyvinyl alcohol (PVA) (Yoshie et al., 1995) or poly(ethylene oxide) (PEO) (You et al., 2003), but alternatively it can be plasticized by incorporating different monomer types during bacterial fermentation. Copolymers of hydroxybutyrate (HB) with hydroxyvalerate (HV), i.e. PHBV, present lower crystallinity (Serafim et al., 2008), and therefore, decreased stiffness and brittleness. Additionally, the incorporation of hydroxyvalerate units results in reduced melting temperature without reducing the thermal stability of the material (Chen \& Wang, 2002; Feng et al., 2002), hence widening the processing window of the material. On the other hand, a decrease on the crystallinity is known to impair the barrier properties of polymeric materials, which might be a disadvantage for the use of PHBV in packaging applications. An additional concern is related to the high operational costs associated to the PHAs production due to the use of expensive pure substrates and the requirement of sterile conditions and extensive reactor maintenance (Moita \& Lemos, 2012). The use of microbial mixed cultures, which are selected on the basis of their capacity for PHAs storage, instead of pure cultures, represents an interesting alternative for reducing the production costs.

Thus, it is clear that although these biopolymers represent an appealing alternative to conventional petroleum-based polymeric materials, there are still several drawbacks associated to their use in packaging applications. Therefore, the main challenge nowadays consists in the development of competitive eco-friendly biopolymers, which must be economically viable, processable by conventional industrial manufacturing techniques and which have similar performance to that of 
conventional petroleum-based polymers. In particular, extensive research is currently being carried out with the aim of enhancing the thermal stability, barrier and mechanical properties of biopolymers for their use within the food packaging field.

\section{NANOCOMPOSITE POLYMERIC MATERIALS}

As already mentioned, in order to tune the properties of polymeric materials and adapt them to the packaging requirements, the main adopted strategies are polymer blending, development of multilayer systems and production of composite materials. Polymeric composites consist on polymers loaded with inorganic or organic fillers with different possible geometries. For reinforcing purposes, a good interaction between matrix and filler is highly desired, which is often one of the major challenges faced when developing new nanocomposite materials. It has been observed that the matrix-filler interactions significantly improve when reducing the size of the reinforcing agent, always considering that both phases are compatible and that the filler is properly dispersed (de Azeredo, 2009). Macroscopic reinforcing components usually contain defects, which become less important as the reinforcing particles are smaller (Ludueña et al., 2007). Therefore, shifting from micro- to nanosized particles leads to better performance of composite materials, although it can also lead to increased agglomeration of the filler particles. Additionally, whereas the addition of macro- or microscopic fillers may affect some of the matrix properties, such as transparency, mechanical and barrier performance, the incorporation of well dispersed nanofillers limits the possible detrimental effect of the filler and therefore, nanocomposites display higher thermal, mechanical and barrier performance at low loadings (i.e. concentrations lower than $5 \mathrm{wt.}$ - $\%$ ), as well as higher transparency and toughness than conventional composites (Siró \& Plackett, 2010; Sorrentino et al., 2007). It is 
also worth noting that due to the large surface area of nanoparticles, they present a higher specific area to establish interactions with the polymeric matrix and as a result, the adhesion at the matrix/filler interface may be improved.

As a consequence, nanotechnology represents an efficient tool for the production of polymeric packaging materials with improved properties. Nanotechnology is, by definition, the creation and utilization of structures with at least one dimension in the nanometre length scale (i.e. less than $100 \mathrm{~nm}$ ) that creates novel properties and phenomena otherwise not displayed by either isolated molecules or bulk materials. Thus, the term nanocomposite refers to composite materials containing typically low additions of some kind of nanoparticles, i.e. fillers which have at least one dimension in the nanometric range. The development of nanocomposites has been claimed to be an efficient strategy to deal with the issues associated to the use of polymers or biopolymers for food packaging applications, since it is possible to tailor the properties of polymeric materials by incorporating highly dispersed nanofillers, such as nanoclays, carbon nanotubes and nanofibres, cellulose nanowhiskers, zinc oxide nanoparticles and graphenes. In contrast, the use of nanoparticles in the food packaging field still presents some issues, i.e. the lack of knowledge about the impact of nanomaterials when inserted into bioplastics during service and the possible decomposition and/or migration of the nanoparticles and how they may affect the actual inherent bioplastic migration levels. However, the prospects for natural additives such as food-contact complying nanoclays and nanobiofibres due to edibility and/or resorbability or biocompatibility may not be of so much concern in biopackaging.

Nanoclays have been the most widely studied nanofillers and it has been broadly reported in the scientific literature that addition to biopolymers of low loadings of nanoclays, with thicknesses in the nanometre scale and with high 
aspect ratios, can have a strong enhancing effect over some material properties such as mechanical performance, thermal stability, UV-Vis protection, processability and barrier properties (Cabedo et al., 2004; Cyras et al., 2008; Dean et al., 2007; Petersson \& Oksman, 2006; Plackett et al., 2006; Sanchez-Garcia et al., 2010b; Sanchez-Garcia \& Lagaron, 2010a; Yua et al., 2003). However, due to the hydrophilicity of most nanoclays, attaining a homogeneous dispersion of these in organic polymers may be complicated. As a result, organoclays, which are products from interactions between clay minerals and organic compounds, are mostly used for nanocomposite applications instead of unmodified nanoclays. This organophilization is crucial for the successful exfoliation, i.e. complete delamination and random dispersion, of nanoclays in most polymeric matrices.

On the other hand, cellulosic nanofillers, represent an interesting alternative to nanoclays for the production of lightweight, high-strength, ecofriendly nanocomposites. The use of cellulosic nanofillers in nanocomposites has numerous advantages such as their low density, high surface area, renewable nature, biodegradability, low cost and great availability of the raw material and high specific properties (Siqueira et al., 2010). As a result, there is a growing interest in the study and use of cellulosic nanofillers for the production of fully biobased nanocomposites. Moreover, it has been very recently demonstrated that the migration levels of nanocomposites of PLA reinforced with both native and surface modified cellulose nanocrystals were below the overall migration limits indicated in the current legislation in both non-polar and polar simulants (Fortunati et al., 2012). 


\subsection{Electrospinning and solution blow spinning as novel techniques for the production of nanocomposite polymeric materials}

Several processing techniques are available for the production of nanocomposite polymeric materials. Although extensive literature may be found on the production of nanocomposites by solution casting, this technique is only acceptable for laboratory scale, whereas melt compounding techniques are usually applied for the industrial manufacturing of nanocomposites. Besides these conventional processing methods, during the past decade a growing interest has been focused on the novel electrospinning technique, which unlike conventional fibre spinning processes, such as wet spinning, dry spinning or melt spinning, which are capable of producing fibres down to the micrometer range, is capable of producing fibres in the sub-micron range. This technique, together with the even more recent solution blow spinning technique, is gaining more and more interest for the fabrication of polymer nanofibres in a wide range of applications.

Electrospinning is a versatile method to produce continuous polymer fibres with diameters in the sub-micron range through the action of an external electric field applied between two electrodes and imposed on a polymer solution or melt. When the electrical force at the interface of the polymer solution exceeds the surface tension, a charged jet is formed. The jet initially extends in a straight line, then undergoes a vigorous whipping motion caused by the electrohydrodynamic instabilities. As the solvent in the jet solution evaporates, the polymer is collected onto a grounded substrate to form a non-woven mat with large surface-to-volume ratio (Kim et al., 2006). This technique has received substantial attention for the fabrication of polymer nanofibres with applicability as textiles (Schreuder-Gibson et al., 2002), wound dressings (Ignatova et al., 2009), tissue engineering scaffolds (Jeong et al., 2010), electronic devices (Liu et al., 2004) and, more recently, in the nanocomposites field (Ji et al., 2006; Olsson et al., 2010; Peresin et al., 2010), 
since it allows the production of hybrid fibres incorporating nanofillers with interesting properties.

Both PLA and PHBV fibres have been produced by electrospinning (Fang et al., 2004; Kim et al., 2003; Sombatmankhong et al., 2006; Zeng et al., 2004) since these materials present great interest, especially for applications within the biomedical field. Moreover, a wide variety of materials have been incorporated into PLA and PHBV fibres in order to achieve the properties required for specific applications. Some examples include PLA and PHBV fibres for controlled release of antibiotics and drugs (Wang et al., 2012; Xu et al., 2010), PLA fibres loaded with silver nanoparticles (Kim et al., 2010) as well as PHBV fibres containing plant polyphenols (Kim et al., 2009b) with antimicrobial properties and PLA fibres with conductive properties through the incorporation of polyaniline (PANI) (Abdul Rahman et al., 2010).

Due to their potential as reinforcing agents for polymeric matrices, nanoclays (Kim et al., 2007; Yu \& Cebe, 2009; Zhou et al., 2006) and cellulose nanowhiskers (CNW) (Olsson et al., 2010; Peresin et al., 2010; Rojas et al., 2009; Zhou et al., 2011; Zoppe et al., 2009) have been incorporated into several polymers through electrospinning to produce reinforced hybrid fibres. In regard to other processing methods, when using hydrophobic polymers, the high hydrophilicity of CNW may lead to a lack of adhesion between the matrix and the CNW (Xiang et al., 2009). In that case, the choice of a suitable solvent for both the polymeric matrix and the nano-additive, as well as the physical state of the nanowhiskers, i.e. freeze-dried or hydrated, are key factors for their optimal incorporation and dispersion within the matrix and they will be studied for different polymeric systems throughout the present work. 
As an alternative to electrospinning, a novel technique known as solution blow spinning has been recently developed and has been successfully applied to produce micro and nanofibres of PLA (Oliveira et al., 2011), PMMA and PS (Medeiros et al., 2009). In the solution blow spinning process, the polymeric solution is pumped through an inner nozzle, while a high pressure gas, such as air or nitrogen, flows through a concentric outer nozzle. As the polymeric solution leaves the inner nozzle by forming a drop at the tip, it is subjected to the high pressure gas pumped through the outer nozzle and, therefore, the droplet is stretched and forms a cone similar to Taylor's cone in electrospinning (Medeiros et al., 2009). As the polymeric solution is stretched by the compressed gas, the solvent evaporates and, hence, polymeric fibres are obtained (Medeiros et al., 2009; Oliveira et al., 2011). Solution blow spinning presents several advantages over electrospinning, such as the possibility of applying higher feeding rates, lower costs, use of solvents not limited by their dielectric constants and reduced damage of living cells, proteins and other biomaterials when incorporated into fibres (Oliveira et al., 2011).

Although these techniques are commonly used for the production of nanofibres incorporating functional additives for specific applications, in this work we also put forward the production of hybrid fibres as a vehicle for the incorporation of highly dispersed CNW into hydrophobic polymers.

\section{CELLULOSE AS A SOURCE OF CRYSTALLINE NANOFILLERS}

Cellulose is one of the most abundant biopolymers found in nature. It is the major cell-wall component of plants and, therefore, it is often extracted from vegetal resources such as wood, cotton, flax, hemp, etc. Nevertheless, cellulose can also be extracted from algae and from some marine animals, such as tunicates, as 
well as synthesized by some bacterial species. The properties of cellulose may be different depending on the raw material and as a consequence, when extracting cellulose nanocrystals, their aspect ratio, crystallinity and thermostability may be influenced by the cellulosic native material.

\subsection{Structural characteristics of cellulose}

Regardless of its source, cellulose consists of a linear homopolysaccharide of poly- $\beta(1,4)-\mathrm{D}$-glucopyranoside chains linked by $\beta$-1-4-linkages, forming rodlike crystal units which are organized in a highly ordered manner (Delmer \& Amor, 1995; Mutwil et al., 2008). This is the basic structural component of cellulose and it is commonly referred to as cellulose "microfibrils", "nanofibrils", "nanocrystals" or "nanowhiskers". These crystal units are held together in a paracrystalline matrix and linked along the axis by disordered amorphous domains. The $\beta(1,4)$-Dglucopyranoside chains are aligned parallel along the longitudinal axis of the microfibril and they can be configured slightly different depending on how the chains are twisted around their axis and interact by intramolecular hydrogen bonding with neighbouring chains, thereby creating different allomorphs. Native cellulose has a crystalline structure of cellulose I allomorph, which at the same time is a composite of two crystalline phases, $\mathrm{I}_{\alpha}$ and $\mathrm{I}_{\beta}$, which have been assigned to triclinic and monoclinic unit cells, respectively (Atalla \& VanderHart, 1984; Sugiyama et al., 1991b; VanderHart \& Atalla, 1984). The ratio of these two allomorphs is different depending on the cellulose source. The cellulose $I_{\alpha}$ is an unstable phase and tends to transform into the $\mathrm{I}_{\beta}$ allomorph upon thermal heating, especially in polar media such as dilute alkali solutions (Yamamoto \& Horii, 1993). Cellulose can also present the cellulose II allomorph, which is also known as regenerated cellulose and is found in this material when precipitated out of alkali solutions. Whereas the structure of cellulose I is made up of parallel chains 
(Sugiyama et al., 1991a), the crystalline structure of cellulose II is described as antiparallel (Saxena \& Brown Jr, 2005). Cellulose II is the most thermodynamically stable form of cellulose, although cellulose extracted from natural resources consists of cellulose I.

\subsection{Bacterial cellulose versus plant cellulose}

As previously commented, cellulose can be extracted from a wide variety of raw materials, being the plant-derived resources the most commonly used ones. Cellulose is found in the walls of vegetal resources and it is usually associated to other materials such as hemicelluloses and lignin. Therefore, a first purification step, which usually involves alkali and bleaching treatments with $\mathrm{NaClO}_{2}$, is necessary in that case to remove these other components and obtain purified cellulose microfibres. On the contrary, cellulose synthesized by bacteria is directly produced as highly crystalline, nearly pure cellulose and, therefore, a purification step similar to that applied for isolating plant derived cellulose is not required. Only bacteria cells and absorbed culture medium need to be removed after collecting bacterial cellulose pellicles and this is usually done by cleaning with boiling water and with sodium hydroxide aqueous solutions. This fact, together with the outstanding properties of bacterial cellulose, have made it to gain enormous interest as a biomaterial for medicine and cosmetics (Ping et al., 2009; Wang et al., 2011), papermaking processes (Surma-Slusarska et al., 2008; Yousefi et al., 2012) and more recently, as an alternative to plant cellulose for the extraction of cellulose nanowhiskers (George et al., 2011; George \& Siddaramaiah, 2012; Martínez-Sanz et al., 2011; Park et al., 2012). Furthermore, as compared to plantderived cellulose, bacterial cellulose shows a finer web-like network structure, higher water holding capacity and higher crystallinity (Iguchi et al., 2000). 
Bacterial cellulose is synthesised by bacteria belonging to the genera Acetobacter, Rhizobium, Agrobacterium, and Sarcina (Jonas \& Farah, 1998). These bacteria may be found in vinegar, alcoholic beverages, fruit juices, fruits and vegetables. Nevertheless, the most efficient production is carried out by the bacterial species Gluconacetobacter xylinus in a rich saccharide medium under static condition at around $28-30^{\circ} \mathrm{C}$ (Iguchi et al., 2000). Under these conditions, bacteria consume the saccharides present in the culture medium and produce a highly hydrated pellicle of cellulose in the liquid/air interface. This cellulose is composed of a ribbon-shaped assembly of microfibrils, with a width of 40-60 nm (Hirai et al., 2002). There are several theories which try to explain the reason why bacteria build this cellulose layer. For example, it was hypothesized that bacteria generate cellulose to protect themselves from UV light (Scott Williams \& Cannon, 1989), to maintain their position close to the culture medium surface, where the supply of oxygen is more abundant (Schramm \& Hestrin, 1954) or to protect themselves from other bacteria and from heavy-metal ions (Iguchi et al., 2000).

\section{EXTRACTION OF CELLULOSE NANOWHISKERS}

For their application as nanofillers, cellulose elementary fibrils are usually isolated from native cellulose. This is usually done by subjecting cellulosic materials to either mechanical disintegration (mechanical shearing at high pressure) for the production of microfibrillated cellulose (MFC), or to an acid hydrolysis treatment for the preparation of cellulose nanowhiskers (CNW). Whereas CNW present a highly crystalline structure, MFC are flexible fibrils containing both amorphous and crystalline domains.

When subjecting cellulose to hydrolysis with strong acids such as sulphuric acid or hydrochloric acid, a preferential digestion of the amorphous domains of the 
material and cleavage of the nanofibrils' bundles is produced (Rånby, 1949), thus, breaking down the hierarchical structure of the material into crystalline nanofibres or nanocrystals, usually referred to as cellulose nanowhiskers. The morphology and crystallinity of the so-obtained $\mathrm{CNW}$ depends on the cellulose source and the hydrolysis conditions. While CNW extracted from vegetal resources such as cotton or wood typically have a length of 100-300 nm and width of 5-20 nm (Araki et al., 1998; Favier et al., 1995; Siqueira et al., 2009), CNW obtained from tunicates and bacterial cellulose may have several micrometers in length and a width of 5-50 nm (De Souza Lima \& Borsali, 2004; Hirai et al., 2009; Martínez-Sanz et al., 2011). Regarding the hydrolysis conditions, the acid concentration, cellulose/acid ratio, temperature and hydrolysis time are factors which determine the CNW's morphology. The aspect ratio $(\mathrm{L} / \mathrm{D})$ is a critical parameter which has a remarkable influence on the reinforcing capacity of the nanofiller when incorporating it into a polymeric matrix (Eichhorn et al., 2010). Materials with aspect ratios higher than 30 , such as tunicin whiskers $(\mathrm{L} / \mathrm{d} \sim 67)$ have been reported to provide a considerably higher reinforcement effect as compared to nanofillers having lower aspect ratios, such as Avicel whiskers (L/d 10) (Azizi Samir et al., 2005). Nevertheless, it has also been reported that for aspect ratios larger than 100, the Young's modulus reaches a plateau corresponding to the maximum point of reinforcement (Eichhorn et al., 2010). Therefore, the acid hydrolysis conditions must be carefully studied and controlled in order to obtain a material with the desired morphology.

\subsection{Extraction of cellulose nanowhiskers by hydrolysis with sulphuric acid}

The most widely used procedure for the extraction of CNW consists of sulphuric acid treatment followed by filtration or centrifugation. Sulphuric acid hydrolysis leads to stable aqueous suspensions of cellulose nanocrystals which are negatively charged and thus, do not tend to aggregate. During the hydrolysis 
process, esterification of the surface hydroxyl groups from cellulose takes place and, as a consequence, sulphate groups are introduced (Rånby, 1949). Despite the advantage of obtaining stable suspensions, the presence of sulphate groups in the outer surface of the material has been proven to strongly decrease the thermal stability of the material (Roman \& Winter, 2004), which is also a key factor when intending to use $\mathrm{CNW}$ as a nanoreinforcement. Hydrolysis time has been proven to be a crucial factor which mainly affects the aspect ratio and surface charge of the produced CNW (Beck-Candanedo et al., 2005; Dong et al., 1998). Too short hydrolysis times may lead to the production of large microfibrils and aggregates with no significant effect on the crystallinity of the raw material, whereas cellulose may completely be digested to yield their component sugar molecules if too long hydrolysis times are applied.

In the case of $\mathrm{CNW}$ extracted from vegetal cellulose microfibres, the hydrolysis procedure with sulphuric acid has already been standardized and applied in several works (Jiang et al., 2008; Petersson et al., 2007; Sanchez-Garcia \& Lagaron, 2010b). Typical hydrolysis conditions are cellulose/acid ratio of $10 \mathrm{~g} / 100 \mathrm{~mL}$, sulphuric acid concentration of $9.1 \mathrm{M}$, hydrolysis temperature of $44^{\circ} \mathrm{C}$ and hydrolysis time of $130 \mathrm{~min}$. Greater digestion times have been observed to lead to carbonization and darkening of the product (Sanchez-Garcia \& Lagaron, 2010b). After hydrolysis, the liquid is subjected to several centrifugation cycles to remove the acid and the degraded cellulose and CNW are obtained from the turbid liquid supernatant, while bigger cellulosic material fractions and some impurities (if the raw material contains hemicelluloses and lignin) remain in the solid precipitate. The supernatant, which usually presents a $\mathrm{pH}$ close to $3-3.5$, is then neutralized with sodium hydroxide and subsequently subjected to dialysis. One of the drawbacks of the extraction of CNW by this acid digestion procedure is that low extraction yields are often attained. In this sense, bacterial cellulose may present a 
clear advantage. Since for bacterial cellulose there are no impurities to remove, it was suggested to extract $\mathrm{BCNW}$ after strong acid hydrolysis from the centrifugation precipitate instead of the supernatant (Olsson et al., 2010), hence increasing the overall extraction yield. However, the highly crystalline network structure of bacterial cellulose requires strong hydrolysis conditions in order to break down the morphology of fibril bundles and partial carbonization or degradation of the material can take place if the hydrolysis conditions are not carefully studied and optimized. Therefore taking into account previous works on the extraction of CNW and BCNW by sulphuric acid hydrolysis, very low yields are attained by applying the methods described in literature but, on the other hand, stronger hydrolysis conditions may lead to excessive hydrolysis and degradation of the material. Thus, it would be desirable to develop and standardize a new method for the extraction of thermally stable $\mathrm{BCNW}$ which results in higher yields.

\section{NANOCOMPOSITES CONTAINING CELLULOSE NANOWHISKERS}

Cellulosic nanocrystals or nanowhiskers are increasingly being used as reinforcing agents for new and inexpensive biodegradable materials since they present excellent mechanical properties as well as fully degradable and renewable character. Modulus values in excess of $100 \mathrm{GPa}$ have been reported for cellulose nanocrystals, and mechanical strength values are close to 7-8 GPa (Hsieh et al., 2008; Iwamoto et al., 2009; Nishiyama, 2009). In addition to these remarkable mechanical properties, cellulose nanocrystals present other interesting properties such as high barrier to gases (Belbekhouche et al., 2011; Fukuzumi et al., 2009), high specific surface area (Olsson et al., 2010) and low density (ca. $1500 \mathrm{~kg} / \mathrm{m}^{3}$ ) (Henriksson \& Berglund, 2007), which make them attractive for their use in nanocomposite materials. However, the use of $\mathrm{CNW}$ as nanofillers presents some major disadvantages, such as their high tendency for self-association due to their 
strongly interacting surface hydroxyl groups, which makes it difficult to re-disperse them once they have been subjected to a drying process; the limitation on the processing temperature of nanocomposites, since $\mathrm{CNW}$ start degrading at temperatures close to $200^{\circ} \mathrm{C}$; and their highly hydrophilic nature, which causes incompatibility issues with most organic solvents and hydrophobic thermoplastic matrices. Thus, achieving a high dispersion of $\mathrm{CNW}$ when incorporated into polymeric matrices may be an arduous task but, on the other hand, it is a requirement for significantly improving the properties of the base material.

\subsection{Surface modification of cellulose nanofillers}

Several strategies have been proposed to overcome the dispersion issues originated by the high hydrophilicity of CNW. One method to enable the dispersion of $\mathrm{CNW}$ in organic media consists in coating their surface with surfactants having polar heads and long hydrophobic tails. Whereas the hydrophilic head adsorbs on the cellulose surface, the hydrophobic tail is soluble in the organic phase, thus preventing aggregation of cellulose crystals by steric stabilization. By this approach stable suspensions of surfactant-coated cellulose crystals were obtained in tetrahydrofuran (THF), toluene and cyclohexane (Heux et al., 2000; Kim et al., 2009a). However, this strategy presents one major drawback. The high compatibility between the organic solvent and the surfactant may lead to the use of high amounts of surfactant, in some cases representing a higher weight than that of CNW, to coat the surface of CNW (Heux et al., 2000). It has been shown that the use of high amounts of surfactant can also decrease the crystallinity and increase the porosity of the material (Petersson et al., 2007).

An alternative consists on chemical surface modification by reaction of the hydroxyl groups present on the surface of CNW with organomodifying agents. CNW have been successfully modified by acetylation (Goffin et al., 2011a; Sassi \& 
Chanzy, 1995; Tomé et al., 2011), oxidation (Cao et al., 2009; Montanari et al., 2005) and silanization (Goussé et al., 2004; Pei et al., 2010; Raquez et al., 2012). Although surface modification has been seen to enhance the compatibility of CNW with organic solvents and hydrophobic polymeric matrices, some studies proved that the extent of surface modification has to be limited to avoid a detrimental effect on the structure and properties of CNW (Andresen et al., 2006; Goussé et al., 2004; Ifuku et al., 2007).

Another possible surface modification involves grafting of polymeric chains by attachment of pre-synthesized polymers with reactive end groups to the surface of CNW using a coupling agent (grafting-to or grafting onto) or by in situ surface-initiated polymerization from immobilized initiators on the substrate (grafting-from). Although polymeric chains such as poly( $\varepsilon$-caprolactone) (PCL) were successfully grafted onto the surface of CNW (Habibi \& Dufresne, 2008), the grafting efficiency was very low due to the fact that steric crowding for the attachment increased during the reaction as the polymer chains had to diffuse through the layer of already attached brushes to reach the reactive sites on the surface. In contrast, the grafting-from technique is generally more suitable due the higher grafting density achieved and to the better control of the chains length. CNW have been grafted with PCL (Habibi et al., 2008; Lin et al., 2009) and PLA (Goffin et al., 2012; Goffin et al., 2011a) by ring-opening polymerization. Despite the fact that, using this approach, the matrix-filler adhesion was significantly enhanced, the effects of incorporating grafted $\mathrm{CNW}$ on the barrier and mechanical properties of nanocomposites have not been extensively studied yet.

To summarize, surface modification of CNW seems a promising solution for their compatibilization with hydrophobic matrices, although it may bring issues 
related to the biodegradability, life cycle analysis, price and migration in nanocomposite materials used in food packaging.

\subsection{Nanocomposites produced by solution casting}

The most widely used procedure for the preparation of cellulose nanocomposites is the solution casting method, where CNW are mixed with a polymeric solution and cast. The film is then formed after evaporation of the solvent. This technique can be used either with water-soluble polymers, in which case, fresh CNW suspensions are mixed with the polymeric solution, or with nonhydrosoluble systems, in which case surface modified CNW may be used, or unmodified $\mathrm{CNW}$ may be subjected to solvent exchange procedures with the purpose of maintaining the $\mathrm{CNW}$ in their non-agglomerated wet state in the organic solvent.

Water is obviously the preferred medium for preparing $\mathrm{CNW}$ nanocomposites as aqueous suspensions of CNW are relatively stable. CNW have been incorporated into hydrophilic matrices such as polyvinyl alcohol (PVOH) (Kvien \& Oksman, 2007), starch (Chen et al., 2009) and carrageenan (SanchezGarcia et al., 2010a) attaining a high level of CNW dispersion. However, these materials are extremely sensitive to moisture, thus limiting their application.

Regarding hydrophobic matrices, CNW have been incorporated into PLA (Hossain et al., 2012; Petersson et al., 2007; Sanchez-Garcia \& Lagaron, 2010b) and PHBV (Jiang et al., 2008; Ten et al., 2012a; Ten et al., 2010) by solution casting. For PLA cast nanocomposites it was observed that the dispersion could be improved by either surfactant coating or solvent exchange with tert-Butanol, although the high amount of surfactant used to coat the CNW's surface was detrimental for the mechanical properties of the nanocomposites (Petersson et al, 
2007). In a different study, it was observed that a greater dispersion was achieved when incorporating freeze-dried plant-derived CNW directly dispersing them by sonication as compared to the incorporation of $\mathrm{CNW}$ subjected to a solvent exchange process in chloroform (Sanchez-Garcia \& Lagaron, 2010b). Optimum dispersion and barrier enhancement was found for nanocomposites containing CNW loadings below 3 wt.-\% (Sanchez-Garcia \& Lagaron, 2010b). In contrast, a more recent study showed that CNW were largely aggregated when incorporated into PLA. In that case, it was possible to increase the tensile strength and Young's modulus of nanocomposites as compared to pure PLA, although the elongation at break was dramatically decreased (Hossain et al., 2012). The use of polyethylene glycol (PEG) as compatibilizing agent has also been investigated and it was observed that when adding PEG the tensile strength and elongation at break improved by $56.7 \%$ and $48 \%$ as compared to the PLA-CNW nanocomposites (Qu et al., 2011).

Regarding PHBV, several works reported on the development of cast nanocomposites with $\mathrm{CNW}$ homogeneously dispersed for concentrations up to 2.3 wt.-\%, whereas agglomeration took place for greater nanofiller loadings (Ten et al., 2012a; Ten et al., 2012b). With the addition of PEG into the system, CNW were evenly distributed within nanocomposites with concentrations up to $5 \mathrm{wt.}-\% \mathrm{CNW}$ (Jiang et al., 2008; Ten et al., 2010). However, the solvent exchange procedure was the most efficient way of dispersing unmodified $\mathrm{CNW}$, allowing the incorporation and dispersion of up to $10 \mathrm{wt} . \mathrm{\%} \mathrm{CNW}$ (Yu et al., 2012). In all these cases, the incorporation of CNW gave rise to increased Young's modulus and tensile strength as compared to the neat PHBV, although the ductility of the materials was impaired and some of those works reported a significant decrease in the elongation at break (Jiang et al., 2008; Yu et al., 2012). 
Therefore, it may be concluded that the solution casting technique is a relatively easy route to produce nanocomposites loaded with CNW, with improved mechanical and barrier properties. In the case of hydrophilic matrices, aqueous dispersions of CNW are easily produced, whereas for hydrophobic matrices, CNW may be dispersed by either mechanical methods (homogenization and sonication) or by solvent exchange procedures. Nevertheless, this technique is not suitable for industrial applications and when aiming to produce commercial packaging materials, efforts should be focused on the production of nanocomposites by means of melt compounding techniques.

\subsection{Nanocomposites produced by melt compounding}

As already discussed along the previous section, nanocomposites of biopolyesters loaded with $\mathrm{CNW}$, with improved properties, have already been successfully produced via solution casting. However, only very few studies have reported on the production of nanocomposites reinforced with cellulose nanowhiskers via meaningful industrial processing techniques, such as melt compounding methods. One of the main issues associated to the production of melt compounded nanocomposites is the difficulty of achieving a good dispersion of the nanofiller within the matrix. In the case of $\mathrm{CNW}$, their poor compatibility with hydrophobic thermoplastic matrices in the melt state results in weak polymernanofiller interactions and complicates even further dispersion, resulting in agglomeration of CNW and poor adhesion with the matrix. This is a major concern since it has limited the production of CNW nanocomposites to laboratory scale. Therefore, considerable research has been carried out to overcome this issue and several strategies have been developed over the last few years.

An attempt to prepare nanocomposites of PLA reinforced with CNW by pumping a suspension of $\mathrm{CNW}$ in $\mathrm{DMAc} / \mathrm{LiCl}$ into the polymer melt during the 
extrusion process was described (Oksman et al., 2006). Nevertheless, aggregation and thermal degradation took place to a certain extent and no barrier property enhancement was obtained or reported. As an alternative, the use of a surfactant was seen to improve the dispersion of CNW but, at the same time, it led to PLA degradation (Bondeson \& Oksman, 2007a). Subsequently, the possibility of using poly(vinyl alcohol) (PVOH) as compatibilizer was investigated, but phase separation between PLA and PVOH took place and CNW were seen to remain primarily in the PVOH phase (Bondeson \& Oksman, 2007b). Despite the use of PEG as compatibilizer, CNW also agglomerated when incorporated into PHBV by melt processing, leading to composites with reduced mechanical properties (Jiang et al., 2008).

As an alternative, other works reported on the production of PLA melt processed nanocomposites incorporating cellulosic fillers by pre-mixing high concentrations of the unmodified filler with PLA in organic solvents and subsequently diluting these masterbatches by melt compounding (Iwatake et al., 2008; Jonoobi et al., 2010). By this methodology relatively low contents of cellulosic fillers were uniformly distributed within the matrix, but the mechanical properties of PLA were significantly improved. This method could have, however, some drawbacks during the industrial implementation on top of other issues such as the efficient elimination of the entrapped solvent. In addition, surface modification of CNW by acetylation previous to the masterbatch preparation did not show either improved dispersion of the nanofiller nor improved mechanical properties as compared to the unmodified CNW (Jonoobi et al., 2012).

More recent works opted for surface modification and polymer grafting as a way to increase the matrix-filler interactions and thus, enhance the dispersion of cellulosic fillers within hydrophobic polymers. By means of CNW silanization it 
was possible to improve the dispersion of the nanofiller in PLA melt compounded nanocomposites (Raquez et al., 2012). On the other hand, carboxymethylation of CNW followed by esterification with 1-hexanol resulted in poor matrix-filler interactions and insufficient nanofiller dispersion (Eyholzer et al., 2012). Grafting of PLA chains onto the surface of CNW by ring-opening polymerization, followed by incorporation of these modified CNW into PLA by melt blending was seen to enhance the compatibility between the matrix and the nanofiller (Goffin et al., 2011a). The same strategy was used for the production of poly(e-caprolactone) (PCL) CNW-loaded melt compounded nanocomposites by using PCL-grafted CNW masterbatches produced by ring-opening polymerization (Goffin et al., 2011b). This approach was seen to significantly improve the dispersion and the compatibility between the $\mathrm{CNW}$ and the hydrophobic matrices. Nevertheless, the impact on the barrier properties of the nanocomposites was not reported.

To summarize, from analysis of the existing literature it seems that surface modification by grafting polymerization prior to the melt compounding step was the most apparently successful approach for enhancing the dispersion of CNW within non-polar polymeric matrices, although further research should be carried out in order to investigate the effect of incorporating polymer-grafted CNW on the mechanical and barrier properties of the developed nanocomposites. Thus, in most of the above studies the barrier performance was not reported and hence the impact of these technologies in the mass transport properties of low molecular weight substances is unknown. Additionally, it is clear that there has not been much work being carried out concerning the development of efficient processes to incorporate highly dispersed unmodified nanocellulose crystals into polymers by the industrially meaningful melt compounding processing method. 


\section{References}

Abdul Rahman, N., Gizdavic-Nikolaidis, M., Ray, S., Easteal, A. J., \& TravasSejdic, J. (2010). Functional electrospun nanofibres of poly(lactic acid) blends with polyaniline or poly(aniline-co-benzoic acid). Synthetic Metals, 160(17-18), 20152022.

Andresen, M., Johansson, L. S., Tanem, B. S., \& Stenius, P. (2006). Properties and characterization of hydrophobized microfibrillated cellulose. Cellulose, 13(6), 665677.

Araki, J., Wada, M., Kuga, S., \& Okano, T. (1998). Flow properties of microcrystalline cellulose suspension prepared by acid treatment of native cellulose. Colloids and Surfaces A: Physicochemical and Engineering Aspects, 142(1), 75-82.

ASTM International, W. C., PA (2010). ASTM Standard D996-10a, 2010, "Standard Terminology of Packaging and Distribution Environments".

Atalla, R. H., \& VanderHart, D. L. (1984). Native cellulose: A composite of two distinct crystalline forms. Science, 223(4633), 283-285.

Auras, R., Harte, B., \& Selke, S. (2004a). Effect of water on the oxygen barrier properties of poly(ethylene terephthalate) and polylactide films. Journal of Applied Polymer Science, 92(3), 1790-1803.

Auras, R., Harte, B., \& Selke, S. (2004b). An Overview of Polylactides as Packaging Materials. Macromolecular Bioscience, 4(9), 835-864.

Azizi Samir, M. A. S., Alloin, F., \& Dufresne, A. (2005). Review of recent research into cellulosic whiskers, their properties and their application in nanocomposite field. Biomacromolecules, 6(2), 612-626.

Barham, P. J., Keller, A., Otun, E. L., \& Holmes, P. A. (1984). Crystallization and morphology of a bacterial thermoplastic: poly-3-hydroxybutyrate. Journal of Materials Science, 19(9), 2781-2794.

Beck-Candanedo, S., Roman, M., \& Gray, D. G. (2005). Effect of reaction conditions on the properties and behavior of wood cellulose nanocrystal suspensions. Biomacromolecules, 6(2), 1048-1054. 
Belbekhouche, S., Bras, J., Siqueira, G., Chappey, C., Lebrun, L., Khelifi, B., Marais, S., \& Dufresne, A. (2011). Water sorption behavior and gas barrier properties of cellulose whiskers and microfibrils films. Carbohydrate Polymers, 83(4), 1740-1748.

Betty Lucy López, O., Amanda Inés Mejía, G., \& Ligia Sierra, G. (1999). Biodegradability of poly(vinyl alcohol). Polymer Engineering and Science, 39(8), 1346-1352.

Bondeson, D., \& Oksman, K. (2007a). Dispersion and characteristics of surfactant modified cellulose whiskers nanocomposites. Composite Interfaces, 14(7-9), 617630 .

Bondeson, D., \& Oksman, K. (2007b). Polylactic acid/cellulose whisker nanocomposites modified by polyvinyl alcohol. Composites Part A: Applied Science and Manufacturing, 38(12), 2486-2492.

Cabedo, L., Giménez, E., Lagaron, J. M., Gavara, R., \& Saura, J. J. (2004). Development of EVOH-kaolinite nanocomposites. Polymer, 45(15), 5233-5238.

Cao, X., Habibi, Y., \& Lucia, L. A. (2009). One-pot polymerization, surface grafting, and processing of waterborne polyurethane-cellulose nanocrystal nanocomposites. Journal of Materials Chemistry, 19(38), 7137-7145.

Chen, L. J., \& Wang, M. (2002). Production and evaluation of biodegradable composites based on PHB-PHV copolymer. Biomaterials, 23(13), 2631-2639.

Chen, Y., Liu, C., Chang, P. R., Cao, X., \& Anderson, D. P. (2009). Bionanocomposites based on pea starch and cellulose nanowhiskers hydrolyzed from pea hull fibre: Effect of hydrolysis time. Carbohydrate Polymers, 76(4), 607615 .

Choi, J. S., \& Park, W. H. (2004). Effect of biodegradable plasticizers on thermal and mechanical properties of poly(3-hydroxybutyrate). Polymer Testing, 23(4), 455-460.

Coleman, M. M., Yang, X., Zhang, H., \& Painter, P. C. (1993). Ethylene-co-vinyl alcohol blends. Journal of Macromolecular Science - Physics, B32(3), 295-326. 
Cyras, V. P., Manfredi, L. B., Ton-That, M. T., \& Vázquez, A. (2008). Physical and mechanical properties of thermoplastic starch/montmorillonite nanocomposite films. Carbohydrate Polymers, 73(1), 55-63.

de Azeredo, H. M. C. (2009). Nanocomposites for food packaging applications. Food Research International, 42(9), 1240-1253.

De Souza Lima, M. M., \& Borsali, R. (2004). Rodlike cellulose microcrystals: Structure, properties, and applications. Macromolecular Rapid Communications, 25(7), 771-787.

Dean, K., Yu, L., \& Wu, D. Y. (2007). Preparation and characterization of meltextruded thermoplastic starch/clay nanocomposites. Composites Science and Technology, 67(3-4), 413-421.

Delmer, D. P., \& Amor, Y. (1995). Cellulose biosynthesis. Plant Cell, 7(7), 9871000 .

Dong, X. M., Revol, J. F., \& Gray, D. G. (1998). Effect of microcrystallite preparation conditions on the formation of colloid crystals of cellulose. Cellulose, $5(1), 19-32$.

Drumright, R. E., Gruber, P. R., \& Henton, D. E. (2000). Polylactic acid technology. Advanced Materials, 12(23), 1841-1846.

Eichhorn, S. J., Dufresne, A., Aranguren, M., Marcovich, N. E., Capadona, J. R., Rowan, S. J., Weder, C., Thielemans, W., Roman, M., Renneckar, S., Gindl, W., Veigel, S., Keckes, J., Yano, H., Abe, K., Nogi, M., Nakagaito, A. N., Mangalam, A., Simonsen, J., Benight, A. S., Bismarck, A., Berglund, L. A., \& Peijs, T. (2010). Review: Current international research into cellulose nanofibres and nanocomposites. Journal of Materials Science, 45(1), 1-33.

Eyholzer, C., Tingaut, P., Zimmermann, T., \& Oksman, K. (2012). Dispersion and Reinforcing Potential of Carboxymethylated Nanofibrillated Cellulose Powders Modified with 1-Hexanol in Extruded Poly(Lactic Acid) (PLA) Composites. Journal of Polymers and the Environment, 1-11.

Fang, Z., Zhang, L., Han, T., \& Hu, P. (2004). Studies on the morphology and structure of electrospun PHBV fibers. Acta Polymerica Sinica(4), 500-505. 
Favier, V., Chanzy, H., \& Cavaille, J. Y. (1995). Polymer nanocomposites reinforced by cellulose whiskers. Macromolecules, 28(18), 6365-6367.

Feng, L., Watanabe, T., Wang, Y., Kichise, T., Fukuchi, T., Chen, G. Q., Doi, Y., \& Inoue, Y. (2002). Studies on comonomer compositional distribution of bacterial poly(3-hydroxybutyrate-co-3-hydroxyhexanoate)s and thermal characteristics of their factions. Biomacromolecules, 3(5), 1071-1077.

Fortunati, E., Peltzer, M., Armentano, I., Torre, L., Jiménez, A., \& Kenny, J. M. (2012). Effects of modified cellulose nanocrystals on the barrier and migration properties of PLA nano-biocomposites. Carbohydrate Polymers, 90(2), 948-956.

Fukuzumi, H., Saito, T., Iwata, T., Kumamoto, Y., \& Isogai, A. (2009). Transparent and high gas barrier films of cellulose nanofibers prepared by TEMPO-mediated oxidation. Biomacromolecules, 10(1), 162-165.

George, J., Ramana, K. V., Bawa, A. S., \& Siddaramaiah (2011). Bacterial cellulose nanocrystals exhibiting high thermal stability and their polymer nanocomposites. International Journal of Biological Macromolecules, 48(1), 5057 .

George, J., \& Siddaramaiah (2012). High performance edible nanocomposite films containing bacterial cellulose nanocrystals. Carbohydrate Polymers, 87(3), 20312037.

Goffin, A. L., Habibi, Y., Raquez, J. M., \& Dubois, P. (2012). Polyester-grafted cellulose nanowhiskers: A new approach for tuning the microstructure of immiscible polyester blends. ACS Applied Materials and Interfaces, 4(7), 33643371.

Goffin, A. L., Raquez, J. M., Duquesne, E., Siqueira, G., Habibi, Y., Dufresne, A., \& Dubois, P. (2011a). From interfacial ring-opening polymerization to melt processing of cellulose nanowhisker-filled polylactide-based nanocomposites. Biomacromolecules, 12(7), 2456-2465.

Goffin, A. L., Raquez, J. M., Duquesne, E., Siqueira, G., Habibi, Y., Dufresne, A., \& Dubois, P. (2011b). Poly( $\varepsilon$-caprolactone) based nanocomposites reinforced by surface-grafted cellulose nanowhiskers via extrusion processing: Morphology, rheology, and thermo-mechanical properties. Polymer, 52(7), 1532-1538. 
Goussé, C., Chanzy, H., Cerrada, M. L., \& Fleury, E. (2004). Surface silylation of cellulose microfibrils: Preparation and rheological properties. Polymer, 45(5), $1569-1575$.

Habibi, Y., \& Dufresne, A. (2008). Highly Filled Bionanocomposites from Functionalized Polysaccharide Nanocrystals. Biomacromolecules, 9(7), 1974-1980.

Habibi, Y., Goffin, A. L., Schiltz, N., Duquesne, E., Dubois, P., \& Dufresne, A. (2008). Bionanocomposites based on poly(e-caprolactone)-grafted cellulose nanocrystals by ring-opening polymerization. Journal of Materials Chemistry, $18(41), 5002-5010$.

Henriksson, M., \& Berglund, L. A. (2007). Structure and properties of cellulose nanocomposite films containing melamine formaldehyde. Journal of Applied Polymer Science, 106(4), 2817-2824.

Heux, L., Chauve, G., \& Bonini, C. (2000). Nonflocculating and chiral-nematic self-ordering of cellulose microcrystals suspensions in nonpolar solvents. Langmuir, 16(21), 8210-8212.

Hirai, A., Inui, O., Horii, F., \& Tsuji, M. (2009). Phase separation behavior in aqueous suspensions of bacterial cellulose nanocrystals prepared by sulfuric acid treatment. Langmuir, 25(1), 497-502.

Hirai, A., Tsuji, M., \& Horii, F. (2002). TEM study of band-like cellulose assemblies produced by Acetobacter xylinum at $4 \hat{\mathrm{A}}^{\circ} \mathrm{C}$. Cellulose, 9(2), 105-113.

Hossain, K. M. Z., Ahmed, I., Parsons, A. J., Scotchford, C. A., Walker, G. S., Thielemans, W., \& Rudd, C. D. (2012). Physico-chemical and mechanical properties of nanocomposites prepared using cellulose nanowhiskers and poly(lactic acid). Journal of Materials Science, 47(6), 2675-2686.

Hsieh, Y. C., Yano, H., Nogi, M., \& Eichhorn, S. J. (2008). An estimation of the Young's modulus of bacterial cellulose filaments. Cellulose, 15(4), 507-513.

Ifuku, S., Nogi, M., Abe, K., Handa, K., Nakatsubo, F., \& Yano, H. (2007). Surface modification of bacterial cellulose nanofibers for property enhancement of optically transparent composites: Dependence on acetyl-group DS. Biomacromolecules, 8(6), 1973-1978. 
Ignatova, M., Manolova, N., Markova, N., \& Rashkov, I. (2009). Electrospun nonwoven nanofibrous hybrid mats based on chitosan and PLA for wound-dressing applications. Macromolecular Bioscience, 9(1), 102-111.

Iguchi, M., Yamanaka, S., \& Budhiono, A. (2000). Bacterial cellulose - a masterpiece of nature's arts. Journal of Materials Science, 35(2), 261-270.

Iwamoto, S., Kai, W., Isogai, A., \& Iwata, T. (2009). Elastic modulus of single cellulose microfibrils from tunicate measured by atomic force microscopy. Biomacromolecules, 10(9), 2571-2576.

Iwanami, T., \& Hirai, Y. (1983). Ethylene vinyl alcohol resins for gas-barrier material. Tappi Journal, 66(10), 85-90.

Iwatake, A., Nogi, M., \& Yano, H. (2008). Cellulose nanofiber-reinforced polylactic acid. Composites Science and Technology, 68(9), 2103-2106.

Jeong, S. I., Krebs, M. D., Bonino, C. A., Khan, S. A., \& Alsberg, E. (2010). Electrospun alginate nanofibers with controlled cell adhesion for tissue engineering. Macromolecular Bioscience, 10(8), 934-943.

Ji, Y., Li, B., Ge, S., Sokolov, J. C., \& Rafailovich, M. H. (2006). Structure and nanomechanical characterization of electrospun PS/clay nanocomposite fibers. Langmuir, 22(3), 1321-1328.

Jiang, L., Morelius, E., Zhang, J., Wolcott, M., \& Holbery, J. (2008). Study of the poly(3-hydroxybutyrate-co-3-hydroxyvalerate)/cellulose nanowhisker composites prepared by solution casting and melt processing. Journal of Composite Materials, 42(24), 2629-2645.

Jonas, R., \& Farah, L. F. (1998). Production and application of microbial cellulose. Polymer Degradation and Stability, 59(1-3), 101-106.

Jonoobi, M., Harun, J., Mathew, A. P., \& Oksman, K. (2010). Mechanical properties of cellulose nanofiber (CNF) reinforced polylactic acid (PLA) prepared by twin screw extrusion. Composites Science and Technology, 70(12), 1742-1747.

Jonoobi, M., Mathew, A. P., Abdi, M. M., Makinejad, M. D., \& Oksman, K. (2012). A Comparison of Modified and Unmodified Cellulose Nanofiber Reinforced Polylactic Acid (PLA) Prepared by Twin Screw Extrusion. Journal of Polymers and the Environment, 1-7. 
Kim, C. W., Kim, D. S., Kang, S. Y., Marquez, M., \& Joo, Y. L. (2006). Structural studies of electrospun cellulose nanofibers. Polymer, 47(14), 5097-5107.

Kim, E. S., Kim, S. H., \& Lee, C. H. (2010). Electrospinning of polylactide fibers containing silver nanoparticles. Macromolecular Research, 18(3), 215-221.

Kim, G. M., Michler, G. H., Ania, F., \& Calleja, F. J. B. (2007). Temperature dependence of polymorphism in electrospun nanofibres of PA6 and PA6/clay nanocomposite. Polymer, 48(16), 4814-4823.

Kim, J., Montero, G., Habibi, Y., Hinestroza, J. P., Genzer, J., Argyropoulos, D. S., \& Rojas, O. J. (2009a). Dispersion of cellulose crystallites by nonionic surfactants in a hydrophobic polymer matrix. Polymer Engineering and Science, 49(10), 20542061.

Kim, K., Yu, M., Zong, X., Chiu, J., Fang, D., Seo, Y. S., Hsiao, B. S., Chu, B., \& Hadjiargyrou, M. (2003). Control of degradation rate and hydrophilicity in electrospun non-woven poly(D,L-lactide) nanofiber scaffolds for biomedical applications. Biomaterials, 24(27), 4977-4985.

Kim, Y. J., Kim, S. N., Kwon, O. K., Park, M. R., Kang, I. K., \& Lee, S. G. (2009b). Preparation and characterization of electrospun nanofibers containing natural antimicrobials. Polymer (Korea), 33(4), 307-312.

Kvien, I., \& Oksman, K. (2007). Orientation of cellulose nanowhiskers in polyvinyl alcohol. Applied Physics A: Materials Science and Processing, 87(4), 641-643.

Lagaron, J. M., Powell, A. K., \& Bonner, G. (2001). Permeation of water, methanol, fuel and alcohol-containing fuels in high-barrier ethylene-vinyl alcohol copolymer. Polymer Testing, 20(5), 569-577.

Lin, N., Chen, G., Huang, J., Dufresne, A., \& Chang, P. R. (2009). Effects of polymer-grafted natural nanocrystals on the structure and mechanical properties of poly(lactic acid): A case of cellulose whisker-graft-polycaprolactone. Journal of Applied Polymer Science, 113(5), 3417-3425.

Liu, H., Kameoka, J., Czaplewski, D. A., \& Craighead, H. G. (2004). Polymeric nanowire chemical sensor. Nano Letters, 4(4), 671-675. 
Lopez-Rubio, A., \& Lagaron, J. M. (2008). Improving the resistance to humid heat sterilization of EVOH copolymers through blending. Journal of Applied Polymer Science, 109(1), 174-181.

Ludueña, L. N., Alvarez, V. A., \& Vazquez, A. (2007). Processing and microstructure of PCL/clay nanocomposites. Materials Science and Engineering A, 460-461, 121-129.

Lundgren, D. G., Alper, R., Schnaitman, C., \& Marchessault, R. H. (1965). Characterization of poly-b-hydroxybutyrate extracted from different bacteria. $J$. Bacteriol., 89, 245-251.

Lunt, J. (1998). Large-scale production, properties and commercial applications of poly lactic acid polymers. Polymer Degradation and Stability, 59(1-3), 145-152.

Martínez-Sanz, M., Lopez-Rubio, A., \& Lagaron, J. M. (2011). Optimization of the nanofabrication by acid hydrolysis of bacterial cellulose nanowhiskers. Carbohydrate Polymers, 85(1), 228-236.

Medeiros, E. S., Glenn, G. M., Klamczynski, A. P., Orts, W. J., \& Mattoso, L. H. C. (2009). Solution blow spinning: A new method to produce micro- and nanofibers from polymer solutions. Journal of Applied Polymer Science, 113(4), 2322-2330.

Mejía G, A. I., López O, B. L., \& Sierra, L. (2001). Biodegradation of poly(vinylalcohol-co-ethylene) with the fungus phanerochaete chrysosporium. Materials Research Innovations, 4(2-3), 148-154.

Mitomo, H., Takahashi, T., Ito, H., \& Saito, T. (1999). Biosynthesis and characterization of poly(3-hydroxybutyrate-co-3-hydroxyvalerate) produced by Burkholderia cepacia D1. International Journal of Biological Macromolecules, 24(4), 311-318.

Moita, R., \& Lemos, P. C. (2012). Biopolymers production from mixed cultures and pyrolysis by-products. Journal of Biotechnology, 157(4), 578-583.

Montanari, S., Roumani, M., Heux, L., \& Vignon, M. R. (2005). Topochemistry of carboxylated cellulose nanocrystals resulting from TEMPO-mediated oxidation. Macromolecules, 38(5), 1665-1671. 
Mutwil, M., Debolt, S., \& Persson, S. (2008). Cellulose synthesis: a complex complex. Current Opinion in Plant Biology, 11(3), 252-257.

Nishiyama, Y. (2009). Structure and properties of the cellulose microfibril. Journal of Wood Science, 55(4), 241-249.

Oksman, K., Mathew, A. P., Bondeson, D., \& Kvien, I. (2006). Manufacturing process of cellulose whiskers/polylactic acid nanocomposites. Composites Science and Technology, 66(15), 2776-2784.

Oliveira, J. E., Moraes, E. A., Costa, R. G. F., Afonso, A. S., Mattoso, L. H. C., Orts, W. J., \& Medeiros, E. S. (2011). Nano and submicrometric fibers of poly(D, L -lactide) obtained by solution blow spinning: Process and solution variables. Journal of Applied Polymer Science, 122(5), 3396-3405.

Olsson, R. T., Kraemer, R., Lopez-Rubio, A., Torres-Giner, S., Ocio, M. J., \& Lagaron, J. M. (2010). Extraction of microfibrils from bacterial cellulose networks for electrospinning of anisotropic biohybrid fiber yarns. Macromolecules, 43(9), 4201-4209.

Park, D. J., Choi, Y., Heo, S., Cho, S. Y., \& Jin, H. J. (2012). Bacterial cellulose nanocrystals-embedded silk nanofibers. Journal of Nanoscience and Nanotechnology, 12(7), 6139-6144.

Pei, A., Zhou, Q., \& Berglund, L. A. (2010). Functionalized cellulose nanocrystals as biobased nucleation agents in poly(l-lactide) (PLLA) - Crystallization and mechanical property effects. Composites Science and Technology, 70(5), 815-821.

Peresin, M. S., Habibi, Y., Zoppe, J. O., Pawlak, J. J., \& Rojas, O. J. (2010). Nanofiber composites of polyvinyl alcohol and cellulose nanocrystals: Manufacture and characterization. Biomacromolecules, 11(3), 674-681.

Petersson, L., Kvien, I., \& Oksman, K. (2007). Structure and thermal properties of poly(lactic acid)/cellulose whiskers nanocomposite materials. Composites Science and Technology, 67(11-12), 2535-2544.

Petersson, L., \& Oksman, K. (2006). Biopolymer based nanocomposites: Comparing layered silicates and microcrystalline cellulose as nanoreinforcement Composites Science and Technology, 66(13), 2187-2196. 
Ping, W., Yi, S., Yuanyuan, J., Jingtong, Z., Zongliang, W., Yanyan, C., \& Yulai, Z. (2009). Study on the feasibility of bacterial cellulose as tissue engineering scaffold. Advanced Materials Research pp. 147-150).

Plackett, D. V., Holm, V. K., Johansen, P., Ndoni, S., Nielsen, P. V., SipilainenMalm, T., Södergård, A., \& Verstichel, S. (2006). Characterization of Lpolylactide and L-polylactide-polycaprolactone co-polymer films for use in cheesepackaging applications. Packaging Technology and Science, 19(1), 1-24.

Rånby, B. G. (1949). Aqueous colloidal solutions of cellulose micelles. Acta Chem. Scand., 3, 649-650.

Raquez, J. M., Murena, Y., Goffin, A. L., Habibi, Y., Ruelle, B., DeBuyl, F., \& Dubois, P. (2012). Surface-modification of cellulose nanowhiskers and their use as nanoreinforcers into polylactide: A sustainably-integrated approach. Composites Science and Technology, 72(5), 544-549.

Rojas, O. J., Montero, G. A., \& Habibi, Y. (2009). Electrospun nanocomposites from polystyrene loaded with cellulose nanowhiskers. Journal of Applied Polymer Science, 113(2), 927-935.

Roman, M., \& Winter, W. T. (2004). Effect of sulfate groups from sulfuric acid hydrolysis on the thermal degradation behavior of bacterial cellulose. Biomacromolecules, 5(5), 1671-1677.

Sanchez-Garcia, M. D., Hilliou, L., \& Lagaron, J. M. (2010a). Morphology and water barrier properties of nanobiocomposites of k/i-hybrid carrageenan and cellulose nanowhiskers. Journal of Agricultural and Food Chemistry, 58(24), 12847-12857.

Sanchez-Garcia, M. D., Hilliou, L., \& Lagaron, J. M. (2010b). Nanobiocomposites of Carrageenan, Zein, and Mica of interest in food packaging and coating applications. Journal of Agricultural and Food Chemistry, 58(11), 6884-6894.

Sanchez-Garcia, M. D., \& Lagaron, J. M. (2010a). Novel clay-based nanobiocomposites of biopolyesters with synergistic barrier to UV light, gas, and vapour. Journal of Applied Polymer Science, 118(1), 188-199.

Sanchez-Garcia, M. D., \& Lagaron, J. M. (2010b). On the use of plant cellulose nanowhiskers to enhance the barrier properties of polylactic acid. Cellulose, 17(5), 987-1004. 
Sassi, J. F., \& Chanzy, H. (1995). Ultrastructural aspects of the acetylation of cellulose. Cellulose, 2(2), 111-127.

Saxena, I. M., \& Brown Jr, R. M. (2005). Cellulose biosynthesis: Current views and evolving concepts. Annals of Botany, 96(1), 9-21.

Schramm, M., \& Hestrin, S. (1954). Factors affecting production of cellulose at the air/liquid interface of a culture of Acetobacter xylinum. Journal of General Microbiology, 11(1), 123-129.

Schreuder-Gibson, H., Gibson, P., Senecal, K., Sennett, M., Walker, J., Yeomans, W., Ziegler, D., \& Tsai, P. P. (2002). Protective textile materials based on electrospun nanofibers. Journal of Advanced Materials, 34(3), 44-55.

Scott Williams, W. S., \& Cannon, R. E. (1989). Alternative environmental roles for cellulose produced by Acetobacter xylinum. Applied and Environmental Microbiology, 55(10), 2448-2452.

Serafim, L. S., Lemos, P. C., Torres, C., Reis, M. A. M., \& Ramos, A. M. (2008).

The Influence of Process Parameters on the Characteristics of Polyhydroxyalkanoates Produced by Mixed Cultures. Macromolecular Bioscience, 8(4), 355-366.

Siqueira, G., Bras, J., \& Dufresne, A. (2009). Cellulose whiskers versus microfibrils: Influence of the nature of the nanoparticle and its surface functionalization on the thermal and mechanical properties of nanocomposites. Biomacromolecules, 10(2), 425-432.

Siqueira, G., Bras, J., \& Dufresne, A. (2010). Cellulosic bionanocomposites: A review of preparation, properties and applications. Polymers, 2(4), 728-765.

Siró, I., \& Plackett, D. (2010). Microfibrillated cellulose and new nanocomposite materials: A review. Cellulose, 17(3), 459-494.

Sombatmankhong, K., Suwantong, O., Waleetorncheepsawat, S., \& Supaphol, P. (2006). Electrospun fiber mats of poly(3-hydroxybutyrate), poly(3hydroxybutyrate-co-3-hydroxyvalerate), and their blends. Journal of Polymer Science, Part B: Polymer Physics, 44(19), 2923-2933. 
Sorrentino, A., Gorrasi, G., \& Vittoria, V. (2007). Potential perspectives of bionanocomposites for food packaging applications. Trends in Food Science \& Technology, 18(2), 84-95.

Sugiyama, J., Persson, J., \& Chanzy, H. (1991a). Combined infrared and electron diffraction study of the polymorphism of native celluloses. Macromolecules, 24(9), 2461-2466.

Sugiyama, J., Vuong, R., \& Chanzy, H. (1991b). Electron diffraction study on the two crystalline phases occurring in native cellulose from an algal cell wall. Macromolecules, 24(14), 4168-4175.

Surma-Slusarska, B., Presler, S., \& Danielewicz, D. (2008). Characteristics of bacterial cellulose obtained from Acetobacter Xylinum culture for application in papermaking. Fibres and Textiles in Eastern Europe, 16(4), 108-111.

Ten, E., Bahr, D. F., Li, B., Jiang, L., \& Wolcott, M. P. (2012a). Effects of cellulose nanowhiskers on mechanical, dielectric, and rheological properties of poly(3-hydroxybutyrate-co-3-hydroxyvalerate)/cellulose nanowhisker composites. Industrial and Engineering Chemistry Research, 51(7), 2941-2951.

Ten, E., Jiang, L., \& Wolcott, M. P. (2012b). Crystallization kinetics of poly(3hydroxybutyrate-co-3-hydroxyvalerate)/ cellulose nanowhiskers composites. Carbohydrate Polymers, 90(1), 541-550.

Ten, E., Turtle, J., Bahr, D., Jiang, L., \& Wolcott, M. (2010). Thermal and mechanical properties of poly(3-hydroxybutyrate-co-3-hydroxyvalerate)/cellulose nanowhiskers composites. Polymer, 51(12), 2652-2660.

Tomé, L. C., Pinto, R. J. B., Trovatti, E., Freire, C. S. R., Silvestre, A. J. D., Neto, C. P., \& Gandini, A. (2011). Transparent bionanocomposites with improved properties prepared from acetylated bacterial cellulose and poly(lactic acid) through a simple approach. Green Chemistry, 13(2), 419-427.

VanderHart, D. L., \& Atalla, R. H. (1984). Studies of microstructure in native celluloses using solid-state 13C NMR. Macromolecules, 17(8), 1465-1472.

Wang, J., Zhu, Y., \& Du, J. (2011). Bacterial cellulose: A natural nanomaterial for biomedical applications. Journal of Mechanics in Medicine and Biology, 11(2), 285-306. 
Wang, W., Cao, J., Lan, P., \& Wu, W. (2012). Drug release from electrospun fibers of poly(3-hydroxybutyrate-co-3- hydroxyvalerate) grafted with poly $(\mathrm{N}$ vinylpyrrolidone). Journal of Applied Polymer Science, 124(3), 1919-1928.

Xiang, C., Joo, Y. L., \& Frey, M. W. (2009). Nanocomposite fibers electrospun from poly(Lactic Acid)/cellulose nanocrystals. Journal of Biobased Materials and Bioenergy, 3(2), 147-155.

Xu, X., Zhong, W., Zhou, S., Trajtman, A., \& Alfa, M. (2010). Electrospun PEGPLA nanofibrous membrane for sustained Release of hydrophilic antibiotics. Journal of Applied Polymer Science, 118(1), 588-595.

Yamamoto, H., \& Horii, F. (1993). CP/MAS 13C NMR analysis of the crystal transformation induced for Valonia cellulose by annealing at high temperatures. Macromolecules, 26(6), 1313-1317.

Yoshie, N., Azuma, Y., Sakurai, M., \& Inoue, Y. (1995). Crystallization and compatibility of poly(vinyl alcohol)/poly(3-hydroxybutyrate) blends: influence of blend composition and tacticity of poly(vinyl alcohol). Journal of Applied Polymer Science, 56(1), 17-24.

You, J. W., Chiu, H. J., \& Don, T. M. (2003). Spherulitic morphology and crystallization kinetics of melt-miscible blends of poly(3-hydroxybutyrate) with low molecular weight poly(ethylene oxide). Polymer, 44(15), 4355-4362.

Yousefi, H., Faezipour, M., Hedjazi, S., Mousavi, M. M., Azusa, Y., \& Heidari, A. H. (2012). Comparative study of paper and nanopaper properties prepared from bacterial cellulose nanofibers and fibers/ground cellulose nanofibers of canola straw. Industrial Crops and Products, 43, 732-737.

Yu, H. Y., Qin, Z. Y., Liu, Y. N., Chen, L., Liu, N., \& Zhou, Z. (2012). Simultaneous improvement of mechanical properties and thermal stability of bacterial polyester by cellulose nanocrystals. Carbohydrate Polymers, 89(3), 971978.

Yu, L., \& Cebe, P. (2009). Crystal polymorphism in electrospun composite nanofibers of poly(vinylidene fluoride) with nanoclay. Polymer, 50(9), 2133-2141.

Yua, Y. H., Lin, C. Y., Yeh, J. M., \& Lin, W. H. (2003). Preparation and properties of poly(vinyl alcohol)-clay nanocomposite materials. Polymer, 44(12), 3553-3560. 
Zeng, J., Chen, X., Liang, Q., Xu, X., \& Jing, X. (2004). Enzymatic degradation of poly(L-lactide) and poly(E-caprolactone) electrospun fibers. Macromolecular Bioscience, 4(12), 1118-1125.

Zhou, C., Chu, R., Wu, R., \& Wu, Q. (2011). Electrospun polyethylene oxide/cellulose nanocrystal composite nanofibrous mats with homogeneous and heterogeneous microstructures. Biomacromolecules, 12(7), 2617-2625.

Zhou, H., Kim, K. W., Giannelis, E., \& Joo, Y. L. (2006). Nanofibers from polylactic acid nanocomposites: Effect of nanoclays on molecular structures. ACS Symposium Series pp. 217-230).

Zoppe, J. O., Peresin, M. S., Habibi, Y., Venditti, R. A., \& Rojas, O. J. (2009). Reinforcing poly( $\varepsilon$-caprolactone) nanofibers with cellulose nanocrystals. ACS Applied Materials and Interfaces, 1(9), 1996-2004. 

II. OBJECTIVES 



\section{GENERAL AND SPECIFIC OBJECTIVES}

Just as discussed in the previous section, bacterial cellulose nanowhiskers present excellent properties which may be interesting for the development of food packaging materials. On one hand, they may be used as nanofillers for tuning the properties of polymeric materials through the production of nanocomposites. On the other hand, the extremely high crystallinity of bacterial cellulose nanowhiskers may be an advantage for the development of high barrier cellulose-based materials. In this context, the general objective of this work was the following:

The development of nanocomposites based on highly crystalline and thermally stable cellulose nanowhiskers extracted from bacterial cellulose, with interest in food packaging applications.

For this purpose, several steps had to be sequentially developed. Although cellulose nanowhiskers have been widely produced from vegetal resources, their extraction from bacterial cellulose is a relatively new procedure and the process was not optimized or standardized. Therefore, the first step consisted on the study and optimization of the extraction process of bacterial cellulose nanowhiskers to produce nanocrystals with the desired properties in terms of thermal stability, aspect ratio and crystallinity.

The next step consisted on the incorporation of bacterial cellulose nanowhiskers into a relatively polar matrix, such as EVOH, which presents a relatively good compatibility with the nanowhiskers. Along this second phase, several strategies were developed for the incorporation of the nanofiller into $\mathrm{EVOH}$ by means of electrospinning and subsequently, by melt compounding, identifying the difficulties associated to these processing techniques and developing strategies 
to overcome these problems. Given the difficulty of dispersing cellulose nanowhiskers by melt compounding, several pre-incorporation methods were developed and the produced nanocomposites were characterized.

Subsequently, the third objective involved the incorporation of highly dispersed bacterial cellulose nanowhiskers into biopolyesters such as PLA and PHBV to improve their properties. In this case, the strategies previously developed for the incorporation of the highly hydrophilic bacterial cellulose nanowhiskers into $\mathrm{EVOH}$ had to be adapted for their incorporation into hydrophobic matrices, ensuring a high level of nanofiller dispersion. In addition to the development of pre-incorporation strategies for dispersing the unmodified nanocrystals by melt compounding, the surface modification of bacterial cellulose nanowhiskers was investigated as an alternative route for improving their compatibility with hydrophobic polymers.

Finally, the last objective aimed at developing films based on bacterial cellulose nanowhiskers with high barrier properties. The challenge associated to this objective lies on the extremely high moisture sensitivity of cellulose nanowhiskers. Thus, hydrophobic coatings which effectively protected the cellulose nanowhiskers films from moisture were developed through several procedures, providing a good adhesion between the inner hydrophilic layer and the outer hydrophobic coatings.

\section{WORK PLAN}

In order to accomplish the previously detailed objectives of this work, the following specific work plan was carried out: 
- Develop a method for the incorporation and dispersion of BCNW into EVOH electrospun fibres, optimizing the method in terms of fibres morphology, degree of cellulose nanowhiskers incorporation and thermal properties and maximizing the amount of cellulose nanowhiskers incorporated into the fibres.

- Investigate the factors that affect the extraction of BCNW by means of sulphuric acid hydrolysis and optimize the method to produce nanocrystals presenting high aspect ratio, crystallinity and thermal stability.

- Produce EVOH nanocomposites loaded with highly dispersed bacterial and plant cellulose nanowhiskers by melt compounding by means of several preincorporation methods.

- Incorporate BCNW into a hydrophobic polymer such as PLA by means of electrospinning and maximize the nanofiller loading.

- Prepare PLA nanocomposites with enhanced barrier and mechanical properties by incorporating highly dispersed BCNW through different pre-incorporation approaches, followed by melt compounding.

- Develop high barrier BCNW films with reduced moisture sensitivity by coating with hydrophobic materials, enhancing the adhesion between the BCNW layer and the hydrophobic coatings.

- Evaluate the efficiency of BCNW's surface modification to improve their compatibility with a hydrophobic polymer such as PLA. 
- Synthesize PLA hybrid fibres with antimicrobial properties by means of the novel solution blow spinning technique and evaluate the effect of BCNW addition.

- Analyze the influence of the valerate content on the properties of PHAs synthesized by microbial mixed cultures, as well as produce nanocomposites loaded with BCNW by solution casting. 
III. RESULTS AND DISCUSSION 



\section{GENERAL INTRODUCTION TO RESULTS}

The various chapters included within this section are briefly described and their rationale chronologically connected.

As previously detailed, the present work was aimed to deal with the thermal stability and/or barrier issues presented by many polymeric and, specially, biopolymeric materials which limit their applicability within the food packaging sector. In order to cope with these drawbacks, the use of highly crystalline biobased nanofillers, such as bacterial cellulose nanowhiskers (BCNW), was suggested. Two different approaches were proposed for the development of food packaging materials. The first one consisted on the incorporation of BCNW into several polymeric matrixes to tune the properties of the base material, whereas the second strategy involved the production of BCNW films coated with hydrophobic materials.

For the development of nanocomposites incorporating BCNW, the use of melt compounding as the processing technique was mainly considered, as it is industrially viable for the manufacturing of packaging materials. However, the production of melt compounded materials containing $\mathrm{BCNW}$ involved some major concerns, such as the low compatibility between the highly hydrophilic BCNW and many hydrophobic polymeric materials. For this reason, a strategy was developed to incorporate relatively high loadings of highly dispersed BCNW into a polymer, previous to the melt compounding step, in order to enhance the dispersion of $\mathrm{BCNW}$ in the final nanocomposites.

Firstly, ethylene vinyl alcohol copolymers $(\mathrm{EVOH})$ were selected as the polymeric matrices, due to their relatively good compatibility with $\mathrm{BCNW}$. The 
incorporation of $\mathrm{BCNW}$ into $\mathrm{EVOH}$ by means of the electrospinning technique was initially evaluated as a possible pre-incorporation method. The optimization of the development of these hybrid EVOH-BCNW electrospun fibres, as well as their characterization, are compiled in Chapter I. Subsequently in Chapter II, the amount of BCNW incorporated into the fibres was maximized and first trials on the production of melt compounded EVOH-BCNW nanocomposites using the electrospun hybrid fibers as master-batches were carried out.

Although it was observed that the pre-incorporation through electrospinning enhanced the dispersion of $\mathrm{BCNW}$ as compared to direct melt mixing, BCNW were seen to undergo thermal degradation when processed, hence preventing the use of these BCNW for melt compounding. Therefore, at that point, it was essential to study the BCNW extraction process and optimize it in terms of crystallinity, aspect ratio and thermal stability of the generated nanowhiskers. These results are presented in Chapter III.

Once thermally stable BCNW were produced, the next step consisted in the development of EVOH-BCNW nanocomposites by melt compounding. Both the pre-incorporation by means of electrospinning and by solution precipitation were proposed to enhance the dispersion of $\mathrm{BCNW}$ within the melt compounded materials. Additionally, nanocomposites were produced by incorporating plantderived cellulose nanowhiskers to compare their performance with those containing BCNW. Chapter IV contains the morphological and thermal characterization of the synthesized materials, while the water barrier and mechanical properties are compiled in Chapter $\mathbf{V}$.

After confirming the high dispersion of $\mathrm{BCNW}$ in melt processed $\mathrm{EVOH}$ nanocomposites by the novel pre-incorporation techniques, the next step was to 
adapt these strategies for the production of nanocomposites using conventional hydrophobic biopolymers, such as PLA or PHAs.

Throughout Chapter VI, the production of hybrid PLA-BCNW fibres by means of electrospinning is described. In this chapter, the selection of a suitable solvent system, taking also into account the physical state of BCNW, was studied in order to maximize the BCNW's incorporation and dispersion degree within the fibres.

Subsequently, PLA-BCNW nanocomposites were prepared by melt compounding and the direct melt mixing was compared to the pre-incorporation of BCNW into PLA electrospun fibres or into EVOH precipitated solutions. Chapter VII gathers the morphological and thermal characterization of the produced nanocomposites, as well as the evaluation of their mechanical and barrier properties.

As previously mentioned, besides using $\mathrm{BCNW}$ as nanoadditives for nanocomposite materials, their use as base material was also evaluated. The production and characterization of high barrier films based on BCNW coated with hydrophobic layers is described in Chapter VIII. A novel strategy was developed for coating the BCNW film with hydrophobic layers with the aim of preserving its high barrier properties within a wide range of relative humidity conditions and at the same time guaranteeing a good adhesion between the different layers. Moreover, the efficiency of this novel approach was compared to that of more conventional coating methods. 
We also considered interesting to include some additional results which involve alternative methodologies for the production of PLA-BCNW nanocomposites.

As an alternative to the developed pre-incorporation strategies, graft copolymerization with glycidyl methacrylate was evaluated as a method for producing modified nanowhiskers presenting improved compatibility with hydrophobic polymers. The production of poly(glycidyl methacrylate)-grafted BCNW, as well as their incorporation into PLA by a combination of casting and compression molding and the characterization of the produced nanocomposites, comparing them with the addition of neat BCNW, is described in Chapter IX.

Moreover, in Chapter $\mathbf{X}$ we investigated the use of the novel blow spinning technique as an alternative for the production of hybrid PLA-BCNW fibres. This technique opens a wide range of possibilities since it allows applying higher feeding rates, using a wider range of solvents and reducing the operational costs as compared to electrospinning. However, it is highly unexplored and, therefore, the whole process for the production of hybrid fibres needed to be optimized. Additionally, antimicrobial agents were incorporated into the blow spun fibres to generate active antimicrobial packaging materials and the role of $\mathrm{BCNW}$ on the release of the antimicrobial agents and, thus, on the inhibitory effect against Listeria monocytogenes was studied.

Finally, Chapter XI contains some preliminary results, developed within the frame of the European project "EcoBioCAP", in which BCNW were incorporated into polyhydroxyalkanoates (PHAs) by means of solution casting. In this work PHAs with different valerate contents were synthesized from microbial mixed cultures and, the effect of the valerate ratio on the properties of the base materials were first examined. After that, $\mathrm{BCNW}$ were incorporated into these materials and 
their effect on the thermal, mechanical and barrier properties of PHAs was reported.

As complementary results to the various chapters, a complete characterization of some representative electrospinning solutions is gathered within the Annexes section. These results are useful for elucidating the effect of BCNW incorporation on the solution properties and their impact on the morphology of electrospun fibres. 



\title{
Chapter I
}

DEVELOPMENT OF ELECTROSPUN EVOH FIBRES

REINFORCED WITH BACTERIAL CELLULOSE

NANOWHISKERS. PART I: CHARACTERIZATION AND METHOD OPTIMIZATION

\author{
Cellulose, 18(2), 335-347 (2011) \\ Marta Martínez Sanz ${ }^{1}$, Richard T. Olsson ${ }^{2}$, Amparo López Rubio ${ }^{1}$, José \\ María Lagarón ${ }^{1}$ \\ ${ }^{1}$ Novel Materials and Nanotechnology Group, IATA, CSIC. Avd. Agustín \\ Escardino, 7, 46980. Paterna, Valencia. Spain \\ ${ }^{2}$ Department of Fiber and Polymer Technology, Royal Institute of \\ Technology. Teknikringen, 56, 100 44. Stockholm. Sweden
}





\begin{abstract}
In the present study, hybrid electrospun EVOH fibres reinforced with bacterial cellulose nanowhiskers (BCNW) were developed and characterized. The nanowhiskers, obtained by sulphuric acid digestion of native bacterial cellulose mats generated by Gluconacetobacter xylinum, were morphologically characterized by SEM and optical microscopy with polarized light and revealed a highly crystalline structure of nanofibrils aggregates. XRD analyses suggested a crystalline structure corresponding to the cellulose I allomorph. It was also confirmed by means of FT-IR spectroscopy that amorphous regions were preferentially digested by the acid treatment, whereas TGA analyses showed a decrease in the thermal stability of the nanowhiskers most likely due to incorporation of sulphate groups and the inherent acidity remaining in the filler even after extensive washing cycles. A method was developed for improving the incorporation of $\mathrm{BCNW}$ within the $\mathrm{EVOH}$ electrospun fibres, consisting on the addition of the BCNW in the form of a centrifuged precipitate, versus the most conventionally employed freeze-dried nanowhiskers. DSC analyses showed a significant increase in the glass transition temperature of the composites during the second heating run, which may be related to the acidic character of the nanofiller. Finally, sonication was seen to enhance interfacial interaction but to reduce the incorporation of the filler in the matrix in the case of the centrifuged material.
\end{abstract}

Keywords: Bacterial cellulose, electrospinning, nanowhiskers, EVOH, hybrid fibres. 


\section{INTRODUCTION}

Cellulose is the most abundant biopolymer found in nature, as it is the major cell-wall component of plants. Plant-derived cellulose has been widely used as reinforcement in polymeric matrixes (Anglès \& Dufresne, 2001; Garcia de Rodriguez et al., 2006; Oksman et al., 2006; Orts et al., 2005). Besides cellulose from plants, cellulose is also secreted extracellularly as synthesized cellulose fibres by some bacterial species and it is known as bacterial cellulose (BC). Plant cellulose and $\mathrm{BC}$ have the same chemical structure although they have different structural organization and mechanical properties. Compared with plant cellulose, $\mathrm{BC}$ possesses higher water holding capacity, higher purity and crystallinity and a finer web-like network (Iguchi et al., 2000; Wan et al., 2007). Thus, cellulose derived from plants is unpurified cellulose associated with other kinds of natural polymers like lignin and hemicellulose, while $\mathrm{BC}$ is predominantly pure cellulose consisting of the highly crystalline nanofibrils held together by a paracrystalline matrix (Iguchi et al., 2000).

Bacterial cellulose is synthesised by bacteria belonging to the genera Acetobacter, Rhizobium, Agrobacterium, and Sarcina (Jonas \& Farah, 1998). However, the most efficient production is carried out by the bacterial species Gluconacetobacter xylinus in a rich saccharide medium under static condition at around $28-30^{\circ} \mathrm{C}$ (Iguchi et al., 2000). The attained extracellular cellulose consists of a highly hydrated pellicle made up of a random assembly of ribbon-shaped fibers, less than $100 \mathrm{~nm}$ wide, which are composed of a bundle of nanofibrils of 2 to $4 \mathrm{~nm}$ in diameter (Yamanaka et al., 1989).

Due to its unique structure and properties, i.e. high purity, high crystallinity, high mechanical strength, low density and good biocompatibility, bacterial 
cellulose has found many applications in paper, textile, food industries and as a biomaterial in cosmetics and medicine (Bielecki et al., 2002; Iguchi et al., 2000; Zhou et al., 2007). Those remarkable properties have made bacterial cellulose interesting as reinforcing filler for polymeric matrixes such as polyvinyl alcohol (PVA), cellulose acetate butyrate (CAB), poly (ethylene oxide) (PEO) and starch (Gindl \& Keckes, 2004; Millon \& Wan, 2006; Park et al., 2007; Wan et al., 2009).

It is well-known that native cellulose, when subjected to strong acid hydrolysis, can be readily hydrolyzed to micro- or nanocrystalline cellulose, socalled throughout the paper bacterial cellulose nanowhiskers (BCNW) (Bondeson et al., 2006). The present work focuses on the production of nanowhiskers by sulphuric acid hydrolysis of $\mathrm{BC}$ mats and their incorporation in a polymeric matrix.

The BCNW have great potential for reinforcing electrospun polymeric fibres. Electrospinning is a versatile method to produce continuous polymer fibres with diameters in the sub-micron range through the action of an external electric field applied between two electrodes and imposed on a polymer solution or melt. When the electrical force at the interface of the polymer solution exceeds the surface tension, a charged jet is formed. The jet initially extends in a straight line, then undergoes a vigorous whipping motion caused by the electrohydrodynamic instabilities. As the solvent in the jet solution evaporates, the polymer is collected onto a grounded substrate to form a non-woven mat with significant large surfaceto-volume ratio (Kim et al. 2006). Since recently, this technique has received substantial attention for the fabrication of polymer nanofibres in a wide range of applications that demand high-performance fibres. Electrospinning has recently been applied to obtain cellulose fibres (Kim et al., 2005; Kim et al., 2006) as well 
as hybrid fibres reinforced by cellulose whiskers (Olsson et al., 2010; Peresin et al., 2010).

The present work reports on the production and characterization of $\mathrm{EVOH}$ electrospun fibres incorporating $\mathrm{BCNW}$. The method for incorporating the $\mathrm{BCNW}$ was optimized in order to improve their dispersion in the $\mathrm{EVOH}$ electrospun fibres and maximize performance. The properties of the electrospun fibres obtained by the optimized and more traditional methods (using freeze-dried nanowhiskers) were studied and compared to pure EVOH fibres. 


\section{MATERIALS AND METHODS}

\subsection{Materials}

Ethylene-vinyl alcohol copolymer grade (Soarnol) EVOH29 (containing 29 mol\% of ethylene) was supplied by The Nippon Synthetic Chemical Industry Co., Ltd. (NIPPON GOHSEI) (Japan). Sulphuric acid 96\% and 2-propanol were purchased from Panreac (Barcelona, Spain).

\subsection{Preparation of bacterial cellulose mats}

The bacterial strain Gluconacetobacter xylinus 7351, obtained from the Spanish type culture collection (CECT) was incubated in a static culture medium composed of $20 \mathrm{~g}$ glucose, $5 \mathrm{~g}$ yeast-extract, $1.15 \mathrm{~g}$ citric acid, $5.7 \mathrm{~g} \mathrm{MgSO}_{4} \cdot 7 \mathrm{H}_{2} \mathrm{O}$ and $12.25 \mathrm{~g}$ buffered peptone water, per litre of water, at $30^{\circ} \mathrm{C}$. All of the cells were pre-cultured in a test tube containing $5 \mathrm{ml}$ of media. When a thin layer of cellulose was detected on top of the surface, they were transferred to $200 \mathrm{ml}$ bottles and subsequently to the final culture, containing 20 litres of media. The obtained bacterial cellulose pellicles, about $5 \mathrm{~cm}$ thick, were cut into small pieces (aprox. $2 \times 2 \mathrm{~cm}^{2}$ ). Those pieces were boiled repeated times in distilled water and then boiled in a $10 \%(\mathrm{v} / \mathrm{v}) \mathrm{NaOH}$ aqueous solution in order to remove bacteria cells and the absorbed culture media. Finally, the $\mathrm{pH}$ was lowered to 7 by boiling in distilled water several times. Figure 1 shows the visual aspect of the material as obtained and after purification. 

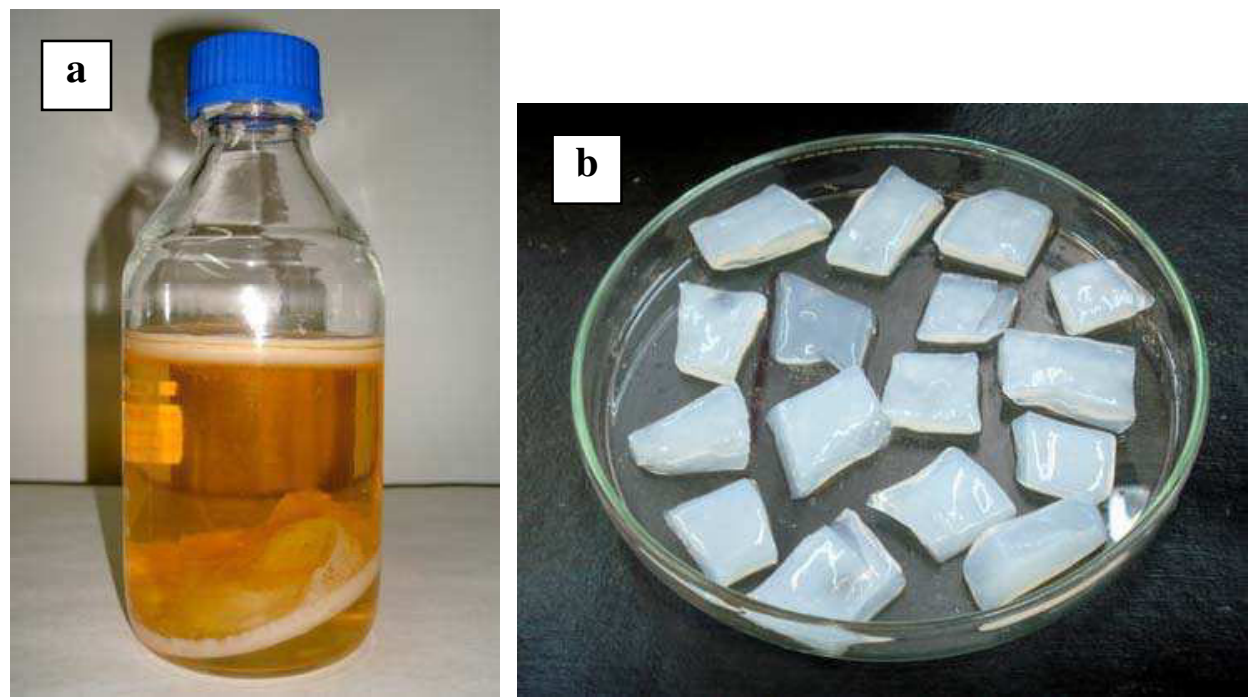

Figure 1. Bacterial cellulose mats (a) as formed and (b) after purification with water and $\mathrm{NaOH}$ solution.

\subsection{Preparation of bacterial cellulose nanowhiskers}

Once neutral $\mathrm{pH}$ was reached, bacterial cellulose pellicles were dried in order to remove all the absorbed water and then treated with $50 \%(\mathrm{v} / \mathrm{v})$ sulphuric $\mathrm{acid} /$ water, in a cellulose/acid ratio of approximately $7 \mathrm{~g} / \mathrm{L}$, at $50^{\circ} \mathrm{C}$ for five days until a homogeneous solution was obtained. The cellulose nanowhiskers were obtained as a white precipitate after 10 centrifugation and washing cycles at $12,500 \mathrm{rpm}$ and $15^{\circ} \mathrm{C}$ for 20 minutes. One fraction of the precipitate was kept refrigerated and centrifuged just before use (from now on "centrifuged BCNW"), whereas another fraction was freeze-dried and ground into powder (freeze-dried $\mathrm{BCNW})$. The humidity of the centrifuged nanowhiskers was determined in order to calculate the amount of whiskers per gram of centrifuged precipitate. 


\subsection{Electrospinning}

Bacterial cellulose nanowhiskers were incorporated into $5 \%(\mathrm{w} / \mathrm{v}) \mathrm{EVOH}$ solutions in 70/30 (v/v) 2-propanol/water and hybrid fibres were generated by electrospinning. Concentrations of cellulose nanowhiskers both centrifuged and freeze-dried, ranging from $1 \%$ to $8 \%(w / w)$ regarding the EVOH weight, were prepared.

Cellulose nanowhiskers were dispersed in the solvent by intense homogenization (Ultra-turrax). Furthermore, in the case of the 8 wt.-\% BCNW composites, an additional step of sonication was carried out to the BCNW solution prior to addition to the polymer in order to ascertain if a better dispersion can be achieved. Viscosity of pure EVOH and 8 wt.-\% BCNW solutions was determined at $50^{\circ} \mathrm{C}$ using a VISCO BASIC Plus L Viscometer (Fungilab, Spain) with a LCP low viscosity adapter.

The electrospinning apparatus was assembled in-house as described elsewhere (Torres-Giner et al., 2008). Solutions were transferred to $5 \mathrm{ml}$ plastic syringes and connected through PTFE tubes to a stainless steel needle $(\varnothing 0.9 \mathrm{~mm})$. An electrode was clamped to the needle tip and connected to a high-voltage $0-30 \mathrm{kV}$ power supply operating at $10-12 \mathrm{kV}$, and polymer solution was fed into the needle at a rate of $0.6 \mathrm{ml} / \mathrm{h}$ by a syringe pump (KD Scientific Inc., Holliston, U.S.A.). The counter electrode was connected to a rectangular plate covered by aluminum foil, which was placed parallel to the needle to collect the electrospun fibres. The distance between the needle and the plate was $12 \mathrm{~cm}$ and experiments were carried out at ambient temperature. 


\subsection{Scanning Electron Microscopy (SEM)}

SEM was conducted on a Hitachi microscope (Hitachi S-4100) at an accelerating voltage of 10-15 KV and a working distance of $12-16 \mathrm{~mm}$. Freezedried BCNWs, electrospun mats and fibres' sections cryo-fractured after immersion in liquid nitrogen were sputtered with a gold-palladium mixture under vacuum before their morphology was examined using SEM.

Fibre diameters of the electrospun fibres were measured by means of the Adobe Photoshop CS3 extended software from the SEM micrographs in their original magnification.

\subsection{Transmission Electron Microscopy (TEM)}

One drop $(8 \mu \mathrm{L})$ of a $0.001 \%$ aqueous suspension of centrifuged BCNW was allowed to dry on a carbon coated grid (200 mesh). The crystals were stained with uranyl acetate. TEM was performed using a JEOL 1010 equipped with a digital Bioscan (Gatan) image acquisition system at $80 \mathrm{KV}$.

\subsection{Optical microscopy}

Polarized light microscopy (PLM) examinations were performed using a Nikon Eclipse 90i optical microscope (IZASA, Spain) equipped with a 5megapixels cooled digital colour microphotography camera Nikon Digital Sight DS-5Mc. Captured images were analyzed and processed by using Nis-Elements BR software.

\subsection{FT-IR analysis}

Transmission FT-IR experiments were recorded in a controlled chamber at $21^{\circ} \mathrm{C}$ and $40 \% \mathrm{RH}$ using a Bruker (Rheinstetten, Germany) FT-IR Tensor 37 
equipment. The spectra were taken at $1 \mathrm{~cm}^{-1}$ resolution averaging a minimum of 10 scans. Analysis of the spectra was performed using Grams/AI 7.02 (Galactic Industries, Salem, NH, USA) software. Bacterial cellulose before acid digestion and the obtained nanowhiskers samples of ca. $2 \mathrm{mg}$ were ground and dispersed in $200 \mathrm{mg}$ of spectroscopic grade $\mathrm{KBr}$. A pellet was then formed by compressing the sample at ca. $150 \mathrm{MPa}$. A calibration curve was obtained by recording the IR spectra of pellets containing $6 \mathrm{mg}$ of EVOH-BC nanowhiskers samples with nanowhiskers' concentrations ranging from 10 wt.- $\%$ to 40 wt.- $\%$. Then, the spectra of pellets containing $2 \mathrm{mg}$ of electrospun fibres were collected using the same conditions.

\subsection{X-ray Diffraction (XRD)}

X-ray diffraction was carried out on a D5005 Bruker diffractometer. The instrument was equipped with a $\mathrm{Cu}$ tube and a secondary monochromator. The configuration of the equipment was $\theta-2 \theta$ and the samples were examined over the angular range of $5^{\circ}$ to $45^{\circ}$ with a step size of $0.02^{\circ}$ and a count time of $4 \mathrm{~s}$ per point.

Peak fitting was carried out using Igor software package (Wavemetrics, Lake Oswego, Oregon). Gaussian function was used to fit the experimental diffraction profiles obtained. For the fitting procedure, the reflections considered were (i) three at $14.8^{\circ}, 16.4^{\circ}$ and $22.5^{\circ} 2 \theta$ (corresponding to the $101,10 \overline{1}$ and 002 crystal planes respectively) assigned to the cellulose I allomorph, and (ii) the amorphous halo centered at $\sim 18.5^{\circ} 2 \theta$. The crystallinity index CI (XD) was determined by the method reported by Wang et al. (Wang et al. 2007): 


$$
\mathrm{CI}(\mathrm{XD})=\frac{\sum A_{\text {Crystal }}}{A_{\text {Total }}} \times 100
$$

where $A_{\text {Total }}$ is the sum of the areas under all the diffraction peaks and $\Sigma A_{\text {Crystal }}$ is the sum of the areas corresponding to crystalline peaks.

The crystallite sizes were estimated from the $101,10 \overline{1}$ and 002 lattice planes of cellulose I using the well-known Scherrer equation (Ahtee et al. 1983):

$$
D_{(h k l)}=\frac{k \cdot \lambda}{B_{(h k l)} \cdot \cos \theta}
$$

where $D_{(h k l)}$ is the size of the crystallite (nm), $k$ is the Scherrer constant (0.94), $\lambda$ is the X-ray wavelength, $B_{(h k l)}$ is the full-width at half-maximum of the reflection $\mathrm{hkl}$ and $2 \theta$ is the corresponding Bragg angle.

\subsection{Differential scanning calorimetry (DSC)}

DSC experiments were carried out in a Perkin-Elmer DSC-7 calorimeter. The sample treatment consisted of an initial conditioning step from $30^{\circ} \mathrm{C}$ to $120^{\circ} \mathrm{C}$, followed by an isothermal step at $120^{\circ} \mathrm{C}$ for 1 minute (to eliminate residual water from the samples) and a cooling step down to $30^{\circ} \mathrm{C}$, then, the first heating melting step from $30^{\circ} \mathrm{C}$ to $220^{\circ} \mathrm{C}$, a subsequent cooling down to $30^{\circ} \mathrm{C}$ and a second heating melting step up to $220^{\circ} \mathrm{C}$. The heating and cooling rates for the runs were $10^{\circ} \mathrm{C} / \mathrm{min}$ and the typical sample weight was around $3 \mathrm{mg}$. Calibration was performed using an indium sample. All tests were carried out, at least, in duplicate.

\subsection{Thermogravimetric analysis (TGA)}

Thermogravimetric (TG) curves were recorded with a TA Instruments model Q500 TGA. The samples (ca. $20 \mathrm{mg}$ ) were heated from $50^{\circ} \mathrm{C}$ to $600^{\circ} \mathrm{C}$ with a 
heating rate of $10^{\circ} \mathrm{C} / \mathrm{min}$ under nitrogen atmosphere. Derivative TG curves (DTG) express the weight loss rate as a function of temperature.

\section{RESULTS AND DISCUSSION}

\subsection{Characterization of $\mathrm{BCNW}$}

The morphology of the centrifuged BCNW and of the freeze-dried samples was studied by TEM and SEM, respectively, revealing after staining the presence of networks of nanofibrils having cross-sections smaller than $30 \mathrm{~nm}$, which by freeze-drying aggregate forming bundles with cross-sections smaller than $800 \mathrm{~nm}$, as shown in Figure 2. Additionally, optical microscopy observations with polarized light of freeze-dried material confirmed, as shown in Figure 3, that after acid treatment highly crystalline anisotropic structures of nanofibrils aggregates were obtained. This is suggested by the observation of the strong birefringence arising from the sample (De Souza Lima \& Borsali, 2004).

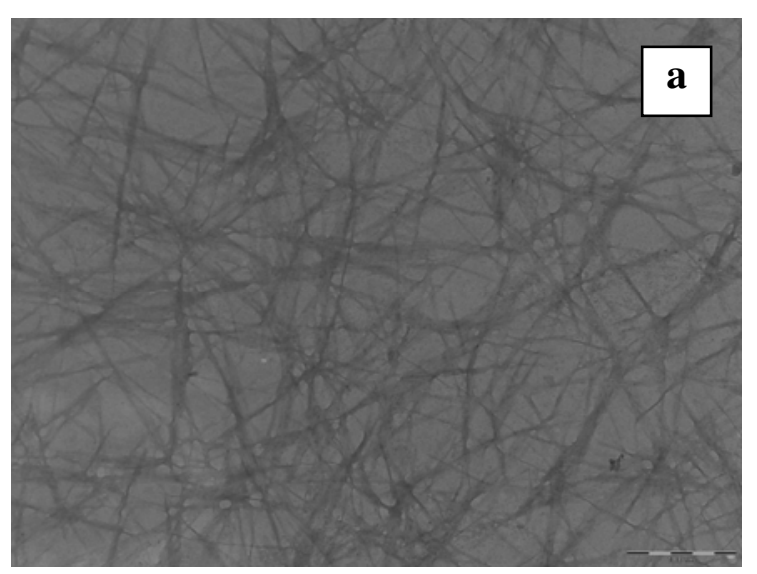




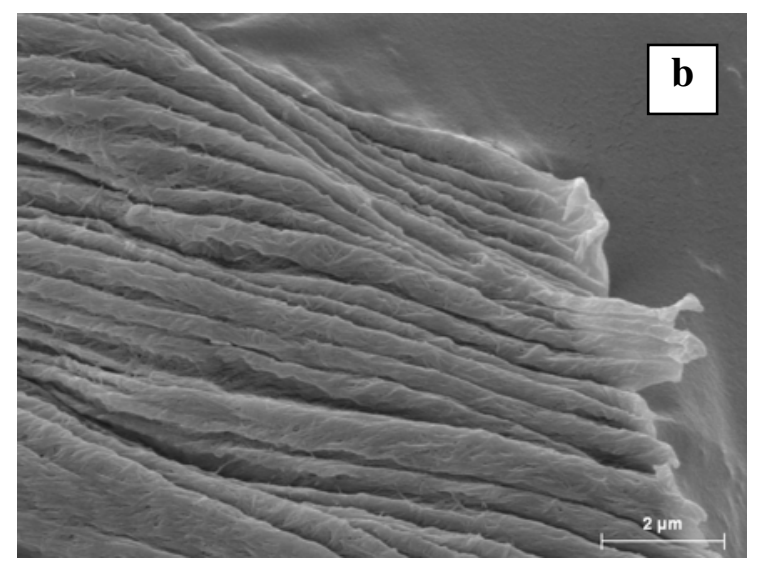

Figure 2. TEM micrographs of centrifuged BCNW (a) and SEM micrographs of freeze-dried BCNW (b). The scale markers are 1 micron in picture (a) and of 2 microns in picture (b).

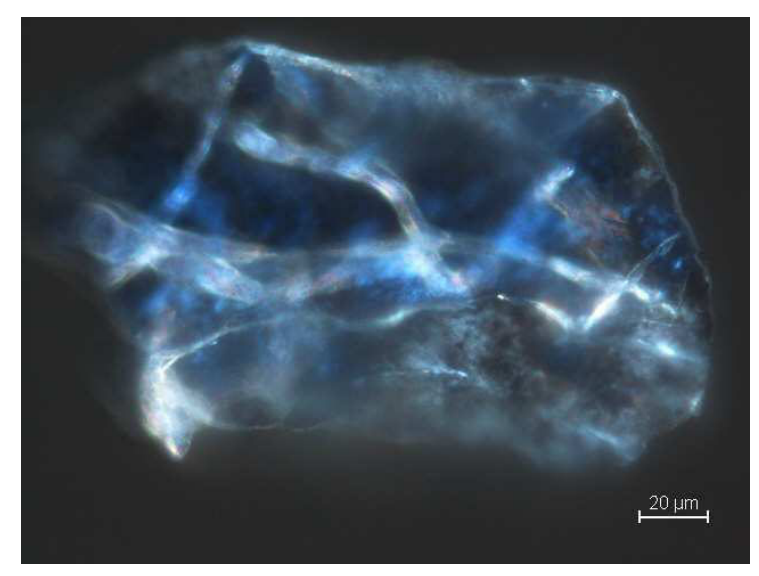

Figure 3. Polarized light optical microscopy image of freeze-dried BCNW.

The expected increase in the overall crystallinity of the resulting nanowhiskers as a result of the sulphuric acid breakdown of the $\mathrm{BC}$ mats was assessed by XRD and FT-IR analyses. This is caused by a more rapid and selective digestion of the non-crystalline domains by the acid treatment. The XRD 
patterns of bacterial cellulose and the corresponding nanowhiskers obtained after acid treatment are shown in Figure 4. Three major diffraction peaks are observed for both samples at $14.5^{\circ}, 16.4^{\circ}$ and $22.5^{\circ} 2 \theta$. According to the literature (Moharram \& Mahmoud, 2007), these diffraction peaks are ascribed to the cellulose I crystallographic planes $101,10 \overline{1}$ and 002 , respectively. Crystallinity indexes and crystallite sizes determined from the XRD data are listed in Table 1. The obtained crystallinity index for the bacterial cellulose (73.1\%) was found to be higher than values reported in previous studies (55.6\%) and it is similar to that of cotton lint plant cellulose (72.2\%) (Wong et al., 2009). As expected, the acid hydrolysis treatment led to an increase in the crystallinity of the material up to $82.2 \%$, which is comparable to that reported for commercial microcrystalline cellulose (MCC) (87.6\%) (Wong et al., 2009). Additionally, the average crystallite size calculated from the three crystalline planes of cellulose I increased after the hydrolysis, hence suggesting that, apart from digesting the amorphous regions, smaller and/or more defective crystals are also hydrolyzed during the acid treatment (cf. Table 1). 
Table 1. Crystallinity index $[\mathrm{CI}(\mathrm{XD})]$ and crystallite sizes $\left(D_{(101)}, D_{(1 \overline{0} 1)}\right.$ and $\left.D_{(002)}\right)$ determined from the XRD patterns from native bacterial cellulose (BC) and the obtained nanowhiskers (BCNW).

\begin{tabular}{|c|c|c|}
\cline { 2 - 3 } \multicolumn{1}{c|}{} & BC & BCNW \\
\hline CI (XD) (\%) & 73.1 & 82.2 \\
\hline$D_{(101)}(\mathrm{nm})$ & 0.68 & 0.83 \\
\hline$D_{(1 \overline{0} 1)}(\mathrm{nm})$ & 1.47 & 1.61 \\
\hline$D_{(002)}(\mathrm{nm})$ & 1.05 & 1.12 \\
\hline
\end{tabular}

Additionally, FT-IR analyses of raw bacterial cellulose and cellulose nanowhiskers were carried out in order to further study the structural and chemical effects of the acid treatment. A qualitative analysis of the FT-IR spectra shown in Figure 5 suggests that, after the acid treatment, a more crystalline material is obtained, since sharpening of some of the bands is observed after the acid hydrolysis. According to previous studies (Oh et al., 2005b), the bands at $4000-2995 \mathrm{~cm}^{-1}, 2900 \mathrm{~cm}^{-1}, 1430 \mathrm{~cm}^{-1}, 1375 \mathrm{~cm}^{-1}$ and $900 \mathrm{~cm}^{-1}$ are known to be especially sensitive to the cellulose molecular order. The shape of these bands was previously related to the amount of crystalline versus amorphous fractions in cellulose, that is, broadening of these bands was related to greater disorder in the polysaccharide phase morphology. The band ratio $\mathrm{A}_{1430} / \mathrm{A}_{900}$, which was used in previous studies (Oh et al., 2005a; Oh et al., 2005b) to estimate cellulose molecular order by FTIR, increased from 3.18 for $\mathrm{BC}$ to 4.72 for $\mathrm{BCNW}$, thus 
confirming the efficiency of the acid treatment in generating a more crystalline morphology and in good agreement with the X-ray data.

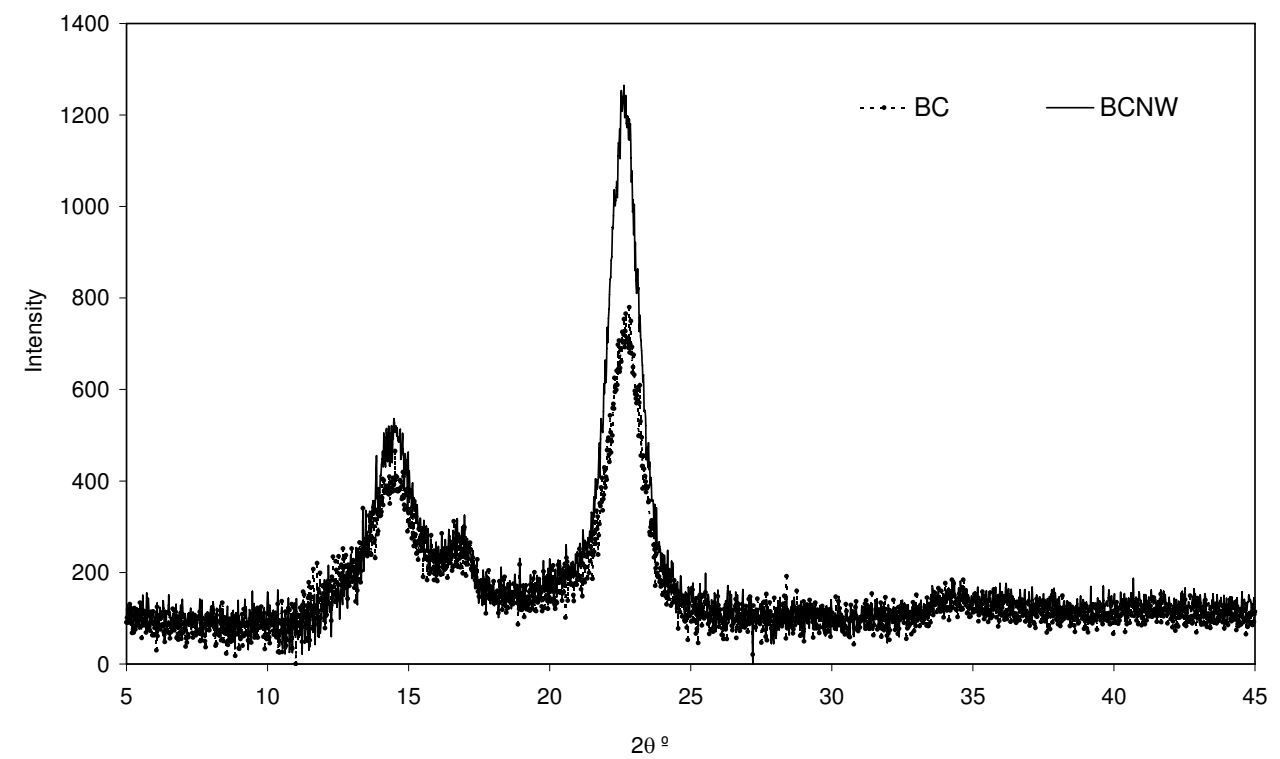

Figure 4. X-ray diffraction patterns of bacterial cellulose (BC) and of the extracted bacterial cellulose nanowhiskers (BCNW). 


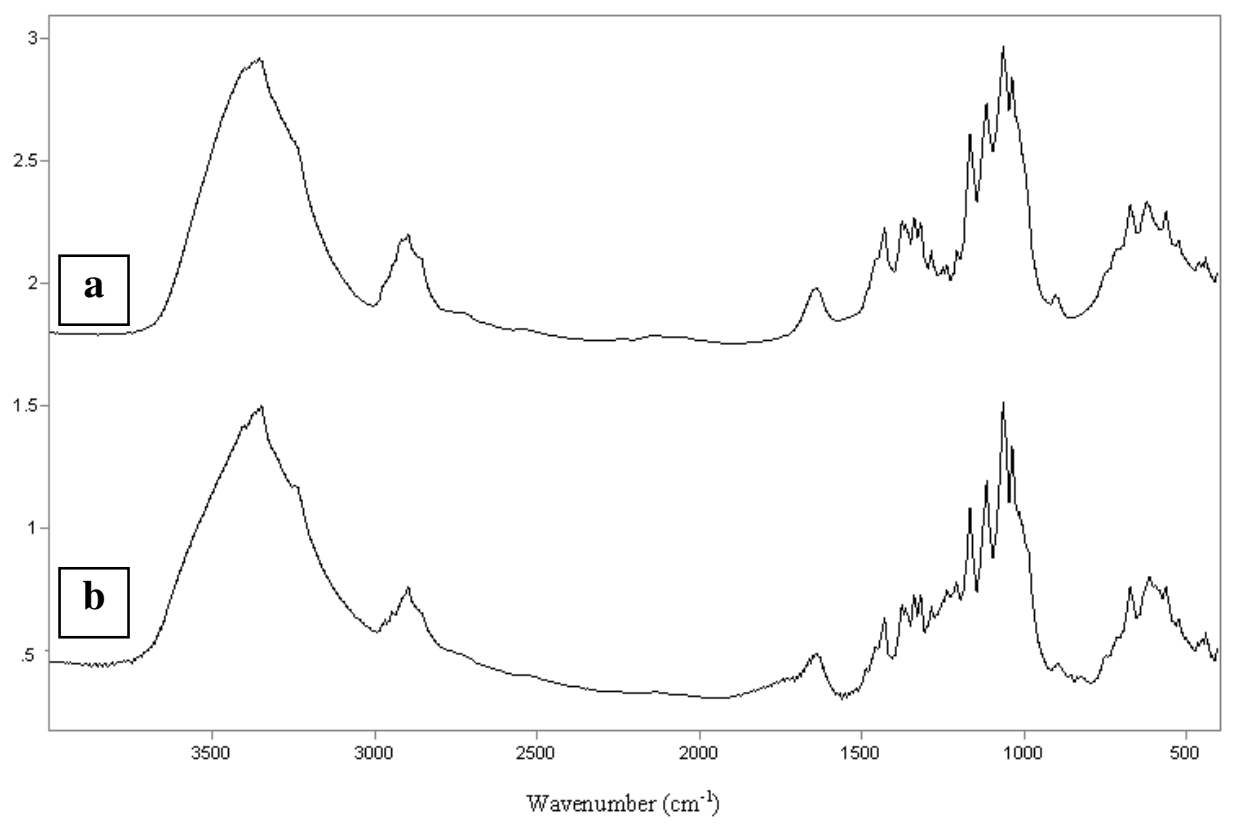

Figure 5. FT-IR spectra of (a) bacterial cellulose (BC) and (b) freeze-dried BCNW.

Previous studies have pointed out that treatment with the sulphuric acid reagent has an effect on the thermal stability of the cellulose crystals (Roman \& Winter, 2004). This effect results in lower thermal stability and in broadening of the degradation temperature range. The longer the hydrolysis time the stronger the breakdown of the mats into nanowhiskers but the lower the thermal stability attained due to increased sulphate incorporation into the $\mathrm{BC}$. We also anticipate, in light of current results which will be reported elsewhere, that the remaining acidity of the nanoproduct, even after extensive washing, can play a role in reducing thermal stability. In the present study, extensive acid treatment than that reported in a previous study (Roman \& Winter, 2004) was required to ensure digestion and breakdown of the thick cellulose mats. It should be mentioned that, despite the fact that 10 centrifugation cycles were carried out after the acid digestion of the 
samples, the $\mathrm{pH}$ of the obtained BCNW was still of ca. 3, suggesting that the nanomaterial remains essentially acid. Thermogravimetric analyses of raw BC and cellulose nanocrystals after the severe acid treatment showed that the degradation temperature decreased for the extracted nanomaterial (see Figure 6). Degradation takes place between approximately 175 and $325^{\circ} \mathrm{C}$ in the case of $\mathrm{BC}$, whereas, it occurs between 100 and $225^{\circ} \mathrm{C}$ after the acid treatment in BCNW. The effect of neutralization, dialysis and other processes to advance both nanofabrication and thermal stability for the cellulosic material will be reported elsewhere.

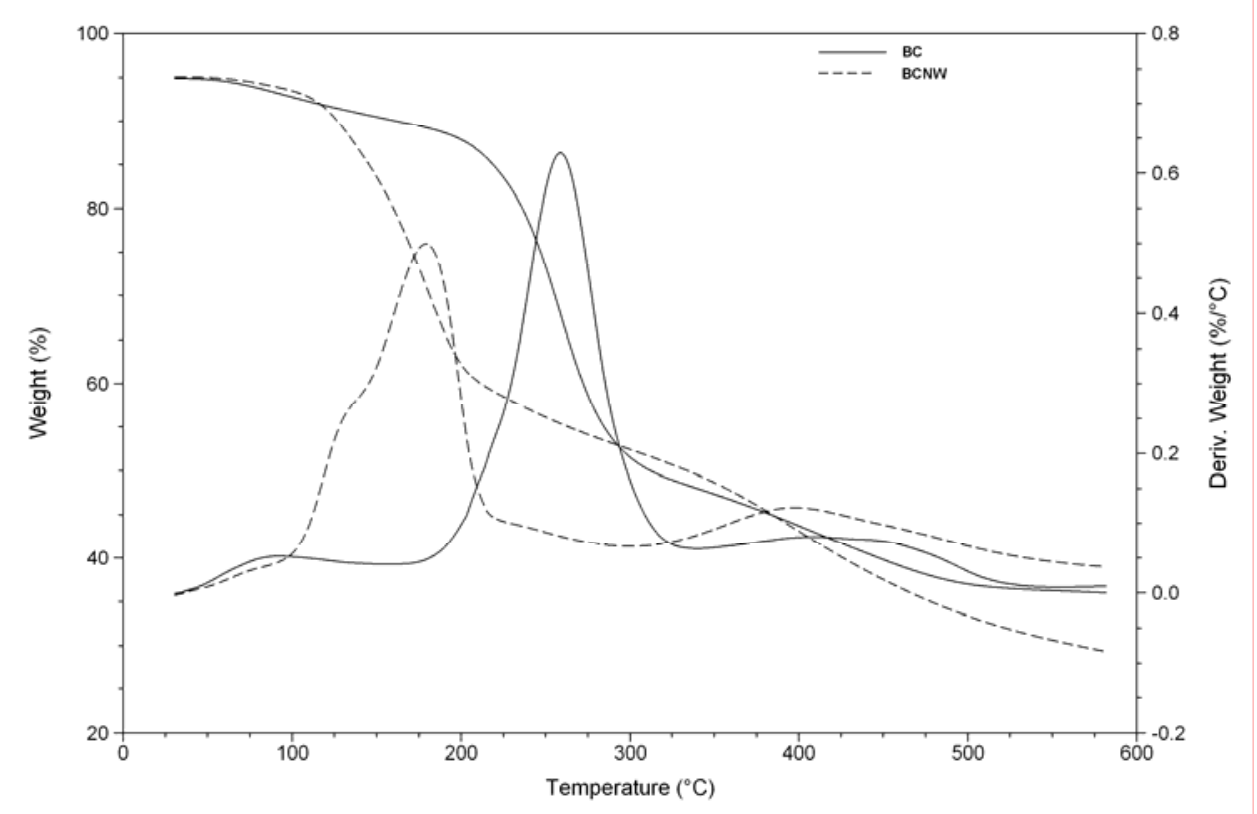

Figure 6. TG and DTG curves of native $\mathrm{BC}$ and $\mathrm{BCNW}$.

\subsection{Electrospinning of EVOH with BCNW}

The main goal of the present work was to study the suitability of the electrospinning technique as a way to incorporate $\mathrm{BCNW}$ in $\mathrm{EVOH}$ matrixes and 
to optimize the process in order to improve the dispersion of the whiskers within the fibres.

Firstly, BCNW were incorporated into the electrospinning solution both in the form of a precipitate obtained after centrifugation of the nanowhiskers' solution, and as freeze-dried powders in order to check which one of the methods led to improved dispersion of the cellulose whiskers within the EVOH matrixes. Additionally, several concentrations of centrifuged BCNW (with respect to EVOH weight) were used to study the corresponding change in properties on electrospun fibres. Furthermore, the effect of adding a sonication step for a fixed concentration of nanowhiskers was studied both in the case of centrifuged and freeze-dried BCNW.

Figure 7 shows the SEM micrographs of pure EVOH electrospun fibres and the related biohybrid ones obtained from solutions containing 5 wt.- $\%$ of centrifuged BCNW. Pure EVOH fibres show a beaded morphology, indicating that the chosen concentration of the polymer is not the optimal for obtaining pure EVOH fibres having a uniform morphology. Higher concentrations, on the other hand, led to lower feasible loadings of the filler during electrospinning. Nevertheless, it was observed that, when adding relatively low concentrations of $\mathrm{BCNW}$, the electrospun hybrid fibres presented a more homogeneous morphology, with lesser beading, but at the same time, with increased fibre diameter (see Figure 7b).

The effect of increasing the amount of centrifuged nanowhiskers in the electrospinning solution was studied. As shown in Figure 8, increasing the concentration of whiskers led to a significant decrease in the diameter of the achieved electrospun fibres, from an average diameter of $234.6 \mathrm{~nm}$ for the fibres obtained from 1 wt.-\% BCNW to an average diameter of $190.98 \mathrm{~nm}$ for those 
obtained from 8 wt.-\% BCNW, and to a more uniform morphology. Increasing the BCNW concentration up to $8 \mathrm{wt}$. - $\%$ produced statistically significant differences in the diameter of the fibres with respect to the pure EVOH and the $1 \mathrm{wt} .-\% \mathrm{BCNW}$ samples (with a $95 \%$ confidence level).This decrease in the diameter of electrospun fibres when increasing the amount of cellulose nanowhiskers in the electrospinning solution has been previously reported for polystyrene and poly(vinyl alcohol) electrospun fibres (Peresin et al., 2010; Rojas et al., 2009) with CNW concentrations up to 15 wt. $\%$ and was related to an increase in the fibres conductivity when incorporating negatively charged $\mathrm{CNW}$ in the electrospinning solution. In addition to a decrease in the fibres' diameter, the BCNW incorporation gave rise to less beaded fibres. As seen in Figure 7, pure EVOH fibres have a beaded morphology, thus causing the size distribution to be highly displaced towards greater diameters, i.e. a long tail is observed for this sample in Figure 8. This tail is considerably reduced by incorporating BCNW into the EVOH fibres, just as shown in Figure 8.
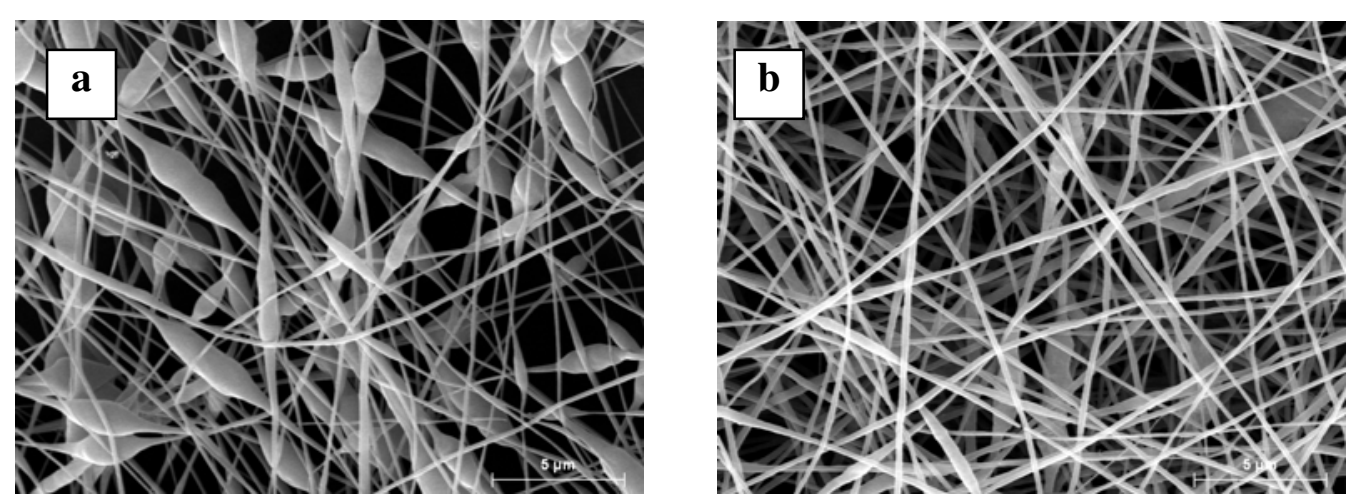

Figure 7. SEM micrographs of electrospun fibres obtained from (a) EVOH and (b)

$\mathrm{EVOH}+5$ wt. $-\%$ centrifuged BCNW. 


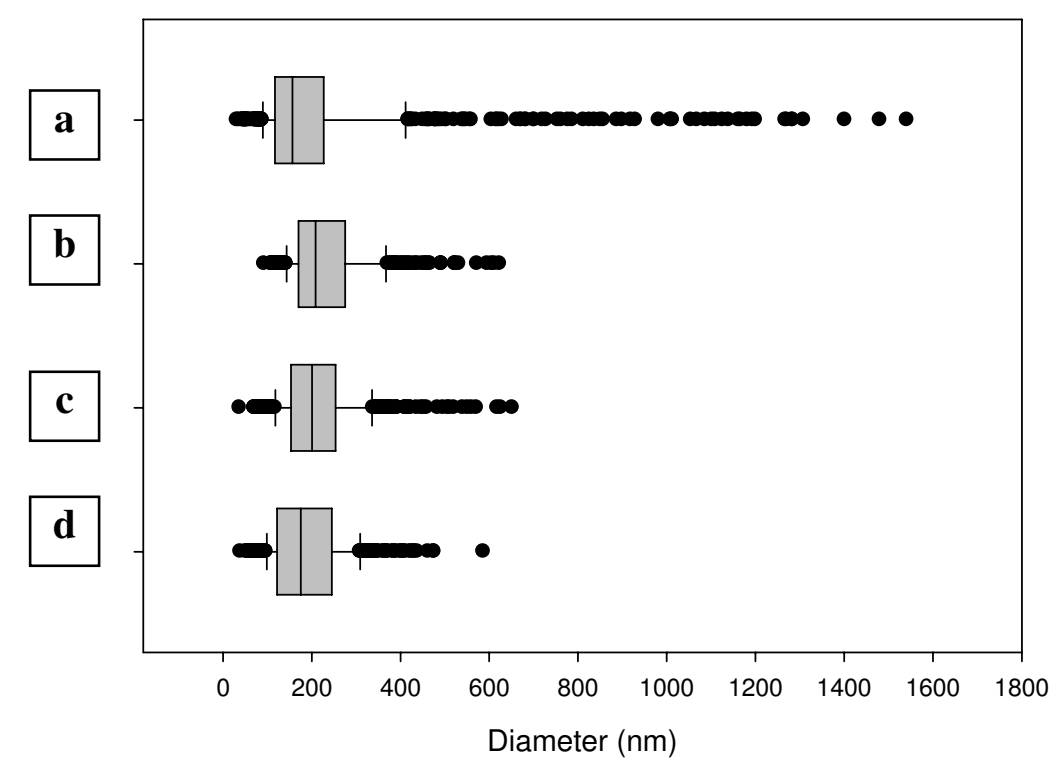

Figure 8. Box plot of size distribution of electrospun fibres obtained from (a) EVOH; (b) EVOH + 1 wt.- $\%$ centrifuged BCNW; (c) EVOH + 5 wt.- $\%$ centrifuged BCNW; (d) EVOH +8 wt.- $\%$ centrifuged BCNW.

A concentration of $8 \mathrm{wt} .-\%$ was chosen to compare the morphology of fibres incorporating freeze-dried and centrifuged whiskers because it provided stable electrospinning conditions for the composites, as observed for centrifuged BCNWs, and a reasonable filler loading for characterization. Table 2 shows the viscosity of electrospinning solutions and the mean diameter of electrospun fibres. It was not possible to measure the viscosity of the $8 \mathrm{wt} .-\%$ sonicated centrifuged $\mathrm{BCNW}$ solution, since it was a heterogeneous gel-like suspension containing clear agglomerates. Clearly, by adding BCNW to the EVOH solution and thus increasing the solids content, an increase is produced in viscosity of the electrospinning solutions. Additionally, as observed in Table 2, for EVOH-BCNW solutions having the same solids content, an increase in the viscosity seems to give rise to a decrease in the diameter of the achieved electrospun fibres. 
Table 2. Viscosity of electrospinning solutions and mean diameter of the corresponding electrospun fibres. "S" refers to the solutions that were subjected to sonication.

\begin{tabular}{|l|c|c|}
\cline { 2 - 3 } \multicolumn{1}{c|}{} & Viscosity (cP) & Mean fibre diameter (nm) \\
\hline 5 wt.-\% EVOH & 27.27 & 224.47 \\
\hline 8 wt.-\% Centrifuged BCNW & 1387.70 & 190.98 \\
\hline 8 wt.-\% Freeze-dried BCNW & 33.97 & 381.54 \\
\hline 8 wt.-\% Centrifuged BCNW S & not measurable & 285.50 \\
\hline 8 wt.-\% Freeze-dried BCNW S & 353.24 & 248.52 \\
\hline
\end{tabular}

Figure 9 shows the cross-section distribution of electrospun composite fibres containing both centrifuged and freeze-dried BCNW. Freeze-drying gives rise to fibres with a less uniform size distribution, displaced towards greater diameters, and presenting beaded morphologies.

The sonication step has different effects depending on the processing method for the whiskers, as shown in Figure 10. For the 8 wt.-\% centrifuged BCNW solution, adding a sonication step leads to bigger and more beaded fibres. On the other hand, for the 8 wt.- $\%$ freeze-dried BCNW solution, sonication significantly increases the viscosity of the solution and, subsequently, there is a decrease in both the diameter of the fibres and the amount of beads formed. 

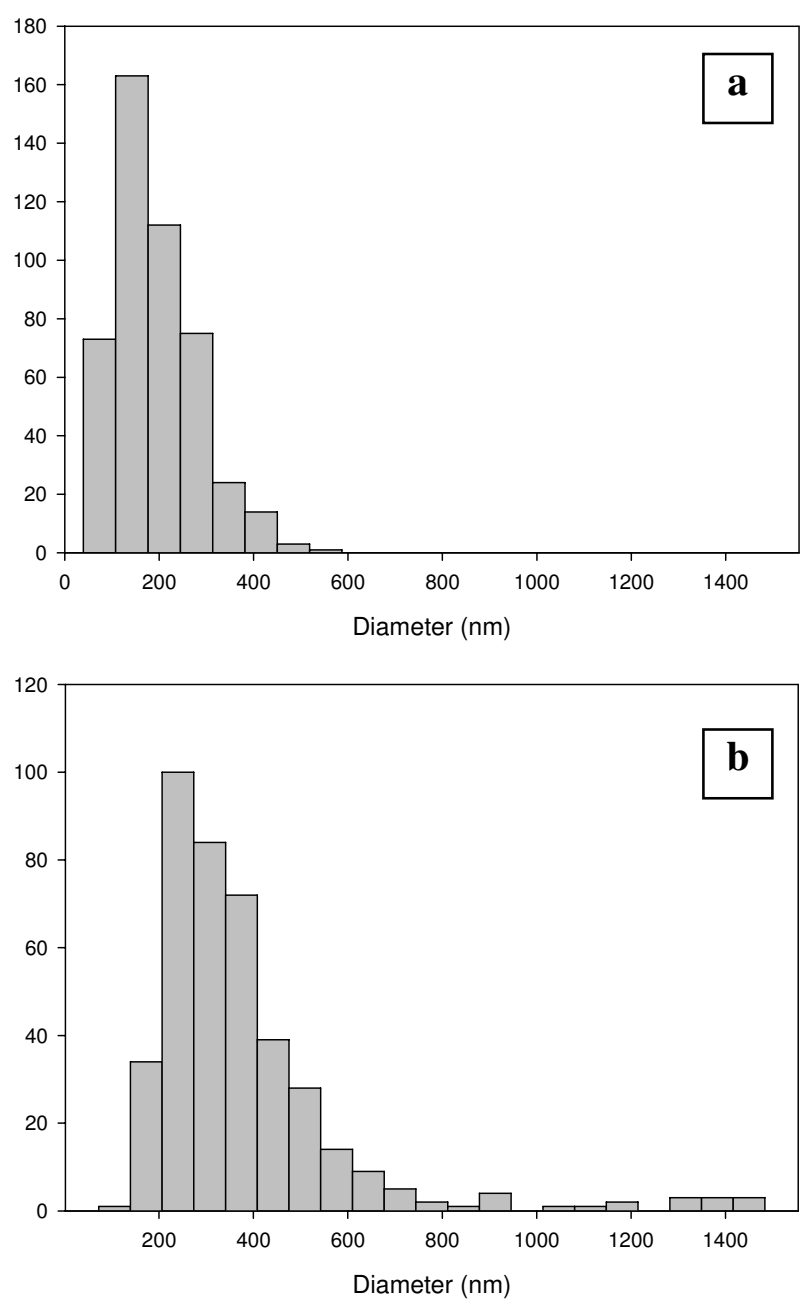

Figure 9. Histograms (taken from at least 400 measurements) representing the size distribution of electrospun EVOH-based fibres obtained from solutions containing: (a) 8 wt.- $\%$ of centrifuged BCNW and (b) 8 wt.- $\%$ of freeze-dried BCNW. 

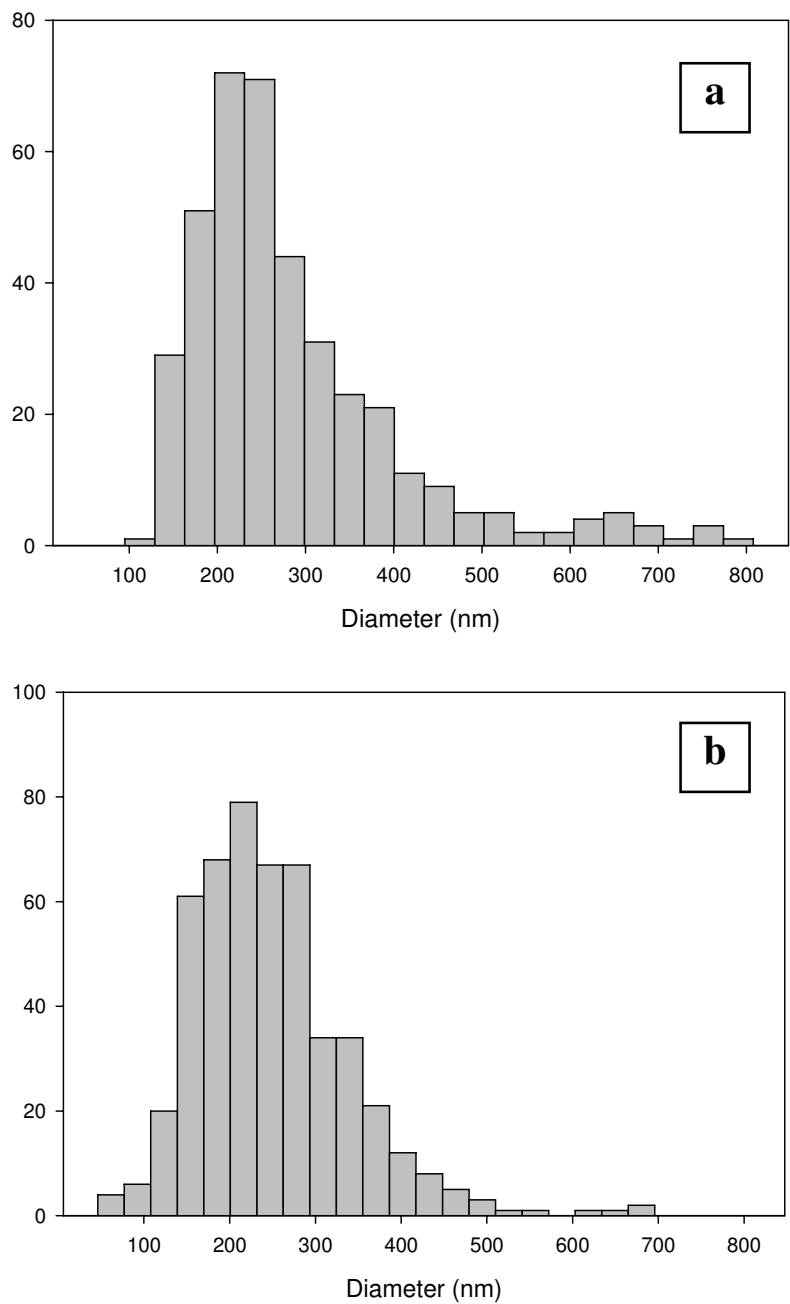

Figure 10. Histograms (taken from at least 400 measurements) representing the size distribution of electrospun EVOH-based fibres obtained from solutions containing: (a) 8 wt.- $\%$ of sonicated centrifuged BCNW and (b) 8 wt.- $\%$ of sonicated freeze-dried BCNW.

The various electrospun samples were finally analysed using transmission FTIR spectroscopy, in order to determine whether the expected incorporation of 
nanowhiskers into the $\mathrm{EVOH}$ electrospun fibres had been achieved during electrospinning. Thus, in order to estimate the amount of BCNW incorporated into the electrospun fibres from the electrospinning solutions, a calibration curve with known amounts of the two components was previously generated (result not shown). Spectra of $\mathrm{KBr}$ pellets containing different concentrations of EVOH and BCNW were analyzed to locate a characteristic band which could be used to estimate the concentration of whiskers. Due to the similar chemical structure, most characteristic cellulose bands do overlap with infrared bands of EVOH. However, after careful analyses of the whole spectral range, the band at $1165 \mathrm{~cm}^{-1}$, which corresponds to the C-O-C asymmetric stretching (Carrillo et al., 2004), was chosen as the characteristic band for cellulose, since the contribution of $\mathrm{EVOH}$ to this range was relatively small. The intensity of this band was divided by the intensity of the band at $838 \mathrm{~cm}^{-1}$, which corresponds to skeletal vibrations and $\mathrm{CH}_{2}$ rocking of EVOH (Lagaron et al., 2003). Subsequently, the IR spectra of the electrospun fibres were analyzed and the percentages of $\mathrm{BCNW}$ incorporated into the fibres from the solutions were estimated.

Figure 11 shows the FT-IR spectra of fibres obtained from solutions containing 8 wt.-\% of freeze-dried and centrifuged whiskers. From observation of Figure 11, it seems that freeze-dried whiskers were not completely incorporated into the EVOHbased electrospun fibres since the $\mathrm{BC}$ characteristic peaks are not present in the spectrum of this material. On the contrary, the degree of incorporation of centrifuged whiskers seems greater, as deduced from the increase in intensity of the characteristic bands when increasing the amount of whiskers added to the fibres. Indeed, the degree of incorporation estimated by applying the calibration equation for this particular sample was 7.5 wt.-\% for centrifuged BCNW versus only 2.4 wt.-\% in the case of freeze-dried BCNW. Even though the calculated degree of BCNWs' incorporation can be used just as an estimation, this result indicates that 
agglomeration of freeze-dried BCNWs took place in the electrospinning solution and thus, a significant amount of the nanofiller was not incorporated but remained as a residue in the electrospinning syringe.

The effect of sonication, in agreement with SEM observations, is different for freeze-dried and centrifuged whiskers. The intensity of the characteristic peaks of cellulose slightly decreased when sonication was applied to centrifuged BCNW whereas it produces the opposite effect in the case of freeze-dried BCNW, suggesting a higher degree of incorporation caused by sonication in the latter case. When applying sonication, the degree of incorporation fell down to a $3.7 \%$ in the case of centrifuged $\mathrm{BCNW}$, caused by re-agglomeration of a heterogeneous gellike material, while for freeze-dried BCNW it increased up to $4 \%$.

These differences in the concentration of BCNW effectively incorporated into the fibres can be related to the viscosity of the several electrospinning solutions. Higher viscosities seem to be associated with a better dispersion of the nanofiller, therefore leading to higher incorporation degrees. At the same time, these incorporation degrees can also explain the differences observed in the diameters of fibres (see Table 2), so that the higher the amount of nanowhiskers incorporated into the fibres, the lower the average diameter of the electrospun fibres. This effect has been previously reported for hybrid PVA-CNW fibres and it has been related to an increase in the conductivity of the electrospinning solution when incorporating the negatively charged nanowhiskers (Peresin et al., 2010). 


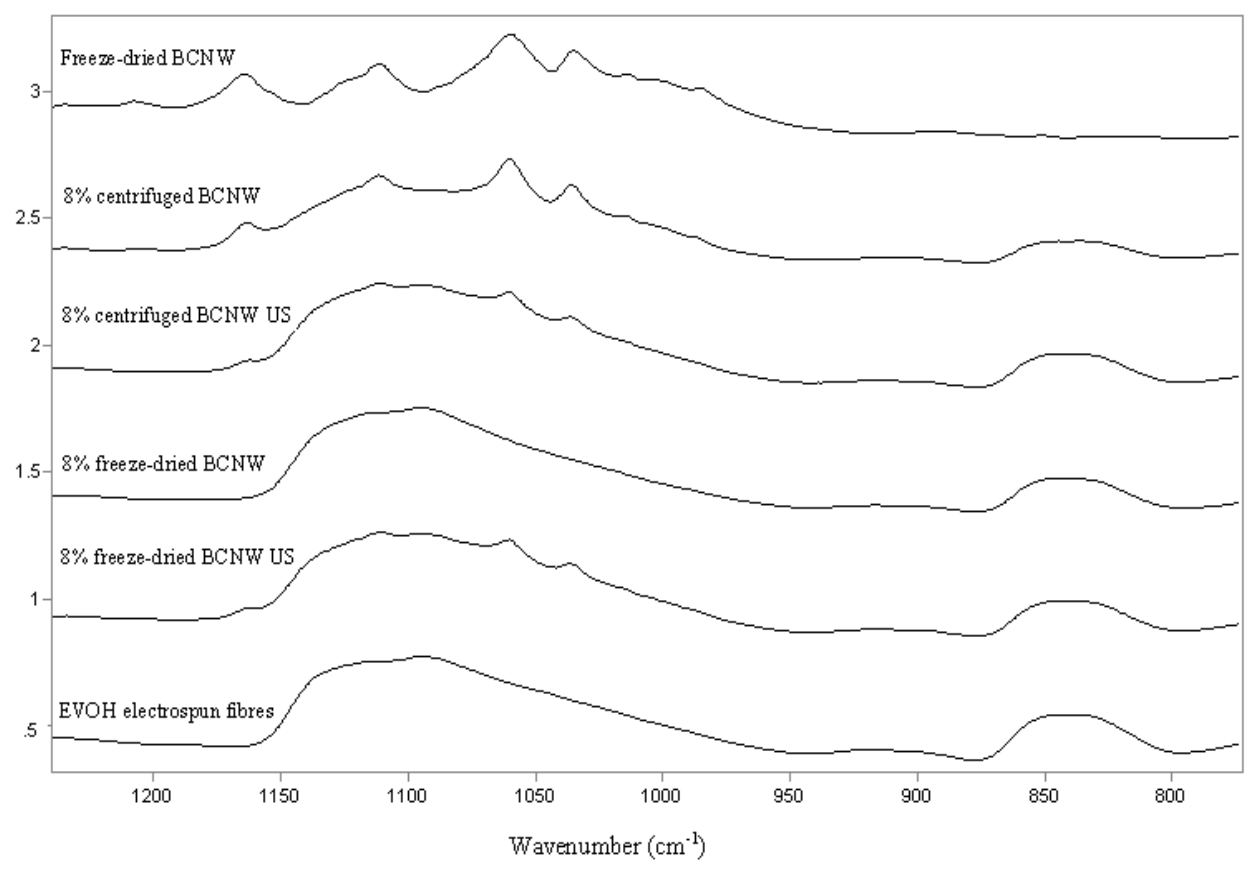

Figure 11. FT-IR spectra of: Freeze-dried BCNW; electrospun fibres obtained from $\mathrm{EVOH}+8$ wt. $\%$ centrifuged $\mathrm{BCNW}$; electrospun fibres obtained from $\mathrm{EVOH}+8$ wt. $-\%$ sonicated centrifuged $\mathrm{BCNW}$; electrospun fibres obtained from $\mathrm{EVOH}+8$ wt.- $\%$ freeze-dried $\mathrm{BCNW}$; electrospun fibres obtained from $\mathrm{EVOH}+8$ wt.-\% sonicated freeze-dried BCNW; and pure EVOH electrospun fibres. Data have been offset for clarity.

DSC analyses of all the samples were carried out in order to investigate the change in thermal properties of electrospun fibres as a result of the addition of BCNW. Table 3 gathers the melting point, melting enthalpies and the glass transition temperature $\left(\mathrm{T}_{\mathrm{g}}\right)$ of the electrospun fibres. From the first heating run, it is clearly observed that depending on the method of incorporation of BCNW the thermal properties vary. The addition of centrifuged BCNW leads to a significant decrease in the melting enthalpy, being this effect more pronounced when increasing the BCNWs concentration. This result indicates that the presence of 
dispersed whiskers along the fibres is partially impeding the organization of the EVOH polymeric chains into ordered structures during the electrospinning process. Similar results indicating that nanoparticles may hinder the EVOH crystallization process have been previously reported for $\mathrm{EVOH} /$ organoclay composites (Artzi et al., 2005). In contrast, the melting enthalpy of fibres containing freeze-dried BCNW whether sonicated or not was not significantly affected, although a melting temperature drop was observed in the sonicated sample, hence suggesting that the crystallinity content of the material may not be significantly affected but smaller or more defective crystals are formed due to higher dispersion after sonication of this sample. In summary, while freeze-dried BCNW do not affect the crystallinity content, addition of centrifuged BCNW partially hinders the crystallization of EVOH. This different behaviour could be ascribed to the different physical state of the incorporated whiskers: for the freeze-dried samples, BCNW were forming agglomerates and had to be re-dispersed in the solution, while for the centrifuged samples, as they were initially hydrated, they could easily be dispersed in the aqueous solutions.

The $\mathrm{T}_{\mathrm{g}}$ of the various materials obtained from the first DSC heating run was not significantly altered by introducing $\mathrm{BCNW}$ into the electrospun fibres regardless the incorporation method, as reported previously for bacterial cellulose whisker-based composites (Grunert \& Winter, 2002).

However, during the second heating run, except for the pure EVOH and the fibres obtained from solutions containing 1 wt.-\% of centrifuged BCNW, no melting endotherm was observed, thus indicating that the BCNW incorporated into the EVOH matrixes prevent the material from re-crystallizing during the relatively 
slower cooling run when compared to the rapid crystallization process that takes place during electrospinning.

Interestingly, a significant increase in the $T_{g}$ of the hybrid composite was obtained from the second heating run, which seems to increase with the amount of reinforcing agent in the $\mathrm{EVOH}$ matrixes. The explanation for this stiffening behaviour after the second endotherm is mostly likely related to a partial degradation of the acid BCNWs and will be more extensively studied in the second part of this work.

The increase in the $T_{g}$ of the material observed during the second heating run, is more pronounced in the fibers containing the centrifuged whiskers (without sonication), indicating that higher amounts of BCNW are incorporated into the fibres and, thus, confirming the higher efficiency of this incorporation method. Overall, by adding ca. 8 wt.- $\%$ of whiskers, the $\mathrm{T}_{\mathrm{g}}$ of the EVOH composite increased by approximately $10^{\circ} \mathrm{C}$. Moreover, as previously suggested by FT-IR and confirmed by the smaller increase in $\mathrm{T}_{\mathrm{g}}$, sonication previous to addition of the centrifuged $\mathrm{BCNW}$, results in a lower degree of incorporation of whiskers into the fibres although it seems that leads to a more efficient stiffening (see last column in Table 3). Thus, it is interesting to observe that the relative increase in $T_{g}$ normalized per "true" filler loading incorporated in the fibres as determined by FTIR, suggests that after sonication, even when the filler incorporation becomes lower, the stiffening efficiency of the incorporated BCNW is higher.

In the case of freeze-dried BCNW, sonication produced a significant increase in the $T_{g}$ with regard to the non-sonicated counterpart suggesting, in good agreement with the FT-IR results, that a higher amount of nanowhiskers was incorporated into the fibres and that these promoted a very efficient interfacial 
interaction with the polymer. Despite the fact that the amount of $\mathrm{BCNW}$ incorporated into the fibres was lower than intended, in view of the nanofiller fraction added to the solution, the highest relative increase in the $T_{g}$ was achieved by sonication with both centrifuged and freeze-dried BCNW.

As a result, sonication brings in advantages in promoting interactions with the matrix but can also cause re-agglomeration and excessive viscosity for electrospinning in the centrifuged filler and, since the objective of this work was to generate electrospun fibres with high loadings of dispersed $\mathrm{BCNW}$ in the matrix, the use of this additional step is not advisable.

Table 3. DSC maximum of melting $\left(T_{m}\right)$, melting enthalpy $\left(\Delta H_{m}\right)$, glass transition temperature $\left(\mathrm{T}_{\mathrm{g} 1}\right)$, of electrospun fibres obtained from the first heating run and glass transition temperature $\left(\mathrm{T}_{\mathrm{g} 2}\right)$, obtained from the second heating run and ratio between the increase in the $\mathrm{T}_{\mathrm{g} 2}$ (with respect to pure $\mathrm{EVOH}$ fibres) and the incorporated BCNW (wt.-\%) loading as determined by FTIR.

\begin{tabular}{|c|c|c|c|c|c|}
\cline { 2 - 6 } \multicolumn{1}{c|}{} & $\mathrm{T}_{\mathrm{m}}\left({ }^{\circ} \mathrm{C}\right)$ & $\begin{array}{c}\Delta \mathrm{H}_{\mathrm{m}} \\
(\mathrm{J} / \mathrm{g} \text { EVOH})\end{array}$ & $\mathrm{T}_{\mathrm{g} 1}\left({ }^{\circ} \mathrm{C}\right)$ & $\mathrm{T}_{\mathrm{g} 2}\left({ }^{\circ} \mathrm{C}\right)$ & $\begin{array}{c}\Delta \mathrm{T}_{\mathrm{g} 2} / \% \\
\mathrm{BCNW}\end{array}$ \\
\hline EVOH & $191.4 \pm 0.7$ & $73.4 \pm 0.4$ & $72.6 \pm 0.1$ & $61.8 \pm 0.6$ & --- \\
\hline $\begin{array}{c}\text { EVOH + 1\% } \\
\text { Centrifuged BCNW }\end{array}$ & $191.4 \pm 0$ & $69.6 \pm 0.9$ & $72.3 \pm 0.1$ & $63.4 \pm 0.0$ & 1.60 \\
\hline $\begin{array}{c}\text { EVOH + 5\% } \\
\text { Centrifuged BCNW }\end{array}$ & $188.5 \pm 1.7$ & $58.8 \pm 4.0$ & $72.4 \pm 0.3$ & $69.6 \pm 0.9$ & 1.56 \\
\hline $\begin{array}{c}\text { EVOH + 8\% } \\
\text { Centrifuged BCNW }\end{array}$ & $188.3 \pm 0.6$ & $56.9 \pm 1.1$ & $72.5 \pm 0.2$ & $72.4 \pm 0.3$ & 1.41 \\
\hline $\begin{array}{c}\text { EVOH + 8\% } \\
\text { Centrifuged BCNW } \\
\text { (US) }\end{array}$ & $187.8 \pm 0.8$ & $57.0 \pm 0.4$ & $72.3 \pm 0.2$ & $70.8 \pm 0.1$ & 2.43 \\
\hline $\begin{array}{c}\text { EVOH + 8\% Freeze- } \\
\text { dried BCNW }\end{array}$ & $187.5 \pm 1.2$ & $75.1 \pm 3.5$ & $72.6 \pm 0.5$ & $64.7 \pm 0.5$ & 1.21 \\
\hline $\begin{array}{c}\text { EVOH + 8\% Freeze- } \\
\text { dried BCNW (US) }\end{array}$ & $185.2 \pm 0.7$ & $72.04 \pm 1.4$ & $72.0 \pm 0.4$ & $72.3 \pm 0.2$ & 2.63 \\
\hline
\end{tabular}




\section{CONCLUSIONS}

This study shows that, in agreement with previous research, treatment of purified bacterial cellulose with sulphuric acid is an effective way of extracting cellulose nanowhiskers, consisting of highly crystalline cellulose I structures of nanofibrils aggregates. However, the thermal stability of the repeatedly washed cellulosic material was seen to decrease after the sulphuric acid treatment.

Hybrid BC nanowhiskers and EVOH fibres were generated by means of electrospinning having a more uniform morphology than the pure polymer electrospun fibres. A morphology of less beaded fibres, having the smallest diameter, was obtained with centrifuged $\mathrm{BCNWs}$ and increasing the concentration up to 8 wt.- $\%$.

Taking into account the relative increase in the $T_{g}$ as well as the degree of incorporation of $\mathrm{BCNW}$ into the electrospun fibres calculated from the FTIR spectra, it was confirmed that a more effective incorporation of nanowhiskers was achieved when adding them in the form of a centrifuged precipitate without applying sonication.

Sonication was found to more efficiently increase the $T_{\mathrm{g}}$ of the composite per filler content, probably due to stronger induced interfacial interaction of the BCNWs with the matrix. Additionally, sonication improved the incorporation level of the nanofiller when added as a freeze-dried product, although it produced the contrary effect on centrifuged nanowhiskers.

These results highlight the adequacy of the method developed for the incorporation and proper dispersion of $\mathrm{BCNW}$ into $\mathrm{EVOH}$ matrixes, which yielded novel hybrid electrospun fibres. 


\section{REFERENCES}

Anglès, M. N., \& Dufresne, A. (2001). Plasticized starch/tunicin whiskers nanocomposite materials. 2: Mechanical behavior. Macromolecules, 34(9), 29212931.

Artzi, N., Narkis, M., \& Siegmann, A. (2005). Review of melt-processed nanocomposites based on EVOH/organoclay. Journal of Polymer Science, Part B: Polymer Physics, 43(15), 1931-1943.

Bielecki, S., Krystynowicz, A., Turkiewicz, M., \& Kalinowska, H. (2002). Bacterial cellulose. Biopolymers, 5, 37-90.

Bondeson, D., Mathew, A., \& Oksman, K. (2006). Optimization of the isolation of nanocrystals from microcrystalline cellulose by acid hydrolysis. Cellulose, 13(2), 171-180.

Carrillo, F., Colom, X., Suñol, J. J., \& Saurina, J. (2004). Structural FTIR analysis and thermal characterisation of lyocell and viscose-type fibres. European Polymer Journal, 40(9), 2229-2234.

De Souza Lima, M. M., \& Borsali, R. (2004). Rodlike cellulose microcrystals: Structure, properties, and applications. Macromolecular Rapid Communications, 25(7), 771-787.

Garcia de Rodriguez, N. L., Thielemans, W., \& Dufresne, A. (2006). Sisal cellulose whiskers reinforced polyvinyl acetate nanocomposites. Cellulose, 13(3), 261-270.

Gindl, W., \& Keckes, J. (2004). Tensile properties of cellulose acetate butyrate composites reinforced with bacterial cellulose. Composites Science and Technology, 64(15 SPEC. ISS.), 2407-2413.

Grunert, M., \& Winter, W. T. (2002). Nanocomposites of cellulose acetate butyrate reinforced with cellulose nanocrystals. Journal of Polymers and the Environment, $10(1-2), 27-30$.

Iguchi, M., Yamanaka, S., \& Budhiono, A. (2000). Bacterial cellulose - a masterpiece of nature's arts. Journal of Materials Science, 35(2), 261-270. 
Jonas, R., \& Farah, L. F. (1998). Production and application of microbial cellulose. Polymer Degradation and Stability, 59(1-3), 101-106.

Kim, C. W., Frey, M. W., Marquez, M., \& Joo, Y. L. (2005). Preparation of submicron-scale, electrospun cellulose fibers via direct dissolution. Journal of Polymer Science, Part B: Polymer Physics, 43(13), 1673-1683.

Kim, C. W., Kim, D. S., Kang, S. Y., Marquez, M., \& Joo, Y. L. (2006). Structural studies of electrospun cellulose nanofibers. Polymer, 47(14), 5097-5107.

Lagaron, J. M., Gimenez, E., Catala, R., \& Gavara, R. (2003). Mechanisms of moisture sorption in barrier polymers used in food packaging: Amorphous polyamide vs. high-barrier ethylene-vinyl alcohol copolymer studied by vibrational spectroscopy. Macromolecular Chemistry and Physics, 204(4), 704-713.

Millon, L. E., \& Wan, W. K. (2006). The polyvinyl alcohol-bacterial cellulose system as a new nanocomposite for biomedical applications. Journal of Biomedical Materials Research - Part B Applied Biomaterials, 79(2), 245-253.

Moharram, M. A., \& Mahmoud, O. M. (2007). X-Ray diffraction methods in the study of the effect of microwave heating on the transformation of cellulose $\mathrm{i}$ into cellulose II during mercerization. Journal of Applied Polymer Science, 105(5), 2978-2983.

Oh, S. Y., Dong, I. Y., Shin, Y., Hwan, C. K., Hak, Y. K., Yong, S. C., Won, H. P., \& Ji, H. Y. (2005a). Crystalline structure analysis of cellulose treated with sodium hydroxide and carbon dioxide by means of X-ray diffraction and FTIR spectroscopy. Carbohydrate Research, 340(15), 2376-2391.

Oh, S. Y., Yoo, D. I., Shin, Y., \& Seo, G. (2005b). FTIR analysis of cellulose treated with sodium hydroxide and carbon dioxide. Carbohydrate Research, $340(3), 417-428$.

Oksman, K., Mathew, A. P., Bondeson, D., \& Kvien, I. (2006). Manufacturing process of cellulose whiskers/polylactic acid nanocomposites. Composites Science and Technology, 66(15), 2776-2784.

Olsson, R. T., Kraemer, R., Lopez-Rubio, A., Torres-Giner, S., Ocio, M. J., \& Lagaron, J. M. (2010). Extraction of microfibrils from bacterial cellulose networks for electrospinning of anisotropic biohybrid fiber yarns. Macromolecules, 43(9), 4201-4209. 
Orts, W. J., Shey, J., Imam, S. H., Glenn, G. M., Guttman, M. E., \& Revol, J. F. (2005). Application of cellulose microfibrils in polymer nanocomposites. Journal of Polymers and the Environment, 13(4), 301-306.

Park, W. I., Kang, M., Kim, H. S., \& Jin, H. J. (2007). Electrospinning of poly(ethylene oxide) with bacterial cellulose whiskers. Macromolecular Symposia, 249-250, 289-294.

Peresin, M. S., Habibi, Y., Zoppe, J. O., Pawlak, J. J., \& Rojas, O. J. (2010). Nanofiber composites of polyvinyl alcohol and cellulose nanocrystals: Manufacture and characterization. Biomacromolecules, 11(3), 674-681.

Rojas, O. J., Montero, G. A., \& Habibi, Y. (2009). Electrospun nanocomposites from polystyrene loaded with cellulose nanowhiskers. Journal of Applied Polymer Science, 113(2), 927-935.

Roman, M., \& Winter, W. T. (2004). Effect of sulfate groups from sulfuric acid hydrolysis on the thermal degradation behavior of bacterial cellulose. Biomacromolecules, 5(5), 1671-1677.

Torres-Giner, S., Ocio, M. J., \& Lagaron, J. M. (2008). Development of active antimicrobial fiber based chitosan polysaccharide nanostructures using electrospinning. Engineering in Life Sciences, 8(3), 303-314.

Wan, Y. Z., Huang, Y., Yuan, C. D., Raman, S., Zhu, Y., Jiang, H. J., He, F., \& Gao, C. (2007). Biomimetic synthesis of hydroxyapatite/bacterial cellulose nanocomposites for biomedical applications. Materials Science and Engineering $C$, 27(4), 855-864.

Wan, Y. Z., Luo, H., He, F., Liang, H., Huang, Y., \& Li, X. L. (2009). Mechanical, moisture absorption, and biodegradation behaviours of bacterial cellulose fibrereinforced starch biocomposites. Composites Science and Technology, 69(7-8), 1212-1217.

Wong, S.-S., Kasapis, S., \& Tan, Y. M. (2009). Bacterial and plant cellulose modification using ultrasound irradiation. Carbohydrate Polymers, 77(2), 280-287.

Yamanaka, S., Watanabe, K., Kitamura, N., Iguchi, M., Mitsuhashi, S., Nishi, Y., \& Uryu, M. (1989). The structure and mechanical properties of sheets prepared from bacterial cellulose. Journal of Materials Science, 24(9), 3141-3145. 
Zhou, L. L., Sun, D. P., Hu, L. Y., Li, Y. W., \& Yang, J. Z. (2007). Effect of addition of sodium alginate on bacterial cellulose production by Acetobacter xylinum. Journal of Industrial Microbiology and Biotechnology, 34(7), 483-489. 


\section{Chapter II}

\section{DEVELOPMENT OF BACTERIAL CELLULOSE NANOWHISKERS REINFORCED EVOH COMPOSITES BY ELECTROSPINNING}

Journal of Applied Polymer Science, 124(2), 1398-1408 (2012)

Marta Martínez Sanz ${ }^{1}$, Richard T. Olsson ${ }^{2}$, Amparo López Rubio ${ }^{1}$, José María Lagarón ${ }^{1}$

${ }^{1}$ Novel Materials and Nanotechnology Group, IATA, CSIC. Avd. Agustín Escardino, 7, 46980. Paterna, Valencia. Spain

${ }^{2}$ Department of Fiber and Polymer Technology, Royal Institute of Technology. Teknikringen, 56, 100 44. Stockholm. Sweden 



\begin{abstract}
In the current study, hybrid electrospun EVOH fibres reinforced with bacterial cellulose nanowhiskers (BCNW) were developed and characterized. Additionally, electrospinning was suggested as a method for the incorporation of well-dispersed $\mathrm{BCNW}$ into an $\mathrm{EVOH}$ matrix by melt compounding.
\end{abstract}

With the aim of maximizing the BCNW's loading in the electrospun fibres, an optimized method was applied for generating fibres from solutions containing up to 40 wt.-\% BCNW. As demonstrated by FT-IR spectroscopy, it was possible to incorporate BCNWs concentrations up to ca. 24 wt.- $\%$, although a complete incorporation of the nanofiller into the fibres was only achieved with solutions containing up to $20 \mathrm{wt} .-\%$ of the filler DSC analyses suggested that the incorporation of the nanofiller reduced the crystallinity of the as-obtained $\mathrm{EVOH}$ fibers and produced an increase in the glass transition temperature of these during the second heating run. Thermogravimetric analyses showed that even though EVOH protects the nanowhiskers from thermal degradation, the electrospun hybrid fibres present a relatively lower thermal stability than the pure EVOH fibres. FT-IR analyses of the samples subjected to different thermal treatments confirmed that the stiffening effect observed by DSC only occurs after melting of the EVOH phase and is cooperative with a partial acid chemical development in the BCNWs, which promotes strong chemical interactions between the polymeric matrix and the nanofiller.

Finally, the hybrid electrospun fibres were incorporated into pure EVOH by melt compounding to produce composite films. This methodology showed higher stability and dispersion of the BCNW than direct addition of the freeze-dried nanofiller to EVOH. 
Keywords: Bacterial cellulose, electrospinning, nanocomposites, EVOH, melt compounding. 


\section{INTRODUCTION}

The electrospinning technique has recently attracted considerable interest since it is a versatile method to produce continuous polymer fibres with diameters in the sub-micron range with applicability as textiles (Schreuder-Gibson et al., 2002), wound dressings (Ignatova et al., 2009), tissue engineering scaffolds (Jeong et al., 2010), electronic devices (Liu et al., 2004) and, more recently, in the nanocomposites field (Ji et al., 2006; Olsson et al., 2010; Peresin et al., 2010). Since recently, great efforts are being focused on the use of nanofillers from renewable resources and, specifically, cellulose nanowhiskers have gained great interest for their use as nanoreinforcement in electrospun fibres. Electrospinning has recently been applied to obtain cellulose fibres (Kim et al., 2005; Kim et al., 2006) as well as hybrid fibres reinforced by cellulose whiskers.

Cellulose is one of the most abundant biopolymers found in nature and it is commonly extracted from vegetal resources such as wood, cotton and linter. However, it can also be synthesized by some bacterial species, which in a culture medium rich in polysaccharides are able to produce a layer of bacterial cellulose (BC). With the aim of removing amorphous regions, cellulosic materials are usually subjected to acid hydrolysis, breaking down the hierarchical structure of the material into crystalline nanocrystals, commonly known as cellulose nanowhiskers $(\mathrm{CNW})$. As a result of their remarkable mechanical properties, as well as their fully degradable and renewable character, cellulose nanowhiskers have been widely used as reinforcing filler for polymeric matrixes such as PLA (Petersson et al., 2007; Sanchez-Garcia \& Lagaron, 2010), PHBV (Jiang et al., 2008; Ten et al., 2010), starch (Kvien et al., 2007) and polyvinyl acetate (Garcia de Rodriguez et al., 2006). 
Cellulose nanowhiskers have been used to reinforce electrospun polystyrene nanofibres (Rojas et al., 2009). The material was added as a freeze-dried product and the dispersion of the nanoreinforcement in THF was improved by adding a non-ionic surfactant. Cellulose nanocrystals were successfully incorporated from aqueous suspensions into electrospun poly (vinyl alcohol) fibres with cellulose nanowhiskers loadings up to $15 \%$, improving the thermomechanical properties of the material (Peresin et al., 2010). FT-IR analyses confirmed the presence of the nanofiller within the matrix. Nevertheless, visualization of the nanowhiskers inside the electrospun fibres was not possible by means of TEM, likely because of the lack of contrast between the two components of the fibres. Cryo-SEM and FESEM of ultrathin cross-sections of the electrospun mats were developed (Peresin et al., 2010) but did not lead to a clear identification of the cellulose nanocrystals.

Bacterial cellulose whiskers have been recently incorporated into electrospun nanofibres of poly(ethylene oxide) from aqueous dispersions, showing a partial aggregation of the nanofiller inside the fibres as observed by TEM (Park et al., 2007). Additionally, bacterial cellulose microfibrils' solutions in DMF/THF obtained through the solvent exchange method, were used to generate electrospun reinforced poly(methyl methacrylate) fibres showing a high degree of dispersion of the cellulose microbrils (Olsson et al., 2010).

The polymeric matrix chosen in this case is an ethylene vinyl alcohol copolymer $(\mathrm{EVOH})$, which is a semicrystalline polymer with excellent barrier properties to gases and food aroma compounds. The main reason for choosing this matrix is its hydrophilicity, which potentially makes it compatible with the $\mathrm{BCNW}$ without the need for surface modification of the whiskers. Electrospinning of EVOH copolymers from 2-propanol-water solutions (Kenawy et al., 2002) as well as EVOH membranes end-capped with sulfonic acid (Zhang et al., 2005) 
have been previously developed. In any case, hybrid electrospun EVOH fibres incorporating nanofillers have not been previously reported.

In a previous study (Martínez-Sanz et al., 2011), electrospun EVOH fibres loaded with bacterial cellulose nanowhiskers $(\mathrm{BCNW})$ were produced and the method was optimized with the aim of improving the incorporation degree and dispersion of the nanofiller. It was demonstrated that partially hydrated BCNWs were more efficiently incorporated into the fibres than the freeze-dried ones.

The present work reports on the characterization of EVOH electrospun fibres obtained from polymeric solutions containing concentrations of BCNW up to 40 wt.- $\%$ by means of the previously optimized method. The incorporation degree of the filler and the corresponding thermal properties of the composite fibres were studied in order to determine the highest BCNWs' concentration which allowed an efficient incorporation. With the aim of understanding the surprising increase observed in the glass transition temperature $\left(\mathrm{T}_{\mathrm{g}}\right)$ of the fibres after being subjected to one heating step beyond the EVOH melting point, the thermal stability and chemical changes suffered by the hybrid fibres after heating were also monitored by FTIR spectroscopy. Finally, the effectiveness of electrospinning as a vehicle for incorporating well-dispersed BCNW into an EVOH matrix by means of melt compounding was investigated. 


\section{MATERIALS AND METHODS}

\subsection{Materials}

Ethylene-vinyl alcohol copolymer grade (Soarnol) EVOH29 (containing 29 mol\% of ethylene) was supplied by The Nippon Synthetic Chemical Industry Co., Ltd. (NIPPON GOHSEI) (Japan). Sulphuric acid 96\% and 2-propanol were purchased from Panreac (Barcelona, Spain).

\subsection{Preparation of bacterial cellulose mats}

Bacterial cellulose mats were obtained by following the same procedure as described in a previous work (Martínez-Sanz et al., 2011). Briefly, the bacterial strain Gluconacetobacter xylinus 7351 was incubated in a modified Hestrin/Shramm medium at $30^{\circ} \mathrm{C}$. All of the cells were pre-cultured in a test tube containing $5 \mathrm{~mL}$ of medium and re-inoculated into larger volumes until obtaining the final $20 \mathrm{~L}$ culture medium. The synthesized bacterial cellulose pellicles, about $5 \mathrm{~cm}$ thick, were cut into small pieces (aprox. $2 \times 2 \mathrm{~cm}^{2}$ ) and subsequently sterilized and cleaned in boiling water and then in a $10 \%(\mathrm{v} / \mathrm{v}) \mathrm{NaOH}$ aqueous solution in order to remove bacteria cells and the absorbed culture media. Finally, the $\mathrm{pH}$ was lowered to 7 by boiling in distilled water several times.

\subsection{Preparation of bacterial cellulose nanowhiskers}

Bacterial cellulose nanowhiskers were obtained as a partially hydrated precipitate ("centrifuged BCNW") after subjecting the bacterial cellulose mats to hydrolysis with sulphuric acid. The material (ca. $1 \mathrm{~kg}$ of partially hydrated bacterial cellulose) was treated with $1 \mathrm{~L}$ of $50 \%(\mathrm{v} / \mathrm{v})$ sulphuric acid/water, in a cellulose/acid ratio of approximately $7 \mathrm{~g} / \mathrm{L}$, at $50^{\circ} \mathrm{C}$ for five days (ca. 120 hours) until a homogeneous solution was obtained. This solution was subjected to 10 centrifugation and washing cycles at $12,500 \mathrm{rpm}$ and $15^{\circ} \mathrm{C}$ for 20 minutes and 
BCNW were obtained as a white precipitate. The humidity of the material was determined and the yield of the extraction process was estimated to be $79.64 \%$ respect to the dried native bacterial cellulose. The material was kept refrigerated until use.

\subsection{Electrospinning}

Bacterial cellulose nanowhiskers were incorporated into 4.1\%, 4.6\%, 4.8\%, $5 \%$ and $5.5 \%(\mathrm{w} / \mathrm{v})$ EVOH solutions in 70/30 (v/v) 2-propanol/water and hybrid fibres were generated by electrospinning. Cellulose nanowhiskers were dispersed in the solvent by intense homogenization (Ultra-turrax). Concentration of cellulose nanowhiskers were varied from $5 \%$ to $40 \%$ (w/w) regarding the EVOH weight in order to obtain solutions with a total solids concentration of $5.75 \%$ $(\mathrm{w} / \mathrm{w})$.

The electrospinning equipment was the same as described in a previous work (Martínez-Sanz et al., 2011). Solutions were transferred to $5 \mathrm{ml}$ plastic syringes and connected through PTFE tubes to a stainless steel needle $(\varnothing 0.9 \mathrm{~mm})$. An electrode was clamped to the needle tip and connected to a high-voltage $0-30 \mathrm{kV}$ power supply operating at $10-12 \mathrm{kV}$, and polymer solution was fed into the needle at a rate of $0.6 \mathrm{~mL} / \mathrm{h}$ by a syringe pump (KD Scientific Inc., Holliston, U.S.A.). The counter electrode was connected to a rectangular plate covered by aluminum foil, which was placed parallel to the needle to collect the electrospun fibres. The distance between the needle and the plate was $12 \mathrm{~cm}$ and experiments were carried out at ambient temperature.

\subsection{Preparation of films}

The BCNW were incorporated into EVOH fibres by electrospinning with the aim of improving the dispersion of the nanofiller within the matrix during a subsequent melt compounding step. This proprietary procedure (Lagaron et al., 
2010 ) is thought to be a solution to resolve the problem of the difficulties in dispersion of the direct addition of nanofillers using melt compounding routes. Thus, after optimizing the amount of BCNW incorporated into the hybrid fibres, electrospun EVOH fibres containing $15 \%(\mathrm{w} / \mathrm{w})$ of $\mathrm{BCNW}$ were melt compounded in an internal mixer with EVOH29 pellets in order to obtain a blend having a final concentration of 3 wt.-\% BCNW (sample code: $3 \%$ BCNW ES). One fraction of this blend was ground to powder and reprocessed in order to asses the effect of further processing on the dispersion and stability of the composite (sample code: 3\% BCNW ES2). In addition, pure EVOH and EVOH blended with freeze-dried BCNW (sample code: $\mathrm{EVOH} 29$ and 3\% BCNW FD, respectively) were melt compounded in a similar manner for comparison purposes.

Adequate amounts of EVOH pellets were melt mixed with the freeze-dried $\mathrm{BCNW}$ or the fibre's powder (i.e. $11.64 \mathrm{~g}$ of $\mathrm{EVOH}$ pellets with $0.36 \mathrm{~g}$ of freezedried $\mathrm{BCNW}$, and $9.24 \mathrm{~g}$ of $\mathrm{EVOH}$ pellets with $2.76 \mathrm{~g}$ of electrospun $\mathrm{EVOH}-$ BCNW fibres). All the blends were prepared in a Brabender Plastograph double screw mini-mixer with $16 \mathrm{~g}$ capacity, during $3 \mathrm{~min}$ at $190^{\circ} \mathrm{C}$ and using $100 \mathrm{rpm}$ as the screw speed. The materials were then converted into films by compression molding using a hot-plate hydraulic press at $180^{\circ} \mathrm{C}$ and $2 \mathrm{MPa}$ for $3 \mathrm{~min}$, followed by fast cooling with water.

\subsection{Scanning Electron Microscopy (SEM)}

SEM was conducted on a Hitachi microscope (Hitachi S-4100) at an accelerating voltage of $10-15 \mathrm{KV}$ and a working distance of $12-16 \mathrm{~mm}$. The electrospun mats were sputtered with a gold-palladium mixture under vacuum before their morphology was examined using SEM. 
Fibre diameters of the electrospun fibres were measured by means of the Adobe Photoshop CS3 extended software from the SEM micrographs in their original magnification.

\subsection{Optical microscopy}

Polarized light microscopy (PLM) examinations were performed using a Nikon Eclipse 90i optical microscope (IZASA, Spain) equipped with a 5megapixels cooled digital colour microphotography camera Nikon Digital Sight DS-5Mc. Captured images were analyzed and processed by using Nis-Elements BR software.

\subsection{Transmission and Attenuated Total Reflectance (ATR) FT-IR analysis}

Transmission FT-IR experiments were recorded in a controlled chamber at $21^{\circ} \mathrm{C}$ and $40 \% \mathrm{RH}$ using a Bruker (Rheinstetten, Germany) FT-IR Tensor 37 equipment. The spectra were taken at $1 \mathrm{~cm}^{-1}$ resolution averaging a minimum of 10 scans. Analysis of the spectra was performed using Grams/AI 7.02 (Galactic Industries, Salem, NH, USA) software. Samples of ca. $2 \mathrm{mg}$ of electrospun fibres were ground and dispersed in $200 \mathrm{mg}$ of spectroscopic grade $\mathrm{KBr}$. A pellet was then formed by compressing the sample at ca. $150 \mathrm{MPa}$. A calibration curve was obtained by recording the IR spectra of pellets containing $6 \mathrm{mg}$ of EVOH-BC nanowhiskers samples with nanowhiskers' concentrations ranging from $10 \mathrm{wt} .-\%$ to 40 wt. $\%$. The detailed procedure can be found elsewhere ${ }^{20}$. Briefly, the intensity of the band at $1165 \mathrm{~cm}^{-1}$, which was chosen as characteristic for cellulose, was divided by the intensity of the band at $838 \mathrm{~cm}^{-1}$, which was assigned to the EVOH contribution. Subsequently, the IR spectra of the electrospun fibres were analyzed and the percentages of $\mathrm{BCNW}$ incorporated into the fibres from the solutions were estimated. 
ATR-FTIR spectra of $\mathrm{BCNW}$ and electrospun EVOH/BCNW exposed to different thermal treatments were collected in the same environmental conditions as the transmission experiments, coupling the ATR accessory GoldenGate of Specac Ltd. (Orpington, UK) to the above mentioned FT-IR equipment. All spectra were recorded within the wavenumber range of $4000-600 \mathrm{~cm}^{-1}$ by averaging 20 scans at $4 \mathrm{~cm}^{-1}$ resolution.

\subsection{Differential scanning calorimetry (DSC)}

DSC experiments were carried out in a Perkin-Elmer DSC-7 calorimeter. Samples of ca. $3 \mathrm{mg}$ were subjected to the same treatment applied in the first part of this study, i.e. an initial conditioning step from $30^{\circ} \mathrm{C}$ to $120^{\circ} \mathrm{C}$ and two heating steps up to $220^{\circ} \mathrm{C}$. The heating and cooling rates for the runs were $10^{\circ} \mathrm{C} / \mathrm{min}$.

\subsection{Thermogravimetric analysis (TGA)}

Thermogravimetric (TG) curves were recorded with a TA Instruments model Q500 TGA. The samples (ca. $20 \mathrm{mg}$ ) were heated from $50^{\circ} \mathrm{C}$ to $600^{\circ} \mathrm{C}$ with a heating rate of $10^{\circ} \mathrm{C} / \mathrm{min}$ under nitrogen atmosphere. 


\section{RESULTS AND DISCUSSION}

\subsection{Fibre morphology and degree of incorporation of the BCNW}

In the present study, $\mathrm{BCNW}$ extracted from $\mathrm{BC}$ by sulfuric acid digestion were incorporated into EVOH through electrospinning. These $\mathrm{BCNW}$ present a morphology of nanofibrils with cross-sections smaller than $30 \mathrm{~nm}$, having a crystallinity index of $82.2 \%$, as previously reported (Martínez-Sanz et al., 2011). The production of electrospun EVOH fibres containing $\mathrm{BCNW}$ has been previously reported and the method was optimized in terms of efficient nanofiller incorporation for a maximum loading of $8 \mathrm{wt} .-\%$ BCNW (Martínez-Sanz et al., 2011).

With the purpose of further increasing the amount of nanowhiskers incorporated into the fibres, several hybrid materials were developed adding various amounts of centrifuged $\mathrm{BCNW}$, but fixing the total solids concentration of the electrospinning solutions at 5.75 wt.- $\%$, i.e. the maximum solids concentration which provided stable electrospinning conditions for the composites. This was done by varying both the nanowhiskers and the EVOH concentration, and aimed at obtaining less viscous solutions to incorporate higher loadings of the reinforcing bacterial cellulose filler.

Solutions containing a fixed solids concentration of 5.75 wt.- $\%$ and the following concentrations of $\mathrm{BCNW}$ (with respect to the EVOH weight) were prepared and incorporated into fibres by electrospinning: 5 wt.- $\%$ BCNW (5.5 wt.$\% \mathrm{EVOH}$ in the solution), 15 wt.-\% BCNW (5 wt.-\% EVOH in the solution), 20 wt.-\% BCNW (4.8 wt.-\% EVOH in the solution), 25 wt.-\% BCNW (4.6 wt.-\% EVOH in the solution) and $40 \mathrm{wt} .-\% \mathrm{BCNW}$ (4.1 wt.-\% EVOH in the solution). Increasing the amount of $\mathrm{BCNW}$ in the solution up to $50 \mathrm{wt} .-\%$ did not lead to 
fibrillar morphologies, because electrospraying phenomena occurred; thus, the maximum concentration of nanowhiskers in the electrospinning solution that yielded fibres was $40 \mathrm{wt} .-\%$. Additionally, control electrospun fibres were prepared with the EVOH concentrations previously listed.

Figure 1 shows the SEM micrograph and polarized light microscopy image of fibres obtained from solutions containing 15 wt.- $\%$ of BCNW. For all the electrospun materials, morphologies containing some beads, similar to the ones observed in a previous work with lower BCNW's loadings (Martínez-Sanz et al., 2011), were obtained. It was also confirmed by polarized light optical microscopy that these fibres presented a highly homogeneous dispersion of highly crystalline $\mathrm{BCNW}$, since fibres of pure $\mathrm{EVOH}$ did not show birefringence under crossed polarizers. As observed in Figure 1c, fibres' beads appear as brighter areas when observed through polarized light. This birefringence suggests that BCNW may be agglomerated in those areas and thus, beads have a BCNW concentration higher than equilibrium. By varying the $\mathrm{EVOH} / \mathrm{BCNW}$ ratio, uniformity and diameters of fibres were affected, as seen in Figure 2. From this figure, it is observed that increasing the amount of whiskers in the solutions leads to a decrease in the attained fibre diameter and to a more uniform size distribution. Nevertheless, this was not the case for the materials obtained from solutions containing 40 wt.- $\%$ of the filler, as in these materials an increase in the diameter of the fibres was obtained, as well as a more beaded morphology. A decrease in the fibres' diameter when increasing the concentration of cellulose nanowhiskers incorporated into electrospun fibres has been previously discussed in several works (Martínez-Sanz et al., 2011; Peresin et al., 2010; Rojas et al., 2009) and it was attributed to an increase in the fibres conductivity when incorporating negatively charged cellulose nanowhiskers. This may suggest, among other things, that the incorporation of BCNW in the case of fibres generated from 40 wt.- $\%$ BCNW solutions is lower 
than expected. Probably, high concentrations of BCNW lead to agglomeration of $\mathrm{BCNW}$ in the electrospinning solution and thus, it is likely that a significant amount of the nanofiller remains as a residue in the electrospinning syringe.
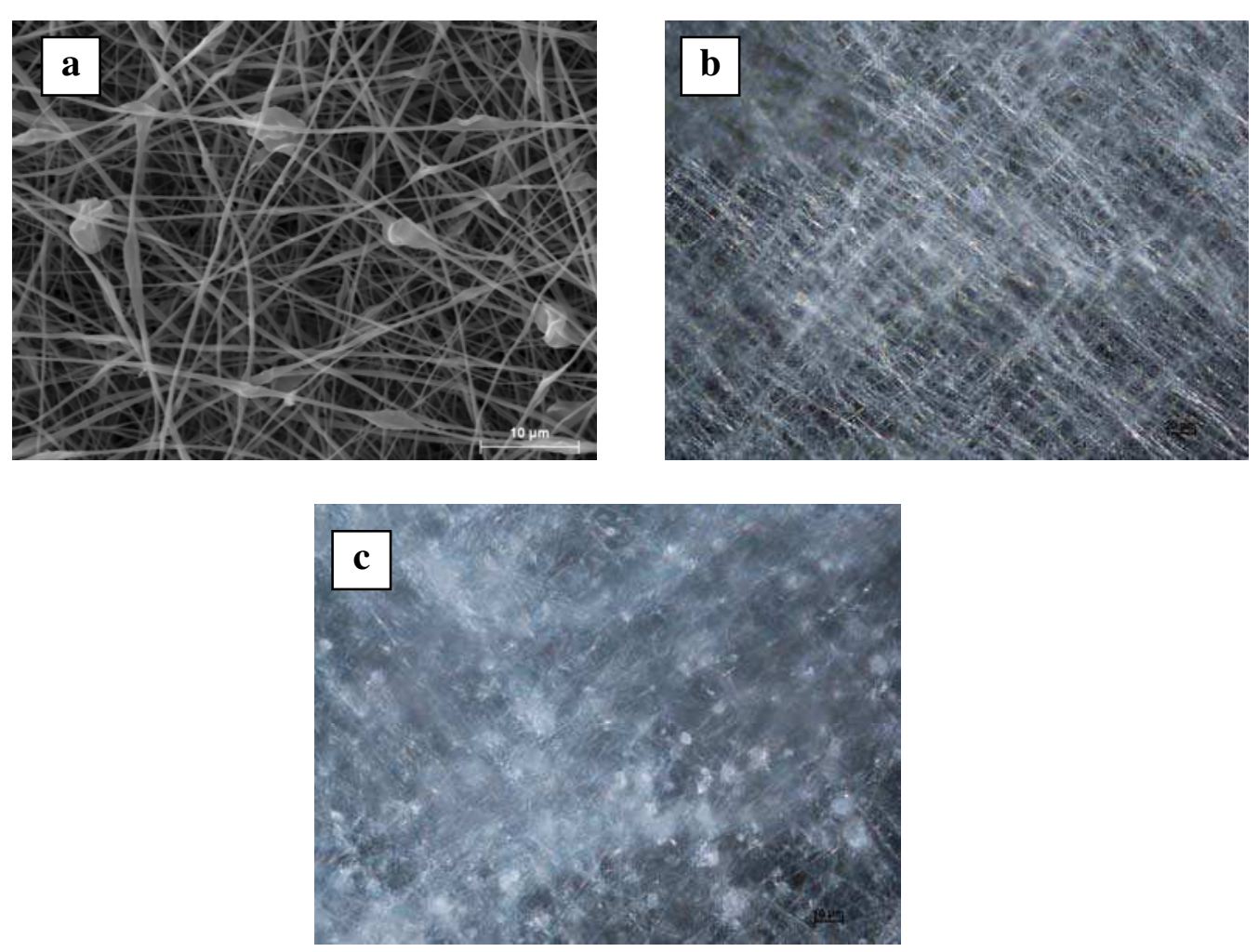

Figure 1. SEM micrograph (a) and polarized light optical microscopy image of electrospun fibres obtained from $\mathrm{EVOH}+15$ wt.-\% BCNW (b) and from $\mathrm{EVOH}+$ $40 \mathrm{wt} .-\% \mathrm{BCNW}$ (c). The scale markers correspond to 10 microns in picture (a) and (c), and to 20 microns in picture (b). 


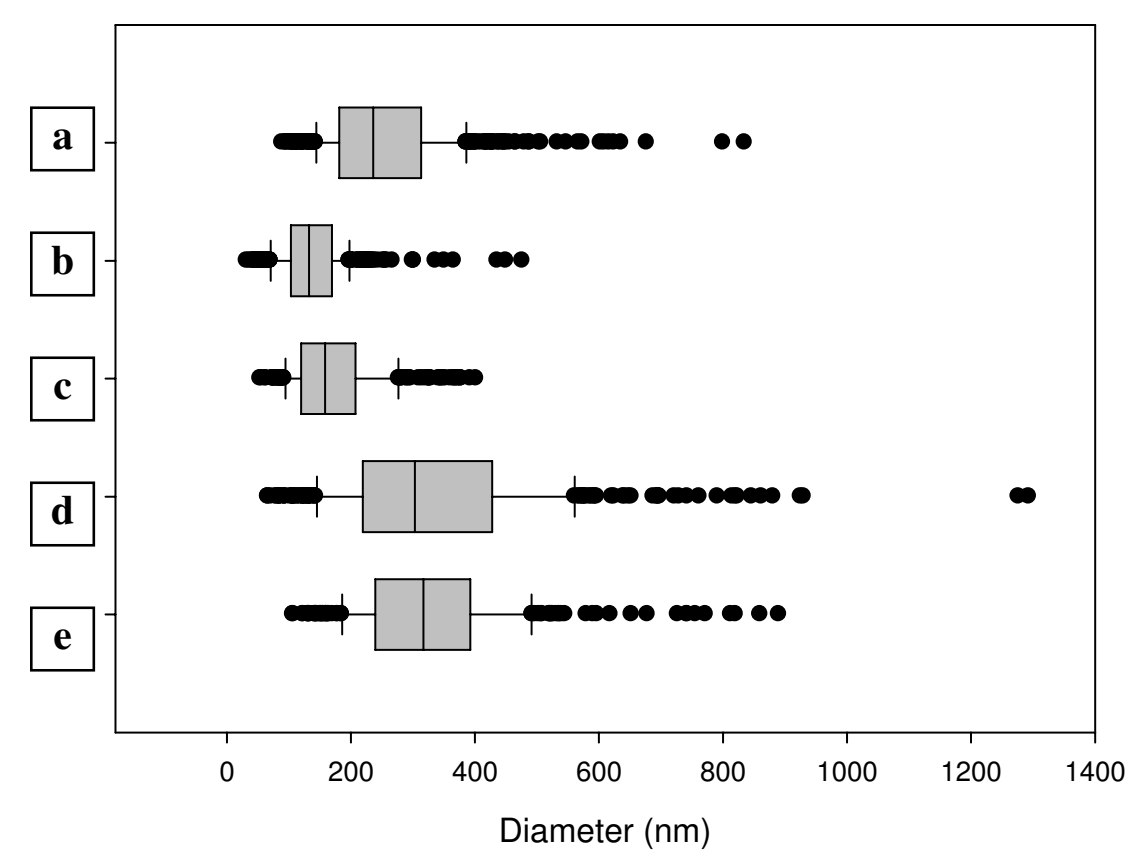

Figure 2. Box plot of size distribution of electrospun fibres obtained from (a) EVOH + 40 wt.- $\%$ BCNW; (b) EVOH + 25 wt.- $\%$ BCNW; (c) EVOH + 20 wt.- $\%$ BCNW; (d) EVOH + 15 wt.-\% BCNW; (e) EVOH + 5 wt.-\% BCNW. The division within the boxes represents the median of the data, whereas the vertical limits represent the lowest and highest data within $1.5 x$ interquartile range. Data not included within this range are plotted as dots and correspond to outliers (anomalous data) which in this case are most likely a consequence of the appearance of beads.

The FT-IR technique was used in the different electrospun fibres to check the degree of filler incorporation into EVOH across the different materials. Figure 3 shows the IR spectra in the range of interest of electrospun fibres with different nanowhiskers' concentrations. By applying a calibration curve developed in a previous work (Martínez-Sanz et al., 2011), which relates the ratio between the intensities of the bands at $1165 \mathrm{~cm}^{-1}$ and at $838 \mathrm{~cm}^{-1}$ with the BCNWs' 
concentration, the degree of nanowhiskers' incorporation was estimated. Figure 3 displays the estimated amount of BCNW retained in the fibres for the compositions used. The highest concentration of BCNW was obtained for the 25 wt.- $\%$ BNNW solution, however only solutions containing up to $20 \mathrm{wt}$.- $\%$ BCNW were seen to achieve a complete incorporation of the nanofiller present in solution into the electrospun fibres. This result confirms that the incorporation degree of BCNW is significantly lower than expected in the case of fibres generated from 40 wt.- $\%$ BCNW solutions, just as previously suggested by morphological observations.

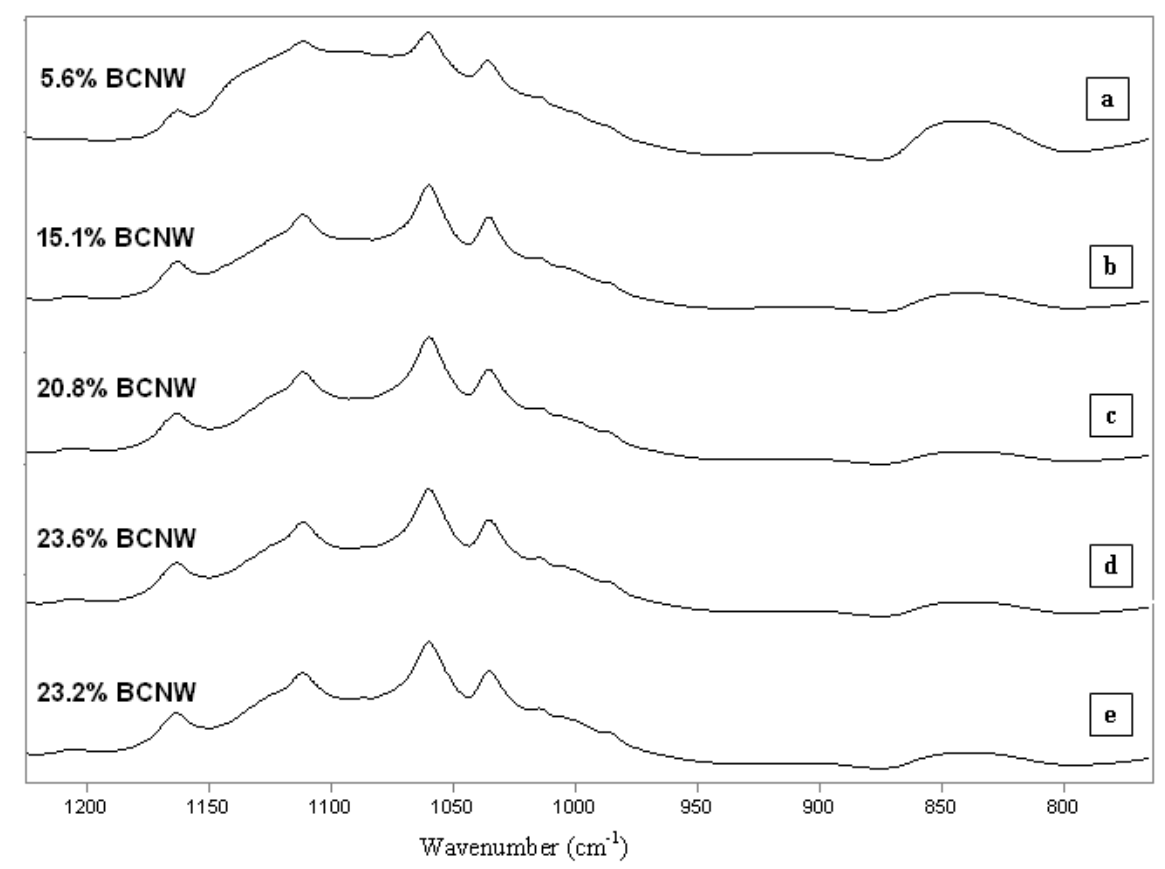

Figure 3. FT-IR spectra and estimated degree of BCNW incorporated into electrospun fibres obtained from EVOH solutions containing: (a) 5\% BCNW; (b) $15 \% \mathrm{BCNW}$; (c) 20\% BCNW; (d) 25\% BCNW; and (e) 40\% BCNW. Data have been offset for clarity. 


\subsection{Thermal properties}

DSC analysis was carried out in order to study the thermal properties of electrospun fibres. Table 1 shows the melting point, melting enthalpy and the glass transition temperature of the electrospun fibres. From the first heating run it is deduced, in agreement with previous results (Martínez-Sanz et al., 2011), that by increasing the nanowhiskers content, the melting point and melting enthalpy of the fibres decrease. Cellulose nanowhiskers, when added as a partially hydrated precipitate, seem to interfere in the crystallization of EVOH during the formation of the fibers giving rise to a more amorphous structure with smaller or more defective crystallites. It is also observed that during the first heating run, no significant changes in the glass transition temperature $\left(\mathrm{T}_{\mathrm{g}}\right)$ are produced when incorporating $\mathrm{BCNW}$ into the fibres as compared to the corresponding pure $\mathrm{EVOH}$ fibres.

Just as observed in a previous work (Martínez-Sanz et al., 2011), no melting endotherm was detected for the fibres incorporating $\mathrm{BCNW}$, thus indicating that the $\mathrm{BCNW}$ incorporated into the $\mathrm{EVOH}$ matrixes prevent the material from recrystallizing during the spinning process.

On the other hand, there is a significant increase in the $T_{g}$ during the second heating run with increasing the BCNW content (see Figure 4). Just as observed in Figure 4 , this increase is more obvious when increasing the concentration up to 20 wt.- $\%$, being less significant when increasing the concentration from $20 \mathrm{wt} .-\%$ to 25 wt.-\% in agreement with the FT-IR incorporation results which indicated that in the latter case the actual amount of BCNW incorporated into the fibres is below 25 wt.- $\%$. Therefore, the lower relative increase in the $T_{g}$ observed is related to the fact that no complete incorporation occurs for concentrations of BCNW higher than $20 \mathrm{wt} . \%$. From these results it is deduced that incorporating BCNW in 
relatively low concentrations does significantly increase the rigidity of the amorphous phase (as estimated during the second DSC heating run) of the hybrid composite.

Table 1. DSC maximum of melting $\left(T_{m}\right)$, melting enthalpy $(\Delta H)$ and glass transition temperature $\left(\mathrm{T}_{\mathrm{g} 1}\right)$, of electrospun fibres obtained during the first heating run and glass transition temperature $\left(\mathrm{T}_{\mathrm{g} 2}\right)$, obtained during the second heating run.

\begin{tabular}{|c|c|c|c|c|}
\hline & $\mathrm{T}_{\mathrm{m}}\left({ }^{\circ} \mathrm{C}\right)$ & $\Delta \mathrm{H}(\mathrm{J} / \mathrm{g}$ EVOH $)$ & $\mathrm{T}_{\mathrm{g} 1}\left({ }^{\circ} \mathrm{C}\right)$ & $\mathrm{T}_{\mathrm{g} 2}\left({ }^{\circ} \mathrm{C}\right)$ \\
\hline $5.48 \% \mathrm{EVOH}$ & $190.6 \pm 0.8$ & $79.1 \pm 1.6$ & $66.6 \pm 1.0$ & $63.0 \pm 0.6$ \\
\hline $\begin{array}{c}5.48 \% \mathrm{EVOH}+5 \% \\
\mathrm{BCNW}\end{array}$ & $188.8 \pm 0.4$ & $69.1 \pm 0.8$ & $66.2 \pm 2.2$ & $63.9 \pm 0.4$ \\
\hline $5 \% \mathrm{EVOH}$ & $192.5 \pm 0.8$ & $79.2 \pm 0.1$ & $67.3 \pm 1.8$ & $62.7 \pm 0.1$ \\
\hline $\begin{array}{c}5 \% \mathrm{EVOH}+15 \% \\
\mathrm{BCNW}\end{array}$ & $188.2 \pm 2.0$ & $43.9 \pm 0.3$ & $68.7 \pm 0.2$ & $67.8 \pm 0.1$ \\
\hline $4.79 \% \mathrm{EVOH}$ & $191.9 \pm 0.9$ & $78.8 \pm 3.5$ & $67.2 \pm 2.8$ & $63.1 \pm 1.3$ \\
\hline $\begin{array}{c}4.79 \% \mathrm{EVOH}+ \\
20 \% \mathrm{BCNW}\end{array}$ & $185.5 \pm 0.1$ & $37.9 \pm 0.9$ & $69.5 \pm 0.3$ & $75.0 \pm 0.2$ \\
\hline $4.6 \% \mathrm{EVOH}$ & $190.9 \pm 1.4$ & $77.3 \pm 1.2$ & $69.1 \pm 0.4$ & $63.3 \pm 0.6$ \\
\hline $\begin{array}{c}4.6 \% \mathrm{EVOH}+25 \% \\
\mathrm{BCNW}\end{array}$ & $187.2 \pm 0.8$ & $33.8 \pm 1.5$ & $68.0 \pm 0.4$ & $76.2 \pm 0.3$ \\
\hline $4.1 \% \mathrm{EVOH}$ & $192.4 \pm 1.4$ & $70.7 \pm 1.1$ & $63.6 \pm 2.2$ & $62.6 \pm 0.3$ \\
\hline $\begin{array}{c}4.1 \% \mathrm{EVOH}+40 \% \\
\mathrm{BCNW}\end{array}$ & $184.4 \pm 0.2$ & $49.7 \pm 2.0$ & $66.3 \pm 2.6$ & $76.5 \pm 0.2$ \\
\hline
\end{tabular}




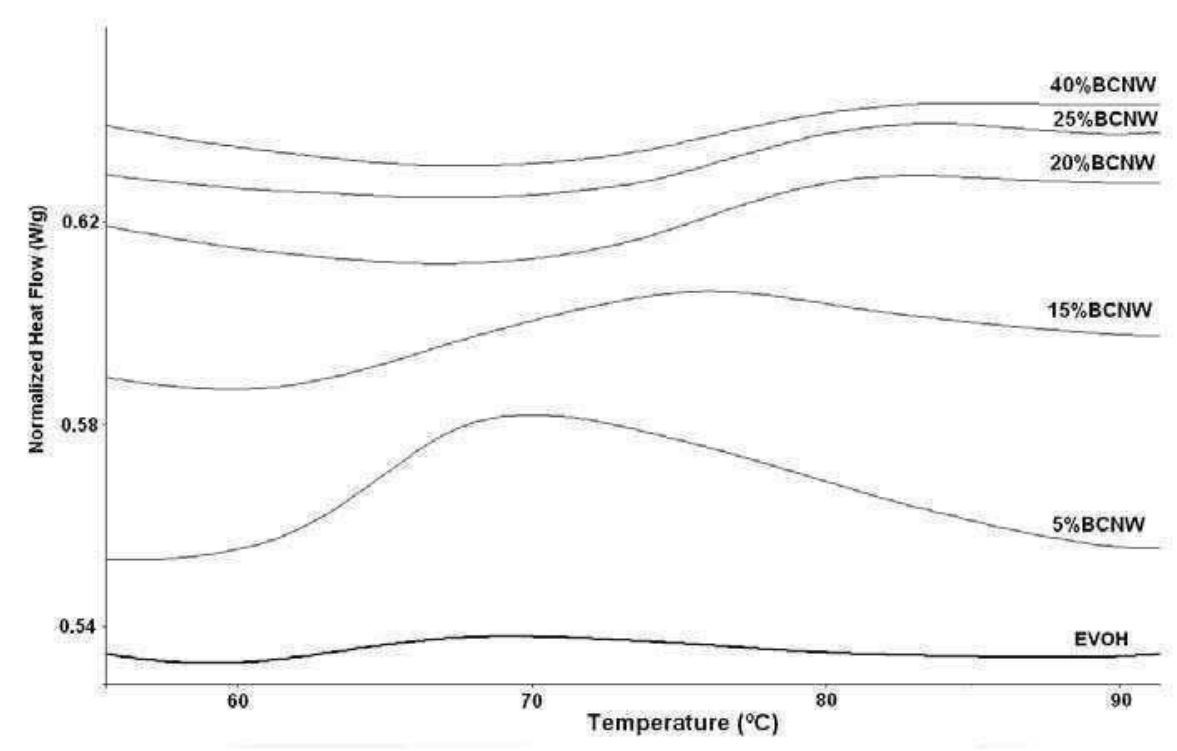

Figure 4. DSC curves obtained during the second heating run. Curves show the glass transition temperature of electrospun fibres obtained from solutions containing pure $\mathrm{EVOH}, 5 \% \mathrm{BCNW}, 15 \% \mathrm{BCNW}, 20 \% \mathrm{BCNW}, 25 \% \mathrm{BCNW}$, and $40 \% \mathrm{BCNW}$.

Thermogravimetric analyses showed previously that BCNWs extracted by sulfuric acid treatment have a relatively low thermal stability (Martínez-Sanz et al., 2011). With the aim of studying the effect of incorporating BCNWs on the thermal stability of the electrospun hybrid fibres, TGAs were carried out. Figure 5 shows the experimental results for pure EVOH electrospun fibres and hybrid EVOH$\mathrm{BCNW}$ fibre mats. The mass loss below $100^{\circ} \mathrm{C}$ is ascribed to water loss. In the case of pure $\mathrm{EVOH}$, the main weight loss occurs within the temperature range 300$430^{\circ} \mathrm{C}$. At $430^{\circ} \mathrm{C}$ a loss of $95 \%$ is observed and the loss above this temperature is ascribed to char. On the other hand, fibres containing EVOH and BCNW present a degradation profile composed of three steps. The first step takes place between $125-290^{\circ} \mathrm{C}$ with a weight loss of $21 \%$. This step is ascribed to cellulose degradation 
processes such as depolymerization, dehydration and decomposition of glycosyl units (Rojas et al., 2009). It has been previously reported that in the case of isolated nanowhiskers, this process takes place in the range of $100-225^{\circ} \mathrm{C}$ (Martínez-Sanz et al., 2011). This slight increase in the degradation temperature suggests that the EVOH matrix partially protects the cellulose whiskers in the composite from thermal degradation. The second step, with a mass loss of 30\%, occurs between $290-400^{\circ} \mathrm{C}$ and most likely corresponds to EVOH degradation. Finally, the third step takes place above $400^{\circ} \mathrm{C}$ and corresponds to the oxidation and breakdown of the charred residue. Increasing the concentration of nanowhiskers did not affect significantly the TGA profile. These results suggest that $\mathrm{BCNW}$ partially decrease the thermal stability of EVOH electrospun fibres, which may be caused by the presence of sulfate groups and residual acidity on the nanowhiskers surface as a consequence of the acid hydrolysis (Roman \& Winter, 2004). Specifically, for the fibres containing 40 wt.- $\%$ BCNW, a weight loss of $14.9 \%$ was observed below $220^{\circ} \mathrm{C}$ (maximum temperature reached during the DSC runs), suggesting that some cellulose chemical alterations which may be responsible for the increase in the $\mathrm{T}_{\mathrm{g}}$ observed during the second DSC heating run take place during the first heating run. 


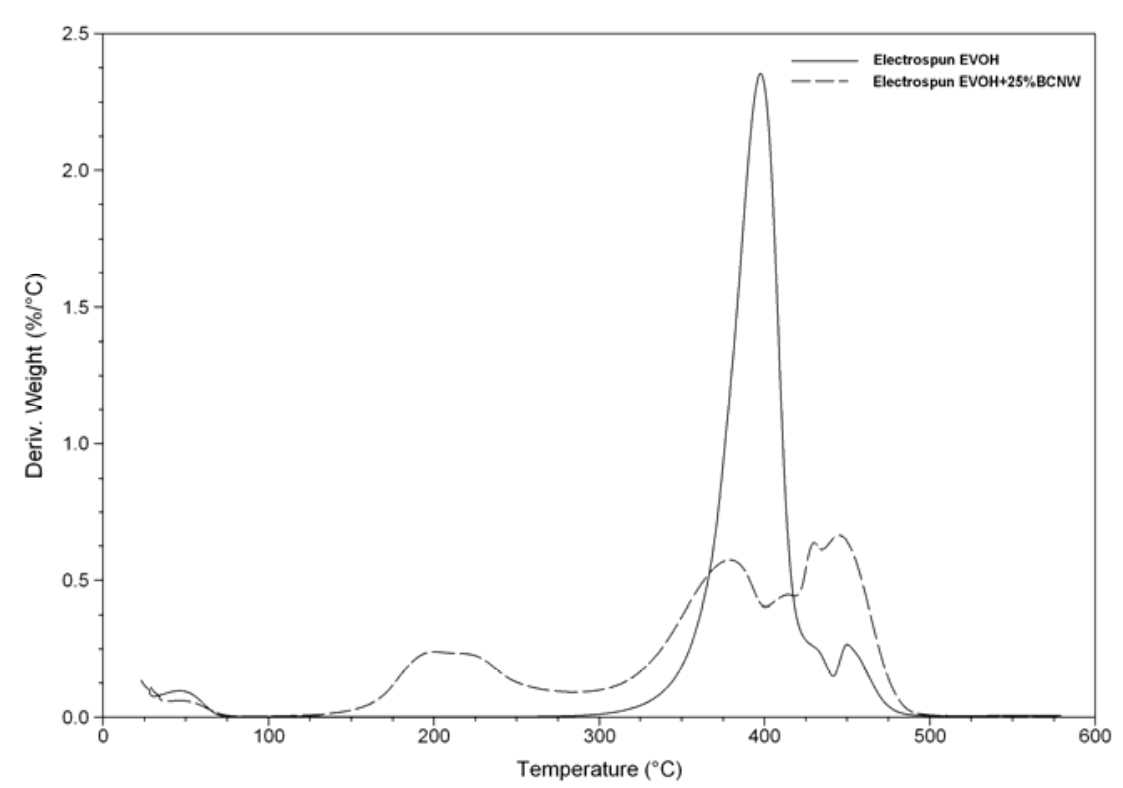

Figure 5. DTG curves of electrospun fibres obtained from EVOH and from EVOH +25 wt. $-\%$ BCNW.

In order to study the degradation processes during the DSC heating runs in detail, ATR-FTIR spectra of BCNW subjected to the same DSC program as the electrospun fibres (i.e., two heating runs up to $220^{\circ} \mathrm{C}$ ) and electrospun fibres obtained from solutions containing $40 \%$ wt.- $\%$ BCNW subjected to one heating step up to $220^{\circ} \mathrm{C}$ and to the complete DSC program, were analyzed.

The ATR-FTIR spectra in Figure 6 clearly indicate that degradation of the isolated BCNW takes place after two DSC heating runs. The decrease in intensity of the broad band between 3000 and $3600 \mathrm{~cm}^{-1}$, corresponding to $-\mathrm{OH}$ stretching intramolecular hydrogen bonds, indicates that dehydration has taken place. Furthermore, the intensity of all the cellulose characteristic bands located between 1035 and $1430 \mathrm{~cm}^{-1}$ diminishes as a consequence of heat-induced chemical 
alterations. Additionally, the degraded sample shows two bands at $1715 \mathrm{~cm}^{-1}$ and $1621 \mathrm{~cm}^{-1}$, which have been previously related to the thermo-oxidative degradation of cellulose (Jain et al., 1987; Roman \& Winter, 2004) and correspond to carbonyl groups and unsaturated carbon-carbon groups. Visual examination of the sample after the DSC program confirmed that BCNWs have experienced a severe thermal degradation, since they presented the typical blackish colour associated to the production of char.

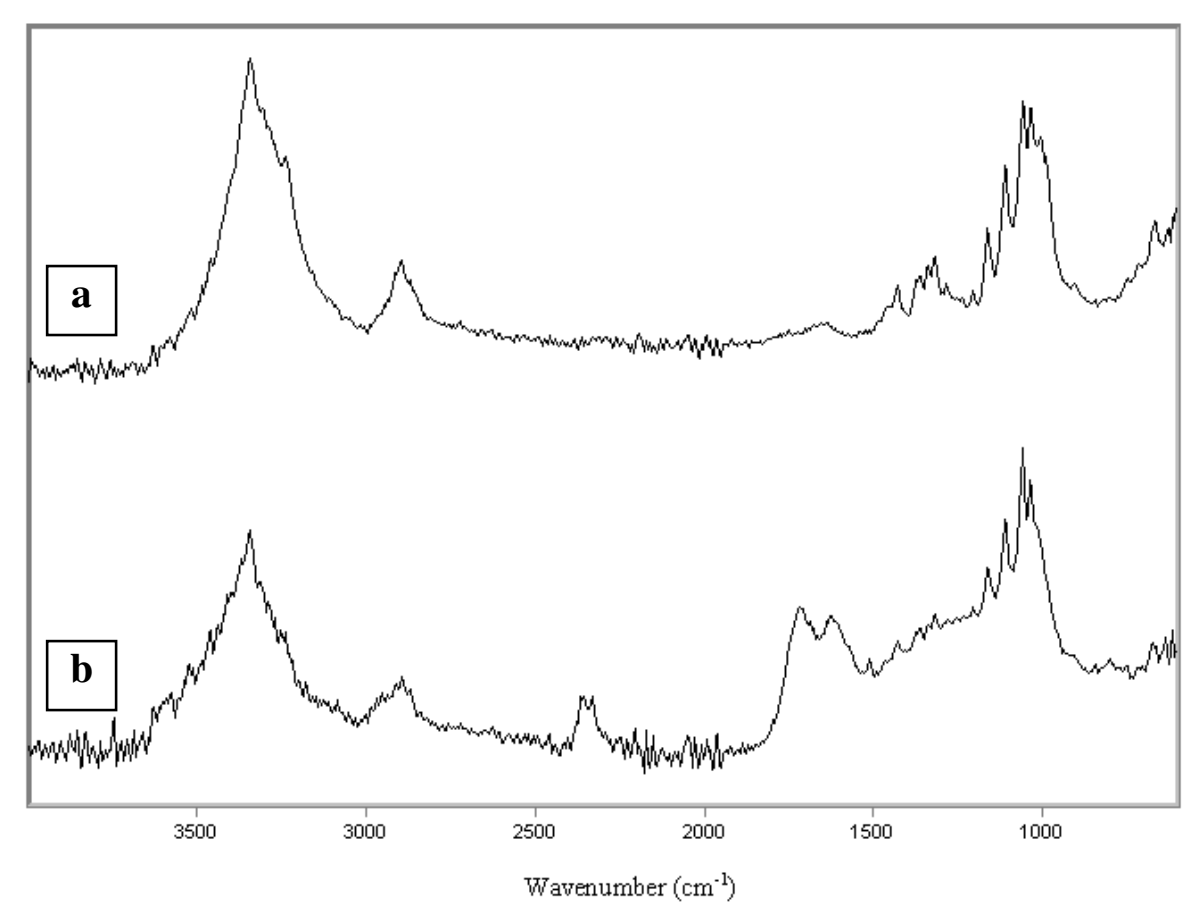

Figure 6. ATR-FTIR spectra of (a) freeze-dried BCNW and (b) freeze-dried BCNW after being subjected to the DSC heating-cooling program.

Figure 7 shows the ATR-FTIR spectra of electrospun EVOH fibres derived from the solution containing 40 wt.- $\%$ of BCNW before and after being subjected to a heating step up to $220^{\circ} \mathrm{C}$, and to the complete DSC program consisting in two 
consecutive heating runs up to $220^{\circ} \mathrm{C}$. As observed for the pure $\mathrm{BCNW}$, just by subjecting the composite fibres to one heating step, there is a significant decrease in the intensity of bands corresponding to $-\mathrm{OH}$ stretching intramolecular hydrogen bonds and to $-\mathrm{CH}$ stretching. The decrease in the cellulose characteristic bands located between 1035 and $1430 \mathrm{~cm}^{-1}$ is clearly less significant for the electrospun fibres than for the pure $\mathrm{BCNWs}$, thus indicating that the $\mathrm{EVOH}$ matrix is reducing the extent of the chemical alteration processes in the composite. In comparison with the pure BCNW sample, visual examination of both electrospun fibres samples presented a light yellow colour, suggesting that samples were just partially degraded.

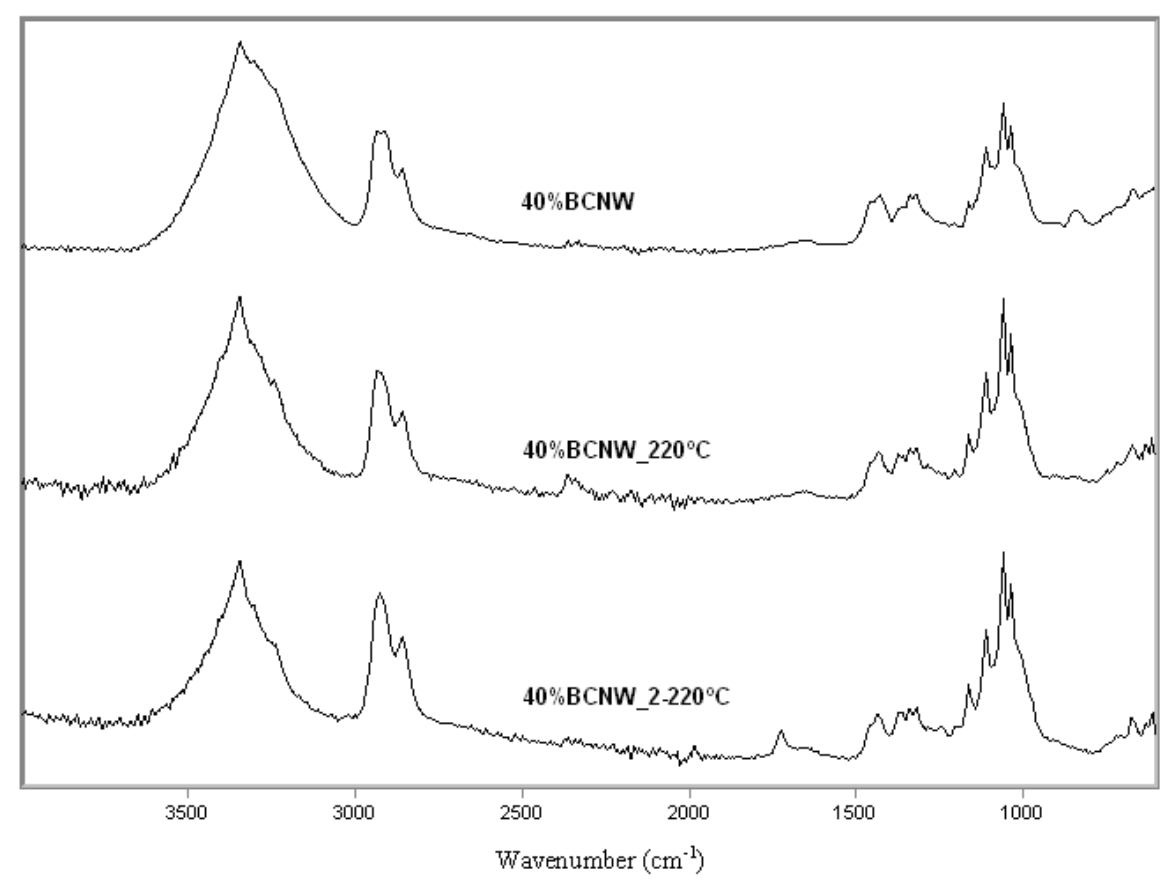

Figure 7. ATR-FTIR spectra of fibres obtained from the solution containing $\mathrm{EVOH}+40 \mathrm{wt} .-\% \mathrm{BCNW}$ (top spectrum); after one heating step up to $220^{\circ} \mathrm{C}$ (middle spectrum); and after two heating steps up to $220^{\circ} \mathrm{C}$ (bottom spectrum). 
An interesting fact is that, after applying one heating run, the material does not present the bands at $1715 \mathrm{~cm}^{-1}$ or $1621 \mathrm{~cm}^{-1}$, whereas when applying two heating steps, the band at $1715 \mathrm{~cm}^{-1}$ corresponding to the presence of carbonyl groups and thus, to oxidative degradation, is clearly observed. Previous works proposed a degradation mechanism of cellulose described as follows. At a heating rate higher than $2^{\circ} \mathrm{C} / \mathrm{min}$ cellulose first undergoes a decrease in its degree of polymerization. In more advanced degradation steps, dehydration, decarboxylation, decarbonylation and ring scission take place and carbonyl bonds are formed (Julien et al., 1993). According to this mechanism, when heating up to $220^{\circ} \mathrm{C}$ cellulose is partially degraded, as concluded by the decrease in its characteristic bands, but two heating steps up to $220^{\circ} \mathrm{C}$ are needed in order to reach more severe degradation for the material.

On the other hand, the band at $838 \mathrm{~cm}^{-1}$, which is ascribed to skeletal vibrations and $\mathrm{CH}_{2}$ rocking of EVOH (Lagaron et al., 2003), disappears after the first heating run. This fact, together with the decrease in bands of $-\mathrm{OH}$ stretching intramolecular hydrogen bonds, could be indicating that interactions between the $\mathrm{OH}$ groups of cellulose and $\mathrm{EVOH}$ have been developed as a consequence of heating, therefore impeding the skeletal vibrations of the matrix and resulting in stiffening.

As a conclusion of the FT-IR analyses, when the sample is subjected to one heating step up to $220^{\circ} \mathrm{C}$, the cellulose present in the fibres begins to undergo thermal degradation and, as a consequence, strong interactions between EVOH and cellulose are promoted. These developed interactions may cause an increase in the material stiffness and thus, be responsible for the increase in the $T_{g}$ observed during the second heating run. During the subsequent second heating step, the material suffers a more advanced degradation giving rise to the formation of 
carbonyl bonds. Finally, these interactions will have a stronger influence on the melting and crystallization behavior of hybrid materials during this second heating.

Further experiments of preconditioning by annealing of the fibre composites at increasing temperatures were also carried out, in order to check whether it was possible to enhance the $T_{g}$ of the hybrid composite material without having to erase the thermal history and consequently eliminate the ultrathin fibrilar morphology. If this was feasible, then it could also be possible to obtain thermally enhanced electrospun fibrils. Thus, preconditioning or annealing of the sample obtained from the solution containing $20 \mathrm{wt} .-\%$ of $\mathrm{BCNW}$ at both $170^{\circ} \mathrm{C}$ (just before the onset of the $\mathrm{EVOH}$ phase melting) and $190^{\circ} \mathrm{C}$ (corresponding to the endset of the $\mathrm{EVOH}$ phase melting) for 10 minutes was carried out followed by the usual first melting run up to $220^{\circ} \mathrm{C}$. From the results, the $\mathrm{T}_{\mathrm{g}}$ of the sample annealed at $170^{\circ} \mathrm{C}$ did not change compared to pure $\mathrm{EVOH}$ but it was much higher, i.e. at $73^{\circ} \mathrm{C}$, immediately after melting, suggesting that thermal reinforcement does not take place before melting of the EVOH phase occurs in the electrospun composite fibre mats.

As a result, the stronger interfacial interaction between matrix and filler is not only related to chemical alterations produced in the nanofiller during the melting run but it is also be caused by the cooperative melting of the EVOH phase and the subsequent enhancement in the interaction between filler and matrix. On the other hand, further studies using neutralized BCNWs (results not shown) exhibited a much better thermal stability than the acidic ones as they undergo thermal degradation at temperatures higher than $200^{\circ} \mathrm{C}$. Electrospun fibres incorporating those neutralized nanowhiskers were developed and the results will be reported elsewhere. In anticipation to that and just for the sake of the current discussion, it was in fact found out that an increase in the $T_{g}$ of the hybrid fibres was not observed. This latter result confirms that in order to obtain a stiffening effect on the 
composite electrospun fibres, it is required that BCNWs remain acid to promote strong interactions with the molten EVOH matrix.

At this point, it becomes clear that the electrospinning process applied succeeds in incorporating highly dispersed fractions of BCNW into the EVOH matrix but per se it does not result in a stiffening effect of the material. It is the partial thermally-induced interaction of by the acidic nanofiller with the molten matrix what promotes a strong interfacial adhesion between the filler and the matrix. Nevertheless, this reinforcing effect is obtained at the expense of producing fibres which have a relatively low thermal stability and thus, perhaps a limited applicability.

\subsection{Incorporation of BCNW into EVOH by melt compounding}

Once the production of electrospun hybrid fibres was optimized, those fibres were used as a vehicle for the incorporation of well-dispersed BCNW into an EVOH matrix by means of melt mixing. The appearance and thermal properties of the attained material were studied and compared to the blend obtained by direct melt mixing of freeze-dried BCNW with the polymeric matrix.

Figure 8 shows typical optical photographs of the films obtained from the different blends. All the films present a relatively good contact transparency although clear thermal degradation of the filler took place by direct incorporation of this into the polymer. Thus, it is clearly observed that freeze-dried BCNW undergoes severe thermal degradation during the melt mixing process and thus, the filler appears as black spots distributed along the film (Figure 8c). This was not unexpected since the applied processing temperature of $190^{\circ} \mathrm{C}$ is somewhat above the degradation onset temperature of BCNW (see above). However, the composite incorporating electrospun fibres, were highly transparent (Figure 8b), with little 
spots suggesting that thermal degradation is less relevant and hence that the BCNW within the electrospun fibres are more stable as suggested above. By subjecting the material to an additional melt mixing step, i.e. by reprocessing, the obtained film presented now large dark spots evenly distributed along the film (Figure 8d). This observation suggests that the obtained $\mathrm{BCNW}$ are rather unstable at the $\mathrm{EVOH}$ melt mixing temperature and caution should be taken when processing the material.

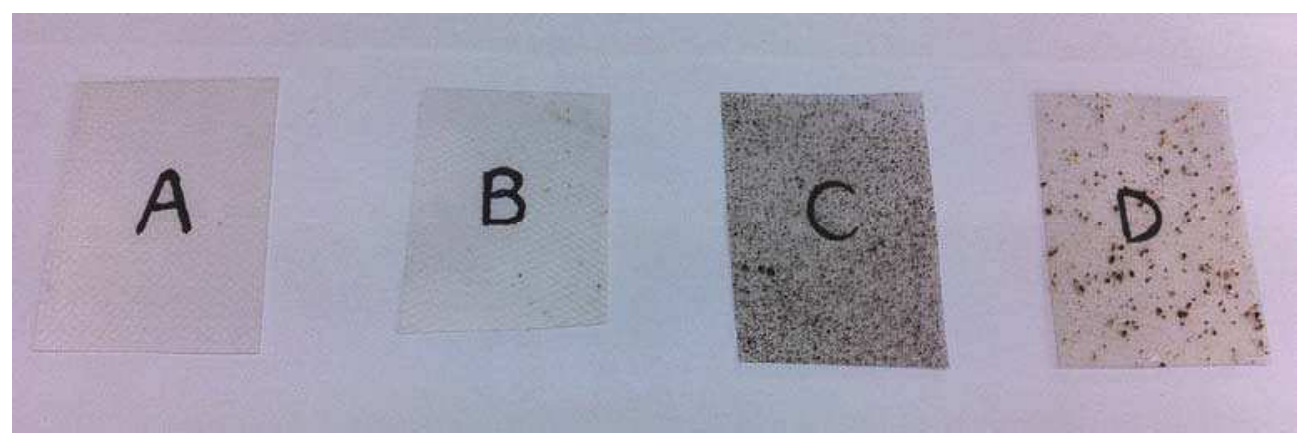

Figure 8. Photographs of films obtained by melt compounding of (A) EVOH29; (B) $3 \%$ BCNW ES; (C) $3 \%$ BCNW FD and (D) $3 \%$ BCNW ES2.

The films were also observed with polarized light to assess the birefringence arising from the $\mathrm{BCNW}$ within the films and hence the crystalline filler dispersion in the polymeric matrix (see Figure 9). From the results, it is confirmed that the most efficient procedure for the incorporation, stability and dispersion of BCNW consists in the production of hybrid electrospun fibres previous to the melt mixing step with virgin EVOH. By reprocessing this material, $\mathrm{BCNW}$ tend to degrade and agglomerate to a significant extent. Less agglomeration occurs when incorporating freeze-dried BCNW, but as expected, the bright areas corresponding to crystalline domains of the filler are not seen confirming that the nanofiller has suffered severe thermal degradation and agglomeration. 

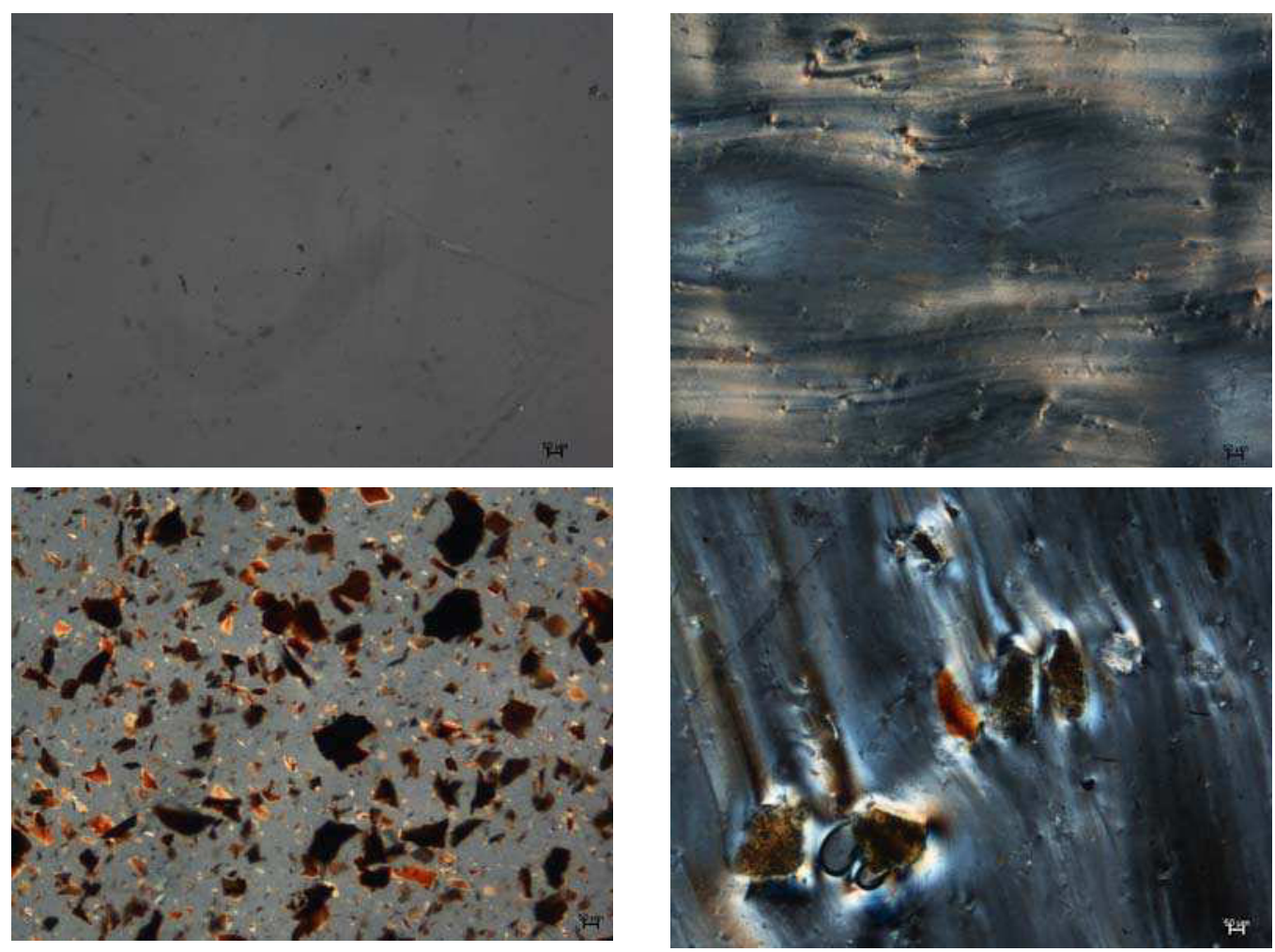

Figure 9. Polarized light optical microscopy images of the (top-left) EVOH29 film; (top-right) 3\% BCNW ES film; (bottom-left) 3\% BCNW FD film and (bottom-right) 3\% BCNW ES2 film. Scale markers are 50 micrometres.

Finally, DSC analyses were carried out in order to study the effect of the incorporation method on the thermal properties of the composite films. In Table 2, the melting enthalpy of the EVOH films is lower than that of electrospun EVOH fibres (see Table 1) indicating that lower crystallinity is obtained by the compression molding and rapid cooling. It is also clearly observed that when incorporating $\mathrm{BCNW}$ the melting temperature decreases as compared to neat EVOH indicating that smaller or more defective crystals are being formed. In the case of the 3\%BCNW ES sample, a significant decrease in the melting enthalpy is 
also observed. It was previously suggested that BCNW hinder the crystallization process of $\mathrm{EVOH}$ when incorporating them into electrospun fibres and therefore, a decrease in the melting enthalpy of composites incorporating electrospun fibres was something to expect. Obviously, areas corresponding to BCNW which suffered thermal degradation present a much lower melting enthalpy. On the other hand, when the material is re-processed or when freeze-dried BCNW are directly melt mixed with EVOH, the melting enthalpy is not significantly altered, suggesting that degraded $\mathrm{BCNW}$ do not present an obstacle for the $\mathrm{EVOH}$ crystallinity. Regarding the glass transition temperature, it was previously observed that for low loadings, such as $5 \mathrm{wt} .-\%$, no significant improvements were detected and hence, for a loading of $3 \mathrm{wt} .-\%$ the $\mathrm{T}_{\mathrm{g}}$ suffers just a slightly decrease. Only those areas corresponding to partially degraded BCNW present an increase in the polymer $T_{g}$, confirming the fact that the stiffening effect of the nanofiller is related to its acidic character and the subsequent interactions between matrix and filler established when applying a thermal treatment that leads to chemical alterations if the filler. 
Table 2. DSC maximum of melting $\left(T_{m}\right)$, melting enthalpy $(\Delta H)$ and glass transition temperature $\left(\mathrm{T}_{\mathrm{g} 1}\right)$, obtained during the first heating run and glass transition temperature $\left(\mathrm{T}_{\mathrm{g} 2}\right)$, obtained during the second heating run, of EVOH-

BCNW films obtained by melt compounding.

\begin{tabular}{|c|c|c|c|c|}
\cline { 2 - 5 } \multicolumn{1}{c|}{} & $\mathrm{T}_{\mathrm{m}}\left({ }^{\circ} \mathrm{C}\right)$ & $\Delta \mathrm{H}(\mathrm{J} / \mathrm{g}$ EVOH $)$ & $\mathrm{T}_{\mathrm{g} 1}\left({ }^{\circ} \mathrm{C}\right)$ & $\mathrm{T}_{\mathrm{g} 2}\left({ }^{\circ} \mathrm{C}\right)$ \\
\hline EVOH29 & $191.0 \pm 0.2$ & $62.0 \pm 0.1$ & $64.3 \pm 0.8$ & $63.9 \pm 0.3$ \\
\hline $3 \%$ BCNW ES & $188.7 \pm 0.2$ & $52.3 \pm 3.3$ & $63.0 \pm 0.2$ & $62.4 \pm 0.2$ \\
\hline $3 \%$ BCNW FD & $189.2 \pm 0.2$ & $62.2 \pm 4.7$ & $63.0 \pm 0.1$ & $62.9 \pm 0.1$ \\
\hline $3 \%$ BCNW ES2 & $188.1 \pm 0.6$ & $67.5 \pm 9.0$ & $62.6 \pm 0.1$ & $62.7 \pm 0.1$ \\
\hline
\end{tabular}

* Refers to areas containing brown spots. 


\section{CONCLUSIONS}

By using an optimized method electrospun EVOH-BCNW fibres were generated from solutions with nanowhiskers concentrations up to $40 \mathrm{wt}$. $\%$. As observed by SEM, morphologies of smaller average diameters and more uniform fibres were attained when increasing the nanofiller concentration.

By means of FT-IR, it was estimated that an amount of ca. 24 wt.-\% BCNW was the actual maximum concentration incorporated into the fibres. On the other hand, the incorporation of the nanofiller was only proven to be complete in concentrations up to $20 \mathrm{wt}$. $\%$ BCNW. Additionally, DSC analyses showed that the incorporation of BCNWs hinders the crystallization of EVOH and produces an increase in the $T_{g}$ of the fibres after one heating step. Furthermore, those effects are directly related to the amount of BCNW effectively incorporated into the fibres, being less pronounced for concentrations higher than $20 \mathrm{wt} .-\%$ nanowhiskers.

The increase in the $\mathrm{T}_{\mathrm{g}}$ can be explained by the acidic character of the incorporated BCNWs, which is responsible, on the other hand, for the decrease in the thermal stability of the hybrid fibres as compared to pure EVOH fibres. It was observed that, when subjected to thermal treatments beyond the EVOH matrix melting point, the hybrid fibres seem to undergo a chemistry development in which strong interactions are formed between hydroxyl groups from cellulose and EVOH. As a consequence of those established interactions, a significant stiffening of the fibres is produced, reflected in a consistent increase in the $T_{g}$ of the material. Therefore, there is a compromise between the stiffening effect induced by heating of the material and the thermal stability of the fibres. 
Finally, electrospun fibres were employed for the incorporation of $\mathrm{BCNW}$ into EVOH via melt compounding. As assessed by optical and polarized optical microscopy, the degree of dispersion achieved and the stability of the filler was found to be much higher than that attained when direct melt mixing of freeze-dried BCNW with the polymeric matrix. No $\mathrm{T}_{\mathrm{g}}$ enhancement was found on the composite films at the low filler loadings used, unless clear degradation took place, although the crystallization of EVOH was somewhat hindered, especially when incorporating hybrid electrospun fibres.

Nevertheless, it has been demonstrated that the electrospinning technique can be used as an efficient vehicle for the incorporation of well-dispersed BCNW into an EVOH matrix by melt compounding. However, the nanofabrication process of BCNW needs to be optimized in order to obtain a more thermally stable material which can be processed with EVOH by melt compounding without suffering thermal degradation. Further results on this direction will be reported elsewhere. 


\section{REFERENCES}

Garcia de Rodriguez, N. L., Thielemans, W., \& Dufresne, A. (2006). Sisal cellulose whiskers reinforced polyvinyl acetate nanocomposites. Cellulose, 13(3), 261-270.

Ignatova, M., Manolova, N., Markova, N., \& Rashkov, I. (2009). Electrospun nonwoven nanofibrous hybrid mats based on chitosan and PLA for wound-dressing applications. Macromolecular Bioscience, 9(1), 102-111.

Jain, R. K., Lal, K., \& Bhatnagar, H. L. (1987). Thermal, morphological and spectroscopic studies in cellulose modified with phosphorus, nitrogen, sulphur and halogens. Journal of Applied Polymer Science, 33(2), 247-282.

Jeong, S. I., Krebs, M. D., Bonino, C. A., Khan, S. A., \& Alsberg, E. (2010). Electrospun alginate nanofibers with controlled cell adhesion for tissue engineering. Macromolecular Bioscience, 10(8), 934-943.

Ji, Y., Li, B., Ge, S., Sokolov, J. C., \& Rafailovich, M. H. (2006). Structure and nanomechanical characterization of electrospun PS/clay nanocomposite fibers. Langmuir, 22(3), 1321-1328.

Jiang, L., Morelius, E., Zhang, J., Wolcott, M., \& Holbery, J. (2008). Study of the poly(3-hydroxybutyrate-co-3-hydroxyvalerate)/cellulose nanowhisker composites prepared by solution casting and melt processing. Journal of Composite Materials, 42(24), 2629-2645.

Julien, S., Chornet, E., \& Overend, R. P. (1993). Influence of acid pretreatment $(\mathrm{H} 2 \mathrm{SO} 4, \mathrm{HCl}, \mathrm{HNO} 3)$ on reaction selectivity in the vacuum pyrolysis of cellulose. Journal of Analytical and Applied Pyrolysis, 27(1), 25-43.

Kenawy, E.-R., Bowlin, G. L., Mansfield, K., Layman, J., Simpson, D. G., Sanders, E. H., \& Wnek, G. E. (2002). Release of tetracycline hydrochloride from electrospun poly(ethylene-co-vinylacetate), poly(lactic acid), and a blend. Journal of Controlled Release, 81(1-2), 57-64.

Kim, C. W., Frey, M. W., Marquez, M., \& Joo, Y. L. (2005). Preparation of submicron-scale, electrospun cellulose fibers via direct dissolution. Journal of Polymer Science, Part B: Polymer Physics, 43(13), 1673-1683. 
Kim, C. W., Kim, D. S., Kang, S. Y., Marquez, M., \& Joo, Y. L. (2006). Structural studies of electrospun cellulose nanofibers. Polymer, 47(14), 5097-5107.

Kvien, I., Sugiyama, J., Votrubec, M., \& Oksman, K. (2007). Characterization of starch based nanocomposites. Journal of Materials Science, 42(19), 8163-8171.

Lagaron, J. M., Gimenez, E., Catala, R., \& Gavara, R. (2003). Mechanisms of moisture sorption in barrier polymers used in food packaging: Amorphous polyamide vs. high-barrier ethylene-vinyl alcohol copolymer studied by vibrational spectroscopy. Macromolecular Chemistry and Physics, 204(4), 704-713.

Lagaron, J. M., Martínez-Sanz, M., \& Lopez-Rubio, A. (2010). Patent Application P30663.

Liu, H., Kameoka, J., Czaplewski, D. A., \& Craighead, H. G. (2004). Polymeric nanowire chemical sensor. Nano Letters, 4(4), 671-675.

Martínez-Sanz, M., Olsson, R. T., Lopez-Rubio, A., \& Lagaron, J. M. (2011). Development of electrospun EVOH fibres reinforced with bacterial cellulose nanowhiskers. Part I: Characterization and method optimization. Cellulose, 18(2), 335-347.

Olsson, R. T., Kraemer, R., Lopez-Rubio, A., Torres-Giner, S., Ocio, M. J., \& Lagaron, J. M. (2010). Extraction of microfibrils from bacterial cellulose networks for electrospinning of anisotropic biohybrid fiber yarns. Macromolecules, 43(9), 4201-4209.

Park, W. I., Kang, M., Kim, H. S., \& Jin, H. J. (2007). Electrospinning of poly(ethylene oxide) with bacterial cellulose whiskers. Macromolecular Symposia, 249-250, 289-294.

Peresin, M. S., Habibi, Y., Zoppe, J. O., Pawlak, J. J., \& Rojas, O. J. (2010). Nanofiber composites of polyvinyl alcohol and cellulose nanocrystals: Manufacture and characterization. Biomacromolecules, 11(3), 674-681.

Petersson, L., Kvien, I., \& Oksman, K. (2007). Structure and thermal properties of poly(lactic acid)/cellulose whiskers nanocomposite materials. Composites Science and Technology, 67(11-12), 2535-2544. 
Rojas, O. J., Montero, G. A., \& Habibi, Y. (2009). Electrospun nanocomposites from polystyrene loaded with cellulose nanowhiskers. Journal of Applied Polymer Science, 113(2), 927-935.

Roman, M., \& Winter, W. T. (2004). Effect of sulfate groups from sulfuric acid hydrolysis on the thermal degradation behavior of bacterial cellulose. Biomacromolecules, 5(5), 1671-1677.

Sanchez-Garcia, M. D., \& Lagaron, J. M. (2010). On the use of plant cellulose nanowhiskers to enhance the barrier properties of polylactic acid. Cellulose, 17(5), 987-1004.

Schreuder-Gibson, H., Gibson, P., Senecal, K., Sennett, M., Walker, J., Yeomans, W., Ziegler, D., \& Tsai, P. P. (2002). Protective textile materials based on electrospun nanofibers. Journal of Advanced Materials, 34(3), 44-55.

Ten, E., Turtle, J., Bahr, D., Jiang, L., \& Wolcott, M. (2010). Thermal and mechanical properties of poly(3-hydroxybutyrate-co-3-hydroxyvalerate)/cellulose nanowhiskers composites. Polymer, 51(12), 2652-2660.

Zhang, Y. J., Huang, Y. D., Wang, L., Li, F. F., \& Gong, G. F. (2005). Electrospun non-woven membrane of poly(ethylene covinyl alcohol) end-capped with potassium sulfonate. Materials Chemistry and Physics, 91(1), 217-222. 
Chapter III

OPTIMIZATION OF THE NANOFABRICATION BY ACID HYDROLYSIS OF BACTERIAL CELLULOSE NANOWHISKERS

Carbohydrate Polymers, 85(1), 228-236. (2011)

Marta Martínez Sanz, Amparo López Rubio, José María Lagarón

Novel Materials and Nanotechnology Group, IATA, CSIC. Avd. Agustín

Escardino, 7, 46980. Paterna, Valencia. Spain 



\begin{abstract}
This work aims at examining the various factors that affect cellulose nanowhiskers (CNWs) extraction from bacterial cellulose (BC). Specifically, the effect of sulphuric acid hydrolysis time and further treatments such as neutralization and dialysis on the properties of the obtained nanoparticles was studied. The morphology of BCNWs was examined by TEM, showing a decrease in the nanowhiskers' length when increasing hydrolysis time as expected. The XRD patterns of the different samples showed a crystalline structure characteristic of the cellulose I allomorph. From the calculated crystallinity indexes it was deduced that long hydrolysis times, such as 48 hours, are required when intending to digest a significant fraction of amorphous material and thus, obtaining a significant increase in crystallinity by comparison with the native $\mathrm{BC}$. Nevertheless, as a consequence of this extensive acid hydrolysis treatment, the thermal stability of the material is significantly decreased, making it unsuitable for most melt-compoundable polymer-based nanocomposites applications. On the other hand, neutralization produced a slight increase in the crystallinity index, and, most importantly, it led to a remarkable increase on the BCNWs thermal stability, as determined by TGA. Furthermore, it was found out that dialysis applied after neutralization did not present any additional improvement on the BCNWs' properties.
\end{abstract}

Keywords: Bacterial cellulose; cellulose; morphology, nanowhiskers; nanocrystals. 


\section{INTRODUCTION}

Cellulose is one of the most abundant biopolymers on earth. Vegetal resources such as wood, cotton and linter are the most commonly raw materials employed to extract cellulose. Nevertheless, cellulose can be also synthesized by some bacterial species, such as Gluconacetobacter xylinum. In a static culture medium rich in polysaccharides, this bacterial species is able to produce a layer of bacterial cellulose (BC) in the liquid/air interface. This highly hydrated pellicle consists of a random assembly of ribbon-shaped fibrils, less than $100 \mathrm{~nm}$ wide, which are composed of a bundle of nanofibrils (Yamanaka et al., 1989). Although plant-derived cellulose (PC) and $\mathrm{BC}$ have the same chemical structure, they have different structural organization and mechanical properties. BC shows a finer web-like network structure, higher water holding capacity and higher crystallinity (Iguchi et al., 2000; Wan et al., 2007). Furthermore, while PC is naturally associated with other kinds of biopolymers such as hemicelluloses and lignin, BC is practically pure cellulose. Due to its outstanding properties, i.e. high purity, high crystallinity, high mechanical strength, low density and biocompatibility, bacterial cellulose has become an interesting material with applications in biomedicine (Czaja et al., 2006; Klemm et al., 2001; Svensson et al., 2005), paper industry and, more recently, as a reinforcement agent for polymeric matrixes (Gindl \& Keckes, 2004; Park et al., 2007; Wan et al., 2009).

For their application as nanofillers, cellulosic materials are usually subjected to hydrolysis with strong acids such as sulphuric acid or hydrochloric acid, which produce a preferential digestion of the amorphous domains of the material and cleavage of the nanofibril bundles (Rånby, 1949), therefore breaking down the hierarchical structure of the material into crystalline nanofibres or nanocrystals, usually referred to as cellulose nanowhiskers (CNWs). The morphology of the 
obtained CNWs depends on the cellulose source and the hydrolysis conditions. While CNWs extracted from vegetal resources such as cotton or wood typically have a length of 100-300 nm and width of 5-20 nm (Araki et al., 1998; Favier et al., 1995; Siqueira et al., 2009), CNWs obtained from tunicin and bacterial cellulose may have several micrometres in length and a width of 5-50 nm (Araki \& Kuga, 2001; De Souza Lima et al., 2003; Hirai et al., 2009). Regarding the hydrolysis conditions, the acid concentration, cellulose/acid ratio, temperature and hydrolysis time are factors which determine the CNWs' morphology. The CNWs' aspect ratio $(\mathrm{L} / \mathrm{D})$ is a crucial parameter which has a remarkable influence on the reinforcing capacity of the nanofiller when incorporating it into a polymeric matrix (Eichhorn et al., 2010). Therefore, the acid hydrolysis conditions must be carefully studied and controlled in order to obtain a material with the desired morphology.

The most widely used procedure for the extraction of cellulose nanowhiskers consists of sulphuric acid treatment followed by filtration or centrifugation. Sulphuric acid hydrolysis leads to stable aqueous suspensions of cellulose nanocrystals which are negatively charged and thus, do not tend to aggregate. During the hydrolysis process, esterification of the surface hydroxyl groups from cellulose takes place and as a consequence, sulphate groups are introduced (Rånby, 1949). Despite the advantage of obtaining stable suspensions, the presence of sulphate groups in the outer surface of the material has been proved to strongly decrease the thermal stability of the material (Roman \& Winter, 2004), which is also a key factor when intending to use CNWs as nanoreinforcement.

Typical CNWs extraction methods involve centrifugation after hydrolysis with the purpose of removing acid and the degraded material. After several centrifugation cycles CNWs are usually obtained from the turbid liquid 
supernatant, while bigger cellulosic material fractions and some impurities remain in the solid precipitate. Taking into account that in the case of $\mathrm{BC}$ there is no hemicellulose or lignin to remove, previous studies proposed an extraction method in which BCNWs are obtained in the centrifugation precipitate instead of the supernatant and, thus, the yield can be as high as $89 \%$ based on the dry weight of bacterial cellulose (Martínez-Sanz et al., 2011; Olsson et al., 2010) versus yields around $1-5 \%$ when the whiskers are obtained from the liquid supernatant. In contrast with this great advantage, the highly crystalline network structure of $\mathrm{BC}$ requires strong hydrolysis conditions in order to break down the morphology of fibril bundles and individual nanofibrils can not be yielded without partial carbonization and degradation of the material (Olsson et al., 2010).

In a previous study, it was found that BCNWs with a crystallinity index of ca. $86 \%$ were obtained after applying a relatively strong sulphuric acid hydrolysis. Nevertheless, the thermostability of the material was significantly diminished with respect to the untreated $\mathrm{BC}$ and $\mathrm{BCNWs}$ started to degrade at approximately $100^{\circ} \mathrm{C}$ (Martínez-Sanz et al., 2011), which is far below the typical processing temperatures for processing most thermoplastics. In the present study, the effects of sulphuric acid hydrolysis time and post-treatments on the morphology, crystallinity and thermostability of BCNWs were studied for the first time. The hydrolysis time ranged from a typical duration of 2 hours to a long treatment of 69 hours, similar to the previous work mentioned above. The effect of neutralization and dialysis after the acid treatment on the thermal stability was also studied. The objective was to optimize the BCNWs extraction process in order to obtain a material with a high crystallinity index and high thermal stability and having a proper morphology which makes it suitable for nanocomposites applications. 


\section{MATERIALS AND METHODS}

\subsection{Preparation of bacterial cellulose mats}

The bacterial strain Gluconacetobacter xylinus 7351, obtained from the Spanish type culture collection (CECT) was incubated in a static culture medium composed of $20 \mathrm{~g}$ glucose, $5 \mathrm{~g}$ yeast-extract, $1.15 \mathrm{~g}$ citric acid, $5.7 \mathrm{~g} \mathrm{MgSO}_{4} \cdot 7 \mathrm{H}_{2} \mathrm{O}$ and $12.25 \mathrm{~g}$ buffered peptone water, per litre of water, at $30^{\circ} \mathrm{C}$. All of the cells were pre-cultured in a test tube containing $5 \mathrm{ml}$ of media. When a thin layer of cellulose was detected on top of the surface, they were transferred to $200 \mathrm{ml}$ bottles and subsequently to the final culture, containing 20 litres of media. The obtained bacterial cellulose pellicles, about $5 \mathrm{~cm}$ thick, were cut into small pieces (ca. $2 \times 2 \mathrm{~cm}^{2}$ ). Those pieces were boiled repeated times in distilled water and then boiled in an aqueous solution of $10 \%(\mathrm{v} / \mathrm{v}) \mathrm{NaOH}(\mathrm{Ph}$. Eur., Panreac Quimica Sau) in order to remove bacterial cells and the absorbed culture media. Finally, the $\mathrm{pH}$ was lowered to 7 by boiling in distilled water several times.

\subsection{Sulphuric acid hydrolysis}

Once neutral $\mathrm{pH}$ was reached, bacterial cellulose pellicles were ground in a blender. One fraction of the gel-like material was then compressed in order to remove most of the absorbed water, and another fraction was freeze-dried and ground into powder. The dried or freeze-dried cellulosic material was then treated with $301 \mathrm{~mL}$ sulphuric acid ( $96 \%$ Panreac)/L water, in a cellulose/acid ratio of approximately $8-10 \mathrm{~g} / \mathrm{L}$, at $50^{\circ} \mathrm{C}$ for a fixed period of time (cf. Table 1).

The cellulose nanowhiskers were obtained as a white precipitate after several centrifugation and washing cycles at $12,500 \mathrm{rpm}$ and $15^{\circ} \mathrm{C}$ for 20 minutes. The $\mathrm{pH}$ of the samples was measured after the washing-centrifugation cycles, being around 2 for all the samples. 


\subsection{BCNWs post-treatments}

In order to study the influence of $\mathrm{pH}$ in thermal stability, all the samples were re-suspended in deionised water and neutralized with sodium hydroxide until neutral $\mathrm{pH}$ and subsequently centrifuged to obtain the final product as a partially hydrated precipitate (BCNW 2hN, BCNW 48hN and BCNW 69hN).

Furthermore, and additional step of dialysis was applied to sample $69 \mathrm{hN}$ in order to evaluate the effect of this process in the material. Thus, the precipitate obtained after neutralization and centrifugation was re-suspended in water and subsequently subjected to dialysis against deionised water during one week. The product inside the dialysis membrane was then freeze-dried (BCNW 69hND).

The humidity of the centrifuged nanowhiskers was determined in order to calculate the amount of whiskers per gram of centrifugation precipitate. A fraction of each sample was freeze-dried for XRD, FT-IR and TGA analyses.

Table 1. Conditions for the sulfuric acid hydrolysis of bacterial cellulose.

\begin{tabular}{|c|c|c|c|c|}
\hline Sample code & Cellulose & $\begin{array}{c}\text { Hydrolisys } \\
\text { time }(\mathrm{h})\end{array}$ & $\begin{array}{c}\mathrm{H}_{2} \mathrm{SO}_{4} \text { concentration } \\
(\%(\mathrm{w} / \mathrm{v}))\end{array}$ & $\mathrm{pH}$ \\
\hline BCNW 2h & Freeze-dried & 2 & 55.4 & 2.16 \\
\hline BCNW 2hN & Freeze-dried & 2 & 55.4 & 6.40 \\
\hline BCNW 48h & Dried & 48 & 50.7 & 2.00 \\
\hline BCNW 48hN & Dried & 48 & 50.7 & 6.83 \\
\hline BCNW 69hN & Freeze-dried & 69 & 55.4 & 6.61 \\
\hline BCNW 69hND & Freeze-dried & 69 & 55.4 & 5.28 \\
\hline
\end{tabular}

\subsection{Transmission Electron Microscopy (TEM)}

One drop $(8 \mu \mathrm{L})$ of a $0.001 \%$ aqueous suspension of $\mathrm{BCNW}$ was allowed to dry on a carbon coated grid (200 mesh). The crystals were stained with uranyl 
acetate. TEM was performed using a JEOL 1010 equipped with a digital Bioscan (Gatan) image acquisition system at $80 \mathrm{KV}$.

\subsection{X-ray Diffraction (XRD)}

X-ray diffraction was carried out on a D5005 Bruker diffractometer. The instrument was equipped with a $\mathrm{Cu}$ tube and a secondary monochromator. The configuration of the equipment was $\theta-2 \theta$ and the samples were examined over the angular range of $5^{\circ}$ to $45^{\circ}$ with a step size of $0.02^{\circ}$ and a count time of $4 \mathrm{~s}$ per point.

Peak fitting was carried out using Igor software package (Wavemetrics, Lake Oswego, Oregon). Gaussian function was used to fit the experimental diffraction profiles obtained. For the fitting procedure, the reflections considered were (i) three at $14.8^{\circ}, 16.4^{\circ}$ and $22.5^{\circ}$ (corresponding to $101,10 \overline{1}$ and 002 crystal planes respectively) assigned to the cellulose I allomorph, and (ii) the amorphous halo centered at approximately $18.5^{\circ} 2 \theta$. The crystallinity index CI (XD) was determined by the method reported by Wang et al. (Wang et al., 2007):

$$
\mathrm{CI}(\mathrm{XD})=\frac{\sum A_{\text {Crystal }}}{A_{\text {Total }}} \times 100
$$

where $A_{\text {Total }}$ is the sum of the areas under all the diffraction peaks and $\Sigma A_{C r y s t a l}$ is the sum of the areas corresponding to crystalline peaks.

The crystallite sizes were estimated from the $101,10 \overline{1}$ and 002 lattice planes of cellulose I using the well-known Scherrer equation:

$$
D_{(h k l)}=\frac{k \cdot \lambda}{B_{(h k l)} \cdot \cos \theta}
$$


where $D_{(h k l)}$ is the size of the crystallite $(\mathrm{nm}), k$ is the Scherrer constant (0.94), $\lambda$ is the X-ray wavelength, $B_{(h k l)}$ is the full-width at half-maximum of the reflection hkl and $2 \theta$ is the corresponding Bragg angle.

\subsection{FT-IR analysis}

Bacterial cellulose before acid digestion and the obtained nanowhiskers samples of ca. $2 \mathrm{mg}$ were ground and dispersed in $200 \mathrm{mg}$ of spectroscopic grade $\mathrm{KBr}$. A pellet was then formed by compressing the sample at ca. $150 \mathrm{MPa}$.

FT-IR experiments were recorded in transmission mode in a controlled chamber at $21^{\circ} \mathrm{C}$ and $40 \% \mathrm{RH}$ using a Bruker (Rheinstetten, Germany) FT-IR Tensor 37 equipment. The spectra were taken at $1 \mathrm{~cm}^{-1}$ resolution averaging a minimum of 10 scans. Analysis of the spectra was performed using Grams/AI 7.02 (Galactic Industries, Salem, NH, USA) software.

\subsection{Thermogravimetric analysis (TGA)}

Thermogravimetric (TG) curves were recorded with a TA Instruments model Q500 TGA. The samples (ca. $20 \mathrm{mg}$ ) were heated from $50^{\circ} \mathrm{C}$ to $600^{\circ} \mathrm{C}$ with a heating rate of $10^{\circ} \mathrm{C} / \mathrm{min}$ under nitrogen atmosphere. Derivative TG curves (DTG) express the weight loss rate as a function of temperature.

\subsection{Statistical analysis}

One-way analysis of the variance (ANOVA) was performed using XLSTATPro (Win) 7.5.3 (Addinsoft, NY) software package. Comparisons between samples were evaluated using the Tukey test $(\alpha=0.05)$. 


\section{RESULTS AND DISCUSSION}

BCNWs were obtained by sulphuric acid digestion of bacterial cellulose (BC) and the effects of hydrolysis time and post-treatments on the obtained nanoparticles's properties were studied. Initially, freeze-dried BC was subjected to a short hydrolysis process of two hours, which is the typical hydrolysis time applied to vegetal cellulosic materials. However, after two hours the hydrolysis solution was not completely homogeneous, indicating that this hydrolysis time may not be enough to digest the amorphous domains of the material. Therefore, longer hydrolysis treatments were applied to both dried and freeze-dried cellulose. The time needed to obtain a homogeneous solution was 48 hours and 69 hours respectively.

As previous studies pointed out that sulphuric acid hydrolysis causes a decrease in the thermal stability of the cellulosic material, samples were additionally neutralized with sodium hydroxide and further subjected to dialysis to evaluate if the thermal properties of the BCNWs improved by these posttreatments.

\subsection{Morphological characterization of BCNWs}

The morphology of BCNW suspensions was studied by means of TEM and the cross-sections and lengths of each sample were estimated from several measurements on TEM micrographs. Since analyzed areas are very small compared to the total sample area, the results obtained from TEM should be considered as a rough estimation of the actual size of the nanowhiskers and the aim of these measurements is to compare between the different samples. 
From observation of Figure 1 and Table 2 it can be deduced that no major changes in the BCNWs' cross-sections were induced by varying the acid hydrolysis conditions or the subsequent treatments. However, it appears that by increasing the hydrolysis time up to 48 hours, the cross-section decreases (with a $95 \%$ confidence level), which may indicate that only for long hydrolysis times, such as 48 hours, the acid is able to start breaking down the fibrils' bundles thus decreasing the amount of nanofibrils which conform them. Nevertheless, the wide variability of the data precludes from drawing absolute conclusions about the cross-sections of the nanowhiskers obtained.

On the other hand, a trend of decreasing BCNWs' length is observed when increasing the hydrolysis time. This reduction in length has been previously reported in cellulose samples when treated with strong acids, which produce the preferential digestion of disordered regions along the cellulose fibrils, thus resulting in shorter nanocrystals (Azizi Samir et al., 2005). Therefore, this shortening of cellulose nanofibrils, which is more obvious when increasing the hydrolysis time from 2 hours up to 48 hours, indicates that longer acid treatments lead to more crystalline materials in which a greater amount of amorphous regions have been digested along the fibrils. In contrast, subsequent neutralization or dialysis of the samples did not lead to significant changes in the BCNW length.

It can also be deduced from the present results that, for long hydrolysis times, the fact that the native $\mathrm{BC}$ used is freeze-dried (vs. dried) does not lead to a morphology of more aggregated nanowhiskers and no significant effect on the nanowhiskers' dimensions is observed. 

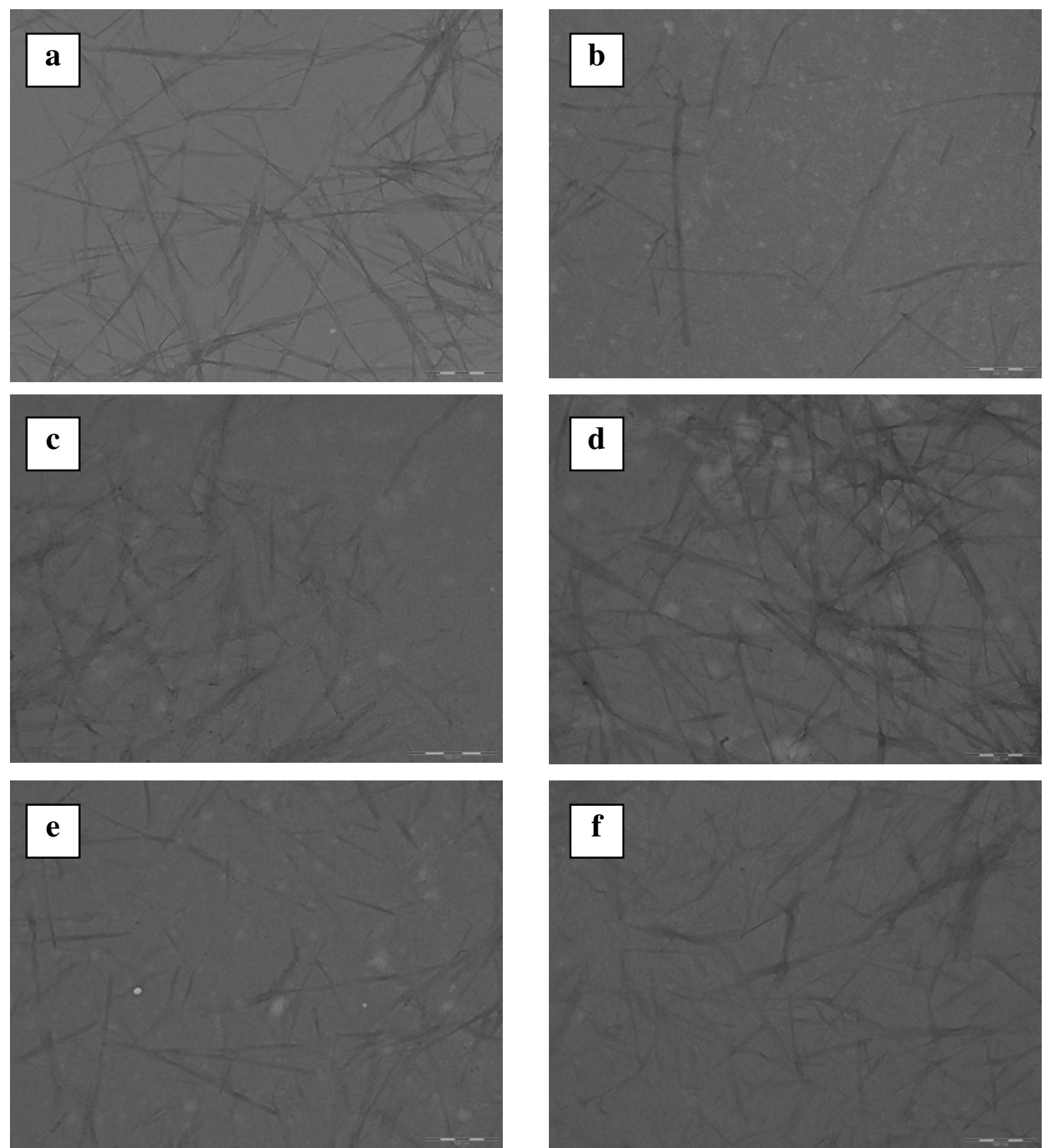

Figure 1. TEM micrographs of: (a) BCNW hydrolyzed for 2 hours; (b) same as (a) after neutralizing with $\mathrm{NaOH}$; (c) BCNW hydrolyzed for 48 hours; (d) same as (c) after neutralizing with $\mathrm{NaOH}$; (e) BCNW hydrolyzed for 69 hours and neutralized with $\mathrm{NaOH}$; (f) same as (e) after dialysis. Scale markers correspond to 500 nanometres. 
Table 2. Dimensions of BCNW prepared by different acid hydrolysis conditions.

Measurements obtained from TEM micrographs.

\begin{tabular}{|c|c|c|c|}
\hline Sample & Cross-section (nm) & Length (nm) & $\begin{array}{c}\text { Aspect Ratio } \\
(\mathrm{L} / \mathrm{D})\end{array}$ \\
\hline BCNW 2h & ${ }^{\mathrm{a}} 27.79(8.71)$ & ${ }^{\mathrm{a}} 1449.51(406.53)$ & ${ }^{\mathrm{a}} 52.16(10.71)$ \\
\hline BCNW 2hN & ${ }^{\mathrm{a}} 29.62(10.37)$ & ${ }^{\mathrm{a}} 881.94(543.89)$ & ${ }^{\mathrm{b}} 29.78(16.80)$ \\
\hline BCNW 48h & ${ }^{\mathrm{b}} 20.09(5.45)$ & ${ }^{\mathrm{b}} 468.75(250.57)$ & ${ }^{\mathrm{b}} 23.33(6.28)$ \\
\hline BCNW 48hN & ${ }^{\mathrm{b}} 18.49(5.32)$ & ${ }^{\mathrm{b}} 567.11(295.76)$ & ${ }^{\mathrm{b}} 30.67(15.90)$ \\
\hline BCNW 69hN & ${ }^{\mathrm{b}} 20.81(7.66)$ & ${ }^{\mathrm{b}} 599.60(325.26)$ & ${ }^{\mathrm{b}} 28.81(16.38)$ \\
\hline BCNW 69hND & ${ }^{\mathrm{b}} 19.34(5.27)$ & ${ }^{\mathrm{b}} 470.29(334.52)$ & ${ }^{\mathrm{b}} 24.32(12.06)$ \\
\hline
\end{tabular}

Values between brackets correspond to standard deviations. The $\mathrm{a}$ and $\mathrm{b}$ letters correspond to the ANOVA statistical analysis and Tukey test of the data that indicate that with a $95 \%$ confidence level, the values are significantly different.

The aspect ratio of the BCNWs is an important parameter which conditions the reinforcing effect of the nanowhiskers when incorporated into a polymeric matrix. Materials with aspect ratios higher than 30 , such as tunicin whiskers $(\mathrm{L} / \mathrm{d} \sim 67$ ) have been reported to provide a considerably higher reinforcement effect as compared to nanofillers having lower aspect ratios, such as Avicel whiskers (L/d 10) (Azizi Samir et al., 2005). Nevertheless, it has also been reported that for aspect ratios larger than 100, the Young's modulus reaches a plateau corresponding to the maximum point of reinforcement (Eichhorn et al., 2010). As shown in Table 2 , the greatest aspect ratio corresponds to a hydrolysis time of 2 hours, decreasing down to 20-30 for longer treatments and, thus, from an aspect ratio viewpoint it would seem that the shortest treatment would provide the most adequate BCNWs. 
However, in order to determine the optimum acid hydrolysis conditions, other factors such as the crystallinity index and the thermal stability of the obtained BCNWs, which will be discussed in later sections of this study, have to be also taken into account. The effect of increasing the hydrolysis time and of applying post-treatments like neutralization or dialysis after the acid hydrolysis over the crystallinity and thermal stability of the material is discussed in what follows.

\subsection{Effect of acid hydrolysis time on the crystallinity and thermal stability of BCNWs}

Sulphuric acid treatment of cellulosic materials has been widely used as a way to extract cellulose nanocrystals since it causes a preferential hydrolysis of disordered or amorphous regions of the material through a surface reaction process, whereas crystalline domains have a higher resistance to acid attack and remain intact under controlled conditions (De Souza Lima \& Borsali, 2004). By varying the hydrolysis time, it is possible to modify the crystallinity index of the obtained material and produce whiskers with controlled aspect ratio (Beck-Candanedo et al., 2005; Yun et al., 2010). Too short hydrolysis reactions will not lead to significant changes in the crystallinity of the material since, in the case of BC, the structure of ribbon-shaped crystalline bundles is not easily penetrated by acid molecules (Zhao et al., 2007). On the other hand, a too long reaction time will lead to the digestion of the crystalline domains of $\mathrm{BC}$, thus leading to a decrease in the crystallinity. Previous studies revealed that in the case of $\mathrm{BC}$, longer hydrolysis times than those used for plant cellulose are required to obtain a material with a crystallinity index of $82.2 \%$ (Martínez-Sanz et al., 2011).

In this work, in order to estimate the effect of hydrolysis time on the crystallinity and thermostability of the obtained BCNWs, two different acid digestion times were studied: a relatively short reaction time of 2 hours and a 
longer hydrolysis of 48 hours. Table 3 gathers the crystallinity index and the crystallite sizes calculated from the 101, $10 \overline{1}$ and 002 lattice planes of cellulose I for untreated $\mathrm{BC}$ and its corresponding nanowhiskers obtained after different hydrolysis times, calculated from the X-ray diffraction patterns shown in Figure 2.

As shown in Figure 2, the untreated BC and the obtained BCNWs show three major diffraction peaks at $14.5^{\circ}, 16.4^{\circ}$ and $22.5^{\circ} 2 \theta$. According to the literature (Moharram \& Mahmoud, 2007), these diffraction peaks are ascribed to the crystallographic planes $101,10 \overline{1}$ and 002 from the cellulose I allomorph. The crystallinity index calculated for the untreated $\mathrm{BC}(79.06 \%)$ is similar to that reported in a previous study for $\mathrm{BC}$ obtained through the same process $(73.1 \%)$ (Martínez-Sanz et al., 2011). After 2 hours of acid hydrolysis the crystallinity index of the material is not significantly altered, indicating that 2 hours is not enough time for the acid to digest the amorphous material. Although 2 hours is an hydrolysis time typically used for the extraction of cellulose nanowhiskers from vegetal resources, the structure of bacterial cellulose, consisting in the association of nanofibrils into highly crystalline ribbon-shaped bundles, hinders the penetration of the acid into those bundles and thus, it has been reported that acid hydrolysis of bacterial cellulose may be slower than for cotton or wood (Yun et al., 2010). On the other hand, the crystallinity increases up to $90.31 \%$ after 48 hours. The increase of $11.25 \%$ in the crystallinity index of the material is similar to the increase of $\sim 9 \%$ previously reported for a hydrolysis time of five days (Martínez-Sanz et al., 2011). This indicates that long hydrolysis times are required in order to cause a significant increase on the crystallinity of bacterial cellulose. Additionally, as showed in Table 3, an increase of the crystallite size in the 101 crystalline plane with increasing the hydrolysis time is observed, probably indicating that the 
smaller or more defective crystals are being digested by means of the sulphuric acid treatment as would be expected.

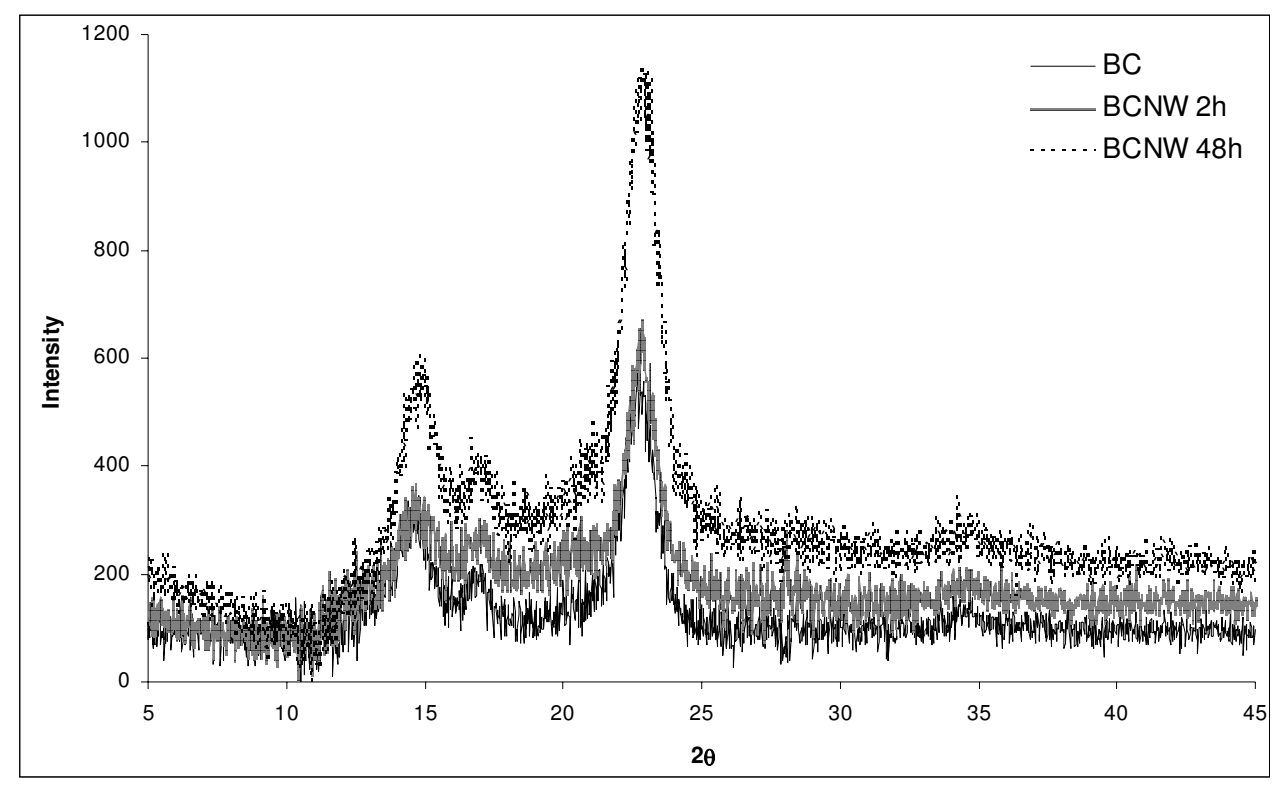

Figure 2. X-ray diffraction patterns of native bacterial cellulose $(\mathrm{BC})$ and the obtained nanowhiskers (BCNW) after 2 hours and 48 hours of sulfuric acid hydrolysis. 
Table 3. Crystallinity index (CI) and crystallite sizes $\left(D_{(101)}, D_{(1 \overline{1} 1)}\right.$ and $\left.D_{(002)}\right)$ determined from the XRD patterns from native bacterial cellulose (BC) and the obtained nanowhiskers (BCNW) with different hydrolysis times. Values between brackets correspond to standard deviations.

\begin{tabular}{|c|c|c|c|c|}
\hline Sample & CI (\%) & $D_{(101)}(\mathrm{nm})$ & $D_{(1 \overline{0} 1)}(\mathrm{nm})$ & $D_{(002)}(\mathrm{nm})$ \\
\hline $\mathrm{BC}$ & ${ }^{\mathrm{a}} 79.06(0.44)$ & ${ }^{\mathrm{a}} 0.84(0.04)$ & ${ }^{\mathrm{a}} 1.74(0.07)$ & ${ }^{\mathrm{a}} 1.06(0.01)$ \\
\hline BCNW 2h & ${ }^{\mathrm{a}} 76.64(0.62)$ & ${ }^{\mathrm{b}} 1.16(0.01)$ & ${ }^{\mathrm{a}} 1.74(0.03)$ & ${ }^{\mathrm{b}} 1.17(0.00)$ \\
\hline BCNW 48h & ${ }^{\mathrm{b}} 90.31(0.79)$ & ${ }^{\mathrm{c}} 1.37(0.02)$ & ${ }^{\mathrm{a}} 1.50(0.27)$ & ${ }^{\mathrm{a}} 1.04(0.02)$ \\
\hline
\end{tabular}

Values between brackets correspond to standard deviations. The a and $\mathrm{b}$ letters correspond to the ANOVA statistical analysis and Tukey test of the data that indicate that with a $95 \%$ confidence level, the values are significantly different.

In addition to XRD, FT-IR analyses of native $\mathrm{BC}$ and the obtained nanowhiskers were developed in order to study the structural and chemical effects of the sulphuric acid hydrolysis. A qualitative analysis of the FT-IR spectra shown in Figure 3 confirms that after the 2 hours of hydrolysis, the crystallinity of the material has been slightly increased since sharpening of characteristic cellulose bands is observed. According to the literature (Oh et al., 2005), the bands at 4000$2995 \mathrm{~cm}^{-1}, 2900 \mathrm{~cm}^{-1}, 1430 \mathrm{~cm}^{-1}, 1375 \mathrm{~cm}^{-1}$ and $900 \mathrm{~cm}^{-1}$ are known to be especially sensitive to the cellulose molecular order. Broadening of these bands is related to greater disorder in the polysaccharide phase morphology and thus, the shape of these bands can be related to the amount of crystalline versus amorphous fractions in cellulose. Even though the crystallinity index estimated by means of XRD is not significantly altered by the acid treatment, in the case of the 2 hours hydrolysis a slight sharpening is observed especially in the broad band between 3000 and $3700 \mathrm{~cm}^{-1}$, and the bands at $2900 \mathrm{~cm}^{-1}$ and $1430 \mathrm{~cm}^{-1}$, corresponding to $\mathrm{OH}$ stretching intramolecular hydrogen bonds, $\mathrm{CH}$ stretching and $\mathrm{CH}_{2}$ symmetric 
bending, respectively. In the case of the 48 hours hydrolyzed sample, sharpening of the previous bands is more intense, hence confirming the increase in the crystallinity index of the material. A shoulder appearing at $1720 \mathrm{~cm}^{-1}$, which is ascribed to carbonyl groups and has been previously related to the thermooxidative degradation of cellulose (Araki et al., 1998; Jain et al., 1987) and that can be detected in cellulose with a degree of oxidation as low as 0.12 (Kim, Kuga, Wada, Okano, \& Kondo, 2000), confirms that degradation is occurring to some extent.

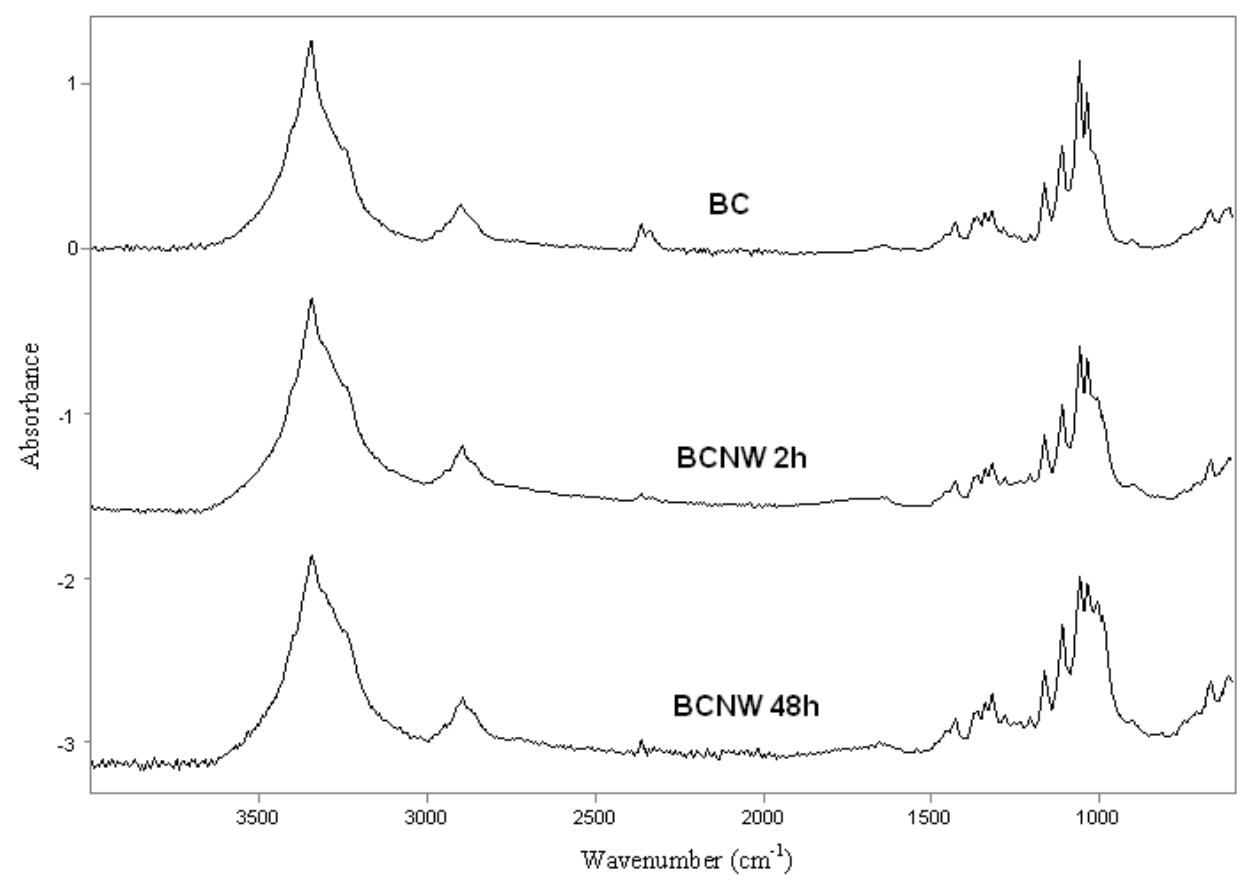

Figure 3. FTIR spectra of native bacterial cellulose (BC) and the obtained nanowhiskers (BCNW) after 2 hours and 48 hours of sulfuric acid hydrolysis.

As reported in previous studies, treatment with sulphuric acid has an effect on the thermal stability of cellulose crystals (Araki et al., 1998; Martínez-Sanz et al., 
2011; Rosa et al., 2010). This effect results in lower degradation temperature and in broadening of the degradation range. The longer the hydrolysis time the stronger the break down of the mats into nanowhiskers but the lower the thermal stability attained due to increased sulphate incorporation into the BC.

Thermogravimetric analyses were carried out to confirm this effect on thermal stability of BCNW. Figure 4 shows the TG and DTG curves of native BC and BCNW obtained after different hydrolysis times. It is observed that there is a significant change in the degradation profile of $\mathrm{BC}$ after applying acid hydrolysis. In all the samples, the mass loss below $100^{\circ} \mathrm{C}$ is ascribed to water loss. The first degradation step, with an onset temperature of $175^{\circ} \mathrm{C}, 92.26^{\circ} \mathrm{C}$ and $98.23^{\circ} \mathrm{C}$ for $\mathrm{BC}$, $\mathrm{BCNW} 2 \mathrm{~h}$ and $\mathrm{BCNW} 48 \mathrm{~h}$ respectively, corresponds to cellulose degradation processes such as depolymerisation, dehydration and decomposition of glycosyl units (Araki et al., 1998). In the case of the nanowhiskers obtained after 48 hours of hydrolysis (BCNW 48h), this degradation process is divided into two steps, as shown in the DTG curve. It has been previously suggested that degradation process of highly sulphated samples is best described in terms of two sub-processes (Araki et al., 1998; Julien et al., 1993). The first sub-process corresponds to the degradation of the more accessible regions, which are highly sulphated, and the second sub-process corresponds to the breakdown of the crystalline fraction which has not been attacked by sulphuric acid. In the case of the 2 hours hydrolysis sample, the first sub-process is not observed in the DTG curve but a small shoulder appears instead, indicating that this hydrolysis time is not enough to yield a great amount of highly sulphated regions. Finally, the second degradation step, which takes place above $275^{\circ} \mathrm{C}$, corresponds to the oxidation and breakdown of the charred residue. 
As listed in Table 4, there is a noticeable shift of the degradation to lower temperatures when applying the sulphuric acid treatment and degradation takes place over a broader temperature range when increasing the hydrolysis time. Nevertheless, there is no great difference in the degradation onset temperature between the 2 hours and 48 hours treated BCNW, which could be related to the fact that the $\mathrm{pH}$ of the material is very similar for both of them (see Table 1).

Table 4. Onset temperature, degradation temperature of the first process $\left(T_{D 1}\right)$, degradation temperature of the second process $\left(\mathrm{T}_{\mathrm{D} 2}\right)$ and corresponding weight losses $\left(\mathrm{WL}_{1}\right.$ and $\left.\mathrm{WL}_{2}\right)$ of native bacterial cellulose $(\mathrm{BC})$ and the obtained nanowhiskers (BCNW) with different hydrolysis times.

\begin{tabular}{|c|c|c|c|c|c|}
\hline Sample & Onset $\mathrm{T}\left({ }^{\circ} \mathrm{C}\right)$ & $\mathrm{T}_{\mathrm{D} 1}\left({ }^{\circ} \mathrm{C}\right)$ & $\mathrm{WL}_{1}(\%)$ & $\mathrm{T}_{\mathrm{D} 2}\left({ }^{\circ} \mathrm{C}\right)$ & $\mathrm{WL}_{2}(\%)$ \\
\hline $\mathrm{BC}$ & 169.1 & 258.7 & 32.02 & 408.0 & 24.91 \\
\hline BCNW 2h & 93.1 & 188.3 & 29.6 & 371.7 & 29.26 \\
\hline \multirow{2}{*}{ BCNW 48h } & 98.8 & 163.4 & 10.47 & 361.1 & 28.61 \\
& & 206.8 & 12.98 & & \\
\hline
\end{tabular}



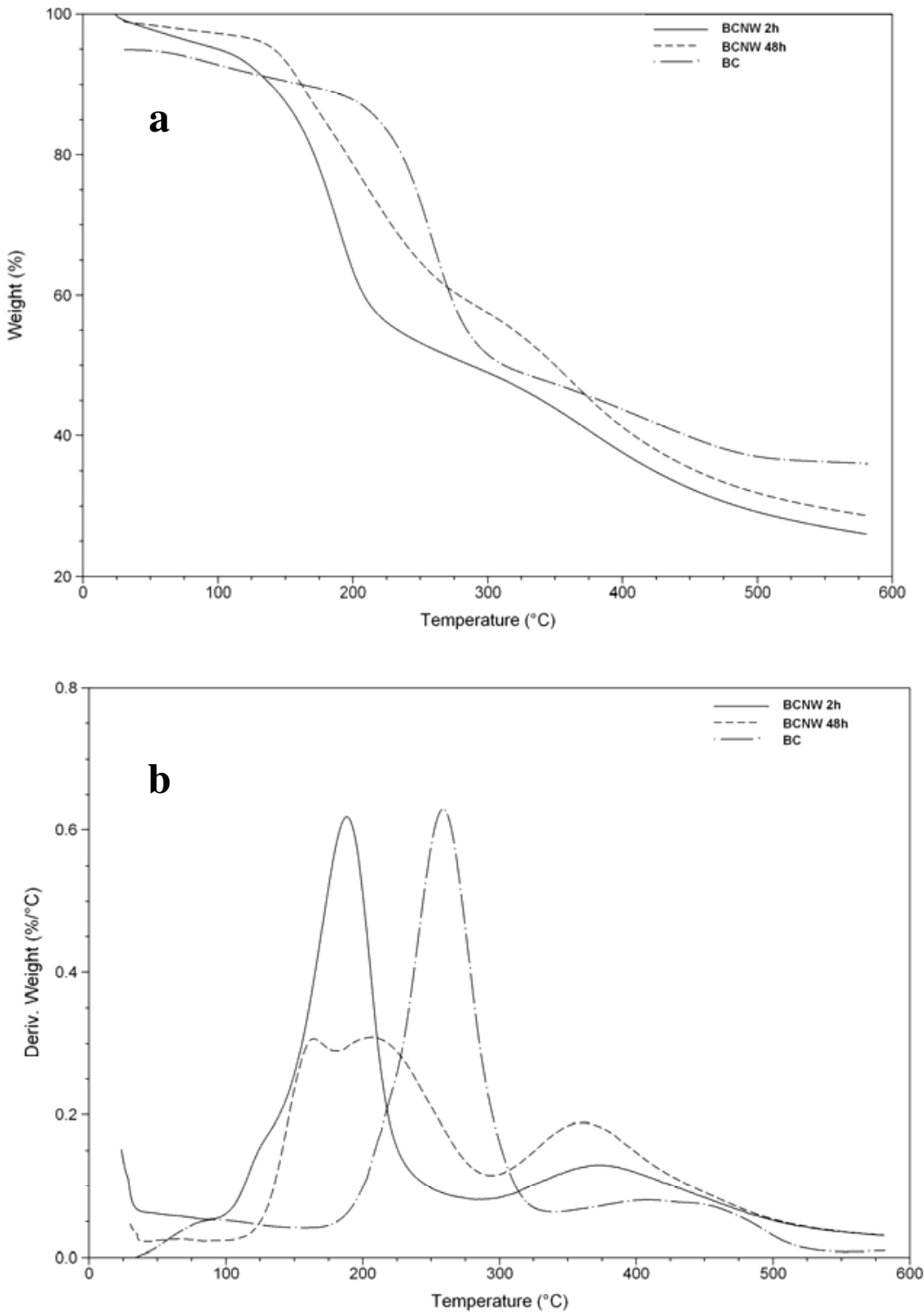

Figure 4. TG (a) and DTG curves (b) of native BC, BCNW 2h and BCNW 48h.

As a conclusion, a 2 hours sulphuric acid hydrolysis treatment applied to $\mathrm{BC}$ led to materials with a crystallinity index similar to the native $\mathrm{BC}$ but with 
significantly lower thermal stability. On the other hand, when subjecting the material to a more extensive hydrolysis treatment, a significant increase in the crystallinity of the product was observed without further decreasing the degradation onset temperature as compared to the short hydrolysis time. The increase in the crystallites' size and the appearance of a shoulder in the FT-IR spectra corresponding to carbonyl groups, suggest that partial digestion of small or defective crystalline domains takes place with long hydrolysis times. In both cases, the obtained BCNW have a considerably lower thermal stability than that of BC. With the aim of increasing the thermal stability of the material, neutralization of BCNW suspensions obtained after hydrolysis was carried out.

\subsection{Effect of neutralization and dialysis on the crystallinity and thermal stability of BCNWs}

Previous studies pointed out that when neutralizing the acid sulphate groups of cellulose nanowhiskers suspensions with $\mathrm{NaOH}$, the thermal stability of the material increased (Favier et al., 1995). BCNW suspensions of the previously analyzed samples were subjected to neutralization and the changes in the thermostability and crystallinity of the materials were studied. Furthermore, an additional sample was obtained after neutralizing a suspension of BCNWs subjected to 69 hours of hydrolysis. Dialysis was subsequently applied to this sample to evaluate if additional improvements in thermal stability or crystallinity occurred.

Table 5 lists the crystallinity indexes of the different samples, obtained from the diffraction patterns shown in Figure 5. It is observed that after neutralizing the material, a slight increase in the crystallinity index is observed for both the 2 hours and 48 hours hydrolyzed BCNWs, (cf. Table 3 vs. Table 5). Nevertheless, this crystallinity increase is significant only for the 48 hours hydrolyzed sample (with a 
$95 \%$ confidence level). On the other hand, the crystallite sizes of the cellulose I in the 101 lattice plane are significantly decreased (with a 95\% confidence level) after neutralizing the material, although these remain bigger for the samples subjected to longer hydrolysis times. This may indicate that the slight increase observed in the crystallinity of the material could be caused by the formation of new but smaller crystals as a consequence of the $\mathrm{NaOH}$ addition. It was also confirmed that the observed increase in crystallinity was not due to the formation of sodium sulphate. This salt can be produced by the reaction of free sulphate groups with sodium and it is usually found in the material when the neutralized suspension consists in the turbid supernatant obtained after several centrifugation cycles. In this case, the material consists of the centrifugation precipitate, so that if any of this salt was formed, it was removed with the liquid supernatant. Furthermore, the XRD patterns of the materials do not show any evidence that the salt is present in the material. Therefore, the process of adding sodium hydroxide until neutral $\mathrm{pH}$ may have a nucleating effect on samples which have been subjected to an extensive hydrolysis time, leading to the formation of new cellulose I crystals and, thus, increasing the overall crystallinity index of the material. To the best of our knowledge, this effect has not been previously reported.

It is also deduced from the result that increasing the hydrolysis time from 48 hours up to 69 hours does not significantly alter the amount of crystalline fraction in the material but the crystallite size from the 101 plane is still increased.

Table 5. Crystallinity index (CI) and crystallite sizes $\left(D_{(101)}, D_{(1 \overline{0} 1)}\right.$ and $\left.D_{(002)}\right)$ determined from the XRD patterns from neutralized or neutralized/dialyzed 
BCNW obtained after different hydrolysis times. Values between brackets correspond to standard deviations.

\begin{tabular}{|c|c|c|c|c|}
\hline Sample & CI (\%) & $D_{(101)}(\mathrm{nm})$ & $D_{(1 \overline{0} 1)}(\mathrm{nm})$ & $D_{(002)}(\mathrm{nm})$ \\
\hline BCNW $2 \mathrm{hN}$ & ${ }^{\mathrm{a}} 80.41(2.56)$ & ${ }^{\mathrm{a}} 0.89(0.03)$ & ${ }^{\mathrm{b}} 1.60(0.05)$ & ${ }^{\mathrm{a}} 1.05(0.00)$ \\
\hline BCNW 48hN & ${ }^{\mathrm{b}} 95.30(0.26)$ & ${ }^{\mathrm{b}} 1.04(0.00)$ & ${ }^{\mathrm{b}} 1.63(0.01)$ & ${ }^{\mathrm{c}} 1.15(0.00)$ \\
\hline BCNW 69hN & ${ }^{\mathrm{b}} 94.92(0.25)$ & ${ }^{\mathrm{c}} 1.13(0.01)$ & ${ }^{\mathrm{a}} 1.21(0.11)$ & ${ }^{\mathrm{bc}} 1.11(0.02)$ \\
\hline $\begin{array}{l}\text { BCNW } \\
69 \mathrm{hND}\end{array}$ & ${ }^{\mathrm{a}} 77.26(2.03)$ & ${ }^{\mathrm{a}} 0.89(0.02)$ & ${ }^{\mathrm{b}} 1.53(0.02)$ & ${ }^{\mathrm{ab}} 1.07(0.00)$ \\
\hline
\end{tabular}

Values between brackets correspond to standard deviations. The $\mathrm{a}, \mathrm{b}$ and $\mathrm{c}$ letters correspond to the ANOVA statistical analysis and Tukey test of the data that indicate that with a $95 \%$ confidence level, the values are significantly different.

As shown in Table 5, when subjecting the 69 hours hydrolyzed sample to dialysis, the crystallinity index is significantly diminished. In addition, the crystallite sizes from the 101 and 101 lattice planes are significantly altered, getting values close to the ones corresponding to the $\mathrm{BCNW} 2 \mathrm{hN}$ sample. It might be possible that when incorporating an additional step of dialysis, the smallest cellulose I crystals, i.e. those crystals which suffered a more intense acid digestion, are able to pass through the membrane pores and just the bigger ones remain inside the membrane. If this is the case, it would not be desirable to add a dialysis step to the BCNWs' extraction process.

Taking into account the crystallinity indexes, the optimum hydrolysis conditions would be 48 hours and subsequent neutralization of the product. 


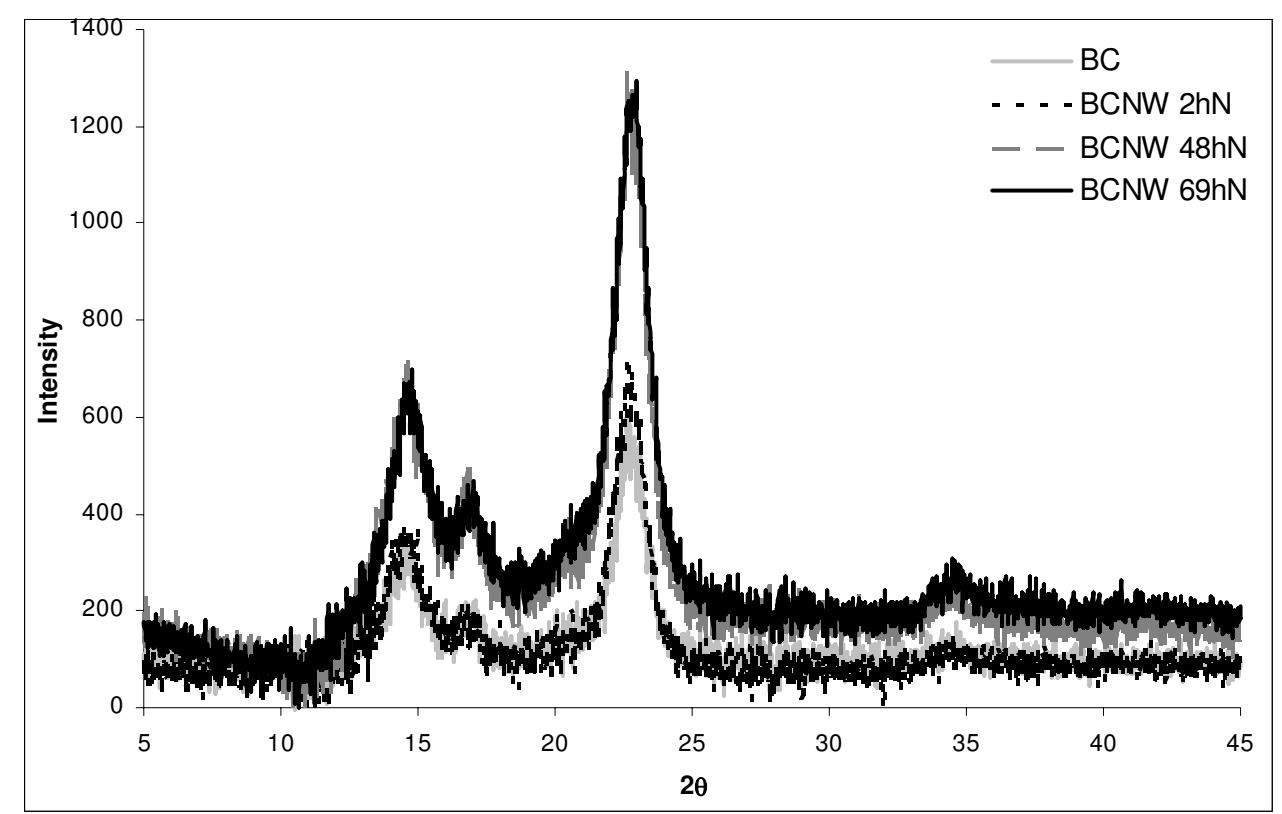

Figure 5. X-ray diffraction patterns of native bacterial cellulose (BC) and the obtained nanowhiskers (BCNW) after 2 hours and 48 hours of sulfuric acid hydrolysis.

The FT-IR spectra of the BCNW before and after being neutralized are shown in Figure 6. After neutralization of the material, the shoulder present at $1730 \mathrm{~cm}^{-1}$ completely disappears indicating that the sulphate groups have been properly neutralized. Apart from a slight increase in the intensity of cellulose characteristic bands such as the ones appearing at 2896, 1430 and $1163 \mathrm{~cm}^{-1}$ (corresponding to $\mathrm{CH}$ stretching, $\mathrm{CH}_{2}$ symmetric bending at $\mathrm{C}-6$ and $\mathrm{COC}$ bending at $\beta$-glycosidic bond, respectively), there are no other significant changes in the spectra after neutralizing, confirming that no chemical modification of the material has taken place. 
After dialysis the opposite effect is observed, i.e., a decrease in the intensity of most cellulose characteristic bands is observed, which is in accordance with the remarkable decrease in crystallinity observed by means of XRD.

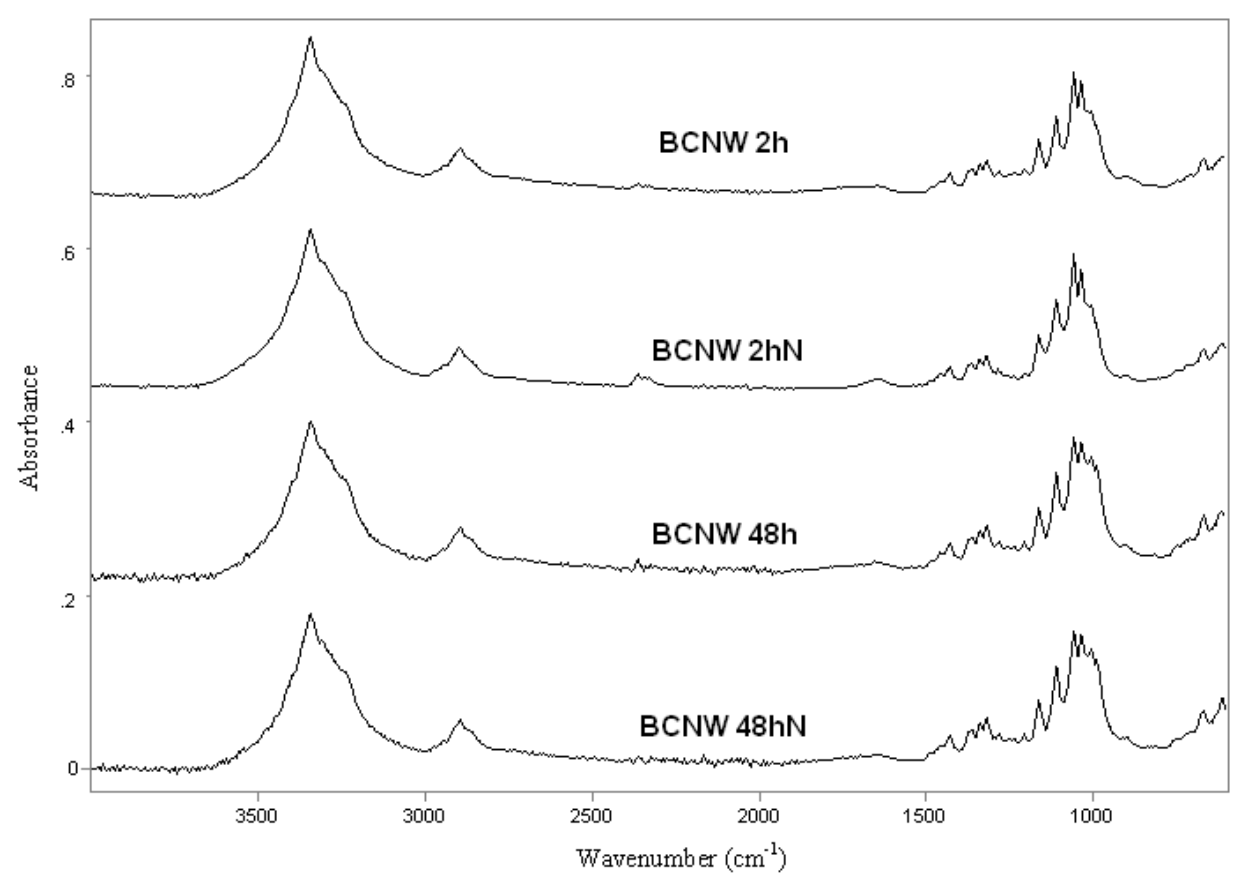

Figure 6. FTIR spectra of BCNW before and after neutralization.

Regarding the thermal stability of the material, neutralization clearly shifts the degradation of the material towards higher temperatures, also leading to the occurrence of the process within a narrower temperature range due to the higher $\mathrm{pH}$ of the material, as shown in Figure 7. It is also observed that neutralized samples present a different degradation profile consisting in just one pyrolysis process. This effect has been previously observed for cellulose nanocrystals (CNC) (Julien et al., 1993). It was suggested that the first degradation process is related to the primary pyrolysis of $\mathrm{CNC}$ catalyzed by sulphate groups present in the surface 
of the material. When comparing the neutralized samples, it is also observed that when the hydrolysis time applied is longer, the degradation range gets wider, which is probably due to the particles' size heterogeneity caused by the longer acid treatment, which is able to yield some smaller particles.

Since sulphuric acid is a well-know dehydration catalyst, it facilitates the formation of char residue (Kim et al., 2000). Indeed, it can be observed that in the case of BCNWs with sulphate groups the amount of char residue at $600{ }^{\circ} \mathrm{C}$ is remarkably larger than for neutralized samples.

On the other hand, if comparing the TGA profiles of the neutralized samples with the BC, it can be seen that the thermal stability of the neutralized BCNWs is even higher than the one of the native $\mathrm{BC}$, displaying higher degradation temperatures and narrower degradation profiles but lower char residues at $600^{\circ} \mathrm{C}$. This highlights the convenience of neutralizing the samples after a long hydrolysis treatment since, in that way, amorphous domains which are thermally weaker than the crystalline fractions are digested by the sulphuric acid and besides, sulphate groups introduced during hydrolysis are removed. As a result, a material with a greater thermal stability than pure $\mathrm{BC}$ is obtained. 

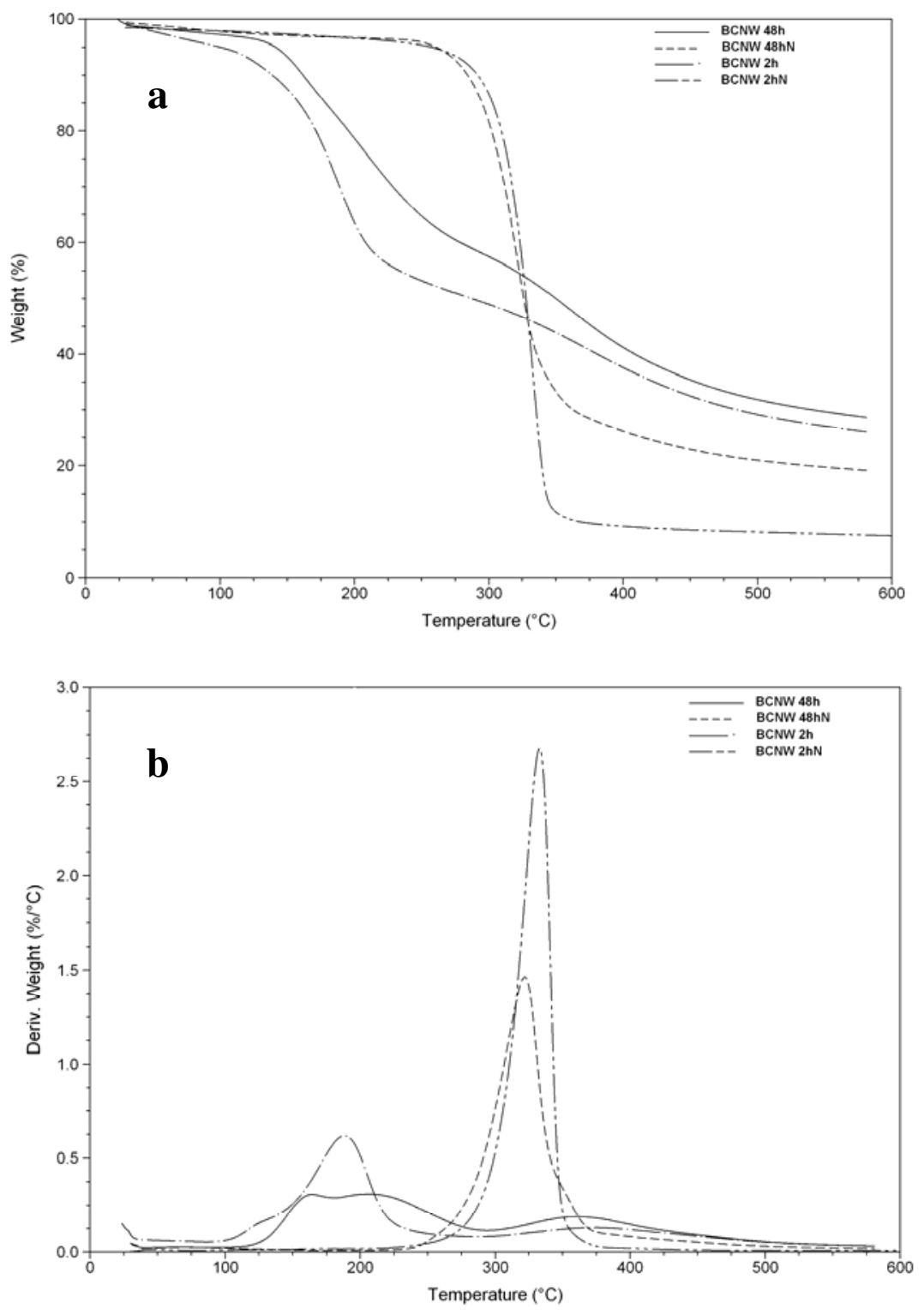

Figure 7. TG (a) and DTG curves (b) of BCNW $2 \mathrm{~h}$ and BCNW $48 \mathrm{~h}$ before and after neutralization. 
The effect of the dialysis process on the thermal stability is shown in Figure 8. After dialysis the degradation is shifted to a lower onset temperature and takes place over a wider temperature range. The DTG curve presents three degradation steps, similar as it was observed for the sulphated samples. Nevertheless, the weight loss produced during the first and third steps is not significant if compared with the one produced during the second degradation step and, thus, only one degradation step was considered for the results listed in Table 6. This effect is probably due to the more acidic $\mathrm{pH}$ of the material after the dialysis process (see Table 1), i.e. some of the $\mathrm{Na}^{+}$alkaline ions which were interacting with the sulphate groups present in the surface of the material may have passed through the dialysis membrane and therefore there is a small fraction of cellulose chains which start degrading at a lower temperature due to the catalytic action of the sulphate groups. Again, these results confirm that a dialysis step is unsuitable for the extraction of BCNWs using the method presented here.

According to the results, the most thermally stable material is obtained when neutralizing the BCNWs without applying any further dialysis step. 

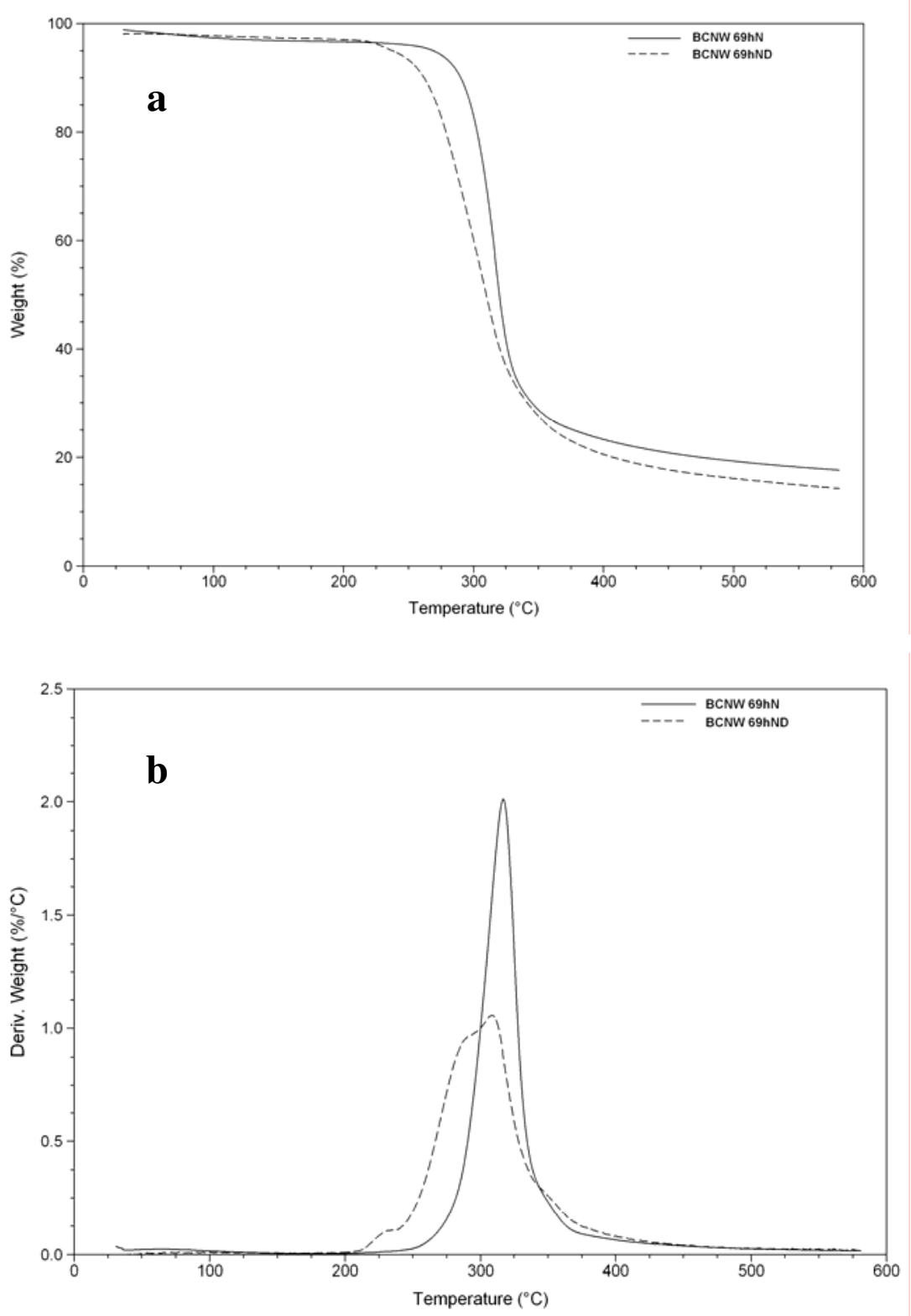

Figure 8. TG (a) and DTG curves (b) of neutralized BCNW 69h before and after dialysis. 
Table 6. Onset temperature, degradation temperature of the first process $\left(T_{D 1}\right)$, degradation temperature of the second process $\left(\mathrm{T}_{\mathrm{D} 2}\right)$ and corresponding weight losses $\left(\mathrm{WL}_{1}\right.$ and $\left.\mathrm{WL}_{2}\right)$ of neutralized or neutralized/dialyzed $\mathrm{BCNW}$ obtained after different hydrolysis times.

\begin{tabular}{|c|c|c|c|}
\hline Sample & Onset $\mathrm{T}\left({ }^{\circ} \mathrm{C}\right)$ & $\mathrm{T}_{\mathrm{D} 1}\left({ }^{\circ} \mathrm{C}\right)$ & $\mathrm{WL}_{1}(\%)$ \\
\hline $\mathrm{BC} 2 \mathrm{hN}$ & 212.3 & 332.5 & 61.98 \\
\hline $\mathrm{BCNW} 48 \mathrm{hN}$ & 226.7 & 322.0 & 43.82 \\
\hline BCNW 69hN & 222.5 & 317.0 & 43.77 \\
\hline BCNW 69hND & 204.0 & 308.5 & 48.7 \\
\hline
\end{tabular}




\section{CONCLUSIONS}

This study intends to characterize the effect of various acid hydrolysis treatments in the morphology and thermal properties of BCNWs. Sulphuric acid treatment of bacterial cellulose yields cellulose nanowhiskers, with a nanofibrillar crystalline morphology consisting of the cellulose I crystal allomorph and with a high aspect ratio ranging from 20 to 50 depending on the applied hydrolysis conditions. The length of BCNWs has been found to decrease when applying a relatively long hydrolysis time compared to a 2 hours treatment. Furthermore, it was observed that short times ( 2 hours) which are typically applied for plant cellulose whiskers' extraction, are not enough to digest the amorphous domains of the material and, thus, the crystallinity index is not significantly altered. Nevertheless, when applying longer hydrolysis treatments, such as 48 hours, a considerable increase in the crystallinity index of the BCNWs is observed, suggesting that the acid has been able to attack the amorphous regions which are holding together the nanofibrils' bundles. In general, the sulphuric acid treatment, even at short hydrolysis times, leads to a remarkable decrease in the thermostability of the cellulosic materials.

Neutralization after hydrolysis gives rise to an important increase in the thermostability of BCNWs, obtaining a material which can be processed at temperatures above $200^{\circ} \mathrm{C}$. It also causes a small increase in the crystallinity index, without modifying its morphology or chemical structure. On the other hand, an additional step of dialysis after neutralization does not lead to any additional improvement but to a decrease in the crystallinity and thermal stability of the material. From the results, it can be stated that long sulphuric acid hydrolysis times such as 48 hours, followed by neutralization allow the production of highly crystalline BCNWs, which have a high aspect ratio and a thermal stability high enough to use them as reinforcing agent in melt-compoundable nanocomposites. 


\section{REFERENCES}

Araki, J., \& Kuga, S. (2001). Effect of trace electrolyte on liquid crystal type of cellulose microcrystals. Langmuir, 17(15), 4493-4496.

Araki, J., Wada, M., Kuga, S., \& Okano, T. (1998). Flow properties of microcrystalline cellulose suspension prepared by acid treatment of native cellulose. Colloids and Surfaces A: Physicochemical and Engineering Aspects, 142(1), 75-82.

Azizi Samir, M. A. S., Alloin, F., \& Dufresne, A. (2005). Review of recent research into cellulosic whiskers, their properties and their application in nanocomposite field. Biomacromolecules, 6(2), 612-626.

Beck-Candanedo, S., Roman, M., \& Gray, D. G. (2005). Effect of reaction conditions on the properties and behavior of wood cellulose nanocrystal suspensions. Biomacromolecules, 6(2), 1048-1054.

Czaja, W., Krystynowicz, A., Bielecki, S., \& Brown Jr, R. M. (2006). Microbial cellulose - The natural power to heal wounds. Biomaterials, 27(2), 145-151.

De Souza Lima, M. M., \& Borsali, R. (2004). Rodlike cellulose microcrystals: Structure, properties, and applications. Macromolecular Rapid Communications, 25(7), 771-787.

De Souza Lima, M. M., Wong, J. T., Paillet, M., Borsali, R., \& Pecora, R. (2003). Translational and rotational dynamics of rodlike cellulose whiskers. Langmuir, 19(1), 24-29.

Eichhorn, S. J., Dufresne, A., Aranguren, M., Marcovich, N. E., Capadona, J. R., Rowan, S. J., Weder, C., Thielemans, W., Roman, M., Renneckar, S., Gindl, W., Veigel, S., Keckes, J., Yano, H., Abe, K., Nogi, M., Nakagaito, A. N., Mangalam, A., Simonsen, J., Benight, A. S., Bismarck, A., Berglund, L. A., \& Peijs, T. (2010). Review: Current international research into cellulose nanofibres and nanocomposites. Journal of Materials Science, 45(1), 1-33.

Favier, V., Chanzy, H., \& Cavaillé, J. Y. (1995). Polymer nanocomposites reinforced by cellulose whiskers. Macromolecules, 28(18), 6365-6367. 
Gindl, W., \& Keckes, J. (2004). Tensile properties of cellulose acetate butyrate composites reinforced with bacterial cellulose. Composites Science and Technology, 64(15 SPEC. ISS.), 2407-2413.

Hirai, A., Inui, O., Horii, F., \& Tsuji, M. (2009). Phase separation behavior in aqueous suspensions of bacterial cellulose nanocrystals prepared by sulfuric acid treatment. Langmuir, 25(1), 497-502.

Iguchi, M., Yamanaka, S., \& Budhiono, A. (2000). Bacterial cellulose - a masterpiece of nature's arts. Journal of Materials Science, 35(2), 261-270.

Jain, R. K., Lal, K., \& Bhatnagar, H. L. (1987). Thermal, morphological and spectroscopic studies in cellulose modified with phosphorus, nitrogen, sulphur and halogens. Journal of Applied Polymer Science, 33(2), 247-282.

Julien, S., Chornet, E., \& Overend, R. P. (1993). Influence of acid pretreatment $(\mathrm{H} 2 \mathrm{SO} 4, \mathrm{HCl}, \mathrm{HNO})$ on reaction selectivity in the vacuum pyrolysis of cellulose. Journal of Analytical and Applied Pyrolysis, 27(1), 25-43.

Kim, U. J., Kuga, S., Wada, M., Okano, T., \& Kondo, T. (2000). Periodate oxidation of crystalline cellulose. Biomacromolecules, 1(3), 488-492.

Klemm, D., Schumann, D., Udhardt, U., \& Marsch, S. (2001). Bacterial synthesized cellulose - Artificial blood vessels for microsurgery. Progress in Polymer Science (Oxford), 26(9), 1561-1603.

Martínez-Sanz, M., Olsson, R. T., Lopez-Rubio, A., \& Lagaron, J. M. (2011). Development of electrospun EVOH fibres reinforced with bacterial cellulose nanowhiskers. Part I: Characterization and method optimization. Cellulose, 18(2), 335-347.

Moharram, M. A., \& Mahmoud, O. M. (2007). X-Ray diffraction methods in the study of the effect of microwave heating on the transformation of cellulose i into cellulose II during mercerization. Journal of Applied Polymer Science, 105(5), 2978-2983.

Oh, S. Y., Yoo, D. I., Shin, Y., \& Seo, G. (2005). FTIR analysis of cellulose treated with sodium hydroxide and carbon dioxide. Carbohydrate Research, 340(3), 417428 . 
Olsson, R. T., Azizi Samir, M. A. S., Salazar-Alvarez, G., Belova, L., Ström, V., Berglund, L. A., Ikkala, O., Nogués, J., \& Gedde, U. W. (2010). Making flexible magnetic aerogels and stiff magnetic nanopaper using cellulose nanofibrils as templates. Nature Nanotechnology, 5(8), 584-588.

Park, W. I., Kang, M., Kim, H. S., \& Jin, H. J. (2007). Electrospinning of poly(ethylene oxide) with bacterial cellulose whiskers. Macromolecular Symposia, 249-250, 289-294.

Rånby, B. G. (1949). Aqueous colloidal solutions of cellulose micelles. Acta Chem. Scand., 3, 649-650.

Roman, M., \& Winter, W. T. (2004). Effect of sulfate groups from sulfuric acid hydrolysis on the thermal degradation behavior of bacterial cellulose. Biomacromolecules, 5(5), 1671-1677.

Rosa, M. F., Medeiros, E. S., Malmonge, J. A., Gregorski, K. S., Wood, D. F., Mattoso, L. H. C., Glenn, G., Orts, W. J., \& Imam, S. H. (2010). Cellulose nanowhiskers from coconut husk fibers: Effect of preparation conditions on their thermal and morphological behavior. Carbohydrate Polymers, 81(1), 83-92.

Siqueira, G., Bras, J., \& Dufresne, A. (2009). Cellulose whiskers versus microfibrils: Influence of the nature of the nanoparticle and its surface functionalization on the thermal and mechanical properties of nanocomposites. Biomacromolecules, 10(2), 425-432.

Svensson, A., Nicklasson, E., Harrah, T., Panilaitis, B., Kaplan, D. L., Brittberg, M., \& Gatenholm, P. (2005). Bacterial cellulose as a potential scaffold for tissue engineering of cartilage. Biomaterials, 26(4), 419-431.

Wan, Y. Z., Huang, Y., Yuan, C. D., Raman, S., Zhu, Y., Jiang, H. J., He, F., \& Gao, C. (2007). Biomimetic synthesis of hydroxyapatite/bacterial cellulose nanocomposites for biomedical applications. Materials Science and Engineering $C$, 27(4), 855-864.

Wan, Y. Z., Luo, H., He, F., Liang, H., Huang, Y., \& Li, X. L. (2009). Mechanical, moisture absorption, and biodegradation behaviours of bacterial cellulose fibrereinforced starch biocomposites. Composites Science and Technology, 69(7-8), 1212-1217. 
Wang, N., Ding, E., \& Cheng, R. (2007). Thermal degradation behaviors of spherical cellulose nanocrystals with sulfate groups. Polymer, 48(12), 3486-3493.

Yamanaka, S., Watanabe, K., Kitamura, N., Iguchi, M., Mitsuhashi, S., Nishi, Y., \& Uryu, M. (1989). The structure and mechanical properties of sheets prepared from bacterial cellulose. Journal of Materials Science, 24(9), 3141-3145.

Yun, Y. S., Cho, S. Y., \& Jin, H. J. (2010). Flow-induced liquid crystalline solutions prepared from aspect ratio-controlled bacterial cellulose nanowhiskers. Molecular Crystals and Liquid Crystals, 519, 141-148.

Zhao, H., Kwak, J. H., Conrad Zhang, Z., Brown, H. M., Arey, B. W., \& Holladay, J. E. (2007). Studying cellulose fiber structure by SEM, XRD, NMR and acid hydrolysis. Carbohydrate Polymers, 68(2), 235-241. 



\section{Chapter IV}

\section{NANOCOMPOSITES OF ETHYLENE VINYL ALCOHOL COPOLYMER WITH THERMALLY RESISTANT CELLULOSE NANOWHISKERS BY MELT COMPOUNDING (I): MORPHOLOGY AND THERMAL PROPERTIES}

Journal of Applied Polymer Science, 128(5), 2666-2678 (2013)

Marta Martínez Sanz, Amparo López Rubio, José María Lagarón

Novel Materials and Nanotechnology Group, IATA, CSIC. Avd. Agustín Escardino, 7, 46980. Paterna, Valencia. Spain 



\begin{abstract}
In this study, ethylene-vinyl alcohol copolymer (EVOH) nanocomposites were prepared by melt compounding using both plant cellulose (CNW) and bacterial cellulose nanowhiskers (BCNW) as nanofillers. Electrospinning and a "dissolution precipitation" method were used as strategies for incorporation of cellulose nanowhiskers in EVOH prior to melt compounding with the aim of enhancing the degree of dispersion of the nanocrystals as compared to direct melt-mixing of the freeze-dried product with the polymer. As revealed by morphological characterization, the proposed pre-incorporation methods led to a significant improvement in the dispersion of the nanofiller in the final nanocomposite films. Furthermore, it was possible to incorporate concentrations as high as 4 wt.- $\%$ BCNW without causing significant agglomeration of the nanofiller, whereas increasing the $\mathrm{CNW}$ concentration up to $3 \mathrm{wt} .-\%$ induced agglomeration. Finally, DSC studies indicated that the crystalline content was significantly reduced when the incorporation method led to a poor dispersion of the nanocrystals, whereas high nanofiller dispersion resulted in thermal properties similar to those of the neat EVOH.
\end{abstract}

Keywords: Bacterial cellulose, nanowhiskers, EVOH, melt compounding, nanocomposites. 


\section{INTRODUCTION}

The great interest of using materials obtained from renewable sources, on which currently many efforts are being focused, is one of the reasons why the use of cellulosic materials as reinforcement agents in nanocomposites has recently gained so much attention. Cellulose is one of the most abundant biopolymers found in nature and it is commonly extracted from vegetal resources such as wood, cotton and linter. However, it can also be synthesized by some bacterial species, such as Gluconacetobacter xylinus which, in a culture medium rich in polysaccharides, are able to produce a layer of bacterial cellulose (BC). Compared with plant-derived cellulose (PC), BC shows a finer web-like network structure, higher water holding capacity and higher crystallinity (Iguchi et al., 2000; Wan et al., 2007).

For their application in nanocomposites, cellulosic materials are commonly subjected to acid hydrolysis, breaking down the hierarchical structure of the material into crystalline nanofibres or nanocrystals, usually known as cellulose nanowhiskers $(\mathrm{CNW})$. The hydrolysis conditions strongly influence the morphology of the extracted $\mathrm{CNW}$ and their aspect ratio (L/D), which has a remarkable influence on the reinforcing capacity when incorporating the nanofiller into a polymeric matrix (Eichhom et al., 2010). In addition to the hydrolysis conditions, the cellulose source has an important effect on the morphology of the obtained nanowhiskers. While CNW extracted from vegetal resources typically have a length of 100-300 nm and a width of 5-20 nm(Araki et al., 1998; Favier et al., 1995), those obtained from bacterial cellulose (BCNW) may have several micrometres in length and a width of 5-50 nm (De Souza Lima \& Borsali, 2004; Hirai et al., 2009). 
Due to their fully degradable and renewable character and good mechanical properties, the use of $\mathrm{CNW}$ as reinforcing fillers for polymeric matrixes has grown considerably. Plant-derived cellulose nanowhiskers $(\mathrm{CNW})$ have been incorporated into a wide variety of materials, specifically biopolymers such as poly(lactic acid) (PLA) (Petersson et al., 2007; Sanchez-Garcia \& Lagaron, 2010), poly(3-hydroxybutyrate-co-3-hydroxyvalerate) (PHVB) (Ten et al., 2010), starch (Kvien et al., 2007) and cellulose acetate butyrate (CAB) (Petersson et al., 2009). Solution casting has been the most widely used technique for the incorporation of CNW. Nevertheless, very few reports exist on the production of nanocomposites reinforced with cellulose nanowhiskers via conventional industrial thermoplastic processing techniques, such as melt compounding methods. When aiming at the development of nanocomposite materials through melt compounding, one of the main issues is to achieve a good dispersion of the nanofiller within the matrix. An attempt to prepare nanocomposites of PLA reinforced with $\mathrm{CNW}$ by pumping a suspension of $\mathrm{CNW}$ in $\mathrm{DMAc} / \mathrm{LiCl}$ into the polymer melt during the extrusion process was reported (Oksman et al., 2006). Nevertheless, aggregation and thermal degradation took place to a certain extent. TGA analyses showed that $\mathrm{DMAc} / \mathrm{LiCl}$ was responsible for the decreased thermal stability of $\mathrm{CNW}$, which degraded during melt processing. The so-obtained nanocomposites did not show any improvement on the mechanical properties when compared to pure PLA. However, this was due to decreased mechanical properties of PLA when processed with DMAc/LiCl. Compared to PLA treated with $\mathrm{DMAc} / \mathrm{LiCl}, \mathrm{CNW}$ had a positive effect on the mechanical properties of PLA, increasing both the elastic modulus and the elongation at break. Subsequently, the possibility of using poly(vinyl alcohol) (PVA) as a compatibilizer for the nanowhiskers was investigated, but a poor dispersion of them was observed in the PLA matrix (Bondeson \& Oksman, 2007b). On the other hand, the use of an anionic surfactant effectively enhanced CNW dispersion 
in PLA by extrusion hence increasing both tensile strength and elongation at break. However, the addition of the surfactant caused PLA thermal degradation (Bondeson \& Oksman, 2007a). CNW were also incorporated into PHBV by melt processing (Jiang et al., 2008). Despite using polyethylene glycol (PEG) as a compatibilizer, CNW could not be homogeneously dispersed within the matrix and PHBV/CNW composites exhibited decreased strength. More recently, surface grafting of poly(E-caprolactone) to cellulose nanocrystals by ring-opening polymerization has been reported (Goffin et al., 2011). PCL-grafted CNW were highly dispersed when incorporated into PCL by melt blending, resulting in improved thermo-mechanical properties.

In comparison with plant-derived $\mathrm{CNW}$, the use of bacterial cellulose nanowhiskers (BCNW) is relatively recent and it has been less frequently addressed in the literature (Blaker et al., 2010; George et al., 2011; George \& Siddaramaiah, 2011; Martínez-Sanz et al., 2011b; Martínez-Sanz et al., 2012; Olsson et al., 2010; Park et al., 2007; Roman \& Winter, 2006; Yun et al., 2010). Nevertheless, this material presents excellent properties, which make it very attractive as nanofiller. Transparent composites of acrylic and epoxy resins reinforced with up to $70 \%$ bacterial cellulose nanofibres showed a low thermal expansion coefficient and mechanical strength five times that of engineered plastics (Yano et al., 2005). Electrospinning has been investigated for the incorporation of BCNW into poly(ethylene oxide) (PEO) (Park et al., 2007), poly(methyl methacrylate) (PMMA) (Olsson et al., 2010) and ethylene-vinyl alcohol (EVOH) copolymers (Martínez-Sanz et al., 2011b; Martínez-Sanz et al., 2012). A previous work (Martínez-Sanz et al., 2012) suggested the use of electrospinning as a vehicle for the incorporation of highly dispersed nonthermally stable $\mathrm{BCNW}$ into $\mathrm{EVOH}$. It was demonstrated how this methodology of incorporating $\mathrm{BCNW}$ within electrospun structures led to relatively higher 
stability and dispersion of the BCNW compared to the direct addition of the freeze-dried nanofiller to the matrix. Nevertheless, the low thermal stability of the non-thermally stabilized nanofiller gave rise to a certain degree of degradation during melt compounding of the material.

In this first study of a series of two papers, the use of the electrospinning technique, as well as a solution-precipitation method, were proposed as means of incorporating homogeneously distributed thermally stable BCNW and also plant $\mathrm{CNW}$ into an EVOH matrix. The purpose of this work was to improve the dispersion of the highly optimized BCNW filler in the polymeric material obtained after a subsequent melt mixing step. In this first paper, the morphology and thermal properties of films obtained through the cited and proprietary methods (Lagaron et al., 2010, 2011) were studied and compared to the films produced by direct melt mixing of the thermally stabilized freeze-dried cellulosic material. The effect of the nanofiller loading in the morphology of the nanocomposites was also evaluated. Finally, a comparative study between films incorporating $\mathrm{BCNW}$ and $\mathrm{CNW}$ was performed to determine the influence of the cellulose source in the properties of the obtained nanocomposites. In a second study, the mechanical and barrier properties of the produced nanocomposites will be presented and discussed. 


\section{MATERIALS AND METHODS}

\subsection{Materials}

Ethylene-vinyl alcohol copolymer grade (Soarnol) EVOH32 (containing 32 mol\% of ethylene) was supplied by The Nippon Synthetic Chemical Industry Co., Ltd. (NIPPON GOHSEI) (Japan). Sulfuric acid 96\% and 2-propanol were purchased from Panreac (Barcelona, Spain).

Bacterial cellulose (BC) mats were obtained following a procedure similar to the one described in a previous work (Martínez-Sanz et al., 2011b) and were supplied by BioInicia S.L. (Valencia, Spain).

For the production of plant cellulose nanowhiskers, a purified cellulose microfibre grade from CreaFill Fibers Corp. (US), having an average fibre length of $60 \mu \mathrm{m}$ and an average fibre width of $20 \mu \mathrm{m}$, was used as raw material. According to the manufacturer specifications, these fibres had an $\alpha$-cellulose content in excess of $99.5 \%$.

\subsection{Preparation of heat stable bacterial cellulose nanowhiskers (BCNW)}

Bacterial cellulose pellicles were ground in a blender and the gel-like material was then compressed in order to remove most of the absorbed water. The dried material was then treated with $301 \mathrm{ml}$ sulfuric acid/1 water, in a cellulose/acid ratio of approximately $7 \mathrm{~g} / 1$, at $50^{\circ} \mathrm{C}$ for three days until a homogeneous solution was obtained. The cellulose nanowhiskers were obtained as a white precipitate after several centrifugation and washing cycles at $12,500 \mathrm{rpm}$ and $15^{\circ} \mathrm{C}$ for 20 minutes. After that, the material was re-suspended in deionised water and neutralized with sodium hydroxide until neutral $\mathrm{pH}$ and, subsequently, centrifuged to obtain the final product as a partially hydrated precipitate. This last step is 
thought to turn the filler heat stable. The humidity of the material was determined and the yield of the extraction process was estimated to be $\sim 80 \%$ with respect to the dried BC. The product was kept refrigerated and one fraction was freeze-dried for further analyses.

\subsection{Preparation of plant cellulose nanowhiskers (CNW)}

Highly purified $\alpha$-cellulose microfibres (CMF) were hydrolyzed in $9.1 \mathrm{~mol} / 1$ sulfuric acid, in a $10 \mathrm{~g} / 100 \mathrm{ml}$ cellulose/acid ratio, at $37^{\circ} \mathrm{C}$ for $130 \mathrm{~min}$, as previously described in the literature (Jiang et al., 2008; Sanchez-Garcia \& Lagaron, 2010). After several centrifugation cycles, the turbid supernatant containing cellulose nanowhiskers was collected and subjected to neutralization, followed by dialysis. Subsequently, the suspension was freeze-dried thus obtaining the cellulose nanowhiskers. The yield of the process was $\sim 5 \%$ with respect to the raw $\alpha$-cellulose.

\subsection{Electrospinning}

Electrospun hybrid fibres were generated by using $5 \%(\mathrm{w} / \mathrm{v})$ EVOH solutions in 70/30 (v/v) 2-propanol/water. Both pure EVOH and the EVOH solutions containing a concentration of $15 \%(\mathrm{w} / \mathrm{w}) \mathrm{BCNW}$ with regard to the $\mathrm{EVOH}$ weight, were used to generate electrospun fibres. Bacterial cellulose nanowhiskers, in the form of a partially hydrated precipitate, were dispersed in the solvent by intense homogenization (Ultra-turrax). The optimization of this process was carried out in previous works (Martínez-Sanz et al., 2011b; Martínez-Sanz et al., 2012).

The electrospinning apparatus was a Fluidnatek ${ }^{\circledR}$ basic equipment manufactured by the engineering division of BioInicia S.L., (Valencia, Spain). Solutions were transferred to $5 \mathrm{ml}$ plastic syringes and connected through PTFE 
tubes to a stainless steel needle $(\varnothing 0.9 \mathrm{~mm})$. An electrode was clamped to the needle tip and connected to a high-voltage $0-30 \mathrm{kV}$ power supply operating at 12 $14 \mathrm{kV}$, and polymer solution was fed into the needle at a rate of $0.6 \mathrm{ml} / \mathrm{h}$ by a syringe pump (KD Scientific Inc., Holliston, U.S.A.). The counter electrode was connected to a rectangular plate covered by aluminum foil, which was placed parallel to the needle to collect the electrospun fibres. The distance between the needle and the plate was set at $11 \mathrm{~cm}$ and experiments were carried out at ambient temperature.

\subsection{Preparation of films}

EVOH nanocomposite films were prepared using 3 different methods: the traditional method of directly melt mixing the polymeric matrix with the freezedried nanofiller, and two other patent-pending methods (Lagaron et al., 2010, 2011) of incorporating cellulose nanowhiskers into the EVOH matrix, previous to the melt compounding stage, as explained below.

The first method consisted in the incorporation of cellulose nanowhiskers into EVOH32 fibres by means of the electrospinning technique. Electrospun EVOH fibres containing $15 \%(\mathrm{w} / \mathrm{w})$ BCNW were melt-mixed with virgin EVOH32 pellets in order to obtain a diluted composite having a final concentration of 2 wt.$\%$ BCNW (sample code: 2\% BCNW ES).

The second method involved the preparation of EVOH32 solutions containing a $15 \%(\mathrm{w} / \mathrm{w})$ of $\mathrm{CNW}$ or BCNW. Partially hydrated BCNW and freeze-dried CNW were dispersed in water by means of homogenization (Ultra-turrax) and sonication. This aqueous dispersion was mixed with 2-propanol so that the final ratio was 70/30 (v/v) 2-propanol/water and a 5\% (w/v) EVOH was dissolved together with the nanowhiskers. These solutions were then quenched and 
precipitated by adding liquid nitrogen and the obtained product was then dried at $60^{\circ} \mathrm{C}$ until complete evaporation of the remaining solvent and subsequently ground into a powder. This powder was then used to produce films by meltmixing the adequate amount of it with virgin $\mathrm{EVOH} 32$ pellets in order to obtain films containing 1, 2 and 3 wt.- $\%$ CNW (sample codes: $1 \% \mathrm{CNW}$ FD-P, $2 \% \mathrm{CNW}$ FD-P and 3\% CNW FD-P) and 1, 2, 3 and 4 wt.- $\%$ BCNW (sample codes: 1\% BCNW P, 2\% BCNW P, 3\% BCNW P and 4\% BCNW P). Additionally, films containing 2 wt.- $\%$ of freeze-dried BCNWs and BC were prepared by repeating the same process as described immediately above (sample codes: $2 \%$ BCNW FD$\mathrm{P}$ and 2\%BC FD-P, respectively).

Regarding the traditional method, films containing 2 wt.- $\%$ of $\mathrm{CNW}$ and $\mathrm{BCNW}$ were produced by melt-mixing the freeze-dried material with the required amount of EVOH32 pellets (sample codes: $2 \% \mathrm{CNW}$ FD and 2\% BCNW FD, respectively).

All the blends were prepared in a Brabender Plastograph mixer during $3 \mathrm{~min}$ at $100 \mathrm{rpm}$ and $185^{\circ} \mathrm{C}$. The batches were subsequently compression moulded into films using a hot-plate hydraulic press $\left(180^{\circ} \mathrm{C}\right.$ and $2 \mathrm{MPa}$ for $\left.4 \mathrm{~min}\right)$ and rapidly cooled down using air and water. The films produced had a thickness of ca. 100 $\mu \mathrm{m}$ and each film was characterized using a Mitutoyo micrometer by averaging four measurements.

\subsection{Scanning Electron Microscopy (SEM)}

SEM was conducted on a Hitachi microscope (Hitachi S-4100) at an accelerating voltage of $10-15 \mathrm{KV}$ and a working distance of 12-16 mm. Electrospun fibres and films cryo-fractured after immersion in liquid nitrogen were sputtered with a gold-palladium mixture under vacuum before their 
morphology was examined using SEM. Fibre diameters of the electrospun fibres were measured by means of the Adobe Photoshop CS3 extended software from the SEM micrographs in their original magnification.

\subsection{Transmission Electron Microscopy (TEM)}

One drop $(8 \mu \mathrm{L})$ of a $0.001 \%$ aqueous suspension of $\mathrm{CNW}$ and $\mathrm{BCNW}$ was allowed to dry on a carbon coated grid (200 mesh). The crystals were stained with a 2 wt.-\% solution of uranyl acetate. Additionally, ultra-thin sections of microtomed composite sheets were observed through TEM. The samples were also stained with uranyl acetate. TEM was performed using a JEOL 1010 equipped with a digital Bioscan (Gatan) image acquisition system at $80 \mathrm{KV}$.

\subsection{Transmission and Attenuated Total Reflectance (ATR) FT-IR analysis}

Transmission FT-IR experiments were recorded in a controlled chamber at $21^{\circ} \mathrm{C}$ and $40 \% \mathrm{RH}$ using a Bruker (Rheinstetten, Germany) FT-IR Tensor 37 equipment. The spectra were taken at $1 \mathrm{~cm}^{-1}$ resolution averaging a minimum of 10 scans. Analysis of the spectra was performed using Grams/AI 7.02 (Galactic Industries, Salem, NH, USA) software. Samples of ca. $2 \mathrm{mg}$ of electrospun fibres were ground and dispersed in $200 \mathrm{mg}$ of spectroscopic grade $\mathrm{KBr}$. A pellet was then formed by compressing the sample at ca. $150 \mathrm{MPa}$. A calibration curve was obtained by recording the IR spectra of pellets containing $6 \mathrm{mg}$ of EVOH-BC nanowhiskers samples with nanowhiskers' concentrations ranging from $10 \mathrm{wt} .-\%$ to $40 \mathrm{wt} .-\%$. The detailed procedure can be found elsewhere (Martínez-Sanz et al., 2011b). Briefly, the intensity of the band at $1165 \mathrm{~cm}^{-1}$, which was chosen as characteristic for cellulose, was divided by the intensity of the band at $838 \mathrm{~cm}^{-1}$, which was assigned to the EVOH contribution. Subsequently, the IR spectra of the electrospun fibres were analyzed and the percentages of $\mathrm{BCNW}$ incorporated into the fibres from the solutions were estimated. 
ATR-FTIR spectra of cellulose microfibres, $\mathrm{BC}, \mathrm{CNW}, \mathrm{BCNW}$ and all the obtained films were collected in the same environmental conditions as the transmission experiments, coupling the ATR accessory GoldenGate of Specac Ltd. (Orpington, UK) to the above mentioned FT-IR equipment. All spectra were recorded by averaging 20 scans at $4 \mathrm{~cm}^{-1}$ resolution.

\subsection{X-ray Diffraction (XRD)}

X-ray diffraction was carried out on a D5005 Bruker diffractometer. The instrument was equipped with a $\mathrm{Cu}$ tube and a secondary monochromator. The samples were examined over the angular range of $5^{\circ}$ to $45^{\circ}$ with a step size of $0.02^{\circ}$ and a count time of $4 \mathrm{~s}$ per point.

Peak fitting was carried out using Igor software package (Wavemetrics, Lake Oswego, Oregon). Gaussian function was used to fit the experimental diffraction profiles obtained. For the fitting procedure, the reflections considered were (i) three at $14.8^{\circ}, 16.4^{\circ}$ and $22.5^{\circ} 2 \theta$ (corresponding to the $101,10 \overline{1}$ and 002 crystal planes respectively) assigned to the cellulose I allomorph, and (ii) the amorphous halo centered at $\sim 18.5^{\circ} 2 \theta$. The crystallinity index CI (XD) was determined by the method reported by Wang et al. (Wang et al., 2007):

$$
\mathrm{CI}(\mathrm{XD})=\frac{\sum A_{\text {Crystal }}}{A_{\text {Total }}} \times 100
$$

where $A_{\text {Total }}$ is the sum of the areas under all the diffraction peaks and $\Sigma A_{\text {Crystal }}$ is the sum of the areas corresponding to crystalline peaks. 
The crystallite sizes were estimated from the $101,10 \overline{1}$ and 002 lattice planes of cellulose I using the well-known Scherrer equation:

$$
D_{(h k l)}=\frac{k \cdot \lambda}{B_{(h k l)} \cdot \cos \theta}
$$

where $D_{(h k l)}$ is the size of the crystallite $(\mathrm{nm}), k$ is the Scherrer constant (0.94), $\lambda$ is the X-ray wavelength, $B_{(h k l)}$ is the full-width at half-maximum of the reflection hkl and $2 \theta$ is the corresponding Bragg angle.

\subsection{Differential scanning calorimetry (DSC)}

DSC experiments were carried out in a Perkin-Elmer DSC-7 calorimeter. The sample treatment consisted of a first heating melting step from $30^{\circ} \mathrm{C}$ to $220^{\circ} \mathrm{C}$, a subsequent cooling down to $30^{\circ} \mathrm{C}$ and a second heating melting step up to $220^{\circ} \mathrm{C}$. The heating and cooling rates for the runs were $10^{\circ} \mathrm{C} / \mathrm{min}$ and the typical sample weight was around $3 \mathrm{mg}$. Calibration was performed using an indium sample and the slope of the thermal scans was corrected by subtracting similar scans of an empty pan. All tests were carried out, at least, in duplicate.

The crystallinity (\%) of the EVOH was estimated from the corrected enthalpy for the EVOH content in the nanocomposites, using the ratio between the enthalpy of the studied material and the enthalpy of a perfect EVOH crystal, i.e. $X_{C}(\%)=\frac{\Delta H_{p}}{\Delta H_{p}^{2}} \times 100$

, where $\Delta H_{\ell}$ is the enthalpy of fusion of the studied specimen and $\Delta H_{\ell}^{0}$ is the enthalpy of fusion of a totally crystalline material. The $\triangle E Y$ used for this equation was $216.6 \mathrm{~J} / \mathrm{g}$ for the EVOH (Lagaron et al., 2001). 


\subsection{Thermogravimetric analysis (TGA)}

Thermogravimetric (TG) curves were recorded with a TA Instruments model Q500 TGA. The samples (ca. $20 \mathrm{mg}$ ) were heated from $50^{\circ} \mathrm{C}$ to $600^{\circ} \mathrm{C}$ at a heating rate of $10^{\circ} \mathrm{C} / \mathrm{min}$ under nitrogen atmosphere. Derivative TG curves (DTG) express the weight loss rate as a function of temperature. 


\section{RESULTS AND DISCUSSION}

\subsection{Characterization of bacterial and plant cellulose nanowhiskers}

The overall objective of this study was to optimize the dispersion of the cellulosic nanofillers in the polymeric matrix when producing films by the melt compounding technique. In addition to different pre-incorporation methods, the effects of the nanowhiskers' loading and of the cellulose source on the thermal properties of the materials were also evaluated in this first study.

The morphology of the two different nanofillers used in this work, i.e. plant $(\mathrm{CNW})$ and bacterial cellulose nanowhiskers $(\mathrm{BCNW})$, obtained through sulfuric acid hydrolysis, was studied by TEM (cf. Figure 1). BCNWs were extracted by the optimized method developed in a previous work (Martínez-Sanz et al., 2011a) and showed the same morphology as observed before, with an average cross-section of ca. $18 \mathrm{~nm}$ and length of ca. $570 \mathrm{~nm}$. On the other hand, the CNWs extracted by the standard extraction method (Petersson et al., 2007; Sanchez-Garcia \& Lagaron, 2010) displayed a morphology of shorter whiskers of ca. $287 \mathrm{~nm}$ length and ca. 24 $\mathrm{nm}$ cross-section, which were aggregated to a greater extent, since they had been previously subjected to a freeze-drying process which was not applied to the BCNWs. Furthermore, the length of the produced CNWs was in the same range as that previously reported after using similar extraction procedures (Bondeson et al., 2006; Petersson et al., 2007), but with a wider cross-section, probably because the applied hydrolysis temperature was lower than that reported in previous works. 

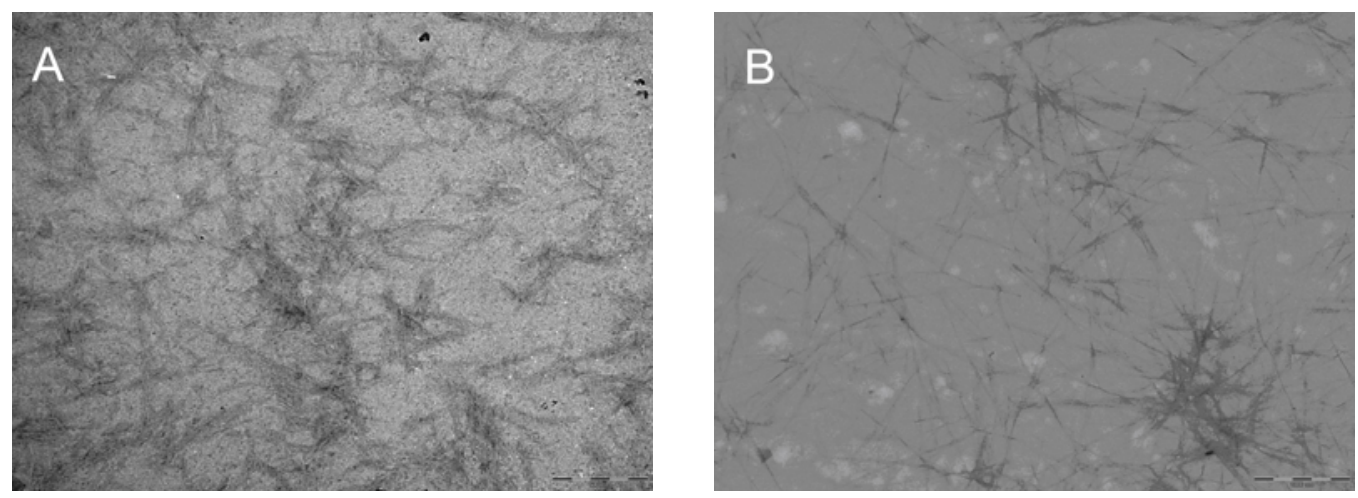

Figure 1. TEM micrographs of CNW (a) and BCNW (b). Scale markers correspond to $1000 \mathrm{~nm}$ in picture (a) and $500 \mathrm{~nm}$ in picture (b).

The expected increase in the overall crystallinity of the resulting nanowhiskers as a result of the sulfuric acid digestion of the native bacterial or plant cellulose was assessed by XRD and FT-IR analyses.

The XRD patterns of bacterial cellulose (BC), plant cellulose microfibres (CMF) and the corresponding nanowhiskers obtained after acid treatment are shown in Figure 2. In the case of bacterial cellulose, three major diffraction peaks were observed at $14.5^{\circ}, 16.4^{\circ}$ and $22.5^{\circ} 2 \theta$ which, according to the literature (Moharram \& Mahmoud, 2007), are ascribed to the cellulose I crystallographic planes $101,10 \overline{1}$ and 002 , respectively. On the other hand, the diffraction patterns obtained for the plant microfibers and nanowhiskers correspond to those previously reported for plant-derived cellulose(Bondeson et al., 2006; Elanthikkal et al., 2010), (Bondeson et al., 2006; Elanthikkal et al., 2010) showing one major diffraction peak located at $22^{\circ} 2 \theta$ and a shoulder in the region $14-17^{\circ}$ 20. Crystallinity indexes and crystallite sizes determined from the XRD data are compiled in Table 1. As expected, the applied acid hydrolysis produced an increase of $16-19 \%$ in the crystallinity index of both materials. Additionally, the 
average crystallite size calculated from the crystalline planes of cellulose I increased after the hydrolysis, thus suggesting that smaller and/or more defective crystals were hydrolyzed during the acid treatment (cf. Table 1). BC presented a crystallinity value similar to that previously reported for BC with (Wong et al., 2009) and without (Martínez-Sanz et al., 2011b; Roman \& Winter, 2004) sonication treatment, whereas BCNW obtained through the optimized method applied in this work presented higher crystallinity index than that reported for less severe acid hydrolysis conditions (Roman \& Winter, 2004). On the other hand, plant CNW presented a crystallinity index lower than that reported for microcrystalline cellulose (ca.87\%) (Wong et al., 2009) or nanowhiskers extracted from Avicel (ca. 81\%) (Filson \& Dawson-Andoh, 2009) since the raw cellulose microfibres used in this work presented lower crystallinity than the raw materials used in the mentioned studies. It is worth noting that the crystallinity index of bacterial cellulose was noticeably higher than that of the plant-derived cellulose microfibres, hence, highlighting the convenience of bacterial cellulose when aiming at obtaining highly crystalline whiskers. 

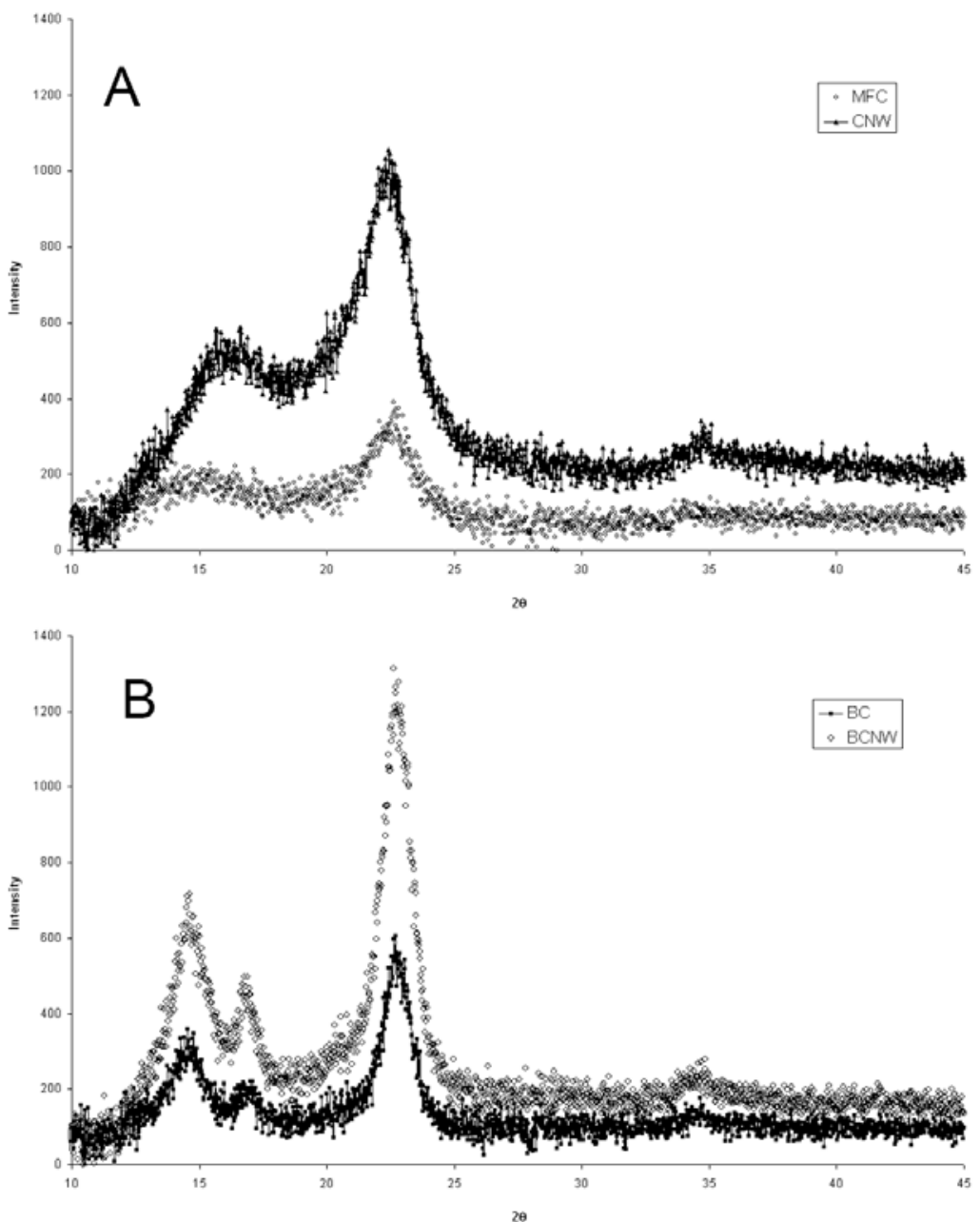

Figure 2. X-ray diffraction patterns of (a) plant cellulose microfibres (MFC) and the extracted cellulose nanowhiskers (CNW) and (b) bacterial cellulose (BC) and bacterial cellulose nanowhiskers (BCNW). 
Table 1. Crystallinity index $[\mathrm{CI}(\mathrm{XD})]$ and crystallite sizes $\left(D_{(101)}, D_{(1 \overline{0} 1)}\right.$ and $\left.D_{(002)}\right)$ determined from the XRD patterns of native cellulose microfibres (CMF) and bacterial cellulose $(\mathrm{BC})$ and of the obtained nanowhiskers (CNW and $\mathrm{BCNW}$ ).

\begin{tabular}{|c|c|c|c|c|}
\cline { 2 - 5 } \multicolumn{1}{c|}{} & CMF & CNW & BC & BCNW \\
\hline CI (XD) (\%) & $41.4 \pm 0.1$ & $60.2 \pm 0.1$ & $79.1 \pm 0.4$ & $95.3 \pm 0.3$ \\
\hline$D_{(101)}(\mathrm{nm})$ & $0.5 \pm 0.0$ & $1.0 \pm 0.0$ & $0.8 \pm 0.0$ & $1.0 \pm 0.0$ \\
\hline$D_{(1 \overline{0} 1)}(\mathrm{nm})$ & --- & --- & $1.7 \pm 0.1$ & $1.6 \pm 0.0$ \\
\hline$D_{(002)}(\mathrm{nm})$ & $0.7 \pm 0.0$ & $0.8 \pm 0.0$ & $1.1 \pm 0.0$ & $1.2 \pm 0.0$ \\
\hline
\end{tabular}

Additionally, differences in crystallinity between bacterial and plant-derived cellulose were evaluated by means of ATR-FTIR analyses. The shape of the bands at 4000-2995 $\mathrm{cm}^{-1}, 2900 \mathrm{~cm}^{-1}, 1430 \mathrm{~cm}^{-1}, 1375 \mathrm{~cm}^{-1}$ and $900 \mathrm{~cm}^{-1}$ has been previously related to the amount of crystalline versus amorphous fractions in cellulose, that is, broadening of these bands was related to greater molecular disorder in the polysaccharide phase morphology (Oh et al., 2005). From Figure 3 , it can be observed that the intensity of these bands was higher in the case of bacterial cellulose and, moreover, that the applied acid treatments gave rise to an increase in the crystallinity of both materials. Therefore, in agreement with the $\mathrm{XRD}$ results, the efficiency of the sulfuric acid treatments and the higher crystallinity of bacterial cellulose are confirmed. 


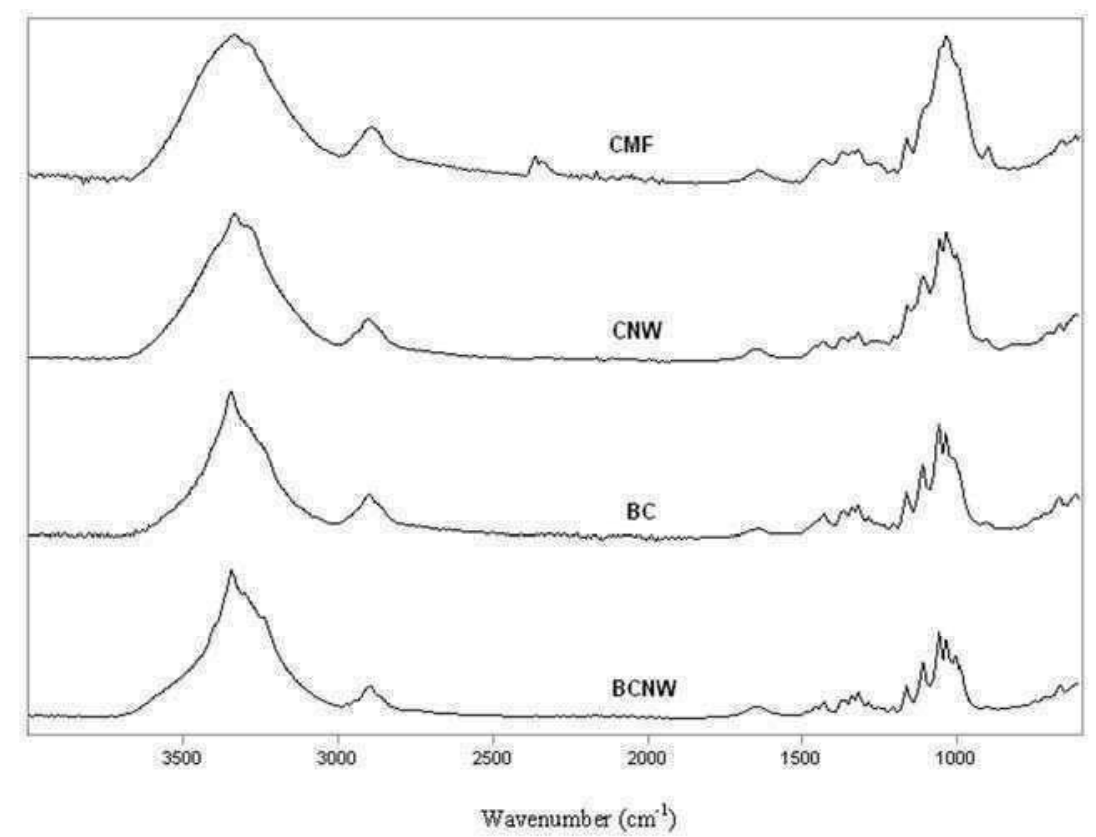

Figure 3. ATR-FTIR spectra of, from top to bottom, cellulose microfibres (CMF), $\mathrm{CNW}$, native bacterial cellulose (BC) and BCNW.

The thermal stability of the obtained nanocrystals was studied through TGA. As shown in Figure 4, BCNW presented greater thermal stability than CNW. Whereas degradation began at $186^{\circ} \mathrm{C}$ for the $\mathrm{CNW}$, the onset temperature for $\mathrm{BCNW}$ was $226^{\circ} \mathrm{C}$. This increased thermal stability of BCNW was probably a result of its higher crystallinity. Nevertheless, none of the materials underwent thermal degradation at $185^{\circ} \mathrm{C}$, which was the temperature applied during the melt mixing processing of the materials for the production of nanocomposite films. It has been previously demonstrated that the neutralization step applied after the acid treatment is essential for obtaining a more thermally stable material. No mention to neutralization is provided in most of the literature dealing with CNW (Araki et al., 1998; Ayuk et al., 2009; Petersson et al., 2009; Ten et al., 2010). From our experience, even after extensive washing cycles, if neutralization is not applied, the 
material remains acid (Martínez-Sanz et al., 2011a; Martínez-Sanz et al., 2012). However, this may not have been a noticeable issue since solution casting has been the main processing method for this filler in most of the existing literature. Thus, the greater thermal stability achieved for the cellulose nanofillers is one of the differentiating features of this work compared to previous published results.

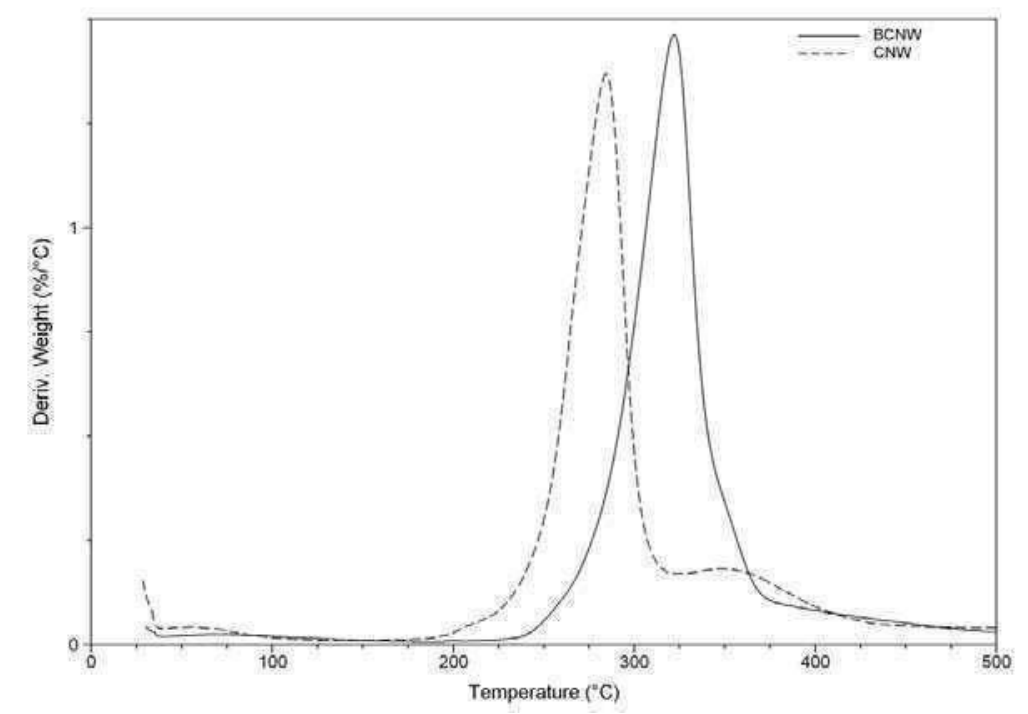

Figure 4. DTG curves of plant cellulose and bacterial cellulose nanowhiskers

(CNW and BCNW, respectively).

Various strategies were developed in this work to obtain EVOH films incorporating thermally stable cellulose nanowhiskers and to ascertain the most suitable incorporation method, which leads to a better dispersion of the nanofiller. Since bacterial and plant-derived cellulose nanowhiskers presented differences in crystallinity, morphology and thermal properties, EVOH films with different characteristics were expected to be obtained when incorporating them as nanofillers. The following part of this study deals with the morphological and 
thermal characterization of the polymeric films obtained through the different incorporation methods using both reinforcing materials.

It should be noted that previous works (Martínez-Sanz et al., 2011b; MartínezSanz et al., 2012) published by our group that made use of BCNW were carried out with a less stable form of BCNW (not neutralized BCNW) and, therefore, this study reports for the first time on the morphology and properties of EVOH nanocomposites containing thermally stable $\mathrm{BCNW}$. EVOH is a relatively high temperature processing polymer and, therefore, thermally stable fillers are required when melt compounding routes are devised. The additional interest in this polymer arises because it can be solubilised in polar solvents and, thus, high loadings of water/alcohol dispersible fillers can be incorporated in this polymeric matrix. Moreover, EVOH can undergo melt compounding for later dilution of the filler using conventional plastics melt processing techniques. So in a way, it is an excellent carrier for polar nanofillers which are aimed to be later dispersed into this or into any other polymer matrices to reinforce them.

\subsection{Nanocomposite EVOH films reinforced with bacterial cellulose nanowhiskers (BCNW)}

In the case of bacterial cellulose, two main incorporation methods were developed in order to compare their efficiency in dispersing the nanowhiskers. Both the previously described electrospinning technique and a precipitation method were used. The precipitation method was carried out using both partially hydrated nanowhiskers, just as done for the electrospinning method, and additionally, freeze-dried nanowhiskers (cf. "materials and methods" section for more details). The product batches obtained through these methods were then melt mixed with EVOH in order to obtain films with 2 wt.-\% BCNW and were compared to the traditional method of directly melt mixing freeze-dried $\mathrm{BCNW}$ 
with EVOH. The reason for using a 2 w.- $\%$ CNW loading, was that previous works found it to be the optimum reinforcing level in cellulose-based nanocomposites for barrier enhancement (Sanchez-Garcia \& Lagaron, 2010).

With the aim of assessing that the incorporation of BCNW into the EVOH matrix was similar in the case of the electrospinning and precipitation methods, i.e. 15 wt.-\% BCNW, FT-IR analyses were carried out. Just like in previous works (Martínez-Sanz et al., 2011b; Martínez-Sanz et al., 2012), the ratio between the intensity of the band at $1165 \mathrm{~cm}^{-1}$ and the band at $838 \mathrm{~cm}^{-1}$, which correspond to the C-O-C asymmetric stretching (Carrillo et al., 2004) and to skeletal vibrations and $\mathrm{CH}_{2}$ rocking of $\mathrm{EVOH}$ (Lagaron et al., 2003) respectively, was calculated in order to estimate the BCNWs incorporation degree by applying the previously obtained calibration curve. The obtained spectra are shown in Figure 5, where it is clearly observed how the cellulose characteristic bands, i.e. those at 1164, 1111, 1055 and $1035 \mathrm{~cm}^{-1}$, are present both in the electrospun fibres and in the material obtained after precipitation. The estimated BCNWs' incorporation was $15 \%$ in the case of the precipitated material whereas it was approximately $12 \%$ in the case of the electrospun fibres. 


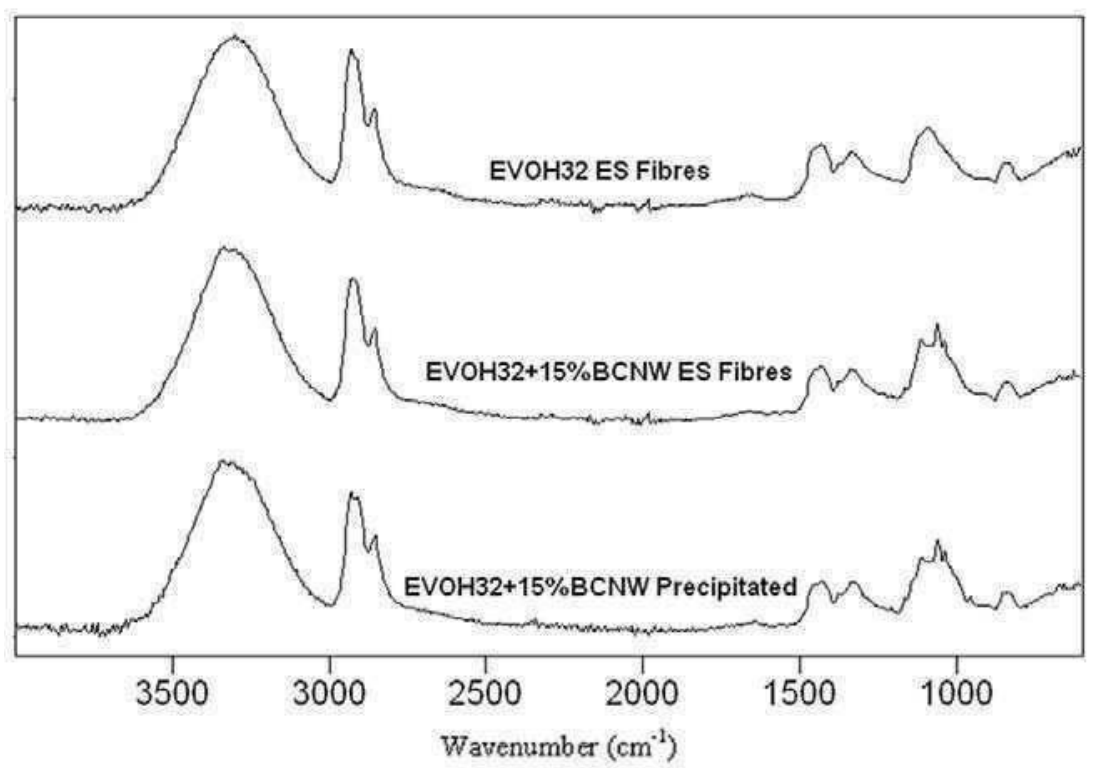

Figure 5. FT-IR spectra of electrospun EVOH32 fibres, electrospun EVOH32 fibres containing 15 wt.-\% BCNW and EVOH32 incorporating 15 wt.-\% BCNW by means of the precipitation method.

\subsubsection{Morphology and thermal properties of electrospun and precipitated hybrid}

\section{EVOH-BCNW materials}

The morphology and thermal properties of the materials obtained by the two incorporation methods were analyzed before the melt mixing step. As observed in Figure 6 , the morphology of electrospun fibres was altered by adding BCNW, i.e. a more homogeneous and less beaded fibres were obtained when compared to the pure EVOH fibres. By averaging ca. 100 measurements of the fibres crosssections obtained from SEM micrographs, it was observed that the mean diameter of electrospun fibres decreased from $182 \pm 79 \mathrm{~nm}$, for pure EVOH fibres, to $132 \pm$ $53 \mathrm{~nm}$ when incorporating $15 \% \mathrm{BCNW}$. This reduction in the average diameter of electrospun fibres has been previously reported and ascribed to an increase in the 
conductivity of the electrospinning solution when incorporating cellulose nanowhiskers (Martínez-Sanz et al., 2011b; Peresin et al., 2010).
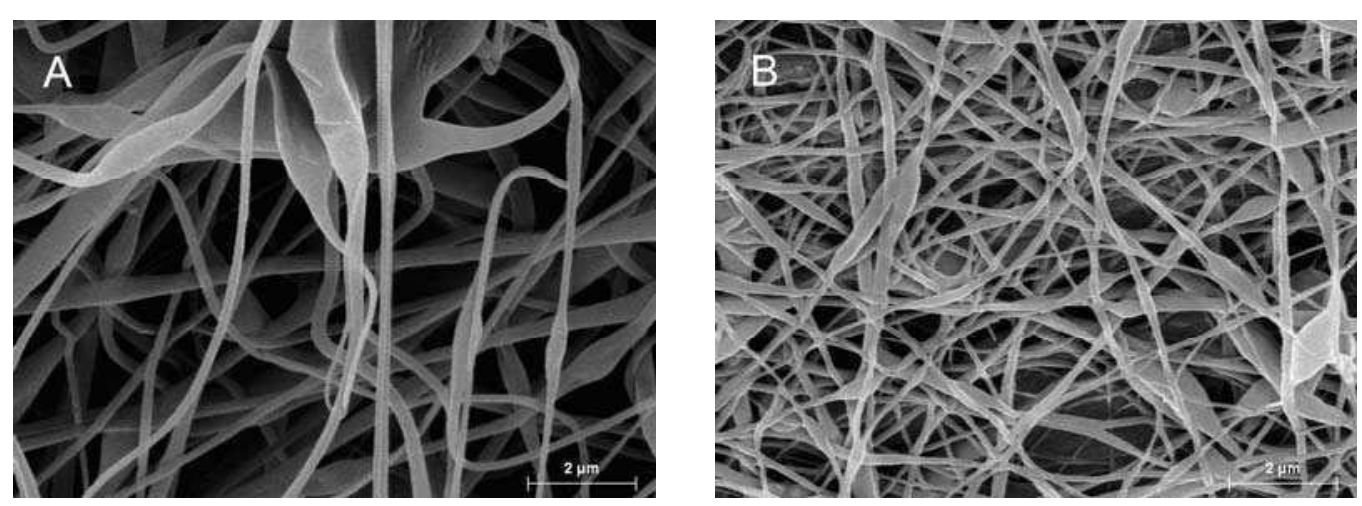

Figure 6. SEM micrographs of electrospun EVOH32 fibres and electrospun EVOH32 fibres containing 15 wt.-\% BCNW.

When incorporating neutralized BCNWs, an increase in the melting enthalpy of electrospun fibres was observed compared to pure EVOH fibres. On the contrary, the melting enthalpy of the material subjected to the precipitation method was noticeably decreased when compared to pure EVOH since, in this case, the polymeric matrix was quenched so that the crystallization process of EVOH was impaired. 
Table 2. DSC maximum of melting $\left(\mathrm{T}_{\mathrm{m} 1}\right)$, melting enthalpy $\left(\Delta \mathrm{H}_{\mathrm{m} 1}\right)$ and degree of crystallinity $\left(\mathrm{X}_{\mathrm{c}}\right)$ of neat $\mathrm{EVOH}$ and materials incorporating 15 wt.-\% BCNW, obtained from the first heating run and melting temperature $\left(\mathrm{T}_{\mathrm{m} 2}\right)$, melting enthalpy $\left(\Delta \mathrm{H}_{\mathrm{m} 2}\right)$ and glass transition temperature $\left(\mathrm{T}_{\mathrm{g}}\right)$, obtained from the second heating run.

\begin{tabular}{|c|c|c|c|c|c|c|}
\hline & $\mathrm{T}_{\mathrm{m}}\left({ }^{\circ} \mathrm{C}\right)$ & $\begin{array}{c}\Delta \mathrm{H}_{\mathrm{m} 1}(\mathrm{~J} / \mathrm{g} \\
\mathrm{EVOH})\end{array}$ & $X_{c}(\%)$ & $\begin{array}{l}\mathrm{T}_{\mathrm{m} 2} \\
\left({ }^{\circ} \mathrm{C}\right)\end{array}$ & $\begin{array}{c}\Delta \mathrm{H}_{\mathrm{m} 2} \\
(\mathrm{~J} / \mathrm{g} \\
\mathrm{EVOH})\end{array}$ & $\mathrm{T}_{\mathrm{g}}\left({ }^{\circ} \mathrm{C}\right)$ \\
\hline $\begin{array}{l}\text { EVOH } \\
\text { pellets }\end{array}$ & $\begin{array}{c}182.8 \pm \\
0.4\end{array}$ & $74.8 \pm 1.8$ & $\begin{array}{c}34.5 \pm \\
0.8\end{array}$ & $\begin{array}{l}183.8 \\
\pm 0.1\end{array}$ & $\begin{array}{c}58.4 \pm \\
1.2\end{array}$ & $\begin{array}{c}60.9 \pm \\
0.3\end{array}$ \\
\hline $\begin{array}{c}\text { Electrospun } \\
\text { EVOH }\end{array}$ & $\begin{array}{c}184.5 \pm \\
0.4\end{array}$ & $72.4 \pm 2.3$ & $\begin{array}{c}33.4 \pm \\
1.1\end{array}$ & $\begin{array}{l}183.5 \\
\pm 0.5\end{array}$ & $\begin{array}{c}60.9 \pm \\
3.1\end{array}$ & $\begin{array}{c}57.6 \pm \\
0.2\end{array}$ \\
\hline $\begin{array}{c}\text { Precipitated } \\
\text { EVOH }+15 \% \mathrm{BCNW}\end{array}$ & $\begin{array}{c}181.0 \pm \\
0.5\end{array}$ & $49.0 \pm 2.7$ & $\begin{array}{c}22.6 \pm \\
1.2\end{array}$ & $\begin{array}{l}179.3 \\
\pm 0.4\end{array}$ & $\begin{array}{c}33.7 \pm \\
1.1\end{array}$ & $\begin{array}{c}58.3 \pm \\
0.2\end{array}$ \\
\hline $\begin{array}{c}\text { Electrospun } \\
\text { EVOH }+15 \% \mathrm{BCNW}\end{array}$ & $\begin{array}{c}182.9 \pm \\
0.1\end{array}$ & $91.0 \pm 2.1$ & $\begin{array}{c}42.0 \pm \\
1.0\end{array}$ & $\begin{array}{l}181.9 \\
\pm 0.6\end{array}$ & $\begin{array}{c}67.7 \pm \\
2.6\end{array}$ & $\begin{array}{c}57.9 \pm \\
0.2\end{array}$ \\
\hline
\end{tabular}

\subsubsection{Morphology of EVOH nanocomposite films containing 2 wt.-\% BCNW}

Figure 7 shows the photographs of the obtained EVOH-BCNW films. Firstly, it is observed that all the films produced through the precipitation method presented a similar contact transparency, which was not apparently modified with respect to the pure $\mathrm{EVOH}$ film, thus, indicating that a good dispersion of the nanofiller must have been achieved. However, the sample with 4 wt.-\% showed a darker colour probably due to the high content of the nanofiller. Excellent contact transparency was also observed for the sample with 2 wt.-\% BCNW incorporated through electrospun fibres. On the other hand, brown spots were observed in the films obtained by direct addition of freeze-dried BCNW (cf. Figure 7F). Nevertheless, when using the precipitation method for incorporating freeze-dried BCNW (Figure 7E), those brown spots completely disappeared, thus indicating that the dispersion of the nanofiller may be significantly enhanced by this 
procedure. When using freeze-dried bacterial cellulose microfibres instead of whiskers as the filler, white agglomerates were clearly observed in the obtained films even though the filler was incorporated through the precipitation method (image not shown).
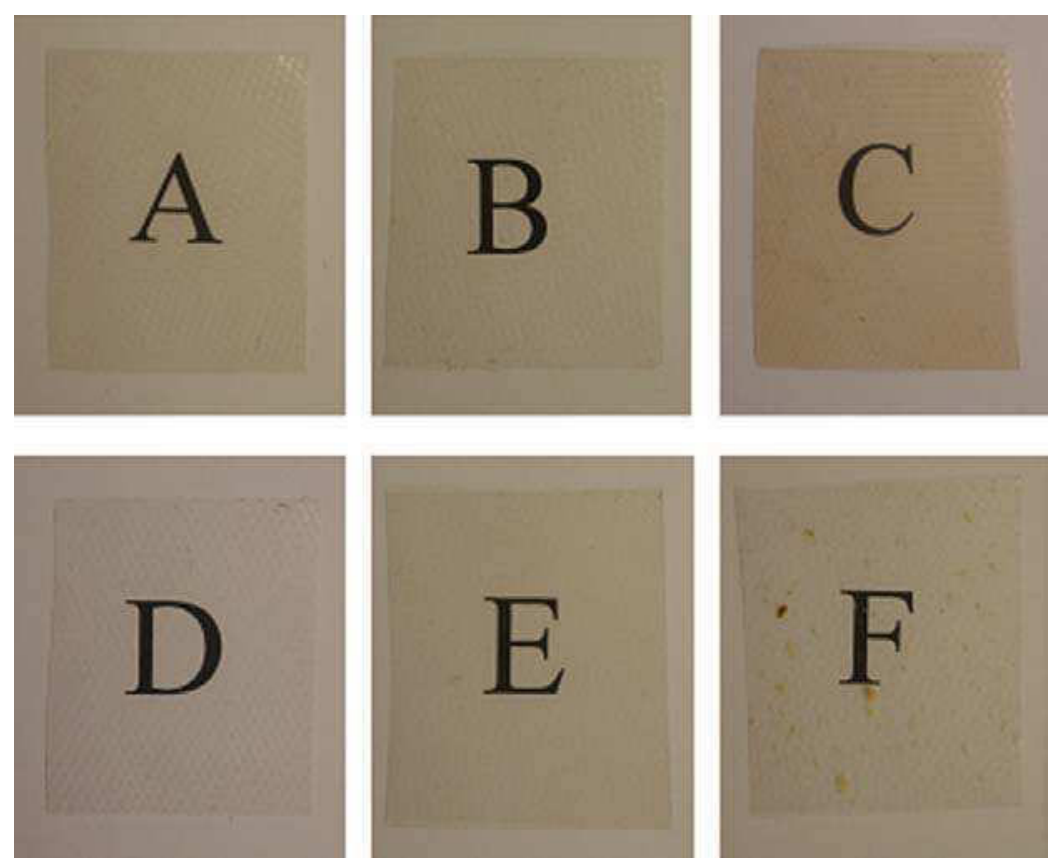

Figure 7. Photographs of films containing: (A) Pure EVOH; (B) EVOH+2 wt.-\% BCNW precipitated; (C) EVOH+4 wt.-\% BCNW precipitated; (D) EVOH+2 wt.-\% BCNW ES; (E) EVOH+2 wt.-\% BCNW freeze-dried/precipitated and (F) $\mathrm{EVOH}+2$ wt.- $\% \mathrm{BCNW}$ freeze-dried.

To thoroughly study the morphology and the dispersion of the nanofiller in the nanocomposite films, cryo-fractured surfaces were observed by SEM. BCNW could be easily identified in Figure 8, since they appeared either as white dots or forming bundles in Figure 8D. The filler seemed to be homogeneously distributed within the matrix presenting a similar morphology to that observed for starch 
nanocomposites reinforced with tunicin whiskers (Anglès \& Dufresne, 2001) and for poly(vinyl alcohol) reinforced with cellulose nanofibres (Qua et al., 2009).

When comparing the fracture surface of the different 2 wt.- $\%$ samples (Figure 8 ), the first noticeable observation was that the dispersion of the nanofiller was poor when directly melt mixing the freeze-dried $\mathrm{BCNW}$ with the $\mathrm{EVOH}$ matrix. In this specific case, BCNWs were aggregated presenting an average cross-section of $157 \mathrm{~nm}$ and there were some nanowhiskers bundles having cross-sections up to $560 \mathrm{~nm}$. Surprisingly, when applying the precipitation method, the dispersion of the freeze-dried product was significantly improved, presenting a cross-section of $75 \pm 26 \mathrm{~nm}$ with no visible bundles.

Another interesting result is that the dispersion of the nanofiller was very similar when using both partially hydrated or freeze-dried BCNW and applying the precipitation method. A very good dispersion was also achieved when incorporating $2 \mathrm{wt} .-\% \mathrm{BCNW}$ through electrospinning, being the average nanofiller cross-section of $46 \pm 14 \mathrm{~nm}$ vs. $81 \pm 20 \mathrm{~nm}$ for the samples obtained through the precipitation method.

In any case, the determined cross-sections were much higher than the BCNW's diameter, which could be due to a charge concentration effect caused by the emergence of BCNW from the examined surface (Anglès \& Dufresne, 2001). In conclusion, all the developed incorporation methods represented an improvement compared to the direct melt mixing of freeze-dried BCNW. Even when using untreated freeze-dried $\mathrm{BC}$ as the filler, smaller agglomerates were observed and the dispersion was enhanced by means of the precipitation step. 

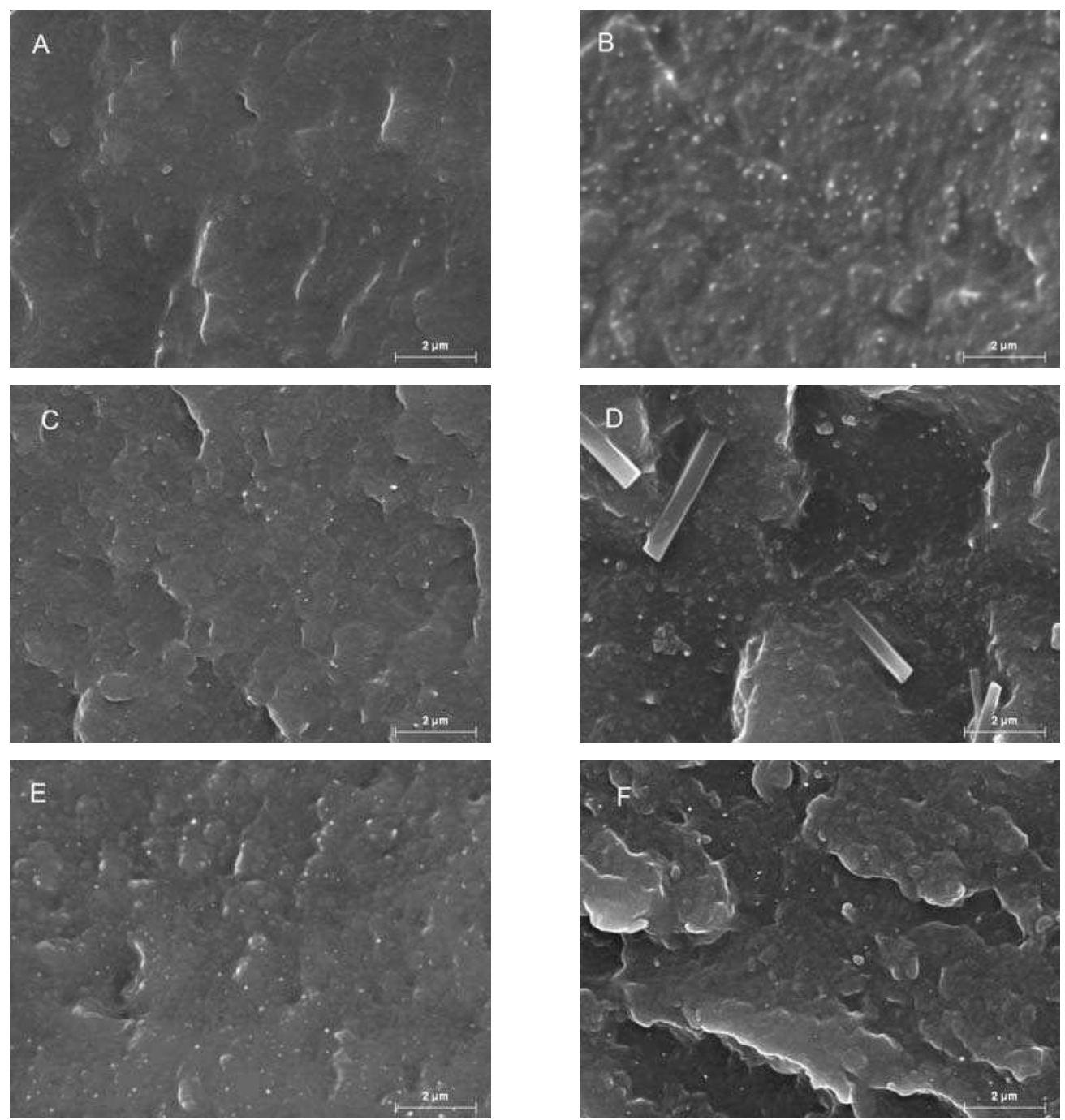

Figure 8. SEM micrographs of the cryo-fractured section obtained from EVOH films: (a) Pure EVOH; (b) 2\% BCNW P; (c) 2\% BCNW ES; (d) 2\% BCNW FD; (e) $2 \%$ BCNW FD-P and (f) $2 \%$ BC FD-P. Scale markers correspond to 2 micrometres. 


\subsubsection{Effect of BCNW loading on the morphology of EVOH nanocomposites}

In addition to the 2 wt.- $\%$ BCNW films, different concentrations of partially hydrated whiskers were incorporated by the precipitation method (1, 3 and 4 wt.$\% \mathrm{BCNW}$ ). The ATR-FTIR spectra of all the produced films were recorded and it was observed that the previously mentioned characteristic bands from cellulose were only apparent for concentrations greater than 3 wt.- $\%$ BCNW (results not shown). It was observed by visual examination of EVOH-BCNW films that the films containing more than 2 wt.- $\%$ BCNW had a yellowish colour, but still maintained good optical characteristics (cf. Figure 7C). The effect of increasing the BCNW concentration in the dispersion when applying the precipitation method was studied by TEM. No significant agglomeration effect was observed when increasing the nanofiller concentration up to 4 wt.-\%, as seen in Figure 9. As calculated from the cryo-SEM images (not shown), the BCNW were distributed within the matrix presenting cross-sections of $44 \pm 16 \mathrm{~nm}, 81 \pm 20 \mathrm{~nm}$, $37 \pm 14 \mathrm{~nm}$ and $44 \pm 35 \mathrm{~nm}$, respectively for the 1, 2, 3 and 4 wt. $\%$ precipitated BCNW films. 


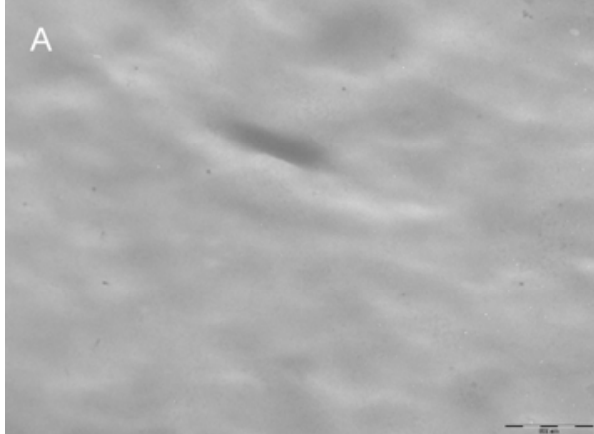

C

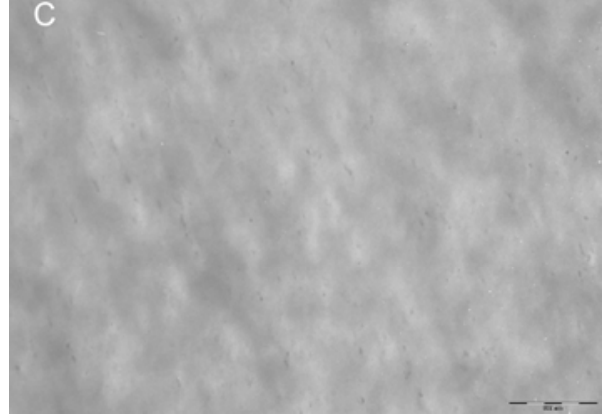

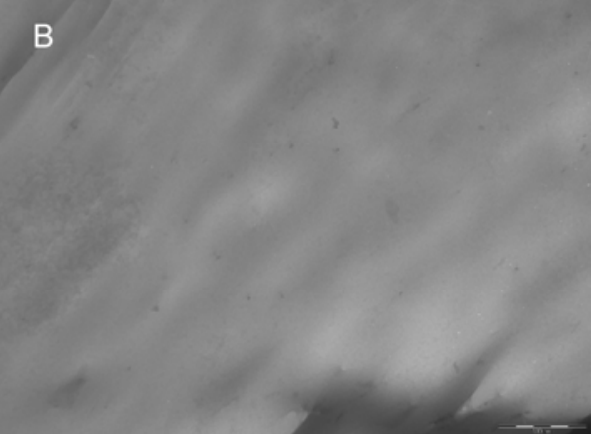

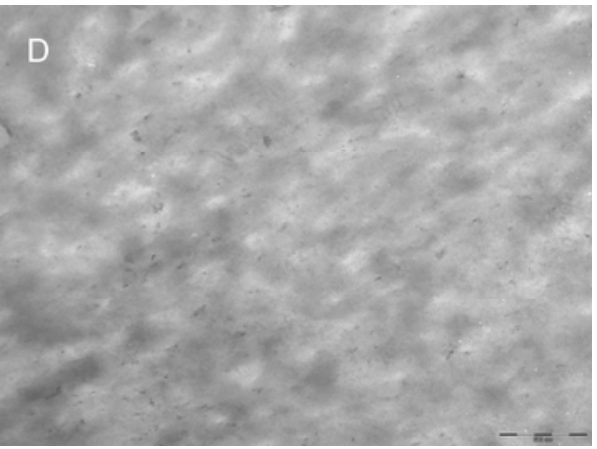

Figure 9. TEM micrographs of EVOH films containing: (a) $1 \mathrm{wt} .-\% \mathrm{BCNW}$ precipitated; (b) 2 wt.-\% BCNW precipitated; (c) 3 wt.-\% BCNW precipitated and

(d) 4 wt.- $\%$ BCNW precipitated. Scale markers correspond to 500 nanometres.

\subsubsection{Thermal properties of the various EVOH nanocomposites developed with} $B C N W$

With the aim of investigating the effects of the BCNW addition on the thermal properties of the EVOH nanocomposites, DSC analyses of all the samples were carried out. The melting temperature $\left(T_{m}\right)$ and melting enthalpy $(\Delta H)$ normalized to the EVOH content of the nanocomposite films were obtained from the DSC first heating run, whereas the glass transition temperature $\left(T_{g}\right)$ was determined from the second heating run (see Table 3). 
A general trend of decreasing melting enthalpy is observed when incorporating $\mathrm{BCNW}$ or $\mathrm{BC}$ into the $\mathrm{EVOH}$ matrix through melt mixing, regardless the method of incorporation or the loading amount, thus indicating that the nanofiller is somehow hindering the crystallization process of the polymer. The same result has been previously observed for poly(oxyethylene) reinforced with tunicin cellulose nanowhiskers and was attributed to an increase in the viscosity of the polymer melt caused by the presence of whiskers which leads to an increase in the activation energy needed for the diffusion of the chains (Azizi Samir et al., 2004). Regarding the $T_{g}$, no significant changes are produced in comparison with the pure EVOH film.

When comparing the different incorporation methods for a fixed concentration of $2 \% \mathrm{BCNW}$, it is observed that the $2 \% \mathrm{BCNW} \mathrm{P}$ and $2 \% \mathrm{BCNW}$ ES films displayed slightly higher melting temperatures than the rest of the $2 \% \mathrm{BCNW}$ films, suggesting that bigger or denser EVOH crystals were formed in both cases. However, a decrease in the crystallinity of the films obtained through the precipitation method was observed when compared to the pure EVOH. Similarly, lower crystallinity values were also observed for the films containing $2 \% \mathrm{BCNW}$ FD and untreated $\mathrm{BC}$, although it should be emphasized that there was a high variability of the data (cf. standard deviation values) precluding to draw any conclusion. 
Table 3. DSC maximum of melting $\left(\mathrm{T}_{\mathrm{m}}\right)$, melting enthalpy $(\Delta \mathrm{H})$, peak width and EVOH crystallinity $\left(\mathrm{X}_{\mathrm{c}}\right)$ of EVOH films, obtained during the first heating run and glass transition temperature $\left(\mathrm{T}_{\mathrm{g}}\right)$, obtained during the second heating run.

\begin{tabular}{|c|c|c|c|c|c|}
\cline { 2 - 6 } \multicolumn{1}{c|}{} & $\mathrm{T}_{\mathrm{m}}\left({ }^{\circ} \mathrm{C}\right)$ & $\Delta \mathrm{H}_{\mathrm{m}}$ & $\begin{array}{c}\text { Peak } \\
\text { (J/g EVOH })\end{array}$ & \multirow{2}{*}{$\mathrm{X}_{\mathrm{c}}(\%)$} & $\mathrm{T}_{\mathrm{g}}\left({ }^{\circ} \mathrm{C}\right)$ \\
\hline EVOH & $177.7 \pm 1.5$ & $76.5 \pm 0.1$ & $7.1 \pm 0.5$ & $35.3 \pm 0.0$ & $59.5 \pm 0.8$ \\
\hline $1 \%$ BCNW P & $177.7 \pm 0.5$ & $67.0 \pm 10.5$ & $7.8 \pm 0.2$ & $31.0 \pm 4.8$ & $59.9 \pm 0.2$ \\
\hline $2 \%$ BCNW P & $178.5 \pm 0.2$ & $68.9 \pm 4.4$ & $7.1 \pm 0.4$ & $31.8 \pm 2.0$ & $58.6 \pm 0.0$ \\
\hline $3 \%$ BCNW P & $176.8 \pm 0.0$ & $64.4 \pm 5.2$ & $7.7 \pm 0.1$ & $29.7 \pm 2.4$ & $59.7 \pm 0.7$ \\
\hline $4 \%$ BCNW P & $177.2 \pm 0.2$ & $72.1 \pm 1.2$ & $9.6 \pm 0.0$ & $33.3 \pm 0.6$ & $58.7 \pm 0.5$ \\
\hline $2 \%$ BCNW ES & $178.0 \pm 0.0$ & $75.8 \pm 2.3$ & $7.3 \pm 1.7$ & $35.0 \pm 1.1$ & $58.6 \pm 0.1$ \\
\hline $2 \%$ BCNW FD & $177.4 \pm 0.1$ & $71.9 \pm 0.9$ & $6.0 \pm 0.2$ & $33.2 \pm 0.4$ & $58.5 \pm 0.1$ \\
\hline $2 \%$ BCNW FD-P & $177.9 \pm 1.1$ & $75.4 \pm 3.2$ & $8.8 \pm 0.1$ & $34.8 \pm 1.5$ & $60.1 \pm 0.3$ \\
\hline $2 \%$ BC FD-P & $177.3 \pm 0.1$ & $67.2 \pm 8.0$ & $8.3 \pm 1.1$ & $31.0 \pm 3.7$ & $59.9 \pm 0.7$ \\
\hline
\end{tabular}

\subsection{Nanocomposite EVOH films reinforced with plant cellulose nanowhiskers (CNW)}

With the purpose of comparing the effect of adding bacterial and plant cellulose nanowhiskers, films were produced by incorporating the latter ones through the precipitation method, obtaining final concentrations of 1, 2 and $3 \mathrm{wt}$.$\% \mathrm{CNW}$. Additionally, the method of directly melt mixing EVOH with freezedried CNW was also carried out for obtaining a film with 2 wt.- $\%$ CNW. 
3.3.1 Morphological characteristics of EVOH nanocomposites with plant-derived $C N W$

The visual aspect of the obtained films is showed in Figure 10. As observed, no aggregates were detected in the films obtained by means of the precipitation method, while black spots, typical from thermal degradation, were present in the film obtained through direct melt mixing of freeze-dried CNW. Just as observed for the $\mathrm{BCNW}$, when increasing the nanowhiskers loading, the films got a yellowish colour. When comparing the 2 wt.-\% CNW FD-P film with the 2 wt.- $\%$ BCNW FD-P, the former appeared to be slightly darker but it still showed a very good contact transparency.
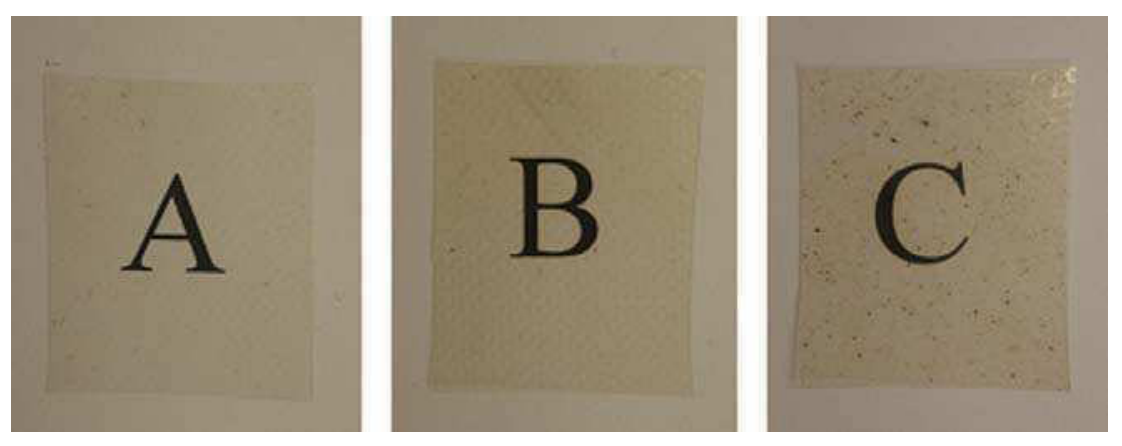

Figure 10. Photographs of films: (A) 1\% CNW FD-P; (B) 2\% CNW FD-P and (C) $2 \%$ CNW FD.

As observed by SEM of cryo-fractured film sections, a good dispersion of the nanofiller was attained using the precipitation method, although small agglomerates were detected (see Figure 11A). The sizes of CNW's cross-sections were determined from SEM pictures of cryo-fractured surfaces and corresponded to $39 \pm 16 \mathrm{~nm}, 60 \pm 25 \mathrm{~nm}$ and $139 \pm 74 \mathrm{~nm}$ for the 1, 2 and $3 \%$ CNW FD-P, respectively. When comparing the $2 \% \mathrm{CNW}$ FD-P with the film obtained exactly 
through the same incorporation method, i.e. $2 \%$ BCNW FD-P, no significant differences were detected in the cross-section dimensions of the nanofiller.

Similarly to what was observed for the BCNW films, in the case of direct melt mixing of the freeze-dried nanowhiskers, bundles were observed in the fractured section of the film (see Figure 11B). In this case they presented a cross-section of $112 \pm 63 \mathrm{~nm}$ and appeared to be much shorter than the ones observed in the BCNW film. The difference in the nanowhiskers length was probably due to the different production method used for each material. In the case of BCNW they were obtained from the centrifugation precipitate, whereas CNW were recovered from the centrifugation supernatant where the shorter nanowhiskers are concentrated. 

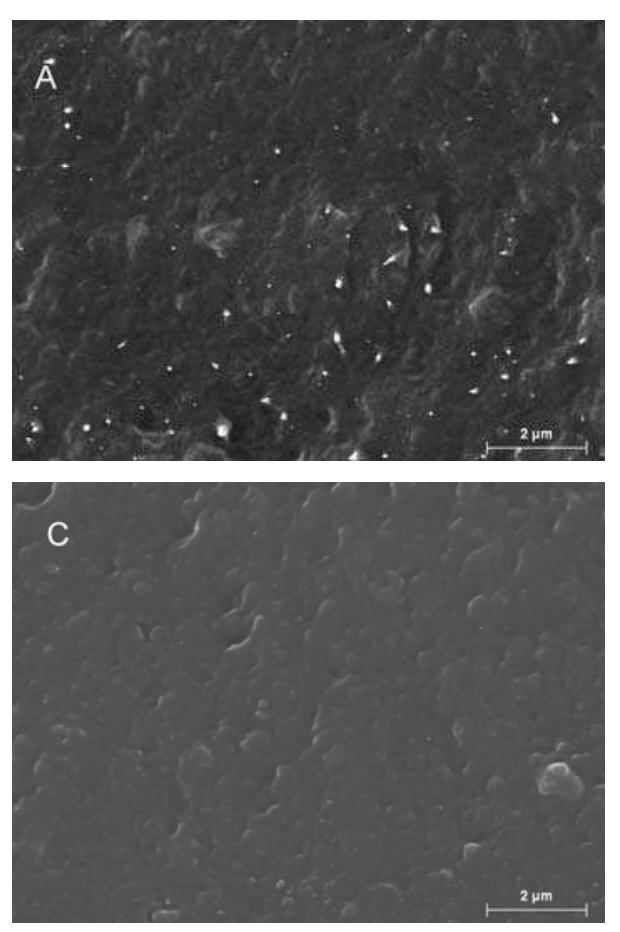
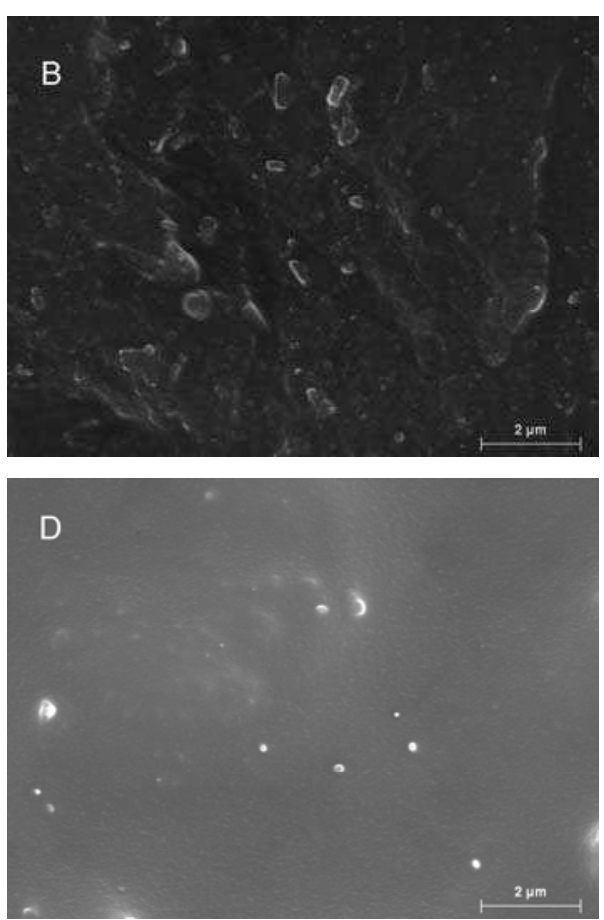

Figure 11. SEM micrographs of the cryo-fractured section obtained from films: (a) $2 \%$ CNW FD-P ,(b) 2\% CNW FD, (c) $1 \%$ CNW FD-P and (d) $3 \%$ CNW FD-P.

Scale markers correspond to 2 micrometres.

\subsubsection{Thermal properties of EVOH nanocomposites with plant-derived CNW}

Thermal properties of films incorporating CNW are gathered in Table 4. While no significant differences were observed for the melting temperature and $T_{g}$ of the nanocomposites obtained through the precipitation method, a slight decrease in the melting enthalpy of the materials was seen when increasing the CNW concentration. This could be related to the increased agglomeration observed when increasing the CNW loading, which led to a certain disruption of the EVOH crystalline phase. This effect was not observed for BCNW since no significant agglomeration took place for the range of concentrations studied. 
In contrast, a significant decrease in the melting temperature and melting enthalpy of the nanocomposite incorporating freeze-dried CNW was observed compared to the pure EVOH since the agglomerated nanocrystals effectively distorted the EVOH crystalline network, resulting in smaller or more defective crystals. It is also worth noting the increase in peak width observed for this latter material, pointing out the greater heterogeneity of EVOH crystals present in the nanocomposite obtained through the traditional method.

Table 4. DSC maximum of melting $\left(T_{m}\right)$, melting enthalpy $(\Delta H)$, peak width and EVOH crystallinity $\left(\mathrm{X}_{\mathrm{c}}\right)$ of EVOH films, obtained during the first heating run and glass transition temperature $\left(\mathrm{T}_{\mathrm{g}}\right)$, obtained during the second heating run.

\begin{tabular}{|c|c|c|c|c|c|}
\cline { 2 - 6 } \multicolumn{1}{c|}{} & $\mathrm{T}_{\mathrm{m}}\left({ }^{\circ} \mathrm{C}\right)$ & $\begin{array}{c}\Delta \mathrm{H}_{\mathrm{m}} \\
(\mathrm{J} / \mathrm{g} \text { EVOH })\end{array}$ & Peak Width & $\mathrm{X}_{\mathrm{c}}(\%)$ & $\mathrm{T}_{\mathrm{g}}\left({ }^{\circ} \mathrm{C}\right)$ \\
\hline EVOH & $177.7 \pm 1.5$ & $76.5 \pm 0.1$ & $7.1 \pm 0.5$ & $35.3 \pm 0.0$ & $59.5 \pm 0.8$ \\
\hline $1 \% \mathrm{CNW} P$ & $177.6 \pm 0.3$ & $65.6 \pm 0.7$ & $7.7 \pm 0.0$ & $30.3 \pm 0.3$ & $58.9 \pm 0.1$ \\
\hline $2 \% \mathrm{CNW} P$ & $178.0 \pm 0.4$ & $63.4 \pm 1.2$ & $6.1 \pm 0.9$ & $29.3 \pm 0.5$ & $60.5 \pm 0.7$ \\
\hline $3 \% \mathrm{CNW} P$ & $178.0 \pm 0.0$ & $61.7 \pm 5.0$ & $7.5 \pm 1.4$ & $28.5 \pm 2.3$ & $60.3 \pm 0.2$ \\
\hline $2 \% \mathrm{CNW}$ FD & $176.6 \pm 0.1$ & $66.8 \pm 0.8$ & $11.2 \pm 4.9$ & $30.9 \pm 0.4$ & $59.5 \pm 0.1$ \\
\hline
\end{tabular}




\section{CONCLUSIONS}

In this first study, EVOH/cellulose nanowhiskers composite films were produced by melt mixing and the effects of the cellulose source, nanofiller concentration and pre-incorporation method in the visual aspect, morphology and thermal properties of the generated materials were investigated. Both bacterial and plant-derived cellulose nanowhiskers were used as nanofillers, being the cellulose source not a relevant factor for the degree of dispersion attained within the EVOH matrix. Non-hydrolyzed bacterial cellulose fibres $(\mathrm{BC})$ were also used to generate nanocomposites and, even though the size of the filler was considerably greater, a good dispersion was also seen. Most importantly, the method for incorporating the nanowhiskers prior to the melt compounding step largely determined the morphology of the obtained nanocomposites. Thus, except for the case of direct melt mixing of the polymer with the freeze-dried nanomaterial, which resulted in agglomeration of the fillers, a homogeneous dispersion of the fillers was encountered using the two pre-incorporation strategies developed in this work.

In terms of thermal properties, the evidenced agglomeration observed for the films incorporating 2 wt.- $\%$ freeze-dried $\mathrm{CNW}$ and $\mathrm{BCNW}$, was reflected in a decrease in the melting temperature and melting enthalpy, indicating that nonhomogeneously dispersed nanofiller hindered EVOH crystallization. The agglomeration effect observed when increasing the CNW loading, which was not observed for $\mathrm{BCNW}$ in the range screened, resulted in decreased crystallinity of the $\mathrm{EVOH}$ matrix as well. In the case of the nanocomposite containing $\mathrm{BC}$, the bigger size of this filler also affected the thermal properties of the matrix decreasing both the temperature and enthalpy of fusion. These results evidence the adequacy of techniques such as electrospinning or precipitation using liquid nitrogen for the incorporation of cellulose nanowhiskers into EVOH matrices 
prior to a melt mixing step in order to obtain EVOH nanocomposites showing a good dispersion of the cellulose fillers. 


\section{REFERENCES}

Anglès, M. N., \& Dufresne, A. (2001). Plasticized starch/tunicin whiskers nanocomposite materials. 2: Mechanical behavior. Macromolecules, 34(9), 29212931.

Araki, J., Wada, M., Kuga, S., \& Okano, T. (1998). Flow properties of microcrystalline cellulose suspension prepared by acid treatment of native cellulose. Colloids and Surfaces A: Physicochemical and Engineering Aspects, 142(1), 75-82.

Ayuk, J. E., Mathew, A. P., \& Oksman, K. (2009). The effect of plasticizer and cellulose nanowhisker content on the dispersion and properties of cellulose acetate butyrate nanocomposites. Journal of Applied Polymer Science, 114(5), 2723-2730.

Azizi Samir, M. A. S., Alloin, F., Sanchez, J. Y., \& Dufresne, A. (2004). Cellulose nanocrystals reinforced poly(oxyethylene). Polymer, 45(12), 4149-4157.

Blaker, J. J., Lee, K. Y., Mantalaris, A., \& Bismarck, A. (2010). Ice-microsphere templating to produce highly porous nanocomposite PLA matrix scaffolds with pores selectively lined by bacterial cellulose nano-whiskers. Composites Science and Technology, 70(13), 1879-1888.

Bondeson, D., Mathew, A., \& Oksman, K. (2006). Optimization of the isolation of nanocrystals from microcrystalline cellulose by acid hydrolysis. Cellulose, 13(2), 171-180.

Bondeson, D., \& Oksman, K. (2007a). Dispersion and characteristics of surfactant modified cellulose whiskers nanocomposites. Composite Interfaces, 14(7-9), 617630 .

Bondeson, D., \& Oksman, K. (2007b). Polylactic acid/cellulose whisker nanocomposites modified by polyvinyl alcohol. Composites Part A: Applied Science and Manufacturing, 38(12), 2486-2492.

Carrillo, F., Colom, X., Suñol, J. J., \& Saurina, J. (2004). Structural FTIR analysis and thermal characterisation of lyocell and viscose-type fibres. European Polymer Journal, 40(9), 2229-2234. 
De Souza Lima, M. M., \& Borsali, R. (2004). Rodlike cellulose microcrystals: Structure, properties, and applications. Macromolecular Rapid Communications, 25(7), 771-787.

Eichhorn, S. J., Dufresne, A., Aranguren, M., Marcovich, N. E., Capadona, J. R., Rowan, S. J., Weder, C., Thielemans, W., Roman, M., Renneckar, S., Gindl, W., Veigel, S., Keckes, J., Yano, H., Abe, K., Nogi, M., Nakagaito, A. N., Mangalam, A., Simonsen, J., Benight, A. S., Bismarck, A., Berglund, L. A., \& Peijs, T. (2010). Review: Current international research into cellulose nanofibres and nanocomposites. Journal of Materials Science, 45(1), 1-33.

Elanthikkal, S., Gopalakrishnapanicker, U., Varghese, S., \& Guthrie, J. T. (2010). Cellulose microfibres produced from banana plant wastes: Isolation and characterization. Carbohydrate Polymers, 80(3), 852-859.

Favier, V., Chanzy, H., \& Cavaille, J. Y. (1995). Polymer nanocomposites reinforced by cellulose whiskers. Macromolecules, 28(18), 6365-6367.

Filson, P. B., \& Dawson-Andoh, B. E. (2009). Sono-chemical preparation of cellulose nanocrystals from lignocellulose derived materials. Bioresource Technology, 100(7), 2259-2264.

George, J., Ramana, K. V., Bawa, A. S., \& Siddaramaiah (2011). Bacterial cellulose nanocrystals exhibiting high thermal stability and their polymer nanocomposites. International Journal of Biological Macromolecules, 48(1), 5057.

George, J., \& Siddaramaiah (2011). High performance edible nanocomposite films containing bacterial cellulose nanocrystals. Carbohydrate Polymers.

Goffin, A. L., Raquez, J. M., Duquesne, E., Siqueira, G., Habibi, Y., Dufresne, A., \& Dubois, P. (2011). Poly( $\varepsilon$-caprolactone) based nanocomposites reinforced by surface-grafted cellulose nanowhiskers via extrusion processing: Morphology, rheology, and thermo-mechanical properties. Polymer, 52(7), 1532-1538.

Hirai, A., Inui, O., Horii, F., \& Tsuji, M. (2009). Phase separation behavior in aqueous suspensions of bacterial cellulose nanocrystals prepared by sulfuric acid treatment. Langmuir, 25(1), 497-502.

Iguchi, M., Yamanaka, S., \& Budhiono, A. (2000). Bacterial cellulose - a masterpiece of nature's arts. Journal of Materials Science, 35(2), 261-270. 
Jiang, L., Morelius, E., Zhang, J., Wolcott, M., \& Holbery, J. (2008). Study of the poly(3-hydroxybutyrate-co-3-hydroxyvalerate)/cellulose nanowhisker composites prepared by solution casting and melt processing. Journal of Composite Materials, 42(24), 2629-2645.

Kvien, I., Sugiyama, J., Votrubec, M., \& Oksman, K. (2007). Characterization of starch based nanocomposites. Journal of Materials Science, 42(19), 8163-8171.

Lagaron, J. M., Gimenez, E., Catala, R., \& Gavara, R. (2003). Mechanisms of moisture sorption in barrier polymers used in food packaging: Amorphous polyamide vs. high-barrier ethylene-vinyl alcohol copolymer studied by vibrational spectroscopy. Macromolecular Chemistry and Physics, 204(4), 704-713.

Lagaron, J. M., Gimenez, E., Saura, J. J., \& Gavara, R. (2001). Phase morphology, crystallinity and mechanical properties of binary blends of high barrier ethylenevinyl alcohol copolymer and amorphous polyamide and a polyamide-containing ionomer. Polymer, 42(17), 7381-7394.

Lagaron, J. M., Martínez-Sanz, M., \& Lopez-Rubio, A. (2010). Patent Application P30663.

Lagaron, J. M., Martínez-Sanz, M., \& Lopez-Rubio, A. (2011). Patent Application P31951.

Martínez-Sanz, M., Lopez-Rubio, A., \& Lagaron, J. (2011a). Optimization of the nanofabrication by acid hydrolysis of bacterial cellulose nanowhiskers. Carbohydrate Polymers, 85(1), 228-236.

Martínez-Sanz, M., Olsson, R. T., Lopez-Rubio, A., \& Lagaron, J. M. (2011b). Development of electrospun EVOH fibres reinforced with bacterial cellulose nanowhiskers. Part I: Characterization and method optimization. Cellulose, 18(2), 335-347.

Martínez-Sanz, M., Olsson, R., Lopez-Rubio, A., \& Lagaron, J. (2012). Development of Bacterial Cellulose Nanowhiskers Reinforced EVOH Composites by Electrospinning. Journal of Applied Polymer Science, 124(2), 1398-1408.

Moharram, M. A., \& Mahmoud, O. M. (2007). X-Ray diffraction methods in the study of the effect of microwave heating on the transformation of cellulose $\mathrm{i}$ into 
cellulose II during mercerization. Journal of Applied Polymer Science, 105(5), 2978-2983.

Oh, S. Y., Yoo, D. I., Shin, Y., \& Seo, G. (2005). FTIR analysis of cellulose treated with sodium hydroxide and carbon dioxide. Carbohydrate Research, 340(3), 417428 .

Oksman, K., Mathew, A. P., Bondeson, D., \& Kvien, I. (2006). Manufacturing process of cellulose whiskers/polylactic acid nanocomposites. Composites Science and Technology, 66(15), 2776-2784.

Olsson, R. T., Kraemer, R., Lopez-Rubio, A., Torres-Giner, S., Ocio, M. J., \& Lagaron, J. M. (2010). Extraction of microfibrils from bacterial cellulose networks for electrospinning of anisotropic biohybrid fiber yarns. Macromolecules, 43(9), 4201-4209.

Park, W. I., Kang, M., Kim, H. S., \& Jin, H. J. (2007). Electrospinning of poly(ethylene oxide) with bacterial cellulose whiskers. Macromolecular Symposia, 249-250, 289-294.

Peresin, M. S., Habibi, Y., Zoppe, J. O., Pawlak, J. J., \& Rojas, O. J. (2010). Nanofiber composites of polyvinyl alcohol and cellulose nanocrystals: Manufacture and characterization. Biomacromolecules, 11(3), 674-681.

Petersson, L., Kvien, I., \& Oksman, K. (2007). Structure and thermal properties of poly(lactic acid)/cellulose whiskers nanocomposite materials. Composites Science and Technology, 67(11-12), 2535-2544.

Petersson, L., Mathew, A. P., \& Oksman, K. (2009). Dispersion and properties of cellulose nanowhiskers and layered silicates in cellulose acetate butyrate nanocomposites. Journal of Applied Polymer Science, 112(4), 2001-2009.

Qua, E. H., Hornsby, P. R., Sharma, H. S. S., Lyons, G., \& McCall, R. D. (2009). Preparation and characterization of Poly(vinyl alcohol) nanocomposites made from cellulose nanofibers. Journal of Applied Polymer Science, 113(4), 2238-2247.

Roman, M., \& Winter, W. T. (2004). Effect of sulfate groups from sulfuric acid hydrolysis on the thermal degradation behavior of bacterial cellulose. Biomacromolecules, 5(5), 1671-1677. 
Roman, M., \& Winter, W. T. (2006). Cellulose nanocrystals for thermoplastic reinforcement: Effect of filler surface chemistry on composite properties. ACS Symposium Series pp. 99-113).

Sanchez-Garcia, M. D., \& Lagaron, J. M. (2010). On the use of plant cellulose nanowhiskers to enhance the barrier properties of polylactic acid. Cellulose, 17(5), 987-1004.

Ten, E., Turtle, J., Bahr, D., Jiang, L., \& Wolcott, M. (2010). Thermal and mechanical properties of poly(3-hydroxybutyrate-co-3-hydroxyvalerate)/cellulose nanowhiskers composites. Polymer, 51(12), 2652-2660.

Wan, Y. Z., Huang, Y., Yuan, C. D., Raman, S., Zhu, Y., Jiang, H. J., He, F., \& Gao, C. (2007). Biomimetic synthesis of hydroxyapatite/bacterial cellulose nanocomposites for biomedical applications. Materials Science and Engineering $C$, $27(4), 855-864$.

Wang, N., Ding, E., \& Cheng, R. (2007). Thermal degradation behaviors of spherical cellulose nanocrystals with sulfate groups. Polymer, 48(12), 3486-3493.

Wong, S.-S., Kasapis, S., \& Tan, Y. M. (2009). Bacterial and plant cellulose modification using ultrasound irradiation. Carbohydrate Polymers, 77(2), 280-287.

Yano, H., Sugiyama, J., Nakagaito, A. N., Nogi, M., Matsuura, T., Hikita, M., \& Handa, K. (2005). Optically transparent composites reinforced with networks of bacterial nanofibers. Advanced Materials, 17(2), 153-155.

Yun, Y. S., Cho, S. Y., \& Jin, H. J. (2010). Flow-induced liquid crystalline solutions prepared from aspect ratio-controlled bacterial cellulose nanowhiskers. Molecular Crystals and Liquid Crystals, 519, 141-148. 



\section{Chapter V}

NANOCOMPOSITES OF ETHYLENE VINYL ALCOHOL COPOLYMER WITH THERMALLY RESISTANT CELLULOSE NANOWHISKERS BY MELT COMPOUNDING (II): WATER BARRIER AND MECHANICAL PROPERTIES

Journal of Applied Polymer Science, 128(3), 2197-2207 (2013)

Marta Martínez Sanz, Amparo López Rubio, José María Lagarón

Novel Materials and Nanotechnology Group, IATA, CSIC. Avd. Agustín Escardino, 7, 46980. Paterna, Valencia. Spain 



\begin{abstract}
In the present work, the crystallinity and crystalline morphology, thermal stability, water barrier and mechanical properties of ethylene vinyl alcohol copolymer (EVOH) nanocomposites prepared by melt compounding and incorporating both plant (CNW) and bacterial cellulose nanowhiskers (BCNW) are reported. An improvement in the water barrier performance was observed, i.e. $67 \%$ permeability drop, only for the microcomposite sample incorporating $2 \mathrm{wt.-} \%$ of bacterial cellulose fibrils. No significant differences in the water barrier properties of the nanocomposites generated through the two studied pre-incorporation methods were observed despite the fact that an excellent dispersion was observed in the previous study. On the other hand, direct melt mixing of the freeze-dried nanofiller with EVOH resulted in increased water permeation. The aggregation of the filler in the latter nanocomposite was also ascribed to the detrimental effect on the mechanical properties. Interestingly, by using the precipitation method, an increase in the elastic modulus and tensile strength of ca. $36 \%$ and $22 \%$, respectively was observed for a $3 \mathrm{wt} .-\%$ BCNW loading, which was thought to coincide with the percolation threshold.
\end{abstract}

Keywords: Cellulose, nanowhiskers, EVOH, melt compounding, barrier properties. 


\section{INTRODUCTION}

Ethylene vinyl alcohol copolymers $(\mathrm{EVOH})$ are random semi-crystalline materials with excellent gas barrier properties to oxygen and organic compounds, considerable chemical resistance and high transparency (Lagaron et al., 2001). An important application of these materials is as barrier layer in multilayer structures to be used in various packaging designs for foodstuffs. The presence of EVOH in the packaging structure is key to food quality and safety because it reduces the ingress of oxygen and the loss of aroma components during extended packaging shelf-life. However, in high relative humidity conditions, the EVOH gas barrier and mechanical properties are significantly deteriorated (Lagaron et al., 2003; López-Rubio et al., 2003). This deterioration is thought to derive from the fact that the inter- and intramolecular hydrogen bonding (so-called self-association) provided by the hydroxyl groups is intercepted by water molecules. This interaction strongly reduces inter-chain cohesion and mechanical integrity and increments the fractional free volume of the polymer (plasticization effect) for the permeants to travel across polymer packages. Therefore, EVOH is commonly found as an intermediate layer in co-extruded multilayer structures protected by, at least, two layers of hydrophobic materials such as polyolefins.

An alternative for enhancing EVOH water barrier performance has been the development of EVOH nanocomposites incorporating low amounts of different nanoclays such as modified montmorillonite (Aktzi et al., 2001; Franco-Urquiza et al., 2010) and kaolin (Cabedo et al., 2004) by using the melt compounding technique. The incorporation of microfibrillated cellulose (MFC) into EVOH by the solution casting technique has also been investigated (Fernández et al., 2008). In this latter case, a decrease in the water barrier properties of the films was observed when incorporating MFC. This detrimental effect was ascribed to 
decreased crystallinity of the matrix and probably also to the hydrophilic character of MFC.

Cellulose nanowhiskers (CNW) have proven to efficiently enhance the barrier properties of polymeric matrixes such as polylactic acid (PLA) (Sanchez-Garcia \& Lagaron, 2010b) and carrageenan (Sanchez-Garcia et al., 2010) when incorporated by means of solution casting. In the case of PLA, improvements of ca. $82 \%$ and $90 \%$ in the water and oxygen permeability, respectively, were reported for 3 wt.-\% CNW loadings. For the same CNW loading, a water permeability drop of ca. $70 \%$ was observed in the carrageenan nanocomposites. In both cases, a high dispersion level of the $\mathrm{CNW}$ across the matrix was a crucial factor for obtaining such outstanding improvements on the barrier properties. Unfortunately, achieving such a good dispersion becomes an issue when using conventional industrial melt processing techniques. Biopolymer composites of poly(3-hydroxybutyrate-co-3-hydroxyvalerate) (PHBV) incorporating CNW were developed by both solution casting and melt compounding (Jiang et al., 2008). Whereas a good dispersion was achieved by means of the first method, the latter one led to CNW's agglomeration despite using polyethylene glycol (PEG) as compatibilizer. As a result, the melt processed PHBV/CNW composites exhibited decreased strength but the glass transition temperature remained unmodified. It has also been attempted to prepare PLA nanocomposites reinforced with CNW by pumping a suspension of $\mathrm{CNW}$ in $\mathrm{DMAc} / \mathrm{LiCl}$ into the polymer melt during the extrusion process (Oksman et al., 2006). In this case aggregation and thermal degradation took place to a certain extent and, even when PVA was used as compatibilizer, it was not possible to attain a morphology of well-dispersed CNW (Bondeson \& Oksman, 2007). 
In the first part of this study, the use of the electrospinning technique, as well as a solution-precipitation method, were proposed as innovative methods for the incorporation of homogeneously distributed bacterial and plant cellulose nanowhiskers into an EVOH matrix by means of melt compounding. The electrospinning technique has been previously applied for the incorporation of CNW in polymeric matrixes such as polystyrene (Rojas et al., 2009), poly(vinyl alcohol) (Peresin et al., 2010) or poly(methyl methacrylate) (Olsson et al., 2010), and the method for generating electrospun EVOH-BCNW hybrid fibres has been optimized in a previous work (Martínez-Sanz et al., 2011). The use of these electrospun fibres as a way of enhancing the dispersion of BCNW in EVOH by melt compounding was also proposed and this method was shown to give rise to a better dispersion of the nanofiller when compared to the direct melt mixing of freeze-dried BCNW with the polymeric matrix (Martínez-Sanz et al., 2012). Nevertheless, due to the acidic character of the BCNW, their thermal stability was not high enough to stand the temperatures applied during melt processing and thermal degradation took place to a certain extent.

In the previous part of this work (Martínez-Sanz, 2013), BCNW with improved thermal stability were also incorporated into electrospun EVOH fibres and this technique was proposed as a way of enhancing the dispersion of the nanofiller in the nanocomposites subsequently obtained by melt compounding. The effects of the incorporation method, the nanofiller loading and cellulose source on the morphology and thermal properties of the developed nanocomposites were investigated. In the current paper, the crystallinity, thermal stability, water barrier properties and mechanical properties of the nanocomposite materials are evaluated and related to the previous morphological observations. 


\section{MATERIALS AND METHODS}

\subsection{Materials}

Ethylene-vinyl alcohol copolymer grade (Soarnol) EVOH32 (containing 32 mol\% of ethylene) was supplied by The Nippon Synthetic Chemical Industry Co., Ltd. (NIPPON GOHSEI) (Japan). Sulfuric acid 96\% and 2-propanol were purchased from Panreac (Barcelona, Spain).

Bacterial cellulose $(\mathrm{BC})$ mats were obtained following a procedure similar to the one described in a previous work (Martínez-Sanz et al., 2011) and were supplied by BioInicia S.L. (Valencia, Spain).

For the production of plant cellulose nanowhiskers, a purified cellulose microfiber grade from CreaFill Fibers Corp. (US), having an average fibre length of $60 \mu \mathrm{m}$ and an average fibre width of $20 \mu \mathrm{m}$, was used as raw material. According to the manufacturer specifications, these fibres had an $\alpha$-cellulose content in excess of $99.5 \%$.

Bacterial cellulose nanowhiskers and plant cellulose nanowhiskers were prepared as described in the previous part of this work (Martínez-Sanz, 2013) and detailed procedures can be found elsewhere (Martínez-Sanz et al., 2011; SanchezGarcia \& Lagaron, 2010b).

\subsection{Preparation of films}

Nanocomposite EVOH films were prepared using 3 different methods: the traditional method of melt mixing the matrix directly with the freeze-dried nanofiller, and two novel methods of incorporating cellulose nanowhiskers in the 
EVOH matrix, previous to the melt compounding stage, just as explained in the previous part of this work (Martínez-Sanz, 2013).

\subsection{X-ray Diffraction (XRD)}

X-ray diffraction was carried out on a D5005 Bruker diffractometer. The instrument was equipped with a $\mathrm{Cu}$ tube and a secondary monochromator. The configuration of the equipment was $\theta-2 \theta$ and the samples were examined over the angular range of $5^{\circ}$ to $45^{\circ}$ with a step size of $0.02^{\circ}$ and a count time of $4 \mathrm{~s}$ per point.

Peak fitting was carried out using Igor software package (Wavemetrics, Lake Oswego, Oregon). A Lorentzian function was used to fit the experimental diffraction profiles obtained. For the fitting procedure, the reflections considered were: (i) three at $11^{\circ}, 20.2^{\circ}$ and $22^{\circ} 2 \theta$ (corresponding to the 100,110 and 200 crystal planes respectively) assigned to the orthorhombic lattice of EVOH (LópezRubio et al., 2003), or four reflections at $10.8^{\circ}, 19.8^{\circ}, 20.2^{\circ}$ and $22.5^{\circ} 2 \theta$ (corresponding to the $100,110,1 \overline{1} 0$ and 200 crystal planes respectively) assigned to the monoclinic lattice of EVOH (López-Rubio et al., 2003); (ii) two at $14.8^{\circ}$ and $16.4^{\circ}$ (corresponding to the 101 and $10 \overline{1}$ crystal planes respectively) assigned to the cellulose I allomorph, for these samples in which the cellulose contribution could be detected; and (iii) the amorphous halo centered at $\sim 20^{\circ} 2 \theta$. The crystallinity index CI (XD) was determined by the method reported by Wang et al. (Wang et al., 2007):

$$
\mathrm{CI}(\mathrm{XD})=\frac{\sum A_{\text {Crystal }}}{A_{\text {Total }}} \times 100
$$


where $A_{\text {Total }}$ is the sum of the areas under all the diffraction peaks and $\Sigma A_{\text {Crystal }}$ is the sum of the areas corresponding to crystalline peaks.

\subsection{Thermogravimetric analysis (TGA)}

Thermogravimetric (TG) curves were recorded with a TA Instruments model Q500 TGA. The samples (ca. $20 \mathrm{mg}$ ) were heated from $50^{\circ} \mathrm{C}$ to $600^{\circ} \mathrm{C}$ with a heating rate of $10^{\circ} \mathrm{C} / \mathrm{min}$ under nitrogen atmosphere. Derivative TG curves (DTG) express the weight loss rate as a function of temperature.

\subsection{Water permeability}

Direct permeability to water vapour was determined from the slope of the weight loss versus time curves at $24^{\circ} \mathrm{C}$. The films were sandwiched between the aluminium top (open O-ring) and bottom (deposit for the permeant) parts of a specifically designed permeability cell with screws. A Viton rubber O-ring was placed between the film and the bottom part of the cell to enhance sealability. These permeability cells containing water as the permeant were then placed inside a desiccator at $0 \% \mathrm{RH}$ and the solvent weight loss through a film area of $0.001 \mathrm{~m}^{2}$ was monitored and plotted as a function of time. The samples were preconditioned at the testing conditions for 24 hours, and to estimate the permeability values of the films, only the linear part of the weight loss data was used to ensure sample steady state conditions. Cells with aluminium films were used as control samples to estimate solvent loss through the sealing. The lower limit of WVP detection of the permeation cells was of ca. $0.008 \cdot 10^{-15} \mathrm{~kg} \cdot \mathrm{m} / \mathrm{s} \cdot \mathrm{m}^{2} \cdot \mathrm{Pa}$ based on the weight loss measurements of the aluminium films. Solvent permeation rates were estimated from the steady-state permeation slopes. Water vapour weight loss was calculated as the total cell weight loss minus the loss through the sealing. The tests were done in duplicate. 


\subsection{Density measurements}

The density of $\mathrm{EVOH}$ and nanocomposite films was determined by the density gradient technique using a density column as described by the ASTM D1505 standard. Briefly, a density gradient column (CEAST) was filled in with two different solvents (toluene and dichloromethane) in order to create a gradient range suitable to determine the density of the EVOH specimens. Standard glass floats were dropped into the column solution and, once they stabilized, a calibration curve was built by relating their position with their known density values. Subsequently, EVOH specimens were added to the column and their densities were calculated by extrapolating their position into the calibration curve.

From the density values obtained, together with the overall crystallinity index $\left(\mathrm{X}_{\mathrm{c}}\right)$, the crystallinity of $\mathrm{BCNW}, \mathrm{BC}$ or $\mathrm{CNW}$ as determined by $\mathrm{XRD}$, the crystalline density of $\mathrm{EVOH}$ calculated from the lattice crystal parameters from the XRD patterns and the crystalline density of cellulose $\left(\rho_{\mathrm{c}}\right.$ cellulose $\left.=1.59 \mathrm{~g} / \mathrm{cm}^{3}\right)$, (O'Sullivan, 1997) the density of the amorphous phase $\left(\rho_{a}\right)$ was determined.

\subsection{Water uptake}

The water uptake was estimated during sorption experiments at $24^{\circ} \mathrm{C}$ and $100 \%$ RH by means of weight gain using an analytical balance Voyager ${ }^{\circledR}$ V11140. Thus, at saturation conditions, no changes in successive weight uptake were observed during the measurements of the specimens.

Solubility (S), required to estimate the diffusion coefficient of water (D) through the films, was estimated from the water uptake at equilibrium, the density of the materials and the water vapour partial pressure at $24^{\circ} \mathrm{C}$. 


\subsection{Mechanical properties}

Tensile tests were carried out at ambient conditions typically at $24^{\circ} \mathrm{C}$ and $50 \%$ RH on an Instron 4400 Universal Tester. Pre-conditioned dumb-bell shaped specimens with initial gauge length of $25 \mathrm{~mm}$ and $5 \mathrm{~mm}$ in width were die-stamped from the films in the machine direction according to the ASTM D638. A fixed crosshead rate of $10 \mathrm{~mm} / \mathrm{min}$ was utilized in all cases and results were taken as the average of four tests.

\subsection{Statistical analysis}

One-way analysis of the variance (ANOVA) was performed using XLSTATPro (Win) 7.5.3 (Addinsoft, NY) software package. Comparisons between samples were evaluated using the Tukey's test. 


\section{RESULTS AND DISCUSSION}

\subsection{Nanocomposite EVOH films reinforced with bacterial cellulose nanowhiskers (BCNW)}

\subsubsection{Effect of bacterial cellulose addition on the crystallinity of the nanocomposite films}

In the previous part of this study, DSC analyses showed that the incorporation of cellulose nanowhiskers slightly reduced the crystallinity of EVOH, especially when aggregation took place or for high nanofiller loadings (Martínez-Sanz, 2013). However, the nanofiller possessed a high crystallinity index and, thus, the effect on the overall crystallinity of the nanocomposite material was expected to depend on the nanowhiskers loading and degree of dispersion. Figure 1a shows the XRD patterns of the neat EVOH film and of the nanocomposite films with 2 wt.-\% BCNW through the different incorporation methods. The contribution of cellulose was observed in all the samples as an increase in the intensity of the peak located at $2 \theta \sim 20^{\circ}$. This peak corresponds to the 002 crystallographic plane of cellulose I (Moharram \& Mahmoud, 2007), which is usually observed at $22.5^{\circ}$ $2 \theta$, and in this case it was overlapped with the 110 reflection of orthorhombic EVOH. Furthermore, for loadings greater than $2 \mathrm{wt.}-\%$, the less intense reflections at $14.8^{\circ}$ and $16.4^{\circ}$, corresponding to the 101 and $10 \overline{1}$ crystal planes from cellulose I respectively, could also be identified in the diffraction patterns (cf. Figure 1b). It is also interesting to note that the incorporation of $\mathrm{BCNW}$ led to a certain modification of the EVOH crystal unit cell. As observed in Figure 1a, while the neat EVOH film displayed the diffraction peaks characteristic from the orthorhombic crystal lattice, probably due to the rapid cooling rate during the film preparation method (López-Rubio et al., 2003), the diffractograms from the 
nanocomposite films showed a broadening of the 110 reflection at $\sim 20^{\circ} 2 \theta$, pointing out that an intermediate state between the orthorhombic lattice and the more thermodynamically stable monoclinic polymorph was developed in these samples. These results indicate that even though addition of BCNW somehow hindered crystallization, as confirmed in the previous part of this work by DSC (Martínez-Sanz, 2013), the crystals formed were thermodynamically more stable (as it will be confirmed later on by the crystal density measurements). This apparent counterintuitive behaviour seems to be caused by the whiskers, which it is hypothesized to impede the growth of crystals and, perhaps, also reduce the likelihood of incorporating defects in the crystallinity. 

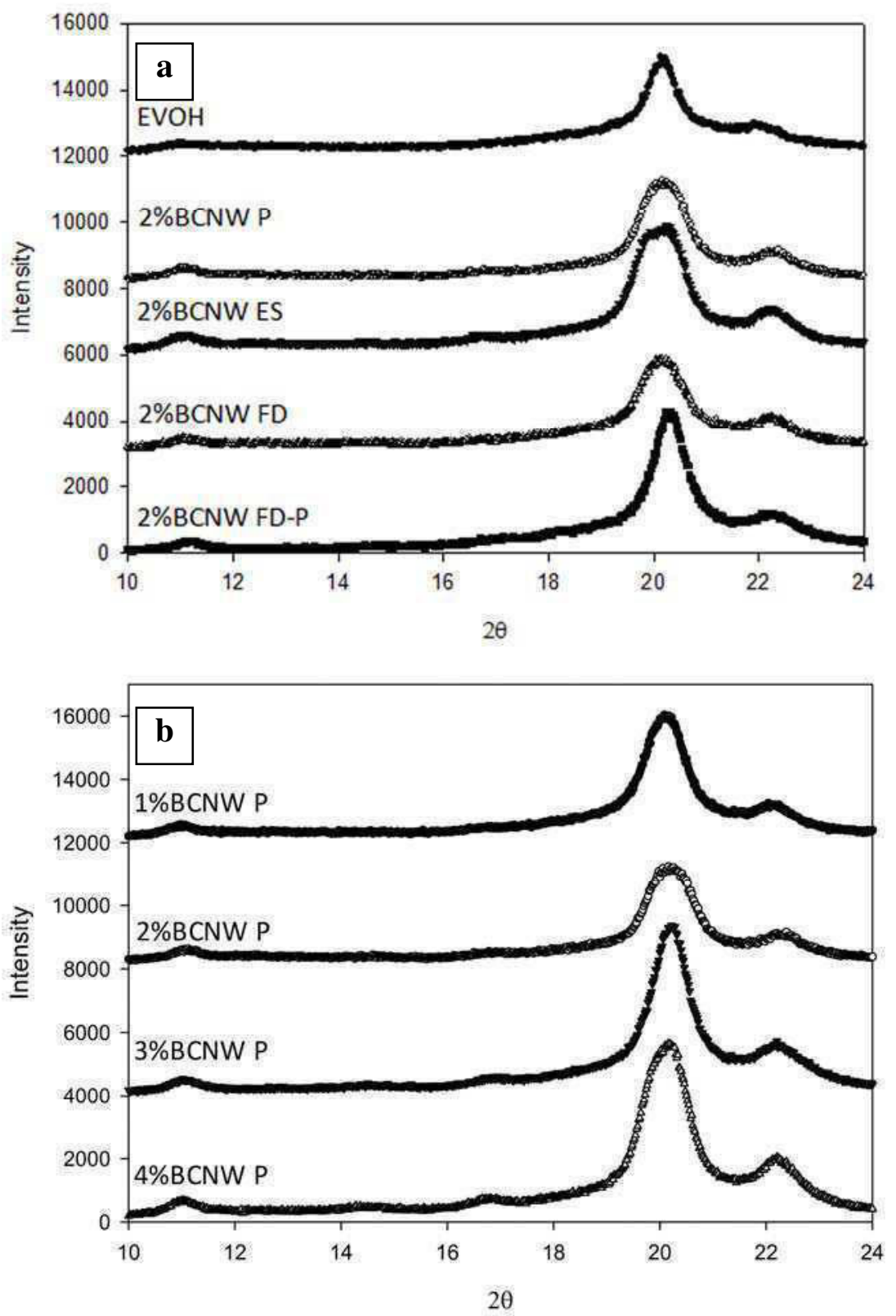

Figure 1. X-ray diffraction patterns of neat EVOH film and films containing 2 wt.$\% \mathrm{BCNW}$ (a) and films containing different concentrations of BCNW incorporated by the precipitation method (b). 
The crystallinity values calculated from these diffraction patterns, as well as the ones obtained for the EVOH matrix by the DSC analyses carried out in the first part of this study (Martínez-Sanz, 2013), are shown in Figure 2 for comparison purposes. It is interesting to see that there was a good agreement between the pure EVOH crystallinity index previously obtained from DSC experiments $(35.3 \pm 0.7)$ and the one calculated from the XRD patterns of the EVOH film $(34.65 \pm 0.01)$. From Figure 2 , it is observed that addition of the highly crystalline $\mathrm{BCNW}$ gave rise to an increase in the overall crystallinity index of the material, which mainly depended on the BCNW's concentration, but also on the degree of filler dispersion, which was related to the incorporation method. The following crystallinity indexes were estimated for nanocomposites produced by the precipitation method: $50.4 \pm 0.2,55.1 \pm 4.5,74.6 \pm 1.1$ and $75.7 \pm 1.7$ for 1, 2, 3 and 4 wt.-\% BCNW loading, respectively. As observed, the crystallinity of the material increased with higher nanofiller loadings, although this increase was more pronounced for concentrations greater than $2 \mathrm{wt} .-\%$.

On the other hand, the sample $2 \% \mathrm{BCNW}$ FD displayed significantly lower crystallinity $(50.0 \pm 0.5)$ than the other samples with the same loading level but prepared using the novel electrospinning and precipitation methods $(55.1 \pm 0.2$, $55.1 \pm 4.5$ and $54.6 \pm 1.6$, for $2 \% \mathrm{BCNW}$ ES, $2 \% \mathrm{BCNW} \mathrm{P}$ and $2 \% \mathrm{BCNW}$ FD-P, respectively). Therefore, in agreement with the morphological study carried out in the previous part of this work, it seems that the agglomeration of BCNW led to lower crystallinity as a result of the detrimental effect of agglomerated nanofiller on the EVOH crystallinity. The nanocomposite containing the $\mathrm{BC}$ microfibres also displayed significantly lower overall crystallinity, due to the combination of the lower EVOH matrix crystallinity and to the fact that this filler had an intrinsic lower crystallinity as it did not undergo the hydrolysis treatment. 


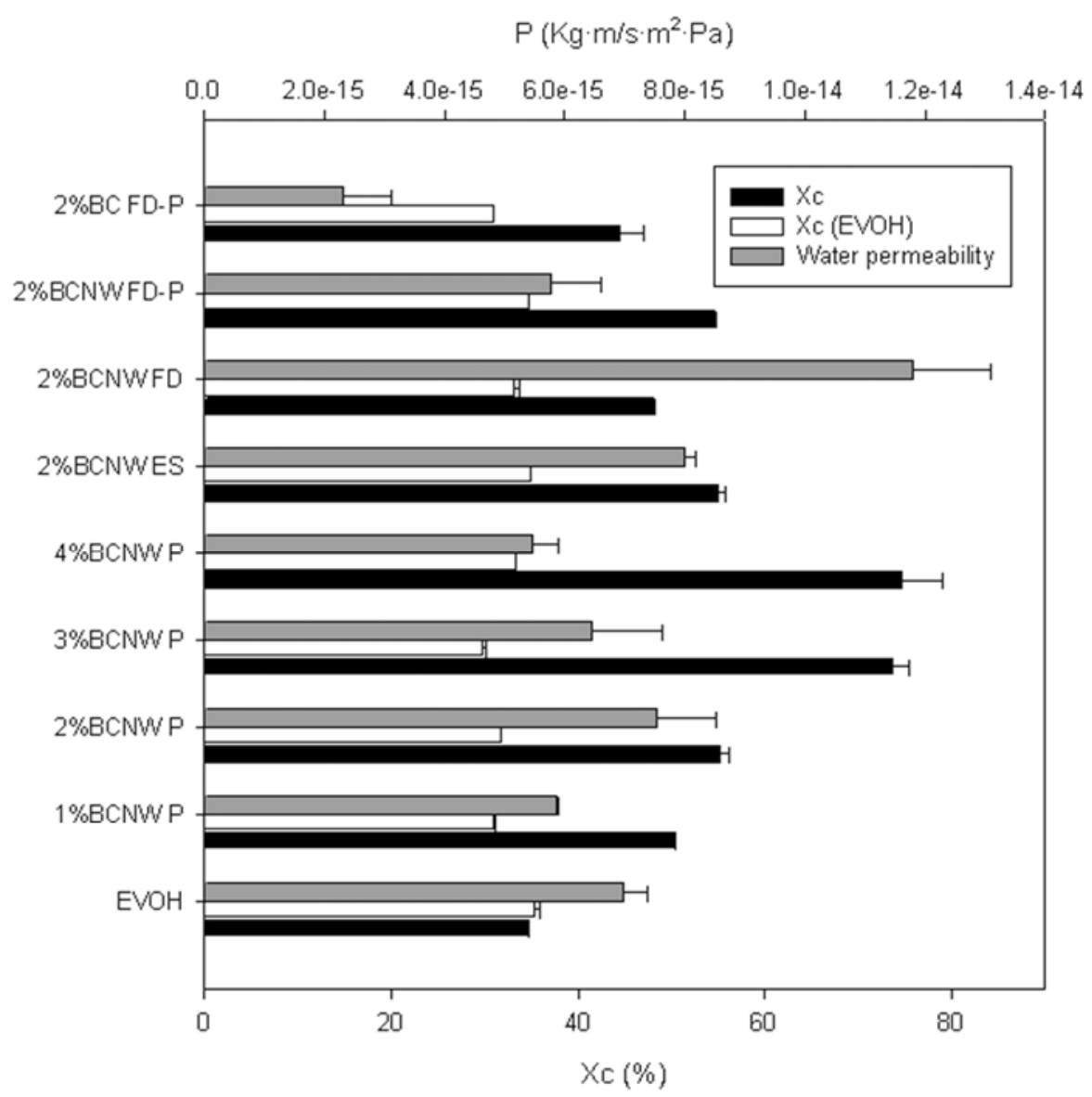

Figure 2. Crystallinity index determined from the XRD patterns (Xc) and crystallinity index of the EVOH matrix obtained by DSC analyses (Martínez-Sanz, 2013) (Xc (EVOH)) (lower axis) and water permeability (upper axis).

\subsubsection{Water permeability of the EVOH nanocomposite films containing bacterial cellulose}

Regarding the water barrier properties, water permeability and sorption experiments were carried out and the results, together with the estimated diffusion coefficient, are summarized in Table 1. The general trend when incorporating 
BCNW into the EVOH films was a slight decrease in the water permeability $(\mathrm{P})$ of the nanocomposites, although for most of the samples there was not a statistically significant effect and there were some exceptions as discussed later on. For most of the nanocomposites, the solubility (directly related to the water uptake) decreased with the incorporation of highly crystalline BCNW, since the amorphous fraction of material which was available for water sorption was reduced.

Interestingly, the incorporation of $\mathrm{BCNW}$ led to a decrease on the amorphous density of the material. This decrease was more obvious at higher nanofiller loadings and it may be related to the disruption of the strong polymer inter- and intra-chain self-association by the dispersed cellulose filler. Thus, the dispersed cellulose interacted with the hydroxyl groups of the polymer, increasing the available free volume, which is in turn filled in by the whiskers.

From the results compiled in Table 1, it clearly seems that the method of nanofiller incorporation had an important effect on the water vapour permeability of the materials. When the traditional method was used, i.e. directly melt mixing the freeze-dried nanowhiskers with EVOH pellets (cf. 2\%BCNW FD), an increase in the permeability of ca. $69 \%$ was observed, being this negative effect mainly explained by increased water diffusion through the film as a consequence of the potential preferential paths generated in areas where the filler agglomerated and by plasticization of these agglomerates. The increase in water permeability was largely avoided by improving the dispersion of the nanofiller via the novel incorporation methods. However, while remarkable reductions in water permeability of ca. $67 \%$ were detected for the $2 \%$ BC FD-P sample, the water permeability in the samples incorporating dispersed BCNW for this specific loading, i.e. $2 \% \mathrm{BCNW}$ ES, $2 \% \mathrm{BCNW} \mathrm{P}$ and $2 \% \mathrm{BCNW}$ FD-P, was not 
significantly modified. Therefore, aside from the degree of dispersion of the filler and the crystallinity of the samples, it seems that more factors come into play when it comes to the barrier performance of the nanocomposite materials. A possible explanation for these results comes again from the interactions developed between the dispersed $\mathrm{BCNW}$ and the EVOH matrix, which resulted in a decrease in the amorphous density which, at the same time, had a direct influence on the water diffusion through the films. As a consequence, the water permeability results are a combination of all the above-mentioned factors, i.e. the advantages of increased crystallinity and dispersion together with the disadvantages of the increased free volume as a consequence of the inter- and intrapolymer disruptions caused by the presence of BCNW. Furthermore, the hydrophilic character of the filler and the morphology of the same should also be taken into account for explaining the water barrier properties. Therefore, the fact that $\mathrm{BC}$ fibres were longer since they had not been digested by sulfuric acid, could also explain the improved permeability observed for this specific material. In a similar way, lower permeability has been reported for microfibrillated cellulose (MFC) films when compared to films containing CNW (Belbekhouche et al., 2011) due to entanglements of longer fibres which lead to increased tortuosity of the diffusion pathway.

Although no significant differences were detected for the permeability of the different $\mathrm{BCNW}$ concentrations incorporated through the precipitation method, a maximum permeability drop of $22 \%$ was observed for the 4 wt.- $\%$ loading. The usual behaviour which has been previously reported for PHBV and PCL matrixes incorporating cellulose microfibers, consists on decreased water barrier properties when increasing the nanofiller loading over $2 \mathrm{wt.} \%$, since higher nanofiller loadings led to agglomeration (Sanchez-Garcia et al., 2008). However, this was not the case for the nanocomposites in the present study since morphological 
observations did not show significant agglomeration of BCNW for the loadings investigated (Martínez-Sanz, 2013). It seems that the crystallinity increase observed for loadings higher than 3 wt.- $\%$ (cf. Figure 2) was responsible for a decrease in the water sorption high enough to counteract the effect of the reduction in the amorphous density of the material.

To better assess the barrier performance, experimental data were compared with the results obtained when applying a theoretical model. Maxwell (Maxwell, 1881) developed a model to describe the conductivity of a two-phase system in which permeable spheres $\left(\mathrm{P}_{\mathrm{d}}\right)$ are dispersed in a continuous permeable matrix $\left(\mathrm{P}_{\mathrm{m}}\right)$. Fricke (Fricke, 1924) extended Maxwell's model to describe the conductivity of a two-phase system in which ellipsoids with permeability $P_{d}$ are dispersed in a more permeable continuous matrix. According to this model, the permeability of the composite system (being $\Phi_{z}$ the volume fraction of the dispersed phase) can be expressed as follows (Paul \& Bucknall, 2000):

$$
P=\left(P_{m}+P_{d} \cdot F\right) /(1+F)
$$

where $\mathrm{P}$ is the permeability of the composite, $\mathrm{P}_{\mathrm{m}}$ is the permeability of the matrix and

$$
\begin{aligned}
& F=\left[\phi_{2} / 1-\phi_{2}\right] \cdot\left[1 /\left(1+(1-M) \cdot\left(P_{d} / P_{m}-1\right)\right)\right] \\
& M=\cos \theta / \sin ^{3}[\theta-1 / 2 \sin 2 \theta] \\
& \cos \theta=W / L
\end{aligned}
$$


$\mathrm{W}$ and $\mathrm{L}$ are the dimensions of the axis of the ellipsoid parallel and perpendicular, respectively, to the direction of transport and $\theta$ is in radians. The following parameters were used in equation $1: \mathrm{P}_{\mathrm{d}} \approx 0, \mathrm{P}_{\mathrm{m}}=100$, and $\mathrm{L} / \mathrm{W}$ of $5,10,30$ and 70.

In order to calculate the volume fraction $\phi$, the following expression was applied (Luo \& Daniel, 2003):

$$
\phi=\frac{w_{r} / \rho_{r}}{w_{r} / \rho_{r}+\left(1-w_{r}\right) / \rho_{m}}
$$

where $\mathrm{w}_{\mathrm{r}}$ refers to the weight fraction of the reinforcement, and $\rho_{\mathrm{r}}$ and $\rho_{\mathrm{m}}$ refer to the density of the reinforcement and the matrix, respectively. In this case, we considered $\rho_{\mathrm{EVOH}}=1.2 \mathrm{~g} / \mathrm{cm}^{3}$ (Lagaron et al., 2001) and $\rho_{\text {cellulose }}=1.6 \mathrm{~g} / \mathrm{cm}^{3}$ (Fricke, 1924).

Figure 3 plots the experimental relative permeability values and the modeling results. It was previously observed by TEM that BCNW presented an aspect ratio of approximately 30 (Martínez-Sanz, 2013). As observed in Figure 3, if considering $\mathrm{L} / \mathrm{W}$ as 30 , the experimental values were above the predicted ones. In order to estimate the barrier efficiency of the nanofiller and separating the effect of the increase in the crystallinity of the material, the permeability values were corrected by dividing them by the crystallinity of the material estimated by XRD (Sanchez-Garcia \& Lagaron, 2010a). When plotting the permeability values corrected by the crystallinity, it is observed that values were better fitted to the 
model when considering L/W as 70 . Thus, it seems that the blocking capacity of the highly crystalline BCNW is underestimated by the theoretical model. Again, it seems that the decrease in the amorphous density of the material was responsible for the increase in the permeability for loadings up to $2 \mathrm{wt.}-\%$, whereas the high crystallinity attained for higher loadings was able to counteract this negative effect, leading to a maximum permeability decrease for the 4 wt.- $\%$ BCNW nanocomposite.

Table 1. Water permeability, Water Uptake, Diffusion Coefficient, crystalline $\left(\rho_{\mathrm{C}}\right)$ and amorphous density $\left(\rho_{\mathrm{a}}\right)$ for $\mathrm{EVOH} 32$ and $\mathrm{EVOH}$ composites incorporating BC and $\mathrm{BCNW}$.

\begin{tabular}{|c|c|c|c|c|c|}
\cline { 2 - 6 } & \multicolumn{1}{c|}{$\begin{array}{c}\mathrm{P} \\
\left(\mathrm{Kg} \cdot \mathrm{m} / \mathrm{s} \cdot \mathrm{m}^{2} \cdot \mathrm{Pa}\right)\end{array}$} & $\begin{array}{c}\text { Water uptake } \\
100 \% \mathrm{RH}(\%)\end{array}$ & $\mathrm{D}\left(\mathrm{m}^{2} / \mathrm{s}\right)$ & $\begin{array}{c}\rho_{\mathrm{C}} \\
\left(\mathrm{g} / \mathrm{cm}^{3}\right)\end{array}$ & $\begin{array}{c}\rho_{\mathrm{a}} \\
\left(\mathrm{g} / \mathrm{cm}^{3}\right)\end{array}$ \\
\hline EVOH32 & ${ }^{\mathrm{b}} 6.99 \pm 0.39 \mathrm{e}^{-15}$ & ${ }^{\mathrm{cd}} 9.25 \pm 0.20$ & ${ }^{\mathrm{abc}} 1.88 \pm 0.04 \mathrm{e}^{-13}$ & 1.48 & 1.09 \\
\hline $1 \%$ BCNW P & ${ }^{\mathrm{b}} 5.88 \pm 0.01 \mathrm{e}^{-15}$ & ${ }^{\mathrm{abc}} 7.93 \pm 0.33$ & ${ }^{\mathrm{abc}} 1.86 \pm 0.08 \mathrm{e}^{-13}$ & 1.48 & 0.99 \\
\hline $2 \%$ BCNW P & ${ }^{\mathrm{b}} 7.55 \pm 0.97 \mathrm{e}^{-15}$ & ${ }^{\mathrm{bcd}} 8.62 \pm 0.43$ & ${ }^{\mathrm{bc}} 2.19 \pm 0.00 \mathrm{e}^{-13}$ & 1.49 & 0.96 \\
\hline $4 \%$ BCNW P & ${ }^{\mathrm{b}} 6.45 \pm 1.19 \mathrm{e}^{-15}$ & ${ }^{\mathrm{abc}} 7.81 \pm 0.28$ & ${ }^{\mathrm{abc}} 2.06 \pm 0.07 \mathrm{e}^{-13}$ & 1.50 & 0.74 \\
\hline $2 \%$ BCNW ES & ${ }^{\mathrm{b}} 7.99 \pm 0.18 \mathrm{e}^{-15}$ & ${ }^{\mathrm{a}} 6.99 \pm 0.94$ & ${ }^{\mathrm{cd}} 2.86 \pm 0.39 \mathrm{e}^{-13}$ & 1.51 & 0.95 \\
\hline $2 \%$ BCNW FD & ${ }^{\mathrm{c}} 11.8 \pm 0.13 \mathrm{e}^{-15}$ & ${ }^{\mathrm{ab}} 7.12 \pm 0.23$ & ${ }^{\mathrm{d}} 4.20 \pm 0.14 \mathrm{e}^{-13}$ & 1.49 & 0.99 \\
\hline F\%BCNW & ${ }^{\mathrm{b}} 5.78 \pm 0.84 \mathrm{e}^{-15}$ & ${ }^{\mathrm{d}} 10.01 \pm 0.01$ & ${ }^{\mathrm{ab}} 1.38 \pm 0.04 \mathrm{e}^{-13}$ & 1.50 & 0.95 \\
\hline $2 \%$ BC FD-P & ${ }^{\mathrm{a}} 2.32 \pm 0.79 \mathrm{e}^{-15}$ & ${ }^{\mathrm{abc}} 7.75 \pm 0.16$ & ${ }^{\mathrm{a}} 0.77 \pm 0.02 \mathrm{e}^{13}$ & 1.50 & 1.02 \\
\hline
\end{tabular}

The $a, b, c$ and $d$ letters correspond to the ANOVA statistical analysis and Tukey test of the data that indicate that with a $95 \%$ confidence level, the values are significantly different. 
The a, b, c and d letters correspond to the ANOVA statistical analysis and Tukey test of the data that indicate that with a $95 \%$ confidence level, the values are significantly different.

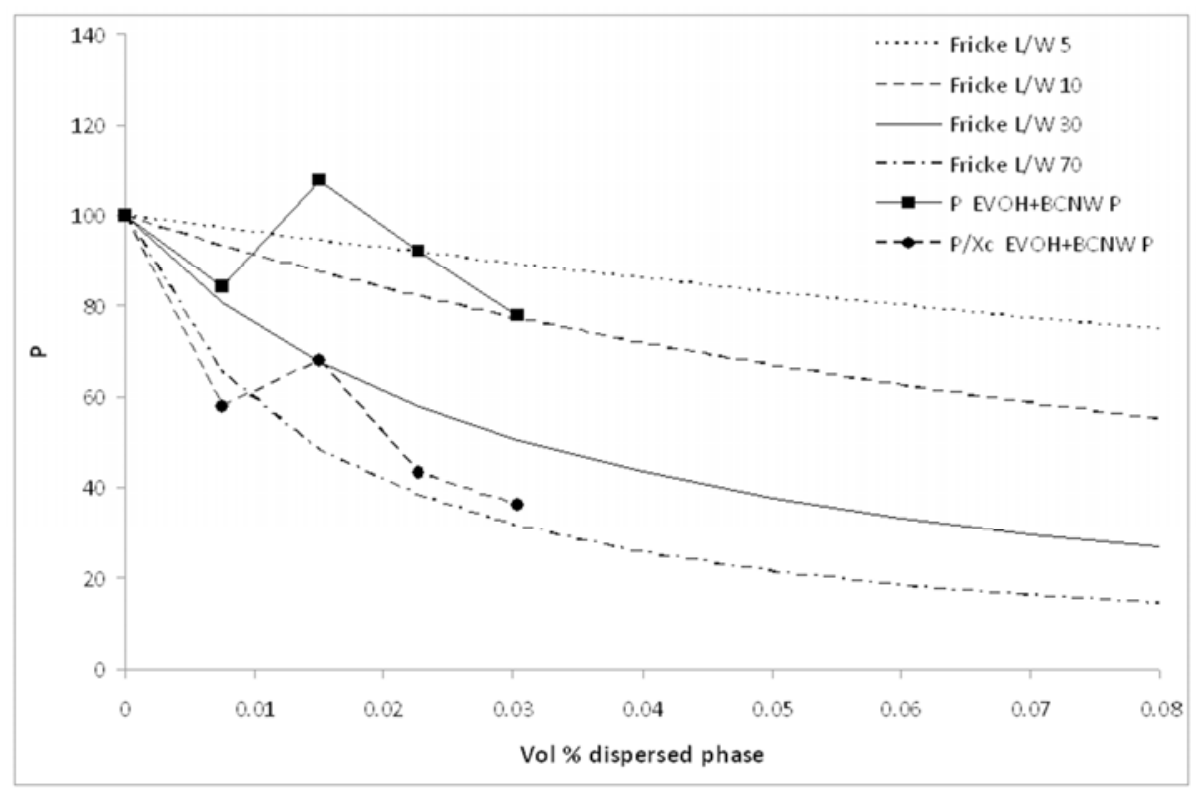

Figure 3. Permeability modelling versus volume percent of a dispersed phase with different aspect ratios L/W and the normalized experimental permeability values.

\subsubsection{Mechanical properties of the different EVOH/BC nanocomposite films}

Table 2 gathers the mechanical properties of neat EVOH and the nanocomposites thereof. From the results it can be concluded that, in general, with the addition of $\mathrm{BCNW}$, the materials become more rigid and brittle. 
For a 2 wt.- $\%$ BCNW loading, a significant increase of $80 \%$ and $18 \%$ in the tensile modulus of the material was observed for the 2\%BCNW FD-P and $2 \% \mathrm{BCNW}$ FD samples respectively, suggesting that when the filler was incorporated as a freeze-dried product, the filler-filler interactions were promoted and thus, a strong nanofiller network was responsible for the stiffening of the nanocomposites.

When comparing amongst the different composite samples containing 2 wt.$\%$ of filler, although a significant reduction in the elongation at break was observed for all of them, the greatest reduction was seen for the 2\% BCNW FD (94\% drop), 2\% BCNW FD-P (94\% drop) and 2\% BC FD-P (92\% drop) samples. It is known that the addition of reinforcing agents in polymeric materials results in a reduction of the elongation at break since they act as stress concentrating components. However, previous works found out that when strong interactions, such as hydrogen bonding, take place between the matrix and the filler, the stress concentration effect is prevented to a certain extent (George et al., 2011). These results suggest a lower interfacial interaction effect and/or poorer dispersion of the nanofiller when handling it in the form of freeze-dried material. On the other hand, and in agreement with morphology observations (Martínez-Sanz, 2013) and water permeability results, it seems that the incorporation of the $\mathrm{BCNW}$ within electrospun fibres or through precipitation from a hydrated nanofiller may be leading to improved interactions with the polymeric matrix and, hence, to a less brittle behaviour (cf. elongation at break results in Table 2).

Regarding the BCNW concentration in the samples obtained through the precipitation method, it was observed that a maximum increase of $36 \%$ and $22 \%$ in the Young's modulus and tensile strength respectively was produced for a 3 wt.-\% loading. Moreover, this concentration did not lead to a significant decrease 
in the elongation at break, while remarkable reductions were observed for the 2 wt.- $\%$ and 4 wt.- $\%$ loadings. It seems that 3 wt.- $\%$ BCNW was the optimum concentration in which both the filler-filler and the matrix-filler interactions were favoured.

It is worth to mention that the incorporation of $\mathrm{BCNW}$ led to a decrease in the energy absorbed by the material at break (i.e. toughness), but in the case of the $2 \% \mathrm{BCNW}$ ES, $3 \% \mathrm{BCNW} \mathrm{P}$ and $1 \% \mathrm{BCNW} \mathrm{P}$ this drop was minimized. It is known that the mobility of the nanofiller within the polymeric matrix and further nanoparticle alignment under applied tensile stress is essential for energy dissipation and, thus, enhanced toughness (Mirzataheri et al., 2010). Hence, it appears that a greater dispersion and mobility of the nanowhiskers was achieved in the former nanocomposites.

Previous studies have reported that the addition of cellulose whiskers resulted in a decrease in the mechanical properties due to poor interfacial adhesion between a hydrophobic matrix and the highly hydrophilic CNW (Sanchez-Garcia \& Lagaron, 2010; Siqueira et al., 2009). Nevertheless, it has also been reported that in addition to the filler-matrix adhesion, the filler-filler interactions are important for the reinforcing capacity of CNW (Oksman et al., 2006; Siqueira et al., 2009). Achieving the so-called percolation threshold, where the nanowhiskers are strongly interconnected by a $3 \mathrm{D}$ network, has been claimed as a crucial condition to obtain strong mechanical reinforcement. By using the following equation, the percolation threshold $\left(v_{k r}\right)$ can be easily estimated on the bases of the aspect ratio (Oksman et al., 2006):

$$
v_{E o}=\frac{0.7}{L / d}
$$


In the above equation, $L / d$ is the aspect ratio. For the nanocomposites incorporating $\mathrm{BCNW}$, with an experimental aspect ratio of ca. 32, the percolation threshold should lay around 2 v.-\% of BCNW. Indeed, as observed in Figure 4, a loading of $2.3 \mathrm{v} .-\%$ (corresponding to a $3 \mathrm{wt} .-\%$ ) gave rise to the optimum in the mechanical properties attained by the addition of BCNW.

Modelling of the mechanical properties using the following Halpin-Tsai equation was also carried out in order to determine the theoretical expectations (Petersson \& Oksman, 2006):

$$
E=\frac{E_{m}(1+\xi \eta \phi)}{1-\eta \phi}, \quad \eta=\frac{E_{r} / E_{m}-1}{E_{r} / E_{m}+\xi}
$$

Where $E_{m}$ and $E_{r}$ refer to the Young's modulus of the matrix and the reinforcement, respectively, $\phi$ is the volume fraction and $\xi$ is calculated from the following expression:

$$
\xi=\frac{2 \cdot \text { Length }}{\text { Thickness }}
$$

The following data were used in the calculations: $\mathrm{E}_{\mathrm{EVOH}}=1.4 \mathrm{GPa}$, $\mathrm{E}_{\text {cellulose }}=167.5 \mathrm{GPa}$ (Tashiro \& Kobayashi, 1991). The BCNW dimensions, which were determined in the first part of this work (Martínez-Sanz, 2013), were 570 x 18 $\mathrm{nm}$.

Figure 4 shows the comparison between the theoretical and experimental results for the Young's modulus. The theoretical calculations were based on fully 
dispersed systems where the filler was aligned in the longitudinal direction and had perfect interfacial adhesion to the matrix. As observed, the experimental results were clearly below the theoretical ones. In our case, the interfacial adhesion between the matrix and the filler was relatively good, as deduced from the morphological examination of the samples (Martínez-Sanz, 2013) and, thus, the results may be caused by the fact that processing by melt compounding was detrimental for the cementation of the cellulose nanowhiskers percolation network. It has been previously reported that the high polymer melt viscosity that occurs during extrusion, limits the random movement and, consequently, hinders the interconnection between CNW. As a result, the percolating structure is not easily formed and the reinforcing efficiency is lower than for nanocomposites obtained by solvent casting (Hajji et al., 1996).

It is worth drawing attention to the remarkable mechanical properties of the $3 \% \mathrm{BCNW} \mathrm{P}$ film. The increase in the elastic modulus and tensile strength as a result of the $\mathrm{BCNW}$ incorporation, indicate that this material was quite stiff and strong, and yet it was relatively ductile if compared to the other nanocomposites. 
Table 2. Young's Modulus, Tensile Strength and Elongation at Break for EVOH32 and $\mathrm{EVOH}$ composites incorporating $\mathrm{BC}$ and $\mathrm{BCNW}$.

\begin{tabular}{|c|c|c|c|c|}
\hline & $\mathrm{E}(\mathrm{GPa})$ & $\begin{array}{c}\text { Tensile strength } \\
\text { (MPa) }\end{array}$ & $\varepsilon_{\mathrm{b}}(\%)$ & Toughness (J) \\
\hline $\mathrm{EVOH}$ & ${ }^{\mathrm{a}} 1.37 \pm 0.18$ & ${ }^{\mathrm{ab}} 51.99 \pm 4.96$ & ${ }^{\mathrm{c}} 93.35 \pm 56.52$ & ${ }^{\mathrm{d}} 0.36 \pm 0.14$ \\
\hline $1 \% \mathrm{BCNW} \mathrm{P}$ & ${ }^{\mathrm{a}} 1.34 \pm 0.11$ & ${ }^{a b} 49.75 \pm 2.59$ & bc $66.13 \pm 46.34$ & ${ }^{\mathrm{bc}} 0.11 \pm 0.03$ \\
\hline $2 \% \mathrm{BCNW} P$ & ${ }^{\mathrm{ab}} 1.51 \pm 0.14$ & ${ }^{\mathrm{abc}} 53.06 \pm 3.23$ & a $11.25 \pm 5.72$ & ${ }^{\mathrm{ab}} 0.04 \pm 0.00$ \\
\hline $3 \% \mathrm{BCNW} \mathrm{P}$ & ${ }^{\mathrm{c}} 1.87 \pm 0.06$ & ${ }^{\mathrm{cd}} 63.56 \pm 1.30$ & ab $34.78 \pm 21.40$ & ${ }^{\mathrm{bc}} 0.14 \pm 0.08$ \\
\hline 4\%BCNW P & ${ }^{\mathrm{ab}} 1.54 \pm 0.11$ & ${ }^{a b c} 55.46 \pm 3.83$ & ${ }^{\mathrm{a}} 13.48 \pm 10.90$ & ${ }^{\mathrm{abc}} 0.07 \pm 0.03$ \\
\hline $\begin{array}{c}2 \% \mathrm{BCNW} \\
\mathrm{ES}\end{array}$ & ${ }^{\mathrm{ab}} 1.45 \pm 0.07$ & ${ }^{\mathrm{a}} 46.81 \pm 0.74$ & ${ }^{a b} 30.85 \pm 16.18$ & ${ }^{c} 0.16 \pm 0.05$ \\
\hline $\begin{array}{c}2 \% \mathrm{BCNW} \\
\mathrm{FD}\end{array}$ & ${ }^{b c} 1.62 \pm 0.22$ & ${ }^{b c} 56.29 \pm 10.60$ & ${ }^{\mathrm{a}} 5.48 \pm 3.31$ & ${ }^{\mathrm{a}} 0.02 \pm 0.02$ \\
\hline $\begin{array}{c}2 \% \mathrm{BCNW} \\
\text { FD-P }\end{array}$ & ${ }^{\mathrm{d}} 2.46 \pm 0.19$ & d $74.46 \pm 4.84$ & a $5.53 \pm 1.17$ & ${ }^{\mathrm{ab}} 0.02 \pm 0.00$ \\
\hline $2 \%$ BC FD-P & ${ }^{a b c} 1.63 \pm 0.11$ & ${ }^{\mathrm{ab}} 50.65 \pm 2.48$ & a $7.97 \pm 1.67$ & ${ }^{\mathrm{abc}} 0.04 \pm 0.03$ \\
\hline
\end{tabular}

The $\mathrm{a}, \mathrm{b}, \mathrm{c}$ and $\mathrm{d}$ letters correspond to the ANOVA statistical analysis and Tukey test of the data that indicate that with a $95 \%$ confidence level, the values are significantly different. 


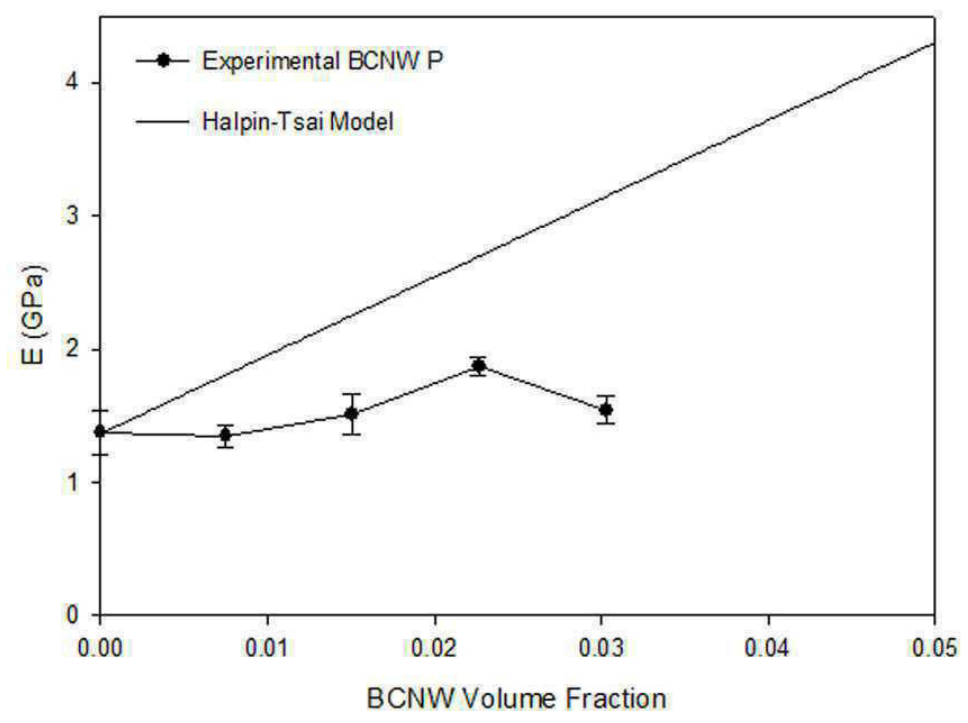

Figure 4. Experimentally measured Young's modulus for EVOH-BCNW P

nanocomposites compared to theoretical predictions by Halpin-Tsai.

\subsubsection{Thermal stability of the different EVOH/BC nanocomposite films}

Finally, the thermal stability of the nanocomposite materials was evaluated through TGA. As determined in the previous stage of this study (Martínez-Sanz, 2013), the incorporated BCNW showed a thermal stability which was improved with respect to previous results (Martínez-Sanz et al., 2011) but still, comparatively lower than that of the polymeric matrix. Table 3 summarizes the parameters determined from the TGA curves. As it can be seen, incorporation of BCNW did not have a great effect on the thermostability of the copolymer. For the samples containing 2 wt.- $\%$ BCNW, the one incorporating freeze-dried nanowhiskers presented the lowest onset degradation temperature and the widest degradation profile, which was probably caused by the lower interaction of the agglomerated filler with the matrix, which resulted in slightly decreased thermal stability of the 
nanocomposite. But even in that case, all the nanocomposites were thermally stable in the temperature range in which $\mathrm{EVOH}$ is typically processed, i.e. below $185^{\circ} \mathrm{C}$.

Table 3. TGA maximum of the weight loss first derivate $\left(T_{D}\right)$ and the corresponding peak onset and endset values for the EVOH based nanocomposites.

\begin{tabular}{|c|c|c|c|}
\cline { 2 - 4 } \multicolumn{1}{c|}{} & Onset $\mathrm{T}\left({ }^{\circ} \mathrm{C}\right)$ & $\mathrm{T}_{\mathrm{D}}\left({ }^{\circ} \mathrm{C}\right)$ & Endset $\mathrm{T}\left({ }^{\circ} \mathrm{C}\right)$ \\
\hline EVOH & 268.9 & 398.7 & 483.6 \\
\hline $2 \%$ BCNW P & 251.7 & 393.7 & 481.1 \\
\hline $3 \%$ BCNW P & 286.7 & 395.2 & 477.2 \\
\hline $4 \%$ BCNW P & 291.4 & 395.4 & 476.5 \\
\hline $2 \%$ BCNW ES & 278.4 & 395.2 & 483.6 \\
\hline $2 \%$ BCNW FD & 265.4 & 395.6 & 480.1 \\
\hline $2 \%$ BCNW FD-P & 271.9 & 394.9 & 479.7 \\
\hline $2 \%$ BC FD-P & 263.6 & 394.8 & 480.8 \\
\hline
\end{tabular}

\subsection{Nanocomposite EVOH films reinforced with plant cellulose nanowhiskers} (CNW)

\subsubsection{Effect of plant CNW addition on the crystallinity of the nanocomposite films}

In the first part of this work, it was observed that the crystallinity of plantderived CNW was lower than that of BCNW (Martínez-Sanz, 2013). Therefore, a lower increase in the overall crystallinity of films incorporating CNW would be expected when compared to the crystallinity of the films containing BCNW. Figure 5 shows the diffraction patterns of the nanocomposites incorporating $\mathrm{CNW}$. In this case, it was not possible to differentiate the contribution of cellulose 
apart from the increase in the peak at $2 \theta \sim 20^{\circ}$ which overlapped with the EVOH contribution. As seen in Figure 6, the overall crystallinity of the nanocomposites increased when raising the nanofiller loading. When comparing the incorporation method, and probably due to the greater agglomeration taking place when directly melt mixing freeze-dried CNW, the crystallinity increase was less pronounced in this specific case.

As expected, the crystallinity increase with CNW was lower than that observed for composites containing BCNW, especially for loadings higher than 2 wt.- $\%$.

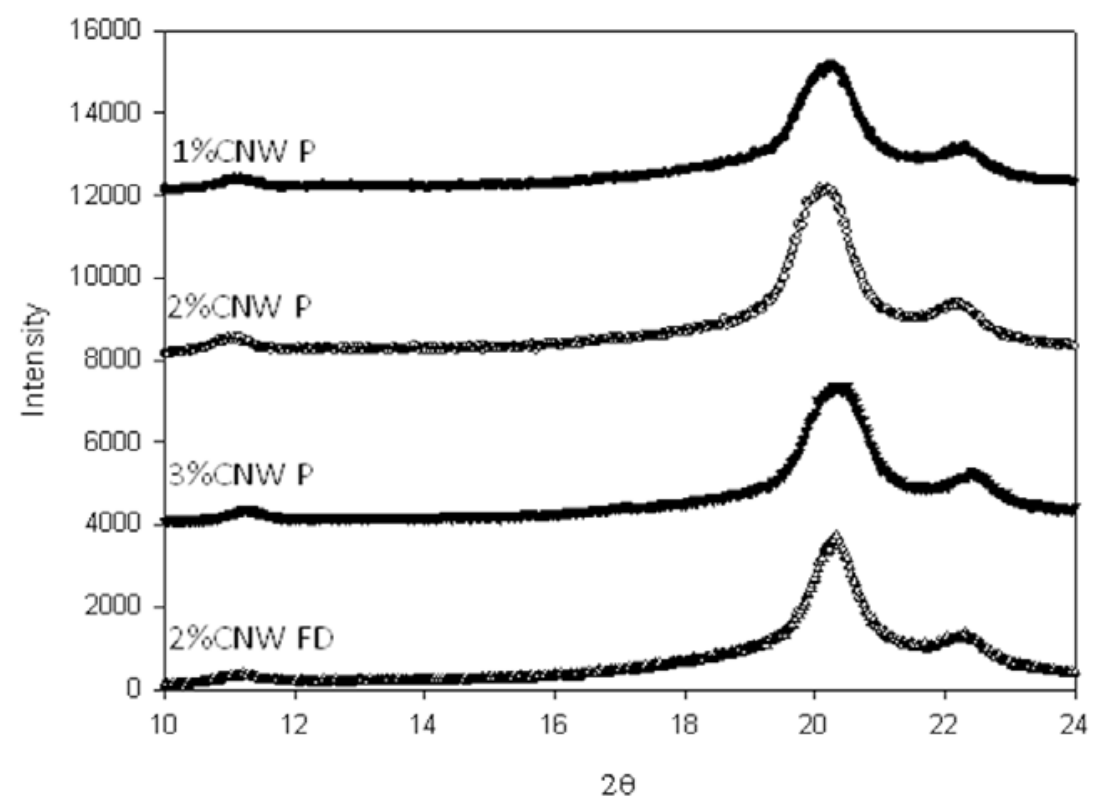

Figure 5. X-ray diffraction patterns of films containing CNW incorporated by the precipitation method and freeze-dried. 


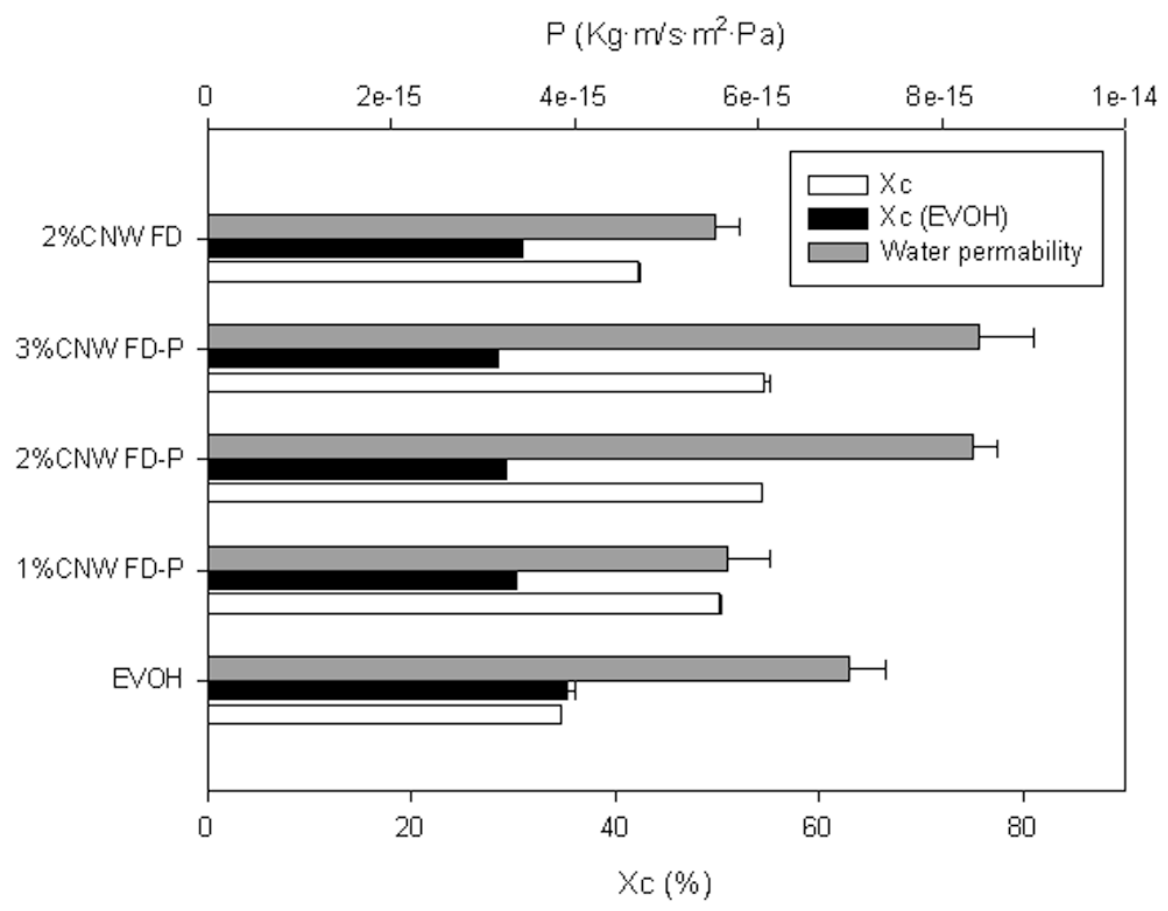

Figure 6. Crystallinity index determined from the XRD patterns $(\mathrm{Xc})$ and crystallinity index of the EVOH matrix obtained by DSC analyses (Xc (EVOH)) (lower axis) and water permeability (upper axis).

\subsubsection{Water permeability of the EVOH nanocomposite films containing plant cellulose nanowhiskers}

Table 4 gathers the water barrier properties of the nanocomposite EVOH films incorporating $\mathrm{CNW}$ as well as the crystalline and amorphous density. Just as observed with the addition of BCNW, the density of the amorphous polymer regions decreased when incorporating $\mathrm{CNW}$. For low loadings a slight decrease in the water permeability was produced, but concentrations greater than 1 wt.- $\%$ led to an increase in the water permeability with respect to that of neat EVOH. This was a result of an increase in the diffusion coefficient, which was high enough to counteract the reduction in the water solubility. In this case, the incorporation of 
freeze-dried CNW was beneficial if compared to the pre-incorporation using the precipitation method, since the latter produced a slight permeability increase. This effect might be mainly caused by a greater reduction in the diffusion coefficient for the freeze-dried $\mathrm{CNW}$, suggesting that, even though agglomeration took place to a certain extent, the resulting morphology seemed to be more favourable for blocking the water diffusion. Nevertheless, the incorporation of $\mathrm{CNW}$ did not produce a statistically significant effect on the permeability when compared to that of neat EVOH.

As observed in Figure 7, for $1 \mathrm{wt} .-\% \mathrm{CNW}$ the permeability drop was higher than expected according to the theoretical model considering an aspect ratio of approximately 12 , which corresponded to the aspect ratio previously determined for CNW (Martínez-Sanz, 2013). When further increasing the concentration of $\mathrm{CNW}$, the experimental values increased showing a completely different behaviour from the model predictions. This discrepancy between the experimental data and the model might be due to a significant agglomeration of the nanofiller when increasing the loading above $1 \mathrm{wt} . \%$. Indeed, in the first part of this work, morphological studies pointed out the fact that the degree of CNW's agglomeration was considerably increased with the CNW's loading. In addition, it was determined that higher degrees of dispersion were achieved with BCNW than with $\mathrm{CNW}$ probably as a consequence of the freeze-drying process applied to the latter ones. This was also manifested in the fact that films incorporating CNW through the precipitation method were more permeable than those containing BCNW mainly due to reduced diffusion when incorporating BCNW. On the contrary, freeze-dried CNW gave rise to lower permeability values when compared to the nanocomposite film incorporating freeze-dried BCNW. The morphology of CNW, which were shorter than BCNW, seemed to favour the blocking capacity when the nanofillers were considerably agglomerated. 
Table 4. Water permeability, Water Uptake, Diffusion Coefficient, crystalline ( $\left.\rho_{\mathrm{C}}\right)$ and amorphous density $\left(\rho_{\mathrm{a}}\right)$ for EVOH32 and EVOH composites incorporating CNW.

\begin{tabular}{|c|c|c|c|c|c|}
\cline { 2 - 6 } \multicolumn{1}{c|}{} & $\mathrm{P}\left(\mathrm{Kg} \cdot \mathrm{m} / \mathrm{s} \cdot \mathrm{m}^{2} \cdot \mathrm{Pa}\right)$ & Water uptake & $\mathrm{D}\left(\mathrm{m}^{2} / \mathrm{s}\right)$ & $\begin{array}{c}\rho_{\mathrm{C}} \\
\left(\mathrm{g} / \mathrm{cm}^{3}\right)\end{array}$ & $\begin{array}{c}\rho_{\mathrm{a}} \\
\left(\mathrm{g} / \mathrm{cm}^{3}\right)\end{array}$ \\
\hline EVOH & ${ }^{\mathrm{ab}} 6.99 \pm 0.39 \mathrm{e}^{-15}$ & ${ }^{\mathrm{a}} 9.25 \pm 0.20$ & ${ }^{\mathrm{b}} 1.88 \pm 0.04 \mathrm{e}^{-13}$ & 1.48 & 1.09 \\
\hline $1 \% \mathrm{CNW} F D-P$ & ${ }^{\mathrm{b}} 5.67 \pm 0.46 \mathrm{e}^{-15}$ & ${ }^{\mathrm{ab}} 8.90 \pm 0.50$ & ${ }^{\mathrm{a}} 1.59 \pm 0.09 \mathrm{e}^{-13}$ & 1.50 & 0.99 \\
\hline $2 \% \mathrm{CNW}$ FD-P & ${ }^{\mathrm{a}} 8.34 \pm 0.27 \mathrm{e}^{-15}$ & ${ }^{\mathrm{b}} 7.97 \pm 0.05$ & ${ }^{\mathrm{b}} 1.91 \pm 0.01 \mathrm{e}^{-13}$ & 1.49 & 0.97 \\
\hline $2 \% \mathrm{CNW}$ FD-P & ${ }^{\mathrm{a}} 8.40 \pm 0.59 \mathrm{e}^{-15}$ & ${ }^{\mathrm{ab}} 8.81 \pm 0.47$ & ${ }^{\mathrm{c}} 2.38 \pm 0.13 \mathrm{e}^{-13}$ & 1.52 & 1.04 \\
\hline
\end{tabular}

The $\mathrm{a}, \mathrm{b}$ and $\mathrm{c}$ letters correspond to the ANOVA statistical analysis and Tukey test of the data that indicate that with a $95 \%$ confidence level, the values are significantly different. 


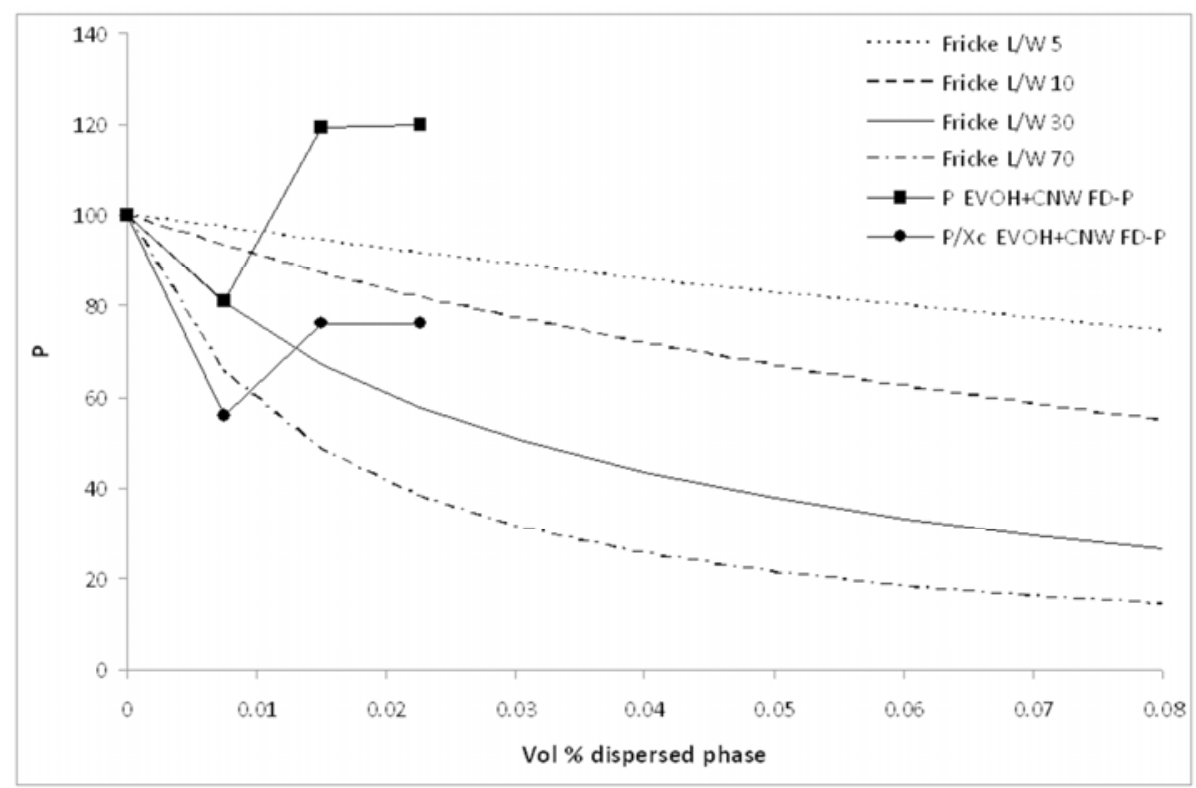

Figure 7. Permeability modelling versus volume percent of a dispersed phase with different aspect ratios $\mathrm{L} / \mathrm{W}$ and the normalized experimental permeability values.

\subsubsection{Mechanical properties of the different EVOH nanocomposite films containing plant $\mathrm{CNW}$}

Mechanical properties of CNW nanocomposites are summarized in Table 5. From these results it can be deduced that the incorporation of CNW did not lead to remarkable improvements on the mechanical properties of the EVOH films. In general, greater tensile modulus, tensile strength and decreased elongation at break were observed when increasing the CNW loading. An increase of 3\%, 10.2\% and $10.2 \%$ in the elastic modulus was observed for the nanocomposites containing 1,2 and 3 wt.- $\% \mathrm{CNW}$, respectively. For the same samples, a decrease of $1.6 \%$ and increases of $0.7 \%$ and $7.8 \%$ were produced in the tensile strength. Therefore, the materials became more rigid and stronger with the incorporation of CNW through the precipitation method. At the same time, the ductility of the composites was 
gradually diminished, first increasing a 5.3\% for the $1 \mathrm{wt} .-\%$ specimen and, then, a reduction in the elongation at break of $22.2 \%$ and $75.9 \%$ was observed for the samples incorporating 2 and 3 wt.- $\% \mathrm{CNW}$. In any case, owing to the great variability of data, concentrations lower than $3 \mathrm{wt.}$ - $\%$ did not produce statistically significant improvements.

When incorporating freeze-dried $\mathrm{CNW}$, the material became less ductile as compared to the $2 \%$ CNW FD-P sample due to the lower degree of dispersion and lower matrix-filler adhesion attained in the former one.

The material was significantly stiffer and more brittle when incorporating freeze-dried BCNW through the precipitation method than with CNW, suggesting that stronger filler-filler interactions are developed in the case of BCNW. On the other hand, no significant changes were observed for the direct melt mixing of freeze-dried CNW and BCNW. 
Table 5. Young's Modulus, Tensile Strength and Elongation at Break for EVOH32 and $\mathrm{EVOH}$ composites incorporating $\mathrm{BC}$ and $\mathrm{BCNW}$.

\begin{tabular}{|c|c|c|c|c|}
\cline { 2 - 5 } \multicolumn{1}{c|}{} & $\mathrm{E}(\mathrm{GPa})$ & $\begin{array}{c}\text { Tensile strength } \\
(\mathrm{MPa})\end{array}$ & $\mathrm{E}_{\mathrm{b}}(\%)$ & Toughness $(\mathrm{J})$ \\
\hline EVOH & ${ }^{\mathrm{a}} 1.37 \pm 0.18$ & ${ }^{\mathrm{a}} 51.99 \pm 4.96$ & ${ }^{\mathrm{a}} 93.35 \pm 56.52$ & $0.36 \pm 0.14$ \\
\hline $1 \% \mathrm{CNW}$ FD-P & ${ }^{\mathrm{ab}} 1.41 \pm 0.11$ & ${ }^{\mathrm{a}} 51.16 \pm 2.73$ & ${ }^{\mathrm{a}} 98.67 \pm 61.85$ & $0.27 \pm 0.18$ \\
\hline $2 \% \mathrm{CNW}$ FD-P & ${ }^{\mathrm{ab}} 1.51 \pm 0.05$ & ${ }^{\mathrm{a}} 52.34 \pm 1.74$ & ${ }^{\mathrm{a}} 72.67 \pm 14.19$ & $0.22 \pm 0.04$ \\
\hline $3 \% \mathrm{CNW}$ FD-P & ${ }^{\mathrm{b}} 1.65 \pm 0.09$ & ${ }^{\mathrm{a}} 56.36 \pm 4.66$ & ${ }^{\mathrm{a}} 22.50 \pm 17.33$ & $0.08 \pm 0.04$ \\
\hline $2 \% \mathrm{CNW} F D$ & ${ }^{\mathrm{ab}} 1.54 \pm 0.08$ & ${ }^{\mathrm{a}} 56.06 \pm 3.19$ & ${ }^{\mathrm{a}} 13.50 \pm 6.61$ & $0.07 \pm 0.04$ \\
\hline
\end{tabular}

The $\mathrm{a}$ and $\mathrm{b}$ letters correspond to the ANOVA statistical analysis and Tukey test

of the data that indicate that with a $95 \%$ confidence level, the values are significantly different.

The elastic modulus experimental values versus the theoretical ones obtained by applying the Halpin-Tsai model are shown in Figure 8. For the nanocomposites incorporating $\mathrm{CNW}$, with an experimental aspect ratio of ca. 12, the percolation threshold should lay around 6 v.- $\%$ of CNW. In this Figure it is observed how the elastic modulus increases with the $\mathrm{CNW}$ loading, but even the maximum $\mathrm{CNW}$ loading tested, i.e. $2.3 \mathrm{v} .-\%$, is far below the percolation threshold and thus it might be possible to further enhance the mechanical properties with higher nanofiller loadings. In the same way that with $\mathrm{BCNW}$, the experimental values were found below the ones predicted by the model, which in this case may be explained by a combination of a certain degree of nanofiller agglomeration and to the fact that the loadings were below the percolation threshold. 


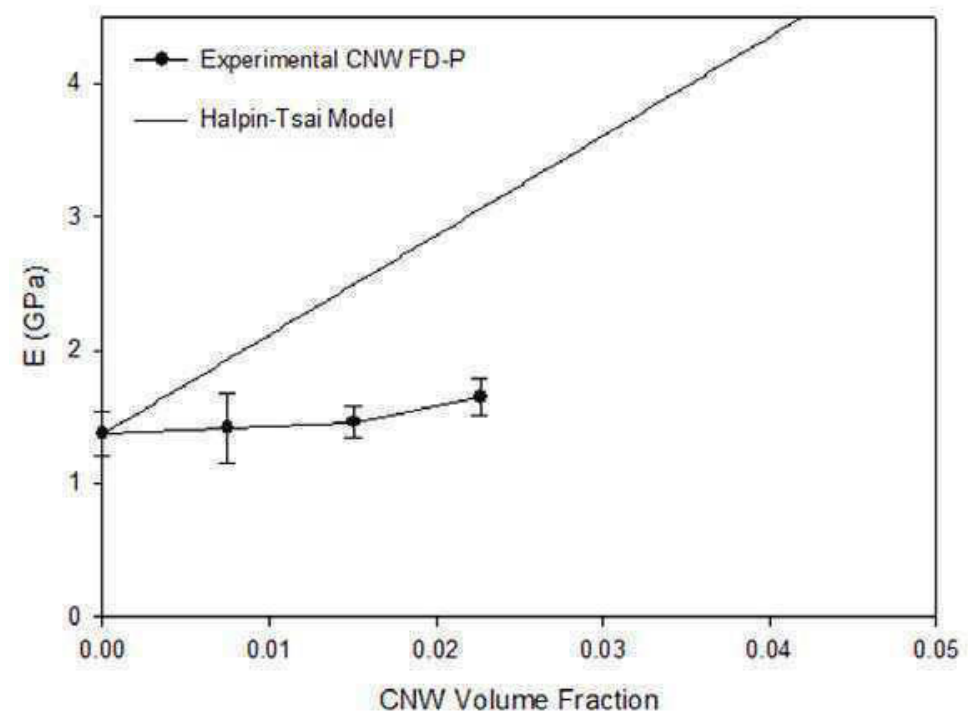

Figure 8. Experimentally measured Young's modulus for EVOH-CNW FD-P nanocomposites compared to theoretical predictions by Halpin-Tsai.

\subsubsection{Thermal stability of the different EVOH/plant CNW nanocomposite films}

Finally, the effect of the CNW's incorporation on the thermal stability of the nanocomposite films was evaluated by TGA. As observed for BCNW, the degree of dispersion of the nanofiller seemed to be related to the degradation profile and thus, poorer dispersion of the filler led to broader degradation range.

From Table 6 it can be observed that degradation temperatures tended to be slightly lower for CNW loaded composites than for those containing BCNW, which is in agreement with the lower thermal stability of CNW previously assessed (Martínez-Sanz, 2013). But again, these nanocomposites showed degradation profiles similar to the ones from neat $\mathrm{EVOH}$ and far above the processing window of EVOH materials. 
Table 6. TGA maximum of the weight loss first derivate $\left(T_{D}\right)$ and the corresponding peak onset and endset values for the EVOH based nanocomposites.

\begin{tabular}{|c|c|c|c|}
\cline { 2 - 4 } \multicolumn{1}{c|}{} & Onset $\mathrm{T}\left({ }^{\circ} \mathrm{C}\right)$ & $\mathrm{T}_{\mathrm{D}}\left({ }^{\circ} \mathrm{C}\right)$ & Endset $\mathrm{T}\left({ }^{\circ} \mathrm{C}\right)$ \\
\hline EVOH & 268.9 & 398.7 & 483.6 \\
\hline 1\%CNW Precip & 287.9 & 377.1 & 478.3 \\
\hline $3 \% \mathrm{CNW}$ Precip & 303.3 & 395.8 & 475.1 \\
\hline $2 \% \mathrm{CNW}$ Precip & 305.6 & 394.9 & 473.7 \\
\hline
\end{tabular}

\section{CONCLUSIONS}

In this work, EVOH/cellulose nanowhiskers composite films were produced by the melt compounding technique and the effects of the cellulose source, nanofiller concentration and pre-incorporation method in the crystallinity, water vapour permeability, mechanical properties and thermal stability of the generated materials were investigated. The crystallinity index of the material was found to increase with improved dispersion and nanofiller loadings and it was also higher for the more crystalline BCNW than for plant CNW. Water permeability was strongly influenced by the filler incorporation method. Therefore, while the agglomeration observed in the films directly incorporating freeze-dried BCNW was detrimental for the nanocomposite barrier properties, increasing the tortuosity of the diffusion pathway by incorporating fibre entanglements, led to a reduction of ca. $67 \%$ for the $2 \%$ BC FD-P sample. However, even though the proposed preincorporation methods led to highly dispersed nanofillers, no significant improvements were observed in the water barrier properties of these materials, which could be explained by the increase in the amorphous density caused by the 
presence of the dispersed fillers, which counteracted the lower water sorption caused by the increase in the overall crystallinity generated.

The mechanical properties were related to the filler-filler and matrix-filler interactions, which were modified by the incorporation method. In this case, the nanofiller loading was an important parameter since reaching the percolation threshold, which corresponded to $3 \%$ wt.- $\% \mathrm{BCNW}$, allowed the production of nanocomposites with increased elastic modulus and tensile strength but still maintaining a relatively ductile behaviour. The incorporation of BCNW through electrospun fibres resulted in nanocomposites with a high dispersion level but, the selected loading was not optimal for the formation of the nanofiller percolation network. As a result, the material did not show any significant improvement on the mechanical and barrier properties. The traditional method of directly incorporating freeze-dried $\mathrm{BCNW}$, was also detrimental for the mechanical properties, as the prevalence of filler-filler interactions due to agglomeration and poor interfacial addition led to a rigid and fragile material. When incorporating plant $\mathrm{CNW}$, the barrier and mechanical properties were not significantly modified, probably due to the fact that greater loadings are required for reaching the percolation threshold. Nevertheless, the incorporation of freeze-dried material seemed to favour the blocking capacity of CNW, which was also higher than for freeze-dried BCNW. Finally, the thermal stability of all the developed EVOH-based materials was high enough for melt processing and was not significantly reduced upon addition of the different cellulose fillers. 


\section{REFERENCES}

Aktzi, N., Nir, Y., Wang, D., Narkis, M., \& Siegmann, A. (2001). EVOH/clay nanocomposites produced by melt processing. Polymer Composites, 22(5), 710720 .

Belbekhouche, S., Bras, J., Siqueira, G., Chappey, C., Lebrun, L., Khelifi, B., Marais, S., \& Dufresne, A. (2011). Water sorption behavior and gas barrier properties of cellulose whiskers and microfibrils films. Carbohydrate Polymers, 83(4), 1740-1748.

Bondeson, D., \& Oksman, K. (2007). Polylactic acid/cellulose whisker nanocomposites modified by polyvinyl alcohol. Composites Part A: Applied Science and Manufacturing, 38(12), 2486-2492.

Cabedo, L., Giménez, E., Lagaron, J. M., Gavara, R., \& Saura, J. J. (2004). Development of EVOH-kaolinite nanocomposites. Polymer, 45(15), 5233-5238.

Fernández, A., Sánchez, M. D., Ankerfors, M., \& Lagaron, J. M. (2008). Effects of ionizing radiation in ethylene-vinyl alcohol copolymers and in composites containing microfibrillated cellulose. Journal of Applied Polymer Science, 109(1), 126-134.

Franco-Urquiza, E., Perez, J. G., Sánchez-Soto, M., Santana, O. O., \& Maspoch, M. L. (2010). The effect of organo-modifier on the structure and properties of poly[ethylene-(vinyl alcohol)]/organo-modified montmorillonite composites. Polymer International, 59(6), 778-786.

Fricke, H. (1924). A mathematical treatment of the electric conductivity and capacity of disperse systems I. The electric conductivity of a suspension of homogeneous spheroids. Physical Review, 24(5), 575-587.

George, J., Ramana, K. V., Bawa, A. S., \& Siddaramaiah (2011). Bacterial cellulose nanocrystals exhibiting high thermal stability and their polymer nanocomposites. International Journal of Biological Macromolecules, 48(1), 5057.

Hajji, P., Cavaille, J. Y., Favier, V., Gauthier, C., \& Vigier, G. (1996). Tensile behavior of nanocomposites from latex and cellulose whiskers. Polymer Composites, 17(4), 612-619. 
Jiang, L., Morelius, E., Zhang, J., Wolcott, M., \& Holbery, J. (2008). Study of the poly(3-hydroxybutyrate-co-3-hydroxyvalerate)/cellulose nanowhisker composites prepared by solution casting and melt processing. Journal of Composite Materials, 42(24), 2629-2645.

Lagaron, J. M., Giménez, E., Altava, B., Del-Valle, V., \& Gavara, R. (2003). Characterization of extruded ethylene-vinyl alcohol copolymer based barrier blends with interest in food packaging applications. Macromolecular Symposia, 198, 473482 .

Lagaron, J. M., Powell, A. K., \& Bonner, G. (2001). Permeation of water, methanol, fuel and alcohol-containing fuels in high-barrier ethylene-vinyl alcohol copolymer. Polymer Testing, 20(5), 569-577.

López-Rubio, A., Lagaron, J. M., Giménez, E., Cava, D., Hernandez-Muñoz, P., Yamamoto, T., \& Gavara, R. (2003). Morphological alterations induced by temperature and humidity in ethylene-vinyl alcohol copolymers. Macromolecules, 36(25), 9467-9476.

Luo, J. J., \& Daniel, I. M. (2003). Characterization and modeling of mechanical behavior of polymer/clay nanocomposites. Composites Science and Technology, 63(11), 1607-1616.

Martínez-Sanz, M., Olsson, R. T., Lopez-Rubio, A., \& Lagaron, J. M. (2011). Development of electrospun EVOH fibres reinforced with bacterial cellulose nanowhiskers. Part I: Characterization and method optimization. Cellulose, 18(2), 335-347.

Martínez-Sanz, M., Olsson, R., Lopez-Rubio, A., \& Lagaron, J. (2012). Development of Bacterial Cellulose Nanowhiskers Reinforced EVOH Composites by Electrospinning. Journal of Applied Polymer Science, 124(2), 1398-1408.

Martínez-Sanz, M. L.-R., A.; Lagaron, J. (2013). Nanocomposites of ethylene vinyl alcohol copolymer with thermally resistant cellulose nanowhiskers by melt compounding (I): Morphology and thermal properties. Journal of Applied Polymer Science, 128(5), 2666-2678.

Maxwell, J. C. (1881). A Treatise on Electricity and Magnetism 
Mirzataheri, M., Atai, M., \& Mahdavian, A. R. (2010). Physical and mechanical properties of nanocomposite barrier film containing encapsulated nanoclay. Journal of Applied Polymer Science, 118(6), 3284-3291.

Moharram, M. A., \& Mahmoud, O. M. (2007). X-Ray diffraction methods in the study of the effect of microwave heating on the transformation of cellulose $\mathrm{i}$ into cellulose II during mercerization. Journal of Applied Polymer Science, 105(5), 2978-2983.

O'Sullivan, A. C. (1997). Cellulose: The structure slowly unravels. Cellulose, 4(3), 173-207.

Oksman, K., Mathew, A. P., Bondeson, D., \& Kvien, I. (2006). Manufacturing process of cellulose whiskers/polylactic acid nanocomposites. Composites Science and Technology, 66(15), 2776-2784.

Olsson, R. T., Kraemer, R., Lopez-Rubio, A., Torres-Giner, S., Ocio, M. J., \& Lagaron, J. M. (2010). Extraction of microfibrils from bacterial cellulose networks for electrospinning of anisotropic biohybrid fiber yarns. Macromolecules, 43(9), 4201-4209.

Paul, D. R., \& Bucknall, C. B. (2000). Polymer Blends. New York: Wiley InterScience.

Peresin, M. S., Habibi, Y., Zoppe, J. O., Pawlak, J. J., \& Rojas, O. J. (2010). Nanofiber composites of polyvinyl alcohol and cellulose nanocrystals: Manufacture and characterization. Biomacromolecules, 11(3), 674-681.

Petersson, L., \& Oksman, K. (2006). Biopolymer based nanocomposites: Comparing layered silicates and microcrystalline cellulose as nanoreinforcement Composites Science and Technology, 66(13), 2187-2196.

Rojas, O. J., Montero, G. A., \& Habibi, Y. (2009). Electrospun nanocomposites from polystyrene loaded with cellulose nanowhiskers. Journal of Applied Polymer Science, 113(2), 927-935.

Sanchez-Garcia, M. D., Gimenez, E., \& Lagaron, J. M. (2008). Morphology and barrier properties of solvent cast composites of thermoplastic biopolymers and purified cellulose fibers. Carbohydrate Polymers, 71(2), 235-244. 
Sanchez-Garcia, M. D., Hilliou, L., \& Lagaron, J. M. (2010). Morphology and water barrier properties of nanobiocomposites of $\hat{\mathrm{I}}^{\circ} / \mathrm{l}$-hybrid carrageenan and cellulose nanowhiskers. Journal of Agricultural and Food Chemistry, 58(24), 12847-12857.

Sanchez-Garcia, M. D., \& Lagaron, J. M. (2010). On the use of plant cellulose nanowhiskers to enhance the barrier properties of polylactic acid. Cellulose, 17(5), 987-1004.

Siqueira, G., Bras, J., \& Dufresne, A. (2009). Cellulose whiskers versus microfibrils: Influence of the nature of the nanoparticle and its surface functionalization on the thermal and mechanical properties of nanocomposites. Biomacromolecules, 10(2), 425-432.

Tashiro, K., \& Kobayashi, M. (1991). Theoretical evaluation of three-dimensional elastic constants of native and regenerated celluloses: role of hydrogen bonds. Polymer, 32(8), 1516-1526.

Wang, N., Ding, E., \& Cheng, R. (2007). Thermal degradation behaviors of spherical cellulose nanocrystals with sulfate groups. Polymer, 48(12), 3486-3493. 



\section{Chapter VI}

\section{DISPERSING BACTERIAL CELLULOSE NANOWHISKERS IN POLYLACTIDES VIA ELECTROHYDRODYNAMIC PROCESSING}

Journal of Polymers and the Environment, under review

Marta Martínez Sanz, Amparo López Rubio, José María Lagarón

Novel Materials and Nanotechnology Group, IATA, CSIC. Avd. Agustín

Escardino, 7, 46980. Paterna, Valencia. Spain 



\begin{abstract}
In the present study, hybrid electrospun polylactide (PLA) fibres reinforced with highly dispersed crystalline bacterial cellulose nanowhiskers (BCNW) in solution concentrations up to 15 wt. $-\%$ were developed and characterized. The overall aim was to encapsulate dispersed BCNW in fibres to be later re-dispersed in virgin PLA by melt compounding. Initially, the suitability of three different solvents (HFP, acetone-chloroform and chloroform/PEG) for fibre production was evaluated and solutions containing 5 wt.- $\%$ BCNW were used to generate electrospun hybrid PLA fibres. These fibres presented a homogeneous morphology, as assessed by SEM, and TEM images demonstrated that BCNW were well distributed along the fibres. DSC analyses showed that the incorporation of polyethylene glycol (PEG) into the fibres resulted in a $T_{g}$ drop due to a plasticization effect and decreased thermal stability as a result of low interactions between the matrix and the BCNW. Subsequently, fibres were produced from the selected solutions (HFP and acetone-chloroform) containing up to 15 wt.- $\%$ $\mathrm{BCNW}$. As a result of the great increase in the viscosity of the solutions, lower solids contents were required, leading to a better dispersion and incorporation degree of BCNW within the fibres. HFP was found to be a more suitable solvent, since higher incorporation levels were estimated by XRD and improved matrixfiller interactions were suggested by a slight increase in the $T_{g}$ of the fibres.
\end{abstract}

Keywords: Bacterial cellulose, Nanowhiskers, Electrospinning, Poly(lactic acid), Fibres. 


\section{INTRODUCTION}

Electrospinning is a simple and versatile method to produce continuous polymer fibres with diameters in the sub-micron range, presenting a large surface to volume ratio, through the action of an external electric field applied between two electrodes and imposed on a polymer solution or melt. The attained fibres have a wide variety of applications, such as tissue engineering scaffolds (Jeong et al., 2010), wound dressings (Cai et al., 2010), textiles (Schreuder-Gibson et al., 2002) and electronic devices (Liu et al., 2004). More recently, this technique has been applied in the nanocomposites field (Ji et al., 2006; Martínez-Sanz et al., 2011b; Olsson et al., 2010; Peresin et al., 2010) since it allows the production of hybrid fibres incorporating nanofillers with interesting properties. In addition, the use of biopolymers such as polylactides (PLA) and polyhydroxyalkanoates (PHAs) for the production of electrospun biofibres is also attracting great interest, especially for applications in the biomedical field (Kim et al., 2003; Ying et al., 2008; Zeng et al., 2004), although these biomaterials have also a great potential for the development of biodegradable packages.

PLA is a biodegradable, aliphatic polyester produced from L- and D-lactic acid, which can be derived from fermentation of corn starch (Lunt, 1998). Furthermore, it is suitable for electrospinning and several works have previously reported the successful production of submicron PLA fibres (Kim et al., 2003; Zeng et al., 2004). Moreover, a wide variety of materials have been incorporated into PLA fibres in order to achieve the properties required for specific applications. Some examples include PLA fibres for controlled release of antibiotics (Xu et al., 2010), PLA containing silver nanoparticles for obtaining fibres with antimicrobial properties (Kim et al., 2010) and PLA fibres with 
conductive properties through the incorporation of polyaniline (PANI) (Abdul Rahman et al., 2010).

Cellulose nanowhiskers (CNW) represent an interesting nanoreinforcing agent for PLA materials. Cellulose is one of the most abundant biopolymers found in nature and it can be extracted from plants and algae. Additionally, it can be synthesized by some bacterial species, such as Gluconacetobacter xylinus, which in a culture medium rich in polysaccharides are able to produce a layer of nearly pure bacterial cellulose (BC). Compared with plant derived cellulose (PC), BC shows a finer web-like network structure, higher water holding capacity and higher crystallinity (Iguchi et al., 2000; Wan et al., 2007). By subjecting BC to acid hydrolysis, it is possible to obtain cellulose nanowhiskers (BCNW) presenting a highly crystalline structure (Martínez-Sanz et al., 2011a), with several micrometres in length and a width of 5-50 nm (De Souza Lima \& Borsali, 2004; Hirai et al., 2009), which have great potential for reinforcing electrospun polymeric fibres. Electrospinning has been investigated for the incorporation of BCNW into poly(ethylene oxide) (PEO) (Park et al., 2007), poly(methyl methacrylate) (PMMA) (Olsson et al., 2010) and ethylene-vinyl alcohol (EVOH) copolymers (Martínez-Sanz et al., 2011b; Martínez-Sanz et al., 2012). One of the main issues in the production of these fibres is to attain a good dispersion of the nanofiller within the matrix. The choice of a solvent which is suitable for both the polymeric matrix and the nano-additive, as well as the physical state of the nanowhiskers, i.e. freeze-dried or hydrated, are key factors for their optimal incorporation and dispersion within the matrix. Due to strong hydrogen bonding, it is very difficult to re-disperse cellulose nanocrystals after subjecting them to a freeze-drying process and it has been demonstrated that the use of BCNW in a partially hydrated state resulted in a more efficient incorporation into EVOH electrospun fibres (Martínez-Sanz et al., 2011b). PLA fibres incorporating plant 
cellulose nanowhiskers with an aspect ratio of ca. 14, previously freeze-dried and re-dispersed in DMF have been reported (Xiang et al., 2009). In this case, it was observed that CNW were distributed mainly on the surface of the fibres. Recently, the production of PLA-BCNW electrospun fibres from solutions in DMF/THF was reported (Liu et al., 2012). For that particular solvent system it was possible to produce electrospun structures with $\mathrm{BCNW}$ concentrations up to $7.5 \mathrm{wt} .-\%$, which was considerably lower than the loading achieved for the optimized solvent system used throughout the present work, i.e. 15 wt.-\% BCNW. Moreover, the dispersion of $\mathrm{BCNW}$ within the electrospun fibres was not investigated. The incorporation of $\mathrm{BCNW}$ was confirmed by the observation of the $-\mathrm{OH}$ band characteristic from cellulose in the FT-IR spectra and by the appearance of the 200 crystalline plane from cellulose in XRD diffractograms, although the degree of BCNW incorporation was not determined by any of these methods. The BCNW filler was claimed to exhibit a nucleating effect since it reduced the cold crystallization temperature of PLA. The glass transition temperature of hybrid fibres was not altered, therefore indicating that BCNW did not have a stiffening effect probably due to the lack of strong interactions being developed between the matrix and the nanofiller.

The present work reports on the production, characterization and optimization of electrospun PLA fibres incorporating BCNW. The method for incorporating the BCNW was optimized in order to improve the filler dispersion in the PLA electrospun fibres and to maximize performance. For that purpose, three different solvents were evaluated and the possibility of using freeze-dried BCNW was also studied. Once the optimum conditions were established, the degree of BCNW effectively incorporated into the fibres was estimated when higher nanofiller loadings were intended. The morphology, thermal properties and thermostability of hybrid fibres were examined and compared to the pure PLA fibres. The high 
incorporation of BCNW and great dispersion within PLA fibres achieved in the present work make the optimized hybrid fibres suitable for the production of nanocomposite films with highly dispersed $\mathrm{BCNW}$ by melt compounding. 


\section{MATERIALS AND METHODS}

\subsection{Materials}

The semicrystalline polylactide (PLA) used was a film extrusion grade produced by Natureworks (with a D-isomer content of approximately $2 \%$ ). The molecular weight had a number-average molecular weight $\left(M_{n}\right)$ of ca. 130,000 $\mathrm{g} / \mathrm{mol}$, and the weight average molecular weight $\left(\mathrm{M}_{\mathrm{w}}\right)$ was ca. $150,000 \mathrm{~g} / \mathrm{mol}$ as reported by the manufacturer.

Sulphuric acid 96\%, acetone 99.5\% and chloroform were purchased from Panreac (Barcelona, Spain). Both 1,1,1,3,3,3-Hexafluoro-2-propanol (HFP) and polyethylene glycol 900 (PEG) were purchased from Fluka (Germany).

\subsection{Preparation of bacterial cellulose mats}

The bacterial strain Gluconacetobacter xylinus 7351, obtained from the Spanish type culture collection (CECT) was incubated in a static culture medium composed of $20 \mathrm{~g}$ glucose, $5 \mathrm{~g}$ yeast-extract, $1.15 \mathrm{~g}$ citric acid, $5.7 \mathrm{~g} \mathrm{MgSO}_{4} \cdot 7 \mathrm{H}_{2} \mathrm{O}$ and $12.25 \mathrm{~g}$ buffered peptone water, per litre of water, at $30^{\circ} \mathrm{C}$. The cells were precultured in a test tube containing $5 \mathrm{ml}$ of media and later transferred and scaled up to a bigger reactor of 201 at BioInicia S.L., Paterna (Spain). Several layers of cellulose obtained using the previously described procedure were thus supplied. The received bacterial cellulose pellicles, about $5 \mathrm{~cm}$ thick, were cut into small pieces (ca. $2 \times 2 \mathrm{~cm}^{2}$ ). These pieces were boiled repeated times in distilled water and then boiled in an aqueous solution of $10 \%(\mathrm{v} / \mathrm{v}) \mathrm{NaOH}$ (Panreac Quimica) in order to remove bacterial cells and the absorbed culture media. Finally, the $\mathrm{pH}$ was lowered to 7 by boiling in distilled water several times. 


\subsection{Preparation of bacterial cellulose nanowhiskers}

Once neutral $\mathrm{pH}$ was reached, bacterial cellulose pellicles were ground in a blender and the gel-like material was then compressed in order to remove most of the absorbed water. The dried material was then treated with $301 \mathrm{~mL}$ sulphuric acid/L water, in a cellulose/acid ratio of approximately $7 \mathrm{~g} / \mathrm{L}$, at $50^{\circ} \mathrm{C}$ for three days until a homogeneous solution was obtained. The cellulose nanowhiskers were obtained as a white precipitate after several centrifugation and washing cycles at $12,500 \mathrm{rpm}$ and $15^{\circ} \mathrm{C}$ for 20 minutes. After that, the material was resuspended in deionised water and neutralized with sodium hydroxide until neutral $\mathrm{pH}$ and subsequently centrifuged to obtain the final product as a partially hydrated precipitate. The product was kept refrigerated and one fraction was freeze-dried for further analyses.

Another fraction of the material was solvent exchanged into acetone and chloroform. The water of the partially hydrated precipitate was replaced by acetone by applying several centrifugation cycles in which the supernatant was removed and replaced with acetone. After evaporation of acetone, the BCNW concentration in the attained precipitate was determined as $2.4 \mathrm{wt} .-\%$.

Additionally, one fraction of this product was subjected to the same exchange process as just described but, in this case, acetone was replaced by chloroform. The concentration of BCNW after evaporating the chloroform was 1.2 wt.- $\%$.

\subsection{Electrospinning}

Three different solvents were evaluated for the production of PLA fibres, i.e. chloroform, acetone/chloroform 60/40 (v/v) and 1,1,1,3,3,3-Hexafluoro-2propanol (HFP). PLA pellets were added to the solvent and stirred at $40^{\circ} \mathrm{C}$ for obtaining 6 wt.- $\%, 8$ wt.- $\%$ and 10 wt.- $\%$ solutions. In the case of chloroform, the 
addition of 20 wt.- $\%$ of PEG (with respect to the total solids content) was required to improve the morphology of the electrospun fibres.

A total solids content of 8 wt.- $\%$ was selected as the optimum for the incorporation of BCNW into PLA fibres. Suspensions of 5 wt.-\% BCNW regarding the PLA weight were prepared by dispersing partially hydrated BCNW into HFP and solvent-exchanged BCNW into chloroform and acetone/chloroform. $\mathrm{BCNW}$ were dispersed in the solvent by applying homogenization (Ultra-turrax) for 2 minutes and sonication for 30 seconds and were then stirred with the PLA at $40^{\circ} \mathrm{C}$.

With the aim of maximizing the BCNW's loading, in a second stage of this work, suspensions of 10-15 wt.- $\%$ BCNW were prepared. It was necessary to modify the total solids content in the range of $6-8$ wt.- $\%$ since raising the nanofiller concentration caused a significant increase in the viscosity of the solutions.

Viscosity of the electrospinning solutions was determined at ambient temperature using a VISCO BASIC Plus L Viscometer (Fungilab, Spain) with a LCP low viscosity adapter.

The electrospinning apparatus a Fluidnatek instrument, trademark of the engineering division of BioInicia S.L. (Valencia, Spain), equipped with a variable high voltage $0-30 \mathrm{kV}$ power supply was used.). Solutions were transferred to $5 \mathrm{ml}$ syringes and connected through PTFE tubes to a stainless steel needle $(\varnothing 0.9$ $\mathrm{mm})$. The voltage applied was $10-12 \mathrm{kV}$, and the polymer solution was fed into the needle at a rate of $0.66 \mathrm{ml} / \mathrm{h}$ by a syringe pump. The counter electrode was connected to a rectangular plate covered by aluminum foil, which was placed 
parallel to the needle to collect the electrospun fibres. The distance between the needle and the plate was $10 \mathrm{~cm}$ and experiments were carried out at ambient conditions.

\subsection{Scanning Electron Microscopy (SEM)}

SEM was conducted on a Hitachi microscope (Hitachi S-4100) at an accelerating voltage of $10-15 \mathrm{KV}$ and a working distance of 12-16mm. Electrospun mats were sputtered with a gold-palladium mixture under vacuum before their morphology was examined using SEM.

Fibre diameters of the electrospun fibres were measured by means of the Adobe Photoshop CS3 extended software from the SEM micrographs in their original magnification.

\subsection{Transmission Electron Microscopy (TEM)}

PLA hybrid fibres were directly electrospun on TEM grids. The material was then stained with uranyl acetate with the purpose of increasing the contrast of the highly crystalline BCNW incorporated into the fibres. TEM was performed using a JEOL 1010 equipped with a digital Bioscan (Gatan) image acquisition system at $80 \mathrm{KV}$.

\subsection{X-ray Diffraction (XRD)}

X-ray diffraction was carried out on a D5005 Bruker diffractometer. The instrument was equipped with a $\mathrm{Cu}$ tube and a secondary monochromator. The configuration of the equipment was $\theta-2 \theta$ and the samples were examined over the angular range of $5^{\circ}$ to $45^{\circ}$ with a step size of $0.02^{\circ}$ and a count time of $4 \mathrm{~s}$ per point. 
Peak fitting was carried out using Igor software package (Wavemetrics, Lake Oswego, Oregon). Gaussian function was used to fit the experimental diffraction profiles obtained. For the fitting procedure, the reflections considered were (i) three at $14.8^{\circ}, 16.4^{\circ}$ and $22.5^{\circ} 2 \theta$ (corresponding to the $101,10 \overline{1}$ and 002 crystal planes respectively) assigned to the cellulose I allomorph, and (ii) the amorphous halo from PLA centered at $\sim 16^{\circ} 2 \theta$. The crystallinity index CI (XD) was determined by the method reported by Wang et al. (Wang et al., 2007):

$$
\mathrm{CI}(\mathrm{XD})=\frac{\sum A_{\text {Crystal }}}{A_{\text {Total }}} \times 100
$$

where $A_{\text {Total }}$ is the sum of the areas under all the diffraction peaks and $\Sigma A_{\text {Crystal }}$ is the sum of the areas corresponding to crystalline peaks.

\subsection{Differential scanning calorimetry (DSC)}

Differential scanning calorimetry (DSC) of PLA electrospun fibres was performed on a Perkin-Elmer DSC 7 thermal analysis system on typically $4 \mathrm{mg}$ of dry material at a scanning speed of $10^{\circ} \mathrm{C} / \mathrm{min}$ from room temperature to the melting point using $\mathrm{N}_{2}$ as the purging gas. The first and second melting endotherms after controlled crystallization at $10^{\circ} \mathrm{C} / \mathrm{min}$ from the melt, were analyzed. Before evaluation, similar runs of an empty pan were substracted from the thermograms. The DSC equipment was calibrated using indium as a standard.

The crystallinity (\%) of the PLA was estimated from the corrected enthalpy for biopolymer content in the hybrid fibres, using the ratio between the enthalpy of the studied material and the enthalpy of a perfect PLA crystal, i.e. $X_{C}(\%)=\frac{\Delta H_{f}-\Delta H_{c}}{\Delta H_{f}^{0}} \times 100$, where $\Delta H_{f}$ is the enthalpy of fusion and $\Delta H_{C}$ 
the enthalpy of cold crystallization of the studied specimen, and $\Delta H_{f}^{0}$ is the enthalpy of fusion of a totally crystalline material. The $\Delta H_{\ell}^{0}$ used for this equation was $93 \mathrm{~J} / \mathrm{g}$ for PLA (Liu et al., 1997).

\subsection{Thermogravimetric analysis (TGA)}

Thermogravimetric (TG) curves were recorded with a TA Instruments model Q500 TGA. The samples (ca. $20 \mathrm{mg}$ ) were heated from $50^{\circ} \mathrm{C}$ to $600^{\circ} \mathrm{C}$ with a heating rate of $10^{\circ} \mathrm{C} / \mathrm{min}$ under nitrogen atmosphere. Derivative TG curves (DTG) expressed the weight loss rate as a function of temperature. 


\section{RESULTS AND DISCUSSION}

\subsection{Selecting solvent and conditions to incorporate BCNW into PLA electrospun fibres}

The main purpose of this work was to develop optimized PLA electrospun fibres incorporating well-dispersed $\mathrm{BCNW}$, which can be later re-dispersed by melt compounding in the biopolymer. When aiming to produce electrospun PLA fibres, several solvents such as DMF (Xiang et al., 2009), chloroform, acetone (Chen et al., 2010) and mixtures of them (Liu et al., 2012) can be used. Three different solvents were evaluated in this study, i.e. chloroform/PEG, acetone/chloroform and 1,1,1,3,3,3-Hexafluoro-2-propanol (HFP), for generating hybrid PLA/BCNW electrospun fibres. A solids content of 8 wt.- $\%$ rendered an optimum morphology of uniform PLA fibres in the three solvent systems and, thus, this solids concentration was selected for preparation of hybrid fibres. Solutions containing BCNW were used to generate hybrid fibres using the three different solvents previously selected for pure PLA fibres. The concentration of the nanofiller was set to $5 \mathrm{wt}$. $\%$ with respect to PLA since higher concentrations led to highly viscous solutions which, in some cases, were not suitable for the electrospinning process.

The nanofiller incorporated into the polymeric matrix consists of highly crystalline nanowhiskers obtained from the acid digestion of bacterial cellulose by following the optimized method described in a previous work (Martínez-Sanz et al., 2011a). The attained BCNW presented an average length (L) of ca. $600 \mathrm{~nm}$ and an average cross-section (W) of ca. $21 \mathrm{~nm}$ having, thus, an aspect ratio (L/W) of 29, which is typical from cellulose nanowhiskers extracted from BC (Liu et al., 2012) and significantly higher than that of plant cellulose nanowhiskers previously 
incorporated into PLA fibres (Xiang et al., 2009). Regarding the crystallinity of the material, as previously estimated from X-ray diffraction analyses, the native BC possessed a crystallinity index of $78 \%$ while it was greatly increased up to $95 \%$ for the BCNW after the acid hydrolysis (Martínez-Sanz et al., 2011a). This material as processed in our group can be subjected to typical processing temperatures for PLA, since the degradation temperature of BCNW, as determined by TGA, was approximately $317^{\circ} \mathrm{C}$ (Martínez-Sanz et al., 2011a).

\subsubsection{Effect of solvent and BCNW addition on the morphology of electrospun PLA} fibres

Figure 1 shows the SEM micrographs of pure PLA electrospun fibres and the related biohybrid ones obtained from solutions containing 5 wt.-\% BCNW. Both pure and hybrid PLA fibres presented a relatively homogeneous morphology, confirming that the chosen solids concentration was the optimal for obtaining uniform fibres. As deduced from the pictures, the solvent used had an effect on the fibres' morphology, being the chloroform the less suitable solvent as it gave rise to less uniform electrospun fibres.

In contrast, thinner and more uniform fibres were obtained from the HFP and acetone-chloroform systems. It is also worth mentioning that when using freezedried BCNW instead of the partially hydrated product, less uniform fibres with beaded morphology were generated (cf. Figure 1g). 

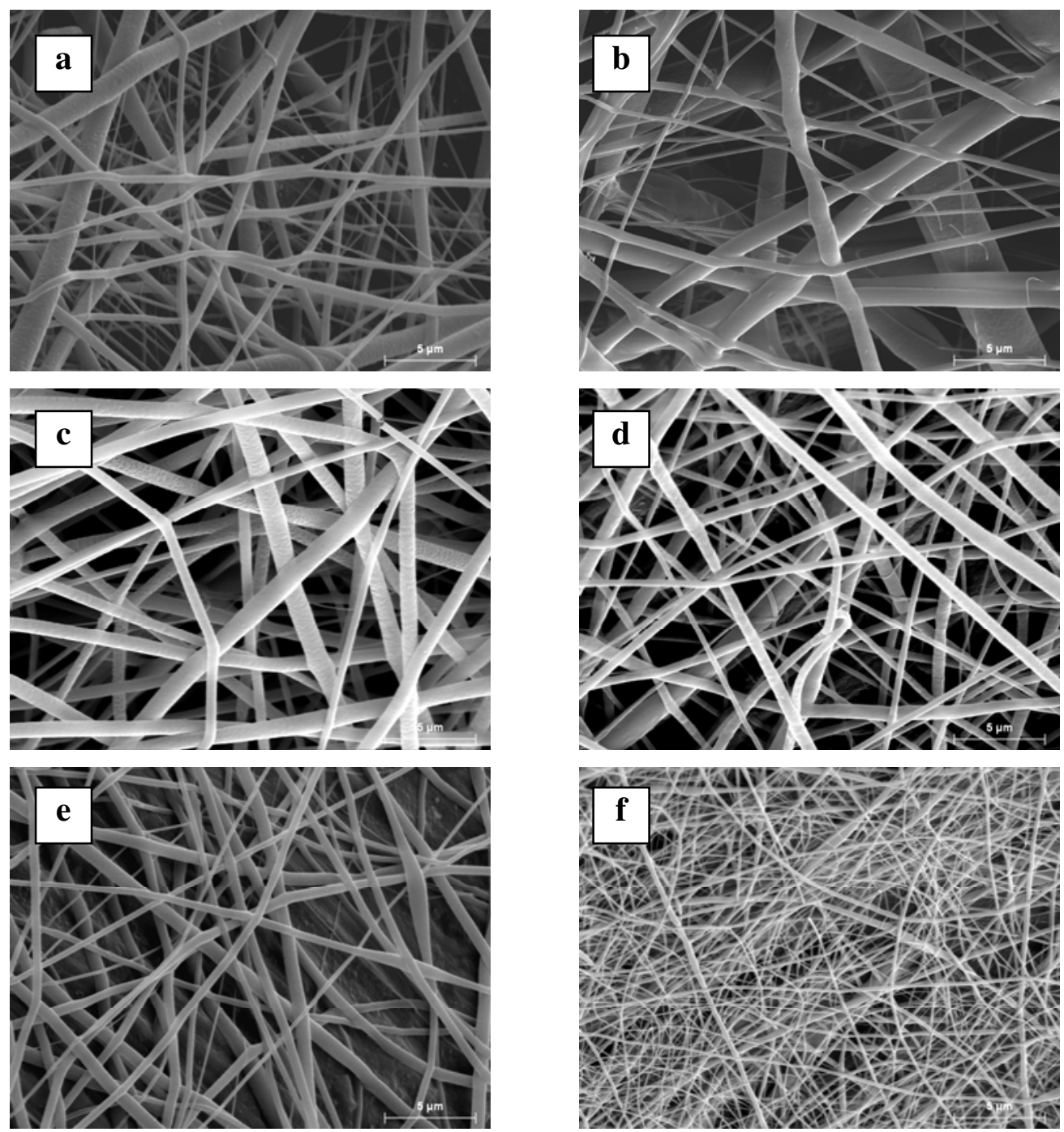


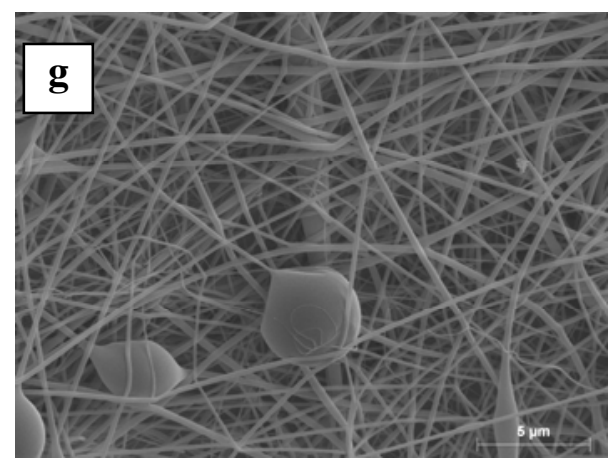

Figure 1. SEM micrographs of electrospun PLA fibres with $8 \mathrm{wt} .-\%$ solids content: (a) PLA + PEG in chloroform, (b) PLA $+\mathrm{PEG}+5 \% \mathrm{BCNW}$ in chloroform, (c) PLA in acetone/chloroform, (d) PLA+5\%BCNW in acetone/chloroform, (e) PLA in HFP, (f) PLA $+5 \% \mathrm{BCNW}$ in HFP and (g) PLA $+5 \% \mathrm{BCNW}$ FD in HFP. Scale markers correspond to 5 micrometers.

With the aim of gaining a better understanding of the changes in morphology of the electrospun fibres, the viscosity of the different electrospinning solutions was measured. Table 1 shows the viscosity values obtained for the various PLA/BCNW solvent solutions and the diameters of the attained electrospun fibres. The first noticeable observation was that when incorporating BCNW into the systems, there was a significant increase in the solutions' viscosity, being this increase much more pronounced for the chloroform and acetone-chloroform solutions. In the case of the chloroform system, the viscosity value was anomalously high and may be a consequence of the presence of surface $\mathrm{OH}$ groups both in the partially hydrated BCNW and the PEG. These $\mathrm{OH}$ groups tend to interact by hydrogen bonding and hence, a strong network was probably created, thus leading to an increase in the solution viscosity. In addition, the greater affinity of the BCNW and PEG could also lead to a certain phase separation with the PLA, fact that would explain the great variability in the diameter of the fibres obtained from this specific biopolymeric solution. For the 
other two solvent systems tested, there was a decrease in the fibres' diameters when incorporating $\mathrm{BCNW}$. This effect was especially remarkable when using HFP as the solvent, which could be explained by the lower viscosity of the latter system. In contrast, when adding freeze-dried BCNW to the HFP solution (instead of the partially hydrated ones), just a slight viscosity increase was observed in comparison with the pure PLA solution. In the case of partially hydrated $\mathrm{BCNW}$, the presence of $\mathrm{OH}$ groups in the surface of the nanowhiskers favoured the development of interactions with the solvent leading to increased viscosity. On the other hand, the freeze-drying process led to the formation of strong intramolecular hydrogen bonds in the BCNW which were not properly disrupted and, thus, the fewer interactions between the nanowhiskers and the biopolymer solution resulted in a lower viscosity and more unstable electrospinning process, as deduced from the greater variability in fibre diameter. 
Table 1. Viscosity of electrospinning solutions and average diameter of the corresponding electrospun fibres.

\begin{tabular}{|l|c|c|}
\cline { 2 - 3 } \multicolumn{1}{l|}{} & Viscosity (cP) & $\begin{array}{c}\text { Average fibre } \\
\text { diameter (nm) }{ }^{*}\end{array}$ \\
\hline PLA HFP (8\%wt) & 119.83 & ${ }^{\mathrm{c}} 483.95 \pm 189.28$ \\
\hline PLA+5\%BCNW HFP (8\%wt) & 380.19 & ${ }^{\mathrm{a}} 100.25 \pm 49.25$ \\
\hline PLA+5\%BCNW FD HFP (8\%wt) & 146.57 & ${ }^{\mathrm{b}} 274.36 \pm 308.11$ \\
\hline PLA acetone/chloroform (8\%wt) & 15.52 & ${ }^{\mathrm{e}} 773.41 \pm 241.95$ \\
\hline PLA+5\%BCNW acetone/chloroform (8\%wt) & 497.90 & ${ }^{\mathrm{cd}} 582.29 \pm 250.04$ \\
\hline PLA+PEG chloroform (8\%wt) & 48.09 & ${ }^{\mathrm{c}} 438.29 \pm 316.86$ \\
\hline PLA+5\%BCNW+PEG chloroform (8\%wt) & 1770.75 & ${ }^{\mathrm{d}} 623.24 \pm 701.22$ \\
\hline
\end{tabular}

$\left.{ }^{*}\right)$ The a, b, c, d and e letters correspond to the ANOVA statistical analysis and

Tukey test of the data that indicate that with a $95 \%$ confidence level, the values are significantly different.

\subsubsection{Dispersion of BCNW within the PLA electrospun fibres}

The dispersion of $\mathrm{BCNW}$ within the electrospun fibres was evaluated by means of TEM. Figure 2 shows representative pictures of the fibres generated from the three different solvent solutions. BCNW seem to be well distributed along the electrospun fibres for the three solvent systems. Nevertheless, it was observed that when applying a freeze-drying process to the filler, the morphology of this within the fibres was strongly modified. Figure 2 clearly shows that while partially hydrated BCNW appeared as a high aspect ratio nanofiller, the freezedried ones presented a morphology of small aggregates with lower aspect ratios. As stated before, the freeze-drying process promoted the occurrence of strong intramolecular bonding which impeded the complete stretching of the 
intramolecular bonding which impeded the complete stretching of the nanowhiskers. Figure 2 also shows that BCNW mostly appeared in the central area of fibres and, for the HFP solvent system, entanglements were produced. Looking at the TEM pictures, it seems that the amount of BCNW incorporated into the fibres was greater for the HFP system, fact that could explain, together with the smaller fibre diameter, the presence of BCNW entanglements.
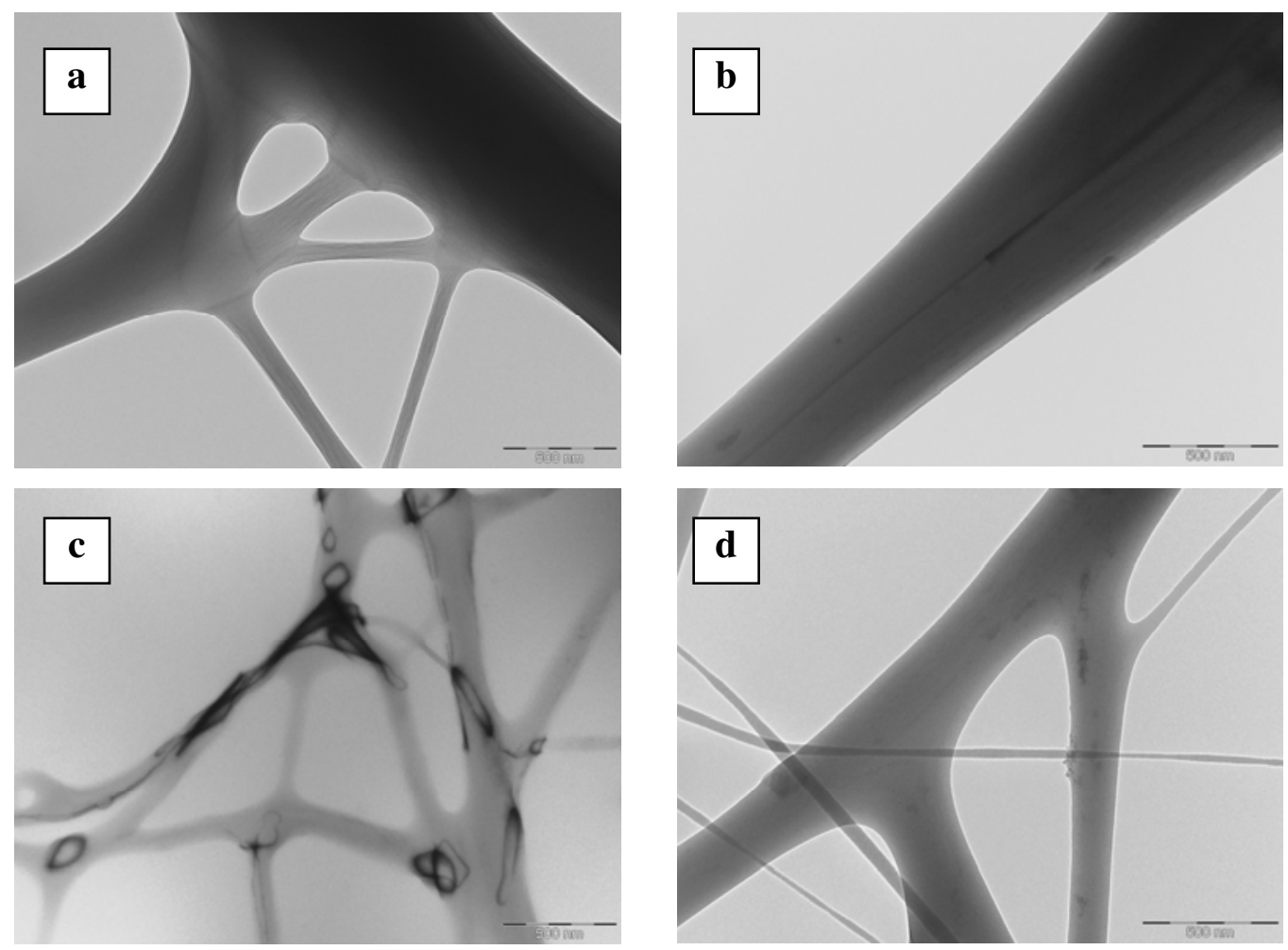

Figure 2. TEM micrographs of electrospun PLA fibres with 8 wt.-\% solids content: (a) PLA $+\mathrm{PEG}+5 \% \mathrm{BCNW}$ in chloroform, (b) PLA $+5 \% \mathrm{BCNW}$ in acetone/chloroform, (c) PLA $+5 \% \mathrm{BCNW}$ in HFP and (d) PLA $+5 \% \mathrm{BCNW}$ FD in HFP. Scale markers correspond to $500 \mathrm{~nm}$. 


\subsubsection{Thermal properties and thermal stability of the hybrid electrospun systems}

Thermal properties of the electrospun pure and hybrid PLA-based fibres are listed in Table 2. The calculated thermal parameters were similar to those previously reported for PLA electrospun fibres generated from DMF solutions (Xiang et al., 2009). From the results in this table, it can be deduced that the solvent used for the electrospinning process had an effect on the thermal properties of the material. It seems that the acetone-chloroform system favoured the crystallization of PLA during the electrospinning process. On the other hand, the $\mathrm{T}_{g}$ observed during the second heating run was slightly higher for the HFP system, indicating that fibres were stiffer in this case. It was also observed that the enthalpy of the materials was significantly decreased after the first heating step (results not shown), i.e. after deleting the thermal history of the fibres, hence suggesting that the electrospinning process favoured the crystallization of PLA. It is worth noting that when incorporating PEG as a compatibilizing agent, the melting temperature was significantly decreased, indicating that, in the presence of PEG, smaller or more defective crystals were formed. Furthermore, the $T_{g}$ of the fibres could not be observed. This result is in agreement with previous works which found out that the addition of PEG decreased the $\mathrm{T}_{\mathrm{g}}$ of PLA about $30^{\circ} \mathrm{C}$ due a to a plasticization effect (Ahmed et al., 2010; Ozkoc \& Kemaloglu, 2009).

The incorporation of low amounts of BCNW had no significant effect on the melting enthalpy and temperature of the electrospun fibres. Nevertheless, the cold crystallization temperature dropped with the addition of BCNW in the HFP and chloroform/PEG systems. This effect has been previously reported for PLA electrospun fibres incorporating plant CNW (Xiang et al., 2009) and suggests that the nanofiller acted as a nucleating agent. The opposite effect was observed for the acetone-chloroform system, as the crystallinity of the PLA fibres was 
Table 2. DSC maximum of melting $\left(\mathrm{T}_{\mathrm{m}}\right)$, cold crystallization temperature $\left(\mathrm{T}_{\mathrm{CC}}\right)$, melting enthalpy $\left(\Delta \mathrm{H}_{\mathrm{m}}\right)$, cold crystallization enthalpy $\left(\Delta \mathrm{H}_{\mathrm{CC}}\right)$, degree of crystallinity $\left(X_{c}\right)$ and glass transition temperature $\left(T_{g 1}\right)$ of electrospun PLA fibres with different solids content, obtained from the first heating run and glass transition temperature $\left(\mathrm{T}_{\mathrm{g} 2}\right)$, obtained from the second heating run.

\begin{tabular}{|c|c|c|c|c|c|c|c|}
\cline { 2 - 8 } \multicolumn{1}{c|}{} & $\mathrm{T}_{\mathrm{m}}\left({ }^{\circ} \mathrm{C}\right)$ & $\begin{array}{c}\mathrm{T}_{\mathrm{CC}} \\
\left({ }^{\circ} \mathrm{C}\right)\end{array}$ & $\begin{array}{c}\Delta \mathrm{H}_{\mathrm{m}} \\
(\mathrm{J} / \mathrm{g}\end{array}$ & $\begin{array}{c}\Delta \mathrm{H}_{\mathrm{CC}} \\
(\mathrm{J} / \mathrm{g}\end{array}$ & $\mathrm{X}_{\mathrm{c}}(\%)$ & $\mathrm{T}_{\mathrm{g} 1}\left({ }^{\circ} \mathrm{C}\right)$ & $\mathrm{T}_{\mathrm{g} 2}\left({ }^{\circ} \mathrm{C}\right)$ \\
\hline PLA HFP & $153.6 \pm$ & $96.5 \pm$ & $46.5 \pm$ & $14.7 \pm$ & $34.2 \pm$ & $57.8 \pm$ & $59.1 \pm$ \\
& 0.1 & 2.9 & 4.8 & 0.6 & 5.8 & 0.3 & 0.0 \\
\hline PLA+5\%BCNW & $153.9 \pm$ & $90.5 \pm$ & $43.8 \pm$ & $13.2 \pm$ & $32.9 \pm$ & $59.0 \pm$ & $60.0 \pm$ \\
HFP & 0.1 & 0.6 & 2.2 & 3.5 & 6.2 & 0.1 & 0.4 \\
\hline PLA+5\%BCNW FD & $153.7 \pm$ & $92.1 \pm$ & $44.0 \pm$ & $10.8 \pm$ & $35.7 \pm$ & $56.1 \pm$ & $58.3 \pm$ \\
HFP & 0.5 & 2.9 & 9.5 & 2.5 & 7.6 & 0.9 & 0.3 \\
\hline PLA & $154.0 \pm$ & $96.5 \pm$ & $56.3 \pm$ & $15.0 \pm$ & $44.4 \pm$ & $57.8 \pm$ & $57.7 \pm$ \\
acetone/chloroform & 0.7 & 0.0 & 3.1 & 1.0 & 4.4 & 0.4 & 0.4 \\
\hline PLA+5\%BCNW & $153.6 \pm$ & $99.3 \pm$ & $58.0 \pm$ & $25.9 \pm$ & $34.6 \pm$ & $57.2 \pm$ & $57.7 \pm$ \\
acetone/chloroform & 0.4 & 1.1 & 4.7 & 1.8 & 3.1 & 0.2 & 0.0 \\
\hline PLA+PEG & $148.4 \pm$ & $92.0 \pm$ & $37.4 \pm$ & $0.4 \pm$ & $39.9 \pm$ & & --- \\
\hline chloroform & 1.2 & 1.2 & 5.4 & 0.1 & 6.2 & & \\
\hline PLA+5\%BCNW+ & $150.6 \pm$ & $79.3 \pm$ & $34.5 \pm$ & $2.6 \pm$ & $34.3 \pm$ & & -- \\
PEG chloroform & 0.4 & 0.4 & 7.7 & 1.3 & 6.9 & & -- \\
\hline
\end{tabular}

Finally, with the aim of determining the effect of the BCNW addition in the thermal stability of the electrospun fibres, TGA analyses were carried out. As deduced from the thermograms shown in Figure 3, the addition of PEG in the chloroform system slightly reduced the degradation temperature of the PLA electrospun fibres but, at the same time, decreased the degradation rate. This 
behaviour has been previously observed for PLA/PEG blends and it was attributed to the fact that inter- and intramolecular transesterification reactions were slowed down as a consequence of the distance between PLA chains imposed by the presence of PEG (Jacobsen \& Fritz, 1996). The degradation profile of the PLAPEG system containing BCNW differed significantly from that of pure PLA fibres. As observed in Figure 3c, the hybrid fibres showed a significantly less thermostable behaviour two degradation steps were detected. The first degradation step corresponded to the overlapping of the degradation peaks of BCNW and PLA, while the second degradation process observed might be associated to the oxidation and breakdown of the charred residue. PEG is thought to cover the surface of $\mathrm{BCNW}$ and to compatibilize the hydrophobic PLA with the hydrophilic nanofiller, but it seems that, in this case, BCNW did not present as good adhesion and compatibilization with the matrix as with the HFP solvent, since it was possible to differentiate the degradation peaks of the matrix and the nanofiller. This result supports the hypothesis of a partial phase separation suggested by morphological and viscosity results.

Whereas no significant effect was observed when incorporating BCNW into the HFP system, the degradation profile was slightly displaced towards higher temperatures when using acetone-chloroform as the solvent. In contrast, when incorporating freeze-dried BCNW, the thermal stability of the fibres developed from the HFP system decreased, suggesting that agglomeration of BCNW caused a detrimental effect in the thermostability of the hybrid PLA fibres. 

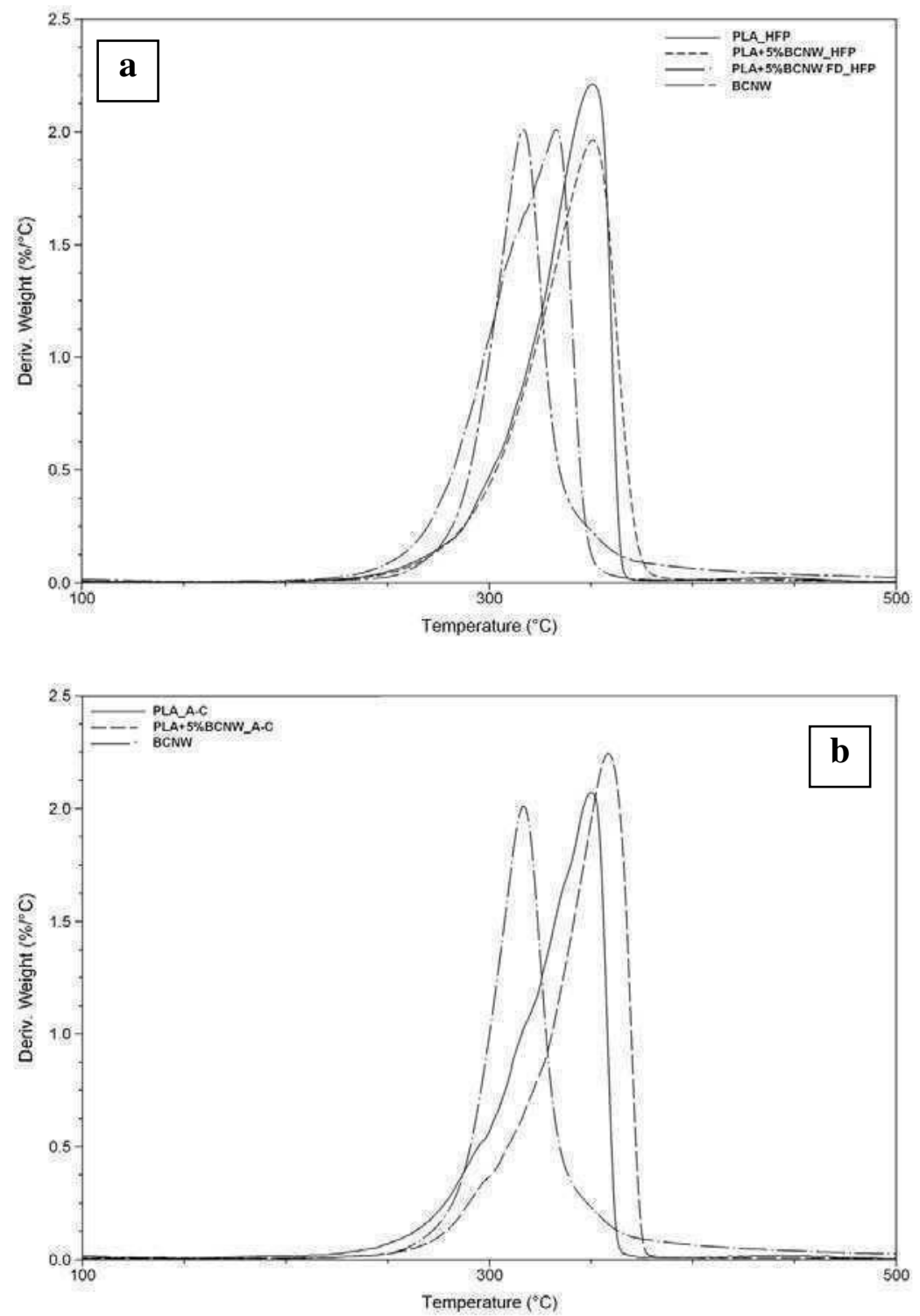


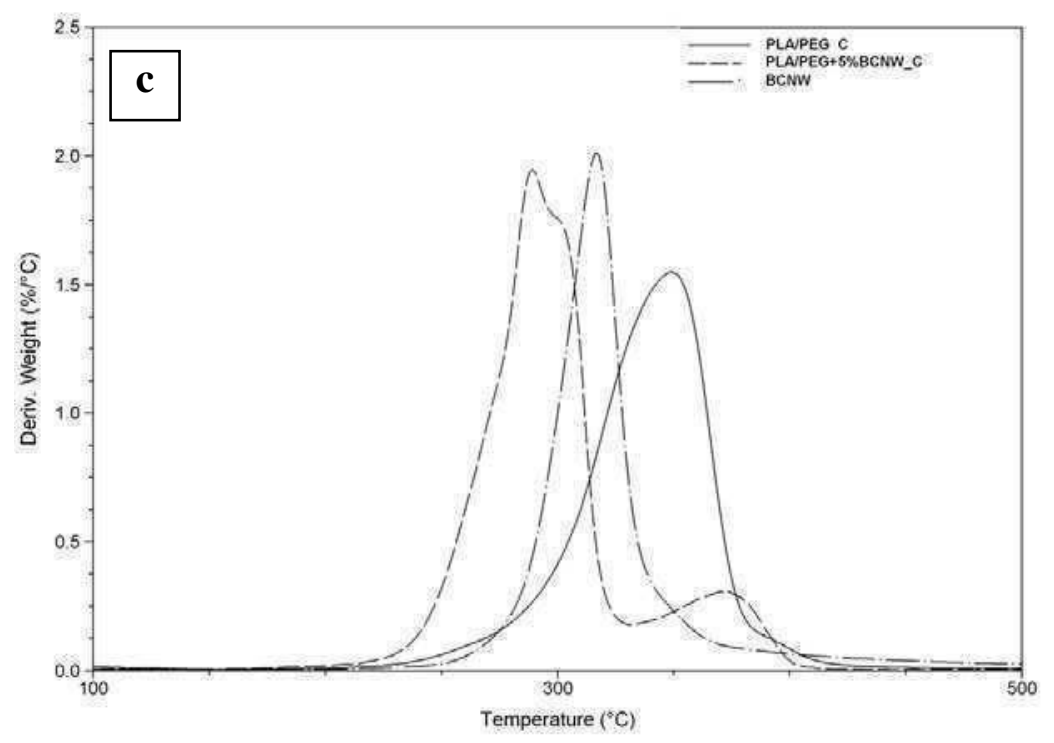

Figure 3. DTG curves of electrospun pure PLA fibres, fibres produced from $5 \% \mathrm{BCNW}$ solutions (partially hydrated and freeze-dried) and native BCNW. (a)

HFP system, (b) acetone-chloroform system and (c) PEG-chloroform system.

As a conclusion of this first part of the study, more heterogeneous fibres were attained when using chloroform/PEG as the solvent due to the poor adhesion between the PEG covered BCNW and the PLA. Moreover, the attained fibres presented decreased thermal stability and the high solution viscosities obtained when increasing the amount of BCNW made these solutions much less suitable for the electrospinning process. Both HFP and acetone-chloroform enabled a proper incorporation of $\mathrm{BCNW}$ into the electrospun fibres, which presented a homogeneous size distribution. Stronger interactions between PLA and BCNW may be taking place in the case of the HFP system as suggested by a slight increase in the $T_{\mathrm{g}}$. Results also suggested that the freeze-drying process gave rise to the establishment of strong intramolecular hydrogen bonds which impeded the stretching of the long BCNW and resulted in decreased thermal properties. 


\subsection{Maximizing the BCNW loading on the PLA fibers}

As a result of the above observations, only the systems using HFP and acetone-chloroform as solvents were selected. Once the most suitable solvents for obtaining hybrid PLA-BCNW electrospun fibres were selected, the maximization on the incorporation of higher nanofiller concentrations was evaluated. Higher loadings were aimed to assess the value of this processing technology to incorporate high quantities of highly dispersed BCNW to later re-disperse them into virgin PLA via melt compounding (Lagaron et al., 2010). By keeping constant the total solids content ( $8 \mathrm{wt} .-\%$ ), it was possible to obtain fibres from solutions containing up to $15 \mathrm{wt} .-\% \mathrm{BCNW}$ for the acetone-chloroform system but when using HFP, concentrations greater than $10 \mathrm{wt} .-\% \mathrm{BCNW}$ led to too high viscosities impeding proper electrospinning of the material. Therefore, the total solids content had to be optimized for each solvent in order to prepare solutions containing $15 \mathrm{wt} .-\% \mathrm{BCNW}$ adequate for the electrospinning process. Two different solids concentrations were tested for each solvent. In the case of the acetone-chloroform solvent, solutions containing 8 wt.- $\%$ and 7 wt.- $\%$ were prepared while for the HFP system, the total solids concentration was set to 7 wt.$\%$ and 6 wt.- $\%$. For any of those solutions, increasing the BCNW loading over a 15 wt. $-\%$ resulted in too high viscosities.

\subsubsection{Degree of effective BCNW incorporation within the PLA electrospun fibres}

In order to estimate the amount of $\mathrm{BCNW}$ that were incorporated into the electrospun fibers, the X-ray diffraction patterns of the various materials were analyzed and the crystallinity index of each sample was estimated. As observed from Figure 4, the peak located at $16.4^{\circ}$, characteristic of the cellulose $10 \overline{1}$ crystalline plane, can be easily detected in all the samples. However, the peaks 
appearing at $14.8^{\circ}$ and $22.5^{\circ}$, assigned to the 101 and 002 crystalline planes from cellulose were only observed in the diffractograms of the fibres generated from HFP solutions, hence suggesting that the incorporation of BCNW might be greater for that system. Crystallinity indexes were calculated through peak fitting of the experimental profiles. For estimating the amount of BCNW incorporated into the fibres, only crystalline peaks corresponding to cellulose were taken into account. Thus, knowing that BCNW possessed a crystallinity index of $95 \%$ as determined by WAXS, the amount of the nanofiller incorporated into the fibres was estimated from the total crystallinity index of each sample. The estimated degree of BCNW incorporation was greater for the samples produced from HFP solutions (ca. 18.wt $\%$ for the sample with 6 wt.- $\%$ solids content and ca. $15 \mathrm{wt} .-\%$ for the sample with 7 wt.- $\%$ solids content), while for the samples generated from acetone/chloroform solutions significantly lower BCNW incorporation degrees were attained (ca. 9.-wt $\%$ for the sample with 7 wt.- $\%$ solids content and ca. 5.$\mathrm{wt} \%$ for the sample with $8 \mathrm{wt} .-\%$ solids content). It is worth noting that these results are qualitative since a certain error associated with curve-fitting had to be assumed (and moreover knowing that the maximum possible content should be 15 wt.-\%). However, although the calculated values may only serve as a good estimation, it becomes clear that the systems obtained using HFP as the solvent were the optimal ones in terms of BCNW incorporation. 


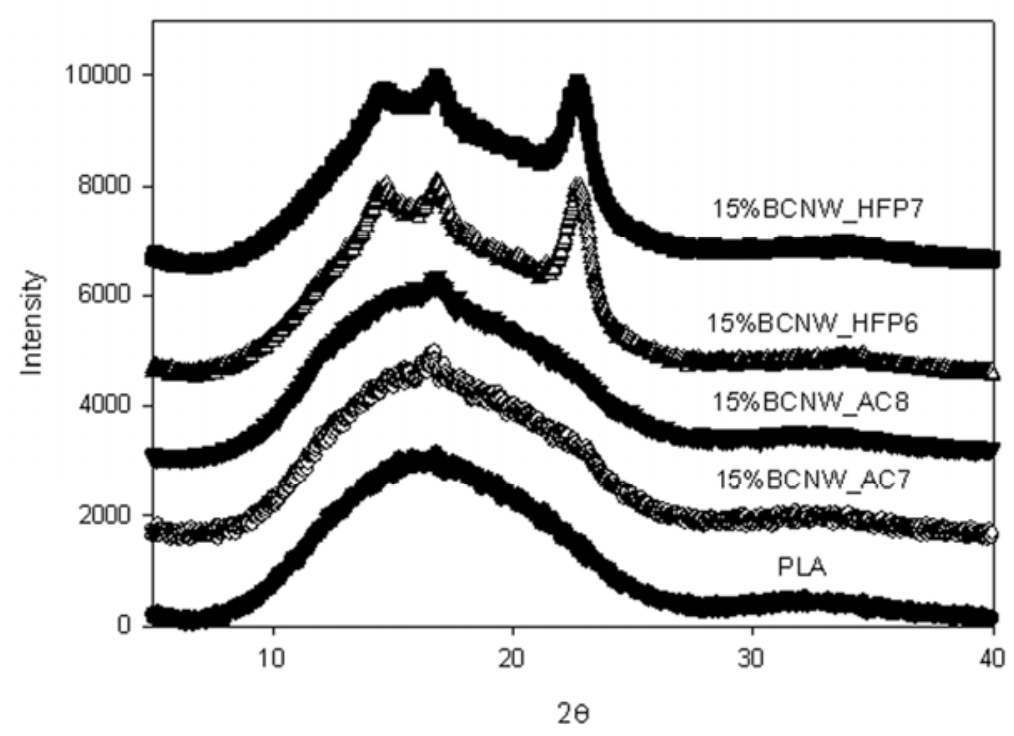

Figure 4. XRD diffraction patterns from pure PLA electrospun fibres and hybrid PLA-BCNW fibres.

\subsubsection{Electrospun fibre morphology and nanofiller dispersion in the optimized} systems

The morphology of the hybrid fibres obtained from the previously described solutions was studied by SEM and representative pictures are shown in Figure 5. Regarding the HFP system, it is worth noting that the morphology of fibres was not significantly altered when increasing the BCNW concentration in the solution from 5 to $10 \mathrm{wt} .-\%$. For the solutions containing $15 \mathrm{wt} .-\%$ BCNW, a lower solids concentration gave rise to the formation of more beaded structures. On the other hand, electrospun fibres generated for solutions of $15 \mathrm{wt} .-\% \mathrm{BCNW}$ in acetonechloroform presented a morphology of thin fibres with a high amount of beads whereas a non-beaded morphology was obtained by decreasing the concentration of solids in the solution to 7 wt.-\%. In any case, as compared to pure PLA fibres, the hybrid ones presented a more uniform size distribution and smaller diameters. 
This effect has been previously observed for electrospun PLA fibres loaded with plant cellulose nanocrystals (Xiang et al., 2009) and has been attributed to increased charge density of the electrospinning solution.
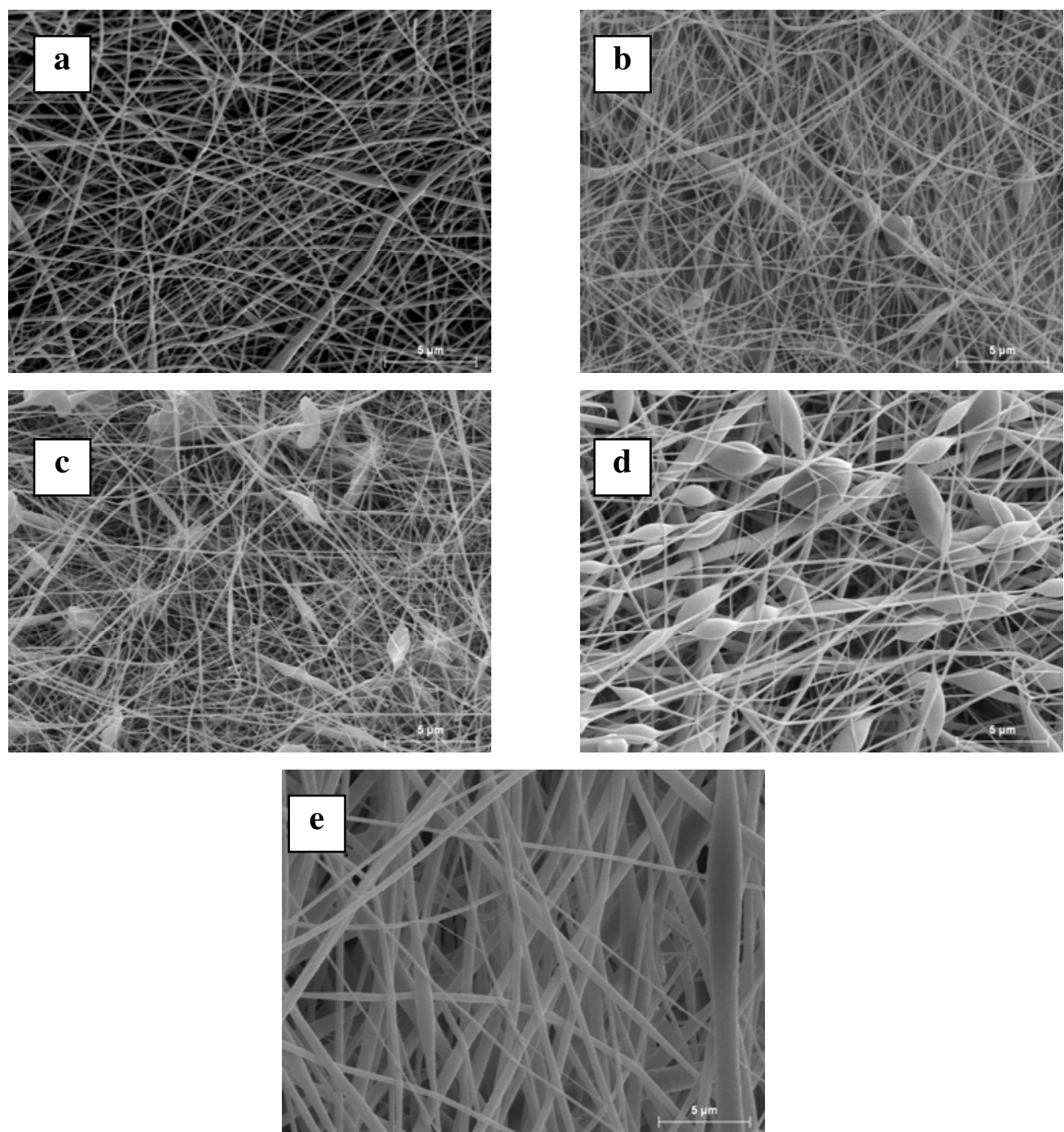

Figure 5. SEM micrographs of electrospun hybrid fibres obtained from solutions of: (a) PLA + 10 wt.- $\%$ BCNW with 8 wt.- $\%$ solids content in HFP, (b) PLA + 15 wt.-\% BCNW with 7 wt.-\% solids content in HFP, (c) PLA + 15 wt.-\% BCNW 
with 6 wt.-\% solids content in HFP, (d) PLA + 15 wt.-\% BCNW with 8 wt.-\% solids content in acetone/chloroform and (e) PLA +15 wt.- $\%$ BCNW with 7 wt.$\%$ solids content in acetone/chloroform. Scale markers correspond to 5 micrometers.

The average fibre diameters together with the viscosities of the electrospinning solutions are listed in Table 3 . As observed, the viscosity of the solutions with a fixed solids concentration increased when raising the BCNW concentration. However, this viscosity increase did not have a significant effect on the average fibres' diameter, indicating that other solution properties, such as conductivity and surface tension play a role in determining fibre morphology. 
Table 3. Viscosity of electrospinning solutions and average diameter of the corresponding electrospun fibres.

\begin{tabular}{|c|c|c|}
\cline { 2 - 3 } \multicolumn{1}{c|}{} & $\begin{array}{c}\text { Viscosity } \\
(\mathrm{cP})\end{array}$ & $\begin{array}{c}\text { Average fibre } \\
\text { diameter }(\mathrm{nm})\end{array}{ }^{(*)}$ \\
\hline PLA+5\%BCNW HFP (8\%wt) & 380.19 & ${ }^{\mathrm{a}} 100.25 \pm 49.25$ \\
\hline PLA+10\%BCNW HFP (8\%wt) & 485.05 & ${ }^{\mathrm{a}} 116.10 \pm 43.75$ \\
\hline PLA+15\%BCNW HFP (6\%wt) & 985.01 & ${ }^{\mathrm{a}} 87.58 \pm 36.77$ \\
\hline PLA+5\%BCNW acetone/chloroform $(8 \% \mathrm{wt})$ & 497.90 & ${ }^{\mathrm{c}} 582.29 \pm 250.04$ \\
\hline PLA+15\%BCNW acetone/chloroform $(8 \% \mathrm{wt})$ & 575.36 & ${ }^{\mathrm{b}} 253.89 \pm 279.96$ \\
\hline PLA $+15 \% \mathrm{BCNW}$ acetone/chloroform $(7 \% \mathrm{wt})$ & 398.64 & ${ }^{\mathrm{c}} 470.02 \pm 385.35$ \\
\hline
\end{tabular}

${ }^{(*)}$ The a, b, and c letters correspond to the ANOVA statistical analysis and Tukey test of the data that indicate that with a $95 \%$ confidence level, the values are significantly different.

In order to investigate the distribution of the $\mathrm{BCNW}$ within the electrospun fibres, TEM analyses were carried out. For the fibres obtained from HFP solutions, it was observed that the nanofiller was homogeneously distributed along the fibres. However, it seems that a higher amount of BCNW was incorporated into the fibres prepared from a 6 wt.- $\%$ solution, just as observed in Figures $6 \mathrm{a}$ and $6 \mathrm{~b}$, thus confirming the above X-ray estimations. Figure $6 \mathrm{~d}$ shows that a relatively high incorporation level of well-dispersed BCNW was also achieved for the fibres generated from acetone-chloroform solution containing $7 \mathrm{wt} .-\%$ solids content, also in good agreement with the X-ray results. In contrast, a fewer amount of BCNW was incorporated in the case of the 8 wt.-\% solids content solution. As mentioned 
before, a more beaded structure was obtained in this case and $\mathrm{BCNW}$ were specially agglomerated in beaded areas, just as shown in Figure 6c.
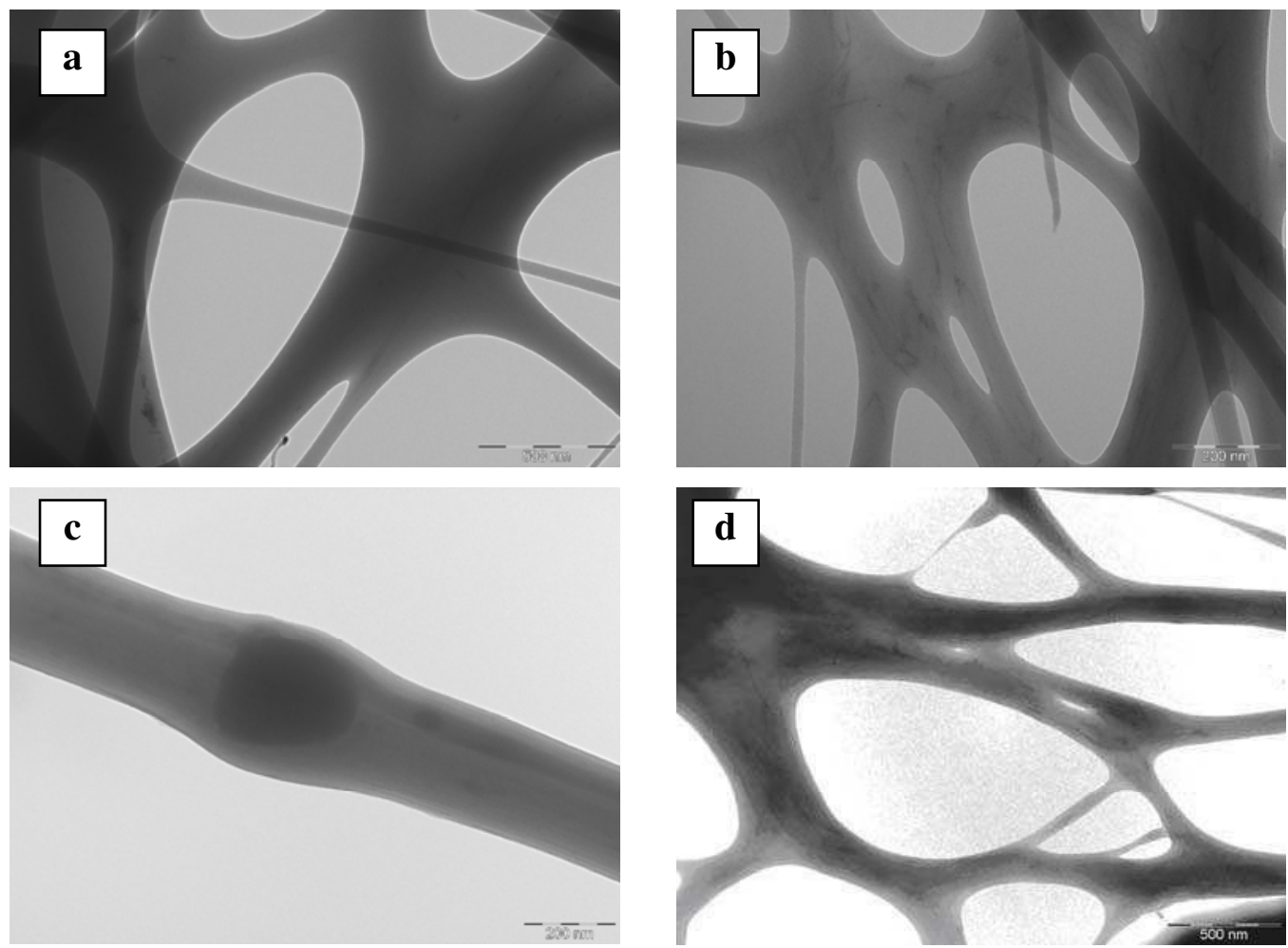

Figure 6. TEM micrographs of electrospun hybrid fibres obtained from solutions of: (a) PLA + 15 wt.-\% BCNW with 7 wt.-\% solids content in HFP, (b) PLA + 15 wt.-\% BCNW with 6 wt.-\% solids content in HFP, (c), PLA + 15 wt.-\% BCNW with 8 wt.- $\%$ solids content in acetone/chloroform and (d) PLA + 15 wt.- $\%$ BCNW with 7 wt.-\% solids content in acetone/chloroform. Scale markers correspond to $500 \mathrm{~nm}$ in (a) and (d), and to $200 \mathrm{~nm}$ in (b) and (c). 
3.2.3 Thermal properties and thermal stability of the optimized nanocomposite electrospun systems

With the aim of investigating the effect of higher BCNW loadings on the thermal properties of the electrospun fibres, DSC analyses were carried out. Table 4 gathers the thermal parameters extracted from the first and second DSC heating runs. When increasing the $\mathrm{BCNW}$ concentration there was an important reduction in the melting enthalpy of the fibres produced from both the HFP and acetonechloroform solutions. Moreover a certain reduction in the crystallinity of PLA when increasing the amount of BCNW effectively incorporated into the fibres was observed. In the case of the fibres generated from the HFP solutions, this reduction was more obvious for 15 wt.- $\%$ BCNW and a solids content of 6 wt.- $\%$, while a very drastic crystallinity drop was observed for the fibres obtained from acetonechloroform solutions containing $15 \mathrm{wt} .-\mathrm{\%}$ BCNW and a solids content of $7 \mathrm{wt.}-\%$. This observation supports XRD and TEM analyses, which suggested that the incorporation of $\mathrm{BCNW}$ seemed to be higher when decreasing the total solids content in both solvent systems. In the case of the acetone-chloroform system, a decrease in the melting temperature was also observed, indicating that smaller or more defective PLA crystals were formed.

Apparently, BCNW had a better level of interaction with the matrix when using HFP as the solvent, which was reflected in an increase on the $\mathrm{T}_{\mathrm{g} 1}$ of hybrid fibres as compared to the pure PLA fibres. For the acetone-chloroform fibres, a slight increase both in the $\mathrm{T}_{\mathrm{g} 1}$ and $\mathrm{T}_{\mathrm{g} 2}$ was observed for fibres generated from 15 wt.- $\%$ BCNW solutions. Nevertheless, the increase in the $T_{\mathrm{g} 1}$ was not statistically significant (with a $95 \%$ confidence level) as compared to the pure PLA fibres. This result again highlights the greater compatibility of the BCNW with the HFP solvent. 
Table 4. DSC maximum of melting $\left(\mathrm{T}_{\mathrm{m}}\right)$, cold crystallization temperature $\left(\mathrm{T}_{\mathrm{CC}}\right)$, melting enthalpy $\left(\Delta \mathrm{H}_{\mathrm{m}}\right)$, cold crystallization enthalpy $\left(\Delta \mathrm{H}_{\mathrm{CC}}\right)$, degree of crystallinity $\left(\mathrm{X}_{\mathrm{c}}\right)$ and glass transition temperature $\left(\mathrm{T}_{\mathrm{g} 1}\right)$ of electrospun PLA fibres with different solids content, obtained from the first heating run and glass transition temperature $\left(\mathrm{T}_{\mathrm{g} 2}\right)$, obtained from the second heating run.

\begin{tabular}{|c|c|c|c|c|c|c|c|}
\hline & $\mathrm{T}_{\mathrm{m}}\left({ }^{\circ} \mathrm{C}\right)$ & $\mathrm{T}_{\mathrm{CC}}\left({ }^{\circ} \mathrm{C}\right)$ & $\Delta \mathrm{H}_{\mathrm{m}}(\mathrm{J} / \mathrm{g}$ PLA $)$ & $\Delta \mathrm{H}_{\mathrm{CC}}(\mathrm{J} / \mathrm{g}$ PLA $)$ & $\mathrm{X}_{\mathrm{c}}(\%)$ & $\mathrm{T}_{\mathrm{g} 1}\left({ }^{\circ} \mathrm{C}\right)$ & $\mathrm{T}_{\mathrm{g} 2}\left({ }^{\circ} \mathrm{C}\right)$ \\
\hline PLA HFP & $153.6 \pm 0.1$ & $96.5 \pm 2.9$ & $46.5 \pm 4.8$ & $14.7 \pm 0.6$ & $34.2 \pm 5.8$ & $57.8 \pm 0.3$ & $59.1 \pm 0.0$ \\
\hline PLA $+5 \%$ BCNW HFP $(8 \% \mathrm{wt})$ & $153.9 \pm 0.1$ & $90.5 \pm 0.6$ & $43.8 \pm 2.2$ & $13.2 \pm 3.5$ & $32.9 \pm 6.2$ & $59.0 \pm 0.1$ & $60.0 \pm 0.4$ \\
\hline PLA $+10 \%$ BCNW HFP ( $8 \%$ wt) & $153.7 \pm 0.0$ & $93.5 \pm 6.6$ & $37.9 \pm 1.0$ & $8.1 \pm 1.2$ & $32.1 \pm 0.2$ & $58.5 \pm 0.4$ & $59.3 \pm 0.6$ \\
\hline PLA+15\%BCNW HFP (7\%wt) & $153.3 \pm 0.8$ & $100.5 \pm 0.7$ & $32.0 \pm 0.5$ & $1.7 \pm 0.2$ & $32.6 \pm 0.9$ & $59.0 \pm 0.0$ & $59.7 \pm 0.7$ \\
\hline PLA+15\%BCNW HFP (6\%wt) & $153.6 \pm 0.4$ & $99.3 \pm 0.6$ & $27.5 \pm 2.9$ & $5.6 \pm 3.5$ & $23.6 \pm 0.6$ & $59.1 \pm 0.1$ & $59.4 \pm 0.0$ \\
\hline PLA acetone/chloroform & $154.0 \pm 0.7$ & $96.5 \pm 0.0$ & $56.3 \pm 3.1$ & $15.0 \pm 1.0$ & $44.4 \pm 4.4$ & $57.8 \pm 0.4$ & $57.7 \pm 0.4$ \\
\hline $\begin{array}{c}\text { PLA }+5 \% \mathrm{BCNW} \\
\text { acetone/chloroform ( } 8 \% \mathrm{wt})\end{array}$ & $153.6 \pm 0.4$ & $99.3 \pm 1.1$ & $58.0 \pm 4.7$ & $25.9 \pm 1.8$ & $34.6 \pm 3.1$ & $57.2 \pm 0.2$ & $57.7 \pm 0.0$ \\
\hline $\begin{array}{c}\text { PLA+15\%BCNW } \\
\text { acetone/chloroform ( } 8 \% \mathrm{wt})\end{array}$ & $151.9 \pm 0.7$ & $97.6 \pm 8.6$ & $36.7 \pm 7.4$ & $15.0 \pm 3.3$ & $23.6 \pm 4.2$ & $58.5 \pm 0.5$ & $58.8 \pm 0.5$ \\
\hline $\begin{array}{c}\text { PLA+15\%BCNW } \\
\text { acetone/chloroform (7\%wt) }\end{array}$ & $151.5 \pm 0.2$ & $97.1 \pm 0.8$ & $37.0 \pm 0.6$ & $28.3 \pm 3.1$ & $9.0 \pm 4.5$ & $58.3 \pm 0.2$ & $58.6 \pm 0.2$ \\
\hline
\end{tabular}


It was previously concluded that the incorporation of relatively low loadings of BCNW did not have a detrimental effect on the thermal stability of the fibres. TGA analyses were developed with fibres incorporating higher BCNW concentrations and the main determined parameters are listed in Table 5. As it can be deduced, the general trend was that by incorporating relatively low amounts of BCNW no great changes were produced in the degradation profile of the fibres. However, for higher incorporation levels, the effect on the degradation temperature of the fibres was different depending on the solvent used for generating the electrospun fibres.

For the fibres obtained from the acetone-chloroform system, a slight increase in the degradation temperature was observed for the materials with 8 wt.- $\%$ solids content, while those obtained from the $7 \mathrm{wt} .-\%$ solids content solution showed a decrease on the degradation temperature. This fact could be indicating that a poor adhesion between the matrix and the nanofiller was occurring in this case. Due to this limited adhesion, the degradation temperature was displaced towards lower values for higher nanofiller incorporation degrees (which were achieved by lowering the solids concentration) as a consequence of the lower thermal stability of the native $\mathrm{BCNW}$.

For the HFP system the degradation occurred over a broader temperature range when $\mathrm{BCNW}$ were incorporated, probably due to a more heterogeneous crystallites size profile. In addition, a slight increase in the degradation temperature and a slower degradation rate was observed for the fibres generated from 15 wt.- $\%$ BCNW solutions when the incorporation of the nanofiller was higher (i.e., for the 6 wt.- $\%$ solids content solution). Once again, these results support the fact that BCNW were more compatible with the HFP solvent, resulting in a better dispersion and compatibilization of BCNW with the PLA matrix and, as a 
consequence, the degradation process was not shifted to the lower temperatures corresponding to the isolated $\mathrm{BCNW}$.

Table 5. TGA maximum of the weight loss first derivate $\left(T_{D}\right)$ and the corresponding peak onset and endset values and the weight loss at $400^{\circ} \mathrm{C}$ for the

PLA hybrid fibres with different solids content.

\begin{tabular}{|c|c|c|c|c|}
\cline { 2 - 5 } \multicolumn{1}{c|}{} & Onset T $\left({ }^{\circ} \mathbf{C}\right)$ & $\left.\mathbf{T}_{\mathbf{D}} \mathbf{(}^{\mathbf{}} \mathbf{C}\right)$ & Endset T $\left({ }^{\circ} \mathbf{C}\right)$ & WL (\%) \\
\hline PLA+5\%BCNW HFP (8\%wt) & 228.3 & 351.1 & 397.1 & 98.5 \\
\hline PLA+15\%BCNW HFP (7\%wt) & 215.5 & 355.2 & 402.7 & 100 \\
\hline PLA+15\%BCNW HFP (6\%wt) & 218.8 & 361.7 & 402.1 & 78.8 \\
\hline $\begin{array}{c}\text { PLA+5\%BCNW } \\
\text { acetone/chloroform (8\%wt) }\end{array}$ & 241.6 & 358.5 & 383.4 & 98.4 \\
\hline $\begin{array}{c}\text { PLA+15\%BCNW } \\
\text { acetone/chloroform (8\%wt) }\end{array}$ & 242.7 & 358.2 & 381.4 & 100 \\
\hline $\begin{array}{c}\text { PLA+15\%BCNW } \\
\text { acetone/chloroform (7\%wt) }\end{array}$ & 215.9 & 341.8 & 369.3 & 99.1 \\
\hline
\end{tabular}




\section{CONCLUSIONS}

This work demonstrates that it is possible to obtain electrospun PLA fibres incorporating well dispersed $\mathrm{BCNW}$ in concentrations up to $15 \mathrm{wt.} \%$, presenting a good thermostability and slightly stiffer behaviour than pure PLA fibres.

Initially, the adequacy of three different solvents such as HFP, acetonechloroform and chloroform (incorporating PEG), was evaluated and both pure and hybrid fibres obtained from solutions with $5 \mathrm{wt} .-\% \mathrm{BCNW}$ content were generated. While TEM analyses showed that partially hydrated BCNW were well dispersed along the fibres for the three solvent systems, when using freeze-dried BCNW, the fibres presented an heterogeneous morphology with beads and BCNW appeared as small aggregates due to the strong intramolecular bonding promoted by the freezedrying process, which hindered the stretching of the nanowhiskers. The chloroform/PEG solution was not suitable for the development of the hybrid fibres, as the presence of PEG was detrimental for the thermal properties of the materials.

In the next stage of the study, fibres with BCNW loadings up to 15 wt.- $\%$ in the solution were produced using HFP and acetone-chloroform as solvents. It was observed that the viscosity of the solutions markedly increased with the addition of $\mathrm{BCNW}$ and, hence, solids concentrations lower than in the previous stage were used, facilitating the electrospinning process and also resulting in a greater degree of BCNW incorporation.

The solvent HFP was found to be more compatible with the BCNW, allowing greater amounts of $\mathrm{BCNW}$ to be incorporated into the fibres just as confirmed by XRD studies and, hence, resulting in stiffer and more thermally stable fibres as compared to the ones obtained from acetone-chloroform solutions. A slight 
increase in the $T_{g}$ of fibres attained from HFP solutions, detected by DSC, suggested that strong interactions between the PLA and the BCNW were developed in this case. It was also confirmed that the DSC crystallinity of the PLA matrix decreased when increasing the amount of BCNW incorporated, being this effect more important for the fibres generated from acetone-chloroform solutions. Finally, it was observed that the thermal stability of the HFP fibres increased by incorporating $\mathrm{BCNW}$, whereas it decreased in the case of the acetone-chloroform fibres due to poorer adhesion between the matrix and the nanofiller. In any case, the attained biohybrid fibres could be subjected to temperatures typically used during melt processing of biopolyesters and, hence, this method of encapsulation of BCNW into PLA fibers can have significant application potential to generate highly dispersed biofiller-reinforced PLA coatings or films. 


\section{REFERENCES}

Abdul Rahman, N., Gizdavic-Nikolaidis, M., Ray, S., Easteal, A. J., \& TravasSejdic, J. (2010). Functional electrospun nanofibres of poly(lactic acid) blends with polyaniline or poly(aniline-co-benzoic acid). Synthetic Metals, 160(17-18), 20152022 .

Ahmed, J., Varshney, S. K., Auras, R., \& Hwang, S. W. (2010). Thermal and rheological properties of L-polylactide/polyethylene glycol/silicate nanocomposites films. Journal of Food Science, 75(8), N97-N108.

Cai, Z. X., Mo, X. M., Zhang, K. H., Fan, L. P., Yin, A. L., He, C. L., \& Wang, H. S. (2010). Fabrication of chitosan/silk fibroin composite nanofibers for Wounddressing Applications. International Journal of Molecular Sciences, 11(9), 35293539 .

Chen, H. C., Tsai, C. H., \& Yang, M. C. (2010). Mechanical properties and biocompatibility of electrospun polylactide/poly(vinylidene fluoride) mats. Journal of Polymer Research, 1-9.

De Souza Lima, M. M., \& Borsali, R. (2004). Rodlike cellulose microcrystals: Structure, properties, and applications. Macromolecular Rapid Communications, 25(7), 771-787.

Hirai, A., Inui, O., Horii, F., \& Tsuji, M. (2009). Phase separation behavior in aqueous suspensions of bacterial cellulose nanocrystals prepared by sulfuric acid treatment. Langmuir, 25(1), 497-502.

Iguchi, M., Yamanaka, S., \& Budhiono, A. (2000). Bacterial cellulose - a masterpiece of nature's arts. Journal of Materials Science, 35(2), 261-270.

Jacobsen, S., \& Fritz, H. G. (1996). Filling of poly(lactic acid) with native starch. Polymer Engineering and Science, 36(22), 2799-2804.

Jeong, S. I., Krebs, M. D., Bonino, C. A., Khan, S. A., \& Alsberg, E. (2010). Electrospun alginate nanofibers with controlled cell adhesion for tissue engineering. Macromolecular Bioscience, 10(8), 934-943. 
Ji, Y., Li, B., Ge, S., Sokolov, J. C., \& Rafailovich, M. H. (2006). Structure and nanomechanical characterization of electrospun PS/clay nanocomposite fibers. Langmuir, 22(3), 1321-1328.

Kim, E. S., Kim, S. H., \& Lee, C. H. (2010). Electrospinning of polylactide fibers containing silver nanoparticles. Macromolecular Research, 18(3), 215-221.

Kim, K., Yu, M., Zong, X., Chiu, J., Fang, D., Seo, Y. S., Hsiao, B. S., Chu, B., \& Hadjiargyrou, M. (2003). Control of degradation rate and hydrophilicity in electrospun non-woven poly(D,L-lactide) nanofiber scaffolds for biomedical applications. Biomaterials, 24(27), 4977-4985.

Lagaron, J. M., Martínez-Sanz, M., \& Lopez-Rubio, A. (2010). Patent Application P30663.

Liu, D., Yuan, X., \& Bhattacharyya, D. (2012). The effects of cellulose nanowhiskers on electrospun poly (lactic acid) nanofibres. Journal of Materials Science, 47(7), 3159-3165.

Liu, H., Kameoka, J., Czaplewski, D. A., \& Craighead, H. G. (2004). Polymeric nanowire chemical sensor. Nano Letters, 4(4), 671-675.

Liu, X., Dever, M., Fair, N., \& Benson, R. S. (1997). Thermal and mechanical properties of poly(lactic acid) and poly(ethylene/butylene succinate) blends. Journal of Environmental Polymer Degradation, 5(4), 225-235.

Lunt, J. (1998). Large-scale production, properties and commercial applications of poly lactic acid polymers. Polymer Degradation and Stability, 59(1-3), 145-152.

Martínez-Sanz, M., Lopez-Rubio, A., \& Lagaron, J. (2011a). Optimization of the nanofabrication by acid hydrolysis of bacterial cellulose nanowhiskers. Carbohydrate Polymers, 85(1), 228-236.

Martínez-Sanz, M., Olsson, R. T., Lopez-Rubio, A., \& Lagaron, J. M. (2011b). Development of electrospun EVOH fibres reinforced with bacterial cellulose nanowhiskers. Part I: Characterization and method optimization. Cellulose, 18(2), 335-347.

Martínez-Sanz, M., Olsson, R., Lopez-Rubio, A., \& Lagaron, J. (2012). Development of Bacterial Cellulose Nanowhiskers Reinforced EVOH Composites by Electrospinning. Journal of Applied Polymer Science, 124(2), 1398-1408. 
Olsson, R. T., Kraemer, R., Lopez-Rubio, A., Torres-Giner, S., Ocio, M. J., \& Lagaron, J. M. (2010). Extraction of microfibrils from bacterial cellulose networks for electrospinning of anisotropic biohybrid fiber yarns. Macromolecules, 43(9), 4201-4209.

Ozkoc, G., \& Kemaloglu, S. (2009). Morphology, biodegradability, mechanical, and thermal properties of nanocomposite films based on PLA and plasticized PLA. Journal of Applied Polymer Science, 114(4), 2481-2487.

Park, W. I., Kang, M., Kim, H. S., \& Jin, H. J. (2007). Electrospinning of poly(ethylene oxide) with bacterial cellulose whiskers. Macromolecular Symposia, 249-250, 289-294.

Peresin, M. S., Habibi, Y., Zoppe, J. O., Pawlak, J. J., \& Rojas, O. J. (2010). Nanofiber composites of polyvinyl alcohol and cellulose nanocrystals: Manufacture and characterization. Biomacromolecules, 11(3), 674-681.

Schreuder-Gibson, H., Gibson, P., Senecal, K., Sennett, M., Walker, J., Yeomans, W., Ziegler, D., \& Tsai, P. P. (2002). Protective textile materials based on electrospun nanofibers. Journal of Advanced Materials, 34(3), 44-55.

Wan, Y. Z., Huang, Y., Yuan, C. D., Raman, S., Zhu, Y., Jiang, H. J., He, F., \& Gao, C. (2007). Biomimetic synthesis of hydroxyapatite/bacterial cellulose nanocomposites for biomedical applications. Materials Science and Engineering $C$, 27(4), 855-864.

Wang, N., Ding, E., \& Cheng, R. (2007). Thermal degradation behaviors of spherical cellulose nanocrystals with sulfate groups. Polymer, 48(12), 3486-3493.

Xiang, C., Joo, Y. L., \& Frey, M. W. (2009). Nanocomposite fibers electrospun from poly(Lactic Acid)/cellulose nanocrystals. Journal of Biobased Materials and Bioenergy, 3(2), 147-155.

Xu, X., Zhong, W., Zhou, S., Trajtman, A., \& Alfa, M. (2010). Electrospun PEGPLA nanofibrous membrane for sustained Release of hydrophilic antibiotics. Journal of Applied Polymer Science, 118(1), 588-595.

Ying, T. H., Ishii, D., Mahara, A., Murakami, S., Yamaoka, T., Sudesh, K., Samian, R., Fujita, M., Maeda, M., \& Iwata, T. (2008). Scaffolds from electrospun 
polyhydroxyalkanoate copolymers: Fabrication, characterization, bioabsorption and tissue response. Biomaterials, 29(10), 1307-1317.

Zeng, J., Chen, X., Liang, Q., Xu, X., \& Jing, X. (2004). Enzymatic degradation of poly(L-lactide) and poly(E-caprolactone) electrospun fibers. Macromolecular Bioscience, 4(12), 1118-1125. 


\section{Chapter VII \\ OPTIMIZATION OF THE DISPERSION OF UNMODIFIED \\ BACTERIAL CELLULOSE NANOWHISKERS INTO \\ POLYLACTIDE VIA MELT COMPOUNDING TO \\ SIGNIFICANTLY ENHANCE BARRIER AND MECHANICAL PROPERTIES}

Biomacromolecules, 13(11), 3887-3899 (2012)

Marta Martínez Sanz, Amparo López Rubio, José María Lagarón

Novel Materials and Nanotechnology Group, IATA, CSIC. Avd. Agustín Escardino, 7, 46980. Paterna, Valencia. Spain 



\begin{abstract}
In the present study, property enhanced polylactide (PLA) nanocomposites containing bacterial cellulose nanowhiskers $(\mathrm{BCNW})$ were prepared by melt compounding. With the aim of improving the nanocrystals' dispersion in the final melt processed nanocomposites, these were pre-incorporated either into PLA nanostructured fibers by electrospinning or into an ethylene vinyl-alcohol copolymer $(\mathrm{EVOH})$ by solution precipitation. An optimized dispersion of the nanofiller in the nanocomposites produced by applying these pre-incorporation methods, when compared to the direct melt mixing of the freeze-dried nanowhiskers with the polymeric matrix, was confirmed by morphological studies. Enhanced dispersion of $\mathrm{BCNW}$ was critical for enhancing the barrier and mechanical properties of the nanocomposites. Thus, for concentrations around the percolation threshold, i.e. 2-3 wt.-\% BCNW, nanocomposites produced by the electrospinning pre-incorporation method showed increased elastic modulus and tensile strength, preserving the ductility of the pure PLA. Moreover, in the optimized nanocomposites the water permeability of PLA was reduced by $43 \%$ and the oxygen barrier also decreased to a significant extent. This paper provides a successful route to solve the long standing issue related to the dispersion of highly polar unmodified cellulose nanowhiskers into PLA via the industrially meaningful melt compounding processing.
\end{abstract}

Keywords: Bacterial cellulose, nanowhiskers, polylactide, melt compounding, nanocomposites. 


\section{INTRODUCTION}

PLA is a biodegradable, aliphatic biopolyester produced from L- and D-lactic acid, which can be derived from fermentation of corn starch (Lunt, 1998). As a result of the growing interest in the development of biodegradable materials for applications such as packaging and medicine, PLA has been extensively studied during the last years and it is already commercially available. Amongst the available biopolymers, PLA is one of the most attractive materials due to its high transparency and relatively easy processability. Furthermore, it is suitable for electrospinning and several works have previously reported the successful production of submicron PLA fibers (Kim et al., 2003; Zeng et al., 2004). Nevertheless, this biopolyester still presents some drawbacks such as low thermal resistance, excessive brittleness and relatively low barrier to oxygen and water vapour as compared to other packaging materials such as polyethylene terephthalate (PET). The incorporation of nanoparticles such as nanoclays and cellulose nanocrystals has been proposed as a strategy for enhancing the properties of PLA and many works have reported on the production of hybrid PLA materials (Bondeson \& Oksman, 2007b; Frone et al., 2011; Nordqvist et al., 2010; Oksman et al., 2006; Sanchez-Garcia et al., 2008; Sanchez-Garcia \& Lagaron, 2010).

Bacterial cellulose nanowhiskers $(\mathrm{BCNW})$ represent an interesting alternative for the production of PLA nanobiocomposites with improved properties. Cellulose is typically extracted from vegetal resources, but it can also be synthesized by some bacterial species, such as Gluconacetobacter xylinus, which in a culture medium rich in polysaccharides is able to produce a layer of nearly pure bacterial cellulose (BC). By subjecting $\mathrm{BC}$ to acid hydrolysis, it is possible to obtain cellulose nanowhiskers $(\mathrm{BCNW})$ presenting a highly crystalline structure 
(Martínez-Sanz et al., 2011a), with several micrometres in length and a width of 5-50 nm (De Souza Lima \& Borsali, 2004; Hirai et al., 2009). One of the main difficulties associated to the use of unmodified cellulose nanowhiskers as reinforcing agents is their high hydrophilicity, which makes it difficult to disperse them in non-polar media. To overcome this issue and allow for the dispersion of cellulose nanowhiskers in organic media, the most common alternatives are the use of surfactants (Petersson et al., 2007), which are able to coat the whiskers, or by surface chemical modification (Grunert \& Winter, 2002). However, the modification of nanowhiskers may bring or complicate further issues related to altering their biobased and biodegradability character, life cycle analysis (LCA), price and also potential migration when for instance used in food packaging. On the other hand, it has been demonstrated that unmodified BCNW should be handled in a partially hydrated state instead of freeze-dried, as it is very difficult to re-disperse BCNW in the latter case due to very strong hydrogen bonding and subsequent self-association (Martínez-Sanz et al., 2011b).

PLA nanocomposites loaded with plant-derived cellulose nanowhiskers with improved properties have been successfully produced via solution casting (Petersson et al., 2007; Qu et al., 2010; Sanchez-Garcia \& Lagaron, 2010). However, only few studies have reported on the production of nanocomposites reinforced with cellulose nanowhiskers via industrial processing techniques, such as melt compounding methods. One of the main issues of melt processing is the difficulty of achieving a good dispersion of the nanofillers within the matrix. The poor compatibility between the highly hydrophilic cellulose nanowhiskers and the hydrophobic PLA in the melt state complicates even further dispersion and gives rise to weak polymer-nanofiller interactions and, thus, agglomeration of the nanocrystals. An attempt to prepare nanocomposites of PLA reinforced with $\mathrm{CNW}$ by pumping a suspension of $\mathrm{CNW}$ in $\mathrm{DMAc} / \mathrm{LiCl}$ into the polymer melt 
during the extrusion process was described (Oksman et al., 2006). Nevertheless, aggregation and thermal degradation took place to a certain extent and no barrier property enhancement were obtained or reported. As an alternative, the use of a surfactant was seen to improve the dispersion of CNW but at the same time it led to PLA degradation (Bondeson \& Oksman, 2007a). Subsequently, the possibility of using poly(vinyl alcohol) ( $\mathrm{PVOH})$ as compatibilizer was investigated, but a poor dispersion in the PLA matrix was observed and CNW were seen to remain primarily in the PVOH phase (Bondeson \& Oksman, 2007b). More recently, a surface treatment based on 3-aminopropyltriethoxysilane was applied to cellulose nanowhiskers in order to improve their compatibility with PLA and stronger nanofiller-matrix adhesion in the interfacial zone was reported (Frone et al., 2011). A recent study also demonstrated that it is possible to produce PLA-CNW nanocomposites by grafting PLA onto the surface of acetylated CNW via ringopening polymerization (Braun et al., 2012). Although these two latter works provide a feasible solution to overcome the low compatibility between PLA and cellulose, just as in previous works, no barrier property enhancement was obtained or reported in any of them.

Another strategy reported in earlier works consisted on the production of PLA melt processed nanocomposites incorporating cellulosic fillers by pre-mixing the unmodified filler with PLA in organic solvents (Iwatake et al., 2008; Jonoobi et al., 2010). By this methodology based on casting, relatively low contents of cellulosic fillers were uniformly distributed within the matrix but the mechanical properties of PLA were significantly improved. This method could have, however, some drawbacks during the industrial implementation on top of other issues such as the potential efficient elimination of the entrapped solvent. 
To summarize, from the previous discussion of the existing literature it is clear that there are two main problems to tackle when trying to incorporate cellulose nanowhiskers into PLA by melt blending. The first one relates to the difficult dispersion of unmodified cellulose nanowhiskers into an organic media and the second, and a more important one, is the incorporation of these into a PLA matrix without agglomeration via melt compounding.

In our efforts to provide solutions to this problem, we carried out several previous studies on the subject which led us to gather the necessary knowledge to carry out the development work presented in this study. Firstly, the incorporation of BCNW into EVOH and PLA fibers by means of electrospinning was explored and the method was optimized in terms of the nanofiller dispersion within the fibres and maximum BCNW loading (Martínez-Sanz et al., 2012b; Martínez-Sanz et al., 2011b). Subsequently, another study was developed in order to optimize the production of BCNW and maximize their thermal stability in order to completely avoid their degradation during conventional melt processing (Martínez-Sanz et al., 2011a).

In the present work, a method based on the production of masterbatches with high concentrations of BCNW was proposed as a way to overcome the low matrix-filler compatibility and attain melt compounded nanocomposites with high level of BCNW's dispersion. Pre-incorporation of BCNW into the polar EVOH has already proven to greatly enhance the dispersion of the nanofiller in melt processed nanocomposites as compared to direct melt blending, although in that case the matrix was hydrophilic and, thus, both components were compatible and readily dispersible in the same solvent and a good adhesion of the nanofiller was promoted (Martínez-Sanz et al., 2013a, b). 
The challenge for the current study was to adapt and subsequently apply the developed pre-incorporation methods to generate PLA nanocomposites with highly dispersed BCNW presenting optimal mechanical and barrier properties, despite the lack of apparent compatibility between these two materials. Therefore, $\mathrm{BCNW}$ were pre-incorporated into PLA fibers by electrospinning or into EVOH by solution precipitation and, subsequently, these masterbatches were melt mixed with the PLA matrix. The morphology and thermal properties of films obtained through the proposed methods were studied and compared to the films produced by direct melt mixing of PLA with the freeze-dried filler. The mechanical and barrier properties of the developed materials will be discussed and related to the morphological observations. 


\section{MATERIALS AND METHODS}

\subsection{Materials}

The semicrystalline polylactide (PLA) used was a film extrusion grade produced by Natureworks (with a D-isomer content of approximately $2 \%$ ). The material had a number-average molecular weight $\left(\mathrm{M}_{\mathrm{n}}\right)$ of ca. 130,000 g/mol, and an average molecular weight $\left(\mathrm{M}_{\mathrm{w}}\right)$ of ca. $150,000 \mathrm{~g} / \mathrm{mol}$ as reported by the manufacturer. Ethylene-vinyl alcohol copolymer grade (Soarnol) EVOH44 (containing $44 \mathrm{~mol} \%$ of ethylene) was supplied by The Nippon Synthetic Chemical Industry Co., Ltd. (NIPPON GOHSEI) (Japan).

Sulphuric acid 96\% and 2-propanol were purchased from Panreac (Barcelona, Spain). 1,1,1,3,3,3-Hexafluoro-2-propanol (HFP) was purchased from Fluka (Germany).

\subsection{Preparation of bacterial cellulose mats}

Bacterial cellulose mats were obtained as described in a previous work (Martínez-Sanz et al., 2011b) and were supplied by BioInicia S.L., Valencia, Spain. Briefly, the bacterial strain Gluconacetobacter xylinus 7351 was incubated in a modified Hestrin/Shramm medium at $30^{\circ} \mathrm{C}$. The cells were pre-cultured in a test tube containing $5 \mathrm{ml}$ of medium and later transferred and scaled up to a bigger reactor of 201 . Several layers of cellulose obtained using the previously described procedure were thus supplied. The received bacterial cellulose pellicles were sterilized and cleaned in boiling water and in a $10 \%(\mathrm{v} / \mathrm{v}) \mathrm{NaOH}$ aqueous solution.

\subsection{Preparation of bacterial cellulose nanowhiskers (BCNW)}

Once neutral $\mathrm{pH}$ was reached, bacterial cellulose pellicles were ground in a blender and the gel-like material was then compressed in order to remove most of 
the absorbed water. The dried material was then treated with $301 \mathrm{ml}$ of sulfuric acid/1 water, in a cellulose/acid ratio of approximately $7 \mathrm{~g} / 1$, at $50^{\circ} \mathrm{C}$ for three days until a homogeneous solution was obtained. The cellulose nanowhiskers were obtained as a white precipitate after several centrifugation and washing cycles at $12,500 \mathrm{rpm}$ and $15^{\circ} \mathrm{C}$ for 20 minutes. After that, the material was re-suspended in deionised water and neutralized with sodium hydroxide until neutral $\mathrm{pH}$ and, subsequently, centrifuged to obtain the final product as a partially hydrated precipitate. This last step is thought to turn the filler heat stable. The humidity of the material was determined and the yield of the extraction process was estimated to be $79.64 \%$ with respect to the dried BC. The product was kept refrigerated and one fraction was freeze-dried for further analyses.

\subsection{Electrospinning}

Electrospun hybrid fibers were generated from PLA-BCNW solutions in HFP. Those solutions contained a total solids content of $6 \mathrm{wt} .-\%$ and the BCNW concentration was $15 \%(\mathrm{w} / \mathrm{w}) \mathrm{BCNW}$, regarding the PLA weight. A previous work showed that a high incorporation degree of BCNW into the electrospun fibers was achieved when using these solutions (Martínez-Sanz et al., 2012a).

Cellulose nanowhiskers, in the form of a partially hydrated precipitate, were dispersed in the solvent by applying intense homogenization (Ultra-turrax) for 2 minutes and sonication for 30 seconds and were then stirred with the PLA at $40^{\circ} \mathrm{C}$.

The electrospinning apparatus was a Fluidnatek ${ }^{\circledR}$ basic equipment, manufactured by the engineering division of BioInicia S.L., Valencia (Spain). Solutions were transferred to $5 \mathrm{ml}$ plastic syringes and connected through an PTFE tube to a stainless steel needle $(\varnothing 0.9 \mathrm{~mm})$. A high-voltage $0-30 \mathrm{kV}$ power supply operating at $10-12 \mathrm{kV}$, and the polymer solution was fed into the needles at 
a rate of $0.66 \mathrm{ml} / \mathrm{h}$ by a syringe pump. The counter electrode was connected to a rectangular plate covered by aluminum foil to collect the electrospun fibers. The distance between the needle and the plate was $10 \mathrm{~cm}$ and experiments were carried out at ambient temperature.

\subsection{Preparation of films}

Nanocomposite PLA films were prepared using 3 different methods: The traditional method of melt mixing the matrix directly with the freeze-dried nanofiller, and by melt compounding of PLA pellets with masterbatches containing 15 wt.-\% BCNW. Those masterbatches were produced by two different routes, as explained below.

The first method consisted in the incorporation of cellulose nanowhiskers into PLA fibers by means of the electrospinning technique. Electrospun PLA fibers containing $15 \%(\mathrm{w} / \mathrm{w})$ BCNW were melt-mixed with PLA pellets in order to obtain blends having a final concentration of 1, 2 and 3 wt.-\% BCNW (sample codes: $1 \%$ BCNW ES, $2 \%$ BCNW ES and 3\% BCNW ES).

The second method involved the preparation of EVOH44 solutions containing a $15 \%(\mathrm{w} / \mathrm{w})$ of $\mathrm{BCNW}$. Partially hydrated BCNW were dispersed in water by means of homogenization (Ultra-turrax) and sonication. This aqueous dispersion was mixed with 2-propanol so that the final ratio was $70 / 30(\mathrm{v} / \mathrm{v}) 2$ propanol/water and a $5 \%(\mathrm{w} / \mathrm{v})$ EVOH was dissolved together with the nanowhiskers. These solutions were then quenched by adding liquid nitrogen and the obtained product was then dried at $60^{\circ} \mathrm{C}$ until complete evaporation of the remaining solvent and grinded to form a powder. This powder was then used to produce films by melt-mixing the adequate amount of it with PLA pellets in order to obtain films containing 1, and 2 wt.- $\%$ BCNW (sample codes: 1\% BCNW P 
and $2 \%$ BCNW P). Additionally, a reference film was prepared by melt mixing PLA with 16 wt.- $\%$ EVOH (as the total concentration of BCNW and EVOH in the $2 \%$ BCNW P film was 16 wt. $-\%$ ) with the purpose of differentiating the effects caused by the $\mathrm{EVOH}$ and those caused by the $\mathrm{BCNW}$ in the nanocomposite films.

Regarding the traditional method, films containing 1 and 2 wt.- $\%$ of BCNW were produced by melt-mixing the freeze-dried material with the required amount of PLA pellets (sample codes: 1\% BCNW FD and 2\% BCNW FD).

PLA blends were prepared in a Brabender Plastograph mixer during $3 \mathrm{~min}$ at $60 \mathrm{rpm}$ and $160^{\circ} \mathrm{C}$. The blends containing EVOH44 were produced by mixing 3 $\min$ at $100 \mathrm{rpm}$ and $170^{\circ} \mathrm{C}$. The batches were then subjected to a rapid coolingdown and they were subsequently compression molded into films using a hotplate hydraulic press $\left(160^{\circ} \mathrm{C}\right.$ or $170^{\circ} \mathrm{C}$ and $2 \mathrm{MPa}$ for $\left.2 \mathrm{~min}\right)$. The so-obtained films had a thickness between 60 and $150 \mu \mathrm{m}$ as measured with a Mitutoyo micrometer by averaging four measurements on each sample.

\subsection{Molecular weight determination}

The molecular weight of neat PLA and of the nanocomposite materials before and after being processed by melt compounding and compression molding was measured in an Ubbelhode viscosimeter at $25^{\circ} \mathrm{C}$. The intrinsic viscosity [ $\eta$ ] for PLA and its nanocomposites was determined for $1 \mathrm{~g} / \mathrm{dl}$ solutions in chloroform and, subsequently, the viscosity-average molecular weight was calculated using the Mark-Houwink-Sakurada equation:

$$
\mathrm{M}_{v}=\mathrm{K} \cdot[\eta]^{\alpha}
$$

where the parameters for PLA in chloroform at $25^{\circ} \mathrm{C}$ are $\alpha=0.79$ and $\mathrm{K}=1.33 \cdot 10^{-3}$ $\mathrm{ml} / \mathrm{g}$ (Van De Witte et al., 1996). 


\subsection{Scanning Electron Microscopy (SEM)}

SEM was conducted on a Hitachi microscope (Hitachi S-4100) at an accelerating voltage of $10 \mathrm{KV}$ and a working distance of 12-16 mm. Electrospun fibers and films cryo-fractured after immersion in liquid nitrogen were sputtered with a gold-palladium mixture under vacuum before their morphology was examined using SEM. The diameters of the electrospun fibers were measured by means of the Adobe Photoshop CS3 extended software from the SEM micrographs in their original magnification.

\subsection{Transmission Electron Microscopy (TEM)}

Ultra-thin sections of microtomed thin composite sheets were observed through TEM. The samples were stained with a $2 \mathrm{wt} .-\%$ solution of uranyl acetate. TEM was performed using a JEOL 1010 equipped with a digital Bioscan (Gatan) image acquisition system at $80 \mathrm{KV}$.

\subsection{Optical microscopy}

Polarized light microscopy (PLM) examinations were performed using a Nikon Eclipse 90i optical microscope (IZASA, Spain) equipped with a 5megapixels cooled digital colour microphotography camera Nikon Digital Sight DS-5Mc. Captured images were analyzed and processed by using Nis-Elements BR software.

\subsection{Attenuated Total Reflectance (ATR) FT-IR analysis}

ATR-FTIR spectra of BCNW and all the obtained films were recorded in a controlled chamber at $21^{\circ} \mathrm{C}$ and $40 \% \mathrm{RH}$ using a Bruker (Rheinstetten, Germany) FT-IR Tensor 37 equipment and coupling the ATR accessory GoldenGate of Specac Ltd. (Orpington, UK). The spectra were taken at $4 \mathrm{~cm}^{-1}$ resolution 
averaging a minimum of 20 scans. Analysis of the spectra was performed using Grams/AI 7.02 (Galactic Industries, Salem, NH, USA) software.

\subsection{X-ray Diffraction (XRD)}

X-ray diffraction was carried out on a D5005 Bruker diffractometer. The instrument was equipped with a $\mathrm{Cu}$ tube and a secondary monochromator. The configuration of the equipment was $\theta-2 \theta$ and the samples were examined over the angular range of $5^{\circ}$ to $45^{\circ}$ with a step size of $0.02^{\circ}$ and a count time of $4 \mathrm{~s}$ per point.

\subsection{Differential scanning calorimetry (DSC)}

Differential scanning calorimetry (DSC) of PLA electrospun fibers was performed on a Perkin-Elmer DSC 7 thermal analysis system on typically $4 \mathrm{mg}$ of dry material at a scanning rate of $10^{\circ} \mathrm{C} / \mathrm{min}$ from room temperature to the melting point using $\mathrm{N}_{2}$ as the purging gas. The first and second melting endotherms after controlled crystallization at $10^{\circ} \mathrm{C} / \mathrm{min}$ from the melt, were analyzed. Before evaluation, similar runs of an empty pan were subtracted from the thermograms. The DSC equipment was calibrated using indium as a standard.

The crystallinity (\%) of the PLA was estimated from the corrected enthalpy for biopolymer content in the hybrid fibers, using the ratio between the enthalpy of the studied material and the enthalpy of a perfect PLA crystal, i.e. $X_{C}(\%)=\frac{\Delta H_{f}-\Delta H_{c}}{\Delta H_{f}^{0}} \times 100$, where $\Delta H_{f}$ is the enthalpy of fusion and $\Delta H_{C}$ the enthalpy of cold crystallization of the studied specimen, and $\Delta H^{0}$ is the enthalpy of fusion of a totally crystalline material. The $\Delta E_{\rho}^{0}$ used for this equation was $93 \mathrm{~J} / \mathrm{g}$ for PLA (Liu et al., 1997). 


\subsection{Thermogravimetric analysis (TGA)}

Thermogravimetric (TG) curves were recorded with a TA Instruments model Q500 TGA. The samples (ca. $20 \mathrm{mg}$ ) were heated from $50^{\circ} \mathrm{C}$ to $600^{\circ} \mathrm{C}$ with a heating rate of $10^{\circ} \mathrm{C} / \mathrm{min}$ under nitrogen atmosphere. Derivative TG curves (DTG) express the weight loss rate as a function of temperature.

\subsection{Water vapour permeability (WVP)}

Direct permeability to water was determined from the slope of the weight loss versus time curves at $24^{\circ} \mathrm{C}$. The films were sandwiched between the aluminium top (open O-ring) and bottom (deposit for the permeant) parts of a specifically designed permeability cell with screws. A Viton rubber O-ring was placed between the film and the bottom part of the cell to enhance sealability. These permeability cells containing water as the permeant were then placed inside a desiccator at $0 \% \mathrm{RH}$ and the solvent weight loss through a film area of $0.001 \mathrm{~m}^{2}$ was monitored and plotted as a function of time. The samples were pre-conditioned at the testing conditions for 24 hours, and to estimate the permeability values of the films, only the linear part of the weight loss data was used to ensure sample steady state conditions. Cells with aluminium films (with thickness of ca. $11 \mu \mathrm{m}$ ) were used as control samples to estimate solvent loss through the sealing. The lower limit of WVP detection of the permeation cells was of ca. $0.008 \cdot 10^{-15} \mathrm{~kg} \cdot \mathrm{m} / \mathrm{s} \cdot \mathrm{m}^{2} \cdot \mathrm{Pa}$ based on the weight loss measurements of the aluminium films. Water vapour weight loss was calculated as the total cell weight loss minus the loss through the sealing. The tests were done in duplicate and averaged.

\subsection{Water uptake}

The water uptake was estimated during the sorption experiments at $24^{\circ} \mathrm{C}$ and $100 \%$ RH by means of weight gain using an analytical balance Voyager ${ }^{\circledR}$ V11140. 
Thus, at saturation conditions, no changes in successive weight uptake were observed during the measurements of the specimens.

Solubility (S), required to estimate the diffusion coefficient of water (D) through the films, was estimated from the water uptake at equilibrium, the density of the materials and the water vapor partial pressure at $24^{\circ} \mathrm{C}$.

\subsection{Mechanical properties}

Tensile tests were carried out at ambient conditions typically at $24^{\circ} \mathrm{C}$ and $50 \%$ RH on an Instron 4400 Universal Tester. Pre-conditioned dumb-bell shaped specimens with initial gauge length of $25 \mathrm{~mm}$ and $5 \mathrm{~mm}$ in width were die-stamped from the films in the machine direction according to the ASTM D638. A fixed crosshead rate of $10 \mathrm{~mm} / \mathrm{min}$ was utilized in all cases and results were taken as the average of, at least, four tests.

\subsection{Oxygen permeability}

The oxygen permeability coefficient was derived from oxygen transmission rate (OTR) measurements recorded using an Oxtran 100 equipment (Modern Control Inc., Minneapolis, MN, US). Experiments were carried out at $24^{\circ} \mathrm{C}$ and at two relative humidities ( $0 \% \mathrm{RH}$ and $80 \% \mathrm{RH}) .80 \%$ relative humidity was generated by a built-in gas bubbler and was checked with a hygrometer placed at the exit of the detector. The samples were purged with nitrogen for a minimum of $20 \mathrm{~h}$ in the humidity equilibrated samples, prior to exposure to an oxygen flow of $10 \mathrm{ml} / \mathrm{min}$. A $5 \mathrm{~cm}^{2}$ sample area was measured by using an in-house developed mask. Reduced sample areas while testing oxygen permeation in high permeable materials enhances the reproducibility of the measurements, permits to select defect-free areas and ensures minimum thickness variations. 
The diffusion coefficient (D) was estimated by the half-time method (Hertlein et al., 1995). The time $t_{1 / 2}$ is the point at which the transfer rate has reached $50 \%$ of the steady state flow. The relationship between the diffusion coefficient D and the time $t_{1 / 2}$ is derived by normalizing the equation of Fick's second law (Hiltner et al., 2005) (equation 1). Taking into account that for $t_{1 / 2}$ the OTR is half of the OTR reached in the steady state, $\mathrm{D}$ can be calculated from equation 2 :

$$
\begin{aligned}
& \operatorname{OTR}(t)=\frac{P p}{l}\left[1+2 \sum_{n=1}^{\infty}(-1)^{n} \exp \left(-\frac{D \pi^{2} n^{2} t}{l^{2}}\right)\right] \\
& D=\frac{l^{2}}{7.199 \cdot t_{1 / 2}}
\end{aligned}
$$

Where $\mathrm{p}$ is the oxygen partial pressure and 1 is the film thickness.

The solubility coefficient (S) was subsequently calculated from the following equation:

$$
P=D \times S
$$

\subsection{Statistical analysis}

One-way analysis of the variance (ANOVA) was performed using Statgraphics 5.1 software package. Comparisons between samples were evaluated using the Tukey test. 


\section{RESULTS AND DISCUSSION}

The main objective of this work was to optimize the dispersion of bacterial cellulose nanowhiskers (BCNW) within PLA matrices when producing nanocomposite films by the melt compounding technique, in order to improve the mechanical and barrier properties of this biopolyester while retaining the inherent transparency of the PLA matrix. The nanofiller, produced by acid hydrolysis of bacterial cellulose pellicles, consisted of highly crystalline BCNW with a crystallinity index of ca. 95\%, as previously estimated by X-ray diffraction (Martínez-Sanz et al., 2011a). The morphology of BCNW extracted by sulphuric acid hydrolysis has been previously studied. In a previous work (Martínez-Sanz et al., 2011a), it was shown that BCNW extracted by the optimized hydrolysis conditions applied in the present work presented an average cross-section (W) of ca. $18 \mathrm{~nm}$ and length (L) of ca. $570 \mathrm{~nm}$ having, thus, an aspect ratio (L/W) of 29. Additionally, TGA analyses showed that BCNW presented a degradation temperature peak at approximately $317^{\circ} \mathrm{C}$ and they could be subjected to the temperatures required for melt compounding of PLA since the degradation onset temperature was at $226^{\circ} \mathrm{C}$ (Martínez-Sanz et al., 2013a).

Three different methods were employed for the incorporation of BCNW into PLA by melt compounding: Melt mixing of PLA with freeze-dried BCNW, preincorporation of BCNW into electrospun PLA fibers and subsequent melt mixing with PLA pellets and pre-incorporation of $\mathrm{BCNW}$ into $\mathrm{EVOH}$ and subsequent melt blending with PLA. The production of PLA hybrid fibers has already been optimized and the chosen system, with 15 wt.-\% BCNW, gave rise to electrospun nanostructured fibers with an average diameter of $90.70 \pm 49.09 \mathrm{~nm}$ (MartínezSanz et al., 2012a). 
Thermal properties of the PLA and EVOH neat polymers and the corresponding hybrid materials after the incorporation of $15 \mathrm{wt} . \% \mathrm{BCNW}$ by electrospinning and precipitation, respectively, are displayed in Table 1. From this table it can be observed that the incorporation of BCNW hinders the crystallization of the polymeric matrices, both for PLA and EVOH; however, this effect was more obvious in the case of the EVOH precipitate containing nanowhiskers. This was due to the quenching of the polymeric matrix when immersed in liquid nitrogen, which hindered proper EVOH crystallization. It is also worth noting that, in the case of electrospun PLA fibers, whereas the $T_{g}$ determined from the second heating run was not significantly altered, before erasing the thermal history of the material, i.e. during the first heating run, the $\mathrm{T}_{\mathrm{g}}$ increased in the hybrid material, indicating that the mobility of the polymeric chains was reduced by the incorporation of BCNW, which might be a consequence of the reported interactions established between the matrix and the nanowhiskers (Martínez-Sanz et al., 2012a). 
Table 1. DSC maximum of melting $\left(\mathrm{T}_{\mathrm{m}}\right)$, melting enthalpy $\left(\Delta \mathrm{H}_{\mathrm{m}}\right)$, degree of crystallinity $\left(\mathrm{X}_{\mathrm{c}}\right)$ and glass transition temperature, obtained from the first $\left(\mathrm{T}_{\mathrm{g} 1}\right)$ and second $\left(\mathrm{T}_{\mathrm{g} 2}\right)$ heating run of electrospun pure PLA fibers, hybrid PLA fibers incorporating 15 wt.- $\% \mathrm{BCNW}$, neat $\mathrm{EVOH}$ and a precipitate of EVOH containing 15 wt.-\% BCNW.

\begin{tabular}{|c|c|c|c|c|c|}
\cline { 2 - 6 } \multicolumn{1}{c|}{} & $\mathrm{T}_{\mathrm{m}}\left({ }^{\circ} \mathrm{C}\right)$ & $\begin{array}{c}\Delta \mathrm{H}_{\mathrm{m}}(\mathrm{J} / \mathrm{g} \text { PLA } \\
\text { or EVOH })\end{array}$ & $\mathrm{X}_{\mathrm{c}}(\%)$ & $\mathrm{T}_{\mathrm{g} 1}\left({ }^{\circ} \mathrm{C}\right)$ & $\mathrm{T}_{\mathrm{g} 2}\left({ }^{\circ} \mathrm{C}\right)$ \\
\hline Electrospun PLA & $153.6 \pm 0.1$ & $46.5 \pm 4.8$ & $34.2 \pm 5.8$ & $57.8 \pm 0.3$ & $59.1 \pm 0.0$ \\
\hline $\begin{array}{c}\text { Electrospun } \\
\text { PLA+15\%BCNW }\end{array}$ & $153.6 \pm 0.4$ & $27.5 \pm 2.9$ & $23.6 \pm 0.6$ & $59.1 \pm 0.1$ & $59.4 \pm 0.0$ \\
\hline EVOH pellets & $160.5 \pm 1.4$ & $73.0 \pm 1.3$ & $33.7 \pm 0.6$ & --- & $49.8 \pm 2.0$ \\
\hline $\begin{array}{c}\text { Precipitated } \\
\text { EVOH+15\%BCNW }\end{array}$ & $157.4 \pm 0.5$ & $38.7 \pm 9.2$ & $17.8 \pm 4.3$ & --- & $48.4 \pm 0.7$ \\
\hline
\end{tabular}

\subsection{Differences in nanocomposite films morphology related to the various} BCNW incorporation methods

The previously described materials incorporating high concentrations of $\mathrm{BCNW}$, as well as freeze-dried nanowhiskers, were subsequently melt mixed with PLA and pressed into films by compression molding. Figure 1 shows the contact transparency images of the obtained PLA-BCNW films. As observed, all the hybrid films except for the ones containing EVOH showed a similar contact transparency, which was not significantly different from that of the pure PLA film. For the case of the films produced using freeze-dried BCNW (Fig. 1F), agglomerates were clearly detected by visual examination, hence indicating that this method led to a poorer dispersion of the nanofiller within the PLA matrix. For the films produced through melt mixing of PLA with electrospun hybrid fibers 
(cf. Fig. 1B and 1C), a good contact transparency was observed, which may indicate a good dispersion of the BCNW. However, a yellowish tone could be detected in these nanocomposite materials when increasing the filler concentration above 2 wt.-\% BCNW. As observed in Figure 1D, the contact transparency was significantly decreased for the PLA films containing EVOH, which was probably the result of the lack of miscibility between the polymers leading to a phase separation in agreement with previous works (Nordqvist et al., 2010; SanchezGarcia et al., 2011). This optical effect was smoothed by incorporating BCNW into the films (cf. Fig. 1E), even though contact transparency was still slightly lower than for the rest of the PLA films. This observation seems to indicate that the addition of BCNW improved the compatibility between both polymeric matrices as it will be later proved.
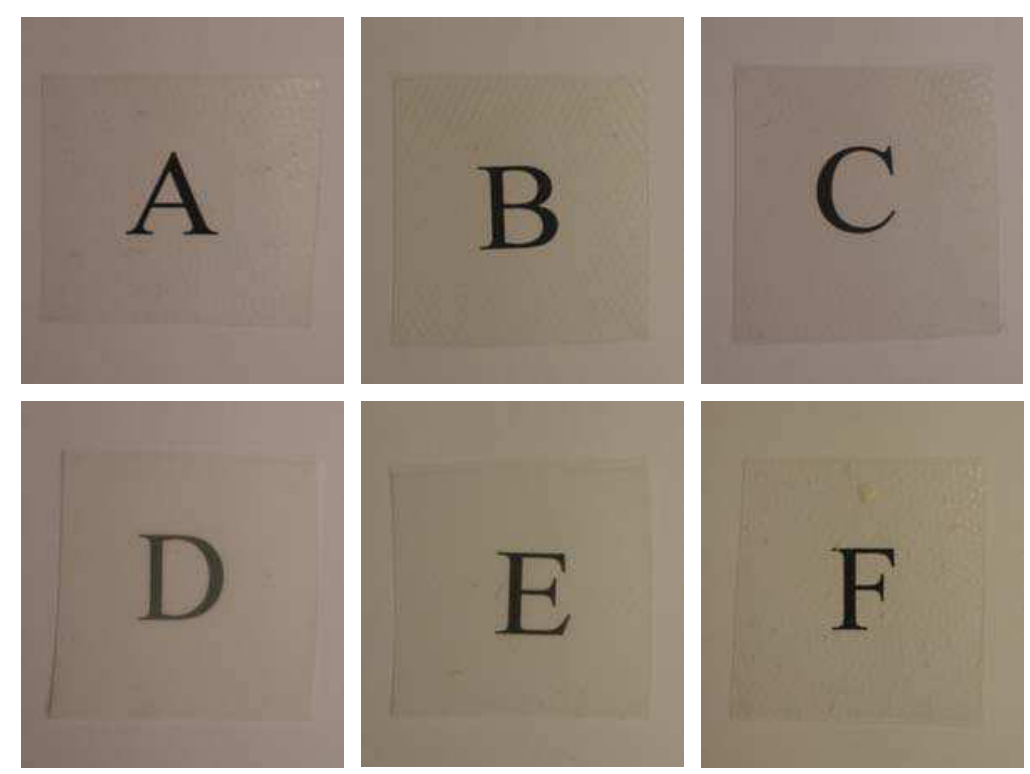

Figure 1. Contact transparency pictures of films containing: (A) Pure PLA; (B) $2 \%$ BCNW ES; (C) 3\% BCNW ES; (D) PLA+16\%EVOH; (E) 2\% BCNW P; (F) 2\% BCNW FD. 
Observation of the different films by optical microscopy with polarized light (cf. Figure 2) confirmed the low dispersion achieved in the case of films incorporating freeze-dried $\mathrm{BCNW}$, in which it was possible to clearly detect nanofiller agglomerates. The degree of dispersion of $\mathrm{BCNW}$ improves significantly within the PLA matrix by pre-incorporating them either through the EVOH precipitate or dispersed into PLA electrospun fibers. In the former case, very small aggregates were detected, whereas in the latter case a highly dispersed system was obtained, even though some small aggregates were still observed in the microscopy pictures. 

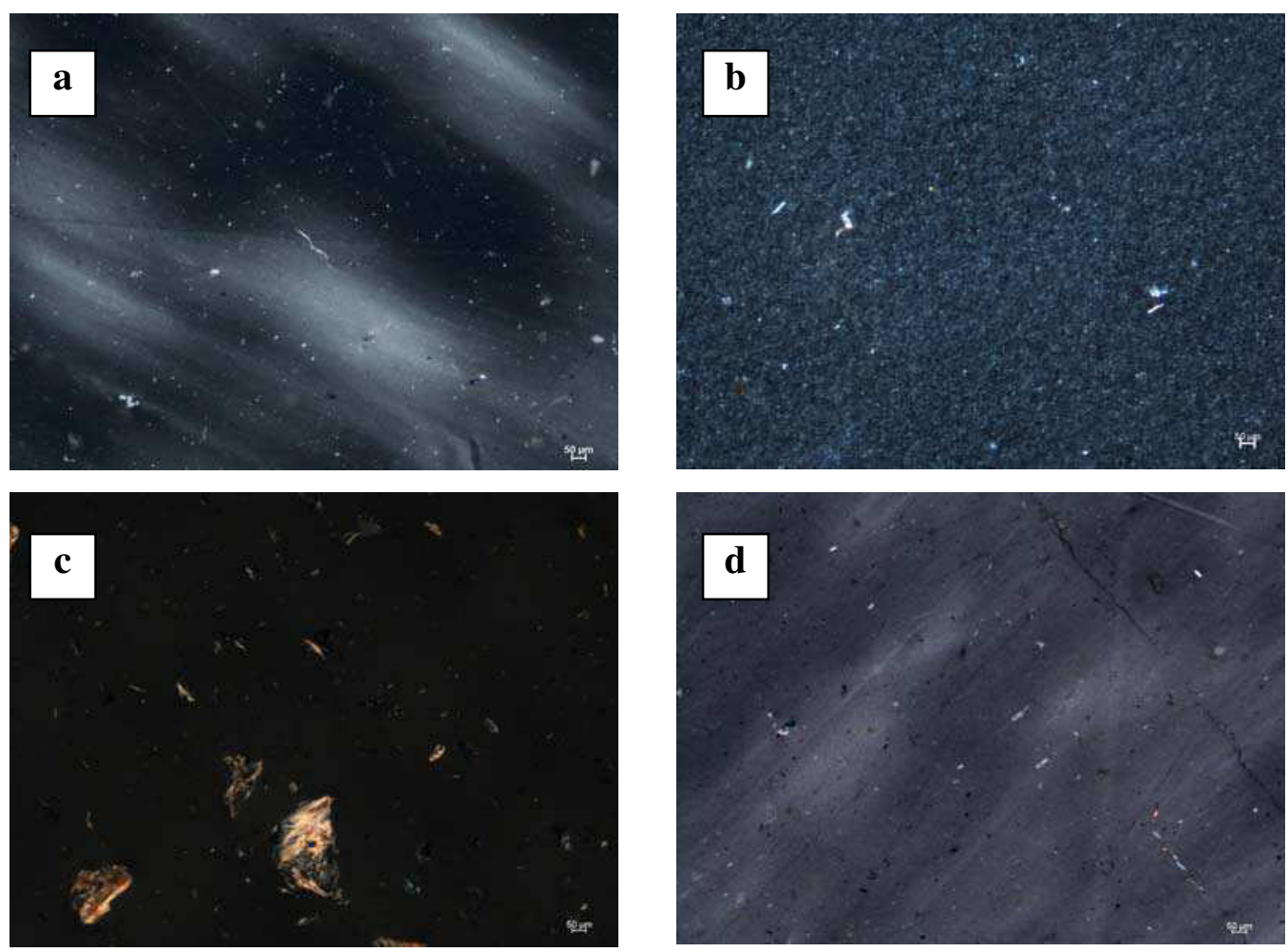

Figure 2. Polarized light optical microscopy images of PLA-BCNW films: (a) 2\% BCNW ES; (b) 2\% BCNW P; (c) 2\% BCNW FD and (d) 3\% BCNW ES. Scale markers correspond to 50 micrometres.

To further study the morphology and the dispersion of the nanofiller in the nanocomposite materials, the cryofractured surfaces of the films were observed by SEM. In Figure 3, it can be observed that the fracture surface of PLA and of the materials with $\mathrm{BCNW}$ did not comparatively exhibit many differences. However, in the nanocomposites some small voided features were clearly seen, particularly for the 2 wt.- $\%$ BCNW ES sample. The morphology of the PLA film incorporating $16 \% \mathrm{EVOH}$ coincides with that observed in a previous work (Nordqvist et al., 2010) for a PLA blend containing 10\%EVOH. A weak adhesion 
between the two polymers was suggested by the appearance of a phase separated structure along the fracture section (cf. Figure $3 b$ ). This lack of adhesion between the PLA matrix and the EVOH was responsible for the previously detected lower transparency of the films. However, the fracture surface became significantly more homogeneous when incorporating BCNW within the EVOH phase (cf. Figure $3 \mathrm{f}$ ). This is in agreement with a previous work in which it was observed that a more homogeneous morphology was attained in melt blended PLA-EVOH composites when amylopectin was incorporated into the system (Nordqvist et al., 2010). In the case of blending with freeze-dried BCNW, pull-outs and voids were observed, with an estimated average cross-section of $354 \pm 151 \mathrm{~nm}$ and $224 \pm 121$ $\mathrm{nm}$ for loadings of $1 \mathrm{wt} .-\%$ and $2 \mathrm{wt} .-\%$ BCNW, respectively (cf. Figure $3 \mathrm{e}$ as an example).

From all the nanocomposites analyzed, it seems that the most homogeneous morphology was achieved when incorporating $\mathrm{BCNW}$ through electrospun fibers (see Figures $3 \mathrm{c}$ and $3 \mathrm{~d}$ ). The films obtained through this incorporation method exhibited a rather homogeneous morphology across the fracture surface, with small voided features having cross-sections of $67.5 \pm 29.9 \mathrm{~nm}, 76.1 \pm 37.8 \mathrm{~nm}$, and $67.2 \pm 29.4 \mathrm{~nm}$ for loadings of 1 wt.- $\%, 2$ wt.- $\%$ and 3 wt.- $\%$ BCNW, respectively. From the estimated cross-sections it can be deduced that BCNW did not suffer significant agglomeration for loadings up to $3 \mathrm{wt} .-\%$.

In conclusion, from the SEM images it seems that, it was possible to obtain a morphology of highly dispersed nanowhiskers when incorporating them by means of electrospinning. 

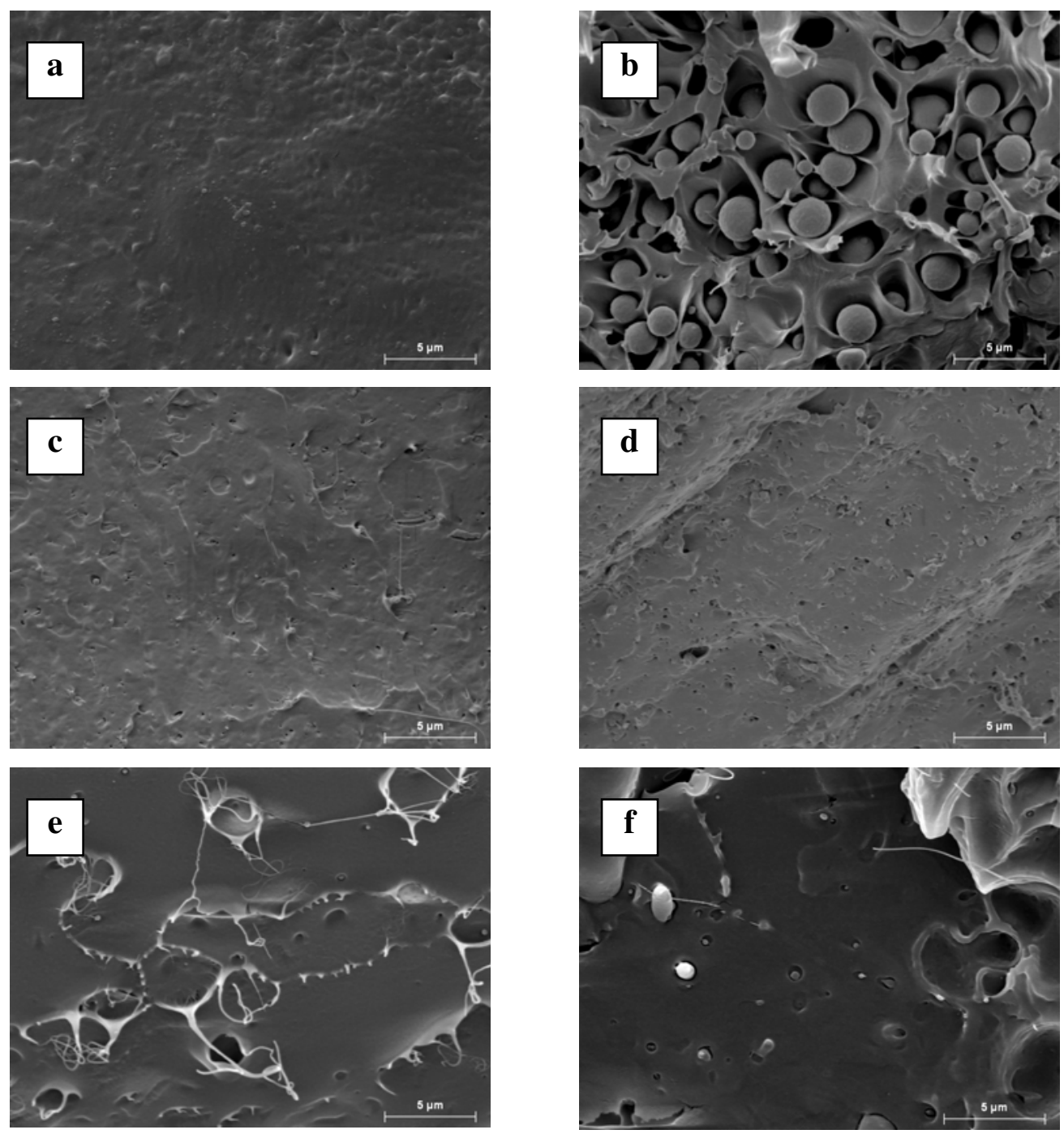

Figure 3. SEM micrographs of the cryo-fractured section obtained from PLA films: (a) Pure PLA; (b) PLA+16\% EVOH; (c) 1\% BCNW ES; (d) 2\% BCNW ES; (e) $2 \% \mathrm{BCNW}$ FD; (f) $2 \% \mathrm{BCNW}$ P. Scale markers correspond to 5 micrometres.

Figure 4 shows selected TEM images of various PLA nanocomposite films. TEM analyses confirmed that the dispersion of BCNW was poor when incorporating them as a freeze-dried material. Even for low concentrations of $1 \mathrm{wt}$.- 
$\%$ BCNW, nanofiller agglomerates could be easily detected (cf. Figure 4c). As a consequence of the freeze-drying process, strong hydrogen bonds between cellulose nanofibrils were established which were kept in the composite material. In the case of $\mathrm{BCNW}$ incorporated through $\mathrm{EVOH}$, a relatively good dispersion of the nanofiller was observed and no further aggregation was detected when increasing the BCNW content from 1 wt.- $\%$ to 2 wt.- $\%$. Nevertheless, BCNW incorporated through $\mathrm{EVOH}$ appeared as very short particles, whereas they presented the expected nanofibrillar morphology when incorporated by means of electrospinning.
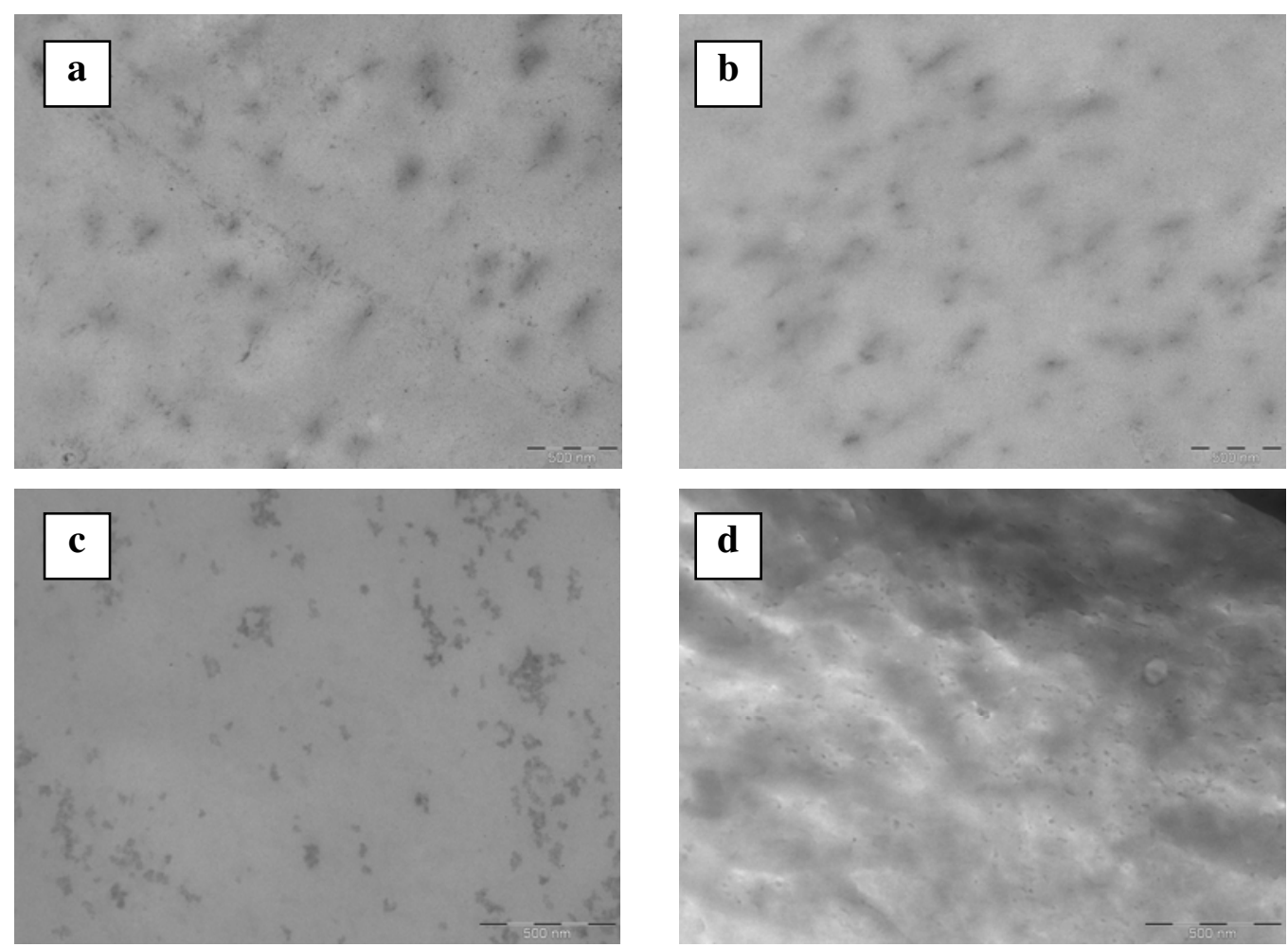

Figure 4. TEM micrographs of PLA films containing: (a) 2 wt.-\% BCNW ES; (b) 3 wt.-\% BCNW ES; (c) 1 wt.-\% BCNW FD and (d) 2 wt.-\% BCNW P. Scale markers correspond to 500 nanometres. 


\subsection{Effect of melt processing on the molecular weight of the PLA-based materials}

Previous studies have shown that melt processing of PLA with nanoadditives such as nanoclays, may lead to a reduction in the molecular weight of the polymer, since hydrolytic and adiabatic thermal degradation take place to a certain extent (Katiyar et al., 2010; Meng et al., 2012). Degradation of PLA and the subsequent molecular weight loss may affect the properties of the nanocomposite films and, therefore, it is important to confirm that the incorporation of BCNW did not involve molecular weight reduction of PLA during melt compounding. Table 2 gathers the molecular weight of PLA as determined by intrinsic viscosity before and after melt compounding and of the nanocomposites incorporating BCNW. As deduced from this table, the molecular weight of PLA was decreased by ca. $15 \%$ when melt processed into a film. A similar reduction was observed when processing PLA by double screw extruder even though the material was thoroughly dried before processing (Katiyar et al., 2010). A higher molecular weight reduction of ca. $33 \%$ with respect to the native PLA was observed for the PLA-EVOH blend probably due to the higher processing temperature applied for melting the EVOH phase and/or to the more hygroscopic nature of the EVOH polymer. The incorporation of BCNW did not lead to further decrease in viscosity in any case, in fact, it seems that BCNW protected the PLA matrix from the viscosity drop and, as a result, the molecular weight of nanocomposites incorporating BCNW was not reduced when compared to the control PLA and PLA/EVOH films, but it was even increased. Nevertheless, it might be expected that the filler itself, even at low additions, may promote some viscosity rise counteracting the molecular weight drop. 
Table 2. Intrinsic viscosity and viscosity-average molecular weight of native PLA pellets, PLA film produced by melt compounding and compression molding and nanocomposites incorporating $\mathrm{BCNW}$.

\begin{tabular}{|c|c|c|}
\cline { 2 - 3 } \multicolumn{1}{c|}{} & {$[\eta](\mathrm{dl} / \mathrm{g})$} & $\mathrm{M}_{v}(\mathrm{~g} / \mathrm{mol})$ \\
\hline Native PLA & 1.08 & $1.23 \cdot 10^{5}$ \\
\hline PLA Film & 0.96 & $1.05 \cdot 10^{5}$ \\
\hline $2 \% \mathrm{BCNW}$ ES & 1.08 & $1.23 \cdot 10^{5}$ \\
\hline $3 \% \mathrm{BCNW}$ ES & 1.08 & $1.23 \cdot 10^{5}$ \\
\hline $1 \% \mathrm{BCNW}$ FD & 1.04 & $1.18 \cdot 10^{5}$ \\
\hline $2 \% \mathrm{BCNW} F D$ & 1.02 & $1.14 \cdot 10^{5}$ \\
\hline PLA+16\%EVOH & 0.80 & $0.83 \cdot 10^{5}$ \\
\hline $1 \% \mathrm{BCNW} \mathrm{P}$ & 0.92 & $0.99 \cdot 10^{5}$ \\
\hline $2 \% \mathrm{BCNW} \mathrm{P}$ & 0.87 & $0.93 \cdot 10^{5}$ \\
\hline
\end{tabular}

\subsection{Thermal properties and thermal stability of the different PLA}

\section{nanocomposites}

With the aim of investigating the effects of the BCNW addition on the thermal properties of the PLA nanocomposites, DSC analyses of all the samples were carried out. The melting temperature $\left(T_{m}\right)$, melting enthalpy $\left(\Delta \mathrm{H}_{\mathrm{m}}\right)$ normalized to the PLA content of the nanocomposite films and the cold crystallization temperature $\left(\mathrm{T}_{\mathrm{CC}}\right)$ were obtained from the DSC first heating run, whereas the glass transition temperature was determined from both the first $\left(\mathrm{T}_{\mathrm{g} 1}\right)$ and the second heating run $\left(\mathrm{T}_{\mathrm{g} 2}\right)$ (cf. Table 3$)$. 
As deduced from the results in Table 3, the melting and glass transition temperatures were, in general, not significantly altered by the incorporation of BCNW. However, the melting enthalpy and the cold crystallization temperature were strongly dependent on the method applied for the incorporation of BCNW and on the subsequent level of nanofiller dispersion. Thus, whereas PLA-BCNW nanocomposites presented only one melting peak, the materials containing EVOH presented an additional melting step corresponding to the $\mathrm{EVOH}$ phase.

Only BCNW incorporated through electrospun fibers seemed to favour the cold crystallization process, significantly reducing the temperature at which crystallization began. A previous study related the decrease in the $T_{C C}$ observed for annealed PLA with the fact that crystallites formed during annealing increased the nucleating sites (Suryanegara et al., 2010). Therefore, it is hypothesized that well-dispersed BCNW crystallites acted as nucleating agents promoting a faster crystallization of PLA during heating. Both the cold crystallization and melting enthalpies were decreased with the addition of electrospun PLA fibers with BCNW but the crystallinity index of these composite materials was, in general, not significantly altered as compared to the pure PLA.

Regarding the glass transition temperature, even though it was previously observed to increase when incorporating BCNW into PLA electrospun fibers, this increase was not observed after erasing the thermal history of the material and, therefore, when melt mixed, the $T_{g}$ of the nanocomposite films was not significantly altered as compared to neat PLA.

When incorporating EVOH into the system, the cold crystallization process took place at a higher temperature and the glass transition temperature dropped 
down, just as listed in Table 3. This was not observed in the same material after incorporating $\mathrm{BCNW}$ (i.e. $2 \% \mathrm{BCNW}$ P), but the thermal properties were not significantly different to the ones of neat PLA. The differences in thermal properties of the PLA/EVOH blend film can be explained by the poor compatibility between both polymeric materials while, as shown before in the morphological analysis, the addition of $\mathrm{BCNW}$ improved their interactions resulting in a more homogeneous material. Additionally, the incorporation of BCNW affected the EVOH phase thermal properties just as deduced from Table 4. A lower EVOH crystallinity was observed for the PLA-EVOH film and addition of $\mathrm{BCNW}$ further reduced it, supporting the hypothesis that strong interactions between $\mathrm{BCNW}$ and $\mathrm{EVOH}$ were developed and, as a result, the crystallization process was impaired. The greater affinity of BCNW with EVOH could imply that stronger interactions were developed with this polymer than with the PLA matrix. Hence, the thermal properties of EVOH were more markedly affected by the incorporation of BCNW than those of PLA. 
Table 3. DSC maximum of melting $\left(\mathrm{T}_{\mathrm{m}}\right)$, melting enthalpy $\left(\Delta \mathrm{H}_{\mathrm{m}}\right)$, cold crystallization temperature $\left(\mathrm{T}_{\mathrm{CC}}\right)$, cold crystallization enthalpy $\left(\Delta \mathrm{H}_{\mathrm{CC}}\right)$, PLA crystallinity $\left(\mathrm{X}_{\mathrm{c}}\right)$ and glass transition temperature of PLA films, obtained during the first $\left(\mathrm{T}_{\mathrm{g} 1}\right)$ and second $\left(\mathrm{T}_{\mathrm{g} 2}\right)$ heating runs.

\begin{tabular}{|l|c|c|c|c|c|c|c|}
\cline { 2 - 7 } \multicolumn{1}{c|}{} & $\mathrm{T}_{\mathrm{m}}\left({ }^{\circ} \mathrm{C}\right)$ & $\begin{array}{c}\Delta \mathrm{H}_{\mathrm{m}}(\mathrm{J} / \mathrm{g} \\
\mathrm{PLA})\end{array}$ & $\mathrm{T}_{\mathrm{CC}}\left({ }^{\circ} \mathrm{C}\right)$ & $\begin{array}{c}\Delta \mathrm{H}_{\mathrm{CC}}(\mathrm{J} / \mathrm{g} \\
\mathrm{PLA})\end{array}$ & $\mathrm{X}_{\mathrm{c}}(\%)$ & $\mathrm{T}_{\mathrm{g} 1}\left({ }^{\circ} \mathrm{C}\right)$ & $\mathrm{T}_{\mathrm{g} 2}\left({ }^{\circ} \mathrm{C}\right)$ \\
\hline PLA & $150.8 \pm 2.5$ & $26.1 \pm 0.7$ & $119.0 \pm 1.8$ & $11.5 \pm 0.5$ & $15.7 \pm 0.2$ & $59.8 \pm 1.8$ & $59.5 \pm 1.1$ \\
\hline $1 \%$ BCNW ES & $151.6 \pm 1.5$ & $21.5 \pm 0.5$ & $104.7 \pm 0.9$ & $4.3 \pm 3.7$ & $18.5 \pm 4.6$ & $58.9 \pm 0.0$ & $59.0 \pm 0.3$ \\
\hline $2 \%$ BCNW ES & $148.5 \pm 2.0$ & $24.9 \pm 1.1$ & $109.7 \pm 1.4$ & $13.3 \pm 0.9$ & $12.5 \pm 0.2$ & $57.9 \pm 0.5$ & $59.3 \pm 0.8$ \\
\hline $3 \%$ BCNW ES & $150.3 \pm 3.2$ & $18.3 \pm 0.6$ & $108.9 \pm 1.9$ & $2.6 \pm 1.6$ & $16.9 \pm 1.1$ & $59.2 \pm 0.6$ & $59.3 \pm 0.3$ \\
\hline $1 \%$ BCNW FD & $150.9 \pm 2.1$ & $23.9 \pm 0.8$ & $118.9 \pm 1.6$ & $9.4 \pm 0.6$ & $15.6 \pm 0.2$ & $57.8 \pm 1.3$ & $59.4 \pm 1.0$ \\
\hline $2 \%$ BCNW FD & $150.2 \pm 0.7$ & $23.8 \pm 2.9$ & $120.4 \pm 3.3$ & $9.3 \pm 0.4$ & $15.6 \pm 2.6$ & $57.4 \pm 2.3$ & $58.9 \pm 0.1$ \\
\hline PLA+16\%EVOH & $151.3 \pm 1.5$ & $21.8 \pm 1.0$ & $122.7 \pm 1.7$ & $8.1 \pm 1.9$ & $14.8 \pm 1.0$ & $56.1 \pm 0.5$ & $59.2 \pm 0.5$ \\
\hline $1 \%$ BCNW P & $151.0 \pm 2.4$ & $27.4 \pm 0.4$ & $120.9 \pm 2.1$ & $10.5 \pm 0.4$ & $18.2 \pm 0.8$ & $58.6 \pm 1.3$ & $59.5 \pm 1.3$ \\
\hline $2 \%$ BCNW P & $149.8 \pm 0.1$ & $25.5 \pm 0.1$ & $119.5 \pm 1.2$ & $7.6 \pm 3.7$ & $19.3 \pm 3.9$ & $59.2 \pm 1.2$ & $58.7 \pm 0.3$ \\
\hline
\end{tabular}


Table 4. DSC maximum of melting $\left(\mathrm{T}_{\mathrm{m}}\right)$, melting enthalpy $\left(\Delta \mathrm{H}_{\mathrm{m}}\right)$ and crystallinity $\left(\mathrm{X}_{\mathrm{c}}\right)$ corresponding to $\mathrm{EVOH}$, obtained during the first heating run.

\begin{tabular}{|lc|c|c|}
\cline { 2 - 4 } \multicolumn{1}{c|}{} & $\mathrm{T}_{\mathrm{m}}\left({ }^{\circ} \mathrm{C}\right)$ & $\Delta \mathrm{H}_{\mathrm{m}}(\mathrm{J} / \mathrm{g}$ EVOH $)$ & $\mathrm{X}_{\mathrm{c}}(\%)$ \\
\hline EVOH44 & $165.6 \pm 0.6$ & $60.6 \pm 3.8$ & $28.0 \pm 1.8$ \\
\hline PLA+16\%EVOH & $163.5 \pm 1.2$ & $28.4 \pm 1.1$ & $13.1 \pm 0.5$ \\
\hline $2 \%$ BCNW P & $162.9 \pm 2.4$ & $10.0 \pm 1.4$ & $4.6 \pm 0.7$ \\
\hline 2\%NW P & $161.0 \pm 0.2$ & $12.6 \pm 2.4$ & $5.8 \pm 1.1$ \\
\hline
\end{tabular}

The thermal stability of the nanocomposite materials was evaluated through TGA. In general, as observed in Table 5, the incorporation of BCNW did not lead to any remarkable effect on the thermal stability of the nanocomposites. Despite the fact that native BCNW are less thermally stable than the PLA matrix, the only case in which the thermal stability was reduced was for the 1 wt.- $\%$ BCNW samples, probably because at greater loadings a somewhat stronger nanowhiskers network was created hence leading to restricted mobility of the polymer chain and limiting thermal degradation, just as it was reported for PHA nanocomposites loaded with cellulose nanocrystals ( $\mathrm{Yu}$ et al., 2012). Incorporation of EVOH slightly decreased the degradation temperature, which might be a consequence of the decreased molecular weight in the PLA promoted by the EVOH (cf. Table 2). In this case, the degradation occurred in two different steps. It is known that the degradation profile of pure EVOH44 presents two steps with degradation temperatures of ca. $377^{\circ} \mathrm{C}$ and $451^{\circ} \mathrm{C}$. The first step corresponds to degradation of the vinyl alcohol component, whereas the second degradation stage is assigned to the ethylene fraction (Alvarez et al., 2003). From the TGA curve of the $\mathrm{PLA} / \mathrm{EVOH}$ blend, the lower temperature of the first peak suggests that the ethylene part of the EVOH polymer was not affected, whereas it seems not to be 
the case for the vinyl alcohol part in the presence of PLA. The slight decrease in the temperature of the first peak during the TGA experiment of the composite PLA/EVOH was, nevertheless, counteracted by the incorporation of BCNW, hence supporting that a better stability for the blend, as well as a better morphology, was promoted by the nanofiller.

Table 5. TGA maximum of the weight loss first derivate $\left(T_{D}\right)$ and the corresponding peak onset values and the residue at $400^{\circ} \mathrm{C}$ for the PLA films.

\begin{tabular}{|c|c|c|c|}
\hline & Onset $\mathrm{T}\left({ }^{\circ} \mathrm{C}\right)$ & $\mathrm{T}_{\mathrm{D}}\left({ }^{\circ} \mathrm{C}\right)$ & Residue at $400^{\circ} \mathrm{C}(\%)$ \\
\hline PLA & 338.6 & 365.3 & 0.8 \\
\hline $1 \% \mathrm{BCNW}$ ES & 336.7 & 353.3 & 0.0 \\
\hline $2 \%$ BCNW ES & 329.4 & 371.2 & 0.0 \\
\hline $3 \% \mathrm{BCNW}$ ES & 342.2 & 368.0 & 1.0 \\
\hline $1 \% \mathrm{BCNW}$ FD & 342.2 & 366.6 & 0.9 \\
\hline $2 \% \mathrm{BCNW} F D$ & 343.1 & 368.9 & 0.0 \\
\hline \multirow{2}{*}{$\mathrm{PLA}+16 \% \mathrm{EVOH}$} & 330.2 & 356.4 & \multirow{2}{*}{11.2} \\
\hline & 398.3 & 453.9 & \\
\hline \multirow{2}{*}{$1 \% \mathrm{BCNW} P$} & 332.6 & 350.2 & \multirow{2}{*}{0.0} \\
\hline & 393.8 & 445.9 & \\
\hline \multirow{2}{*}{$2 \% \mathrm{BCNW} P$} & 335.6 & 365.8 & \multirow{2}{*}{7.6} \\
\hline & 407.4 & 456.6 & \\
\hline \multirow{2}{*}{ EVOH44 } & 353.3 & 376.8 & \multirow{2}{*}{0.0} \\
\hline & 376.8 & 450.8 & \\
\hline
\end{tabular}




\subsection{Crystal structure of the developed PLA nanocomposites}

$\mathrm{X}$-ray diffraction experiments were carried out in order to study the crystalline structure of the developed PLA nanocomposites. Figures $5 \mathrm{a}$ and $5 \mathrm{~b}$ display the XRD patterns of nanocomposites incorporating BCNW by means of different methods and with increasing BCNW loading via electrospun fibers, respectively. As observed in Figure 5a, the crystalline peaks observed in the diffraction patterns were different depending on the incorporation method. Whereas the three characteristic peaks from cellulose, appearing at $14.8^{\circ}, 16.4^{\circ}$ and $22.5^{\circ}$ which corresponded to the $101,10 \overline{1}$ and 002 crystal planes from cellulose I respectively (Moharram \& Mahmoud, 2007), could be detected for the sample incorporating 2 wt.-\% electrospun fibers, only the peak appearing at $22.5^{\circ}$ was discerned in the patterns of the films incorporating the $\mathrm{BCNW}$ via $\mathrm{EVOH}$ precipitation or from freeze-dried material. Additionally, for the sample incorporating $2 \mathrm{wt} .-\% \mathrm{BCNW}$ via $\mathrm{EVOH}$, another peak located at $20.6^{\circ}$, which corresponded to the 110 reflection of orthorhombic EVOH, was observed.

As expected, when increasing the BCNW loading in the samples containing electrospun fibers, the intensity of the cellulose diffraction peaks increased, most markedly in the case of the peaks corresponding to the 101 and $10 \overline{1}$ crystal planes, although the peak corresponding to the 101 plane was not as clearly identified since it was overlapped with the PLA amorphous halo (cf. Figure 5b). From previous works, the peak corresponding to the 002 lattice plane showed the highest intensity in the diffraction patterns of native $\mathrm{BC}$ and $\mathrm{BCNW}$. The fact that the intensity of 101 and $10 \overline{1}$ became more intense after incorporating BCNW into PLA may be indicating that the nanocrystals were preferentially oriented along 
the nanofibrils' main axis direction (Cho et al., 2010), just as suggested by TEM observations (cf. Figure 4).
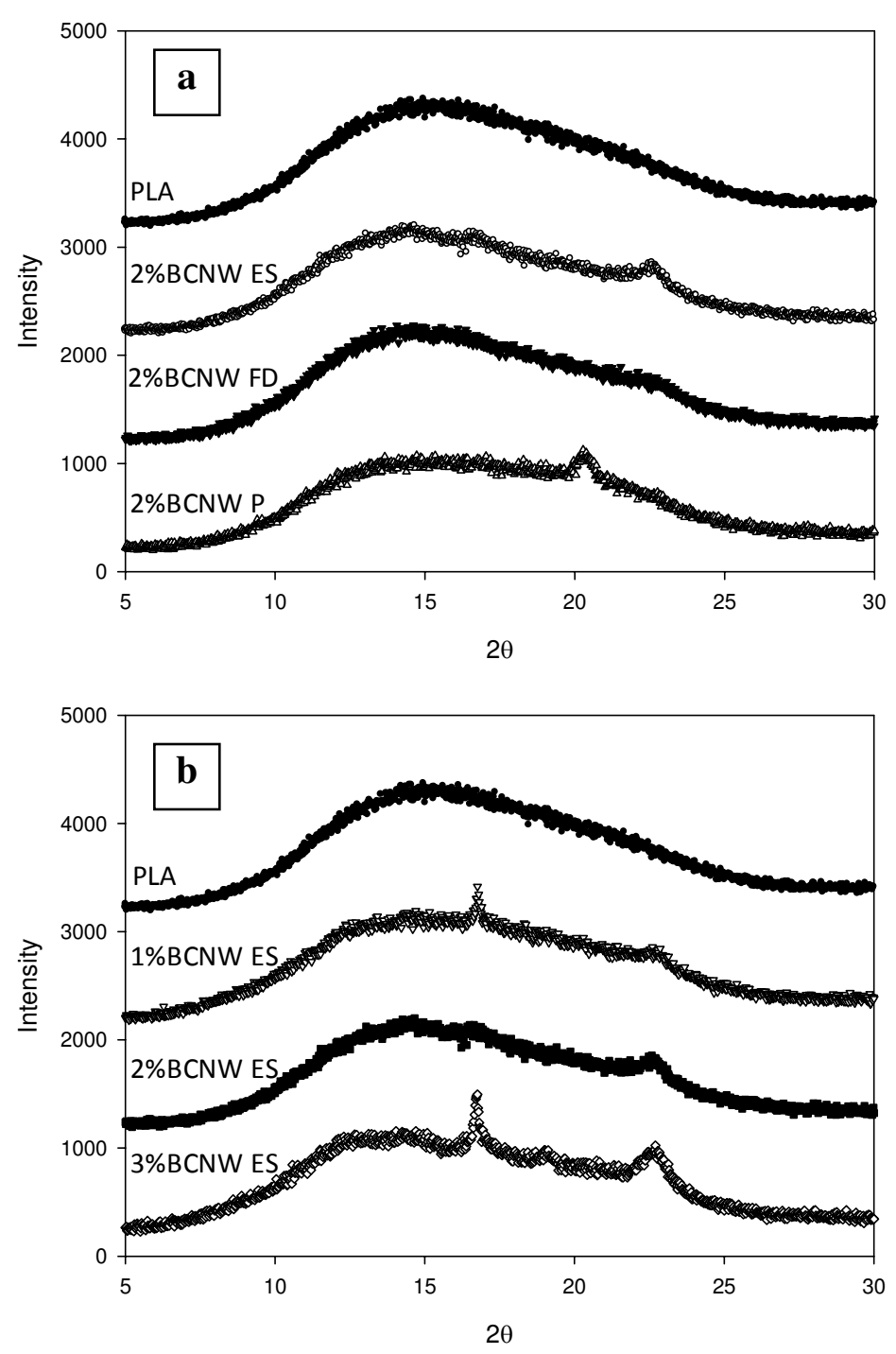

Figure 5. X-ray diffraction patterns of neat PLA films and of films containing 2 wt.-\% BCNW (a) and films containing different concentrations of BCNW incorporated through electrospun fibers (b). 


\subsection{Mechanical properties of PLA nanocomposites}

Table 6 summarizes the mechanical properties of neat PLA and its nanocomposites. From the results it can be observed that the addition of BCNW had a major effect on the Young's modulus and tensile strength resulting in more rigid materials, whereas the elongation at break was not significantly altered.

When comparing the different incorporation methods, the addition of BCNW through electrospun fibers gave rise to the maximum increase in the Young's modulus (ca. 17\% increase for both the 2\% BCNW ES and 3\% BCNW ES samples) and in the tensile strength (ca. 14\% and 13\% increase for 2\% BCNW ES and 3\% BCNW ES, respectively). A previous work reported a similar increase in the Young's modulus and tensile strength (ca. 17\% and 11\%, respectively) for melt processed PLA nanocomposites incorporating 3 wt.- $\%$ of cellulose nanofibers. However, the elongation at break was reduced by ca. $21 \%$, whereas the electrospinning pre-incorporation suggested in this work led to less than $10 \%$ reduction for the 3 wt.- $\%$ BCNW nanocomposite. Additional works reported increased Young's modulus and tensile strength for melt processed PLA incorporating higher amounts of cellulosic fillers, but in all the cases the elongation at break was greatly reduced (Fortunati et al., 2010; Iwatake et al., 2008; Suryanegara et al., 2009).

On the contrary, direct addition of freeze-dried BCNW resulted in less stiff nanocomposites. A previous study with EVOH-BCNW nanocomposites suggested that this stiffening effect is a result of the strong nanofiller network created when filler-filler interactions are promoted (Martínez-Sanz et al., 2013b). It is also worth noting, that the electrospinning pre-incorporation method led, in general, to nanocomposites with greater elongation at break, i.e. less brittle materials. Although the addition of reinforcing agents, which act as stress 
concentrating components, in polymeric materials may typically result in a reduction of the elongation at break, it is known that when strong interactions, such as hydrogen bonding, take place between the matrix and a hygroscopic filler, the stress concentration effect is prevented to a certain extent due to an effect socalled as reinforcing plasticizing phenomenon (George et al., 2011; López-Rubio et al., 2007). Therefore, these results indicate that the incorporation of BCNW by means of electrospinning allowed for a strong nanowhiskers' network to be created and at the same time, it resulted in enhanced dispersion and matrix-filler adhesion.

Previous studies have reported that the addition of cellulose whiskers resulted in a decrease in the mechanical properties due to poor interfacial adhesion between a hydrophobic matrix and the highly hydrophilic CNW (Sanchez-Garcia \& Lagaron, 2010; Siqueira et al., 2009). Nevertheless, it has also been reported that, apart from the filler-matrix adhesion, the filler-filler interactions are important for the reinforcing capacity of CNW (Oksman et al., 2006; Siqueira et al., 2009). Achieving the so-called percolation threshold, where the nanowhiskers are strongly interconnected by a $3 \mathrm{D}$ network, has been claimed as a crucial condition to obtain strong mechanical reinforcement. By using the following equation, the percolation threshold $\left(V_{E s}\right)$ can be easily estimated on the bases of the aspect ratio (Oksman et al., 2006):

$$
v_{B i 0}=\frac{0.7}{L / d}
$$

In the above equation, $L / d$ is the aspect ratio. For the nanocomposites incorporating BCNW, with an experimental aspect ratio of ca. 29 (Martínez-Sanz et al., 2011a), the percolation threshold should lay around 2 v.- $\%$ of BCNW. 
Indeed, as deduced from Table 6, a loading between 1.6 and 2.3 v.- $\%$ (corresponding to 2 and 3 wt.- $\%$ ) gives rise to the optimum in the mechanical properties attained by the addition of $\mathrm{BCNW}$.

Modeling of the mechanical properties using the following Halpin-Tsai equation was also carried out in order to determine the theoretical expectations (Petersson \& Oksman, 2006):

$$
E=\frac{E_{m}(1+\xi \eta \phi)}{1-\eta \phi}, \quad \eta=\frac{E_{r} / E_{m}-1}{E_{r} / E_{m}+\xi}
$$

Where $E_{m}$ and $E_{r}$ refer to the Young's modulus of the matrix and the reinforcement, respectively, $\phi$ is the volume fraction and $\xi$ is calculated from the following expression:

$$
\xi=\frac{2 \cdot \text { Length }}{\text { Thickness }}
$$

The following data were used in the calculations: $\mathrm{E}_{\mathrm{PLA}}=1.85 \mathrm{GPa}$, $\mathrm{E}_{\text {cellulose }}=167.5 \mathrm{GPa}$ (Tashiro \& Kobayashi, 1991). The BCNW dimensions, which were determined in a previous work (Martínez-Sanz et al., 2013a), were 570 x 18 nm.

As observed in Figure 6, the experimental values were well below those predicted by the theoretical model. This fact points out that, as previous studies confirmed (Martínez-Sanz et al., 2013b), processing by melt compounding is detrimental for the cementation of the cellulose nanowhiskers percolation network. It has been previously reported that the high polymer melt viscosity during extrusion, limits the random movement and, consequently, hinders the 
interconnection between $\mathrm{CNW}$, leading to a lower reinforcing efficiency than for instance that previously obtained in an EVOH matrix by solvent casting (Hajji et al., 1996). Nevertheless, it should be mentioned that a previous work in solvent cast PLA containing freeze-dried and solvent exchanged CNW resulted in conventional plasticization of the matrix by addition of $\mathrm{CNW}$, hence presenting not only higher elongation at break but also lower modulus (Sanchez-Garcia \& Lagaron, 2010). This plasticization effect could be related to the fact that solvent cast materials are less dense and crystalline and hence, have higher solubility and permeability to moisture.

Table 6. Young's Modulus, Tensile Strength and Elongation at Break for PLA and its nanocomposites incorporating $\mathrm{BCNW}$.

\begin{tabular}{|c|c|c|c|}
\cline { 2 - 4 } \multicolumn{1}{c|}{} & $\mathrm{E}(\mathrm{GPa})$ & $\begin{array}{c}\text { Tensile strength } \\
(\mathrm{MPa})\end{array}$ & $\varepsilon_{\mathrm{b}}(\%)$ \\
\hline PLA & ${ }^{\mathrm{a}} 1.85 \pm 0.08$ & ${ }^{\mathrm{de}} 53.77 \pm 1.18$ & ${ }^{\mathrm{ab}} 4.93 \pm 0.45$ \\
\hline $1 \%$ BCNW ES & ${ }^{\mathrm{abcd}} 2.01 \pm 0.07$ & ${ }^{\mathrm{ef}} 59.04 \pm 1.94$ & ${ }^{\mathrm{ab}} 5.33 \pm 1.66$ \\
\hline $2 \%$ BCNW ES & ${ }^{\mathrm{cd}} 2.16 \pm 0.08$ & ${ }^{\mathrm{f}} 61.36 \pm 1.59$ & ${ }^{\mathrm{ab}} 3.33 \pm 0.58$ \\
\hline $3 \%$ BCNW ES & ${ }^{\mathrm{d}} 2.16 \pm 0.13$ & ${ }^{\mathrm{f}} 60.89 \pm 4.59$ & ${ }^{\mathrm{ab}} 4.44 \pm 1.08$ \\
\hline $1 \%$ BCNW FD & ${ }^{\mathrm{abc}} 1.95 \pm 0.09$ & ${ }^{\mathrm{cde}} 53.02 \pm 2.97$ & ${ }^{\mathrm{a}} 3.20 \pm 0.46$ \\
\hline $2 \%$ BCNW FD & ${ }^{\mathrm{ab}} 1.89 \pm 0.07$ & ${ }^{\mathrm{a}} 42.67 \pm 2.12$ & ${ }^{\mathrm{a}} 2.67 \pm 0.58$ \\
\hline PLA+16\%EVOH & ${ }^{\mathrm{cd}} 2.11 \pm 0.08$ & ${ }^{\mathrm{bcd}} 50.10 \pm 2.41$ & ${ }^{\mathrm{a}} 2.86 \pm 0.19$ \\
\hline $2 \%$ BCNW P & ${ }^{\mathrm{abc}} 1.95 \pm 0.08$ & ${ }^{\mathrm{abc}} 47.01 \pm 3.58$ & ${ }^{\mathrm{b}} 5.82 \pm 2.47$ \\
\hline $2 \% \mathrm{BCNW} P$ & ${ }^{\mathrm{bcd}} 2.05 \pm 0.07$ & ${ }^{\mathrm{ab}} 46.29 \pm 3.09$ & ${ }^{\mathrm{a}} 2.54 \pm 0.22$ \\
\hline
\end{tabular}


The a, b, c, d, e and f letters correspond to the ANOVA statistical analysis and Tukey test of the data that indicate that with a $95 \%$ confidence level, the values are significantly different.

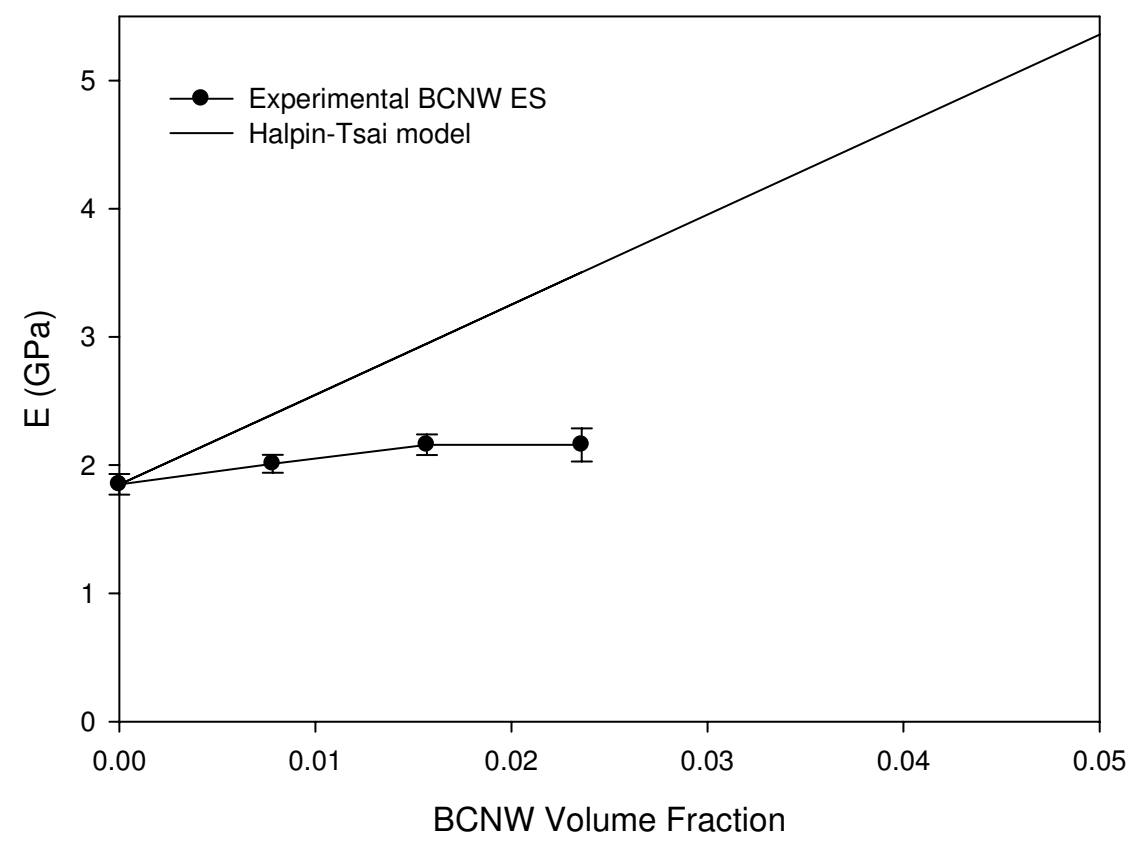

Figure 6. Experimentally measured Young's modulus for PLA-BCNW ES nanocomposites compared to theoretical predictions by Halpin-Tsai.

\subsection{Water and oxygen barrier properties of the different PLA nanocomposites}

Table 7 summarizes the measured water permeability and water uptake values for neat PLA and its nanocomposites. Water uptake of PLA was in agreement with values previously reported (Sanchez-Garcia et al., 2011), whereas the permeability value for neat PLA was lower than that previously reported for cast films (Rhim et al., 2009; Sanchez-Garcia \& Lagaron, 2010) as the melt compounded films produced in the present work were more crystalline and with higher overall 
material density. All the PLA nanocomposites incorporating electrospun fibers had significantly lower water permeability, with a maximum drop of $43 \%$ for the 3 wt.$\%$ BCNW loading, as compared to pure PLA. This effect was the result of a reduction in both solubility and diffusion coefficients. It is thought that welldispersed nanocrystals act as filling and blocking agents, hence reducing the solubility and diffusion through the nanocomposite films. Thus, cellulosic materials are hydrophilic and swell in the presence of water, but inside a hydrophobic matrix, they may actually be confined and more restricted in terms of their interaction with water. The same effect has already been reported for gelatin reinforced with BCNW (George \& Siddaramaiah, 2012) and hydroxypropyl methylcellulose (HPMC) reinforced with microcrystalline cellulose (Bilbao-Sáinz et al., 2010) in which, both, water permeability and sorption were reduced by the nanofiller incorporation. The creation of a strongly hydrogen bonded cellulose network in starch-microfibrillated cellulose nanocomposites was also seen to highly reduce the water uptake of the starch matrix (Svagan et al., 2009). Water sorption reduction was, in these papers, ascribed to the development of interactions between cellulose and the hydrophilic sites of the hydrophilic polymeric matrix, which substituted the polymer-water interactions.

The incorporation of EVOH44, alone or with nanowhiskers, also reduced the water vapour permeability of pure PLA. Even though there was a poor adhesion between PLA and EVOH, EVOH44 was measured to have lower permeability, i.e. $2.5 \cdot 10^{-15} \mathrm{Kg} \cdot \mathrm{m} / \mathrm{s} \cdot \mathrm{m}^{2} \cdot \mathrm{Pa}$, to water than PLA, in agreement with a previous work (López-de-Dicastillo et al., 2010). This fact, together with the confinement of the EVOH phase within the PLA matrix, could result in an overall lower permeability. A similar reduction in the water vapour permeability was observed for nanocomposites that incorporated $\mathrm{BCNW}$ via precipitated $\mathrm{EVOH}$, even when, it 
has observed that the nanofiller improved the compatibility between EVOH and PLA.

In contrast, melt mixing of PLA with freeze-dried BCNW showed a detrimental effect for the water barrier. In this case, the increase in diffusion, via most likely the preferential paths through the interphases between the polymer matrix and the filler agglomerates, oppositely affected the measured reduction in water transport properties.

Again, these results support the fact that the electrospinning method considerably improved the dispersion and filler-matrix interactions, resulting in a maximum decrease of the water permeability of up to $43 \%$ for the $3 \% \mathrm{BCNW}$ ES sample. On the contrary, agglomeration and phase separation occurred when direct melt mixing PLA with freeze-dried BCNW and, therefore, the water permeability increased by up to $32 \%$ for the $2 \% \mathrm{BCNW}$ FD sample.

There is very scarce literature reporting on the water barrier properties of PLA nanocomposites reinforced with cellulose nanowhiskers. Sánchez-García et al. (Sanchez-Garcia \& Lagaron, 2010) observed water permeability reductions of up to $82 \%$ for PLA reinforced with $3 \mathrm{wt} .-\%$ plant cellulose nanowhiskers via solution casting. The casting method allowed for a very good dispersion and distribution of the filler as well as stronger blocking filler effect in the less dense and more permeable solvent cast PLA matrix. 
Table 7. Water permeability, Water Uptake and Diffusion Coefficient for PLA and its nanocomposites incorporating BCNW.

\begin{tabular}{|c|c|c|c|}
\cline { 2 - 4 } \multicolumn{1}{c|}{} & $\mathrm{P}\left(\mathrm{Kg} \cdot \mathrm{m} / \mathrm{s} \cdot \mathrm{m}^{2} \cdot \mathrm{Pa}\right)$ & $\begin{array}{c}\text { Water uptake } \\
100 \% \mathrm{RH}(\%)\end{array}$ & $\mathrm{D}\left(\mathrm{m}^{2} / \mathrm{s}\right)$ \\
\hline PLA & ${ }^{\mathrm{de}} 1.31 \pm 0.01 \mathrm{e}^{-14}$ & ${ }^{\mathrm{bc}} 0.95 \pm 0.15$ & ${ }^{\mathrm{a}} 3.63 \pm 0.94 \mathrm{e}^{-12}$ \\
\hline $1 \%$ BCNW ES & ${ }^{\mathrm{ab}} 0.88 \pm 0.03 \mathrm{e}^{-14}$ & ${ }^{\mathrm{c}} 1.14 \pm 0.01$ & ${ }^{\mathrm{a}} 1.84 \pm 0.08 \mathrm{e}^{-12}$ \\
\hline $2 \% \mathrm{BCNW}$ ES & ${ }^{\mathrm{bcd}} 1.10 \pm 0.02 \mathrm{e}^{-14}$ & ${ }^{\mathrm{bc}} 0.87 \pm 0.01$ & ${ }^{\mathrm{a}} 3.04 \pm 0.10 \mathrm{e}^{-12}$ \\
\hline $1 \% \mathrm{BCNW}$ FD & ${ }^{\mathrm{e}} 1.39 \pm 0.05 \mathrm{e}^{-14}$ & ${ }^{\mathrm{a}} 0.52 \pm 0.09$ & ${ }^{\mathrm{b}} 6.53 \pm 0.90 \mathrm{e}^{-12}$ \\
\hline $2 \% \mathrm{BCNW}$ FD & ${ }^{\mathrm{f}} 1.72 \pm 0.11 \mathrm{e}^{-14}$ & ${ }^{\mathrm{a}} 0.52 \pm 0.07$ & ${ }^{\mathrm{c}} 8.79 \pm 0.67 \mathrm{e}^{-12}$ \\
\hline PLA+16\%EVOH & ${ }^{\mathrm{bc}} 0.98 \pm 0.06 \mathrm{e}^{-14}$ & ${ }^{\mathrm{ab}} 0.79 \pm 0.09$ & ${ }^{\mathrm{a}} 3.33 \pm 0.43 \mathrm{e}^{-12}$ \\
\hline $1 \% \mathrm{BCNW} \mathrm{P}$ & ${ }^{\mathrm{cd}} 1.16 \pm 0.08 \mathrm{e}^{-14}$ & ${ }^{\mathrm{abc}} 0.82 \pm 0.04$ & ${ }^{\mathrm{a}} 3.51 \pm 0.36 \mathrm{e}^{-12}$ \\
\hline $2 \% \mathrm{BCNW} \mathrm{P}$ & ${ }^{\mathrm{bc}} 1.03 \pm 0.03 \mathrm{e}^{-14}$ & ${ }^{\mathrm{bc}} 1.08 \pm 0.12$ & ${ }^{\mathrm{a}} 2.37 \pm 0.34 \mathrm{e}^{-12}$ \\
\hline
\end{tabular}

The $\mathrm{a}, \mathrm{b}, \mathrm{c}, \mathrm{d}$, e and $\mathrm{f}$ letters correspond to the ANOVA statistical analysis and

Tukey test of the data that indicate that with a $95 \%$ confidence level, the values are significantly different.

Oxygen permeability was measured at both $0 \% \mathrm{RH}$ and $80 \% \mathrm{RH}$ and the results are gathered in Table 8 . The permeability values for pure PLA are in agreement with those reported in the literature for melt compounded films (Colomines et al., 2010; Petersen et al., 2001; Sanchez-Garcia et al., 2011). The first observation to highlight is that all the nanocomposite materials had reduced oxygen permeability as compared to PLA at $0 \%$ RH. However, the gas 
permeability was lower, unaffected or even increased when the relative humidity was very high, i.e. $80 \% \mathrm{RH}$.

In general, at $0 \% \mathrm{RH}$ the oxygen solubility of nanocomposites was decreased as compared to PLA. In addition, for highly dispersed BCNW in films containing PLA fibers or EVOH precipitate, there was also a reduction in the diffusion coefficient indicating that $\mathrm{BCNW}$ crystals and the resulting composite morphology increased the tortuosity factor, thus hindering gas diffusion. No great differences were observed between nanocomposite samples; nevertheless, for $0 \% \mathrm{RH}$ the most favorable case, i.e. the film presenting the highest oxygen barrier, was the one incorporating $16 \% \mathrm{EVOH}$, with a reduction of ca. $42 \%$ in the oxygen permeability. The permeability coefficient for this sample was similar to that previously reported for PLA blends with $10 \mathrm{wt} .-\%$ EVOH29 (Sanchez-Garcia et al., 2011).

When increasing the water activity, the oxygen permeability of neat PLA was somewhat reduced, effect that has been previously reported (Auras et al., 2004b; Sanchez-Garcia et al., 2011). However, this effect was less pronounced in the case of the nanocomposites, leading to a reduced permeability drop for the nanocomposites as compared to the neat PLA at $80 \%$ RH. The same effect was reported for PLA blends incorporating EVOH and amylopectin, although, in that case, no overall barrier improvements were achieved at $80 \% \mathrm{RH}$ compared to the neat polymer due to the reduced PLA crystallinity and greater water sensitivity of the blends (Sanchez-Garcia et al., 2011). A reduction on the oxygen permeability at $80 \% \mathrm{RH}$ was reported for PLA solvent cast nanocomposites loaded with plant cellulose nanowhiskers (Sanchez-Garcia \& Lagaron, 2010). However, in that case the permeability value for the neat PLA was significantly higher than the one reported here due to the lower crystallinity and specific morphology of the solvent 
cast polymeric films. In the previous work, the lowest permeability was attained for 2 wt. $-\%$ CNW loading, and corresponded to $1.4 \cdot 10^{-18} \mathrm{~m}^{3} \cdot \mathrm{m} / \mathrm{m}^{2} \cdot \mathrm{s} \cdot \mathrm{Pa}$, which is actually close to the values reported here for the melt compounded nanocomposite films.

The reduction of PLA oxygen permeability when increasing the water activity was a combination of increased diffusion and decreased solubility. It has been previously reported that PLA oxygen diffusion coefficient increases exponentially with water activity due to plasticization of the amorphous phase by water molecules (Auras et al., 2004a). On the other hand, the solubility coefficient decreases linearly with water activity as a consequence of the occupancy of the free volume by water molecules (Auras et al., 2004a). As deduced from Table 8, with the incorporation of $\mathrm{BCNW}$ the increase in the diffusion coefficient at high relative humidity becomes more evident than for the pure PLA, suggesting that the plasticization effect is stronger in the case of the composites. Water molecules can interact with hydroxyl groups from BCNW distorting the network of hydrogen bonds between cellulose chains and/or with the polymeric matrix hence resulting in increased mobility of the polymeric chains for diffusion.

At $80 \% \mathrm{RH}$, the nanocomposites which presented the best oxygen barrier performance were those with 1 wt.-\% BCNW loading. Indeed, reductions in the oxygen permeability coefficient of ca. $26 \%, 13 \%$ and $11 \%$ were observed for the samples incorporating $1 \mathrm{wt} .-\% \mathrm{BCNW}$ via the $\mathrm{EVOH}$ precipitate, using freezedried filler and via electrospun fibers, respectively. Thus, in order to limit the detrimental effect of BCNW on oxygen permeability at high relative humidity conditions, very low loadings should be incorporated into the material. 
Table 8. Oxygen transport properties measured at $0 \% \mathrm{RH}$ and $80 \% \mathrm{RH}$ for PLA and its nanocomposites incorporating BCNW.

\begin{tabular}{|c|c|c|c|c|c|c|}
\hline & $\begin{array}{c}\text { P } 0 \% \mathrm{RH} \\
\left(\mathrm{m}^{3} \cdot \mathrm{m} / \mathrm{m}^{2} \cdot \mathrm{s} \cdot \mathrm{Pa}\right)\end{array}$ & $\begin{array}{c}\text { D 0\%RH } \\
\left(\mathrm{m}^{2} / \mathrm{s}\right)\end{array}$ & $\begin{array}{l}\text { S } 0 \% \text { RH } \\
(\mathrm{g} / \mathrm{g} \cdot \mathrm{Pa})\end{array}$ & $\begin{array}{c}\mathrm{P} 80 \% \mathrm{RH} \\
\left(\mathrm{m}^{3} \cdot \mathrm{m} / \mathrm{m}^{2} \cdot \mathrm{s} \cdot \mathrm{Pa}\right)\end{array}$ & $\begin{array}{c}\text { D } 80 \% \text { RH } \\
\left(\mathrm{m}^{2} / \mathrm{s}\right)\end{array}$ & $\begin{array}{c}\mathrm{S} 80 \% \mathrm{RH} \\
(\mathrm{g} / \mathrm{g} \cdot \mathrm{Pa})\end{array}$ \\
\hline PLA & $2.61 \pm 0.16 \mathrm{e}^{-18}$ & $1.51 \mathrm{e}^{-12}$ & $1.73 \mathrm{e}^{-6}$ & $1.78 \pm 0.13 \mathrm{e}^{-18}$ & $1.83 \mathrm{e}^{-12}$ & $0.97 \mathrm{e}^{-6}$ \\
\hline $1 \% \mathrm{BCNW}$ ES & $2.13 \pm 0.06 \mathrm{e}^{-18}$ & $1.38 \mathrm{e}^{-12}$ & $1.54 \mathrm{e}^{-6}$ & $1.58 \pm 0.02 \mathrm{e}^{-18}$ & $2.11 \mathrm{e}^{-12}$ & $0.75 \mathrm{e}^{-6}$ \\
\hline $2 \% \mathrm{BCNW}$ ES & $1.75 \pm 0.16 \mathrm{e}^{-18}$ & $0.99 \mathrm{e}^{-12}$ & $1.87 \mathrm{e}^{-6}$ & $1.82 \pm 0.04 \mathrm{e}^{-18}$ & $1.96 \mathrm{e}^{-12}$ & $0.95 \mathrm{e}^{-6}$ \\
\hline $3 \% \mathrm{BCNW}$ ES & $1.96 \pm 0.10 \mathrm{e}^{-18}$ & $1.24 \mathrm{e}^{-12}$ & $1.58 \mathrm{e}^{-6}$ & $1.88 \pm 0.06 \mathrm{e}^{-18}$ & $2.23 \mathrm{e}^{-12}$ & $0.84 \mathrm{e}^{-6}$ \\
\hline $1 \% \mathrm{BCNW} F \mathrm{FD}$ & $1.73 \pm 0.08 \mathrm{e}^{-18}$ & $1.43 \mathrm{e}^{-12}$ & $1.21 \mathrm{e}^{-6}$ & $1.55 \pm 0.10 \mathrm{e}^{-18}$ & $1.87 \mathrm{e}^{-12}$ & $0.83 \mathrm{e}^{-6}$ \\
\hline $2 \% \mathrm{BCNW} F D$ & $2.04 \pm 0.14 \mathrm{e}^{-18}$ & $2.01 \mathrm{e}^{-12}$ & $1.01 \mathrm{e}^{-6}$ & $2.23 \pm 0.12 \mathrm{e}^{-18}$ & $2.20 \mathrm{e}^{-12}$ & $1.01 \mathrm{e}^{-6}$ \\
\hline $\mathrm{PLA}+16 \% \mathrm{EVOH}$ & $1.52 \pm 0.04 \mathrm{e}^{-18}$ & $1.34 \mathrm{e}^{-12}$ & $1.13 \mathrm{e}^{-6}$ & $1.69 \pm 0.02 \mathrm{e}^{-18}$ & $1.91 \mathrm{e}^{-12}$ & $0.88 \mathrm{e}^{-6}$ \\
\hline $1 \% \mathrm{BCNW} \mathrm{P}$ & $1.79 \pm 0.02 \mathrm{e}^{-18}$ & $1.30 \mathrm{e}^{-12}$ & $1.38 \mathrm{e}^{-6}$ & $1.31 \pm 0.03 \mathrm{e}^{-18}$ & $1.75 \mathrm{e}^{-12}$ & $0.75 \mathrm{e}^{-6}$ \\
\hline $2 \% \mathrm{BCNW} P$ & $1.87 \pm 0.05 \mathrm{e}^{-18}$ & $1.71 \mathrm{e}^{-12}$ & $1.09 \mathrm{e}^{-6}$ & $1.59 \pm 0.06 \mathrm{e}^{-18}$ & $1.17 \mathrm{e}^{-12}$ & $1.36 \mathrm{e}^{-6}$ \\
\hline PLA literature & $\begin{array}{l}\text { (Colomines et al., } \\
2010) 2.50 \pm 0.09 \mathrm{e}^{-18} \\
\text { (Sanchez-Garcia et al., } \\
2011) 2.26 \pm 0.01 \mathrm{e}^{-18}\end{array}$ & & & $\begin{array}{c}\mathrm{e}^{-18} \\
\text { (Sanchez-Grsen et al., 2001) } 1.75 \\
{ }^{2011)} 1.64 \pm 0.27 \mathrm{e}^{-18}\end{array}$ & & \\
\hline
\end{tabular}




\section{CONCLUSIONS}

In this work, PLA nanocomposite films loaded with bacterial cellulose nanowhiskers $(\mathrm{BCNW})$ were produced by the melt compounding technique and the effects of the pre-incorporation method and cellulose nanowhiskers loading in the morphology, thermal properties, crystallinity, barrier properties and mechanical properties of the generated materials were investigated. Two different pre-incorporation methods, i.e. incorporation of BCNW into PLA electrospun fibers and precipitation of EVOH-BCNW solutions, were developed and compared to the direct melt mixing of freeze-dried BCNW with PLA.

Morphological studies pointed out that by applying these novel preincorporation methods, it was possible to optimize the dispersion of the nanofiller within the PLA matrix. In particular, the electrospinning technique is proven to be a feasible method for the incorporation of BCNW into PLA, leading to a good dispersion for loadings of up to $3 \mathrm{wt.} \%$. As a result of this high dispersion and the favoured matrix-filler interactions the incorporation of $\mathrm{BCNW}$ through electrospinning resulted in better mechanical properties. For concentrations around the percolation threshold, i.e. $2-3$ wt.- $\%$ BCNW, an increase of ca. $17 \%$ in the elastic modulus and of ca. $14 \%$ in the tensile strength, as compared to neat PLA, were attained without significantly decreasing the ductility of the material.

Regarding the barrier properties, water permeability was observed to decrease, up to $43 \%$ for a loading of 3 wt.- $\%$ BCNW, using the electrospinning preincorporation method. This effect was a combination of reduced water sorption and decreased diffusion caused by the blocking capacity of highly dispersed nanowhiskers. Additionally, all the nanocomposites presented a significant increase 
in the oxygen barrier at $0 \% \mathrm{RH}$. Nevertheless, the oxygen barrier at $80 \% \mathrm{RH}$ was only improved for BCNW loadings as low as $1 \mathrm{wt.}$ - $\%$.

This work has demonstrated that the incorporation of BCNW through electrospinning allows for the production of melt compounding PLA nanocomposites with highly dispersed cellulose nanocrystals, resulting in improved water and oxygen barrier and mechanical properties. 


\section{REFERENCES}

Alvarez, V. A., Ruseckaite, R. A., \& Vázquez, A. (2003). Kinetic analysis of thermal degradation in poly(ethylene-vinyl alcohol) copolymers. Journal of Applied Polymer Science, 90(11), 3157-3163.

Auras, R., Harte, B., \& Selke, S. (2004a). Effect of water on the oxygen barrier properties of poly(ethylene terephthalate) and polylactide films. Journal of Applied Polymer Science, 92(3), 1790-1803.

Auras, R., Harte, B., \& Selke, S. (2004b). An overview of polylactides as packaging materials. Macromolecular Bioscience, 4(9), 835-864.

Bilbao-Sáinz, C., Avena-Bustillos, R. J., Wood, D. F., Williams, T. G., \& McHugh, T. H. (2010). Composite edible films based on hydroxypropyl methylcellulose reinforced with microcrystalline cellulose nanoparticles. Journal of Agricultural and Food Chemistry, 58(6), 3753-3760.

Bondeson, D., \& Oksman, K. (2007a). Dispersion and characteristics of surfactant modified cellulose whiskers nanocomposites. Composite Interfaces, 14(7-9), 617630 .

Bondeson, D., \& Oksman, K. (2007b). Polylactic acid/cellulose whisker nanocomposites modified by polyvinyl alcohol. Composites Part A: Applied Science and Manufacturing, 38(12), 2486-2492.

Braun, B., Dorgan, J. R., \& Hollingsworth, L. O. (2012). Supra-Molecular EcoBioNanocomposites Based on Polylactide and Cellulosic Nanowhiskers: Synthesis and Properties. Biomacromolecules, 13(7), 2013-2019.

Cho, H. B., Nakayama, T., Tokoi, Y., Endo, S., Tanaka, S., Suzuki, T., Jiang, W., Suematsu, H., \& Niihara, K. (2010). Facile preparation of a polysiloxane-based hybrid composite with highly-oriented boron nitride nanosheets and an unmodified surface. Composites Science and Technology, 70(12), 1681-1686.

Colomines, G., Ducruet, V., Courgneau, Ä., Guinault, A., \& Domenek, S. (2010). Barrier properties of poly(lactic acid) and its morphological changes induced by aroma compound sorption. Polymer International, 59(6), 818-826. 
De Souza Lima, M. M., \& Borsali, R. (2004). Rodlike cellulose microcrystals: Structure, properties, and applications. Macromolecular Rapid Communications, 25(7), 771-787.

Fortunati, E., Armentano, I., Iannoni, A., \& Kenny, J. M. (2010). Development and thermal behaviour of ternary PLA matrix composites. Polymer Degradation and Stability, 95(11), 2200-2206.

Frone, A. N., Berlioz, S., Chailan, J. F., Panaitescu, D. M., \& Donescu, D. (2011). Cellulose fiber-reinforced polylactic acid. Polymer Composites, 32(6), 976-985.

George, J., Ramana, K. V., Bawa, A. S., \& Siddaramaiah (2011). Bacterial cellulose nanocrystals exhibiting high thermal stability and their polymer nanocomposites. International Journal of Biological Macromolecules, 48(1), 5057.

George, J., \& Siddaramaiah (2012). High performance edible nanocomposite films containing bacterial cellulose nanocrystals. Carbohydrate Polymers, 87(3), 20312037.

Grunert, M., \& Winter, W. T. (2002). Nanocomposites of cellulose acetate butyrate reinforced with cellulose nanocrystals. Journal of Polymers and the Environment, 10(1-2), 27-30.

Hajji, P., Cavaille, J. Y., Favier, V., Gauthier, C., \& Vigier, G. (1996). Tensile behavior of nanocomposites from latex and cellulose whiskers. Polymer Composites, 17(4), 612-619.

Hertlein, J., Singh, R. P., \& Weisser, H. (1995). Prediction of oxygen transport parameters of plastic packaging materials from transient state measurements. Journal of Food Engineering, 24(4), 543-560.

Hiltner, A., Liu, R. Y. F., Hu, Y. S., \& Baer, E. (2005). Oxygen transport as a solid-state structure probe for polymeric materials: A review. Journal of Polymer Science, Part B: Polymer Physics, 43(9), 1047-1063.

Hirai, A., Inui, O., Horii, F., \& Tsuji, M. (2009). Phase separation behavior in aqueous suspensions of bacterial cellulose nanocrystals prepared by sulfuric acid treatment. Langmuir, 25(1), 497-502. 
Iwatake, A., Nogi, M., \& Yano, H. (2008). Cellulose nanofiber-reinforced polylactic acid. Composites Science and Technology, 68(9), 2103-2106.

Jonoobi, M., Harun, J., Mathew, A. P., \& Oksman, K. (2010). Mechanical properties of cellulose nanofiber (CNF) reinforced polylactic acid (PLA) prepared by twin screw extrusion. Composites Science and Technology, 70(12), 1742-1747.

Katiyar, V., Gerds, N., Koch, C. B., Risbo, J., Hansen, H. C. B., \& Plackett, D. (2010). Melt processing of poly(L-lactic acid) in the presence of organomodified anionic or cationic clays. Journal of Applied Polymer Science, 122(1), 112-125.

Kim, K., Yu, M., Zong, X., Chiu, J., Fang, D., Seo, Y. S., Hsiao, B. S., Chu, B., \& Hadjiargyrou, M. (2003). Control of degradation rate and hydrophilicity in electrospun non-woven poly(D,L-lactide) nanofiber scaffolds for biomedical applications. Biomaterials, 24(27), 4977-4985.

Liu, X., Dever, M., Fair, N., \& Benson, R. S. (1997). Thermal and mechanical properties of poly(lactic acid) and poly(ethylene/butylene succinate) blends. Journal of Environmental Polymer Degradation, 5(4), 225-235.

López-de-Dicastillo, C., Gallur, M., Catalá, R., Gavara, R., \& Hernandez-Muñoz, P. (2010). Immobilization of $\beta$-cyclodextrin in ethylene-vinyl alcohol copolymer for active food packaging applications. Journal of Membrane Science, 353(1-2), 184-191.

López-Rubio, A., Lagaron, J. M., Ankerfors, M., Lindström, T., Nordqvist, D., Mattozzi, A., \& Hedenqvist, M. S. (2007). Enhanced film forming and film properties of amylopectin using micro-fibrillated cellulose. Carbohydrate Polymers, 68(4), 718-727.

Lunt, J. (1998). Large-scale production, properties and commercial applications of poly lactic acid polymers. Polymer Degradation and Stability, 59(1-3), 145-152.

Martínez-Sanz, M., Lopez-Rubio, A., \& Lagaron, J. (2011a). Optimization of the nanofabrication by acid hydrolysis of bacterial cellulose nanowhiskers. Carbohydrate Polymers, 85(1), 228-236.

Martínez-Sanz, M., Lopez-Rubio, A., \& Lagaron, J. M. (2012a). Dispersing bacterial cellulose in polylactides via electrohydrodynamic processing. Journal of Polymers and the Environment, under review. 
Martínez-Sanz, M., Olsson, R., Lopez-Rubio, A., \& Lagaron, J. (2012b). Development of Bacterial Cellulose Nanowhiskers Reinforced EVOH Composites by Electrospinning. Journal of Applied Polymer Science, 124(2), 1398-1408.

Martínez-Sanz, M., Olsson, R. T., Lopez-Rubio, A., \& Lagaron, J. M. (2011b). Development of electrospun EVOH fibres reinforced with bacterial cellulose nanowhiskers. Part I: Characterization and method optimization. Cellulose, 18(2), 335-347.

Martínez-Sanz, M. Lopez-Rubio, A.; Lagaron, J. (2013a). Nanocomposites of ethylene vinyl alcohol copolymer with thermally resistant cellulose nanowhiskers by melt compounding (I): Morphology and thermal properties. Journal of Applied Polymer Science, 128(5), 2666-2678.

Martínez-Sanz, M. Lopez-Rubio, A.; Lagaron, J. (2013b). Nanocomposites of ethylene vinyl alcohol copolymer with thermally resistant cellulose nanowhiskers by melt compounding (II): Water barrier and mechanical properties. Journal of Applied Polymer Science, 128(3), 2197-2207.

Meng, Q., Heuzey, M. C., \& Carreau, P. J. (2012). Control of thermal degradation of polylactide/clay nanocomposites during melt processing by chain extension reaction. Polymer Degradation and Stability, 97, 2010-2020.

Moharram, M. A., \& Mahmoud, O. M. (2007). X-Ray diffraction methods in the study of the effect of microwave heating on the transformation of cellulose $\mathrm{i}$ into cellulose II during mercerization. Journal of Applied Polymer Science, 105(5), 2978-2983.

Nordqvist, D., Sanchez-García, M. D., Hedenqvist, M. S., \& Lagaron, J. M. (2010). Incorporating amylopectin in poly(lactic Acid) by melt blending using poly(ethylene-co-vinyl Alcohol) as a thermoplastic carrier. (I) morphological characterization. Journal of Applied Polymer Science, 115(3), 1315-1324.

Oksman, K., Mathew, A. P., Bondeson, D., \& Kvien, I. (2006). Manufacturing process of cellulose whiskers/polylactic acid nanocomposites. Composites Science and Technology, 66(15), 2776-2784.

Petersen, K., Nielsen, P. V., \& Olsen, M. B. (2001). Physical and mechanical properties of biobased materials - Starch, polylactate and polyhydroxybutyrate. Starch/Staerke, 53(8), 356-361. 
Petersson, L., Kvien, I., \& Oksman, K. (2007). Structure and thermal properties of poly(lactic acid)/cellulose whiskers nanocomposite materials. Composites Science and Technology, 67(11-12), 2535-2544.

Petersson, L., \& Oksman, K. (2006). Biopolymer based nanocomposites: Comparing layered silicates and microcrystalline cellulose as nanoreinforcement. Composites Science and Technology, 66(13), 2187-2196.

Qu, P., Gao, Y., Wu, G. F., \& Zhang, L. P. (2010). Nanocomposites of Poly(lactic acid) reinforced with cellulose nanofibrils. BioResources, 5(3), 1811-1823.

Rhim, J. W., Hong, S. I., \& Ha, C. S. (2009). Tensile, water vapor barrier and antimicrobial properties of PLA/nanoclay composite films. LWT - Food Science and Technology, 42(2), 612-617.

Sanchez-Garcia, M. D., Gimenez, E., \& Lagaron, J. M. (2008). Morphology and barrier properties of solvent cast composites of thermoplastic biopolymers and purified cellulose fibers. Carbohydrate Polymers, 71(2), 235-244.

Sanchez-Garcia, M. D., \& Lagaron, J. M. (2010). On the use of plant cellulose nanowhiskers to enhance the barrier properties of polylactic acid. Cellulose, 17(5), 987-1004.

Sanchez-Garcia, M. D., Nordqvist, D., Hedenqvist, M., \& Lagaron, J. M. (2011). Incorporating amylopectin in poly(lactic acid) by melt blending using poly(ethylene-co-vinyl alcohol) as a thermoplastic carrier. II. Physical properties. Journal of Applied Polymer Science, 119(6), 3708-3716.

Siqueira, G., Bras, J., \& Dufresne, A. (2009). Cellulose whiskers versus microfibrils: Influence of the nature of the nanoparticle and its surface functionalization on the thermal and mechanical properties of nanocomposites. Biomacromolecules, 10(2), 425-432.

Suryanegara, L., Nakagaito, A. N., \& Yano, H. (2009). The effect of crystallization of PLA on the thermal and mechanical properties of microfibrillated cellulosereinforced PLA composites. Composites Science and Technology, 69(7â€"8), 1187-1192.

Suryanegara, L., Nakagaito, A. N., \& Yano, H. (2010). Thermo-mechanical properties of microfibrillated cellulose-reinforced partially crystallized PLA composites. Cellulose, 17(4), 771-778. 
Svagan, A. J., Hedenqvist, M. S., \& Berglund, L. (2009). Reduced water vapour sorption in cellulose nanocomposites with starch matrix. Composites Science and Technology, 69(3-4), 500-506.

Tashiro, K., \& Kobayashi, M. (1991). Theoretical evaluation of three-dimensional elastic constants of native and regenerated celluloses: role of hydrogen bonds. Polymer, 32(8), 1516-1526.

Van De Witte, P., Dijkstra, P. J., Van Den Berg, J. W. A., \& Feijen, J. (1996). Phase behavior of polylactides in solvent-nonsolvent mixtures. Journal of Polymer Science, Part B: Polymer Physics, 34(15), 2553-2568.

Yu, H. Y., Qin, Z. Y., Liu, Y. N., Chen, L., Liu, N., \& Zhou, Z. (2012). Simultaneous improvement of mechanical properties and thermal stability of bacterial polyester by cellulose nanocrystals. Carbohydrate Polymers, 89(3), 971978.

Zeng, J., Chen, X., Liang, Q., Xu, X., \& Jing, X. (2004). Enzymatic degradation of poly(L-lactide) and poly(E-caprolactone) electrospun fibers. Macromolecular Bioscience, 4(12), 1118-1125. 
Chapter VIII

\section{HIGH-BARRIER COATED BACTERIAL CELLULOSE NANOWHISKERS FILMS WITH REDUCED MOISTURE SENSITIVITY}

Carbohydrate Polymers, under review

Marta Martínez Sanz, Amparo López Rubio, José María Lagarón

Novel Materials and Nanotechnology Group, IATA, CSIC. Avd. Agustín

Escardino, 7, 46980. Paterna, Valencia. Spain 



\begin{abstract}
This study reports on the development and characterization of bacterial cellulose $(\mathrm{BCNW})$ films coated with hydrophobic layers, presenting enhanced barrier properties. Pure BCNW films showed good transparency and thermal stability, high rigidity and extremely low oxygen permeability at $0 \% \mathrm{RH}$. The dramatic increase in oxygen permeability at $80 \% \mathrm{RH}$, due the hydrophilic character of BCNW, was counteracted through coating the films with annealed PLA electrospun nanostructured fibres or hydrophobic silanes. The use of electrospinning was crucial to attain a good adhesion between the hydrophilic BCNW and the hydrophobic PLA layer. After electrospinning, the fibres were homogenised by annealing, thus obtaining a uniform and continuous coating. Coated systems showed a hydrophobic surface and protected the BCNW from moisture, thus reducing ca. $70 \%$ the water permeability and up to $97 \%$ the oxygen permeability at $80 \% \mathrm{RH}$. Furthermore, this novel approach was seen to protect BCNW films from moisture more efficiently than coating with hydrophobic silanes.
\end{abstract}

Keywords: Bacterial cellulose, nanowhiskers, polylactide, silanes, electrospinning, barrier properties. 


\section{INTRODUCTION}

Cellulose is the most abundant biopolymer found in nature, as it is the major cell-wall component of plants. Although cellulose is commonly extracted from vegetal resources, some bacterial species are able to produce bacterial cellulose (BC) as a highly hydrated pellicle which, compared to plant cellulose, possesses higher water holding capacity, higher crystallinity and a finer web-like network (Iguchi et al., 2000; Wan et al., 2007). Furthermore, one of the main advantages of $\mathrm{BC}$ is that, while cellulose derived from plants is naturally associated with other biopolymers such as hemicellulose and lignin, $\mathrm{BC}$ is predominantly pure cellulose and, thus, no additional processes are needed in order to isolate cellulose.

For their application as nanofillers, cellulosic materials are usually subjected to hydrolysis with strong acids, which produce a preferential digestion of the amorphous domains of the material and cleavage of the nanofibril bundles (Rånby, 1949), breaking down the hierarchical structure of the material into nanocrystals, which are usually referred to as cellulose nanowhiskers (CNW). Bacterial cellulose nanowhiskers (BCNW) present a highly crystalline structure (Martínez-Sanz et al., 2011a), with up to several micrometres in length and a cross-section of 5-50 nm (De Souza Lima \& Borsali, 2004; Hirai et al., 2009).

Due to their attractive properties, such as low density and biodegradability, great interest has been focused lately on the use of cellulose nanocrystals as reinforcing agents in nanocomposites (Kvien et al., 2007; Martínez-Sanz et al., 2013a, d; Petersson et al., 2007; Ten et al., 2010), although due to their high hydrophilic character, which is responsible for their incompatibility with organic solvents and for their poor adhesion to the hydrophobic surface of conventional 
polymeric materials, strategies have to be developed in order to guarantee a proper dispersion of cellulosic nanofillers in polymeric nanocomposites.

In addition to their application as reinforcing agents in nanocomposites, pure cellulose films may be produced from cellulose nanocrystals and microfibrillated cellulose aqueous suspensions via solution casting (Aulin et al., 2010; Belbekhouche et al., 2011; Fukuzumi et al., 2009; Minelli et al., 2010; Plackett et al., 2010; Rodionova et al., 2011; Siró et al., 2011; Syverud \& Stenius, 2009). These films show excellent oxygen barrier properties at low relative humidity due to their high crystallinity and highly compacted structure (Belbekhouche et al., 2011; Minelli et al., 2010; Plackett et al., 2010; Syverud \& Stenius, 2009). It has been reported that the denser structure and the formation of entanglements in films prepared from microfibrillated cellulose gives rise to increased barrier to gases as compared to cellulose nanowhiskers' films (Belbekhouche et al., 2011).

Despite the outstanding barrier properties of cellulose films at low relative humidity, they present a behaviour typical of hydrophilic materials, i.e. the permeability increases sharply in the range of $40-80 \%$ relative humidity (Aulin et al., 2010). This exponential increase on the oxygen permeability when increasing the relative humidity has been attributed to the fact that water molecules adsorbed by the amorphous domains of cellulose may break down hydrogen bonds and, therefore, preferential sites for oxygen diffusion are created (Aulin et al., 2010). In order to reduce the hydrophilicity of cellulose and restrict the detrimental effect of humidity in its properties, hydrophobization of the cellulose surface has been proposed. TEMPO-oxidized cellulose nanofibres' films produced via vacuum filtration, displaying good mechanical properties and high barrier to oxygen at $0 \% \mathrm{RH}$, were effectively hydrophobized by treatment with alkyl ketene dimer although no barrier properties were reported for the hydrophobized films 
(Fukuzumi et al., 2009). In another study, acetylation of microfibrillated cellulose was successfully developed and films from modified cellulose were produced (Rodionova et al., 2011). Although the surface of the films became hydrophobic, it was observed that the substitution of hydroxyl groups led to increased pore volume in the films due to reduced hydrogen bonding between cellulose microfibrils. Thus, only acetylated cellulose films with a low degree of $\mathrm{OH}$ substitution presented improved water vapor permeability as compared to unmodified cellulose films. A similar effect was observed for films produced from silylated microfibrillated cellulose. When high degrees of $\mathrm{OH}$ substitution were achieved, the so-obtained films displayed contact angles typical of super hydrophobic surfaces. However, partial solubilization of cellulose microfibrils was seen to occur for high degrees of substitution (Andresen et al., 2006).

In the present study, highly crystalline BCNW were used to produce films with excellent barrier properties at low relative humidity. Given the high rigidity of the BCNW films, the addition of PEG as plasticizing agent was additionally evaluated. As a strategy for preserving the high barrier of BCNW films at high relative humidity conditions without the need for a previous chemical modification of the cellulose matrix, BCNW films were coated with PLA by a novel method consisting in deposition of fibres by electrospinning followed by homogenization through annealing. Additionally, this approach was compared with a more conventional method which involved the application of hydrophobic silanes layers. 


\section{MATERIALS AND METHODS}

\subsection{Materials}

The semicrystalline polylactide (PLA) used was a film extrusion grade produced by Natureworks (with a D-isomer content of approximately 2\%). The molecular weight had a number-average molecular weight $\left(M_{n}\right)$ of ca. 130,000 $\mathrm{g} / \mathrm{mol}$, and the weight average molecular weight $\left(\mathrm{M}_{\mathrm{w}}\right)$ was ca. $150,000 \mathrm{~g} / \mathrm{mol}$ as reported by the manufacturer.

Vinyltrimethoxysilane (VTMS) and (3-aminopropyl) trimethoxysilane (APTS) were purchased from Sigma-Aldrich (Germany). Sulphuric acid 96\% and 2-propanol were purchased from Panreac (Barcelona, Spain). Both 1,1,1,3,3,3Hexafluoro-2-propanol (HFP) and polyethylene glycol 900 (PEG) were purchased from Fluka (Germany).

\subsection{Preparation of bacterial cellulose mats}

Bacterial cellulose mats were obtained by following the same procedure as described in a previous work (Martínez-Sanz et al., 2011b). Briefly, the bacterial strain Gluconacetobacter xylinus 7351 was incubated in a modified Hestrin/Shramm medium at $30^{\circ} \mathrm{C}$. All of the cells were pre-cultured in a test tube containing $5 \mathrm{~mL}$ of media and later transferred and scaled up to a bigger reactor of $20 \mathrm{~L}$ at BioInicia S.L., Valencia (Spain). The synthesized bacterial cellulose pellicles were sterilized and cleaned in boiling water and in a $10 \%(\mathrm{v} / \mathrm{v}) \mathrm{NaOH}$ aqueous solution.

\subsection{Preparation of bacterial cellulose nanowhiskers (BCNW)}

Once neutral $\mathrm{pH}$ was reached, bacterial cellulose pellicles were ground in a blender and the gel-like material was then compressed in order to remove most of 
the absorbed water. BCNW were produced by applying the optimized method developed in a previous study (Martínez-Sanz et al., 2011a). Briefly, the dried bacterial cellulose was treated with $301 \mathrm{~mL}$ sulphuric acid/L water, in a cellulose/acid ratio of approximately $7 \mathrm{~g} / \mathrm{L}$, at $50^{\circ} \mathrm{C}$ for three days until a homogeneous solution was obtained. The cellulose nanowhiskers were obtained as a white precipitate after several centrifugation and washing cycles at 12,500 $\mathrm{rpm}$ and $15^{\circ} \mathrm{C}$ for 20 minutes. After that, the material was re-suspended in deionised water and neutralized with sodium hydroxide until neutral $\mathrm{pH}$ and subsequently centrifuged to obtain the final product as a partially hydrated precipitate. The humidity of the material was determined and the yield of the extraction process was estimated to be $79.64 \%$ respect to the dried $\mathrm{BC}$.

\subsection{Preparation of BCNW films}

Bacterial cellulose nanowhiskers films were produced from aqueous suspensions of $\mathrm{BCNW} 0.5 \%(\mathrm{w} / \mathrm{v})$. These suspensions were prepared by dispersing the adequate amount of partially hydrated precipitate into $50 \mathrm{~mL}$ of deionised water by means of intense homogenization (Ultra-turrax) for 2 minutes and sonication for 5 minutes. Additional samples were prepared by adding 20 wt.$\%$ polyethylene glycol (PEG) and dispersing it together with the BCNW. The $\mathrm{BCNW} /$ water or BCNW-PEG/water dispersions were subjected to vacuum filtration through a polytetrafluoroethylene (PTFE) membrane with $0.2 \mu \mathrm{m}$ pore size (Sartorius Stedim Biotech GmbH, Germany). After filtration, the material was dried at ambient temperature overnight and BCNW or BCNW-PEG films were then peeled off from the PTFE membranes.

\subsection{Preparation of coated systems}

In order to protect the highly hydrophilic BCNWs' layer, several methods were tested for coating with hydrophobic materials. 
The first method consisted in coating the BCNW or BCNW-PEG films with PLA mats produced by means of the electrospinning technique. PLA solutions in HFP having a total solids content of 8 wt.- $\%$ were used to generate the electrospun fibres. The electrospinning apparatus was provided and assembled by Fluidnatek S.L., Valencia (Spain). Solutions were transferred to $5 \mathrm{~mL}$ plastic syringes and connected through PTFE tubes to a stainless steel needle $(\varnothing 0.9$ $\mathrm{mm})$. An electrode was clamped to the needle tip and connected to a high-voltage $0-30 \mathrm{kV}$ power supply operating at $10-12 \mathrm{kV}$, and the polymer solution was fed into the needle at a rate of $0.66 \mathrm{~mL} / \mathrm{h}$ by a syringe pump. The counter electrode was connected to a circular plate in which the BCNW film was attached. The plate was placed parallel to the needle and both sides of the BCNW film were coated. The distance between the needle and the plate was $6 \mathrm{~cm}$ and experiments were carried out at ambient temperature. By applying this procedure, BCNW and BCNW-PEG films were coated with 40-50 wt.-\% PLA electrospun fibres.

Electrospun PLA coatings presented an opaque and whitish appearance. With the aim of obtaining a transparent and continuous pellicle, an additional heating step was applied. Coated films were first dried at $60^{\circ} \mathrm{C}$ overnight and they were subsequently placed in between hot plates at $160^{\circ} \mathrm{C}$ to melt and homogenize the PLA phase.

The second method involved the hydrophobization of the films surface by coating with layers of two different silanes. Both vinyltrimethoxysilane (VTMS) and (3-aminopropyl) trimethoxysilane (APTS) are suitable for food contact applications. The methoxy functionalities are able to react with the hydroxyl groups of cellulose, thus being possible to produce silane coatings. The liquid silanes were applied on both sides of BCNW films by using a paint roller. 
Subsequently, films were dried at ambient conditions during 10 minutes and then cured at $60^{\circ} \mathrm{C}$ for 48 hours.

\subsection{Scanning Electron Microscopy (SEM)}

SEM was conducted on a Hitachi microscope (Hitachi S-4100) at an accelerating voltage of $10 \mathrm{KV}$ and a working distance of $12-16 \mathrm{~mm}$. BCNW and BCNW-PEG films as well as the coated systems were cryo-fractured after immersion in liquid nitrogen and subsequently sputtered with a gold-palladium mixture under vacuum before their morphology was examined using SEM. Layer thicknesses were measured by means of the Adobe Photoshop CS3 extended software from the SEM micrographs in their original magnification.

\subsection{Attenuated Total Reflectance (ATR) FT-IR analysis}

ATR-FTIR spectra of all the produced films were recorded in a controlled chamber at $21^{\circ} \mathrm{C}$ and $40 \% \mathrm{RH}$ using a Bruker (Rheinstetten, Germany) FT-IR Tensor 37 equipment and coupling the ATR accessory GoldenGate of Specac Ltd. (Orpington, UK). The spectra were taken at $4 \mathrm{~cm}^{-1}$ resolution averaging a minimum of 20 scans. Analysis of the spectra was performed using Grams/AI 7.02 (Galactic Industries, Salem, NH, USA) software.

\subsection{Thermogravimetric analysis (TGA)}

Thermogravimetric (TG) curves were recorded with a TA Instruments model Q500 TGA. The samples (ca. $20 \mathrm{mg}$ ) were heated from $50^{\circ} \mathrm{C}$ to $600^{\circ} \mathrm{C}$ with a heating rate of $10^{\circ} \mathrm{C} / \mathrm{min}$ under nitrogen atmosphere. Derivative TG curves (DTG) express the weight loss rate as a function of temperature. 


\subsection{Mechanical properties}

Tensile tests were carried out at ambient conditions typically at $24^{\circ} \mathrm{C}$ and $50 \%$ RH on an Instron 4400 Universal Tester. Pre-conditioned dumb-bell shaped specimens with initial gauge length of $25 \mathrm{~mm}$ and $5 \mathrm{~mm}$ in width were die-stamped from the films in the machine direction according to the ASTM D638. A fixed crosshead rate of $10 \mathrm{~mm} / \mathrm{min}$ was utilized in all cases and results were taken as the average of, at least, four tests.

\subsection{Water vapour permeability (WVP)}

Direct permeability to water was determined from the slope of the weight gain versus time curves at $24^{\circ} \mathrm{C}$. The films were sandwiched between the aluminium top (open O-ring) and bottom (deposit for the silica gel that provides $0 \% \mathrm{RH}$ ) parts of a specifically designed permeability cell with screws. A Viton rubber O-ring was placed between the film and the bottom part of the cell to enhance sealability. These permeability cells containing silica gel were then placed inside a desiccator at $75 \% \mathrm{RH}$ and the solvent weight gain through a film area of $0.001 \mathrm{~m}^{2}$ was monitored and plotted as a function of time. The samples were preconditioned at the testing conditions for 24 hours, and to estimate the permeability values of the films, only the linear part of the weight gain data was used to ensure sample steady state conditions. Cells with aluminium films (with thickness of ca. $11 \mu \mathrm{m}$ ) were used as control samples to estimate solvent gain through the sealing. The lower limit of WVP detection of the permeation cells was of ca. $4.2 \cdot 10^{-17} \mathrm{~kg} \cdot \mathrm{m} / \mathrm{s} \cdot \mathrm{m}^{2} \cdot \mathrm{Pa}$ based on the weight gain measurements of the aluminium films. Solvent permeation rates were estimated from the steady-state permeation slopes. Water vapour weight gain was calculated as the total cell weight gain minus the gain through the sealing. The tests were done in duplicate. 


\subsection{Water uptake}

The water uptake was estimated during the sorption experiments at $24^{\circ} \mathrm{C}$ and $75 \%$ RH by means of weight gain using an analytical balance Voyager® V11140. Thus, at saturation conditions, no changes in successive weight uptake were observed during the measurements of the specimens.

Solubility (S), required to estimate the diffusion coefficient of water (D) through the films, was estimated from the water uptake at equilibrium, the density of the materials and the water vapour partial pressure at $24^{\circ} \mathrm{C}$.

\subsection{Oxygen permeability}

The oxygen permeability coefficient was derived from oxygen transmission rate (OTR) measurements recorded using an Oxtran 100 equipment (Modern Control Inc., Minneapolis, MN, US). Experiments were carried out at $24^{\circ} \mathrm{C}$ and at two relative humidities $(0 \% \mathrm{RH}$ and $80 \% \mathrm{RH}) .80 \%$ relative humidity was generated by a built-in gas bubbler and was checked with a hygrometer placed at the exit of the detector. The samples were purged with nitrogen for a minimum of $20 \mathrm{~h}$ in the humidity equilibrated samples, prior to exposure to an oxygen flow of $10 \mathrm{ml} / \mathrm{min}$. A $5 \mathrm{~cm}^{2}$ sample area was measured by using an in-house developed mask. Reduced sample areas while testing oxygen permeation in high permeable materials enhances the reproducibility of the measurements, permits to select defect-free areas and ensures minimum thickness variations.

\subsection{Contact angle measurements}

Measurements of contact angle were performed at $24^{\circ} \mathrm{C}$ and ambient relative humidity (ca. 60\%RH) in a Video-Based Contact Angle Meter model OCA 20 (DataPhysics Instruments GmbH, Filderstadt, Germany). Contact angle measurements were obtained by analyzing the shape of a distilled water drop after 
it had been placed over the film for 30 seconds. Image analyses were carried out by SCA20 software. 


\section{RESULTS AND DISCUSSION}

\subsection{BCNW films characterization}

Crystalline cellulose nanowhiskers have been extensively used as reinforcing agents in nanocomposite materials. Previous works have investigated the effect of incorporating cellulose nanowhiskers on the barrier properties of nanocomposite materials, showing significant improvements provided that a high dispersion of the nanowhiskers was achieved (Martínez-Sanz et al., 2012b; Martínez-Sanz et al., 2013a, b). In addition, microfibrillated cellulose and cellulose nanowhiskers films have shown excellent barrier properties at low relative humidity (Belbekhouche et al., 2011; Minelli et al., 2010; Siró et al., 2011). The purpose of this work was to develop high barrier materials by using highly crystalline bacterial cellulose nanowhiskers' films and to enhance the performance of these materials at high relative humidity by coating them with hydrophobic layers.

The BCNW used in the present work were extracted by acid hydrolysis of bacterial cellulose pellicles and showed a crystallinity index of ca. 95\%, as previously estimated by X-ray diffraction (Martínez-Sanz et al., 2011a). The morphology of BCNW produced by sulphuric acid hydrolysis has already been studied and, in a previous work, it was shown that BCNW extracted using the optimized hydrolysis conditions applied in the present work presented an average cross-section (W) of ca. $18 \mathrm{~nm}$ and length (L) of ca. $570 \mathrm{~nm}$ having, thus, an aspect ratio (L/W) of ca. 30 (Martínez-Sanz et al., 2011a).

Pure BCNW films presented a highly compacted nanofibres' layered structure, as shown in Figure 1A. The material presented a highly dense structure, which was held by the strong hydrogen network established between the hydroxyl groups present on the cellulose chains, and no pores could be detected at the applied 
magnification. Figure 1B shows that when incorporating the polyethylene glycol (PEG) as plasticizing agent into the films, a less compacted structure was attained, in which PEG rich domains could be clearly discerned.
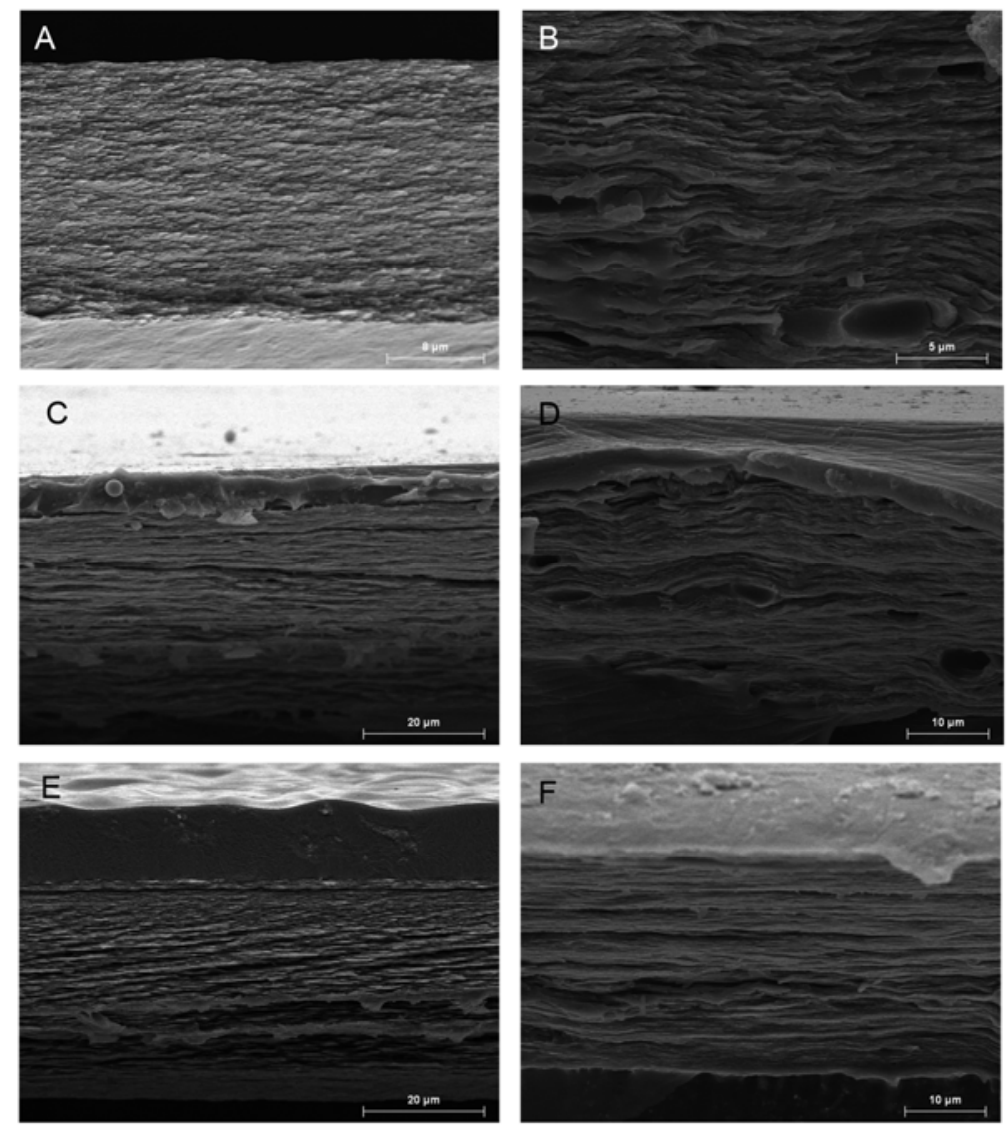

Figure 1. SEM micrograph of cryo-fractured surfaces from: (A) BCNW film; (B)

BCNW-PEG film; (C) BCNW film coated with annealed PLA electrospun nanostructured fibres; (D) BCNW-PEG film coated with annealed PLA electrospun nanostructured fibres; (E) BCNW film coated with APTS and (F) BCNW film coated with VTMS. Scale markers are 8 micrometres in (A), 5 micrometres in (B), 20 micrometres in (C) and (E) and 10 micrometres in (D) and (F). 
Thermal stability of BCNW and BCNW-PEG films was evaluated by TGA (see Figure S1 in the Supporting Information). The onset degradation temperature and the maximum degradation temperature for the BCNW film were determined to be $206.7^{\circ} \mathrm{C}$ and $332.1{ }^{\circ} \mathrm{C}$, respectively, which are values very similar to those previously reported for BCNW produced by the same optimized hydrolysis treatment (Martínez-Sanz et al., 2011a). On the other hand, the film containing PEG presented a wider degradation range, with a lower onset degradation temperature of $174.0{ }^{\circ} \mathrm{C}$ and a higher maximum degradation temperature of 342.3 ${ }^{\circ} \mathrm{C}$. Therefore, it is confirmed that BCNW films can be subjected to temperatures typical for polymeric materials processing methods without suffering thermal degradation. Nevertheless, films containing PEG presented an onset degradation temperature which was close to the temperature at which films were processed.

Table 1 gathers the mechanical properties of BCNW and BCNW-PEG films. As deduced from the table, pure BCNW films displayed a rigid and brittle behaviour, with a higher Young's modulus than that previously reported for MFC films but lower elongation at break. The higher crystallinity of BCNW as compared to MFC may be the reason for this higher rigidity and reduced ductility. With the aim of increasing the ductility of the films, PEG was incorporated into the system. However, it may be observed that its incorporation did not significantly increase the ductility of the material, i.e. the elongation at break, but it led to a reduction in the Young's modulus. According to SEM observations, this effect could be related to the fact that there was a certain phase separation between the crystalline BCNW and the PEG domains. 
Table 1. Young's Modulus, Tensile Strength and Elongation at Break for BCNW and BCNW-PEG films and the various coated systems.

\begin{tabular}{|c|c|c|c|}
\cline { 2 - 4 } \multicolumn{1}{c|}{} & $\mathrm{E}(\mathrm{GPa})$ & $\begin{array}{c}\text { Tensile strength } \\
(\mathrm{MPa})\end{array}$ & $\varepsilon_{\mathrm{b}}(\%)$ \\
\hline BCNW & ${ }^{\mathrm{b}} 7.88 \pm 0.12$ & ${ }^{\mathrm{ab}} 74.55 \pm 11.48$ & ${ }^{\mathrm{a}} 1.04 \pm 0.13$ \\
\hline BCNW-PLA & ${ }^{\mathrm{b}} 7.64 \pm 1.20$ & ${ }^{\mathrm{ab}} 74.93 \pm 32.77$ & ${ }^{\mathrm{a}} 1.07 \pm 0.38$ \\
\hline BCNW-VTMS & ${ }^{\mathrm{b}} 7.49 \pm 0.81$ & ${ }^{\mathrm{ab}} 62.50 \pm 9.06$ & ${ }^{\mathrm{a}} 0.96 \pm 0.13$ \\
\hline BCNW-PEG & ${ }^{\mathrm{ab}} 5.55 \pm 0.52$ & ${ }^{\mathrm{ab}} 51.44 \pm 5.34$ & ${ }^{\mathrm{a}} 1.62 \pm 0.91$ \\
\hline BCNW-PEG-PLA & ${ }^{\mathrm{a}} 2.43 \pm 0.67$ & ${ }^{\mathrm{a}} 11.62 \pm 2.83$ & ${ }^{\mathrm{a}} 0.66 \pm 0.00$ \\
\hline Film PLA (Martínez-Sanz et al., & ${ }^{\mathrm{ab}} 5.10 \pm 2.45$ & ${ }^{\mathrm{b}} 88.87 \pm 29.39$ & ${ }^{\mathrm{a}} 1.56 \pm 0.00$ \\
\hline MFC film literature values (Plackett & $2.85 \pm 0.08$ & $53.77 \pm 1.18$ & $4.93 \pm 0.45$ \\
\hline et al., 2010) & $2.1 \pm 0.1$ & $39.0 \pm 8.0$ & $2.8 \pm 0.9$ \\
\hline MFC carboxymethylated film & $4.4-7.4$ & $182.2-280.7$ & $3.9-12.7$ \\
\hline
\end{tabular}

The $\mathrm{a}$ and $\mathrm{b}$ letters correspond to the ANOVA statistical analysis and Tukey test of the data that indicate that with a $95 \%$ confidence level, the values are significantly different.

Barrier properties of both pure BCNW and BCNW-PEG films are displayed in Table 2 . The water permeability values were similar to that previously reported for microfibrillated cellulose films (Rodionova et al., 2011), whereas the oxygen permeability measured at $0 \% \mathrm{RH}$ was between one and two orders lower than the values reported for microfibrillated cellulose (MFC) films (Minelli et al., 2010; 
Rodionova et al., 2011). This has never been reported before and indicates that BCNW can form more tightly packed films than MFC. The improved barrier properties of the BCNW films may thus be explained by the more compacted structures generated by the vacuum filtration process here applied and by the higher crystallinity of the material as compared to conventional solvent cast microfibrillated cellulose.

Nevertheless, when exposing these materials to high relative humidity conditions, the oxygen permeability dramatically increased. A previous work, in which the oxygen permeability of MFC films was studied at various relative humidities, showed a sharp increase in the oxygen permeability of the films at a relative humidity greater than $70 \% \mathrm{RH}$ (Aulin et al., 2010). This behaviour is typical of hydrophilic materials and it was ascribed to the plasticization effect caused by water adsorbed in the surface of the amorphous MFC domains. Water molecules may disrupt hydrogen bonding hence limiting nanofibril-nanofibril interactions and, thus, resulting in an increased mobility of oxygen molecules within the cellulose network.

In addition, when incorporating PEG into the films, higher values for both the water and oxygen permeability were detected. The reason for incorporating PEG into the films was to reduce the rigidity of the films, but, as observed, this plasticization effect was not achieved for the PEG loading here tested and additionally, the material possessed greater water sensitivity. Therefore, the addition of such concentration of PEG did not present any clear advantage. 
Table 2. Barrier properties of BCNW and BCNW-PEG films and of the various coated systems. The water permeability and water uptake were measured at $75 \% \mathrm{RH}$ and the estimated oxygen diffusion and permeability coefficients were measured at $0 \% \mathrm{RH}$ and $80 \% \mathrm{RH}$. Some literature values from MFC films are also included for comparison purposes.

\begin{tabular}{|c|c|c|c|c|c|}
\hline & $\begin{array}{c}\mathrm{P} \mathrm{H}_{2} \mathrm{O} \\
\left(\mathrm{Kg} \cdot \mathrm{m} / \mathrm{s} \cdot \mathrm{m}^{2} \cdot \mathrm{Pa}\right)\left(\times 10^{-}\right. \\
\left.{ }^{14}\right)\end{array}$ & Water uptake (\%) & $\begin{array}{l}\mathrm{D}\left(\mathrm{m}^{2} / \mathrm{s}\right) \\
\left(\times 10^{-12}\right)\end{array}$ & $\begin{array}{c}\mathrm{P} \mathrm{O}_{2} 0 \% \mathrm{RH} \\
\left(\mathrm{m}^{3} \cdot \mathrm{m} / \mathrm{m}^{2} \cdot \mathrm{s} \cdot \mathrm{Pa}\right)\end{array}$ & $\begin{array}{c}\mathrm{P} \mathrm{O}_{2} 80 \% \mathrm{RH} \\
\left(\mathrm{m}^{3} \cdot \mathrm{m} / \mathrm{m}^{2} \cdot \mathrm{s} \cdot \mathrm{Pa}\right)\end{array}$ \\
\hline BCNW & $3.55 \pm 1.11$ & $4.95 \pm 0.74$ & 1.54 & $6.99 \cdot 10^{-22}$ & $5.97 \pm 0.24 \cdot 10^{-18}$ \\
\hline BCNW-PLA & $1.19 \pm 0.48$ & $4.00 \pm 0.47$ & 1.25 & --- & $0.20 \pm 0.08 \cdot 10^{-18}$ \\
\hline BCNW-VTMS & $3.28 \pm 1.18$ & $4.66 \pm 0.17$ & 1.70 & --- & $5.51 \pm 0.20 \cdot 10^{-18}$ \\
\hline BCNW-APTS & $1.86 \pm 0.33$ & $14.41 \pm 1.28$ & 0.47 & --- & $1.56 \pm 0.12 \cdot 10^{-18}$ \\
\hline BCNW-PEG & $4.81 \pm 1.18$ & $3.40 \pm 0.15$ & 3.78 & $4.06 \cdot 10^{-22}$ & $7.17 \pm 0.20 \cdot 10^{-18}$ \\
\hline $\begin{array}{c}\text { BCNW-PEG- } \\
\text { PLA }\end{array}$ & $1.46 \pm 0.53$ & $4.11 \pm 0.11$ & 0.95 & --- & $1.83 \pm 0.25 \cdot 10^{-18}$ \\
\hline $\begin{array}{c}\text { Film PLA } \\
\text { (Martínez- } \\
\text { Sanz et al., } \\
\text { 2012b) }\end{array}$ & $1.31 \pm 0.01^{(*)}$ & $0.95 \pm 0.15^{(*)}$ & 3.63 & --- & $1.78 \pm 0.13 \cdot 10^{-18}$ \\
\hline MFC film & 3.81 (Rodionova et & --- & --- & $6.67 \pm 2.20 \cdot 10^{-21}$ (Minelli et & $2.20 \cdot 10^{-1 /}$ (Minelli et \\
\hline
\end{tabular}




\begin{tabular}{|c|c|c|c|c|c|}
\hline $\begin{array}{c}\text { literature } \\
\text { values }\end{array}$ & al., 2011) & & & $\begin{array}{c}\text { al., } 2010 \text { ) } \\
2.01 \cdot 10^{-20} \text { (Rodionova et } \\
\text { al., 2011) }\end{array}$ & $\begin{array}{c}\text { al., 2010) } \\
4.26-5.83 \cdot 10^{-20} \\
\text { (Syverud \& Stenius, } \\
2009)^{\left({ }^{* *}\right)} \\
1.82 \pm 0.11 \cdot 10^{-21} \\
\text { (Plackett et al., 2010) } \\
\left({ }^{\star \star}\right)\end{array}$ \\
\hline $\begin{array}{c}\text { MFC } \\
\text { carboxymethyl } \\
\text { ated film } \\
\text { literature } \\
\text { values }\end{array}$ & --- & --- & --- & --- & $\begin{array}{c}4.23-5.71 \cdot 10^{-21} \\
(\text { Siró et al., 2011) } \\
\left.{ }^{(\star *}\right) \\
9.84 \cdot 10^{-21}(\text { Aulin et } \\
\text { al., } 2010)^{\left({ }^{(\star)}\right)}\end{array}$ \\
\hline
\end{tabular}

${ }^{(*)}$ Measured at $100 \%$ RH

${ }^{(* *)}$ Measured at $50 \% \mathrm{RH}$ 
To summarize, BCNW films presented a homogeneous and compact morphology with excellent barrier properties for low relative humidity, whereas due to their hydrophilic character, at high relative humidity (80\%), a considerable increase in the oxygen permeability was observed. The addition of PEG slightly distorted the highly packed structure of the BCNW films, reducing their mechanical performance and increasing their sensitivity to water, thus resulting in a drop in the barrier properties.

\subsection{Optical, morphological, chemical and mechanical characterization of}

\section{the coated systems}

As it has been shown in the previous section, the developed BCNW films presented an excellent barrier to oxygen at low relative humidity. Nevertheless, the major problem of these materials was their high hydrophilicity which makes them very sensitive to water activity, hence reducing drastically the oxygen barrier properties for relative humidities higher than $70 \%$.

With the aim of preserving the low oxygen permeability of the material even at high relative humidity, coating of BCNW with hydrophobic materials was suggested as a feasible route to protect the material from moisture. Nevertheless, the low compatibility of BCNW with hydrophobic materials prevented the use of casting methods to develop multilayer systems or to combine the BCNW with hydrophobic layers through compression moulding, since adhesion between the different layers was very poor and partial or even a complete delamination between the different layers took place (see Figures S2A and S2B in the Supporting Information).

A novel strategy was proposed to overcome this issue and to get uniform layers protecting the $\mathrm{BCNW}$ films, involving the use of the electrospinning technique 
followed by annealing to produce hydrophobic coatings based on PLA. Electrospun PLA fibres were produced by following the optimized procedure described elsewhere (Martínez-Sanz et al., 2012a). These fibres, which presented a uniform morphology (cf. Figure S3 in the Supporting Information), were directly electrospun onto the surface of BCNW and BCNW-PEG films. Subsequently, the coated systems were annealed to temperatures close to the melting point of PLA electrospun fibres, turning the materials nearly transparent (cf. Figure $2 \mathrm{~B}$ and $2 \mathrm{~F}$ ). It is worth mentioning that the film containing PEG presented a slight yellowish colour, which may be indicating that the material underwent partial thermal degradation. This can be explained by the fact that the film containing PEG had an onset degradation temperature close to the annealing temperature applied to the material, just as pointed out by TGA analyses. As observed in Figures 1C and 1D, after heating the coated system, a relatively homogeneous PLA layer was formed on both sides of the BCNW film. The average thickness of the PLA fibres layer was ca. $5 \mu \mathrm{m}$ for both BCNW and BCNW-PEG coated films. It is also interesting to note that the adhesion between the PLA the BCNW layers was very good and no delamination occurred even after cryo-fracturation of the material, just as shown in Figures 1C and 1D. These results highlight the convenience of the electrospinning processing technique as an efficient strategy for coating BCNW films, since it provides an enhanced adhesion between the hydrophilic inner layer and the hydrophobic outer layers without the need for adhesive layers. 

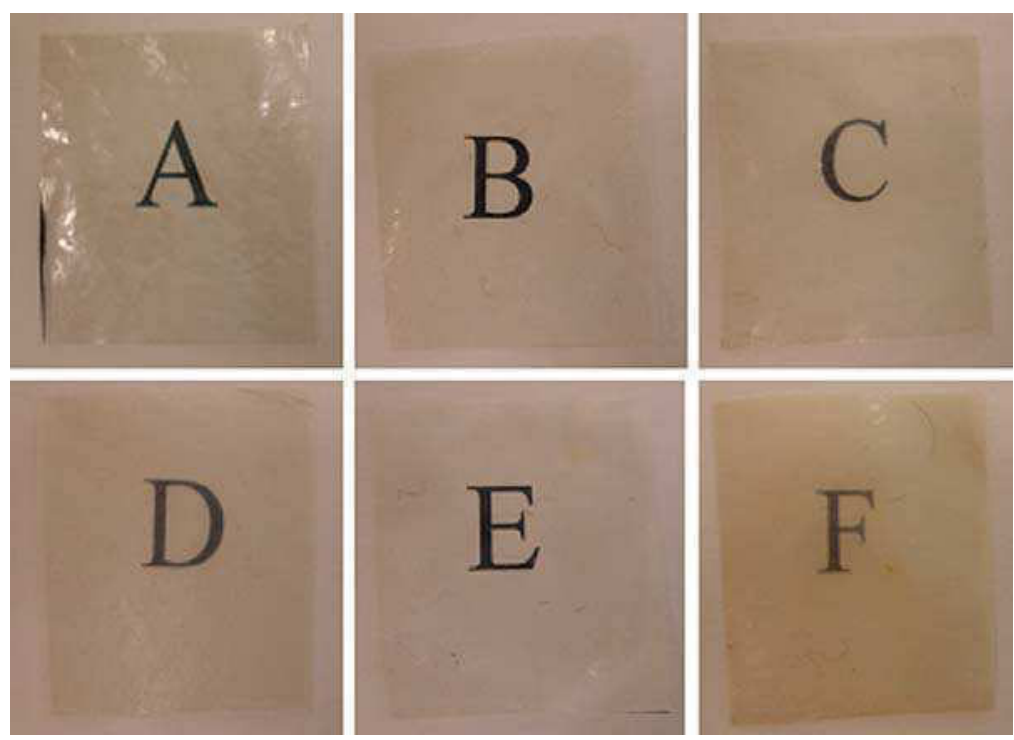

Figure 2. Photographs of BCNW films: (A) Pure BCNW; (B) BCNW film coated with annealed PLA electrospun nanostructured fibres; (C) BCNW film coated with

VTMS; (D) BCNW film coated with APTS; (E) BCNW-PEG film; and (F)

BCNW-PEG film coated with annealed PLA electrospun nanostructured fibres.

Besides being homogeneously distributed, the applied PLA coatings were continuous and hence, as observed in Figure 3, the typical spectrum of PLA was obtained when analysing the coated system surface by ATR-FTIR. From these spectra it can be observed that the broad band located between 3000 and $3700 \mathrm{~cm}^{-1}$, corresponding to $\mathrm{OH}$ stretching intramolecular hydrogen bonds (Carrillo et al., 2004), characteristic of hydrophilic materials, completely disappeared after coating with PLA. Therefore, the last annealing step resulted in efficient nanofiber coalescence and substrate adherence promotion for the discontinuous electrospun fibres deposited onto the BCNW films into a compacted and continuous PLA layer. 


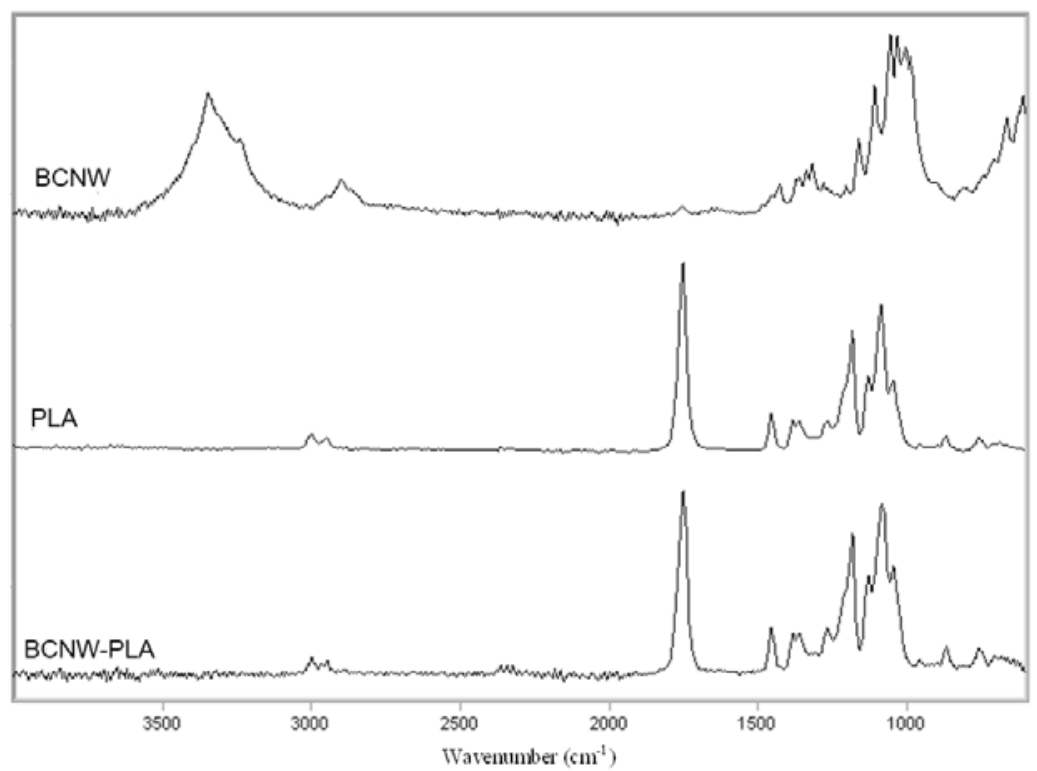

Figure 3. ATR-FTIR spectra of BCNW film, PLA electrospun fibres and BCNW coated with annealed PLA electrospun nanostructured fibres.

To evaluate the efficiency of the coating method based on electrospinning followed by annealing, a second approach already described in the literature was suggested for protecting the BCNW films from moisture. This method consisted in coating with thin layers of silanes, which are thought to react with the hydroxyl groups present in the surface of cellulose and form layers with different functionalities (Daniel, 1999; Luechinger et al., 2005; Tingaut et al., 2011). In this work two different silanes, i.e. (3-aminopropyl)trimethoxysilane (APTS) and vinyltrimethoxysilane (VTMS), both allowed for food-contact applications, were used for coating BCNW films. The morphology of cryo-fractured sections of silane-coated BCNW films is shown in Figures $1 \mathrm{E}$ and $1 \mathrm{~F}$. Despite the fact that both silanes were applied by following the same procedure, the average thickness of the coating was different in each case. For the APTS the outer layer presented an average thickness of $9 \mu \mathrm{m}$ whereas for the VTMS, the average thickness was 0.8 
$\mu \mathrm{m}$. The adhesion between the silane and the BCNW layers seemed to be good in both cases, although, probably due to the different thickness of the coatings, it was easier to identify the interface between both materials for the APTS coated system. As observed in Figures $2 \mathrm{C}$ and 2D, the films prepared by coating with silanes preserved a good contact transparency, although it was slightly diminished when compared to the pure BCNW film.

Figures $4 \mathrm{~A}$ and $4 \mathrm{~B}$ show the mechanism proposed for the reaction between silanes and cellulose based on previous works (Lee \& Kim, 2012). In the presence of moisture, the methoxy groups from the silanes tend to be replaced by hydroxyl groups, thus forming silanols. Hydroxyl groups from cellulose and silanol react and the silanol groups bond to the cellulose chain without modification of its functional group (amino or vinyl). In the case of APTS, amino functional groups can further react with hydroxyl groups from silanols and, therefore, additional layers can be created via hydrogen bonding. This is probably the reason why the thickness of the outer layer was greater for APTS than for VTMS. During the final curing step, the number of hydroxyl groups from silanols is reduced by cross-linking (Angst \& Simmons, 1991). 


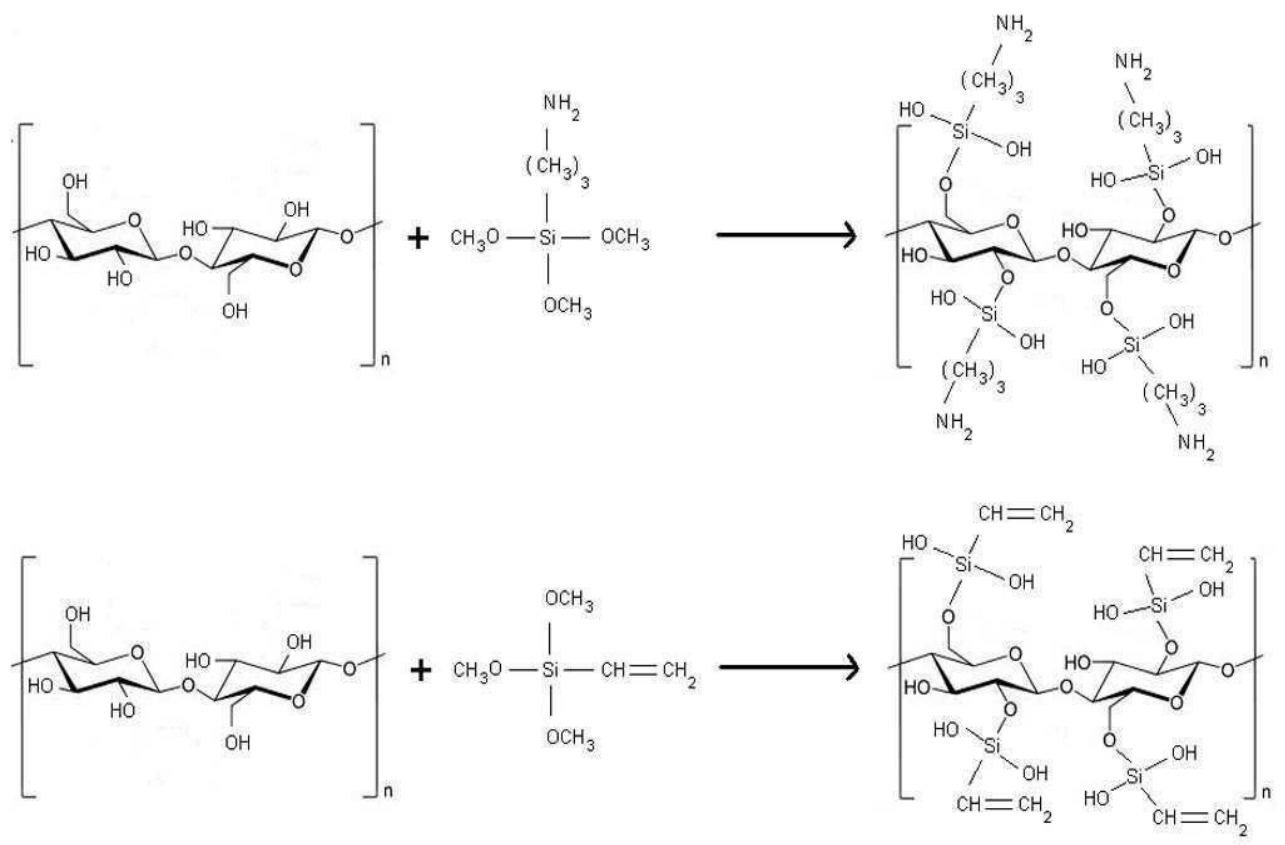

Figure 4. Proposed mechanism for the reaction of BCNW with APTS (A) and with VTMS (B).

In order to further study the interactions established between BCNW and the silanes, ATR-FTIR analyses of pure BCNW films, silanes and silane-coated BCNW films were carried out and the recorded spectra are displayed in Figure 5. The spectrum of BCNW-APTS was different to that of pure BCNW or pure APTS, suggesting that the cellulose hydroxyl groups effectively reacted with some chemical groups from the silane. From the spectra it is also worth noting that a decrease in the intensity of the band located at $2840 \mathrm{~cm}^{-1}$, characteristic from Si-O$\mathrm{CH}_{3}$ (Lee \& Kim, 2012), was observed and a band characteristic from Si-O-C (Lee \& Kim, 2012), located at approximately $1000 \mathrm{~cm}^{-1}$, was discerned after reaction of APTS with cellulose. Additionally, the broad band between 3000 and $3700 \mathrm{~cm}^{-1}$ detected for the coated material, can be assigned to $\mathrm{NH}_{2}$ stretching and 
to $\mathrm{Si}-\mathrm{OH}$ and the peaks at $1635 \mathrm{~cm}^{-1}$ and $1568 \mathrm{~cm}^{-1}$ to $\mathrm{NH}_{2}$ stretching vibration and to the bending band of protonated amines, respectively (Xia et al., 2006). These spectral changes confirmed that indeed methoxy groups from the silane were hydrolysed and the silane was bonded to cellulose. On the other hand, the presence of Si-OH bonds suggests that the curing process to which the films were subjected was not sufficient for completely removing hydroxyl groups through cross-linking.

The spectrum for VTMS was characterized by the major bands appearing at $1075 \mathrm{~cm}^{-1}, 810 \mathrm{~cm}^{-1}$ and $764 \mathrm{~cm}^{-1}$, corresponding to Si-O-R bonds (Velamakanni et al., 2010), $C=C$ stretching (Xie et al., 2010) and C-H out of plane deformation (Rosa et al., 2010), respectively. In addition, two other bands characteristic from the vinyl functional group can be detected at $1410 \mathrm{~cm}^{-1}$, corresponding to $\mathrm{CH}$ deformation vibration in $\mathrm{H}_{2} \mathrm{C}=\mathrm{CH}$ group (Xie et al., 2010) and at $1600 \mathrm{~cm}^{-1}$, assigned to $\mathrm{C}=\mathrm{C}$ stretching (Xie et al., 2010). No significant spectral changes were observed after coating the BCNW layer with VTMS, although a detailed examination allowed distinguishing the band for the vinyl functional group, at ca. $1410 \mathrm{~cm}^{-1}$. In addition, the intensity of the broad band between 3000 and $3600 \mathrm{~cm}^{-1}$ corresponding to $\mathrm{OH}$ stretching intramolecular bonds in cellulose was decreased but not to a great extent since $\mathrm{Si}-\mathrm{OH}$ groups also present a characteristic band in this region. The reason for not detecting major VTMS peaks in the ATR-FTIR spectrum of the coated system may be due to the fact that the outer layer of VTMS was too thin and, thus, the ATR signal was predominantly coming from the inner layer. Therefore, from ATR-FTIR analyses it seems that the amino groups from APTS were much more reactive than vinyl groups from VTMS and as a result, the layers of silane chains were more easily formed for the APTS, through the interaction of amino groups with silanol groups. 


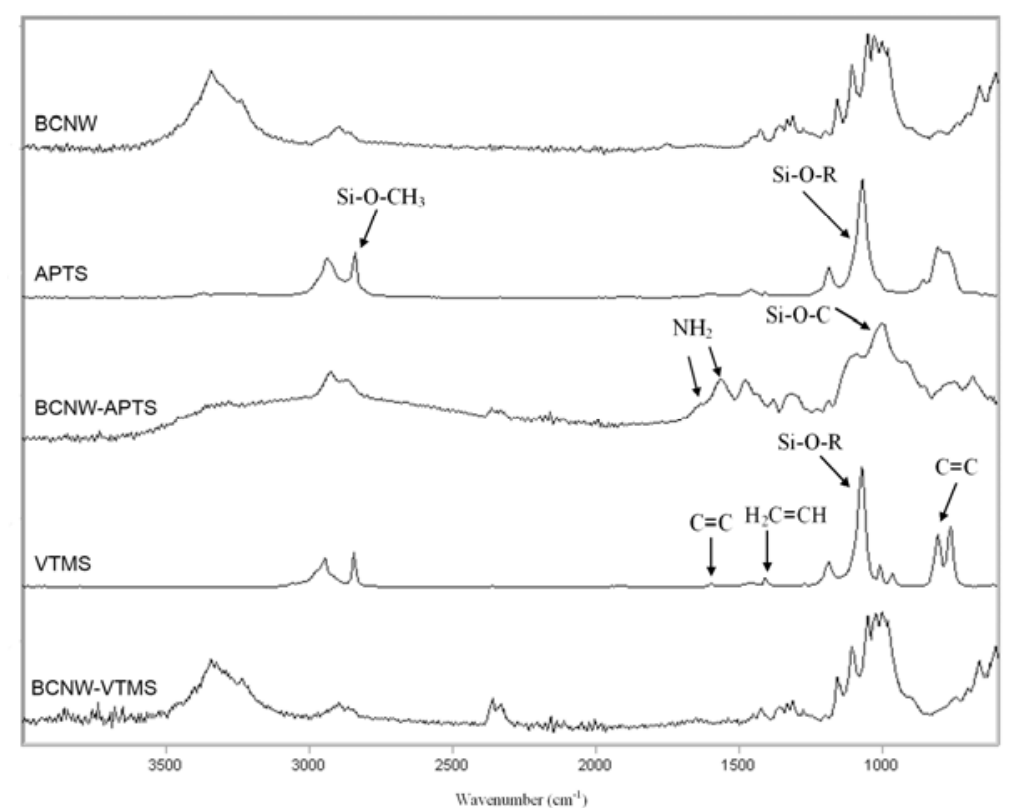

Figure 5. ATR-FTIR spectra of BCNW films and BCNW coated with: (A) APTS and (B) VTMS.

Regarding the mechanical properties of the coated films, as observed in Table 1 , none of the applied coatings seemed to strongly affect the mechanical performance of the neat BCNW and BCNW-PEG films. When the BCNW-PEG film was coated with annealed PLA electrospun nanostructured fibres, the system presented a slightly higher Young's modulus, tensile strength and elongation at break, suggesting that the outer PLA layer might be improving the mechanical performance of the inner layer, probably protecting it from the detrimental effect of moisture and/or PEG migration. The only case in which coating presented a slight unfavourable effect on the mechanical properties corresponded to coating with APTS. In that case, the Young's modulus and tensile strength of the material slightly decreased, although this effect was not statistically significant. 


\subsection{Barrier properties of the coated systems}

The main purpose of this work was to improve the barrier of BCNW at high relative humidity by combining them with outer layers of materials less sensitive to moisture. In order to confirm that this objective was achieved and to select the coated system which showed the higher barrier properties, both water and oxygen permeability of the developed materials were evaluated.

Table 2 gathers water permeability and water uptake values as well as the estimated diffusion coefficients for the developed films. From the results it is observed that BCNW films presented lower water barrier than a PLA film. Similar permeability values have been reported for microfibrillated cellulose films (Rodionova et al., 2011). On the other hand, when coating BCNW or BCNW-PEG films with annealed PLA electrospun nanostructured fibres, water permeability dropped by ca. $66 \%$ and $70 \%$, respectively, thus providing the greatest water barrier from all the developed materials. For the silane-coated materials, APTS was able to reduce water permeability by ca. $48 \%$ whereas a slight drop of ca. $8 \%$ was seen for VTMS-coated films.

The strategy usually applied for improving cellulose barrier properties for high water activities is to modify the surface by introducing hydrophobic functional groups through reaction with the cellulose hydroxyl groups. For example, by acetylating MFC it was possible to decrease water permeability up to $22 \%$ with respect to the unmodified MFC film (Rodionova et al., 2011). Nevertheless, from the results obtained through this work it is observed that coating with annealed PLA electrospun nanostructured fibres reduces water permeability more effectively than surface modification of cellulose, resulting in systems with greater water barrier than that of previously reported materials. It is worth noting that the reduction in water permeability attained for annealed PLA electrospun 
nanostructured fibres coated films was due to a combination of reduced sorption and diffusion. From Table 2 it is also observed that PLA films presented lower sorption but greater diffusion than BCNW films. Therefore, in the coated system the PLA outer layer limited water sorption due to the specific PLA chemistry, whereas the inner BCNW layer provided a highly crystalline and compacted structure, which limited water diffusion through the system.

A relatively low water sorption was observed for BCNW and BCNW-PEG films. The water uptake value obtained for the BCNW film was significantly lower than that previously estimated for MFC films and sisal whisker films produced by solution casting (Aulin et al., 2010; Belbekhouche et al., 2011). Probably due to the very high crystallinity of BCNW there were limited amorphous domains available for water sorption as compared to less crystalline materials. The incorporation of PEG reduced the water uptake since hydroxyl groups from PEG interacted with those from cellulose via hydrogen bonding, hence limiting the amount of free hydroxyl groups available for water sorption. Nevertheless, the negative effect of PEG on the morphology of films, which had a less compacted structure (cf. Figure 1B), resulted in higher diffusion through the system.

When coating BCNW with APTS the sorption was significantly increased, thus confirming that amino and silanol groups were present in the material, just as suggested by the mechanism shown in Figure 4A. However, water molecules remained bonded to silanol and amino groups from the outer coating layer, hence reducing the free volume at the surface and limiting the diffusion to the underneath BCNW film. Previous studies on moisture sorption of organosiloxane layers showed that even though the outer layer was highly hydrophobic, the moisture sorption of silicon dioxide silanized surfaces was greater than for the unsilanized surfaces due to the presence of silanol groups as a result of typically incomplete 
curing. By more extensive curing of the silanol coating, cross-linking was promoted and, thus, the number of silanol groups acting as sorption sites was reduced (Angst \& Simmons, 1991). Further sorption and desorption analyses (results not shown) showed that for the sorption process, the uncoated BCNW film reached the equilibrium faster than the APTS coated system. On the contrary, for the desorption process, the coated system released considerably faster the sorbed water and reached the equilibrium. This result suggests that, in the presence of moisture, hydrogen bonds established between hydroxyl groups in the APTS coating are disrupted after the curing process, hence, water is primarily sorbed by free hydroxyl groups.

Contact angle measurements were additionally carried out to investigate the effect of the applied outer layers on the surface water affinity and results are listed in Table 3. High contact angle values, ranging from $70^{\circ}$ to $90^{\circ}$, are characteristic from hydrophobic surfaces such as silicone or fluorocarbon polymers, while low contact angle values, between $0^{\circ}$ and $30^{\circ}$, are observed for highly hydrophilic surfaces such as glass or mica (Gilliland et al., 2005). The contact angle of the BCNW film, which was similar to that reported for MFC films (Rodionova et al., 2011) and TEMPO-oxidized cellulose nanofibres films (Fukuzumi et al., 2009), was characteristic of hydrophilic materials. As shown in Figure 6, the wettability of films was further increased when incorporating PEG into the system, as a consequence of the hydrophilic character of PEG and the increased roughness of the material, which is known to decrease contact angles for hydrophilic materials (Chau et al., 2009). On the contrary, as observed in Figure 6 and Table 3, the systems coated by annealed PLA electrospun nanostructured fibres or APTS, showed significantly higher contact angles of ca. $70-80^{\circ}$. As a reference, contact angles of up to $82.7^{\circ}, 94^{\circ}$ and $146^{\circ}$ have been reported for films from acetylated MFC (Rodionova et al., 2011), TEMPO-oxidized cellulose nanofibers treated with 
alkylketene dimer (Fukuzumi et al., 2009) and MFC surface treated with chlorodimethyl isopropylsilane (Andresen et al., 2006), respectively, although all of these mentioned works involved chemical modification of the cellulosic material.

Table 3. Contact angles measured after 30 seconds for pure BCNW and BCNW-

PEG films and the various coated systems.

\begin{tabular}{|c|c|}
\cline { 2 - 2 } \multicolumn{1}{c|}{} & Contact angle $\left({ }^{\circ}\right)$ \\
\hline BCNW & ${ }^{\mathrm{b}} 43.8 \pm 0.7$ \\
\hline BCNW-PLA & ${ }^{\mathrm{d}} 77.8 \pm 0.3$ \\
\hline BCNW-VTMS & ${ }^{\mathrm{c}} 64.3 \pm 1.9$ \\
\hline BCNW-APTS & ${ }^{\mathrm{d}} 73.2 \pm 1.6$ \\
\hline BCNW-PEG & ${ }^{\mathrm{a}} 27.3 \pm 2.3$ \\
\hline BCNW-PEG-PLA & ${ }^{\mathrm{e}} 79.6 \pm 1.6$ \\
\hline
\end{tabular}

The $\mathrm{a}, \mathrm{b}, \mathrm{c}, \mathrm{d}$ and e letters correspond to the ANOVA statistical analysis and Tukey test of the data that indicate that with a $95 \%$ confidence level, the values are significantly different.

As indicated by the measured water contact angles, coating of BCNW with annealed PLA electrospun nanostructured fibres or APTS resulted in hydrophobic surfaces. It should be noted that whereas PLA-coated films presented decreased water uptake, APTS-coated films presented the greatest water sorption value for the films tested. In terms of chemical composition, the APTS coating contained amino and hydroxyl groups which were responsible for water sorption, but these groups were partially cross-linked after the curing step and apparently they tended to remain in the inner side of the coating layer, whereas the surface of the coating seemed to be composed of the hydrophobic alcoxysilane regions. Another fact to take into account is that water contact angle measurements are typically carried out 
immediately after deposition of the water droplet. We observed that one hour after deposition of the droplet, water completely expanded over the film surface. Therefore, in agreement with water permeability and sorption experiments, it seems that although the surface of the APTS layer showed, in principle, a hydrophobic behaviour, this layer possessed hydroxyl and amino groups which interacted via hydrogen bonding with water and, thus became hydrophilic upon contact. On the other hand, upon removal of moisture contact, the film recovered its original hydrophobic behaviour.

A
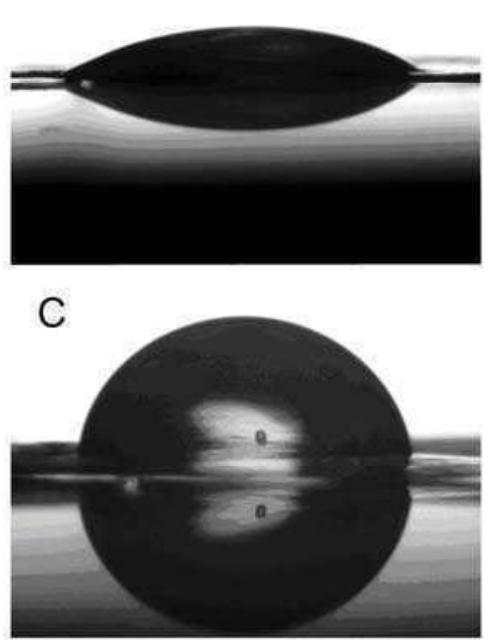

B
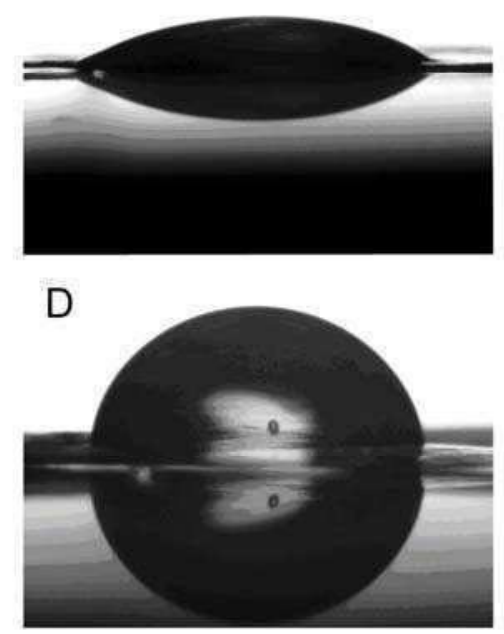

Figure 6. Images of water droplet in contact angle measurements for BCNW film

(A), BCNW-PEG film (B), BCNW coated with annealed PLA electrospun nanostructured fibres $(C)$ and BCNW coated with APTS (D).

It has already been discussed that BCNW films present excellent oxygen barrier at low relative humidity, but their high moisture sensitivity results in dramatically decreased barrier when the relative humidity is higher than $70 \%$ 
(Aulin et al., 2010). Table 2 displays the oxygen permeability values for the developed materials at $80 \% \mathrm{RH}$, i.e. within the range in which the oxygen permeability of the BCNW films is dramatically increased, to a point where the material becomes highly permeable. This strong water sensitivity can limit the usability of cellulosic materials in many applications, as it can compromise barrier properties. From the results, it is observed that the greatest oxygen barrier was attained when coating BCNW films with annealed PLA electrospun nanostructured fibres. Using this method, it was possible to reduce the oxygen permeability by ca. 97\% and 74\% with respect to the BCNW and BCNW-PEG films, respectively at $80 \%$ RH. In agreement with water permeability results, it seems that the outer PLA layer limited the amount of water that reached the inner BCNW layer and, therefore, the oxygen permeability was kept low with increasing water activity.

In the case of the BCNW films coated with silanes it is worth noting that a $74 \%$ reduction in the oxygen permeability was observed when the BCNW film was coated with APTS, whereas coating with VTMS only caused a ca. $8 \%$ reduction. This again was related to the water permeability of the materials, which was significantly lower for APTS. Even though water sorption was high for APTScoated systems, it seems that water molecules remained adsorbed in the outer coating layer and did not significantly penetrate and plasticize the inner BCNW layer.

As observed from Table 2, most oxygen permeability values previously reported for MFC films were measured at $50 \% \mathrm{RH}$ and were reported to be two or three orders of magnitude higher barrier than the ones reported here at $80 \% \mathrm{RH}$. Nevertheless, it should be taken into account that oxygen permeability of cellulosic films is strongly altered by moisture. For example, when increasing the relative humidity from $0 \%$ to $50 \%$, the oxygen permeability increases by three orders of 
magnitude (Kvien et al., 2007). This effect in gas barrier drop is even more evident when increasing the water activity over $70 \%$ RH (Kvien et al., 2007). In fact, the oxygen permeability of the developed BCNW films was significantly lower than that reported for MFC at $80 \%$ RH in a previous work (Petersson \& Oksman, 2006), once again confirming the extremely highly crystalline and packed structure of $\mathrm{BCNW}$ as compared to MFC.

\section{CONCLUSIONS}

In the present work films from highly crystalline BCNW were prepared by vacuum filtration of aqueous suspensions. These films presented a highly compacted structure of nanofibrils' layers, a relatively good thermal stability and excellent barrier to oxygen at low relative humidity. However, the permeability dramatically increased at $80 \% \mathrm{RH}$ due to the disruption of the strong nanocrystals network held by hydrogen bonding between hydroxyl groups from cellulose. The incorporation of PEG resulted in a more heterogeneous structure, with reduced mechanical performance and increased water sensitivity.

A novel approach, involving the coating of the BCNW film by electrospun PLA fibres homogenized by annealing, was developed to protect the BCNW film from moisture. Through this process it was possible to create a uniform and continuous PLA layer which presented a good adhesion with the BCNW layer. A drop of ca. $70 \%$ was estimated for water permeability, which was attributed mainly to reduced water sorption. Additionally, it was possible to limit the effect of moisture on the oxygen permeability and hence, reductions of up to $97 \%$ were detected for the oxygen permeability at $80 \% \mathrm{RH}$. Water contact angles increased up to ca. $80^{\circ}$, thus confirming that by this method the hydrophilic surface of the 
BCNW film was turned into a hydrophobic surface. To evaluate the efficiency of this innovative coating strategy, a second method consisting in the application of silanes outer layers with amino (APTS) and vinyl (VTMS) functional groups was also developed and the results were compared. APTS was seen to generate more hydrophobic surfaces than VTMS, with a water contact angle of $73^{\circ}$, and enhanced the barrier properties of the coated systems more efficiently, providing a decrease of $48 \%$ in water permeability and a $74 \%$ decrease in the oxygen permeability at $80 \%$ RH.

This work has demonstrated that it is possible to produce cellulose-based biomaterials with high barrier to oxygen across relative humidity and also to water vapour by combining an inner layer of a highly crystalline material such as BCNW with outer layers that promote a more hydrophobic behaviour for the overall structure. The use of the electrospinning technique is critical to guarantee a good adhesion between the inner and the outer layers. This enhanced adhesion is one of the key factors for the improved barrier properties attained, which are even better than those attained for other conventional strategies such as coating with hydrophobic silanes. 


\section{REFERENCES}

Andresen, M., Johansson, L. S., Tanem, B. S., \& Stenius, P. (2006). Properties and characterization of hydrophobized microfibrillated cellulose. Cellulose, 13(6), 665677.

Angst, D. L., \& Simmons, G. W. (1991). Moisture absorption characteristics of organosiloxane self-assembled monolayers. Langmuir, 7(10), 2236-2242.

Aulin, C., Gällstedt, M., \& Lindström, T. (2010). Oxygen and oil barrier properties of microfibrillated cellulose films and coatings. Cellulose, 17(3), 559-574.

Belbekhouche, S., Bras, J., Siqueira, G., Chappey, C., Lebrun, L., Khelifi, B., Marais, S., \& Dufresne, A. (2011). Water sorption behavior and gas barrier properties of cellulose whiskers and microfibrils films. Carbohyd. Polym., 83(4), $1740-1748$.

Carrillo, F., Colom, X., Suñol, J. J., \& Saurina, J. (2004). Structural FTIR analysis and thermal characterisation of lyocell and viscose-type fibres. Eur. Polym. J., 40(9), 2229-2234.

Chau, T. T., Bruckard, W. J., Koh, P. T. L., \& Nguyen, A. V. (2009). A review of factors that affect contact angle and implications for flotation practice. Adv. Colloid Interfac., 150(2), 106-115.

Daniel, B. (1999). Functionalized micelle-templated silicas (MTS) and their use as catalysts for fine chemicals. Micropor. Mesopor. Mat., 27(2-3), 329-344.

De Souza Lima, M. M., \& Borsali, R. (2004). Rodlike cellulose microcrystals: Structure, properties, and applications. Macromol. Rapid Comm., 25(7), 771-787.

Fukuzumi, H., Saito, T., Iwata, T., Kumamoto, Y., \& Isogai, A. (2009). Transparent and high gas barrier films of cellulose nanofibers prepared by TEMPO-mediated oxidation. Biomacromolecules, 10(1), 162-165.

Gilliland, J. W., Yokoyama, K., \& Yip, W. T. (2005). Comparative Study of Guest Charge-Charge Interactions within Silica Sol-Gel. J. Phys. Chem. B, 109(11), 4816-4823. 
Hirai, A., Inui, O., Horii, F., \& Tsuji, M. (2009). Phase separation behavior in aqueous suspensions of bacterial cellulose nanocrystals prepared by sulfuric acid treatment. Langmuir, 25(1), 497-502.

Iguchi, M., Yamanaka, S., \& Budhiono, A. (2000). Bacterial cellulose - a masterpiece of nature's arts. J. Mater. Sci., 35(2), 261-270.

Kvien, I., Sugiyama, J., Votrubec, M., \& Oksman, K. (2007). Characterization of starch based nanocomposites. J. Mater. Sci., 42(19), 8163-8171.

Lee, S. J., \& Kim, B. K. (2012). Covalent incorporation of starch derivative into waterborne polyurethane for biodegradability. Carbohyd. Polym., 87(2), 18031809.

Luechinger, M., Prins, R., \& Pirngruber, G. D. (2005). Functionalization of silica surfaces with mixtures of 3-aminopropyl and methyl groups. Micropor. Mesopor. Mat., 85(1-2), 111-118.

Martínez-Sanz, M., Lopez-Rubio, A., \& Lagaron, J. M. (2011a). Optimization of the nanofabrication by acid hydrolysis of bacterial cellulose nanowhiskers. Carbohyd. Polym., 85(1), 228-236.

Martínez-Sanz, M., Olsson, R. T., Lopez-Rubio, A., \& Lagaron, J. M. (2011b). Development of electrospun EVOH fibres reinforced with bacterial cellulose nanowhiskers. Part I: Characterization and method optimization. Cellulose, 18(2), 335-347.

Martínez-Sanz, M., Lopez-Rubio, A., \& Lagaron, J. M. (2012a). Dispersing bacterial cellulose nanowhiskers in polylactides via electrohydrodynamic processing. J. Polym. Environ., under review.

Martínez-Sanz, M., Lopez-Rubio, A., \& Lagaron, J. M. (2012b). Optimization of the Dispersion of Unmodified Bacterial Cellulose Nanowhiskers into Polylactide via Melt Compounding to Significantly Enhance Barrier and Mechanical Properties. Biomacromolecules, 13(11), 3887-3899.

Martínez-Sanz, M., Lopez-Rubio, A., \& Lagaron, J. M. (2013a). Nanocomposites of ethylene vinyl alcohol copolymer with thermally resistant cellulose nanowhiskers by melt compounding (I): Morphology and thermal properties. $J$. Appl. Polym. Sci., 128(5), 2666-2678. 
Martínez-Sanz, M., Lopez-Rubio, A., \& Lagaron, J. M. (2013b). Nanocomposites of ethylene vinyl alcohol copolymer with thermally resistant cellulose nanowhiskers by melt compounding (II): Water barrier and mechanical properties. J. Appl. Polym. Sci., 128(3), 2197-2207.

Minelli, M., Baschetti, M. G., Doghieri, F., Ankerfors, M., Lindström, T., Siró, I., \& Plackett, D. (2010). Investigation of mass transport properties of microfibrillated cellulose (MFC) films. J. Membrane Sci., 358(1-2), 67-75.

Petersson, L., Kvien, I., \& Oksman, K. (2007). Structure and thermal properties of poly(lactic acid)/cellulose whiskers nanocomposite materials. Compos. Sci. Technol., 67(11-12), 2535-2544.

Petersson, L., \& Oksman, K. (2006). Biopolymer based nanocomposites: Comparing layered silicates and microcrystalline cellulose as nanoreinforcement. Compos. Sci. Technol., 66(13), 2187-2196.

Plackett, D., Anturi, H., Hedenqvist, M., Ankerfors, M., Gällstedt, M., Lindström, T., \& Siró, I. (2010). Physical properties and morphology of films prepared from microfibrillated cellulose and microfibrillated cellulose in combination with amylopectin. J. Appl. Polym. Sci., 117(6), 3601-3609.

Rånby, B. G. (1949). Aqueous colloidal solutions of cellulose micelles. Acta Chem. Scand., 3, 649-650.

Rodionova, G., Lenes, M., Eriksen, Ø., \& Gregersen, Ø. (2011). Surface chemical modification of microfibrillated cellulose: Improvement of barrier properties for packaging applications. Cellulose, 18(1), 127-134.

Rosa, M. F., Medeiros, E. S., Malmonge, J. A., Gregorski, K. S., Wood, D. F., Mattoso, L. H. C., Glenn, G., Orts, W. J., \& Imam, S. H. (2010). Cellulose nanowhiskers from coconut husk fibers: Effect of preparation conditions on their thermal and morphological behavior. Carbohyd. Polym., 81(1), 83-92.

Siró, I., Plackett, D., Hedenqvist, M., Ankerfors, M., \& Lindström, T. (2011). Highly transparent films from carboxymethylated microfibrillated cellulose: The effect of multiple homogenization steps on key properties. J. Appl. Polym. Sci., $119(5), 2652-2660$.

Syverud, K., \& Stenius, P. (2009). Strength and barrier properties of MFC films. Cellulose, 16(1), 75-85. 
Ten, E., Turtle, J., Bahr, D., Jiang, L., \& Wolcott, M. (2010). Thermal and mechanical properties of poly(3-hydroxybutyrate-co-3-hydroxyvalerate)/cellulose nanowhiskers composites. Polymer, 51(12), 2652-2660.

Tingaut, P., Hauert, R., \& Zimmermann, T. (2011). Highly efficient and straightforward functionalization of cellulose films with thiol-ene click chemistry. J. Mater. Chem., 21(40), 16066-16076.

Velamakanni, A., Blackwell, D. L., Yang, D., Sonawane, S., Addagulla, S., \& Major, J. S. (2010). Synthesis and characterization of functionalized silane-based copolymers for thermally robust polymer-silica hybrids. Polym. Chem., I(6), 916921.

Wan, Y. Z., Huang, Y., Yuan, C. D., Raman, S., Zhu, Y., Jiang, H. J., He, F., \& Gao, C. (2007). Biomimetic synthesis of hydroxyapatite/bacterial cellulose nanocomposites for biomedical applications. Mater. Sci. Eng., C, 27(4), 855-864.

Xia, B., Xiao, S.-J., Guo, D.-J., Wang, J., Chao, J., Liu, H.-B., Pei, J., Chen, Y.-Q., Tang, Y.-C., \& Liu, J.-N. (2006). Biofunctionalisation of porous silicon (PS) surfaces by using homobifunctional cross-linkers. J. Mater. Chem., 16(6).

Xie, Z., Wang, F., Zhao, N., Wei, W., \& Sun, Y. (2010). Hydrophobisation of activated carbon fiber and the influence on the adsorption selectivity towards carbon disulfide. Appl. Surf. Sci., 257(8), 3596-3602. 


\section{SUPPORTING INFORMATION}

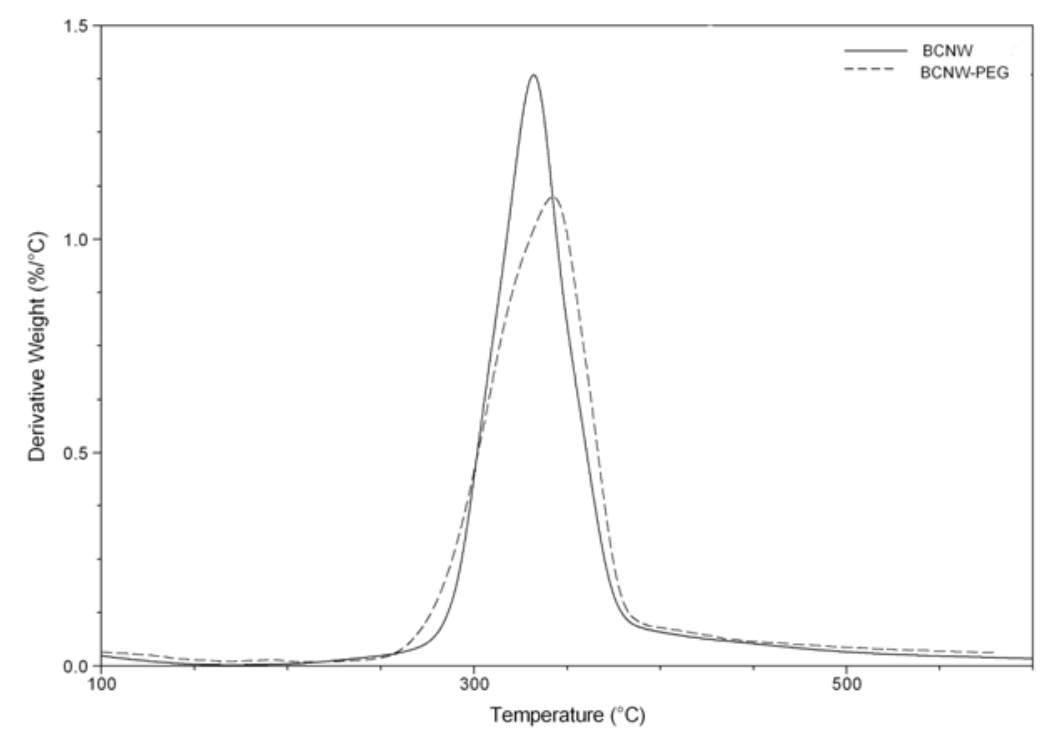

Figure S1. Derivative thermogravimetric curves of BCNW and BCNW-PEG films.
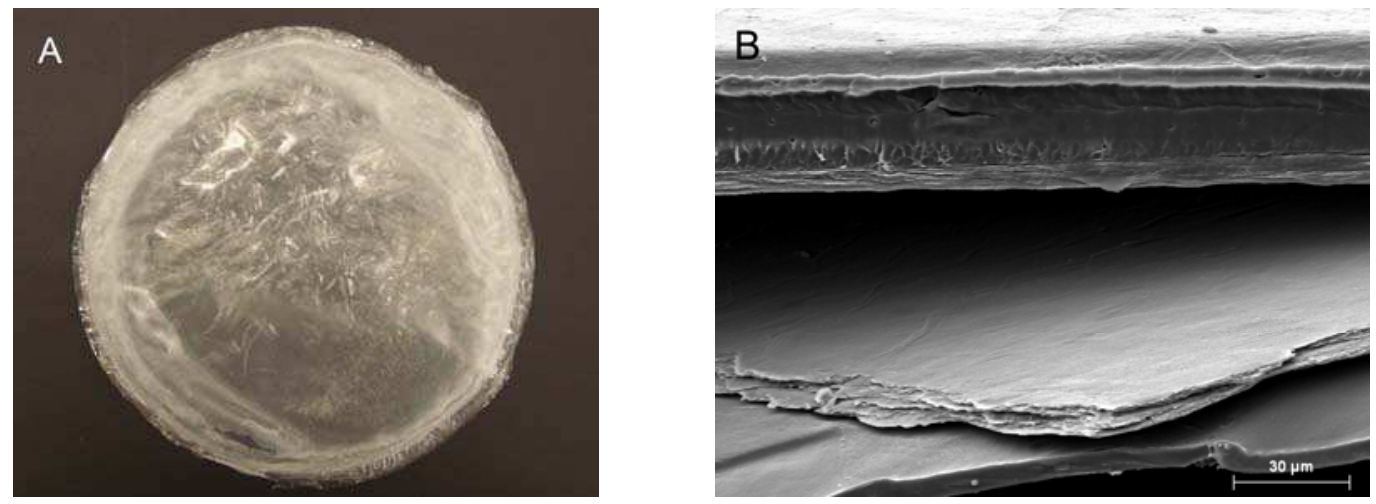

Figure S2. BCNW film coated with PLA outer layers produced by means of compression molding. (A) Visual appearance and (B) SEM micrograph of the cryofractured section, showing the phase separation between the inner BCNW film and the outer PLA film. 


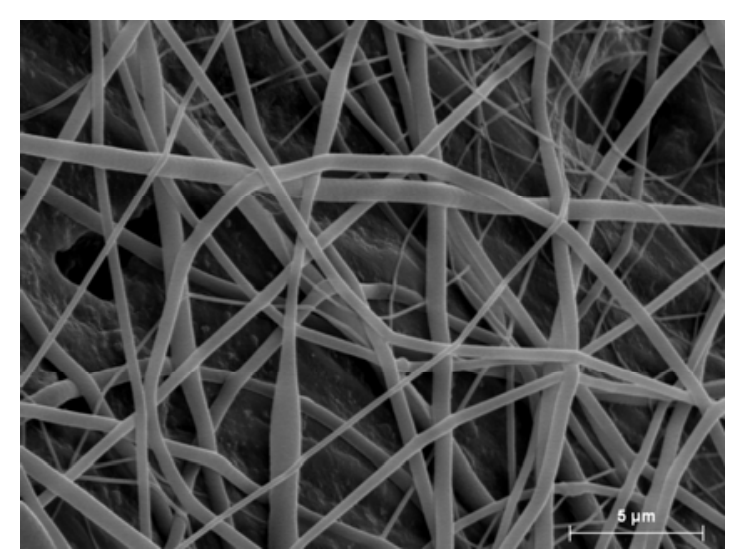

Figure S3. SEM micrograph of electrospun PLA fibres. 


\section{Chapter IX}

\section{INCORPORATION OF POLY(GLYCIDYL METHACRYLATE) GRAFTED BACTERIAL CELLULOSE NANOWHISKERS IN POLY(LACTIC ACID) NANOCOMPOSITES: IMPROVED BARRIER AND MECHANICAL PROPERTIES}

European Polymer Journal, accepted

Marta Martínez Sanz ${ }^{1}$, Mohamed A. Abdelwahab ${ }^{2,3}$, Amparo López Rubio ${ }^{1}$, José María Lagarón ${ }^{1}$, Emo Chiellini ${ }^{2}$, Tina G. Williams ${ }^{4}$, Delilah F. Wood ${ }^{4}$, William J. Orts ${ }^{4}$, Syed H. Imam ${ }^{4}$

${ }^{1}$ Novel Materials and Nanotechnology Group, IATA, CSIC. Avd. Agustín Escardino, 7, 46980. Paterna, Valencia. Spain

${ }^{2}$ Laboratory of Biocative Polymeric Materials for Biomedical and Environmental Applications, Department of Chemistry and Industrial Chemistry, University of Pisa. Via Risorgimento 35, 56126. Pisa. Italy

${ }^{3}$ Department of Chemistry, Tanta University, 31527 Tanta. Egypt

${ }^{4}$ USDA, Agricultural Research Services, WRRC-BCE. 800 Buchanan street. Albany, CA 94710. USA 



\begin{abstract}
Poly(glycidyl methacrylate) (PGMA) was grafted onto bacterial cellulose nanowhiskers (BCNW) by means of a redox-initiated free radical copolymerization reaction. The incorporation of PGMA chains decreased the thermal stability and crystallinity of BCNW.
\end{abstract}

The neat and the PGMA-grafted BCNW were subsequently incorporated as fillers into the PLA matrix. PGMA grafting improved both matrix-filler adhesion and the dispersion of cellulose nanocrystals. However, the dispersion of the nanofiller was still not completely optimized and loadings higher than 3 wt.-\% resulted in increased agglomeration. The incorporation of both neat and PGMAgrafted BCNW significantly reduced the oxygen permeability of PLA for low relative humidity conditions. However, due to the moisture sensitivity of cellulose, smaller improvements were attained when increasing the water activity. The detrimental effect of moisture on the oxygen permeability of nanocomposites was limited by the grafting copolymerization since PGMAgrafted $\mathrm{BCNW}$ seemed to present a more hydrophobic behavior. Furthermore, increased elastic modulus and tensile strength were observed for all the nanocomposites, especially when the concentration of nanocrystals was around the percolation threshold, i.e. 3 wt.-\%, but only nanocomposites containing PGMAgrafted BCNW preserved the ductility of neat PLA.

Keywords: Poly(lactic acid); cellulose nanowhiskers; bacterial cellulose; poly(glycidyl methacrylate); surface modification. 


\section{INTRODUCTION}

Currently, considerable research efforts have been focused on developing new plastic materials with low environmental impact. Biodegradable polymers and materials from renewable resources have attracted increased attention for sustainable development and environmental conservation. In particular, poly(lactic acid) (PLA) and polyhydroxyalkanoates (PHAs) are biodegradable and bio-based materials with promising properties. PLA is an aliphatic polyester synthesized through lactic acid fermentation of natural feedstock such as corn or sugarcane (Auras et al., 2004b; Drumright et al., 2000) and it is one of the most widely used and well-studied bio-based polymers. It is highly transparent and rigid, with thermal and mechanical properties comparable to poly(ethylene terephthalate) (PET) (Auras et al., 2004a). However, its use has been limited because of its brittleness, low heat distortion temperature (softening above $60^{\circ} \mathrm{C}$ ) and relatively low barrier properties as compared to other packaging materials like PET. The incorporation of nanofillers such as nanoclays, carbon nanotubes and cellulose nanocrystals has been proven to be an efficient strategy for enhancing the properties of PLA and PLA-based hybrid materials (Bondeson \& Oksman, 2007; Chang et al., 2003; Di et al., 2005; Martínez-Sanz et al., 2012; Oksman et al., 2006; Paul et al., 2003; Sanchez-Garcia et al., 2010a).

Particularly, cellulose nanowhiskers (CNW) have generated a great deal of interest in the field of nanocomposites because they offer renewable and biodegradable character, high surface area, low density, and high mechanical strength (Habibi et al., 2010). Cellulose is mostly derived from plant sources, but it is also synthesized by some bacterial species, and bacterial cellulose nanowhiskers (BCNW) can be extracted by subjecting bacterial cellulose to an acid hydrolysis treatment (Martínez-Sanz et al., 2011a). These BCNW have a highly crystalline 
structure (Martínez-Sanz et al., 2011a) and offer high aspect ratio (De Souza Lima \& Borsali, 2004; Hirai et al., 2009). The main drawback for CNW is their hydrophilic character, making them difficult to disperse in non-polar media. This may cause CNW to agglomerate in organic solvents and exhibit poor adhesion with hydrophobic matrixes. Surface chemical modification by reaction of the hydroxyl groups present on the surface of cellulose nanocrystals with organomodifying agents has been proposed as one approach to overcome this shortcoming. In this regard, CNW have been successfully modified by acetylation (Goffin et al., 2011a; Sassi \& Chanzy, 1995; Tomé et al., 2011), oxidation (Cao et al., 2012; Montanari et al., 2005), silanization (Goussé et al., 2002; Pei et al., 2010; Raquez et al., 2012) and polymer grafting reactions (Cao et al., 2009; Goffin et al., 2011a, b; Littunen et al., 2011; Shukla \& Athalye, 1995) and incorporation of modified CNW into polymeric matrixes, such as PLA has also been reported (Goffin et al., 2011a; Lin et al., 2011; Pei et al., 2010; Raquez et al., 2012; Tomé et al., 2011).

Plant derived CNW were partially silanized and subsequently incorporated into PLA by solution casting, obtaining nanocomposites with an optimized nanofiller dispersion (Pei et al., 2010). While the tensile strength and Young's modulus increased with the incorporation of silanized $\mathrm{CNW}$, the elongation at break was reduced, suggesting that the matrix-filler adhesion did not improve. Similar results were observed for PLA nanocomposites incorporating acetylated CNW (Lin et al., 2011). In a more recent study, silanized CNW were incorporated into a PLA matrix by melt compounding exhibiting a high level of nanofiller dispersion (Raquez et al., 2012). However, improvements on the tensile or barrier properties were not reported. In another study, PLA chains were grafted onto the surface of CNW by ring-opening polymerization and the subsequent incorporation into PLA by melt blending (Goffin et al., 2011a) indicated enhanced compatibility between the matrix and the nanofiller. No barrier or mechanical properties were reported for 
such material. Surface modification of CNW may be a viable option for enhancing their dispersion in organic solvents and to improve their compatibility with hydrophobic matrixes, but further research is warranted to assess their impact on the mechanical and barrier properties of PLA.

In this study, the surface of BCNW was chemically modified by graft copolymerization of glycidyl methacrylate (GMA) using a redox-initiated freeradical method and modified BCNW were subsequently incorporated into PLA by solution casting. The epoxy group in the GMA chains was expected to react with the carboxylic group of PLA, thus promoting interfacial adhesion between BCNW and the polyester matrix. While cellulose modification by graft copolymerization of (GMA) has been reported (Littunen et al., 2011; Shukla \& Athalye, 1995), information on the incorporation of the grafted filler into polymeric matrixes is lacking. The morphology, thermal properties, oxygen barrier, water affinity and mechanical properties of BCNW and BCNW-PGMA loaded PLA nanocomposites were investigated and compared to determine the influence of surface modification on the nanocomposites performance. 


\section{MATERIALS AND METHODS}

\subsection{Materials}

Poly(lactic acid) (PLA) was a Polylactide Resin 4042D grade (Natureworks, LLC, Minnetonka, MN) with a weight average molecular weight $\left(\mathrm{M}_{\mathrm{w}}\right)$ of ca. $6.6 \times$ $10^{4} \mathrm{~g} / \mathrm{mol}$. Glycidyl methacrylate (GMA) and ammonium cerium (IV) nitrate (CAN) were purchased from Aldrich (St. Louis, MO, USA). Sulfuric acid (96\%) was purchased from Panreac (Barcelona, Spain). Nitric acid, methanol and acetone were supplied by Fisher Scientific (New Jersey, USA). Tetrahydrofuran (THF) and chloroform were purchased from Sigma-Aldrich (St. Louis, MO, USA).

\subsection{Preparation of bacterial cellulose mats}

Bacterial cellulose was obtained according to a published protocol (MartínezSanz et al., 2011b). Briefly, the bacterial cells (Gluconacetobacter xylinus 7351) were grown in a modified Hestrin/Shramm medium at $30^{\circ} \mathrm{C}$. The cells were precultured in a test tube containing $5 \mathrm{ml}$ of media and later transferred and scaled up to a larger reactor of $20 \mathrm{~L}$ at Bioinicia S.L., Valencia (Spain). The synthesized bacterial cellulose pellicles were sterilized and cleaned in boiling water followed by washing in a $10 \%(\mathrm{v} / \mathrm{v}) \mathrm{NaOH}$ aqueous solution.

\subsection{Preparation of bacterial cellulose nanowhiskers (BCNW)}

At a neutral $\mathrm{pH}$, bacterial cellulose $(\mathrm{BC})$ pellicles were ground in a blender and the gel-like material was then compressed to remove most of the absorbed water. This material was then subjected to acid hydrolysis according to a previously optimized method (Martínez-Sanz et al., 2011a). BC was treated with a sulfuric acid solution $(301 \mathrm{~mL}$ sulfuric acid/L water). About $7 \mathrm{~g}$ of $\mathrm{BC}$ was suspended in $1 \mathrm{~L}$ of sulfuric acid solution and it was heated and maintained at $50^{\circ} \mathrm{C}$ with stirring for three days until a homogeneous solution was obtained. The 
cellulose nanowhiskers were recovered as a white precipitate after four centrifugation (12500 rpm, 20 minutes) cycles in a Beckman Avanti J-25 centrifuge with a JA14 rotor. Recovered material was re-suspended in deionized water and neutralized with sodium hydroxide $(7.0 \mathrm{pH})$ and centrifuged (12500 $\mathrm{rpm}, 20$ minutes) to obtain a partially hydrated precipitate which was stored at $4^{\circ} \mathrm{C}$ or lyophilized for subsequent use.

A portion of the material was solvent exchanged into acetone and chloroform. The water of the partially hydrated precipitate was replaced with acetone by applying several centrifugation cycles in which the supernatant was removed and replaced with acetone. After that, several centrifugation cycles were applied and acetone was replaced by chloroform. By means of this procedure BCNW were suspended into chloroform. The concentration of BCNW after chloroform evaporation was 48 wt.- $\%$.

\subsection{Graft copolymerization of BCNW (PGMA-grafted BCNW)}

PGMA-grafted BCNW were prepared according to a previously published study (Littunen et al., 2011). Partially hydrated BCNW were diluted with water to obtain a 0.2 wt.- $\%$ suspension and the $\mathrm{pH}$ was adjusted to 1 with dilute nitric acid. This suspension was stirred for 30 minutes while nitrogen was bubbled through. Ammonium cerium (IV) nitrate (CAN) was added (4 mmol/L) as the initiator and stirred $\left(15\right.$ minutes, $\left.35^{\circ} \mathrm{C}\right)$. The GMA monomer was incorporated gradually over a period of 30 minutes at a concentration of $40 \mathrm{mmol}$ per $\mathrm{g}$ of dry $\mathrm{BCNW}$ and the mixture was stirred for 60 minutes.

After the reaction, the product was centrifuged $(12000 \mathrm{rpm}, 20 \mathrm{~min})$ and the precipitate was repeatedly washed with deionized water (to remove traces of the initiator and the acid) and vacuum filtered. Subsequently, the material was washed 
with THF to separate the homopolymer from the graft copolymer. To do this, the material was suspended in $40 \mathrm{~mL}$ of THF and added dropwise to $400 \mathrm{~mL}$ chilled methanol (ice bath) and continuously stirred overnight after which the material was vacuum filtered and washed with THF again. The PGMA-grafted BCNW was then vacuum dried overnight to remove any traces of methanol.

\subsection{Preparation of PLA-BCNW nanocomposites}

PLA-BCNW nanocomposites were prepared by solution casting followed by compression molding. Chloroform solutions containing $5 \%(\mathrm{w} / \mathrm{v})$ of polymer (PLA) were stirred at room temperature for $48 \mathrm{~h}$. Nanowhiskers (PGMA-grafted and neat $\mathrm{BCNW}$ ) were added to the solutions and dispersed by means of intense homogenization (Ultra-turrax). The samples were placed in an ultrasound bath for $1 \mathrm{~h}$ to remove bubbles. The solutions were poured into glass Petri-dishes and placed on a leveled platform. Chloroform was allowed to evaporate over 3 days and residual solvent was removed from films by drying at $35-40^{\circ} \mathrm{C}$ for $24 \mathrm{~h}$. In order to improve the reaction between PLA and the modified nanowhiskers, about $1 \mathrm{~g}$ of the solution cast samples were further pressed in a Carver press to obtain films of around $300-500 \mu \mathrm{m}$ thickness. For this, samples were placed in a mold and heated to $185^{\circ} \mathrm{C}$ and left isothermally for $3 \mathrm{~min}$ at $28 \mathrm{MPa}$. Films of neat PLA and PLA containing 1, 3 and 5 wt.-\% (relative to PLA weight) of both neat and PGMA-grafted BCNW were produced.

\subsection{Transmission FT-IR analysis}

For FT-IR analysis, about $2 \mathrm{mg}$ of each sample were ground and dispersed in $200 \mathrm{mg}$ of spectroscopic grade $\mathrm{KBr}$. A pellet was then formed by compressing the sample at $150 \mathrm{MPa}$. Transmission FT-IR measurements were carried out under controlled conditions $\left(21^{\circ} \mathrm{C}, 40 \% \mathrm{RH}\right)$ using a Bruker (Rheinstetten, Germany) FT-IR Tensor 37 equipment. The spectra were taken at $1 \mathrm{~cm}^{-1}$ resolution 
averaging a minimum of 10 scans. Analysis of the spectra was performed using Grams/AI 7.02 (Galactic Industries, Salem, NH, USA) software.

\subsection{Scanning Electron Microscopy (SEM)}

Nanocomposites were cryo-fractured in liquid nitrogen to observe the interior of the unstressed composite. The nanocomposite sample was dropped directly into liquid nitrogen and fractured with a pre-chilled razor blade held in a vice-grip. The fractured pieces were picked out of the liquid nitrogen using pre-chilled forceps and placed in a desiccator to thaw and reduce the condensation on the surface of the material. Each specimen was placed on an aluminum stub using double-sided adhesive tape and coated with gold-palladium for $45 \mathrm{~s}$ in a Denton Desk II sputter coating unit (Denton Vacuum USA, Moorestown, NJ). Specimens were viewed in a Hitachi S4700 field emission scanning electron microscope (Hitachi HTA, Japan) at $2 \mathrm{kV}$.

\subsection{Differential Scanning Calorimetry (DSC)}

Differential scanning calorimetry (DSC) was performed on a Perkin-Elmer DSC 7 thermal analysis system. Typically, $4 \mathrm{mg}$ of dry material were analyzed at a scanning rate of $10^{\circ} \mathrm{C} / \mathrm{min}$ from room temperature to the melting point using $\mathrm{N}_{2}$ as the purging gas. The first and second melting endotherms after controlled crystallization at $10^{\circ} \mathrm{C} / \mathrm{min}$ from the melt were analyzed. Before evaluation, similar runs of an empty pan were subtracted from the thermograms. The DSC equipment was calibrated using indium as a standard.

The crystallinity (\%) of the PLA was estimated from the corrected enthalpy for biopolymer content in the hybrid fibers, using the ratio between the enthalpy of the studied material and the enthalpy of a perfect PLA crystal, i.e. 
$X_{C}(\%)=\frac{\Delta H_{f}-\Delta H_{c}}{\Delta H_{f}^{0}} \times 100$, where $\Delta H_{f}$ is the enthalpy of fusion and $\Delta H_{C}$ the enthalpy of cold crystallization of the studied specimen, and $\Delta H^{*}$ is the enthalpy of fusion of a totally crystalline material. The $\Delta \boldsymbol{H}^{*} \mathrm{used}$ for this equation was $93 \mathrm{~J} / \mathrm{g}$ for PLA (Liu et al., 1997).

\subsection{Thermogravimetric Analysis (TGA)}

Thermogravimetric analyses (TGA) were performed under nitrogen atmosphere using a TA Instruments (TGA-2950). The samples were heated from room temperature to $500^{\circ} \mathrm{C}$ at a heating rate of $10^{\circ} \mathrm{C} / \mathrm{min}$ and at a nitrogen gas flow rate of $60 \mathrm{~mL} / \mathrm{min}$. The derivatives of TGA curves (DTG) were obtained using TA analysis software.

\subsection{Oxygen Permeability}

The oxygen permeability (OP) coefficient was derived from oxygen transmission rate (OTR) measurements recorded using an Oxtran 100 equipment (Modern Control Inc., Minneapolis, MN, US). Experiments were carried out at $24^{\circ} \mathrm{C}$ under both $0 \% \mathrm{RH}$ and $80 \% \mathrm{RH}$ humidity. The $80 \%$ relative humidity was generated by a built-in gas bubbler and was checked with a hygrometer placed at the exit of the detector. The samples were purged with nitrogen for a minimum of $20 \mathrm{~h}$ prior to exposure to an oxygen flow $(10 \mathrm{ml} / \mathrm{min})$. A $5 \mathrm{~cm}^{2}$ sample area was measured by using an in-house developed mask. For testing oxygen permeation in highly permeable materials, the sampling area was reduced thus improving the reproducibility of the measurements. 


\subsection{Tensile Testing}

Young's modulus, stress at break, and strain at break were determined according to ASTM method D638M under ambient conditions, using an Instron 5500R Universal Testing Machine (Instron Corp., Canton, MA). Prior to testing, samples were equilibrated for one day at $50 \%$ relative humidity in a chamber containing saturated solutions of calcium nitrate. The testing conditions used were: cross head speed of $5 \mathrm{~mm} / \mathrm{min}$ and load cell of $0.1 \mathrm{kN}$. Dumbbell-shaped samples (0.2-0.5 mm thick) were tested with a gauge length of $20 \mathrm{~mm}$. The reported values were the average of at least 10 measurements.

\subsection{Contact angle measurements}

Measurements of contact angle were performed at $24^{\circ} \mathrm{C}$ and ambient relative humidity $(60 \% \mathrm{RH})$ in a Video-Based Contact Angle Meter model OCA 20 (DataPhysics Instruments GmbH, Filderstadt, Germany). Contact angle measurements were obtained by analyzing the shape of a distilled water drop after it had been placed over the film for 30 seconds. Image analyses were carried out by SCA20 software. 


\section{RESULTS AND DISCUSSION}

\subsection{Characterization of neat BCNW and PGMA-grafted BCNW}

BCNW were modified by grafting glycidyl methacrylate (GMA), according to the grafting mechanism which is shown in Figure 1. Firstly, ceric ion forms a chelate complex with the glucosidic ring of $\mathrm{BCNW}$ that decomposes to generate free radicals on the cellulose backbone. GMA has two reactive functional groups, an acrylic and an epoxy group. The acrylic group is expected to react with the free radicals and lead to graft copolymerization onto the surface of the nanocrystals (Mishra et al., 2003; Stenstad et al., 2008). As a result, BCNW with an epoxy functionality, which is reactive with the carboxylic group of PLA, were generated. 

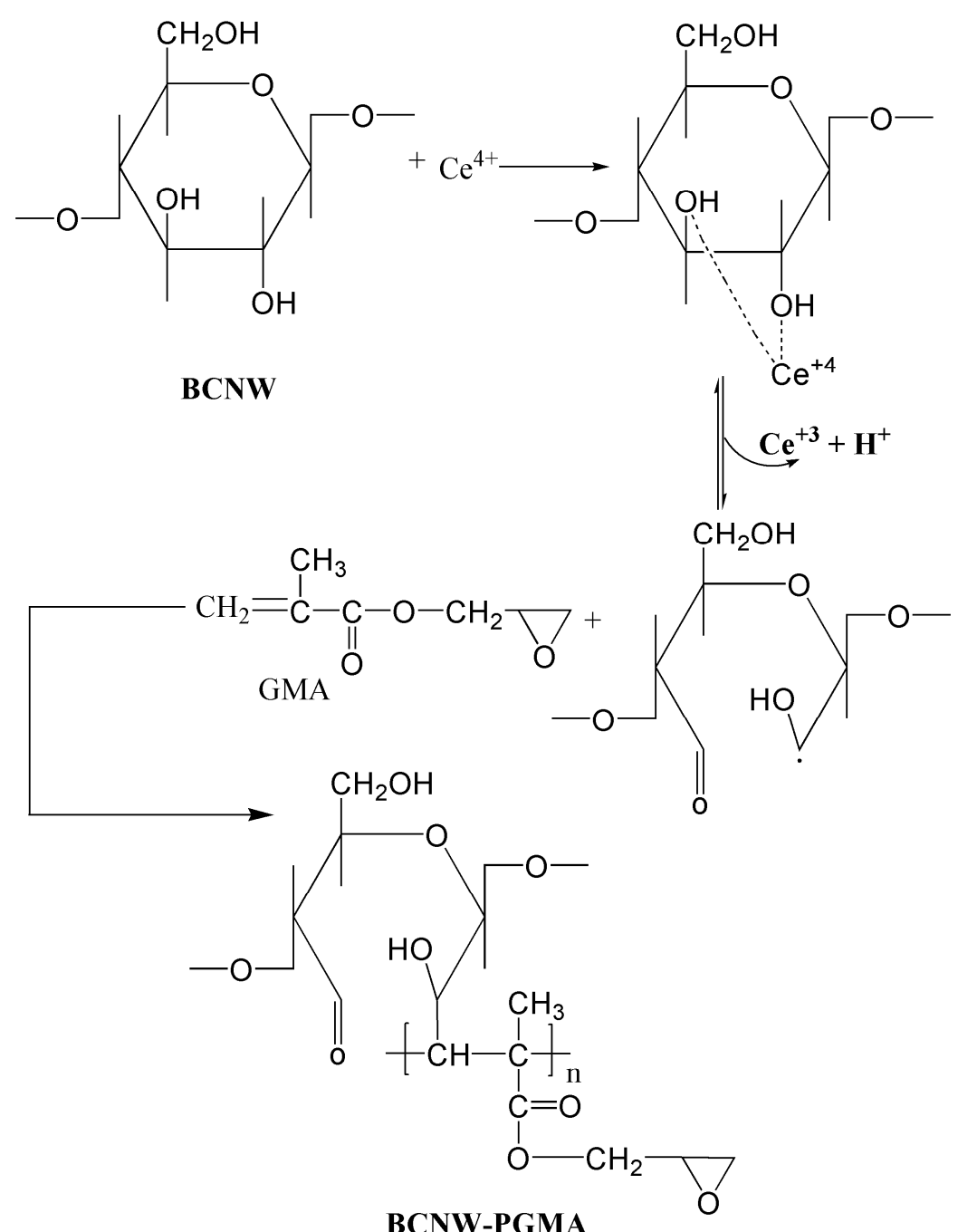

Figure 1. PGMA-BCNW graft copolymerization mechanism.

To characterize the chemical structure and to confirm the grafting of PGMA, FT-IR spectra of the BCNW before and after the copolymerization reaction were analyzed. Both neat and PGMA-grafted BCNW displayed absorption peaks that were characteristic of cellulose (cf. Figure 2a). In addition, the PGMA grafted 
sample showed a new, strong band at $1724 \mathrm{~cm}^{-1}$, characteristic of an ester carbonyl group (Littunen et al., 2011), as well as the peaks at $905 \mathrm{~cm}^{-1}$ and 844 $\mathrm{cm}^{-1}$, which are characteristic of the terminal vinyl group of the PGMA chains and the epoxy group (Littunen et al., 2011) respectively, thus confirming the presence of grafted PGMA.

Previous works demonstrated that the band ratio A1375/A2902, may be used to estimate the cellulose total crystalline index by FT-IR (Carrillo et al., 2004; Nelson et al., 1964). The spectrum of PGMA-grafted BCNW was corrected by subtracting the PGMA spectrum (cf. Figure 2b) and a baseline correction was performed according to a previous work (Nelson et al., 1964). After that, the A1375/A2902 band ratio was calculated, obtaining a value of 0.85 for neat BCNW and 0.17 for PGMA-grafted BCNW. This result suggests that the crystalline structure of the native nanocrystals may have been distorted to a certain extent as a consequence of the grafting reaction. For the graft copolymerization parameters applied in this work, the graft yield was $434 \%$ and the weight fraction of polymer in the modified CNW was $81 \%$ which was quite similar to the work reported previously. Also, the extent of grafting with GMA was much higher when compared to other monomers like methyl methacrylate (MMA), ethyl acrylate (EA), 2-hydroxyethyl methacrylate (HEMA) and butyl acrylate (BuA) (Littunen et al., 2011). Therefore, an extensive grafting may have affected not only the more accessible cellulose amorphous domains but also the crystalline regions. 


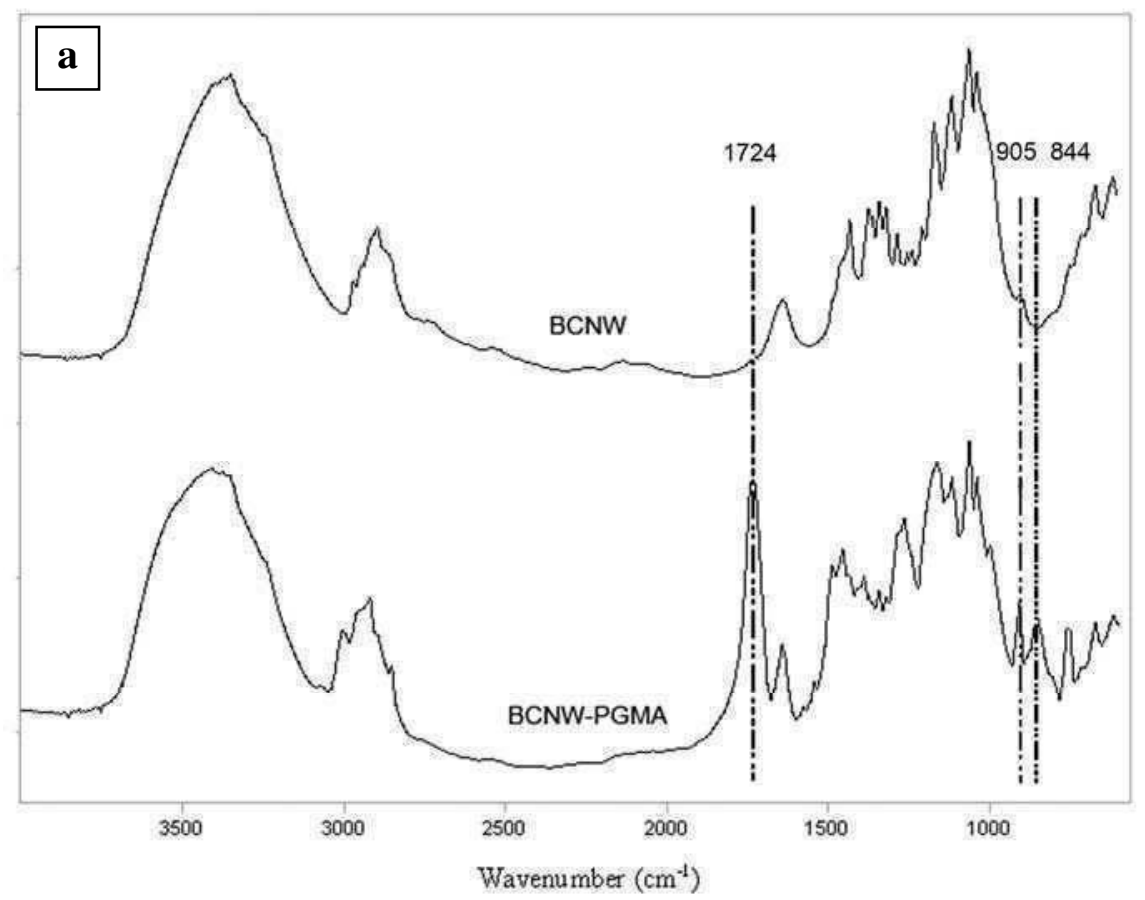




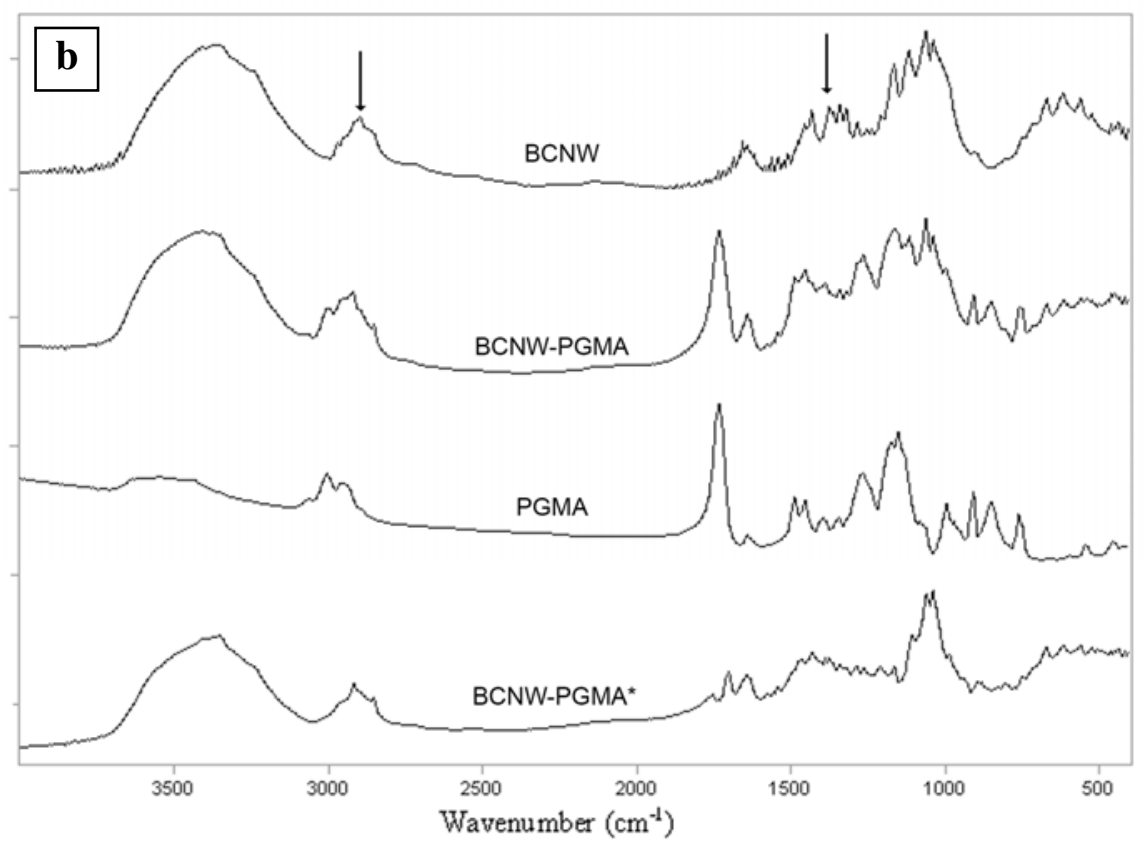

Figure 2. FT-IR spectra of neat BCNW and PGMA-grafted BCNW (a). FT-IR spectra of neat BCNW, PGMA-grafted BCNW, PGMA and PGMA-grafted BCNW after subtraction of the PGMA spectrum. The arrows indicate the bands which were used to estimate the crystallinity ratio in the neat and PGMA-grafted BCNW (b).

As BCNW were intended for use as nanofillers in conventional plastic matrices, it was important to determine the degradation temperature of the material to define the temperature range in which the nanofiller could be processed without suffering thermal degradation. Figure 3 shows the DTG curves of the nanowhiskers before and after PGMA grafting. The surface modification clearly resulted in a material with decreased thermostability. While the neat BCNW sample presented a sharp degradation peak with a maximum at approximately $319^{\circ} \mathrm{C}$, the PGMA-grafted $\mathrm{BCNW}$ sample showed multiple degradation steps. This result is in agreement with previous studies in which 
PGMA was grafted onto cotton cellulose (Shukla \& Athalye, 1995) and nanofibrillated cellulose (Littunen et al., 2011).

As deduced from the TGA parameters presented in Table 1, the degradation of native cellulose took place between ca. $250^{\circ} \mathrm{C}$ and $350^{\circ} \mathrm{C}$, while for the PGMAgrafted filler, degradation occurred over a wider temperature range. Specifically, two different degradation stages could be distinguished for the cellulose fraction, followed by two additional ones for the PGMA. Regarding cellulose degradation, a first peak with a maximum at ca. $221^{\circ} \mathrm{C}$ was observed. This peak could be ascribed to the cellulose grafted fraction which, as a consequence of excessive grafting, could be losing its highly crystalline nature to a certain extent, as previously pointed out by FT-IR analyses. This is in agreement with previous works on cellulose surface modification which have demonstrated that excessive substitution may be detrimental to the structure and properties of cellulose nanowhiskers (Andresen et al., 2006; Ifuku et al., 2007). Another degradation peak for cellulose was observed, with a maximum approximately matching that of neat cellulose, which probably corresponded to the ungrafted cellulose. For the PGMA degradation profile, one major peak and one shoulder peak at ca. $367^{\circ} \mathrm{C}$ and $396^{\circ} \mathrm{C}$ were observed, respectively. In this regard, it has been shown that the degradation of PGMA is a two step process, where one step corresponds to the depolymerisation reaction and the other to the decomposition of esters (Zulfiqar et al., 1990). 


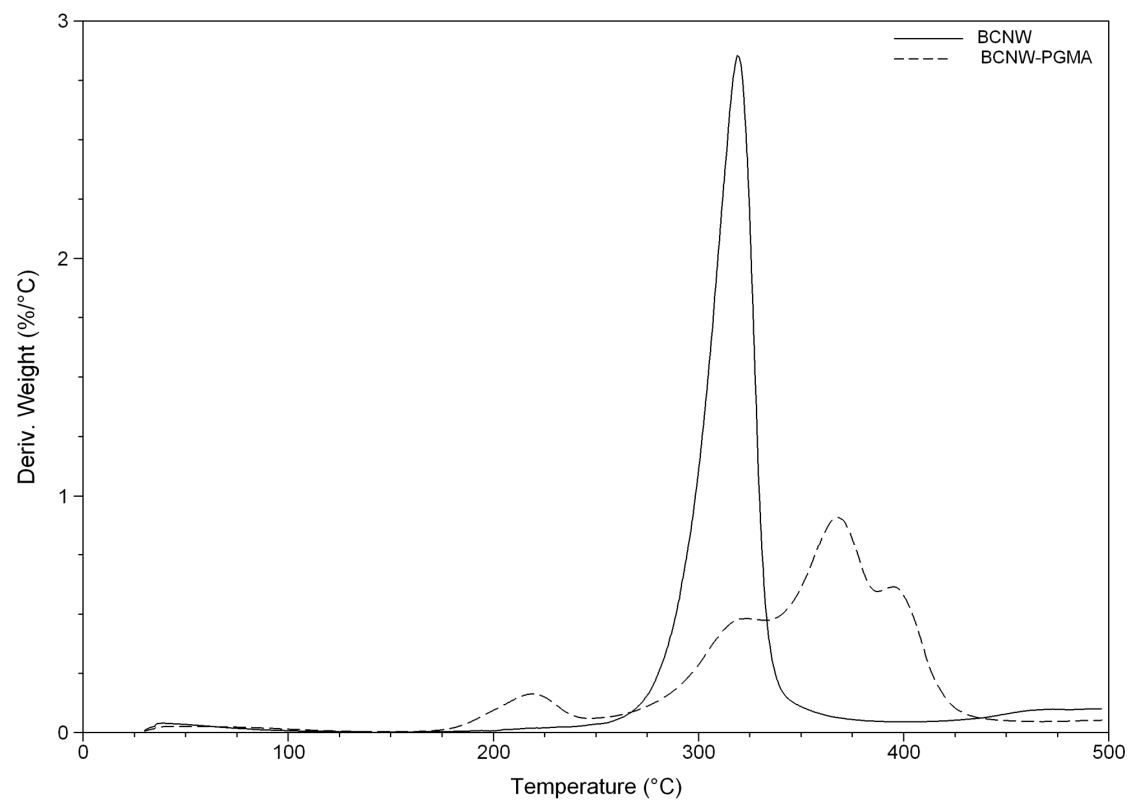

Figure 3. Derivative thermogravimetric curves of neat BCNW and PGMA-grafted BCNW.

Table 1. TGA maximum of the weight loss first derivate $\left(T_{D 1}, T_{D 2}, T_{D 3}\right.$ and $\left.T_{D 4}\right)$ and the corresponding peak onset values $\left(\mathrm{T}_{\text {onset }}\right)$ and the residue at $490^{\circ} \mathrm{C}\left(\mathrm{R}_{490}\right)$ for neat BCNW and PGMA-grafted BCNW.

\begin{tabular}{|c|c|c|c|c|c|c|}
\cline { 2 - 7 } \multicolumn{1}{c|}{} & $\mathrm{T}_{\text {Onset }}\left({ }^{\circ} \mathrm{C}\right)$ & $\mathrm{T}_{\mathrm{D} 1}\left({ }^{\circ} \mathrm{C}\right)$ & $\mathrm{T}_{\mathrm{D} 2}\left({ }^{\circ} \mathrm{C}\right)$ & $\mathrm{T}_{\mathrm{D} 3}\left({ }^{\circ} \mathrm{C}\right)$ & $\mathrm{T}_{\mathrm{D} 4}\left({ }^{\circ} \mathrm{C}\right)$ & $\mathrm{R}_{490}(\%)$ \\
\hline BCNW & $295.5 \pm 2.2$ & ---- & $318.0 \pm 1.3$ & ---- & ---- & $5.5 \pm 3.5$ \\
\hline $\begin{array}{c}\text { PGMA-grafted } \\
\text { BCNW }\end{array}$ & $197.6 \pm 4.8$ & $220.8 \pm 2.6$ & $319.1 \pm 6.5$ & $366.7 \pm 2.2$ & $395.5 \pm 0.6$ & $13.2 \pm 0.9$ \\
\hline
\end{tabular}




\subsection{Characterization of PLA nanocomposites}

The neat and PGMA-grafted BCNW were incorporated in a PLA matrix and morphology, thermal, barrier and mechanical properties of the produced nanocomposites were evaluated.

\subsubsection{Morphological characterization}

Initial examination of the morphology by optical microscopy indicated higher extent of agglomeration in the nanocomposites incorporating neat $\mathrm{BCNW}$ compared to the grafted BCNW as shown in Figures 4 a-f, where cellulose nanocrystals appeared as bright areas. When incorporated in the amount of $5 \mathrm{wt}$. $\%$, both native and grafted BCNW produced agglomeration (cf. Figures $4 \mathrm{e}$ and $4 \mathrm{f}$ ).

To study the dispersion of the nanofiller within the matrix, the cryo-fractured surfaces of nanocomposite films were examined by SEM (Figures $5 \mathrm{a}-\mathrm{g}$ ). For the nanocomposite films, the figures correspond to the areas were agglomerates were detected. Observation of the samples confirmed that neat BCNW agglomerated to a large extent in the nanocomposites (cf. Figures 5b, 5d and 5f). Even though the neat $\mathrm{BCNW}$ had been subjected to a solvent exchange process to improve their dispersion in organic solvents, their hydrophilicity led to low compatibility with the non-polar solvent in which PLA was dissolved. Furthermore, phase separation occurred between the polymeric matrix and the BCNW agglomerates. The agglomeration and lack of adhesion was reduced when the PGMA-grafted BCNW were used. The grafted PGMA chains showed better compatibility with the PLA matrix and, thus, PGMA-grafted BCNW seemed to be better distributed in the film. No phase separation between the PLA and the PGMA-grafted BCNW was apparent in samples (cf. Figures 5c,5e and 5g). Nevertheless, the nanocrystals were still aggregated to a certain extent and it was not possible to obtain 
nanocomposites with individual cellulose nanowhiskers uniformly dispersed in the PLA.

Thus, morphological evaluation by optical microscopy and SEM revealed an improved dispersion of cellulose nanocrystals of the PGMA-grafted BCNW, which showed increased compatibility with the PLA phase and led to good matrix-filler adhesion. A loading of 3 wt.- $\%$ was found to be optimal to avoid large agglomeration for both neat and PGMA-grafted BCNW.
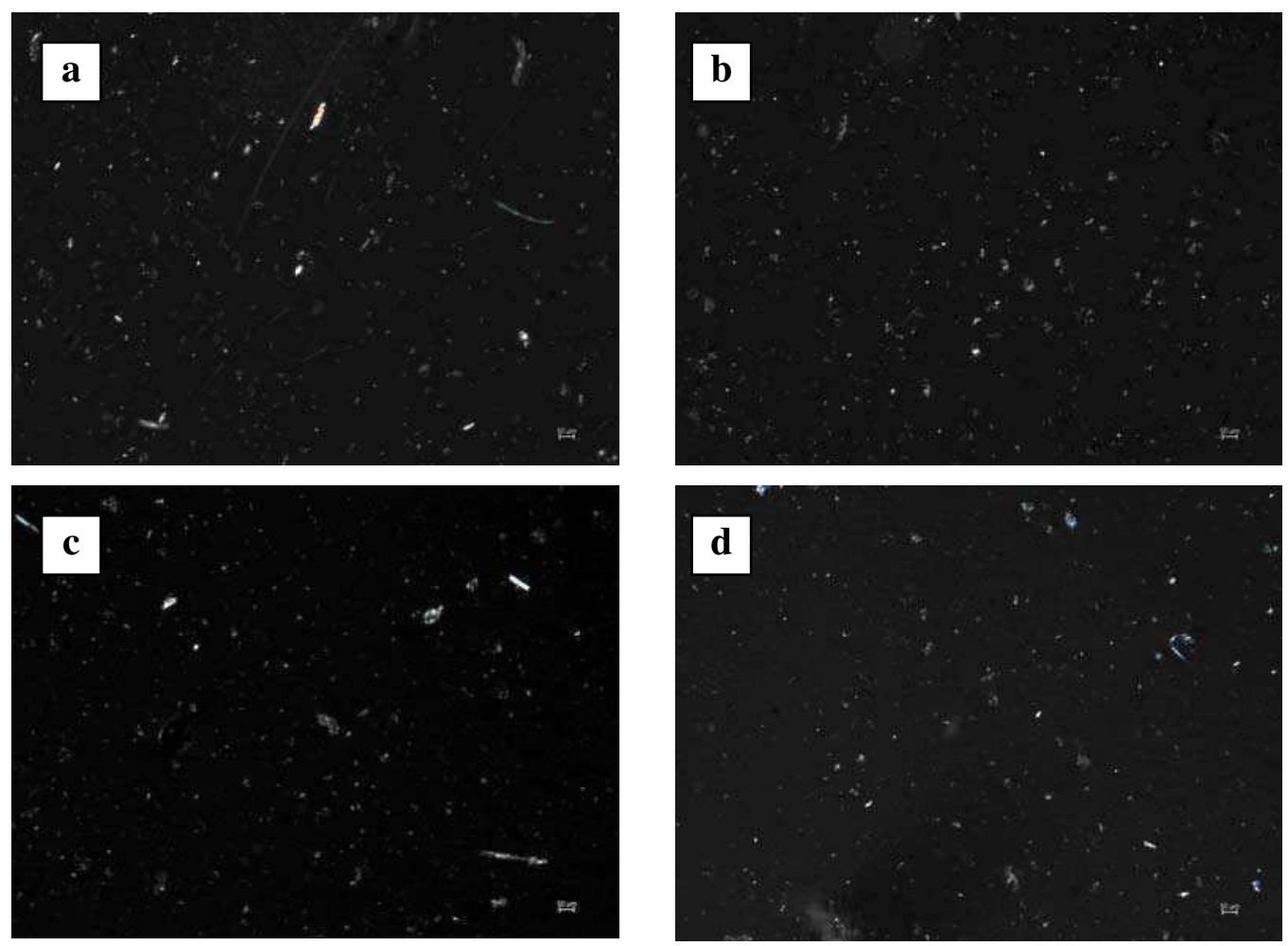

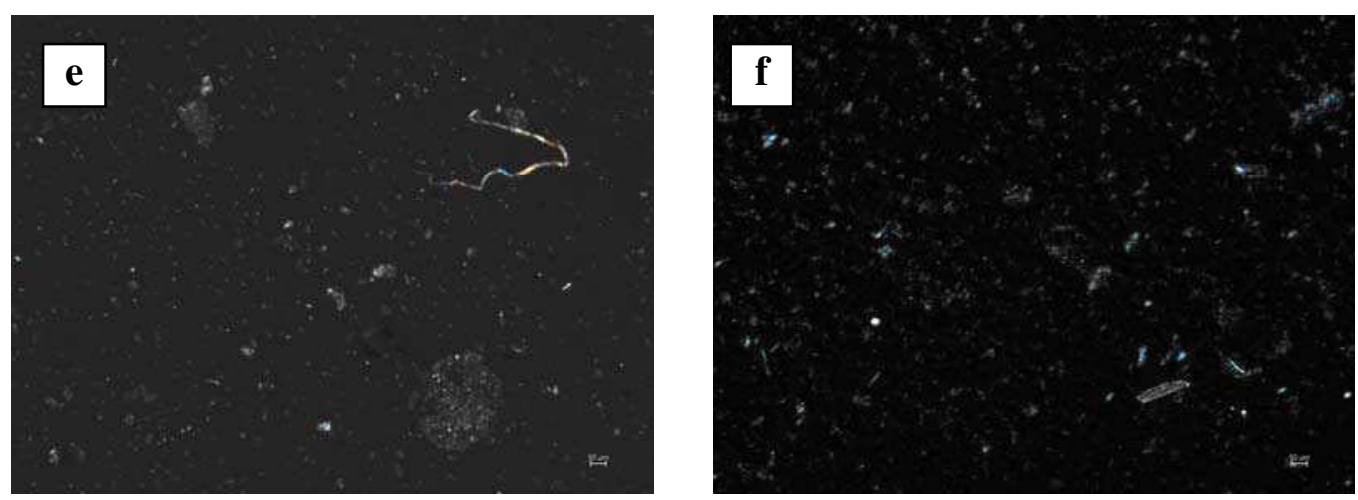

Figure 4. Optical microscopy images taken under polarized light of PLA nanocomposite films loaded with: (a) 1 wt.- $\%$ neat BCNW; (b) 1 wt.-\% PGMAgrafted BCNW; (c) 3 wt.-\% neat BCNW; (d) 3 wt.-\% PGMA-grafted BCNW; (e) 5 wt.-\% neat BCNW and (f) 5 wt.-\% PGMA-grafted BCNW. Scale markers correspond to 50 micrometers.
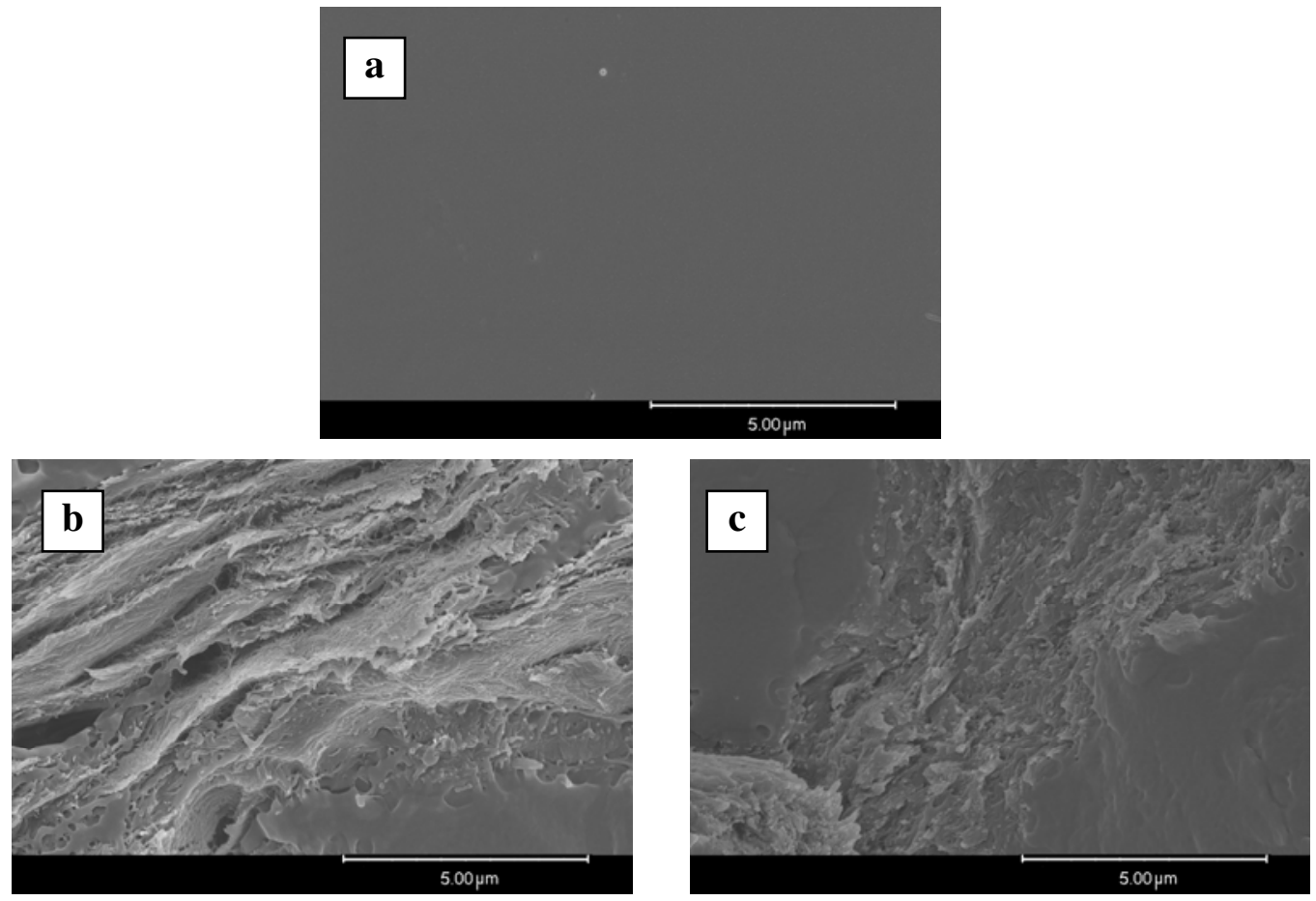

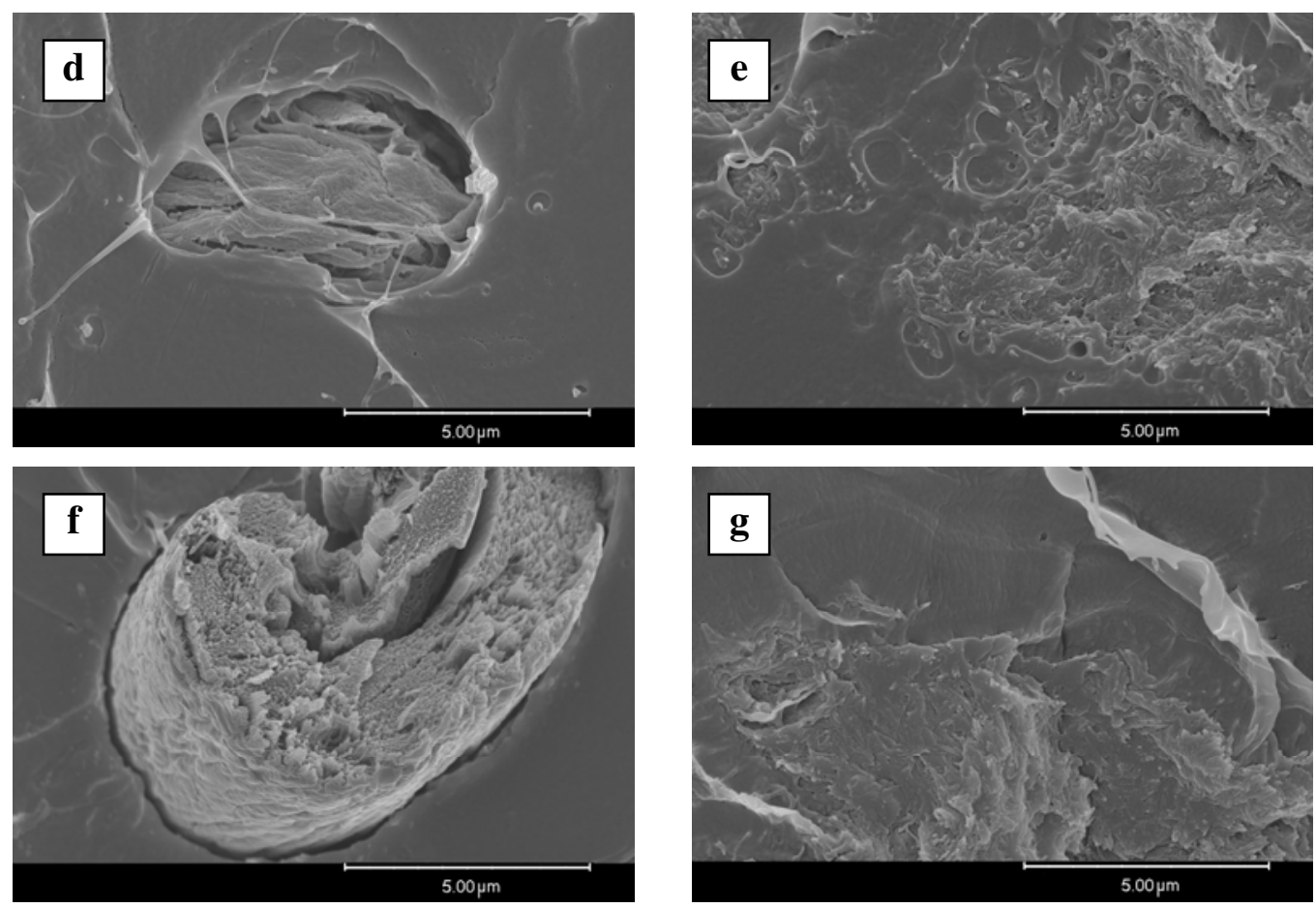

Figure 5. SEM micrographs from the cryo-fractured surface of nanocomposite films: (a) Neat PLA; (b) PLA loaded with 1 wt.-\% neat BCNW; (c) PLA loaded with 1 wt.-\% PGMA-grafted BCNW; (d) PLA loaded with 3 wt.-\% neat BCNW;

(e) PLA loaded with 3 wt.-\% PGMA-grafted BCNW; (f) PLA loaded with 5 wt.-\% neat BCNW and (g) PLA loaded with 5 wt.-\% PGMA-grafted BCNW.

\subsubsection{Thermal properties and thermal stability}

Addition of both native and modified cellulose nanocrystals in the PLA matrix caused a slight increase in the melting temperature which was accompanied by a decrease in the cold crystallization temperature and a significant increase in the crystallinity index (cf. Table 2).

Addition of neat BCNW or PGMA-grafted BCNW had little impact on the melting temperature of the PLA composites. The lower cold crystallization 
temperatures observed in PLA composites containing neat or PGMA-grafted $\mathrm{BCNW}$ indicated that cellulose nanocrystals promoted the crystallization of PLA upon heating. The same effect has been previously reported for PLA nanocomposites processed by melt compounding in which highly dispersed BCNW acted as nucleating agents, promoting a faster crystallization of PLA during heating (Di et al., 2005). This effect was more apparent at lower nanofiller loadings and, therefore, in relation with the morphological characterization, it appears that this nucleating effect was favored by high nanofiller dispersion. A significant increase in the crystallinity index of nanocomposites, compared to neat PLA, further supported the nucleating effect of cellulose nanocrystals. A similar increase in crystallinity was observed in PLA composites containing plant cellulose nanowhiskers produced by solution casting, suggesting that highly dispersed CNW acted as efficient nucleating agents (Sanchez-Garcia et al., 2010a). Notably, the maximum crystallinity increase was seen in samples loaded with 1 wt.-\% nanofiller. Comparatively, samples with higher loadings of PGMA-grafted BCNW had slightly higher crystallinity than those loaded with neat BCNW. The glass transition temperature was not greatly impacted by the presence of cellulose nanowhiskers. These results were not surprising as previous studies have shown that the presence of cellulose nanowhiskers in a PLA matrix had little effect on the $T_{g}$ of nanocomposites, even with a high nanofiller dispersion (Sanchez-Garcia et al., 2010a). 
Table 2. DSC maximum of melting $\left(\mathrm{T}_{\mathrm{m}}\right)$, melting enthalpy $\left(\Delta \mathrm{H}_{\mathrm{m}}\right)$, cold crystallization temperature $\left(\mathrm{T}_{\mathrm{CC}}\right)$, cold crystallization enthalpy $\left(\Delta \mathrm{H}_{\mathrm{CC}}\right)$ and PLA crystallinity $\left(\mathrm{X}_{\mathrm{c}}\right)$ of PLA and its nanocomposite films with native and PGMAgrafted $\mathrm{BCNW}$, obtained during the first heating run and glass transition temperature $\left(\mathrm{T}_{\mathrm{g} 2}\right)$ obtained during the second heating run.

\begin{tabular}{|c|c|c|c|c|c|c|}
\cline { 2 - 7 } \multicolumn{1}{c|}{} & $\mathrm{T}_{\mathrm{m}}\left({ }^{\circ} \mathrm{C}\right)$ & $\Delta \mathrm{H}_{\mathrm{m}}(\mathrm{J} / \mathrm{g})$ & $\mathrm{T}_{\mathrm{CC}}\left({ }^{\circ} \mathrm{C}\right)$ & $\Delta \mathrm{H}_{\mathrm{CC}}(\mathrm{J} / \mathrm{g})$ & $\mathrm{X}_{\mathrm{c}}(\%)$ & $\mathrm{T}_{\mathrm{g} 2}\left({ }^{\circ} \mathrm{C}\right)$ \\
\hline PLA & $167.0 \pm 0.1$ & $29.8 \pm 14.3$ & $106.9 \pm 1.4$ & $21.7 \pm 11.6$ & $8.7 \pm 2.9$ & $61.0 \pm 0.0$ \\
\hline $1 \% \mathrm{BCNW}$ & $167.6 \pm 0.4$ & $42.5 \pm 0.5$ & $100.8 \pm 0.4$ & $27.4 \pm 1.0$ & $16.2 \pm 0.5$ & $59.7 \pm 0.4$ \\
\hline $3 \% \mathrm{BCNW}$ & $167.8 \pm 0.4$ & $41.1 \pm 0.4$ & $103.2 \pm 0.7$ & $30.1 \pm 0.0$ & $11.8 \pm 0.4$ & $60.0 \pm 0.1$ \\
\hline $\begin{array}{c}5 \% \mathrm{BCNW} \\
\text { grafted } \\
\text { BCNW }\end{array}$ & $168.0 \pm 0.9$ & $40.6 \pm 0.2$ & $107.8 \pm 0.6$ & $33.5 \pm 0.2$ & $7.7 \pm 0.0$ & $61.7 \pm 0.7$ \\
\hline $\begin{array}{c}3 \% \text { PGMA- } \\
\text { grafted } \\
\text { BCNW }\end{array}$ & $167.4 \pm 0.2$ & $41.1 \pm 1.6$ & $102.9 \pm 0.2$ & $29.0 \pm 0.7$ & $12.9 \pm 2.5$ & $61.3 \pm 0.1$ \\
\hline $\begin{array}{c}5 \% \text { PGMA- } \\
\text { grafted } \\
\text { BCNW }\end{array}$ & $167.7 \pm 0.0$ & $39.9 \pm 0.1$ & $101.7 \pm 0.9$ & $30.3 \pm 1.2$ & $10.2 \pm 1.4$ & $60.9 \pm 0.0$ \\
\hline
\end{tabular}

Thermal stability of PLA nanocomposites was studied by TGA and Table 3 displays the parameters estimated from thermogravimetric curves. Differences were observed in the thermal stability of the nanocomposites loaded with neat or PGMA-grafted BCNW (Table 3). Low concentrations of neat BCNW slightly increased the thermal stability of the nanocomposites, which was maximum for 3 wt- $\%$ BCNW loading. Other research works have shown that thermal degradation was limited by the incorporation of CNW since a strong nanowhiskers network, which restricted the mobility of the polymer chains, was created (Martínez-Sanz et 
in PLA yielded composites with significantly decreased thermal stability compared to that of neat PLA. As noted earlier, the grafting of PGMA onto the cellulose chains decreased the thermal stability of the nanofiller and, any addition of such fillers in a matrix was then expected to have a detrimental effect on the thermal stability of the nanocomposites. Additionally, the amount of hydroxyl bonds available to establish interactions between cellulose chains may also be reduced by PGMA grafting, diminishing any favorable effect of the nanocrystals network.

Table 3. TGA maximum of the weight loss first derivate $\left(T_{D}\right)$ and the corresponding peak onset values $\left(\mathrm{T}_{\text {onset }}\right)$ and the residue at $490^{\circ} \mathrm{C}\left(\mathrm{R}_{490}\right)$ for neat PLA and PLA nanocomposites with native and PGMA-grafted BCNW.

\begin{tabular}{|c|c|c|c|}
\cline { 2 - 4 } \multicolumn{1}{c|}{} & $\mathrm{T}_{\text {onset }}\left({ }^{\circ} \mathrm{C}\right)$ & $\mathrm{T}_{\mathrm{D}}\left({ }^{\circ} \mathrm{C}\right)$ & $\mathrm{R}_{490}(\%)$ \\
\hline PLA & $328.9 \pm 3.5$ & $362.1 \pm 1.8$ & $0.3 \pm 0.2$ \\
\hline 1\%BCNW & $330.9 \pm 6.3$ & $362.7 \pm 1.5$ & $0.2 \pm 0.1$ \\
\hline 5\%BCNW & $335.5 \pm 1.6$ & $364.1 \pm 0.1$ & $0.1 \pm 0.0$ \\
\hline 1\% PGMA-grafted BCNW & $314.3 \pm 0.1$ & $348.5 \pm 1.0$ & $0.6 \pm 0.0$ \\
\hline 3\% PGMA-grafted BCNW & $316.2 \pm 3.7$ & $349.0 \pm 3.0$ & $0.5 \pm 0.1$ \\
\hline $5 \%$ PGMA-grafted BCNW & $310.5 \pm 0.3$ & $346.6 \pm 3.9$ & $0.5 \pm 0.1$ \\
\hline
\end{tabular}

\subsubsection{Oxygen permeability and surface water affinity}

Oxygen permeability (OP) was measured both at $0 \% \mathrm{RH}$ and $80 \% \mathrm{RH}$ and results are presented in Table 4. The permeability value for neat PLA was similar to that previously reported for melt compounded PLA films (Cava et al., 2006; 
Sanchez-Garcia et al., 2011). Consistent with other studies, PLA displayed increased oxygen barrier at higher relative humidity. This effect is attributed to a combination of increased oxygen diffusion and decreased oxygen solubility at a higher relative humidity (Auras et al., 2004a).

At $0 \% \mathrm{RH}$, the incorporation of native or PGMA-grafted BCNW into the PLA matrix resulted in significant reductions in OP values. However, different trends were observed for the OP values when increasing the neat and PGMA-grafted BCNW loadings. While higher loadings of PGMA-grafted BCNW resulted in an OP drop, a slight increase in the OP was observed when increasing the concentration of neat $\mathrm{BCNW}$. This observation points out that the improved dispersion and matrix-filler adhesion achieved for the PGMA-grafted BCNW were responsible for the improved oxygen barrier attained when increasing their loading. A maximum OP drop of ca. $26 \%$ and ca. $32 \%$ was attained in samples with 1 wt.$\%$ BCNW and 5 wt.-\% BCNW-PGMA, respectively. Such degree of reduction in the OP highlights the OP barrier properties of BCNW in PLA composites. It is also important to mention that, as previously suggested by FT-IR analyses, PGMAgrafted BCNW possessed lower crystallinity than neat BCNW and therefore, they should present, in principle, a less effective barrier impact. This may explain why the OP was slightly lower for neat BCNW than for PGMA-grafted BCNW for a concentration of 1 wt.- $\%$.

Generally, under high relative humidity conditions $(80 \% \mathrm{RH})$ addition of cellulose nanocrystals still reduced the OP values. The only exception was the composite with $5 \mathrm{wt} . \mathrm{-} \%$ BCNW loading. It may also be observed that a trend of increased OP was produced when increasing the nanofiller loading, especially for the neat BCNW. A maximum reduction of ca. $17 \%$ and ca. 13\% was observed in composites with 1 wt.- $\%$ neat BCNW and 1 wt.- $\%$ PGMA-grafted BCNW, 
composites with 1 wt.- $\%$ neat $\mathrm{BCNW}$ and 1 wt.-\% PGMA-grafted BCNW, respectively. It is important to note that the permeability drop observed for neat PLA at higher water activity was reduced or even reversed upon addition of neat BCNW into the matrix. Similar effects were previously reported for PLA-BCNW nanocomposites, which presented optimal oxygen barrier properties for reduced BCNW loadings (Martínez-Sanz et al., 2012). These results could be explained by the fact that the addition of $\mathrm{BCNW}$ further increased the oxygen diffusion coefficient of PLA at high relative humidity due to a stronger plasticization effect caused by the nanowhiskers.

In one study, up to $90 \%$ reduction in the OP at $80 \% \mathrm{RH}$ has been reported for PLA nanocomposites (solvent cast) loaded with cellulose nanowhiskers (SanchezGarcia et al., 2010a). The lowest OP value reported by that study was $1.4 \cdot 10^{-18}$ $\mathrm{m}^{3} \cdot \mathrm{m} / \mathrm{m}^{2} \cdot \mathrm{s} \cdot \mathrm{Pa}$, which is quite similar to the range of OP reported here.

Table 4. Oxygen permeability measured at $0 \% \mathrm{RH}$ and $80 \% \mathrm{RH}$ for PLA and nanocomposites containing neat BCNW and PGMA-grafted BCNW.

\begin{tabular}{|c|c|c|}
\cline { 2 - 3 } \multicolumn{1}{c|}{} & $\mathrm{P} 0 \% \mathrm{RH}\left(\mathrm{m}^{3} \cdot \mathrm{m} / \mathrm{m}^{2} \cdot \mathrm{s} \cdot \mathrm{Pa}\right)$ & $\mathrm{P} 80 \% \mathrm{RH}\left(\mathrm{m}^{3} \cdot \mathrm{m} / \mathrm{m}^{2} \cdot \mathrm{s} \cdot \mathrm{Pa}\right)$ \\
\hline PLA & $2.15 \pm 0.42 \mathrm{e}^{-18}$ & $1.63 \pm 0.12 \mathrm{e}^{-18}$ \\
\hline 3\%BCNW & $1.60 \pm 0.19 \mathrm{e}^{-18}$ & $1.36 \pm 0.21 \mathrm{e}^{-18}$ \\
\hline 5\%BCNW & $1.65 \pm 0.32 \mathrm{e}^{-18}$ & $1.60 \pm 0.20 \mathrm{e}^{-18}$ \\
\hline 1\% PGMA-grafted BCNW & $1.74 \pm 0.10 \mathrm{e}^{-18}$ & $1.86 \pm 0.25 \mathrm{e}^{-18}$ \\
\hline 5\% PGMA-grafted BCNW & $1.46 \pm 0.10 \mathrm{e}^{-18}$ & $1.51 \pm 0.15 \mathrm{e}^{-18}$ \\
\hline
\end{tabular}


The fact that the addition cellulose nanocrystals limited the drop in the OP values of the PLA matrix at high RH is related to the hydrophilic character of cellulose, which allows water molecules to interact with hydroxyl groups from BCNW distorting the hydrogen bonds network established between cellulose chains and/or the polymeric matrix. Thus, water diffusion through the films was promoted at high $\mathrm{RH}$.

The incorporation of PGMA-grafted BCNW provided more evident OP reductions at high relative humidity than the addition of neat $\mathrm{BCNW}$, suggesting that PGMA-grafted BCNW presented a less hydrophilic character. In order to investigate the different water affinity of PLA nanocomposites, contact angle measurements were carried out (results listed in Table 5). Data indicated that the contact angle was not significantly altered in the nanocomposites as compared to neat PLA. Despite BCNW being highly hydrophilic, at low nanofiller loadings all the nanocomposites had contact angles higher than $70^{\circ}$, which are typical of hydrophobic surfaces (Gilliland et al., 2005). With neat BCNW there was a trend of decreasing contact angle, i.e. more hydrophilic surface, when increasing the amount of nanocrystals in the composite. This trend was not observed with PGMAgrafted BCNW. In addition, in the composites with the highest PGMA-grafted BCNW concentration (5wt.-\%), a significantly higher contact angle (i.e. more hydrophobic surface) was observed compared to the composites with neat BCNW. This confirmed that the grafting process replaced hydroxyl groups on the surface with non-polar GMA chains and conferred a more hydrophobic character to the PGMA-grafted BCNW. This also explains why the OP reductions at $80 \% \mathrm{RH}$ were greater in the PGMA-grafted BCNW compared to neat BCNW. 
Table 5. Contact angles measured for PLA and its nanocomposites with neat and PGMA-grafted BCNW.

\begin{tabular}{|c|c|}
\hline & Contact angle $\left({ }^{\circ}\right)$ \\
\hline PLA & $76.3 \pm 1.4^{\mathrm{ab}}$ \\
\hline $1 \% \mathrm{BCNW}$ & $76.2 \pm 1.4^{\mathrm{ab}}$ \\
\hline $3 \% \mathrm{BCNW}$ & $75.2 \pm 1.5^{\mathrm{ab}}$ \\
\hline $5 \% \mathrm{BCNW}$ & $74.2 \pm 1.4^{\mathrm{a}}$ \\
\hline 1\% PGMA-grafted BCNW & $76.6 \pm 1.7^{b}$ \\
\hline 3\% PGMA-grafted BCNW & $75.6 \pm 0.7^{\mathrm{ab}}$ \\
\hline 5\% PGMA-grafted BCNW & $77.0 \pm 0.9^{b}$ \\
\hline
\end{tabular}

The $\mathrm{a}$ and $\mathrm{b}$ letters correspond to the ANOVA statistical analysis and Tukey test of the data indicating that with a $95 \%$ confidence level, the values are significantly different.

\subsubsection{Mechanical properties}

Despite showing some relatively large variability in measurements, addition of both neat and PGMA-grafted BCNW resulted in increased Young's modulus and tensile strength (cf. Table 6). Notably, samples containing PGMA-grafted BCNW were slightly stiffer, with higher Young's modulus and tensile strength, than those with neat BCNW. This probably resulted from better adhesion between the PGMAgrafted BCNW and the matrix and from the higher level of nanocrystals dispersion.

The elongation at break decreased slightly in composites with neat BCNW compared to the neat PLA matrix. Interestingly, this decrease in elongation was not seen in composites with PGMA-grafted BCNW. In general, the addition of 
reinforcing agents in a polymeric matrix results in lower elongation at break values due to the stress contributed by their presence. However, previous studies have shown that the development of some strong interactions, such as hydrogen bonding between the matrix and filler may help reduce the stress concentration effect to a certain extent (George et al., 2011). Results presented here suggest that the surface modification of BCNW promoted the interactions between the PLA matrix and the nanocrystals and at the same time improved their dispersion, resulting in improved mechanical properties.

Interestingly, nanocomposites containing both neat BCNW and PGMA-grafted BCNW had optimal mechanical properties at a loading of 3 wt.- $\%$. This may be related to the presence of a strong network of nanocrystals created at this particular loading. The percolation threshold, where the nanowhiskers are interconnected by a $3 \mathrm{D}$ network, is a crucial condition to obtain strong mechanical reinforcement. By using the following equation, the percolation threshold $\left({ }^{\left(y_{R C}\right.}\right)$ can be estimated as a function of the aspect ratio (Favier, 1995; Sanchez-Garcia et al., 2010b; MartínezSanz et al. 2013):

$$
v_{B o}=\frac{0.7}{L / d}
$$

where $L / d$ is the aspect ratio. As previously reported, BCNW had an aspect ratio of approximately 30 (Martínez-Sanz et al., 2011a). Therefore, the percolation threshold should be reached with 2 v.- $\%$ of BCNW. This is indeed in agreement with the optimum mechanical properties achieved in composites with 3 wt.-\% nanofiller loading (which corresponds to 2.3 v.-\%). The same effect was observed for both EVOH (Martínez-Sanz et al., 2013) and PLA (Martínez-Sanz et al., 2012) 
melt processed nanocomposites loaded with $\mathrm{BCNW}$, which displayed optimal mechanical performance for loadings between $2 \mathrm{wt} .-\%$ and $3 \mathrm{wt} .-\%$.

Thus, the nanocomposite with 3 wt.-\% PGMA-grafted BCNW appears to be optimum in terms of mechanical properties, with an increase of ca. $16 \%$ and $22 \%$ in the Young's modulus and tensile strength, respectively, without impairing the ductility of the material. Similar improvements have been reported for PLA nanocomposites loaded with BCNW prepared by melt compounding, although in that case the nanocomposites were much stiffer due to the higher crystallinity resulting from the melt processing (Martínez-Sanz et al., 2012). In contrast, a plasticization effect was reported for PLA nanocomposites loaded with plantderived CNW prepared by solution casting, presenting not only higher elongation at break but also lower modulus (Sanchez-Garcia et al., 2010a). It seems that due to the lower aspect ratio of vegetal $\mathrm{CNW}$, higher loadings were required in order to achieve improvements in the mechanical properties. The data presented here, show an efficient reinforcement effect provided by the high aspect ratio of the BCNW fillers and the effect of PGMA grafting onto the surface of BNCW to improve their compatibility with the PLA matrix. 
Table 6. Young's modulus (E), tensile strength $\left(\sigma_{\mathrm{B}}\right)$ and elongation at break $\left(\varepsilon_{\mathrm{B}}\right)$ for PLA and nanocomposites containing neat BCNW and PGMA-grafted BCNW.

\begin{tabular}{|c|c|c|c|}
\cline { 2 - 4 } \multicolumn{1}{c|}{} & $\mathrm{E}(\mathrm{GPa})$ & $\sigma_{\mathrm{B}}(\mathrm{MPa})$ & $\varepsilon_{\mathrm{B}}(\%)$ \\
\hline PLA & $2.41 \pm 0.50$ & $45.28 \pm 8.68$ & $4.12 \pm 1.67$ \\
\hline 1\%BCNW & $2.50 \pm 0.18$ & $49.49 \pm 2.11$ & $3.68 \pm 0.65$ \\
\hline 5\%BCNW & $2.57 \pm 0.13$ & $50.64 \pm 7.59$ & $3.53 \pm 1.01$ \\
\hline $1 \%$ PGMA-grafted BCNW & $2.53 \pm 0.14$ & $45.19 \pm 3.04$ & $5.53 \pm 1.98$ \\
\hline $3 \%$ PGMA-grafted BCNW & $2.79 \pm 0.08$ & $55.17 \pm 0.37$ & $4.09 \pm 0.32$ \\
\hline 5\% PGMA-grafted BCNW & $2.61 \pm 0.19$ & $49.34 \pm 5.81$ & $4.02 \pm 0.49$ \\
\hline
\end{tabular}

\section{CONCLUSIONS}

In this work, epoxy functionality was successfully introduced onto the BCNW surface by using cerium (IV), as free-radicals promoter, followed by grafting of glycidyl methacrylate (GMA). The chemical modification of the $\mathrm{BC}$ nanocrystals surface was confirmed by FT-IR and TGA. It was observed that the thermal stability of BCNW was slightly reduced as a result of grafting, most likely due to the distortion of their highly crystalline structure to a certain extent.

Subsequently, neat BCNW and PGMA-grafted BNCW were incorporated in a PLA matrix to prepare nanocomposites by solution casting followed by compression molding. PGMA grafting resulted in enhanced matrix-filler adhesion and in a higher level of nanofiller dispersion, as revealed by morphological 
characterization. However, aggregation of $\mathrm{BCNW}$ took place to a certain extent, especially when the loading was increased above $3 \mathrm{wt} .-\%$.

Incorporation of cellulose nanowhiskers significantly improved the oxygen barrier property of PLA at $0 \% \mathrm{RH}$ even in cases where BCNW were agglomerated. However, as a consequence of the highly hydrophilic character of cellulose, when increasing the relative humidity up to $80 \%$, lower reductions in the oxygen permeability were attained, with optimum values corresponding to low nanofiller loadings. Although the incorporation of $\mathrm{BCNW}$ led to nanocomposites with slightly more hydrophilic surfaces as compared to PLA, PGMA grafting did appear to limit the detrimental effect of neat $\mathrm{BCNW}$ on the oxygen permeability at $80 \%$ RH.

The incorporation of both modified and unmodified BCNW resulted in stiffer materials. With the addition of 3 wt.-\% PGMA-grafted BCNW, corresponding to the percolation threshold, the Young's modulus and tensile strength increased by ca. $16 \%$ and $22 \%$, respectively. Moreover, as a result of the improved matrix-filler adhesion, the ductility of nanocomposites with PGMA-grafted BCNW was not reduced.

Thus, PGMA-grafting of BNCW improved their adhesion and dispersion in a hydrophobic PLA matrix, leading to improved barrier and mechanical properties compared to PLA nanocomposites loaded with neat BCNW. 


\section{REFERENCES}

Andresen, M., Johansson, L. S., Tanem, B. S., \& Stenius, P. (2006). Properties and characterization of hydrophobized microfibrillated cellulose. Cellulose, 13(6), 665677.

Auras, R., Harte, B., \& Selke, S. (2004a). Effect of water on the oxygen barrier properties of poly(ethylene terephthalate) and polylactide films. Journal of Applied Polymer Science, 92(3), 1790-1803.

Auras, R., Harte, B., \& Selke, S. (2004b). An Overview of Polylactides as Packaging Materials. Macromolecular Bioscience, 4(9), 835-864.

Bondeson, D., \& Oksman, K. (2007). Polylactic acid/cellulose whisker nanocomposites modified by polyvinyl alcohol. Composites Part A: Applied Science and Manufacturing, 38(12), 2486-2492.

Cao, X., Ding, B., Yu, J., \& Al-Deyab, S. S. (2012). Cellulose nanowhiskers extracted from TEMPO-oxidized jute fibers. Carbohydrate Polymers, 90(2), 10751080 .

Cao, X., Habibi, Y., \& Lucia, L. A. (2009). One-pot polymerization, surface grafting, and processing of waterborne polyurethane-cellulose nanocrystal nanocomposites. Journal of Materials Chemistry, 19(38), 7137-7145.

Carrillo, F., Colom, X., Suñol, J. J., \& Saurina, J. (2004). Structural FTIR analysis and thermal characterisation of lyocell and viscose-type fibres. European Polymer Journal, 40(9), 2229-2234.

Cava, D., Giménez, E., Gavara, R., \& Lagaron, J. M. (2006). Comparative performance and barrier properties of biodegradable thermoplastics and nanobiocomposites versus PET for food packaging applications. Journal of Plastic Film and Sheeting, 22(4), 265-274.

Chang, J. H., An, Y. U., \& Sur, G. S. (2003). Poly(lactic acid) nanocomposites with various organoclays. I. Thermomechanical properties, morphology and gas permeability. Journal of Polymer Science : Part B: Polymer Physics, 41, 94-103. 
De Souza Lima, M. M., \& Borsali, R. (2004). Rodlike cellulose microcrystals: Structure, properties, and applications. Macromolecular Rapid Communications, 25(7), 771-787.

Di, Y., Iannace, S., Maio, E. D., \& Nicolais, L. (2005). Poly(lactic acid)/organoclay nanocomposites: Thermal, rheological properties and foam processing. Journal of Polymer Science Part B: Polymer Physics, 43(6), 689-698.

Drumright, R. E., Gruber, P. R., \& Henton, D. E. (2000). Polylactic acid technology. Advanced Materials, 12(23), 1841-1846.

Favier, V. (1995). Ph.D. Thesis, Etude de nouveaux matériaux composites obtenus à partir de latex filmogènes et de whiskers de cellulose: effet de percolation mécanique. Joseph Fourier University, Grenoble, France.

George, J., Ramana, K. V., Bawa, A. S., \& Siddaramaiah (2011). Bacterial cellulose nanocrystals exhibiting high thermal stability and their polymer nanocomposites. International Journal of Biological Macromolecules, 48(1), 5057.

Gilliland, J. W., Yokoyama, K., \& Yip, W. T. (2005). Comparative Study of Guest Charge-Charge Interactions within Silica Sol-Gel. Journal of Physical Chemistry $B, 109(11), 4816-4823$.

Goffin, A. L., Raquez, J. M., Duquesne, E., Siqueira, G., Habibi, Y., Dufresne, A., \& Dubois, P. (2011a). From interfacial ring-opening polymerization to melt processing of cellulose nanowhisker-filled polylactide-based nanocomposites. Biomacromolecules, 12(7), 2456-2465.

Goffin, A. L., Raquez, J. M., Duquesne, E., Siqueira, G., Habibi, Y., Dufresne, A., \& Dubois, P. (2011b). Poly( $\varepsilon$-caprolactone) based nanocomposites reinforced by surface-grafted cellulose nanowhiskers via extrusion processing: Morphology, rheology, and thermo-mechanical properties. Polymer, 52(7), 1532-1538.

Goussé, Chanzy, H., Excoffier, G., Soubeyrand, L., \& Fleury, E. (2002). Stable suspensions of partially silylated cellulose whiskers dispersed in organic solvents. Polymer, 43(9), 2645-2651.

Habibi, Y., Lucia, L. A., \& Rojas, O. J. (2010). Cellulose Nanocrystals: Chemistry, Self-Assembly, and Applications. Chemical Reviews, 110(6), 3479-3500. 
Hirai, A., Inui, O., Horii, F., \& Tsuji, M. (2009). Phase separation behavior in aqueous suspensions of bacterial cellulose nanocrystals prepared by sulfuric acid treatment. Langmuir, 25(1), 497-502.

Ifuku, S., Nogi, M., Abe, K., Handa, K., Nakatsubo, F., \& Yano, H. (2007). Surface modification of bacterial cellulose nanofibers for property enhancement of optically transparent composites: Dependence on acetyl-group DS. Biomacromolecules, 8(6), 1973-1978.

Lin, N., Huang, J., Chang, P. R., Feng, J., \& Yu, J. (2011). Surface acetylation of cellulose nanocrystal and its reinforcing function in poly(lactic acid). Carbohydrate Polymers, 83(4), 1834-1842.

Littunen, K., Hippi, U., Johansson, L.-S., Österberg, M., Tammelin, T., Laine, J., \& Seppälä, J. (2011). Free radical graft copolymerization of nanofibrillated cellulose with acrylic monomers. Carbohydrate Polymers, 84(3), 1039-1047.

Liu, X., Dever, M., Fair, N., \& Benson, R. (1997). Thermal and mechanical properties of poly(lactic Acid) and poly(ethylene/butylene Succinate) blends. Journal of Polymers and the Environment, 5(4), 225-235.

Martínez-Sanz, M., Lopez-Rubio, A., \& Lagaron, J. M. (2011a). Optimization of the nanofabrication by acid hydrolysis of bacterial cellulose nanowhiskers. Carbohydrate Polymers, 85(1), 228-236.

Martínez-Sanz, M., Olsson, R. T., Lopez-Rubio, A., \& Lagaron, J. M. (2011b). Development of electrospun EVOH fibres reinforced with bacterial cellulose nanowhiskers. Part I: Characterization and method optimization. Cellulose, 18(2), 335-347.

Martínez-Sanz, M., Lopez-Rubio, A., \& Lagaron, J. M. (2012). Optimization of the dispersion of unmodified bacterial cellulose nanowhiskers into polylactide via melt compounding to significantly enhance barrier and mechanical properties. Biomacromolecules, 13(11), 3887-3899.

Martínez-Sanz, M., Lopez-Rubio, A., \& Lagaron, J. M. (2013). Nanocomposites of ethylene vinyl alcohol copolymer with thermally resistant cellulose nanowhiskers by melt compounding (II): Water barrier and mechanical properties. Journal of Applied Polymer Science, 128(3), 2197-2207. 
Mishra, A., Srinivasan, R., \& Gupta, R. (2003). P. psyllium-g-polyacrylonitrile: Synthesis and characterization. Colloid and Polymer Science, 281(2), 187-189.

Montanari, S., Roumani, M., Heux, L., \& Vignon, M. R. (2005). Topochemistry of carboxylated cellulose nanocrystals resulting from TEMPO-mediated oxidation. Macromolecules, 38(5), 1665-1671.

Nelson, M.L., O'Connor, R.T. (1964). Relation of certain infrared bands to cellulose crystallinity and crystal lattice type. Part I. Spectra of lattice types I, II, III and amorphous cellulose. Journal of Applied Polymer Science, 8(3), 1311.

Oksman, K., Mathew, A. P., Bondeson, D., \& Kvien, I. (2006). Manufacturing process of cellulose whiskers/polylactic acid nanocomposites. Composites Science and Technology, 66, 2776.

Paul, M. A., Alexandre, M., Degee, P., Henrist, C., Rulmont, A., \& Dubois, P. (2003). New nanocomposites materials based on plasticized poly(L-lactide) and organo-modified montmorillonites: thermal and morphological study Polymer, 44, $443-450$

Pei, A., Zhou, Q., \& Berglund, L. A. (2010). Functionalized cellulose nanocrystals as biobased nucleation agents in poly(1-lactide) (PLLA) - Crystallization and mechanical property effects. Composites Science and Technology, 70(5), 815-821.

Raquez, J. M., Murena, Y., Goffin, A. L., Habibi, Y., Ruelle, B., DeBuyl, F., \& Dubois, P. (2012). Surface-modification of cellulose nanowhiskers and their use as nanoreinforcers into polylactide: A sustainably-integrated approach. Composites Science and Technology, 72(5), 544-549.

Sanchez-Garcia, M. D., Gimenez, E., \& Lagaron, J. M. (2010a). On the use of plant cellulose nanowhiskers to enhance the barrier properties of polylactic acid. Cellulose, 17, 987-1004.

Sanchez-Garcia, M. D., Hilliou, L., \& Lagaron, J. M. (2010b). Morphology and Water Barrier Properties of Nanobiocomposites of $\kappa / 1$-Hybrid Carrageenan and Cellulose Nanowhiskers. Journal of Agricultural and Food Chemistry, 58(24), 12847-12857.

Sanchez-Garcia, M. D., Nordqvist, D., Hedenqvist, M., \& Lagaron, J. M. (2011). Incorporating amylopectin in poly(lactic acid) by melt blending using 
poly(ethylene-co-vinyl alcohol) as a thermoplastic carrier. II. Physical properties. Journal of Applied Polymer Science, 119(6), 3708-3716.

Sassi, J. F., \& Chanzy, H. (1995). Ultrastructural aspects of the acetylation of cellulose. Cellulose, 2(2), 111-127.

Shukla, S. R., \& Athalye, A. R. (1995). Mechanical and thermal properties of glycidyl methacrylate grafted cotton cellulose. Journal of Applied Polymer Science, 57(8), 983-988.

Stenstad, P., Andresen, M., Tanem, B., \& Stenius, P. (2008). Chemical surface modifications of microfibrillated cellulose. Cellulose, 15(1), 35-45.

Tomé, L. C., Pinto, R. J. B., Trovatti, E., Freire, C. S. R., Silvestre, A. J. D., Neto, C. P., \& Gandini, A. (2011). Transparent bionanocomposites with improved properties prepared from acetylated bacterial cellulose and poly(lactic acid) through a simple approach. Green Chemistry, 13(2), 419-427.

Yu, L., Dean, K., \& Li, L. (2006). Polymer blends and composites from renewable resources. Progress in Polymer Science, 31(6), 576-602.

Zulfiqar, S., Zulfiqar, M., Nawaz, M., McNeill, I. C., \& Gorman, J. G. (1990). Thermal degradation of poly(glycidyl methacrylate). Polymer Degradation and Stability, 30(2), 195-203. 



\section{Chapter X}

\section{ANTIMICROBIAL PLA-BASED NANOFIBRES DEVELOPED BY SOLUTION BLOW SPINNING}

Journal of Nanoscience and Nanotechnology, under review

Marta Martínez Sanz ${ }^{1}$, Cristina Bilbao-Sainz ${ }^{2}$,Wen-Xian Du ${ }^{2}$, Bor-Sen Chiou $^{2}$,Tina G. Williams ${ }^{2}$, Delilah F. Wood ${ }^{2}$, Syed H. Imam ${ }^{2}$, William J. Orts $^{2}$, Amparo López Rubio ${ }^{1}$, José María Lagarón ${ }^{1}$

${ }^{1}$ Novel Materials and Nanotechnology Group, IATA, CSIC. Avd. Agustín Escardino, 7, 46980. Paterna, Valencia. Spain

${ }^{2}$ USDA, Agricultural Research Services, WRRC-BCE. 800 Buchanan street. Albany, CA 94710. USA 



\begin{abstract}
The present study reports on the development of hybrid PLA fibres loaded with highly crystalline bacterial cellulose nanowhiskers (BCNW) by the novel solution blow spinning method. Furthermore, fibres with antimicrobial properties were generated by incorporating carvacrol and THC as antimicrobial agents and the biocide effect against Listeria monocytogenes was studied.
\end{abstract}

Initially, PLA blow spun fibres containing BCNW were optimized in terms of morphology and thermal properties. The addition of BCNW was seen to significantly increase the viscosity and surface tension of solutions, restricting the capacity to form fibres for concentrations greater than $30 \mathrm{wt} .-\%$ BCNW. $15 \mathrm{wt} .-\%$ BCNW was selected as the optimum nanofiller loading as it led to the most uniform fibres morphology, with BCNW homogeneously distributed along the fibres' axis.

Subsequently, carvacrol and THC were incorporated into the fibres to confer them with antimicrobial properties. The addition of the BCNW filler was not seen to significantly increase the antimicrobial capacity of the fibres by itself and, hence, gelatin was added to help promoting further the hydrophylicity and biocide performance of the fibres. Nevertheless, for the more hydrophilic THC, the biocide capacity of the fibres with gelatin was accentuated further by the presence of the BCNW.

Keywords: Bacterial cellulose, nanowhiskers, blow spinning, poly(lactic acid), antimicrobial properties. 


\section{INTRODUCTION}

Recently, much interest has been focused on the electrospinning technique for the production of continuous polymeric fibres with diameters in the sub-micron range. These fibres can be used in a wide range of applications that demand highperformance materials, such as engineering scaffolds (Jeong et al., 2010), wound dressings (Cai et al., 2010), textiles (Schreuder-Gibson et al., 2002), electronic devices (Liu et al., 2004) and lately, in the nanocomposites field (Martínez-Sanz et al., 2013b; Martínez-Sanz et al., 2011b; Olsson et al., 2010; Peresin et al., 2010). This technique can generate polymeric fibres presenting a large surface to volume ratio, through the action of an external electric field applied between two electrodes and imposed on a polymer solution or melt. As an alternative to electrospinning, a novel technique known as solution blow spinning has been recently developed and has been successfully applied to produce micro and nanofibres of poly(lactic acid) (Oliveira et al., 2011), poly(methyl methacrylate) and polystyrene (Medeiros et al., 2009). In the solution blow spinning process, the polymeric solution is pumped through an inner nozzle, while a high pressure gas, such as air or nitrogen, flows through a concentric outer nozzle. As the polymeric solution leaves the inner nozzle by forming a drop at the tip, it is subjected to the high pressure gas pumped through the outer nozzle and therefore, the droplet is stretched and forms a cone similar to Taylor's cone in electrospinning (Medeiros et al., 2009). As the polymeric solution is stretched by the compressed gas, the solvent evaporates and hence, solid polymeric fibres are obtained (Medeiros et al., 2009; Oliveira et al., 2011). Solution blow spinning presents several advantages over electrospinning, such as the possibility of applying higher feeding rates, lower costs, use of solvents not limited by their dielectric constants and reduced damage of living cells, proteins and other biomaterials when incorporated into fibres (Oliveira et al., 2011). 
In particular, great interest has been focused on the use of biopolymers produced from renewable resources, such as poly(lactic acid) (PLA) and polyhydroxyalkanoates (PHAs), for the production of non-woven materials. PLA, is a biodegradable, aliphatic polyester produced from L- and D-lactic acid, which can be derived from fermentation of corn starch (Lunt, 1998). PLA fibres have already been produced by both electrospinning (Martínez-Sanz et al., 2013b; Torres-Giner et al., 2012; Xiang et al., 2009; Xu et al., 2010) and solution blow spinning (Medeiros et al., 2009; Oliveira et al., 2012a; Oliveira et al., 2011; Oliveira et al., 2012b) and a wide variety of materials have been incorporated into the fibres to tune their properties for specific applications. Some examples include PLA fibres for controlled release of antibiotics (Torres-Giner et al., 2012; Xu et al., 2010), PLA-hydroxyapatite fibres for bone regeneration (Kim et al., 2006; Xu et al., 2007), and PLA fibres loaded with silver nanoparticles with antimicrobial properties (Kim et al., 2010) and loaded with reinforcing agents such as nanoclays $^{20}$ and cellulose nanowhiskers (CNW) (Martínez-Sanz et al., 2013b; Xiang et al., 2009).

Cellulose nanocrystals are widely used as reinforcing agents in nanocomposites due to their interesting properties such as high surface area, low density, biodegradability and high mechanical strength (Habibi et al., 2010). Specifically, bacterial cellulose nanowhiskers (BCNW), which are extracted from cellulose synthesized by bacteria, present a particular interest due to their exceptionally high crystallinity and aspect ratio (Martínez-Sanz et al., 2011a). Within the nanocomposites field, the incorporation of $\mathrm{CNW}$ into electrospun fibres has been mainly used to generate fibres with improved mechanical properties (Herrera et al., 2011; Huang et al., 2011; Rojas et al., 2009). Additionally, electrospinning was recently also proven to be an efficient method 
for the incorporation of highly dispersed cellulose nanocrystals into melt compounded nanocomposites with improved properties (Martínez-Sanz et al., 2012; Martínez-Sanz et al., 2013a).

Another interesting application of electrospun fibres consists on their use as vehicles for controlled release of antimicrobial agents and drugs. Electrospun fibre mats have been proven to release drugs more efficiently than when those substances were incorporated into films by solution casting, mostly due to the larger surface area of fibre mats (Taepaiboon et al., 2006; Tungprapa et al., 2007). Nevertheless, as a consequence of the incorporation of an additional component, the viscosity, surface tension and conductivity of solutions may be affected (Luong-Van et al., 2006) and, thus, the hybrid systems need to be optimized in terms of solvent, solids concentration and electrospinning parameters. In addition, the release of antimicrobial agents from PLA fibres has been found to be strongly affected by relative humidity conditions. Pure PLA fibres loaded with allyl isothiocyanate showed negligible release under dry conditions, whereas at $75 \% \mathrm{RH}$ the release of the antimicrobial agent was triggered (Vega-Lugo \& Lim, 2009). Some other works suggested the use of bi-component fibres, such as PLAPCL (Buschle-Diller et al., 2007), or the incorporation of hydrophilic materials, such as PEG (Xu et al., 2010), in order to optimize the release properties of PLA fibres.

The present study reports on the application of the novel solution blow spinning technique for the production of PLA hybrid fibres incorporating BCNW and antimicrobial agents, which could be of interest in antimicrobial applications. PLA-BCNW fibres were characterized and the nanofiller loading was optimized to produce uniform morphologies. Furthermore, fibres with antimicrobial properties were generated by incorporating carvacrol and THC into the blow 
spinning solutions. BCNW were incorporated to increase the water sorption of the fibres and gelatine was added as a stronger hydrophilic component to facilitate further the release of the antimicrobial agents. 


\section{MATERIALS AND METHODS}

\subsection{Materials}

The poly(lactic acid) (PLA) used was a Polylactide Resin 4042D grade acquired from Natureworks, LLC (Minnetonka, MN) with a weight average molecular weight $\left(\mathrm{M}_{\mathrm{w}}\right)$ of ca. $6.6 \times 10^{4} \mathrm{~g} / \mathrm{mol}$ as reported by the manufacturer.

Sulphuric acid (96\%) was purchased from Panreac (Barcelona, Spain). 1,1,1,3,3,3-Hexafluoro-2-propanol (HFP), Carvacrol and Tetracycline hydrochloride (THC) were purchased from Sigma-Aldrich (St. Louis, MO). Alaska Pollock (Theragra chalcogramma) gelatin was extracted from skins obtained from a commercial fish processing plant in Alaska. The extraction procedures were detailed elsewhere (Avena-Bustillos et al., 2006).

\subsection{Preparation of bacterial cellulose mats}

Bacterial cellulose mats were obtained as described in a previous work (Martínez-Sanz et al., 2011b). Briefly, the bacterial strain Gluconacetobacter xylinus 7351 was incubated in a modified Hestrin/Shramm medium at $30^{\circ} \mathrm{C}$. The cells were pre-cultured in a test tube containing $5 \mathrm{ml}$ of medium and later transferred and scaled up to a bigger reactor of 201 . Several layers of cellulose obtained using the previously described procedure were thus supplied. The received bacterial cellulose pellicles were sterilized and cleaned in boiling water and in a $10 \%(\mathrm{v} / \mathrm{v}) \mathrm{NaOH}$ aqueous solution.

\subsection{Preparation of bacterial cellulose nanowhiskers}

Once neutral $\mathrm{pH}$ was reached, bacterial cellulose pellicles were ground in a blender and the gel-like material was then compressed to remove most of the absorbed water. The dried material was then treated with $301 \mathrm{~mL}$ sulfuric acid/L 
water, in a cellulose/acid ratio of approximately $7 \mathrm{~g} / \mathrm{L}$, at $50^{\circ} \mathrm{C}$ for three days until a homogeneous solution was obtained. The cellulose nanowhiskers were obtained as a white precipitate after several centrifugation and washing cycles at 12,500 rpm and $15^{\circ} \mathrm{C}$ for 20 minutes. After that, the material was re-suspended in deionized water and neutralized with sodium hydroxide until reaching neutral $\mathrm{pH}$. The sample was subsequently centrifuged to obtain the final product as a partially hydrated precipitate. The product was kept refrigerated and one fraction was freeze-dried for further analyses.

\subsection{Solution blow spinning}

Pure PLA blow-spinning solutions were prepared by adding 6 wt.-\% PLA to the HFP solvent and stirring it at ambient temperature. Suspensions of 5 wt.- $\%, 15$ wt.- $\%$ and 30 wt.- $\%$ BCNW with respect to the PLA weight were prepared by dispersing partially hydrated BCNW into HFP. BCNW were dispersed in the solvent by homogenizing (Ultra-turrax) the sample for 1 minute. PLA was then added to the sample and stirred at ambient temperature. The effect of the total solids concentration on the morphology of the fibres was studied by preparing solutions with 4 wt.- $\%, 6$ wt.- $\%$ and 8 wt.- $\%$ total solids for the sample containing 15 wt.-\% BCNW.

Additionally, to confer antimicrobial properties to the blow-spun fibres, either 12 wt.- $\%$ carvacrol or 2 wt.- $\%$ THC were incorporated together with PLA to produce solutions presenting a total solids concentration of $6 \mathrm{wt} . \mathrm{\%} \%$. In order to improve the release of the antimicrobial agents, a loading of $30 \mathrm{wt} .-\%$ of Pollock gelatin was incorporated into blow spinning solutions containing pure PLA and PLA combined with carvacrol or THC and hybrid fibres were generated. Additionally, a loading of 15 wt.-\% BCNW (with respect to the PLA weight) was further incorporated into the hybrid fibres to study the effect of the nanowhiskers 
on the properties of blow spun fibres and on the release of the antimicrobial additives.

The solution blow spinning system consisted of a source of compressed air, a $10 \mathrm{~mL}$ plastic syringe, a syringe pump (KD Scientific Inc., Holliston, U.S.A.) to control the injection rate of the solutions, a spinning apparatus that consisted of a setup with concentric nozzles and a collector with a controllable rotation speed. Solutions were transferred to the syringes and connected through PTFE tubes to the spinning apparatus. The polymer solution was fed at a rate of $0.04 \mathrm{ml} / \mathrm{min}$, the air pressure was set to $0.6 \mathrm{MPa}$, the distance between the needle and the collector was $10 \mathrm{~cm}$ and the collector rotating speed was fixed to $300 \mathrm{rpm}$.

\subsection{Characterization of blow spinning solutions}

Viscosity of the solutions was determined at ambient temperature using a VISCO BASIC Plus L Viscometer (Fungilab, Spain) with a LCP low viscosity adapter. The surface tension of the polymeric solutions was measured using the Wilhemy plate method in an EasyDyne K20 tensiometer (Krüss GmbH, Hamburg, Germany). The measurements were done under ambient conditions (ca. $25^{\circ} \mathrm{C}$ ). Results were given as the average of four measurements with their corresponding standard deviations.

\subsection{Scanning Electron Microscopy (SEM)}

SEM was conducted on a Hitachi S-4700 field emission scanning electron microscope (Hitachi, Japan). Blow-spinning mats were mounted onto aluminum specimen stubs (Ted Pella, Inc) with a double-adhesive coated carbon tab (Electron Microscopy Sciences, Hatfield, PA). The samples were then coated with gold-palladium in a Denton Desk II sputter coating unit (Denton Vacuum, 
U.S.A., Moorestown, NJ). All samples were then viewed and photographed at 2 $\mathrm{kV}$.

Fibre diameters of the blow-spun fibres were measured by using the Adobe Photoshop CS3 extended software from the SEM micrographs in their original magnification. Each sample was prepared in duplicate and the fibre diameter was calculated as the average of the two measurements.

\subsection{Transmission Electron Microscopy (TEM)}

PLA hybrid fibres were directly blow-spun on TEM grids. The material was then stained with uranyl acetate with the purpose of increasing the contrast of the highly crystalline BCNW or the carvacrol incorporated into the fibres. TEM was performed using a FEI (Hillsboro, OR) Tecnai 12 operated at $120 \mathrm{KV}$.

\subsection{Differential scanning calorimetry (DSC)}

Differential scanning calorimetry (DSC) was performed using a Perking Elmer Jade DSC 8000 instrument calibrated with indium $(\mathrm{T}, \Delta \mathrm{H})$ and zinc $(\mathrm{T})$. DSC samples of 4-6 g were weighed in a $40 \mu \mathrm{L}$ stainless steel pan and an empty pan was used as reference. Measurements were carried out under $80 \mathrm{~mL} \cdot \mathrm{min}^{-1}$ nitrogen flow rate and a scanning speed of $10^{\circ} \mathrm{C} / \mathrm{min}$ from $0{ }^{\circ} \mathrm{C}$ to $200{ }^{\circ} \mathrm{C}$. The first and second melting endotherms after controlled crystallization at $10^{\circ} \mathrm{C} / \mathrm{min}$ were analyzed.

The crystallinity (\%) of the PLA was estimated from the corrected enthalpy for biopolymer content in the hybrid fibres, using the ratio between the enthalpy of the studied material and the enthalpy of a perfect PLA crystal, i.e. $X_{C}(\%)=\frac{\Delta H_{f}-\Delta H_{c}}{\Delta H_{f}^{0}} \times 100$, where $\Delta H_{f}$ is the enthalpy of fusion and $\Delta H_{C}$ 
the enthalpy of cold crystallization of the studied specimen, and $\Delta H_{f}^{0}$ is the enthalpy of fusion of a totally crystalline material. The $\Delta H_{f}^{0}$ used for this equation was $93 \mathrm{~J} / \mathrm{g}$ for PLA (Liu et al., 1997).

\subsection{Thermogravimetric analysis (TGA)}

Thermogravimetric analysis (TGA) was performed under nitrogen atmosphere in a TA Instrument TGA 2950. The samples were heated from room temperature to $500^{\circ} \mathrm{C}$ at a heating rate of $10^{\circ} \mathrm{C} / \mathrm{min}$ and a nitrogen gas flow rate of $60 \mathrm{~mL} / \mathrm{min}$. The derivatives of TGA curves (DTG) were obtained using TA analysis software.

\subsection{Antimicrobial properties}

L. monocytogenes used in the present study was obtained from University of California, Berkeley (our strain designation RM2199; original designation strain F2379) isolated from cheese associated with an outbreak. Frozen cultures of $L$. monocytogenes were streaked on Trypticase Soy Agar (TSA) and then incubated at $37^{\circ} \mathrm{C}$ for $24 \mathrm{~h}$. One isolated colony was re-streaked on TSA and then incubated at $37^{\circ} \mathrm{C}$ for $24 \mathrm{~h}$. This was followed by inoculating one isolated colony into a tube with $5 \mathrm{~mL}$ Trypticase Soy Broth and incubating at $37^{\circ} \mathrm{C}$ for $24 \mathrm{~h}$ with agitation. The microbial broth was then serially diluted $(10 \mathrm{x})$ in $0.1 \%$ peptone water.

Overlay diffusion test was used to determine the antimicrobial effect of blow spun fibres against Listeria monocytogenes. Briefly, $0.1 \mathrm{ml}$ of $10^{5}$ colony-formingunits $(\mathrm{CFU}) / \mathrm{mL}$ of bacterial cultures were plated onto each of two TSA plates (replicates). The inoculum was spread evenly throughout each plate and then left to dry for $5 \mathrm{~min}$ in a biosafety hood. On the center of each plate, one aseptically cut 12-mm diameter blow spun fibre disc was deposited over the inoculated agar. The plates were incubated at $37^{\circ} \mathrm{C}$ for $24 \mathrm{~h}$. The inhibition radius around the fibre disc 
(colony-free perimeter) was measured with a digital caliper (Neiko Tools, Ontario, $\mathrm{CA}$ ) in triplicate after $24 \mathrm{~h}$ of incubation. The inhibition area was then calculated. The inhibition areas of two fibre discs per treatment were used for inhibitory zone calculation. Inhibitory effect of fibre disc directly contacted with agar was also recorded. Inhibitory effect under disc was reported as positive when no sign of bacteria growth underneath the fibre disc was observed.

\subsection{Water uptake}

The water uptake was estimated during sorption experiments at $24^{\circ} \mathrm{C}$ and $100 \%$ RH by means of weight gain using an analytical balance Voyager ${ }^{\circledR}$ V11140. Thus, at saturation conditions, no changes in successive weight uptake were observed during the measurements of the specimens. 


\section{RESULTS AND DISCUSSION}

\subsection{Optimization of PLA-BCNW blow spun fibres}

In the first part of the present work, blow spun fibres of PLA were loaded with $\mathrm{BCNW}$ as the reinforcing agent and the morphology and thermal properties of the fibres were investigated to determine the nanofiller loading resulting in optimized BCNW dispersion and fibre properties.

Pure PLA blow spun fibres have previously been produced and optimized (Oliveira et al., 2011). In that study, mixtures of chloroform and acetone were used as the solvent. However, due to the highly hydrophilic character of the nanofiller used in this work, we decided to use a solvent which was compatible with both the polymeric matrix and the BCNW. The solvent 1,1,1,3,3,3-Hexafluoro-2-propanol (HFP) was selected as it has been previously employed for the production of hybrid PLA-BCNW fibres by electrospinning, leading to optimized incorporation and dispersion of the nanofiller (Martínez-Sanz et al., 2013b). From previous experiments, it was found that the optimal solids concentration for pure PLA blow spun fibres was 6 wt.- $\%$ and, therefore, this was considered as the reference material. Subsequently, BCNW were incorporated in a range of concentrations, with $30 \mathrm{wt} .-\%$ being the maximum amount of fibres incorporated in the samples.

The nanofiller incorporated into the polymeric matrix consisted of highly crystalline nanowhiskers obtained from the acid digestion of bacterial cellulose, as described in a previous study (Martínez-Sanz et al., 2011a). The obtained BCNW had an average length (L) of ca. $600 \mathrm{~nm}$ and an average cross-section diameter (W) of ca. $21 \mathrm{~nm}$, resulting in an aspect ratio (L/W) of 29, which is typical of cellulose nanowhiskers extracted from BC (Liu et al., 2012). This material had a high crystallinity index of ca. $95 \%$, as previously estimated from X-ray diffraction 
analyses, and could be subjected to typical processing temperatures for PLA, since the degradation temperature of $\mathrm{BCNW}$, as determined by TGA, was approximately $317^{\circ} \mathrm{C}$ (Martínez-Sanz et al., 2011a).

As observed in Figure 1, the incorporation of BCNW had a strong effect on the morphology of the generated fibres. All the tested nanofiller loadings resulted in homogeneous fibres. Furthermore, for a fixed solids concentration, the diameter of fibres decreased when increasing the amount of BCNW, although this effect was more obvious for concentrations up to 15 wt.- $\%$ BCNW. A similar effect was observed for PLA electrospun fibres and this was ascribed to the surface charges of BCNW and a higher viscosity for greater BCNW loadings (Martínez-Sanz et al., 2013b). On the other hand, as shown in Table 1, for a fixed BCNW loading, the average diameter of fibres increased with the increase in total solids concentration of the polymeric solutions. 

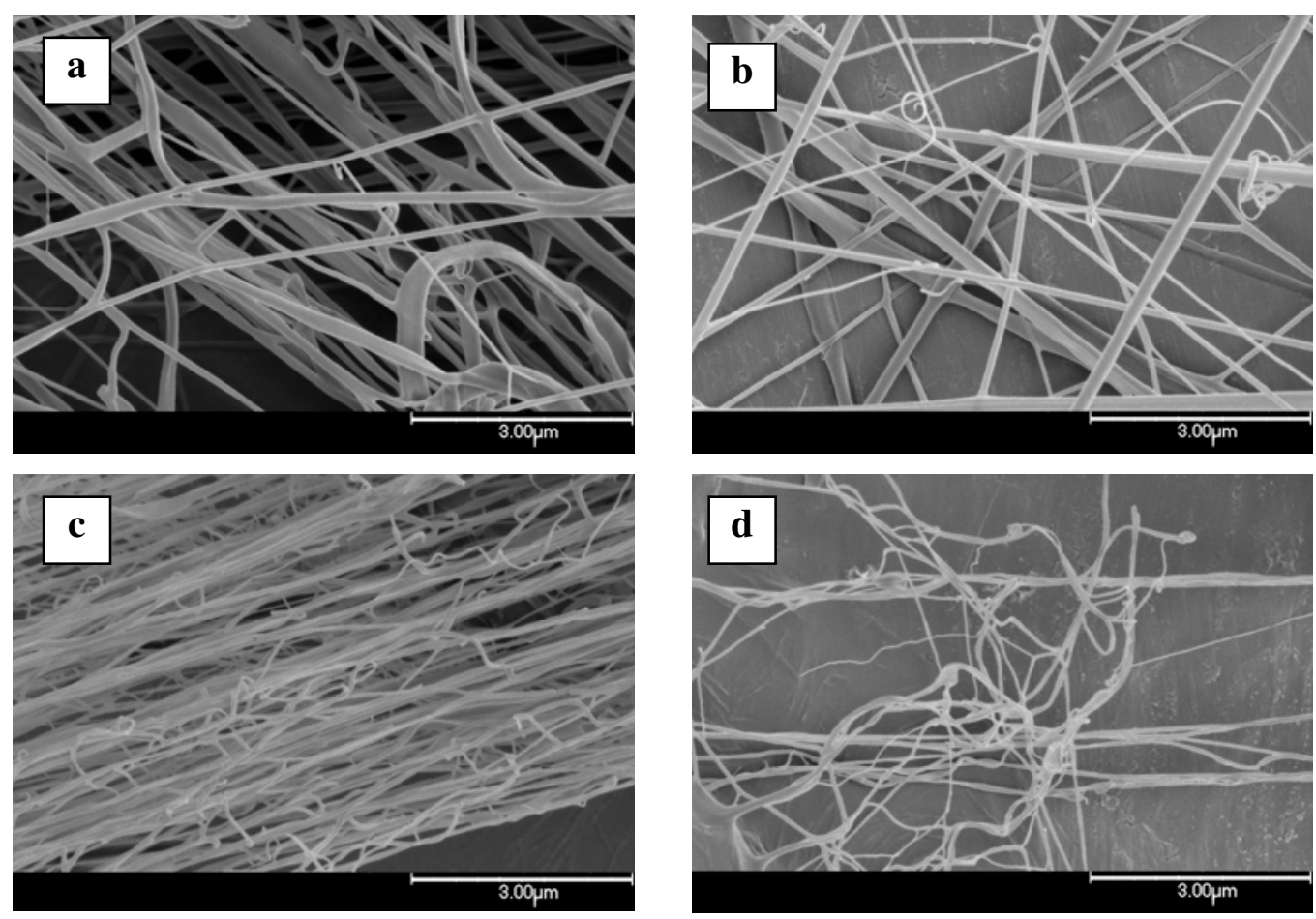

Figure 1. SEM micrographs of electrospun PLA fibres produced from solutions with 6 wt.- $\%$ solids content: (a) Pure PLA, (b) PLA+5\%BCNW, (c)

$\mathrm{PLA}+15 \% \mathrm{BCNW}$ and (d) PLA $+30 \% \mathrm{BCNW}$. Scale markers correspond to 3 microns.

To determine the factors that affect the morphology of fibres in the blow spinning process, the polymeric solutions were characterized and results are presented in Table 1. As deduced from these results, there was a linear relationship between the solids content and the fibre diameters, which can be attributed to the increased viscosity and surface tension of solutions. It has been previously reported that increasing the polymer concentration for PLA blow spun fibres gives rise to thicker and more uniform fibres due to extensive chain entanglement (Oliveira et al., 2011). Also, there seemed to be a linear decrease of the average fibres diameter when increasing the BCNW concentration up to $15 \mathrm{wt} .-\%$, whereas there was no 
further decrease for the $30 \mathrm{wt.} \%$ sample. From Table 1, the incorporation of $\mathrm{BCNW}$ also resulted in higher surface tension and especially in greater viscosity values. This might be attributed to the presence of hydroxyl groups on the surface of BCNW, which favors the development of a strong polymeric network held by hydrogen bonds. The thinner and less uniform fibres obtained for higher BCNW concentrations might be related to the increased surface tension of the solutions and additionally to the highly crystalline character of the nanofiller, which could be decreasing the extensional viscosity or elasticity of the polymeric solution. It was reported that extensional viscosity is not necessarily related to polymer entanglements and thus, uniform fibres can be obtained for solutions with high elastic response even though they are in the dilute regime (Yu et al., 2006).

In conclusion, it was possible to modify the morphology of blow spun fibres by adjusting the viscosity and surface tension of the polymeric solutions. However, by incorporating $\mathrm{BCNW}$ into the system, which increased surface tension and possibly reduced the extensional viscosity of the polymeric solutions, the average diameter tended to decrease. It is also important to note that the effect of BCNW is different for the electrospinning and blow spinning techniques since the incorporation of electrical charges present in the nanowhiskers into the system plays an important role in electrospinning while it does not affect the blow spinning process. 
Table 1. Viscosity and surface tension of blow spinning solutions and average diameter of the corresponding fibres.

\begin{tabular}{|c|c|c|c|}
\cline { 2 - 4 } \multicolumn{1}{c|}{} & Viscosity $(\mathrm{cP})$ & $\begin{array}{c}\text { Surface Tension } \\
(\mathrm{mN} / \mathrm{m})\end{array}$ & Average fibre diameter (nm) \\
\hline PLA 6\%wt & 55.47 & 16.7 & ${ }^{\mathrm{e}} 120.20 \pm 74.22$ \\
\hline PLA+5\%BCNW 6\%wt & 85.16 & 17.0 & ${ }^{\mathrm{d}} 91.00 \pm 56.13$ \\
\hline PLA+15\%BCNW 4\%wt & 383.62 & 19.9 & ${ }^{\mathrm{a}} 34.36 \pm 12.92$ \\
\hline PLA+15\%BCNW 6\%wt & 2410.5 & 25.0 & ${ }^{\mathrm{b}} 46.63 \pm 18.53$ \\
\hline PLA+15\%BCNW 8\%wt & $>2500$ & 30.9 & ${ }^{\mathrm{c}} 75.67 \pm 55.39$ \\
\hline PLA+30\%BCNW 6\%wt & $>2500$ & 42.0 & ${ }^{\mathrm{b}} 46.28 \pm 19.05$ \\
\hline
\end{tabular}

The $a, b, c, d$ and e letters correspond to the ANOVA statistical analysis and

Tukey test of the data that indicate that with a $95 \%$ confidence level, the values are significantly different.

In terms of fibre morphology and BCNW loading, the system with 6 wt.- $\%$ solids content and $15 \mathrm{wt} .-\% \mathrm{BCNW}$ was selected as the optimum composition as it was the maximum loading for which blow spinning solutions were easy to handle and, moreover, it resulted in homogeneous fibres. By staining the BCNW incorporated into the fibres, it was possible to study the distribution of the nanofiller within the fibres by using TEM. As shown in Figure 2, BCNW were homogeneously distributed along the fibres and seemed to be mostly oriented in the fibre axis direction.

In a previous study, fibres were generated by electrospinning from solutions with the same solids content and nanofiller loading, i.e. 6 wt.- $\%$ solids concentration and 15 wt.-\% BCNW loading. The solution had a viscosity of ca. 580 $\mathrm{cP}$ and the average diameter of fibres was $90.70 \mathrm{~nm}$ (Martínez-Sanz et al., 2013b). 
The higher viscosity and diameter achieved by electrospinning can be explained by the significantly higher molecular weight of the PLA used in that work.
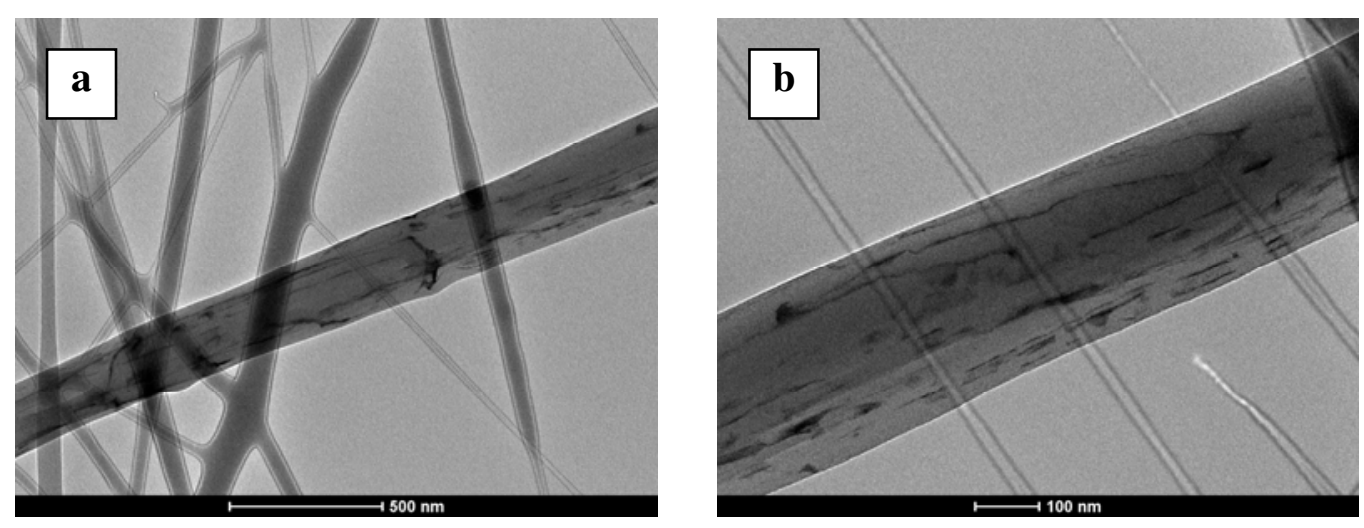

Figure 2. TEM micrographs of blow spun PLA fibres with $15 \mathrm{wt} .-\%$ BCNW from solutions with 6 wt.- $\%$ solids content. Scale marker correspond to $500 \mathrm{~nm}$ (a) and to $100 \mathrm{~nm}(\mathrm{~b})$.

DSC analyses were carried out to investigate the effect of incorporating $\mathrm{BCNW}$ on the thermal properties of the blow spun fibres. The thermal parameters extracted from the first and second DSC heating runs are displayed in Table 2. The incorporation of $\mathrm{BCNW}$ led to a slight increase in the melting temperature and a significant reduction in the cold crystallization temperature. This result suggests that BCNW had a nucleating effect, which was confirmed by a considerable increase in the crystallinity of PLA. However, no significant differences in the crystallinity were found when increasing the BCNW concentration. For the higher molecular weight PLA used to generate electrospun fibres, BCNW showed just the opposite effect, reducing the crystallinity of the PLA matrix (Martínez-Sanz et al., 2013b). Thus, it seems that BCNW might promote the crystallinity for relatively low molecular weight materials, whereas they might disrupt the crystalline network in higher molecular weight samples. 
In addition, the glass transition temperature increased slightly with the addition of $\mathrm{BCNW}$, although this increase was lower than that observed for electrospun fibres (Martínez-Sanz et al., 2013b). This again suggests that BCNW restrict the mobility of polymeric chains to a higher extent in higher molecular weight polymers. In any case, this result indicates that there was a certain interaction between PLA and the nanofiller, which resulted in stiffer fibres.

Table 2. DSC maximum of melting $\left(\mathrm{T}_{\mathrm{m}}\right)$, melting enthalpy $\left(\Delta \mathrm{H}_{\mathrm{m}}\right)$, cold crystallization temperature $\left(\mathrm{T}_{\mathrm{CC}}\right)$, cold crystallization enthalpy $\left(\Delta \mathrm{H}_{\mathrm{CC}}\right)$ and degree of crystallinity $\left(\mathrm{X}_{\mathrm{c}}\right)$ of blow spun PLA fibres with different BCNW content, obtained from the first heating run and glass transition temperature $\left(\mathrm{T}_{\mathrm{g} 2}\right)$, obtained from the second heating run.

\begin{tabular}{|c|c|c|c|c|c|c|}
\cline { 2 - 7 } \multicolumn{1}{c|}{} & $\mathrm{T}_{\mathrm{m}}\left({ }^{\circ} \mathrm{C}\right)$ & $\Delta \mathrm{H}_{\mathrm{m}}(\mathrm{J} / \mathrm{g})$ & $\mathrm{T}_{\mathrm{CC}}\left({ }^{\circ} \mathrm{C}\right)$ & $\Delta \mathrm{H}_{\mathrm{CC}}(\mathrm{J} / \mathrm{g})$ & $\mathrm{X}_{\mathrm{c}}(\%)$ & $\mathrm{T}_{\mathrm{g} 2}\left({ }^{\circ} \mathrm{C}\right)$ \\
\hline $\begin{array}{c}\text { PLA 6\%wt } \\
173.2 \pm 3.6\end{array}$ & $33.0 \pm 1.7$ & $84.1 \pm 0.1$ & $14.3 \pm 0.1$ & $20.1 \pm 1.9$ & $60.2 \pm 3.7$ \\
\hline $\begin{array}{c}\text { PLA+5\% } \\
\text { BCNW 6\%wt }\end{array}$ & $174.9 \pm 3.2$ & $41.6 \pm 0.7$ & $72.2 \pm 0.1$ & $17.1 \pm 2.2$ & $26.3 \pm 3.4$ & $61.0 \pm 4.3$ \\
\hline $\begin{array}{c}\text { PLA+15\% } \\
\text { BCNW 6\%wt }\end{array}$ & $175.4 \pm 3.1$ & $38.4 \pm 2.4$ & $78.6 \pm 3.2$ & $14.4 \pm 1.4$ & $25.8 \pm 4.1$ & $60.6 \pm 4.6$ \\
\hline $\begin{array}{c}\text { PLA+30\% } \\
\text { BCNW 6\%wt }\end{array}$ & $175.5 \pm 0.3$ & $42.9 \pm 1.3$ & $71.4 \pm 1.7$ & $18.4 \pm 0.4$ & $26.4 \pm 0.9$ & $63.9 \pm 1.1$ \\
\hline
\end{tabular}

Since BCNW had lower thermal stability than PLA (Martínez-Sanz et al., 2013b; Martínez-Sanz et al., 2013c), thermogravimetric analyses were carried out to investigate the effect of the nanofiller on the thermal stability of hybrid fibres. From Table 3, it seems that the incorporation of BCNW led to more thermally stable fibres. The same effect has been observed for PLA electrospun fibres (Martínez-Sanz et al., 2013b) and once again suggests that a relatively good level of interaction was established between PLA and BCNW. A previous work showed 
that PHBV nanocomposites incorporating cellulose nanocrystals presented improved thermal stability due to the formation of a strong hydrogen bonds network which reduced the degradation of the polymeric matrix during the first degradation stages (Jiang et al., 2008). The increased crystallinity of the fibres containing BCNW could also have contributed to the improved thermal stability observed.

Table 3. TGA parameters of PLA blow spun hybrid fibres: maximum of the weight loss first derivate $\left(T_{D}\right)$, peak onset and residue at $490^{\circ} \mathrm{C}$.

\begin{tabular}{|c|c|c|c|}
\cline { 2 - 4 } \multicolumn{1}{c|}{} & Onset $\left({ }^{\circ} \mathrm{C}\right)$ & $\mathrm{T}_{\mathrm{D}}\left({ }^{\circ} \mathrm{C}\right)$ & Residue at $490^{\circ} \mathrm{C}(\%)$ \\
\hline PLA 6\%wt & $288.5 \pm 24.8$ & $343.9 \pm 3.9$ & $1.0 \pm 0.2$ \\
\hline PLA+5\%BCNW 6\%wt & $324.7 \pm 3.1$ & $356.6 \pm 1.8$ & $0.7 \pm 0.6$ \\
\hline PLA+15\%BCNW 6\%wt & $325.9 \pm 1.1$ & $357.4 \pm 1.9$ & $2.1 \pm 0.3$ \\
\hline PLA+30\%BCNW 6\%wt & $321.2 \pm 1.2$ & $353.7 \pm 1.7$ & $2.8 \pm 0.4$ \\
\hline
\end{tabular}

In conclusion, it was possible to generate PLA-BCNW hybrid fibres by solution blow spinning. These fibres had increased crystallinity and thermal stability. Moreover, it has been proved that the optimized composition in terms of uniform morphology and ease of processability is the $15 \mathrm{wt} .-\%$ BCNW sample.

\subsection{Development of PLA blow spun fibres with antimicrobials}

After selecting the optimal formulation of hybrid PLA fibres reinforced with BCNW, the objective of the second part of this study was to develop fibres with antimicrobial properties. For this purpose, two different antimicrobial agents were evaluated, i.e. carvacrol and THC. From preliminary tests, it was estimated that for loadings as low as 2 wt.-\% THC hybrid PLA-THC blow spun fibres presented an 
inhibitory effect against Listeria monocytogenes, whereas the carvacrol concentration was raised up to the maximum possible which allowed the formation of fibres, i.e. 12 wt.- $\%$. The reason for increasing the carvacrol loading as much as possible was that no inhibitory effect was detected for hybrid PLA-carvacrol fibres even at high carvacrol loadings.

In addition, $\mathrm{BCNW}$ were incorporated into the system to evaluate their effect on the water sorption of the fibres and the consequent impact on release of the antimicrobials. It was observed that by just adding 15 wt.-\% BCNW, i.e. the optimum loading as determined in the first part of this study, the antimicrobial effect of the fibres was not greatly affected. Therefore, gelatin was incorporated into the fibres to increase their hydrophilic character and promote the release of the antimicrobials. Previous studies have reported that the incorporation of essential oils could have a plasticization effect on the polymeric matrix, especially for relatively high loadings (Ahmad et al., 2012; Giménez et al., 2012; Ramos et al., 2012). Thus, BCNW were also added to the fibres with the aim of evaluating their possible effect as reinforcing agents to counteract the possible plasticization effect caused by the antimicrobials.

The effect of gelatin, the antimicrobial agents and BCNW on the morphology of blow spun fibres is shown in Figure 3. The concentration of gelatin incorporated into the fibres, i.e. 30 wt. $\%$, was the maximum amount for which fibre morphology was obtained. From Figure 3a, the fibres containing gelatin were thicker and more heterogeneous as compared to pure PLA fibres. The subsequent addition of antimicrobial agents resulted in even thicker fibres, with a much more homogeneous size distribution for THC than for carvacrol samples. The incorporation of BCNW into the hybrid PLA-gelatin-antimicrobial agent fibres resulted in a reduction of the average fibre diameter, similarly to the results 
obtained from the first part of this study, preserving the homogeneous morphology for THC-loaded fibres.

Since carvacrol is very volatile, fibres were stained and analyzed by TEM to confirm that it was effectively incorporated. Carvacrol rich areas appear in Figure 4 as darker regions, confirming that the antimicrobial agent was incorporated into the fibres with a certain degree of agglomeration. 

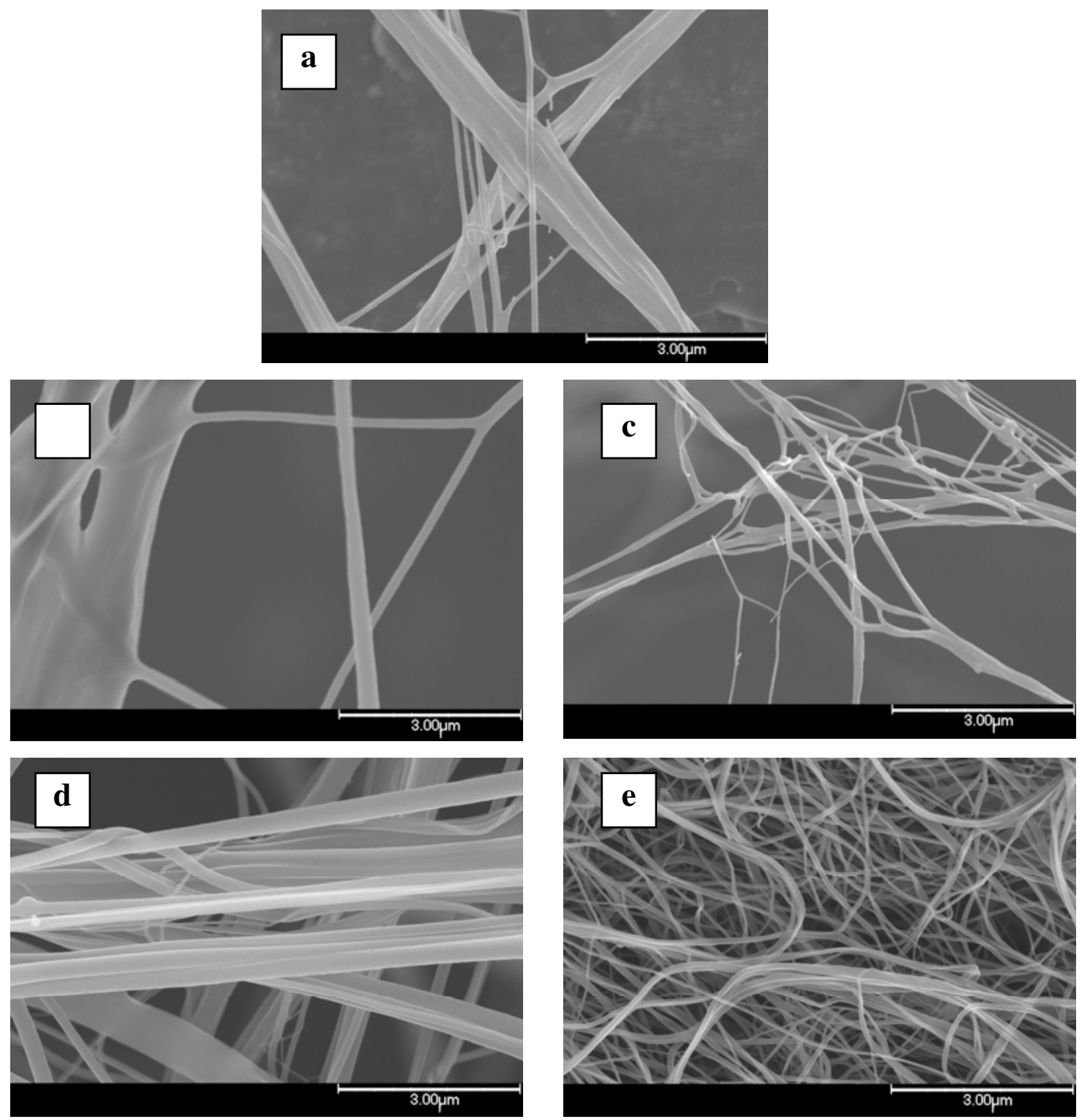

Figure 3. SEM micrographs of electrospun PLA fibres with 6 wt.- $\%$ solids content:

(a) PLA $+30 \%$ Gelatin, (b) PLA $+30 \%$ Gelatin $+12 \%$ Carvacrol, (c) PLA + $30 \%$ Gelatin $+15 \%$ BCNW, (d) PLA $+30 \%$ Gelatin $+2 \%$ THC, and (e) PLA + $30 \%$ Gelatin $+2 \% \mathrm{THC}+15 \% \mathrm{BCNW}$. Scale markers correspond to 3 micrometers. 


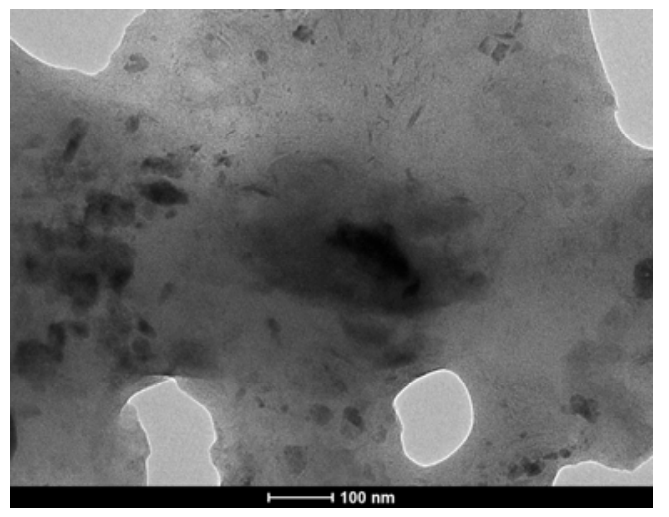

Figure 4. TEM micrograph of blow spun PLA fibres with 12 wt.- $\%$ carvacrol. Scale marker corresponds to $100 \mathrm{~nm}$.

To understand the effect of incorporating the different additives into PLA fibres on their morphology, the viscosity and surface tension of all the solutions were determined. For clarity, results for carvacrol-loaded fibres and THC loadedfibres have been separated into two different tables, since the effects are different depending on the antimicrobial agent. The addition of gelatin resulted in markedly increased viscosity, which might be a result of interactions between PLA and gelatin. This effect was also observed with the addition of BCNW. However, in contrast to $\mathrm{BCNW}$, gelatin did not have an effect on the surface tension values of the blow spinning solutions.

The incorporation of carvacrol or THC into PLA solutions had the same effect, as shown in Tables 4 and 5, with a slight viscosity drop and little change in the surface tension. Nonetheless, each additive had a different effect on the average fibre diameter. For carvacrol-loaded fibres, the diameter decreased as a result of the decreased solution viscosity. In contrast, thicker fibres were obtained with the addition of THC. Previous blow spinning studies indicated that stronger interactions between the solvent and the polymeric material facilitated the 
production of more homogeneous fibres due to a decrease in the segregation of solvent molecules (Medeiros et al., 2009; Oliveira et al., 2011). This should result in the solution having higher extensional viscosity. It seems that due to the hydrophilic character of THC, it possessed greater compatibility with the acidic solvent HFP, whereas the more hydrophobic carvacrol had lower compatibility with HFP.

Solutions containing gelatin and antimicrobials had higher viscosity and surface tension than pure PLA solutions and, consequently, the hybrid blow spun fibres were thicker. The THC fibres were much more homogeneous than the carvacrol fibres since THC seemed to enhance the elastic behaviour of the solutions.

Finally, the additional incorporation of BCNW greatly increased the solution viscosity and surface tension and thinner fibres were generated. This is the same effect observed for pure PLA samples in the first part of this study, thus confirming that, apart from the increase in surface tension, it appears that the highly crystalline $\mathrm{BCNW}$ reduced the extensional viscosity of solutions and, therefore, the ability of the polymeric material to form fibres. 
Table 4. Viscosity and surface tension of blow spinning solutions incorporating carvacrol and average diameter of the corresponding fibres.

\begin{tabular}{|c|c|c|c|}
\cline { 2 - 4 } \multicolumn{1}{c|}{} & Viscosity $(\mathrm{cP})$ & $\begin{array}{c}\text { Surface Tension } \\
(\mathrm{mN} / \mathrm{m})\end{array}$ & $\begin{array}{c}\text { Average fibre } \\
\text { diameter }(\mathrm{nm})\end{array}$ \\
\hline PLA & 55.47 & 16.7 & ${ }^{\mathrm{b}} 120.20 \pm 74.22$ \\
\hline PLA+30\% Gelatin & 548.20 & 16.9 & ${ }^{\mathrm{c}} 188.51 \pm 92.56$ \\
\hline PLA+12\% Carvacrol & 41.17 & 16.8 & ${ }^{\mathrm{a}} 74.60 \pm 34.36$ \\
\hline PLA+30\% Gelatin+12\% & 237.57 & 18.1 & ${ }^{\mathrm{d}} 269.26 \pm 160.13$ \\
\hline $\begin{array}{c}\text { Carvacrol } \\
\text { Carvacrol+15\%BCNW }\end{array}$ & 743.14 & 21.7 & ${ }^{\mathrm{a}} 82.54 \pm 40.97$ \\
\hline
\end{tabular}

The $\mathrm{a}, \mathrm{b}, \mathrm{c}$ and $\mathrm{d}$ letters correspond to the ANOVA statistical analysis and Tukey test of the data that indicate that with a $95 \%$ confidence level, the values are significantly different. 
Table 5. Viscosity and surface tension of blow spinning solutions incorporating THC and average diameter of the corresponding fibres.

\begin{tabular}{|c|c|c|c|}
\cline { 2 - 4 } \multicolumn{1}{c|}{} & $\begin{array}{c}\text { Viscosity } \\
(\mathrm{cP})\end{array}$ & $\begin{array}{c}\text { Surface } \\
\text { Tension } \\
(\mathrm{mN} / \mathrm{m})\end{array}$ & $\begin{array}{r}\text { Average fibre } \\
\text { diameter }(\mathrm{nm})\end{array}$ \\
\hline PLA & 55.47 & 16.7 & ${ }^{\mathrm{b}} 120.20 \pm 74.22$ \\
\hline PLA+30\% Gelatin & 548.20 & 16.9 & ${ }^{\mathrm{c}} 188.51 \pm 92.56$ \\
\hline PLA+2\% THC & 46.20 & 16.9 & ${ }^{\mathrm{e}} 306.87 \pm 141.25$ \\
\hline PLA+30\% Gelatin+2\% & 726.87 & 21.0 & ${ }^{\mathrm{a}} 69.79 \pm 27.39$ \\
\hline THC+15\%BCNW & & 17.9 & \\
\hline
\end{tabular}

The a, b, c, d and e letters correspond to the ANOVA statistical analysis and Tukey test of the data that indicate that with a $95 \%$ confidence level, the values are significantly different.

The effect of the different additives on the thermal properties of fibres was also evaluated using DSC analyses and the results are summarized in Table 6. In general, the incorporation of additives into the PLA fibres resulted, as expected, in the plasticization of the material, leading to decreased glass transition temperatures. This behaviour is typical of certain compounds such as polyethylene glycol (Li \& Huneault, 2007), and indicates that the additive contributed to an increase in the mobility of PLA chains. This was probably due to matrix-filler interactions, which lead to the formation of a less packed crystalline structure.

The addition of gelatin reduced both the cold crystallization and the glass transition temperature. The increased chain mobility induced by the addition of gelatin might be responsible for the increased ability of PLA chains to crystallize upon heating (Li \& Huneault, 2007). The incorporation of the antimicrobial agents 
induced a significant increase in the PLA crystallinity, although smaller or more defective crystals were obtained, as suggested by the lower melting temperatures.

The combination of gelatin and carvacrol led to fibres with increased crystallinity. However, as suggested by the lower melting temperature, the crystals were more defective, allowing for higher mobility of polymeric chains. When the incorporated antimicrobial was THC, the plasticization effect was more obvious and there was a reduction in the crystallinity of PLA. This different effect of carvacrol and THC is in agreement with the blow spinning solution properties and morphological characterizations. Carvacrol probably reduced the elastic behaviour of solutions and increased fibre crystallinity, whereas THC had the opposite effect.

From the first part of this study, BCNW acted as a nucleating agent when incorporated into pure PLA. However, addition of the nanofiller into the fibres containing antimicrobials did not result in more crystalline fibres when compared to neat PLA. Only the melting and cold crystallization temperatures were significantly reduced. Furthermore, the potential stiffening effect of BCNW could not be evidenced since the $\mathrm{T}_{\mathrm{g}}$ of BCNW-loaded fibres could not be detected in the DSC thermograms.

In conclusion, plasticization of fibres took place when adding gelatin, carvacrol or THC. Furthermore, carvacrol promoted crystallinity of PLA to a higher extent than THC. 
Table 6. DSC maximum of melting $\left(\mathrm{T}_{\mathrm{m}}\right)$, melting enthalpy $\left(\Delta \mathrm{H}_{\mathrm{m}}\right)$, cold crystallization temperature $\left(\mathrm{T}_{\mathrm{CC}}\right)$, cold crystallization enthalpy $\left(\Delta \mathrm{H}_{\mathrm{CC}}\right)$ and degree of crystallinity $\left(\mathrm{X}_{\mathrm{c}}\right)$ of blow spun PLA fibres with different solids content, obtained from the first heating run and glass transition temperature $\left(\mathrm{T}_{\mathrm{g} 2}\right)$, obtained from the second heating run.

\begin{tabular}{|c|c|c|c|c|c|c|}
\hline & $\mathrm{T}_{\mathrm{m}}\left({ }^{\circ} \mathrm{C}\right)$ & $\Delta \mathrm{H}_{\mathrm{m}}(\mathrm{J} / \mathrm{g})$ & $\mathrm{T}_{\mathrm{CC}}\left({ }^{\circ} \mathrm{C}\right)$ & $\Delta \mathrm{H}_{\mathrm{CC}}(\mathrm{J} / \mathrm{g})$ & $\mathrm{X}_{\mathrm{c}}(\%)$ & $\mathrm{T}_{\mathrm{g} 2}\left({ }^{\circ} \mathrm{C}\right)$ \\
\hline PLA & $173.2 \pm 3.6$ & $33.0 \pm 1.7$ & $84.1 \pm 0.1$ & $14.3 \pm 0.1$ & $20.1 \pm 1.9$ & $60.2 \pm 3.7$ \\
\hline PLA $+30 \%$ Gelatin & $168.7 \pm 4.4$ & $35.0 \pm 9.2$ & $73.8 \pm 4.4$ & $9.3 \pm 1.3$ & $27.6 \pm 8.6$ & $48.0 \pm 1.1$ \\
\hline PLA $+12 \%$ Carvacrol & $164.1 \pm 0.1$ & $36.9 \pm 2.6$ & $82.1 \pm 0.1$ & $8.2 \pm 3.3$ & $30.9 \pm 0.7$ & $37.7^{(*)}$ \\
\hline $\begin{array}{c}\text { PLA }+30 \% \text { Gelatin }+12 \% \\
\text { Carvacrol }\end{array}$ & $163.9 \pm 2.4$ & $41.1 \pm 4.0$ & $78.4 \pm 0.3$ & $8.8 \pm 6.4$ & $34.7 \pm 11.2$ & $31.4^{(*)}$ \\
\hline $\begin{array}{l}\text { PLA }+30 \% \text { Gelatin }+12 \% \\
\text { Carvacrol }+15 \% \text { BCNW }\end{array}$ & $164.6 \pm 1.2$ & $30.8 \pm 0.6$ & $71.5 \pm 0.7$ & $7.0 \pm 1.6$ & $25.5 \pm 2.3$ & $---{ }^{(*)}$ \\
\hline $\mathrm{PLA}+2 \% \mathrm{THC}$ & $166.0 \pm 5.2$ & $37.2 \pm 6.5$ & $87.7 \pm 0.9$ & $10.9 \pm 8.0$ & $28.2 \pm 0.6$ & $39.8 \pm 1.1$ \\
\hline PLA $+30 \%$ Gelatin $+2 \%$ THC & $158.9 \pm 1.9$ & $23.4 \pm 0.7$ & $85.1 \pm 0.7$ & $12.3 \pm 2.6$ & $12.0 \pm 3.3$ & $29.6 \pm 4.3$ \\
\hline $\begin{array}{c}\text { PLA }+30 \% \text { Gelatin }+2 \% \\
\text { THC }+15 \% \text { BCNW }\end{array}$ & $161.5 \pm 2.4$ & $21.0 \pm 0.6$ & $79.5 \pm 2.2$ & $8.1 \pm 3.8$ & $13.8 \pm 4.8$ & $--{ }^{(*)}$ \\
\hline
\end{tabular}

${ }^{(*)} \mathrm{T}_{\mathrm{g}}$ was very weak or it could not be detected in DSC thermograms. 
Results from TGA analyses are summarized in Table 7. The incorporation of gelatin, carvacrol or THC significantly increased the thermal stability of PLA fibres, which might be related to the PLA crystallinity increase detected by DSC analyses. Previous studies also found that essential oils were able to increase the thermal stability of pure gelatin films due to the development of strong interactions between the matrix and the additives (Ahmad et al., 2012). The combination of gelatin and the antimicrobial agents within the fibres slightly reduced the thermal stability of the material as compared to PLA-gelatin or PLA-antimicrobial agent fibres. However, the thermal stability was still higher than that of pure PLA. Further incorporation of BCNW into the samples did not reduce thermal stability of the material. In the case of carvacrol-loaded fibres, a shoulder appeared at around $300^{\circ} \mathrm{C}$ and the main degradation peak became narrower, whereas this effect was not observed for THC-loaded fibres. It might be possible that a phase separation between the hydrophobic PLA-carvacrol domains and the hydrophilic gelatin$\mathrm{BCNW}$ regions could be taking place to a certain extent, thus leading to different degradation steps. Furthermore, incorporation of gelatin, either alone or combined with other fillers, resulted in a greater amount of residue remaining at $490^{\circ} \mathrm{C}$. This was probably due to the fact that the denaturing of gelatin does not produce volatile substances (Chakrapani et al., 2012). 
Table 7. TGA parameters of PLA blow spun hybrid fibres: maximum of the weight loss first derivate $\left(\mathrm{T}_{\mathrm{D}}\right)$, peak onset and residue at $490^{\circ} \mathrm{C}$.

\begin{tabular}{|c|c|c|c|}
\cline { 2 - 4 } \multicolumn{1}{c|}{} & Onset $\left({ }^{\circ} \mathrm{C}\right)$ & $\mathrm{T}_{\mathrm{D}}\left({ }^{\circ} \mathrm{C}\right)$ & $\begin{array}{c}\text { Residue at } 490^{\circ} \mathrm{C} \\
(\%)\end{array}$ \\
\hline PLA & $288.5 \pm 24.8$ & $343.9 \pm 3.9$ & $1.0 \pm 0.2$ \\
\hline PLA+30\% Gelatin & $326.3 \pm 0.1$ & $351.3 \pm 0.3$ & $5.4 \pm 0.3$ \\
\hline PLA+12\% Carvacrol & $323.5 \pm 0.5$ & $352.7 \pm 1.1$ & $0.3 \pm 0.2$ \\
\hline PLA+30\% Gelatin+12\% Carvacrol & $318.8 \pm 11.3$ & $346.0 \pm 5.2$ & $6.2 \pm 0.1$ \\
\hline $\begin{array}{c}\text { PLA+30\% Gelatin+12\% } \\
\text { Carvacrol+15\%BCNW }\end{array}$ & $331.4 \pm 1.0$ & $356.4 \pm 2.1$ & $3.4 \pm 0.1$ \\
\hline PLA+2\% THC & $336.9 \pm 0.2$ & $362.6 \pm 0.9$ & $1.9 \pm 0.0$ \\
\hline PLA+30\% Gelatin+2\% THC & $329.1 \pm 0.4$ & $356.6 \pm 1.5$ & $6.6 \pm 0.2$ \\
\hline PLA+30\% Gelatin+2\% & $327.6 \pm 1.1$ & $353.6 \pm 2.0$ & $6.9 \pm 0.5$ \\
\hline THC+15\%BCNW & & & \\
\hline
\end{tabular}



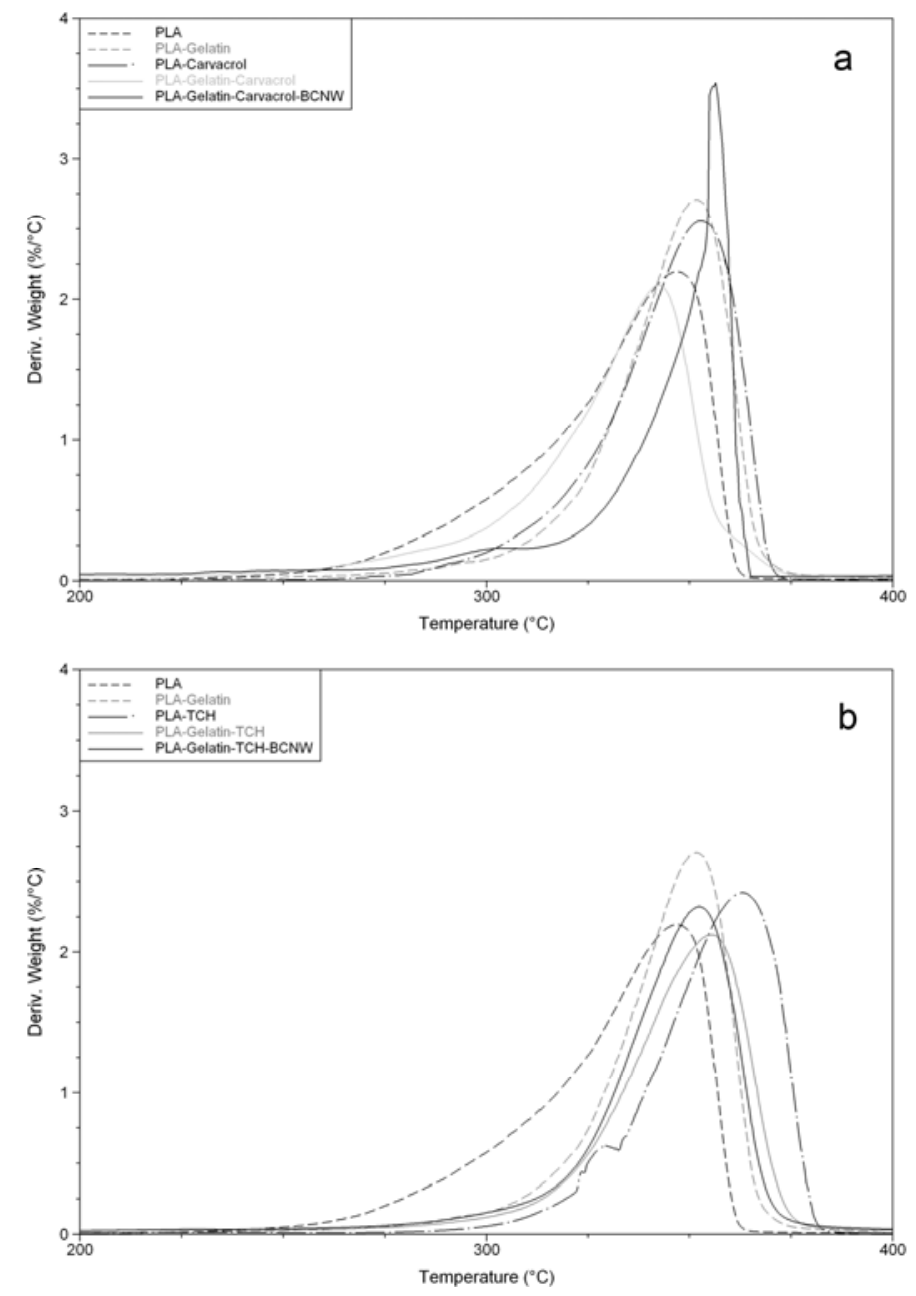

Figure 5. Derivative thermogravimetric curves for PLA and (a) hybrid carvacrolloaded fibres and (b) hybrid THC-loaded fibres.

The main objective of the second part of this study was to develop PLA blow spun fibres with biocide properties. The interest of non-woven mats lies in the fact that they provide a large surface area, which may result in higher release percentages as compared to conventional cast films in various applications such as coatings, filters and medical devices (Kenawy et al., 2002). For that purpose, small 
pieces of the materials were subjected to overlay tests to determine their inhibition against Listeria monocytogenes. From Table 8, PLA fibres loaded with the antimicrobial agents presented low or no inhibitory effect. Previous studies showed that the release of THC from PLA electrospun fibres was relatively low compared to other polymers since the partial crystallinity of PLA impeded penetration of moisture into the fibre structure to facilitate drug release (Kenawy et al., 2002). As deduced from Table 8, by incorporating gelatin into the system, it was possible to produce carvacrol-loaded fibres with antimicrobial effect and to greatly increase the antimicrobial effect of THC-loaded fibres. Other works confirmed that the modification of PLA with hydrophilic agents (Matsumoto et al., 1999) or the increase of the hydrophilic character of PLA by reducing its molecular weight (Matsumoto et al., 1999), improved the release of active components incorporated into the polymeric matrix. In the present study, the incorporation of a hydrophilic material, such as gelatin, may be increasing the amount of moisture sorbed into the fibres. This could disrupt the crystalline structure of PLA and enhance the release of the antimicrobial agents.

The incorporation of BCNW into the fibres had a different effect depending on the nature of the antimicrobial agent. The antimicrobial effect was enhanced for the hydrophilic THC, but reduced for the hydrophobic carvacrol, just as shown in Figure $6 \mathrm{a}$ and Figure $6 \mathrm{~b}$, respectively. It has been previously reported that the incorporation of cellulose nanowhiskers into PLA fibres increased the release of a non-ionic dye into water by a water-sorption induced release mechanism (Xiang et al., 2013). From TGA results, incorporating BCNW into the carvacrol-loaded fibres might lead to stronger interactions between gelatin and $\mathrm{BCNW}$, resulting in phase separation between the hydrophilic and hydrophobic domains within the fibres. In that case, moisture would be selectively sorbed into the gelatin-BCNW 
domains, limiting the hydrolytic degradation of PLA and, thus, the release of carvacrol would not be favoured.

For all compositions studied, THC had higher antimicrobial effect than carvacrol. This again might be related to the hydrophilic character of THC, which could be more easily released when moisture was sorbed into the fibres.
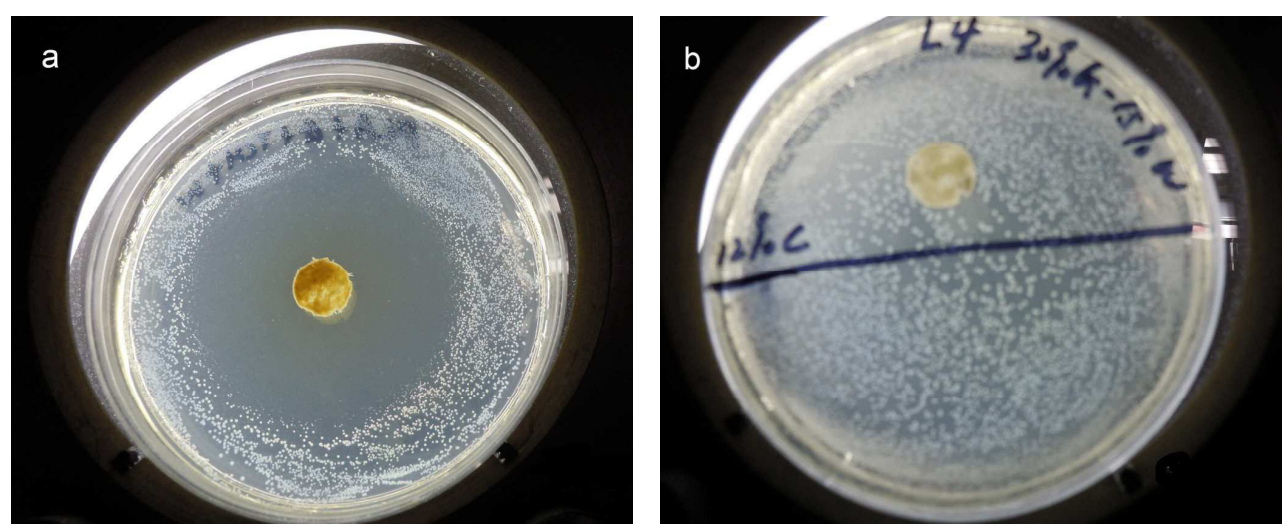

Figure 6. Inhibitory zone of hybrid PLA blow spun fibres: (a) PLA $+30 \%$ Gelatin $+2 \%$ THC $+15 \%$ BCNW and (b) PLA $+30 \%$ Gelatin $+12 \%$ Carvacrol $+15 \% \mathrm{BCNW}$. 
Table 8. Antimicrobial properties of hybrid blow spun fibres against Listeria

\begin{tabular}{|c|c|c|c|}
\cline { 2 - 4 } \multicolumn{1}{c|}{} & $\begin{array}{c}\text { Average film } \\
\text { weight }(\mathrm{g})\end{array}$ & $\begin{array}{c}\text { Inhibitory effect } \\
\text { under film }\end{array}$ & $\begin{array}{c}\text { Average inhibitory } \\
\text { zone }\left(\mathrm{mm}^{2}\right)\end{array}$ \\
\hline PLA & 0.02 & - & 0.00 \\
\hline PLA+12\% Carvacrol & 0.04 & - & 0.00 \\
\hline $\begin{array}{c}\text { PLA+30\% Gelatin+12\% } \\
\text { Carvacrol }\end{array}$ & 0.02 & + & 35.9 \\
\hline $\begin{array}{c}\text { PLA+30\% Gelatin+12\% } \\
\text { Carvacrol+15\%BCNW }\end{array}$ & 0.02 & + & 0.00 \\
\hline PLA+2\% THC & 0.02 & + & 43.1 \\
\hline PLA+30\% Gelatin+2\% THC & 0.03 & + & 1660.0 \\
\hline PLA+30\% Gelatin+2\% & 0.03 & + & 1906.4 \\
\hline THC+15\%BCNW & & & \\
\hline
\end{tabular}

To confirm the different water affinity of the hybrid fibres and the possible effect of sorbed moisture on the release of the antimicrobials, water sorption experiments were carried out. Figure 7 shows the amount of sorbed water for each sample when reaching the equilibrium. The first thing to comment is that the amount of water sorbed into the fibres was significantly higher for all the samples containing THC as compared to the fibres loaded with carvacrol, thus confirming the more hydrophilic character of THC which even incorporated at low loadings had a greater effect on the water sorption of the fibres. This may also explain why THC loaded fibres presented a stronger antimicrobial effect, since sorbed moisture 
could promote to a higher extent the release of this substance due to its higher water affinity. In addition, the stronger antimicrobial effect of the fibres observed when incorporating gelatin was clearly related to the notable increase of the water uptake, which may be leading to the distortion of the PLA crystalline structure or to the plasticization of the PLA amorphous domains where the antimicrobial agents are probably located. The incorporation of BCNW further increases the amount of sorbed moisture, although this effect was only favourable for the fibres loaded with THC, as pointed out by the overlay tests.

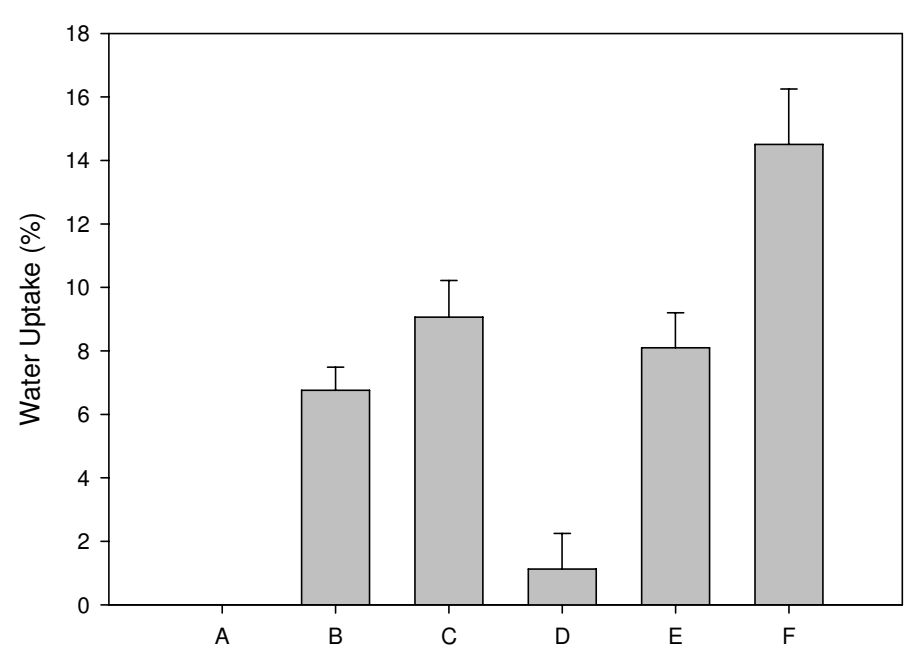

Figure 7. Water uptake values for the PLA blow spun fibres containing antimicrobial agents: (A) PLA+12\% Carvacrol; (B) PLA $+30 \%$ Gelatin $+12 \%$ Carvacrol; (C) PLA $+30 \%$ Gelatin $+12 \%$ Carvacrol $+15 \% \mathrm{BCNW}$; (D) PLA $+2 \%$

THC; (E) PLA $+30 \%$ Gelatin $+2 \%$ THC and (F) PLA $+30 \%$ Gelatin $+2 \%$ $\mathrm{THC}+15 \% \mathrm{BCNW}$. 
From the antimicrobial results, the system containing gelatin, THC and BCNW would be the optimal one. This material was relatively easy to produce by solution blow spinning and had a uniform morphology and good thermal stability, making it suitable for use in applications such as coatings, food packaging pads, textiles or filters.

\section{CONCLUSIONS}

This study demonstrated that it is possible to produce hybrid PLA fibres with antimicrobial properties by incorporating additives and optimizing the formulation of the blow spinning solutions.

In the first part of the study, different loadings of BCNW were incorporated into PLA fibres. Hybrid fibres presented increased crystallinity and thermal stability compared to pure PLA. Additionally, the viscosity and surface tension of solutions increased with higher solids content and higher BCNW concentration, which affected the morphology of the obtained fibres. It seems that BCNW reduced the ability of solutions to form fibres and therefore, their concentration should be restricted to a maximum of $30 \mathrm{wt} .-\%$. In terms of uniform morphology and ease of processability, solutions with $6 \mathrm{wt} .-\%$ total solids and $15 \mathrm{wt} .-\% \mathrm{BCNW}$ were chosen as the optimal ones.

In the second part of this study, fibres with antimicrobial properties were produced by incorporating carvacrol or THC into the system. From the overlay tests, the addition of gelatin was critical for the release of antimicrobial agents, since it favoured water sorption into the fibres, thus facilitating the release of the substances. In general, THC fibres had a higher antimicrobial effect than carvacrol 
fibres, which was probably due to the higher affinity of THC with moisture sorbed into the fibres. This hydrophilic character of THC might also be the cause for stronger antimicrobial effect when highly hydrophilic BCNW were incorporated into THC-loaded fibres. Furthermore, the incorporation of gelatin greatly increased the viscosity of solutions and consequently, less uniform fibres were obtained. Fibres containing THC presented more uniform morphologies than those containing carvacrol, possibly due to the higher compatibility of THC with the solvent. Therefore, solution blow spinning has been proven to be an efficient technique to produce hybrid fibres containing reinforcing and/or antimicrobial agents, thus presenting an alternative to the electrospinning process with higher production rates and lower manufacturing costs. 


\section{REFERENCES}

Ahmad, M., Benjakul, S., Prodpran, T., \& Agustini, T. W. (2012). Physicomechanical and antimicrobial properties of gelatin film from the skin of unicorn leatherjacket incorporated with essential oils. Food Hydrocolloids, 28(1), 189-199.

Avena-Bustillos, R. J., Olsen, C. W., Olson, D. A., Chiou, B., Yee, E., Bechtel, P. J., \& McHugh, T. H. (2006). Water vapor permeability of mammalian and fish gelatin films. Journal of Food Science, 71(4), E202-E207.

Buschle-Diller, G., Cooper, J., Xie, Z., Wu, Y., Waldrup, J., \& Ren, X. (2007). Release of antibiotics from electrospun bicomponent fibers. Cellulose, 14(6), 553562.

Cai, Z. X., Mo, X. M., Zhang, K. H., Fan, L. P., Yin, A. L., He, C. L., \& Wang, H. S. (2010). Fabrication of chitosan/silk fibroin composite nanofibers for Wounddressing Applications. International Journal of Molecular Sciences, 11(9), 35293539 .

Chakrapani, V. Y., Gnanamani, A., Giridev, V. R., Madhusoothanan, M., \& Sekaran, G. (2012). Electrospinning of type I collagen and PCL nanofibers using acetic acid. Journal of Applied Polymer Science.

Giménez, B., Gómez-Guillén, M. C., López-Caballero, M. E., Gómez-Estaca, J., \& Montero, P. (2012). Role of sepiolite in the release of active compounds from gelatin-egg white films. Food Hydrocolloids, 27(2), 475-486.

Habibi, Y., Lucia, L. A., \& Rojas, O. J. (2010). Cellulose nanocrystals: Chemistry, self-assembly, and applications. Chemical Reviews, 110(6), 3479-3500.

Herrera, N. V., Mathew, A. P., Wang, L. Y., \& Oksman, K. (2011). Randomly oriented and aligned cellulose fibres reinforced with cellulose nanowhiskers, prepared by electrospinning. Plastics, Rubber and Composites, 40(2), 57-64.

Huang, J., Liu, L., \& Yao, J. (2011). Electrospinning of Bombyx mori silk fibroin nanofiber mats reinforced by cellulose nanowhiskers. Fibers and Polymers, 12(8), 1002-1006. 
Jeong, S. I., Krebs, M. D., Bonino, C. A., Khan, S. A., \& Alsberg, E. (2010). Electrospun alginate nanofibers with controlled cell adhesion for tissue engineering. Macromolecular Bioscience, 10(8), 934-943.

Jiang, L., Morelius, E., Zhang, J., Wolcott, M., \& Holbery, J. (2008). Study of the poly(3-hydroxybutyrate-co-3-hydroxyvalerate)/cellulose nanowhisker composites prepared by solution casting and melt processing. Journal of Composite Materials, 42(24), 2629-2645.

Kenawy, E.-R., Bowlin, G. L., Mansfield, K., Layman, J., Simpson, D. G., Sanders, E. H., \& Wnek, G. E. (2002). Release of tetracycline hydrochloride from electrospun poly(ethylene-co-vinylacetate), poly(lactic acid), and a blend. Journal of Controlled Release, 81(1-2), 57-64.

Kim, E. S., Kim, S. H., \& Lee, C. H. (2010). Electrospinning of polylactide fibers containing silver nanoparticles. Macromolecular Research, 18(3), 215-221.

Kim, H. W., Lee, H. H., \& Knowles, J. C. (2006). Electrospinning biomedical nanocomposite fibers of hydroxyapaite/ poly(lactic acid) for bone regeneration. Journal of Biomedical Materials Research - Part A, 79(3), 643-649.

Li, H., \& Huneault, M. A. (2007). Effect of nucleation and plasticization on the crystallization of poly(lactic acid). Polymer, 48(23), 6855-6866.

Liu, D., Yuan, X., \& Bhattacharyya, D. (2012). The effects of cellulose nanowhiskers on electrospun poly (lactic acid) nanofibres. Journal of Materials Science, 47(7), 3159-3165.

Liu, H., Kameoka, J., Czaplewski, D. A., \& Craighead, H. G. (2004). Polymeric nanowire chemical sensor. Nano Letters, 4(4), 671-675.

Liu, X., Dever, M., Fair, N., \& Benson, R. S. (1997). Thermal and mechanical properties of poly(lactic acid) and poly(ethylene/butylene succinate) blends. Journal of Environmental Polymer Degradation, 5(4), 225-235.

Lunt, J. (1998). Large-scale production, properties and commercial applications of poly lactic acid polymers. Polymer Degradation and Stability, 59(1-3), 145-152.

Luong-Van, E., Grøndahl, L., Chua, K. N., Leong, K. W., Nurcombe, V., \& Cool, S. M. (2006). Controlled release of heparin from poly( $\varepsilon$-caprolactone) electrospun fibers. Biomaterials, 27(9), 2042-2050. 
Martínez-Sanz, M., Lopez-Rubio, A., \& Lagaron, J. (2011a). Optimization of the nanofabrication by acid hydrolysis of bacterial cellulose nanowhiskers. Carbohydrate Polymers, 85(1), 228-236.

Martínez-Sanz, M., Olsson, R. T., Lopez-Rubio, A., \& Lagaron, J. M. (2011b). Development of electrospun EVOH fibres reinforced with bacterial cellulose nanowhiskers. Part I: Characterization and method optimization. Cellulose, 18(2), 335-347.

Martínez-Sanz, M., Lopez-Rubio, A., \& Lagaron, J. M. (2012). Optimization of the dispersion of unmodified bacterial cellulose nanowhiskers into polylactide via melt compounding to significantly enhance barrier and mechanical properties. Biomacromolecules, 13(11), 3887-3899.

Martínez-Sanz, M. L.-R., A.; Lagaron, J. (2013a). Nanocomposites of ethylene vinyl alcohol copolymer with thermally resistant cellulose nanowhiskers by melt compounding (I): Morphology and thermal properties. Journal of Applied Polymer Science, 128(5), 2666-2678.

Martínez-Sanz, M., Lopez-Rubio, A., \& Lagaron, J. M. (2013b). Dispersing bacterial cellulose in polylactides via electrohydrodynamic processing. Journal of Polymers and the Environment, under review.

Martínez-Sanz, M., Abdelwahab, M. A., Williams, T.G., Lopez-Rubio, A., Lagaron, J. M., Chiellini, E., Orts, W. J., \& Imam, S. H. (2013c). Incorporation of poly(glycidylmethacrylate) grafted bacterial cellulose nanowhiskers in poly(lactic acid) nanocomposites: improved barrier and mechanical properties. European Polymer Journal, under review.

Matsumoto, J., Nakada, Y., Sakurai, K., Nakamura, T., \& Takahashi, Y. (1999). Preparation of nanoparticles consisted of poly(L-lactide)-poly(ethylene glycol)poly(L-lactide) and their evaluation in vitro. International Journal of Pharmaceutics, 185(1), 93-101.

Medeiros, E. S., Glenn, G. M., Klamczynski, A. P., Orts, W. J., \& Mattoso, L. H. C. (2009). Solution blow spinning: A new method to produce micro- and nanofibers from polymer solutions. Journal of Applied Polymer Science, 113(4), 2322-2330. 
Oliveira, J. E., Medeiros, E. S., Cardozo, L., Voll, F., Madureira, E. H., Mattoso, L. H. C., \& Assis, O. B. G. (2012a). Development of poly(lactic acid) nanostructured membranes for the controlled delivery of progesterone to livestock animals. Materials Science and Engineering C, 33(2), 844-849.

Oliveira, J. E., Moraes, E. A., Costa, R. G. F., Afonso, A. S., Mattoso, L. H. C., Orts, W. J., \& Medeiros, E. S. (2011). Nano and submicrometric fibers of poly(D, L -lactide) obtained by solution blow spinning: Process and solution variables. Journal of Applied Polymer Science, 122(5), 3396-3405.

Oliveira, J. E., Zucolotto, V., Mattoso, L. H. C., \& Medeiros, E. S. (2012b). Multiwalled carbon nanotubes and poly(lactic acid) nanocomposite fibrous membranes prepared by solution blow spinning. Journal of Nanoscience and Nanotechnology, 12(3), 2733-2741.

Olsson, R. T., Kraemer, R., Lopez-Rubio, A., Torres-Giner, S., Ocio, M. J., \& Lagaron, J. M. (2010). Extraction of microfibrils from bacterial cellulose networks for electrospinning of anisotropic biohybrid fiber yarns. Macromolecules, 43(9), 4201-4209.

Peresin, M. S., Habibi, Y., Zoppe, J. O., Pawlak, J. J., \& Rojas, O. J. (2010). Nanofiber composites of polyvinyl alcohol and cellulose nanocrystals: Manufacture and characterization. Biomacromolecules, 11(3), 674-681.

Ramos, M., Jiménez, A., Peltzer, M., \& Garrigós, M. C. (2012). Characterization and antimicrobial activity studies of polypropylene films with carvacrol and thymol for active packaging. Journal of Food Engineering, 109(3), 513-519.

Rojas, O. J., Montero, G. A., \& Habibi, Y. (2009). Electrospun nanocomposites from polystyrene loaded with cellulose nanowhiskers. Journal of Applied Polymer Science, 113(2), 927-935.

Schreuder-Gibson, H., Gibson, P., Senecal, K., Sennett, M., Walker, J., Yeomans, W., Ziegler, D., \& Tsai, P. P. (2002). Protective textile materials based on electrospun nanofibers. Journal of Advanced Materials, 34(3), 44-55.

Taepaiboon, P., Rungsardthong, U., \& Supaphol, P. (2006). Drug-loaded electrospun mats of poly(vinyl alcohol) fibres and their release characteristics of four model drugs. Nanotechnology, 17(9), 2317-2329. 
Torres-Giner, S., Martinez-Abad, A., Gimeno-Alcañiz, J. V., Ocio, M. J., \& Lagaron, J. M. (2012). Controlled delivery of gentamicin antibiotic from bioactive electrospun polylactide-based ultrathin fibers. Advanced Engineering Materials, 14(4), B112-B122.

Tungprapa, S., Jangchud, I., \& Supaphol, P. (2007). Release characteristics of four model drugs from drug-loaded electrospunÂ cellulose acetate fiber mats. Polymer, 48(17), 5030-5041.

Vega-Lugo, A. C., \& Lim, L. T. (2009). Controlled release of allyl isothiocyanate using soy protein and poly(lactic acid) electrospun fibers. Food Research International, 42(8), 933-940.

Xiang, C., Joo, Y. L., \& Frey, M. W. (2009). Nanocomposite fibers electrospun from poly(Lactic Acid)/cellulose nanocrystals. Journal of Biobased Materials and Bioenergy, 3(2), 147-155.

Xiang, C., Taylor, A. G., Hinestroza, J. P., \& Frey, M. W. (2013). Controlled release of nonionic compounds from poly(lactic acid)/cellulose nanocrystal nanocomposite fibers. Journal of Applied Polymer Science, 127(1), 79-86.

Xu, X., Chen, X., Liu, A., Hong, Z., \& Jing, X. (2007). Electrospun poly(1-lactide)grafted hydroxyapatite/poly(l-lactide) nanocomposite fibers. European Polymer Journal, 43(8), 3187-3196.

Xu, X., Zhong, W., Zhou, S., Trajtman, A., \& Alfa, M. (2010). Electrospun PEGPLA nanofibrous membrane for sustained Release of hydrophilic antibiotics. Journal of Applied Polymer Science, 118(1), 588-595.

Yu, J. H., Fridrikh, S. V., \& Rutledge, G. C. (2006). The role of elasticity in the formation of electrospun fibers. Polymer, 47(13), 4789-4797. 


\title{
Chapter XI
}

\section{CHARACTERIZATION OF POLYHYDROXYALKANOATES SYNTHESIZED FROM MICROBIAL MIXED CULTURES AND OF THEIR NANOBIOCOMPOSITES WITH BACTERIAL CELLULOSE NANOWHISKERS}

\author{
New Biotechnology, under review
}

Marta Martínez Sanz ${ }^{1}$, Marianna Villano ${ }^{2}$, Catarina Oliveira ${ }^{3,4}$, Maria G.E. Albuquerque $^{3,4}$, Mauro Majone ${ }^{2}$, Maria Reis ${ }^{3,4}$, Amparo López Rubio ${ }^{1}$, José María Lagarón ${ }^{\prime}$

${ }^{1}$ Novel Materials and Nanotechnology Group, IATA, CSIC. Avd. Agustín Escardino, 7, 46980. Paterna, Valencia. Spain

${ }^{2}$ Department of Chemistry, Sapienza University of Rome, P.le Aldo Moro 5, 00185 Rome, (Italy)

${ }^{3}$ Biochemical Engineering Laboratory, Instituto de Biologia Experimental e Tecnológica, Lisbon (Portugal)

${ }^{4}$ CQFB-Requimte, FCT-UNL, Campus da Caparica, 2829-516 Caparica (Portugal) 



\begin{abstract}
The present work reports on the production and characterization of polyhydroxyalkanoates (PHAs) with different valerate contents, which were synthesized from microbial mixed cultures, and the subsequent development of nanocomposites incorporating bacterial cellulose nanowhiskers (BCNW) via solution casting processing. The characterization of the pure biopolyesters showed that the properties of PHAs may be strongly modified by varying the valerate ratio in the poly(3-hydroxybutyrate-co-3-hydroxyvalerate) (PHBV) copolymer, as expected. Increasing the valerate content was seen to greatly decrease the melting temperature and enthalpy of the material, as well as its rigidity and stiffness, resulting in a more ductile behaviour. Additionally, the higher valerate PHA displayed higher permeability to water and oxygen and higher moisture sensitivity. Subsequently, BCNW were incorporated into both PHA grades, achieving a high level of dispersion for a 1 wt.-\% loading, whereas some agglomeration took place for $3 \mathrm{wt} .-\%$ BCNW. As evidenced by DSC analyses, BCNW presented a nucleating effect on the PHA matrixes. BCNW also increased the thermal stability of the polymeric matrixes when properly dispersed due to strong matrix-filler interactions. Barrier properties were seen to depend on relative humidity and improved at low nanofiller loadings and low relative humidity.
\end{abstract}

Keywords: Polyhydroxyalkanoates, bacterial cellulose, nanowhiskers, nanocomposites, barrier properties. 


\section{INTRODUCTION}

Over the last decades, as a result of the growing environmental awareness, a great interest has been focused on the development and optimization of sustainable biodegradable polymeric materials produced from renewable resources, especially within the packaging applications field. Amongst the wide variety of biopolymers which have been developed and studied during the last years, biopolyesters such as polylactic acid (PLA) and polyhydroxyalkanoates (PHAs) have attracted special interest since they are synthesized from renewable resources and present promising properties.

PHAs are a family of biopolyesters produced by a wide variety of bacteria as carbon and energy storage materials (Lundgren et al., 1965). Within this range of materials, the homopolymer poly(3-hydroxybutyrate) (P3HB) has been more extensively studied since it presents mechanical properties similar to those of conventional petroleum-based polymers. In addition, this material possesses a relatively high melting and glass transition temperature (Choi \& Park, 2004; Mitomo et al., 1999), as well as great stiffness since it possesses a relatively high crystallinity (Barham et al., 1984). Nevertheless, it presents some drawbacks, such as excessive brittleness and low thermal stability, making it unstable during melt processing and limiting its applicability. To overcome these issues, two main approaches have been typically developed. The first one consists in blending PHB with other polymers such as poly(vinyl alcohol) (PVA) (Yoshie et al., 1995), poly(methyl acrylate) (PMA) (An et al., 2000) or poly(ethylene oxide) (PEO) (You et al., 2003). In that case, the second polymer must be miscible with PHB and it should be preferably biodegradable. As an alternative, the properties of the homopolymer can be modified by incorporating different monomer types during bacterial fermentation. Copolymers of hydroxybutyrate (HB) with 
hydroxyvalerate (HV), i.e. PHBV, present lower crystallinity for HV contents up to $40-50 \mathrm{~mol} \%$ (Scandola et al., 1992; Serafim et al., 2008; Wang et al., 2001) and therefore, decreased stiffness and brittleness. Additionally, the incorporation of hydroxyvalerate units results in reduced melting temperature without reducing the thermal stability of the material (Chen \& Wang, 2002; Feng et al., 2002), hence widening the processing window of the material. On the other hand, a decrease on the crystallinity is known to impair the barrier properties of polymeric materials (Drieskens et al., 2009), which might be a disadvantage for the use of PHBV in packaging applications.

The industrial production of PHAs has been typically done by using pure microbial cultures. Nevertheless, this process involves high operational costs which account for nearly $11 \%$ of total production costs (Moita \& Lemos, 2012). The use of expensive pure substrates and the requirement of sterile conditions and extensive reactor maintenance are the main causes for these high operational costs. During the last years, extensive research has been carried out in order to decrease costs by increasing the production volumes and using cheaper substrates. In this context, the use of microbial mixed cultures is an interesting alternative. The selection of microorganisms for microbial mixed cultures is done on the basis of their high capacity for PHA storage. This is done by imposing alternate carbon substrate availability conditions (also known as feast and famine conditions). Since several PHA producing microorganisms which can adapt to changes in the substrate are selected, it is possible to use cheap mixed substrates or even wastewaters. In addition, large scale fermentations may be produced without the need for sterile conditions.

The incorporation of nanoparticles, such as nanoclays and cellulose nanocrystals, is an efficient strategy to tailor the properties of polymeric materials 
and, consequently, many works have already reported on the production of PHBV nanocomposites (Jiang et al., 2008b; Sanchez-Garcia \& Lagaron, 2010; Ten et al., 2012; Ten et al., 2010; Yu et al., 2012). The reinforcement of PHBV with cellulose nanowhiskers (CNW) may present particular interest since it would allow the development of fully biodegradable nanocomposites produced from renewable resources. CNW are typically produced by applying an acid hydrolysis process which leads to preferential digestion of cellulose amorphous domains. The native cellulose is, in most cases, extracted from vegetal resources, such as cotton, flax or hemp, since it is the major cell wall component. However, it can also be extracted from algae and marine animals, such as tunicin, as well as synthesized by some bacterial species, such as Gluconacetobacter xylinus. These bacteria are able to produce a layer of nearly pure bacterial cellulose (BC) in the liquid/air interface in a culture medium rich in polysaccharides. Bacterial cellulose presents several advantages over other cellulosic resources, such as its high purity and crystallinity, resulting in bacterial cellulose nanowhiskers (BCNW) with a highly crystalline structure (Martínez-Sanz et al., 2011a) and high aspect ratio (De Souza Lima \& Borsali, 2004; Hirai et al., 2009; Martínez-Sanz et al., 2011a).

To the best of our knowledge, there are no previous works which report on the use of BCNW as nanofiller in PHBV nanocomposites. In addition, there is very scarce literature on the characterization of PHBV grades produced by microbial mixed cultures. The mechanical properties of several PHBV grades with HV contents ranging from $12 \mathrm{~mol} \%$ to $72 \mathrm{~mol} \%$ have been very recently evaluated (Arcos-Hernández et al., 2013), however the barrier properties of these materials have not been reported previously. However, the reinforcement of commercial PHBV grades with plant-derived $\mathrm{CNW}$ has been already reported in several studies (Jiang et al., 2008b; Ten et al., 2012; Ten et al., 2010; Yu et al., 2012). 
Due to the highly hydrophilic character of cellulose nanocrystals, they present low compatibility with PHAs and, therefore, attempts to prepare nanocomposites by melt compounding resulted in high levels of nanofiller agglomeration (Jiang et al., 2008b). In contrast, it was possible to attain a good level of dispersion for nanocomposites prepared by solution casting with loadings of up to $2.3 \mathrm{wt} . \mathrm{\%} \%$ CNW (Ten et al., 2012) and up to 5 wt.-\% CNW containing ca. 30 wt.-\% PEG as compatibilizer (Jiang et al., 2008b) and the incorporation of CNW gave rise to improved mechanical properties. Nonetheless, these previous works focused on the mechanical performance of nanocomposites and did not investigate the effect on barrier properties.

The present work reports on the production and characterization of PHA nanocomposites incorporating BCNW. PHAs with two different valerate contents were produced by microbial mixed cultures and nanocomposites were generated by solution casting. The effects of both valerate content and BCNW addition on the morphology, thermal, mechanical and barrier properties were investigated throughout this work. 


\section{MATERIALS AND METHODS}

\subsection{Materials}

Two different polyhydroxyalkanoate (PHA) grades, with different valerate (HV) contents, were used throughout this study. PHBV8 $(8.4 \mathrm{~mol} \%$ valerate content) and PHBV44 (44 mol\% valerate content) were synthesized by using mixed microbial cultures as specified below.

Sulphuric acid $96 \%$, acetone $99.5 \%$ and chloroform $99 \%$ were purchased from Panreac (Barcelona, Spain).

\subsection{Synthesis of PHAs}

PHAs were produced by using a lab-scale multi-stage process, consisting of a sequencing batch reactor (SBR), a PHA-accumulating reactor, and a final polymer extraction stage. The SBR operated under "feast and famine" conditions in order to select mixed microbial cultures in microorganisms with high storage ability. This enriched microbial consortium was fed with synthetic volatile fatty acid (VFA) mixtures in a fed batch reactor to produce PHA.

For the production of low valerate PHA, the SBR was fed with a mixture of acetic $(0.87 \mathrm{C} \mathrm{mol} / \mathrm{C} \mathrm{mol}$ VFA $)$ and propionic $(0.13 \mathrm{C} \mathrm{mol} / \mathrm{C}$ mol VFA $)$ acid at an organic load rate $(\mathrm{OLR})$ of $260 \mathrm{C} \mathrm{mmol} / \mathrm{L} \cdot \mathrm{d}$. The length of the SBR cycle was 6 hours, each cycle consisting of an initial feed phase (10 minutes), a first reaction phase (70 minutes), a withdrawal phase of the mixed liquor (1 minute), and a second reaction phase (279 minutes). All the other SBR operating conditions were as described elsewhere (Villano et al., 2010). The biomass discharged from the SBR was sent to the PHA-accumulating reactor $(0.3 \mathrm{~L}$ working volume), operated 
in batch mode with each batch lasting 6 hours. Simultaneously with the discharge of the biomass from the SBR, the batch reactor was fed for 30 minutes with acetic and propionic acid (with same composition as above) at an overall OLR of $890 \mathrm{C}$ $\mathrm{mmol} / \mathrm{L} \mathrm{d}$. This very high OLR, along with the lack of nitrogen, were used as a tool to enhance PHA accumulation.

After accumulation, a PHA cell content of around 46 (wt.-\%) was obtained and the polymer was extracted by means of a chemical digestion method, which consists of using a chemical solution to disrupt the cell wall and release the intracellular accumulated PHA, while limiting polymer degradation. Therefore, after 6 hours of accumulation, the entire liquid volume of the batch reactor was automatically sent to the extraction reactor, mixed with the digestion solution (i.e., $\mathrm{NaClO}$ with $5 \% \mathrm{Cl}_{2}$ ), and centrifuged (30 min at $8600 \mathrm{rpm}$ ) in order to separate microbial cells from PHA granules. The obtained PHA was lyophilized for around 96 hours and then dissolved in chloroform $(30-40 \mathrm{~mL}$ per grams of lyophilized biomass) at $37{ }^{\circ} \mathrm{C}$ for at least 3 days. Finally, the polymer rich solution was recovered by filtration and, after solvent evaporation, PHA was obtained in the form of thin films.

For the production of high valerate PHA, two fed-batch tests were carried out in $2 \mathrm{~L}$ reactors in order to produce a poly(3-hydroxybutyrate-co-3-hydroxyvalerate) copolymer using a mixed culture enriched in PHA accumulating microorganisms and a VFA mixture as precursors for PHA production. The culture selection was carried out in a SBR as described in a previous work (Albuquerque et al., 2010). Fed batch-reactors were inoculated at $3 \mathrm{~g} / \mathrm{L}$ VSS of this enriched culture and fed with a synthetic VFA mixture at a concentration of $24.6 \mathrm{~g} / \mathrm{L}$ of total VFAs $(1000 \mathrm{C}$ $\mathrm{mmol} / \mathrm{L}$ ) and a composition on $\mathrm{C} \mathrm{mol} / \mathrm{C}$ mol VFA of 0.3 Acetate; 0.2 Propionic acid; 0.3 Butyric acid and 0.2 Valeric acid. The feed was supplied through a feed- 
on-demand regime, which consisted of an initial pulse of $60 \mathrm{C} \mathrm{mmol} / \mathrm{L}$, followed by $\mathrm{pH}$ control using the VFA mixture as acid dosing solution. No nutrients were added during this storage phase. A PHA cell content of 50\% (wt.- $\%$ ) was attained and the polymer was extracted. In order to recover the polymer, a quenching step (by adding $2 \mathrm{M} \mathrm{HCl}$ ) was performed directly on the mixed liquor, followed by centrifugation (10 min at $9000 \mathrm{rpm}$ ). The recovered biomass was washed and then lyophilized for $24 \mathrm{~h}$. Polymer was extracted from the freeze-dried biomass by being emulsified in chloroform (approximately $50-100 \mathrm{~mL} \mathrm{CHCl}_{3}$ for each $2 \mathrm{~g}$ biomass) and left to dissolve for a period of $72 \mathrm{~h}$ at $37{ }^{\circ} \mathrm{C}$ in a closed bottle. The polymerrich solution was recovered by filtration (to remove biomass residues) and solvent was evaporated overnight, thus forming polymer films.

The concentration and composition of the produced PHAs were determined by gas-chromatography (GC-FID Perkin Elmer 8410) as described elsewhere (Villano et al., 2010).

\subsection{Preparation of bacterial cellulose mats}

Bacterial cellulose mats were obtained by following the same procedure as described in a previous work (Martínez-Sanz et al., 2011b) and were supplied by Bioinicia S.L. (Valencia, Spain). Briefly, the bacterial strain Gluconacetobacter xylinus 7351 was incubated in a modified Hestrin/Shramm medium at $30{ }^{\circ} \mathrm{C}$. The cells were pre-cultured in a test tube containing $5 \mathrm{~mL}$ of medium and later transferred and scaled up to a bigger reactor of $20 \mathrm{~L}$. Several layers of cellulose obtained using the previously described procedure were thus supplied. The received bacterial cellulose pellicles were sterilized and cleaned in boiling water and in a $10 \%(\mathrm{v} / \mathrm{v}) \mathrm{NaOH}$ aqueous solution. 


\subsection{Preparation of bacterial cellulose nanowhiskers (BCNW)}

Once neutral $\mathrm{pH}$ was reached, bacterial cellulose pellicles were ground in a blender and the gel-like material was then compressed in order to remove most of the absorbed water. The dried material was then treated with a sulphuric acid solution (301 $\mathrm{mL}$ sulphuric acid in $1 \mathrm{~L}$ water, in a cellulose/acid ratio of approximately $7 \mathrm{~g} / \mathrm{L}$, at $50{ }^{\circ} \mathrm{C}$ for three days until a homogeneous solution was obtained. The cellulose nanowhiskers were obtained as a white precipitate after several centrifugation and washing cycles at $12,500 \mathrm{rpm}$ and $15^{\circ} \mathrm{C}$ for 20 minutes. After that, the material was re-suspended in deionised water and neutralized with sodium hydroxide until neutral $\mathrm{pH}$ and, subsequently, centrifuged to obtain the final product as a partially hydrated precipitate. The material was then solvent exchanged into chloroform. The water of the partially hydrated precipitate was replaced by acetone by applying several centrifugation cycles in which the supernatant was removed and replaced with acetone. After that, acetone was replaced with chloroform by subjecting the material to additional centrifugation cycles. The concentration of BCNW after evaporating the chloroform was 1.2 wt.$\%$.

\subsection{Preparation of films}

Pure PHA films and nanocomposites loaded with 1 and 3 wt.-\% BCNW were prepared by means of solution casting using chloroform as the solvent. Solvent exchanged $\mathrm{BCNW}$ were dispersed into $50 \mathrm{~mL}$ of chloroform by homogenization (ultra-turrax) for $2 \mathrm{~min}$. Subsequently, the required amount of PHA was added to these suspensions, to give a total solids content of $5 \% \mathrm{w} / \mathrm{v}$, and stirred together at $40{ }^{\circ} \mathrm{C}$ for 2 hours. Finally the solutions were cast onto Petri dishes and films were attained after solvent evaporation at room temperature. The materials were the dried at $60{ }^{\circ} \mathrm{C}$ under vacuum for 24 hours to completely remove the solvent. All 
the prepared materials were kept at room temperature and dry conditions for two weeks before characterization to allow for complete crystallization of the PHAs.

\section{6 ${ }^{1} \mathrm{H}$-Nuclear Magnetic Resonance}

High resolution ${ }^{1} \mathrm{H}-\mathrm{NMR}$ analysis of PHA samples was performed on a DPX 300 NMR spectrometer (Bruker, Germany). Deuterated chloroform $\left(\mathrm{CDCl}_{3}\right)$ was used as both the solvent and the internal standard for NMR characterization. The ${ }^{1} \mathrm{H}-\mathrm{NMR}$ spectra were collected at $300.13 \mathrm{MHz}$ with controlled temperature (25 ${ }^{\circ} \mathrm{C}$ ) and 128 scans. NMR spectra were subsequently analyzed by using GSim software.

In order to determine the valerate content of PHAs, the areas under the peaks located at $0.9 \mathrm{ppm}$, corresponding to the absorption of methyl from hydroxyvalerate, and $1.25 \mathrm{ppm}$, corresponding to the absorption of methyl from hydroxybutyrate (Liu et al., 2010), were integrated. The following equation was used to estimate the valerate content (Bloembergen et al., 1986):

$$
H V(\%)=\frac{\operatorname{areaCH}_{3}(H V)}{\operatorname{areaCH}_{3}(\mathrm{HV})+\operatorname{areaCH}_{3}(\mathrm{HB})} \times 100
$$

\subsection{Molecular weight determination}

Average molecular weights were first determined using a size exclusion chromatography (SEC) apparatus (Waters), which included a solvent delivery system composed of a model 510 pump, a Rheodyne injector, and a refractive index detector model 2410 . The operating temperature was $30^{\circ} \mathrm{C}$, using chloroform as eluent with a flow rate of $1 \mathrm{~mL} / \mathrm{min}$. A series of three Waters Ultrastyragel columns, 103,104 , and $105 \mathrm{~A}^{\circ}$ was used. A universal calibration was performed and the calibration curve was generated with monodisperse polystyrene (PS) standards (in the range $2 \cdot 10^{3}$ to $4 \cdot 10^{6}$; Waters and Polymer Laboratories). The 
calibration curve was correlated with PHB using the Mark-Houwink- Sakurada relationship:

$$
\mathrm{M}_{\mathrm{w}}=\mathrm{K} \cdot[\eta]^{\alpha}
$$

where $[\eta]$ is the intrinsic viscosity and ' $K$ ' and ' $\alpha$ ' are the Mark-Houwink constants, for each polymer/solvent/temperature system (Yau et al., 1979). The values of these constants used for the pairs $\mathrm{PHB} /$ chloroform and PS/chloroform, were respectively $\mathrm{K}=1.18 \cdot 10^{-4} \mathrm{dL} / \mathrm{g}, \alpha=0.794$, and $\mathrm{K}=4.9 \cdot 10^{-5} \mathrm{dL} / \mathrm{g}, \quad \alpha=0.78$ (Kurata \& Tsunashima, 1988). Sample injection volumes of $150 \mathrm{~mL}$ were used.

Additionally, the molecular weight of PHAs was measured in an Ubbelohde viscosimeter at $30{ }^{\circ} \mathrm{C}$. The intrinsic viscosity ([ $\left.\eta\right]$ ) for PHAs was determined for $1 \mathrm{~g} / \mathrm{dL}$ solutions in chloroform and, subsequently, the weight-average molecular weight was calculated using the Mark-Houwink-Sakurada equation, with the same parameters as above specified for PHB solutions in chloroform at $30^{\circ} \mathrm{C}$.

\subsection{Scanning Electron Microscopy (SEM)}

SEM was conducted on a Hitachi microscope (Hitachi S-4100) at an accelerating voltage of $10 \mathrm{KV}$ and a working distance of 12-16 mm. PHAs films cryo-fractured after immersion in liquid nitrogen were sputtered with a goldpalladium mixture under vacuum before their morphology was examined using SEM.

\subsection{Transmission Electron Microscopy (TEM)}

Ultra-thin sections of microtomed thin composite sheets were observed through TEM. The samples were stained with a 2 wt.-\% solution of uranyl acetate. TEM was performed using a JEOL 1010 equipped with a digital Bioscan (Gatan) image acquisition system at $80 \mathrm{KV}$. 


\subsection{Optical microscopy}

Polarized light microscopy (PLM) examinations were performed using a Nikon Eclipse 90i optical microscope (IZASA, Spain) equipped with a 5megapixels cooled digital colour microphotography camera Nikon Digital Sight DS-5Mc. Captured images were analyzed and processed by using Nis-Elements BR software.

\subsection{Attenuated Total Reflectance (ATR) FT-IR analysis}

ATR-FTIR spectra of BCNW and all the obtained films were recorded in a controlled chamber at $21^{\circ} \mathrm{C}$ and $40 \%$ RH using a Bruker (Rheinstetten, Germany) FT-IR Tensor 37 equipment and coupling the ATR accessory GoldenGate of Specac Ltd. (Orpington, UK). The spectra were taken at $4 \mathrm{~cm}^{-1}$ resolution averaging a minimum of 20 scans. Analysis of the spectra was performed using Grams/AI 7.02 (Galactic Industries, Salem, NH, USA) software.

\subsection{Differential scanning calorimetry (DSC)}

Differential scanning calorimetry (DSC) of PHA nanocomposites was performed on a Perkin-Elmer DSC 7 thermal analysis system using $\mathrm{N}_{2}$ as the purging gas. The sample treatment consisted of a first heating step from $-30{ }^{\circ} \mathrm{C}$ to $180{ }^{\circ} \mathrm{C}$, a subsequent cooling down to $-30^{\circ} \mathrm{C}$ and a second heating step up to 180 ${ }^{\circ} \mathrm{C}$. The heating and cooling rates for the runs were $10{ }^{\circ} \mathrm{C} / \mathrm{min}$ and the typical sample weight was $4 \mathrm{mg}$. The first and second melting endotherms, after controlled crystallization at $10{ }^{\circ} \mathrm{C} / \mathrm{min}$ from the melt, were analyzed. Before evaluation, similar runs of an empty pan were subtracted from the thermograms. The DSC equipment was calibrated using indium as a standard.

The overall enthalpy of the analyzed materials was calculated by applying the following formula:

$$
\Delta H_{m}=\Delta H_{m 1}+\Delta H_{m 2}-\Delta H_{C C}
$$


, where $\Delta H_{m 1}$ and $\Delta H_{m 2}$ are the melting enthalpies, corrected for the biopolymer content in the nanocomposite materials, corresponding to the first and the second melting steps, respectively and $\Delta H_{C C}$ is the corrected cold crystallization enthalpy.

\subsection{Thermogravimetric analysis (TGA)}

Thermogravimetric (TG) curves were recorded with a TA Instruments model Q500 TGA. The samples (ca. $20 \mathrm{mg}$ ) were heated from $50{ }^{\circ} \mathrm{C}$ to $600{ }^{\circ} \mathrm{C}$ with a heating rate of $10^{\circ} \mathrm{C} / \mathrm{min}$ under nitrogen atmosphere. Derivative TG curves (DTG) express the weight loss rate as a function of temperature.

\subsection{Water vapour permeability (WVP)}

Direct permeability to water was determined from the slope of the weight loss versus time curves at $24{ }^{\circ} \mathrm{C}$. The films were sandwiched between the aluminium top (open O-ring) and bottom (deposit for the permeant) parts of a specifically designed permeability cell with screws. A Viton rubber O-ring was placed between the film and the bottom part of the cell to enhance sealability. These permeability cells containing water as the permeant were then placed inside a desiccator at $0 \%$ $\mathrm{RH}$ and the solvent weight loss through a film area of $0.001 \mathrm{~m}^{2}$ was monitored and plotted as a function of time. The samples were preconditioned at the testing conditions for 24 hours, and to estimate the permeability values of the films, only the linear part of the weight loss data was used to ensure sample steady state conditions. Cells with aluminium films (with thickness of ca. $11 \mu \mathrm{m}$ ) were used as control samples to estimate solvent loss through the sealing. The lower limit of WVP detection of the permeation cells was of ca. $0.008 \cdot 10^{-15} \mathrm{~kg} \cdot \mathrm{m} / \mathrm{s} \cdot \mathrm{m}^{2} \cdot \mathrm{Pa}$ based on the weight loss measurements of the aluminium films. Water vapour weight loss 
was calculated as the total cell weight loss minus the loss through the sealing. The tests were done in duplicate.

\subsection{Oxygen permeability}

The oxygen permeability coefficient was derived from oxygen transmission rate (OTR) measurements recorded using an Oxtran 100 equipment (Modern Control Inc., Minneapolis, MN, US). Experiments were carried out at $24{ }^{\circ} \mathrm{C}$ and at two relative humidities $(0 \% \mathrm{RH}$ and $80 \% \mathrm{RH}) .80 \%$ relative humidity was generated by a built-in gas bubbler and was checked with a hygrometer placed at the exit of the detector. The samples were purged with nitrogen for a minimum of $20 \mathrm{~h}$ in the humidity equilibrated samples, prior to exposure to an oxygen flow of $10 \mathrm{~mL} / \mathrm{min}$. A $5 \mathrm{~cm}^{2}$ sample area was measured by using an in-house developed mask. Reduced sample areas while testing oxygen permeation in high permeable materials enhances the reproducibility of the measurements, permits to select defect-free areas and ensures minimum thickness variations.

\subsection{Mechanical properties}

Tensile tests were carried out at ambient conditions typically at $24{ }^{\circ} \mathrm{C}$ and $50 \%$ $\mathrm{RH}$ on an Instron 4400 Universal Tester. Pre-conditioned dumb-bell shaped specimens with thicknesses within the range of $130-70 \mu \mathrm{m}$, initial gauge length of $25 \mathrm{~mm}$ and $5 \mathrm{~mm}$ in width were die-stamped from the films in the machine direction according to the ASTM D882. A fixed crosshead rate of $10 \mathrm{~mm} / \mathrm{min}$ was utilized in all cases and results were taken as the average of, at least, four tests. 


\section{RESULTS AND DISCUSSION}

\subsection{Synthesized PHAs characterization}

Two different PHAs, with different valerate contents, were synthesized from microbial mixed cultures and used throughout this study. Both valerate content and molecular weight are known to affect the properties of PHAs (Modi et al., 2011) and, thus, these parameters, as well as the purity of the produced materials, were determined and the results are gathered in Table 1.

As shown in Table 1, both PHA grades presented a relatively high degree of purity, although it was not possible to completely remove biomass residues by the applied extraction procedures, especially in the case of the high valerate content PHA. From the results, it is also worth noting that the valerate content had a significant effect on the molecular weight of the synthesized material. Both the intrinsic viscosity and the weight-average molecular weight were higher when increasing the valerate ratio. There was a discrepancy between the molecular weight determined from intrinsic viscosity values and from size exclusion chromatography, being this difference higher with increased valerate content. This difference may be explained by the fact that the parameters introduced in the Mark-Houwink-Sakurada equation, used to perform the chromatography calibration and to estimate the molecular weight from the intrinsic viscosity values, correspond to $\mathrm{P}(3 \mathrm{HB})$ (Akita et al., 1976) and, thus, these parameters may be not accurate for PHBV, especially when the valerate content increases. Similar values to the ones estimated in this work for PHBV44 have been previously reported for PHBV with 43\% (Wang et al., 2001) and 45\% valerate content (Kunioka \& Doi, 1990) produced by pure microbial cultures. In contrast, the synthesized PHBV8 presented significantly lower molecular weight than that reported previously for a $8 \% \mathrm{HV}$ commercial grade (Jiang et al., 2008a). In 
addition, whereas the molecular weight was affected by the valerate content, no great differences were detected for the polydispersity index, indicating that a narrow chain size distribution was attained in both cases.

Figure 1 displays the ${ }^{1} \mathrm{H}-\mathrm{NMR}$ spectra of both materials. After analyzing these spectra, it was confirmed that the synthesized PHAs did not contain a high degree of impurities since all the detected major bands corresponded to those assigned to PHBV (Bloembergen et al., 1986). The valerate content of each material was also estimated from NMR spectra by integrating the area under the peaks at $0.9 \mathrm{ppm}$ and $1.25 \mathrm{ppm}$, assigned to the resonance absorption of methyl from hydroxyvalerate and methyl from hydroxybutyrate, respectively (Liu et al., 2010). The estimated values were similar to those determined by gas chromatography right after synthesizing the materials $(8.4 \mathrm{~mol} \%$ and $44 \mathrm{~mol} \%$ for the low and high valerate content PHAs, respectively). However, it is worth noting that for the high valerate content material the value estimated by NMR was slightly lower than that determined by GC. This might be indicating that the material could have undergone degradation to a certain extent during the transport and storage phase. 
Table 1. PHAs degree of purity determined by gas chromatography, valerate content estimated by gas chromatography $\left(\mathrm{HV}_{\mathrm{GC}}\right)$ and from NMR spectra $\left(\mathrm{HV}_{\mathrm{NMR}}\right)$, intrinsic viscosity $([\eta])$ and weight-average molecular weight determined from intrinsic viscosity measurements $\left(\mathrm{M}_{\mathrm{w} 1}\right)$ and weight-average molecular weight $\left(\mathrm{M}_{\mathrm{w} 2}\right)$ and polydispersity index $(\mathrm{PD})$ determined from size exclusion chromatography.

\begin{tabular}{|l|c|c|c|c|c|c|c|}
\cline { 2 - 8 } \multicolumn{1}{c|}{} & $\begin{array}{c}\text { PHBV purity } \\
(\mathrm{wt} .-\%)\end{array}$ & $\begin{array}{c}\mathrm{HV}_{\mathrm{GC}} \\
(\mathrm{mol} \%)\end{array}$ & $\begin{array}{c}\mathrm{HV}_{\mathrm{NMR}} \\
(\mathrm{mol} \%)\end{array}$ & {$[\eta](\mathrm{dl} / \mathrm{g})$} & $\begin{array}{c}\mathrm{M}_{\mathrm{w} 1} \\
(\mathrm{~g} / \mathrm{mol})\end{array}$ & $\begin{array}{c}\mathrm{M}_{\mathrm{w} 2} \\
(\mathrm{~g} / \mathrm{mol})\end{array}$ & $\mathrm{PD}$ \\
\hline PHBV8 & $>90$ & 8.4 & 9.0 & 1.04 & $2.10 \cdot 10^{5}$ & $2.87 \cdot 10^{5}$ & 1.8 \\
\hline PHBV44 & 87 & 44 & 36 & 1.56 & $5.40 \cdot 10^{5}$ & $3.30 \cdot 10^{5}$ & 1.5 \\
\hline
\end{tabular}

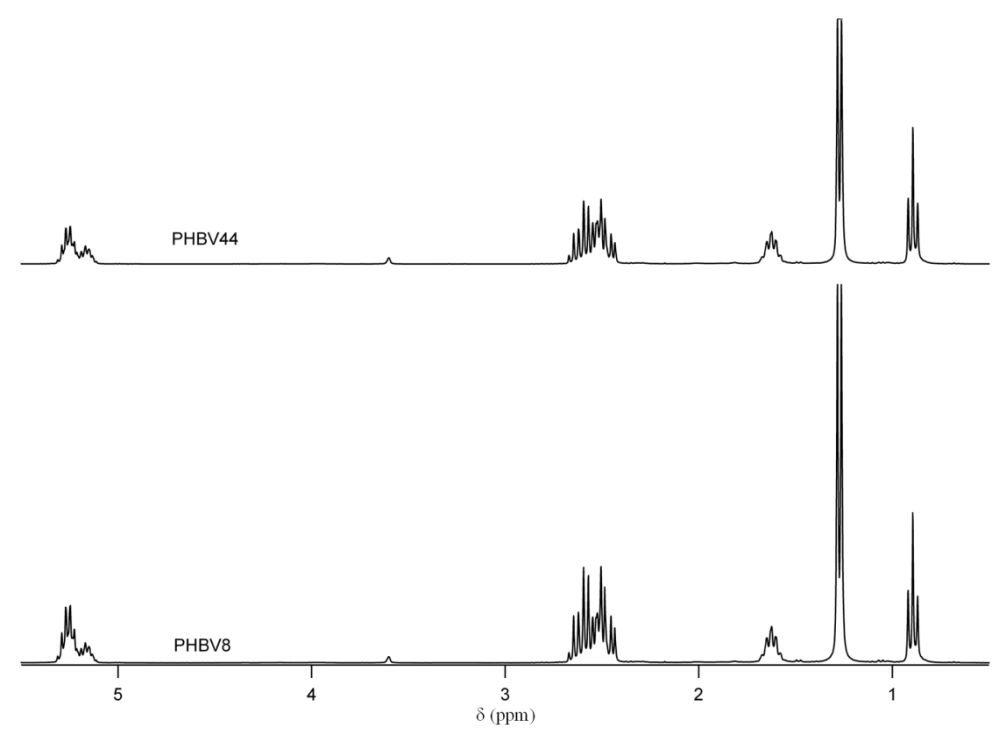

Figure 1. ${ }^{1} \mathrm{H}-\mathrm{NMR}$ spectra of PHBV8 and PHBV44.

In addition, ATR-FTIR spectra of PHAs were recorded to investigate structural changes originated by their different valerate contents (cf. Figure 2). When increasing the valerate content, the PHBV44 showed a shoulder located at 
$1085 \mathrm{~cm}^{-1}$ and a new band at $1008 \mathrm{~cm}^{-1}$, which may correspond to the carbonyl groups from the hydroxyvalerate units. The IR bands located at 1279, 1228 and $1185 \mathrm{~cm}^{-1}$ are known to be sensitive to PHA crystallinity. In particular, the band at $1185 \mathrm{~cm}^{-1}$ has been observed to be the most sensitive one, decreasing when the crystallinity of the material increased (Bloembergen et al., 1986). From the spectra of both materials it was found that the relative intensity of the previous bands which are related to the crystallinity of PHAs was altered when varying the valerate content. As shown in Figure 2b, the relative intensity of the band located at $1185 \mathrm{~cm}^{-1}$ increased while the intensity of the bands appearing at 1279 and 1228 $\mathrm{cm}^{-1}$ decreased for the higher valerate content PHA, hence suggesting that this material possessed lower crystallinity than the low valerate content PHA. In contrast, a previous study reported that no great differences in the crystallinity were detected when increasing the valerate content of PHAs (Bloembergen et al., 1986), although all the analyzed PHAs in that study contained less than $20 \% \mathrm{HV}$, while it is known that the minimum crystallinity is encountered for HV contents within the 40-50 \%mol range (Wang et al., 2001). 

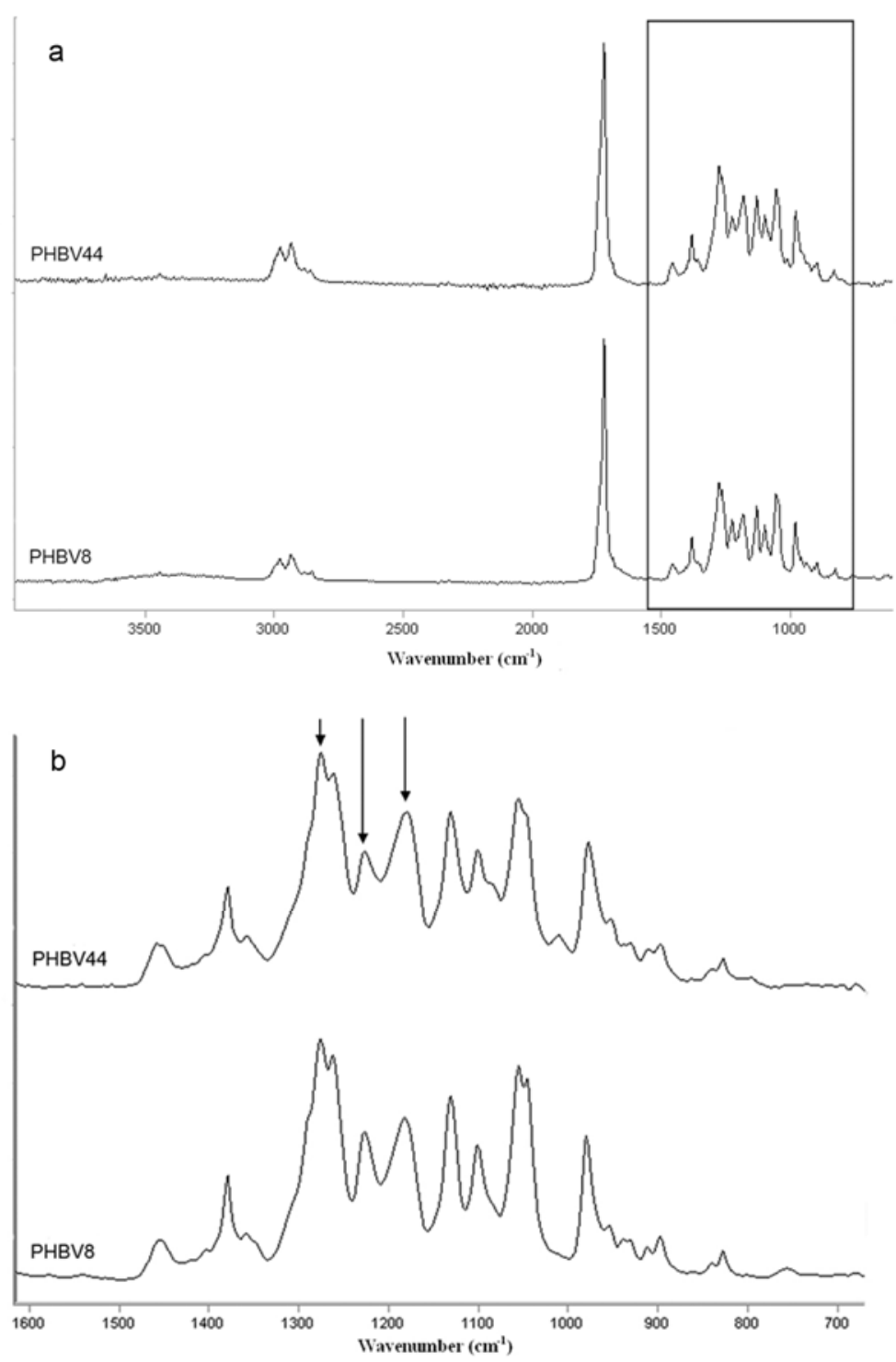

Figure 2. ATR-FTIR spectra of PHBV8 and PHBV44 (a) and detail from the range of interest (b). The arrows indicate the bands which are related to the PHAs crystallinity. 


\subsection{PHA-BCNW nanocomposites characterization}

After characterizing the synthesized PHAs, nanocomposites were produced by incorporating solvent exchanged $\mathrm{BCNW}$ using the solution casting technique. These $\mathrm{BCNW}$ were produced by acid hydrolysis of $\mathrm{BC}$ and presented higher aspect ratio and crystallinity index than those previously reported for plantderived CNW (Martínez-Sanz, 2012a). In particular, BCNW produced by the optimized method applied in this work showed an aspect ratio of ca. 30 and a crystallinity index of about 95\% (Martínez-Sanz et al., 2011a).

\subsubsection{Morphological characterization}

Figure 3 shows contact transparency pictures of the obtained pure PHA and PHA-BCNW nanocomposite films. From this figure, it is clearly observed that the transparency was significantly higher for PHBV44, which may be a result of its presumably lower crystallinity (see DSC analyses in the next section). No agglomerates could be detected by visual examination within any of the nanocomposite films and the transparency was not significantly affected when incorporating $\mathrm{BCNW}$ into the PHAs. This observation suggests that a relatively good dispersion of the nanofiller may have been achieved. Nevertheless, when examining the films by optical microscopy, even though BCNW seemed to be uniformly distributed along the films, some aggregates could be detected, especially in the films containing 3 wt.- $\%$ BCNW, as shown in Figure 4. This observation indicates that when increasing the nanoadditive loading, agglomeration took place to a certain extent. 


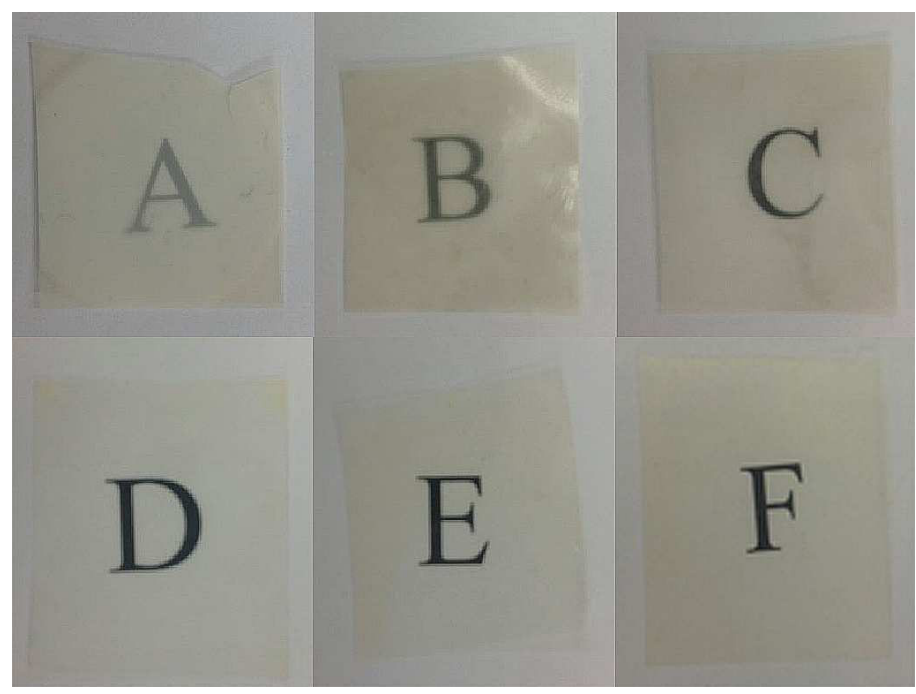

Figure 3. Contact transparency pictures of PHBV-BCNW films: (A) PHBV8; (B) PHBV8 + 1\%BCNW; (C) PHBV8 + 3\%BCNW; (D) PHBV44; (E) PHBV44 + $1 \% \mathrm{BCNW}$ and (F) PHBV44 +3\%BCNW.
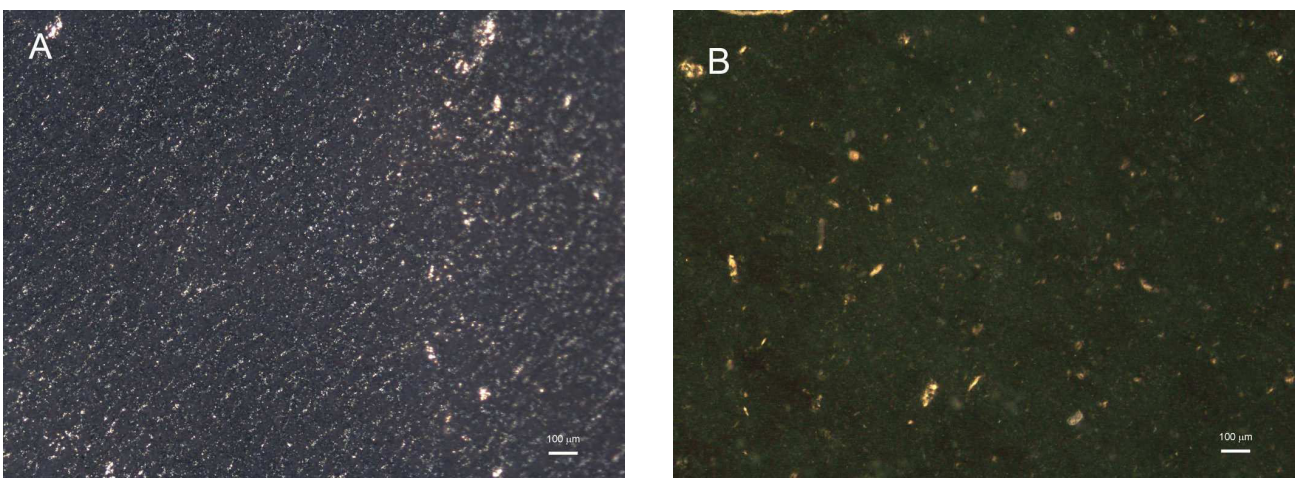

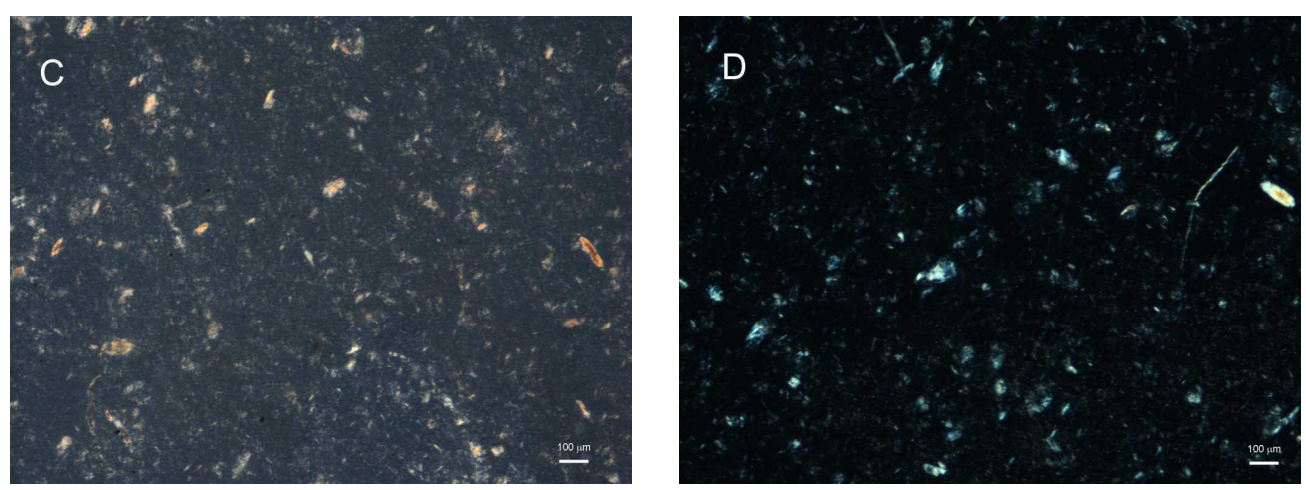

Figure 4. Polarized light optical microscopy image of PHBV-BCNW films: (A) PHBV8 + 1\%BCNW; (B) PHBV8 + 3\%BCNW; (C) PHBV44 + 1\%BCNW and

(D) PHBV44 +3\%BCNW. Scale markers correspond to 100 micrometres.

Surface topography of pure and nanocomposite cryo-fractured films was studied by SEM and representative pictures are shown in Figure 5. As observed in the pure PHA micrographs, these films presented some voids, especially in the case of PHBV44 (cf. Figure 5D). A similar morphology was observed for poly(lactic acid) films prepared by solution casting and in that case, the appearance of voids was attributed to the highly volatile chloroform which escaped during the drying process (Hossain et al., 2012). On the other hand, from the images it seems that the amount of these voids decreased as the BCNW loading increased. SEM observations also indicated that a better dispersion of $\mathrm{BCNW}$ was achieved for low loadings, just as previously suggested by optical microscopy. It is interesting to see that while it was difficult to clearly identify the BCNW within the sections of PHBV8 nanocomposites, agglomerates could be easily detected in the PHBV44 nanocomposites, indicating that a higher dispersion was achieved for the low valerate matrix. In addition, it may be observed that the roughness of the cryofractured sections increased with the nanofiller loading, probably suggesting that agglomeration took place to a certain extent. This observation contrasts with the 
good dispersion reported for PHBV (with $2.5 \% \mathrm{HV}$ ) nanocomposites loaded with concentrations up to $10 \mathrm{wt} .-\%$ of rod-like plant CNW (Yu et al., 2012). It might be possible that the morphology of high aspect ratio $\mathrm{BCNW}$, with higher length than that of plant-derived $\mathrm{CNW}$, may promote the agglomeration of the nanofiller by the development of BCNW entanglements which were not observed for the shorter rod-like plant CNW.

Even though some aggregates are present in the nanocomposite films, BCNW could be highly dispersed in those areas in which they are not visually detected by SEM. In order to further investigate the dispersion of the nanofiller within the matrix, nanocomposite films with $1 \mathrm{wt} .-\%$ BCNW were examined by TEM and representative images are shown in Figure 6. Due to the small size of BCNW, high magnifications had to be applied with the aim of detecting the nanocrystals within the ultrathin film sections. By concentrating the beam of electrons in such small film areas, cracking of the analyzed materials was induced, especially in the case of PHBV44. As a result, it was not possible to obtain images where the BCNW were identified with high precision. However, TEM images confirmed once again that a higher BCNW dispersion was achieved for the PHBV8 matrix than for PHBV44.
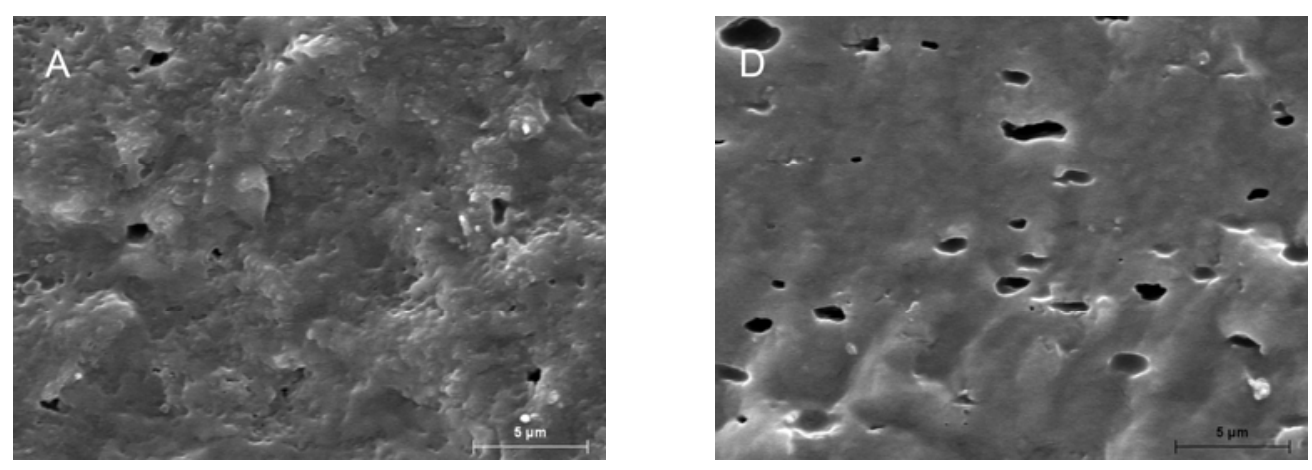

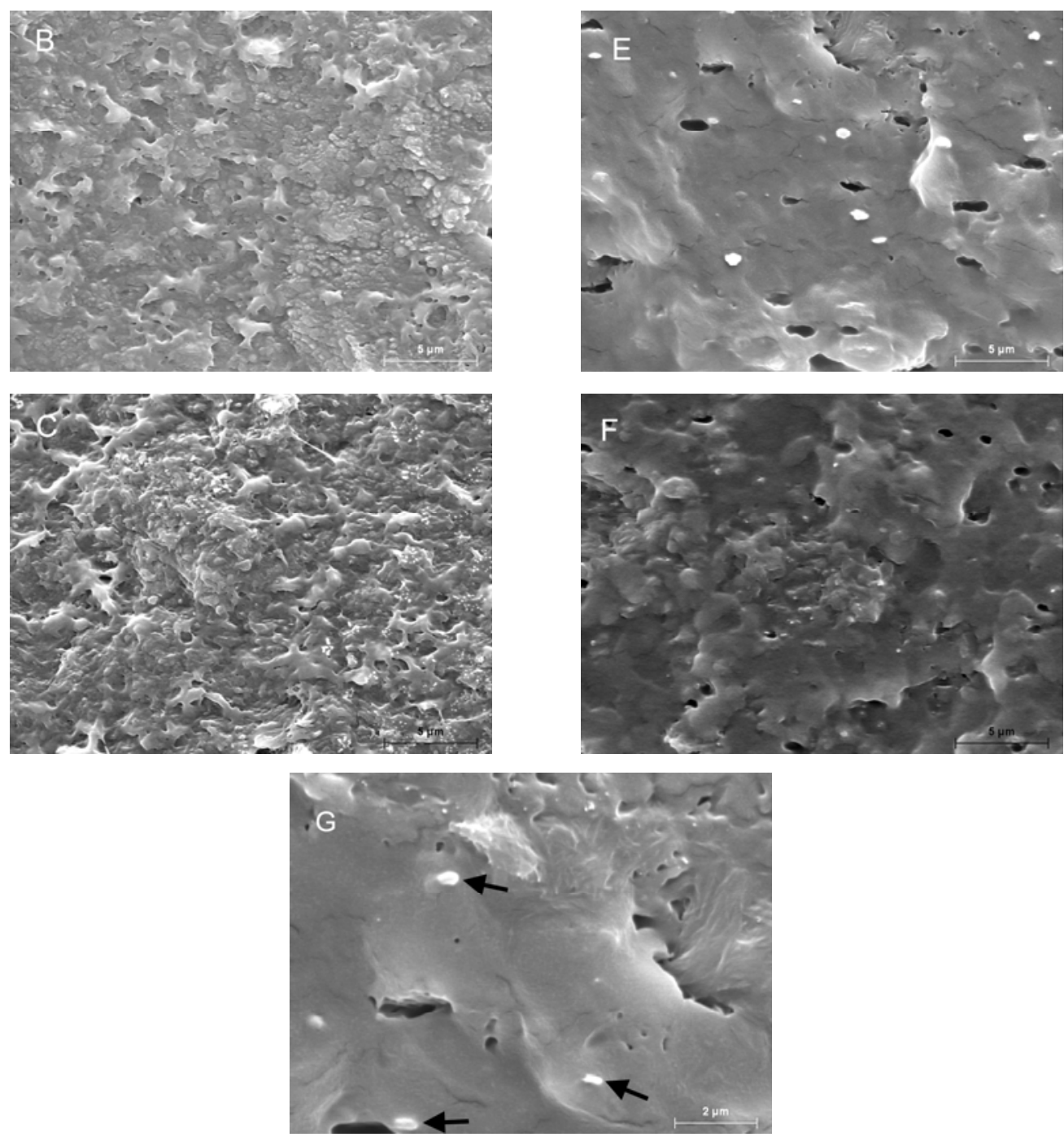

Figure 5. SEM micrographs of cryo-fractured sections of PHBV-BCNW films: (A) PHBV8; (B) PHBV8 + 1\%BCNW; (C) PHBV8 + 3\%BCNW; (D) PHBV44; (E) PHBV44 + 1\%BCNW; and (F) PHBV44 + 3\%BCNW. Scale markers correspond to 5 micrometres. (G) Detail from PHBV44 $+1 \% \mathrm{BCNW}$ at higher magnification. BCNW are identified with arrows. Scale marker corresponds to 2 micrometers. 

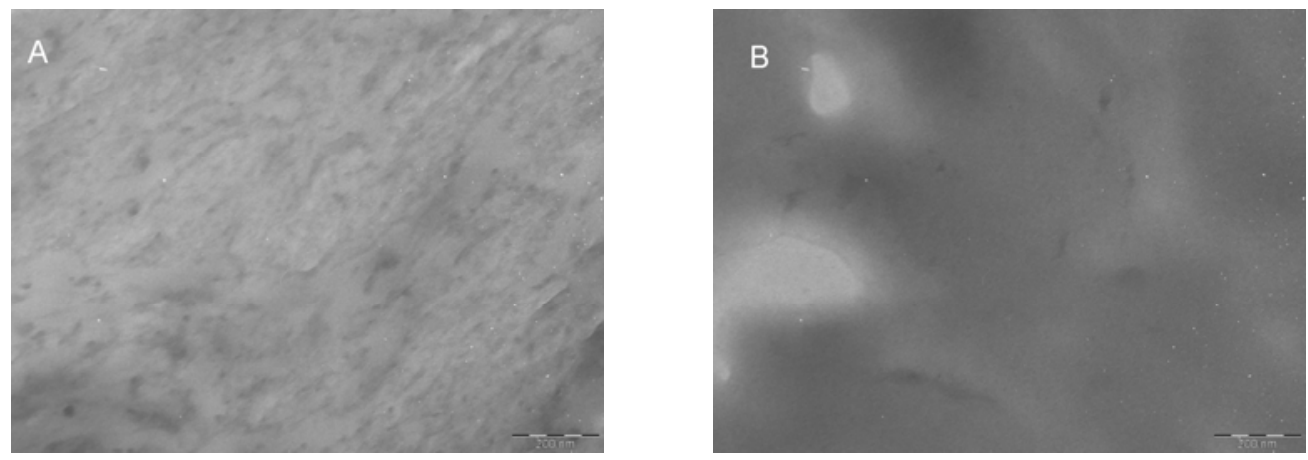

Figure 6. TEM images of PHBV-BCNW films: (A) PHBV8 $+1 \% \mathrm{BCNW}$ and (B) PHBV44 + 1\%BCNW. Scale markers correspond to 200 nanometres.

\subsubsection{Thermal properties and thermal stability}

Table 2 gathers the thermal properties of PHA films as determined from DSC analyses. The two different PHA grades presented a significantly different behaviour. The high valerate content grade displayed lower melting enthalpy and much lower melting point and glass transition temperature. Although the crystallinity index of these materials could not be calculated as the enthalpies of the perfect PHA crystals were not available for these particular valerate contents, the lower melting enthalpy observed for the high valerate PHA together with the previous ATR-FTIR analyses, suggested that by increasing the valerate ratio a more amorphous material was attained. Indeed, a reduction on the crystallinity when increasing the valerate content has already been reported (Chen et al., 2004; Modi et al., 2011) and it was attributed to the hydroxyvalerate units inhibiting the crystallization through hydrogen bonding (Chen et al., 2004). A cold crystallization exotherm was observed on heating for the PHBV8, whereas this was not observed for the PHBV44. Additionally, PHBV8 presented two melting peaks, a melting shoulder followed by a sharper melting peak. This behaviour has been already reported for several PHA grades (Ten et al., 2010) although a single melting peak was observed for low valerate content PHAs (i.e. 5\% HV content) (Modi et al., 
2011). The appearance of two melting peaks has been attributed to the fact that more defective or smaller crystals melted and subsequently recrystallized forming more perfect crystals which melted at higher temperature (Ten et al., 2010). However, in the case of PHBV8 the cold crystallization enthalpy was similar to the first melting enthalpy, hence it might be possible that the first melting step corresponded to the crystals formed during the cold crystallization whereas the second melting step corresponded to the crystals formed during the casting process.

As compared to literature values of PHAs produced by microbial pure cultures, which are given as a reference in Table 2, the materials synthesized in this work presented lower melting point, especially in the case of PHBV8. This is in agreement with a previous work, in which it was reported that PHAs produced by microbial mixed cultures presented lower melting point, crystallinity and glass transition temperature (Serafim et al., 2008).

As shown in Table 2, the addition of BCNW into the PHA matrixes led to an increase in the overall melting enthalpy of the polymeric matrix, with this effect being more obvious for the PHBV44. It should be noted that for both grades the maximum melting enthalpy increase corresponded to a loading of $1 \mathrm{wt} .-\% \mathrm{BCNW}$, which indicates that the better dispersion achieved for this particular concentration favoured the crystallization of PHBV. As observed for the PHBV8 loaded with 1 wt.-\%BCNW, the overall melting enthalpy increase was a result of decreased cold crystallization enthalpy and increased enthalpy for the first melting step. This result suggests that $\mathrm{BCNW}$ act as nucleating sites, promoting the development of smaller crystals, which correspond to the first melting transition.

For PHBV8, the cold crystallization temperature was significantly decreased when incorporating $\mathrm{BCNW}$. Reductions of up to $10^{\circ} \mathrm{C}$ in the cold crystallization 
temperatures have been reported for PHBV nanocomposites loaded with CNW (Jiang et al., 2008b; Ten et al., 2010; Yu et al., 2012) and for PLA nanocomposites incorporating highly dispersed BCNW by melt compounding (Martínez-Sanz et al., 2012). This effect was related to the fact that well-dispersed BCNW crystallites act as nucleating agents promoting a faster crystallization of PLA during heating. Similarly, the BCNW incorporated in this work acted as nucleating sites, favouring the crystallization of the PHAs at a lower temperature.

Glass transition could not be clearly discerned during the first heating run and, therefore, the values reported in Table 2 correspond to those observed during the second heating step. There was an increase in the glass transition temperature with the incorporation of $\mathrm{BCNW}$. This effect was again more pronounced for the PHBV44 matrix and maximum when the dispersion of the nanofiller was optimized, i.e. for $1 \mathrm{wt} .-\% \mathrm{BCNW}$. Glass transition temperature was also seen to increase up to $4{ }^{\circ} \mathrm{C}$ for PHBV $(12 \% \mathrm{HV})$ nanocomposites loaded with plant-derived CNW (Ten et al., 2012). Thus, the addition of highly crystalline cellulose nanowhiskers reduces the mobility of PHBV molecular chains provided that interactions are established between the matrix and the nanofiller. It is also worth mentioning that previous works in which $\mathrm{BCNW}$ were incorporated into PLA (Martínez-Sanz et al., 2012) and EVOH (Martínez-Sanz, 2012b) by melt compounding did not find any significant increase in the $T_{g}$ of the polymeric matrix. Nevertheless, it is known that the interconnection between CNW is hindered by melt compounding as compared to the solution casting technique (Hajji et al., 1996), which could result in a more significant stiffening effect for the latter method. 
Table 2. DSC maximum of melting $\left(\mathrm{T}_{\mathrm{m} 1}\right.$ and $\left.\mathrm{T}_{\mathrm{m} 2}\right)$ and the corresponding melting enthalpies $\left(\Delta \mathrm{H}_{\mathrm{m} 1}\right.$ and $\left.\Delta \mathrm{H}_{\mathrm{m} 2}\right)$, obtained from the first heating run, cold crystallization temperature $\left(\mathrm{T}_{\mathrm{CC}}\right)$ and the corresponding melting enthalpy $\left(\Delta \mathrm{H}_{\mathrm{CC}}\right)$, obtained from the cooling run, and glass transition temperature $\left(\mathrm{T}_{\mathrm{g} 2}\right)$, obtained from the second heating run. $\Delta \mathrm{H}_{\mathrm{m}}$ corresponds to the calculated overall melting enthalpy.

\begin{tabular}{|c|c|c|c|c|c|c|c|c|}
\hline & $\mathrm{T}_{\mathrm{m} 1}\left({ }^{\circ} \mathrm{C}\right)$ & $\begin{array}{l}\Delta \mathrm{H}_{\mathrm{ml}}(\mathrm{J} / \mathrm{g} \\
\mathrm{PHBV}) \\
\end{array}$ & $\mathrm{T}_{\mathrm{m} 2}\left({ }^{\circ} \mathrm{C}\right)$ & $\begin{array}{l}\Delta \mathrm{H}_{\mathrm{m} 2}(\mathrm{~J} / \mathrm{g} \\
\mathrm{PHBV}) \\
\end{array}$ & $\mathrm{T}_{\mathrm{CC}}\left({ }^{\circ} \mathrm{C}\right)$ & $\begin{array}{l}\Delta \mathrm{H}_{\mathrm{CC}}(\mathrm{J} / \mathrm{g} \\
\mathrm{PHBV}) \\
\end{array}$ & $\begin{array}{l}\Delta \mathrm{H}_{\mathrm{m}}(\mathrm{J} / \mathrm{g} \\
\mathrm{PHBV})\end{array}$ & $\mathrm{T}_{\mathrm{g} 2}\left({ }^{\circ} \mathrm{C}\right)$ \\
\hline PHBV8 & $141.6 \pm 0.1$ & $10.2 \pm 2.4$ & $157.5 \pm 1.5$ & $29.1 \pm 1.0$ & $53.0 \pm 4.5$ & $7.3 \pm 0.0$ & $32.0 \pm 2.1$ & $-2.7 \pm 1.0$ \\
\hline $\begin{array}{c}\text { PHBV8+1\%BC } \\
\text { NW }\end{array}$ & $142.0 \pm 0.6$ & $13.3 \pm 1.7$ & $158.7 \pm 0.7$ & $27.5 \pm 0.5$ & $39.2 \pm 2.1$ & $2.8 \pm 0.5$ & $38.0 \pm 2.6$ & $-0.9 \pm 0.5$ \\
\hline $\begin{array}{c}\text { PHBV8+3\%BC } \\
\text { NW }\end{array}$ & $141.1 \pm 0.6$ & $4.6 \pm 1.2$ & $156.8 \pm 0.6$ & $27.6 \pm 3.2$ & $39.2 \pm 1.6$ & $1.0 \pm 0.0$ & $31.2 \pm 2.3$ & $-2.1 \pm 0.9$ \\
\hline PHBV44 & $57.5 \pm 1.4$ & $12.0 \pm 1.0$ & --- & --- & --- & --- & $12.0 \pm 1.0$ & $-8.1 \pm 0.0$ \\
\hline $\begin{array}{c}\text { PHBV44+1\%B } \\
\text { CNW }\end{array}$ & $60.0 \pm 2.8$ & $27.2 \pm 1.9$ & --- & --- & --- & --- & $27.2 \pm 1.9$ & $-5.4 \pm 1.7$ \\
\hline $\begin{array}{c}\text { PHBV } 44+3 \% \mathrm{~B} \\
\text { CNW }\end{array}$ & $56.8 \pm 2.0$ & $17.4 \pm 3.9$ & --- & --- & --- & --- & $17.4 \pm 3.9$ & $-6.6 \pm 0.1$ \\
\hline $\begin{array}{c}\text { PHBV8 } \\
\text { literature } \\
\text { (Savenkova et }^{*} \\
\text { al., 2000) }\end{array}$ & 164.3 & --- & --- & --- & --- & --- & --- & -0.6 \\
\hline $\begin{array}{c}\text { PHBV43 } \\
\text { literature }{ }^{(*)} \\
\text { (Mitomo et al., } \\
1999 \text { ) }\end{array}$ & 73.0 & --- & --- & --- & --- & --- & --- & -8.0 \\
\hline
\end{tabular}


Regarding the thermal stability of PHAs, several studies observed that cellulose nanocrystals were able to improve the thermal stability of PHAs (Yu et al., 2012), whereas a slight decrease in the thermal degradation was observed in other cases (Jiang et al., 2008b; Ten et al., 2010). Table 3 summarizes the thermal parameters of PHA nanocomposites estimated from thermogravimetric analyses. It was observed that for both PHA grades, the degradation onset and maximum degradation temperature were shifted to higher temperatures for a low loading of 1 wt.-\% BCNW. However, further increases in nanofiller loading resulted in decreased thermal stability. A previous work demonstrated that the formation of six-membered ring ester during the first degradation steps of PHA was suppressed by the development of a strong intramolecular network held by hydrogen bonds established between the matrix and the cellulose nanocrystals (Yu et al., 2012). However, once the maximum degradation temperature was reached, hydrogen bonds were broken down and the process was accelerated as a result of the increased thermal conductivity of cellulose nanowhiskers (Yu et al., 2012). In the present study, it has been shown that a certain degree of BCNW agglomeration took place for concentrations higher than 1 wt.-\%. As a result of this agglomeration, the nanocrystals surface presenting hydroxyl groups available to form hydrogen bonds with the polymeric matrix may be reduced and thus, the thermal stability enhancement provided by BCNW was restricted for higher loadings. It is also worth noting that when increasing the amount of BCNW incorporated into the PHAs, the residue remaining at $400{ }^{\circ} \mathrm{C}$ increased, indicating that a higher fraction of material did not volatilize upon thermal degradation.

No great differences were found between the high and the low valerate content PHAs, although the high valerate material showed a narrower degradation profile with a slightly lower degradation temperature. This behaviour is in agreement with 
previous reports which did not find any clear relation between the valerate content and the thermal stability of PHAs (Modi et al., 2011).

Table 3. TGA maximum of the weight loss first derivate $\left(T_{D}\right)$, the corresponding peak onset values and the residue at $400^{\circ} \mathrm{C}$ for the PHA films.

\begin{tabular}{|c|c|c|c|}
\cline { 2 - 4 } \multicolumn{1}{c|}{} & Onset $\mathrm{T}\left({ }^{\circ} \mathrm{C}\right)$ & $\mathrm{T}_{\mathrm{D}}\left({ }^{\circ} \mathrm{C}\right)$ & Residue at $400^{\circ} \mathrm{C}(\%)$ \\
\hline PHBV8 & 224.7 & 290.6 & 0.4 \\
\hline PHBV8+1\%BCNW & 224.4 & 291.8 & 3.5 \\
\hline PHBV8+3\%BCNW & 240.0 & 281.4 & 7.1 \\
\hline PHBV44 & 239.4 & 287.0 & 1.8 \\
\hline PHBV44+1\%BCNW & 245.0 & 290.1 & 3.9 \\
\hline PHBV44+3\%BCNW & 224.1 & 281.5 & 6.5 \\
\hline
\end{tabular}

\subsubsection{Mechanical properties}

Mechanical properties of PHAs and their nanocomposites are summarized in Table 4. From these results, it can be deduced that when increasing the valerate content of PHAs, the elastic modulus and tensile strength decreased and the elongation at break increased markedly. The lower mechanical performance of PHBV44 may be a result of the increased amount of voids created within the films during the casting process. On the other hand, an increased elastic behaviour for higher valerate content PHAs has been previously reported in several studies (Modi et al., 2011; Savenkova et al., 2000). These results are in accordance with DSC analyses, which showed decreased glass transition temperature due to increased segmental mobility in the amorphous phase, which may lead to reduced stiffness, and lower melting enthalpy (which may be indicative of lower crystallinity), resulting in reduced brittleness for the higher valerate PHA. 
As observed in Table 4, no clear trend was detected for PHBV8 films with the addition of BCNW, whereas it seemed to result in more brittle PHBV44 films. In general, the mechanical properties of nanocomposites loaded with BCNW did not present statistically significant differences with respect to those of the pure polymer for both PHA grades. Only the PHBV44 film loaded with 3wt.-\% BCNW displayed a significant reduction for the elongation at break, probably as a result of the BCNW agglomeration observed in this case. These results are in contrast with previous works which reported increased elastic modulus and tensile strength for loadings up to 5 wt.-\% CNW (Jiang et al., 2008b; Ten et al., 2010). In those cases, polyethylene glycol (PEG) was also incorporated into the system and, therefore, the improved mechanical properties may be a result of the PEG matrix-filler compatibilization effect. In another work, a trend of increased modulus and tensile strength was observed for PHBV nanocomposites with loadings up to 2.3 wt.-\% CNW (Ten et al., 2012).

The lack of good adhesion between the nanofiller and the matrix and the nanofiller agglomeration are often causes for decreased mechanical performance of nanocomposites. Nevertheless, it seems that in the case of the nanocomposites with low BCNW loadings, the nanocrystals were nicely dispersed and the matrix-filler adhesion was good, just as suggested by cryo-SEM observations. In addition to the matrix-filler interactions, it is known that the development of strong filler-filler interactions is crucial for attaining optimized mechanical performance (Azizi Samir et al., 2005; Siqueira et al., 2009). Achieving the percolation threshold, where the nanowhiskers are strongly interconnected by a continuous network within a polymeric matrix, has been claimed as a crucial condition to obtain strong mechanical reinforcement. By using the following equation, the percolation threshold $\left(v_{R \varepsilon}\right)$ can be easily estimated on the bases of the aspect ratio (Oksman et al., 2006): 


$$
v_{E i o}=\frac{0.7}{L / d}
$$

In the above equation, $L / d$ is the aspect ratio. For the nanocomposites incorporating $\mathrm{BCNW}$, with an experimental aspect ratio of ca. 30 (Martínez-Sanz et al., 2011a), the percolation threshold should lay around 2.4 v.- $\%$ of BCNW. Given the densities of CNWs $\left(1.5 \mathrm{~g} / \mathrm{cm}^{3}\right)$ (Gindl \& Keckes, 2004) and PHBV (1.2 $\mathrm{g} / \mathrm{cm}^{3}$ ) (Graupner \& Müssig, 2011), the percolation threshold in weight ratio would be 2.6 wt.-\%. However, morphological analyses pointed out that BCNW tended to agglomerate when incorporated in a concentration of 3 wt.- $\%$. Thus, although native $\mathrm{BCNW}$ presented a high aspect ratio, it seems that they formed aggregates when incorporated in higher concentrations and they could also bend forming entanglements, thus displaying an experimental aspect ratio lower than expected when they were incorporated into the PHA matrixes, especially in the case of PHBV44. This hinders the formation of the percolation network since higher nanofiller concentrations are required. Additionally, previous studies suggested that the crystallinity development of the polymeric matrix with the nanocrystals addition may disrupt the cellulose percolation network, therefore decreasing the mechanical performance of the PHAs (Siqueira et al., 2009). 
Table 4. Young's Modulus, Tensile Strength and Elongation at Break for PLA and its nanocomposites incorporating $\mathrm{BCNW}$.

\begin{tabular}{|c|c|c|c|}
\cline { 2 - 4 } \multicolumn{1}{c|}{} & E (GPa) & $\begin{array}{c}\text { Tensile strength } \\
(\mathrm{MPa})\end{array}$ & $\varepsilon_{\mathrm{b}}(\%)$ \\
\hline PHBV8 & ${ }^{\mathrm{b}} 1.14 \pm 0.04$ & ${ }^{\mathrm{b}} 24.49 \pm 1.47$ & ${ }^{\mathrm{a}} 3.13 \pm 0.40$ \\
\hline PHBV8+1\%BCNW & ${ }^{\mathrm{b}} 1.03 \pm 0.16$ & ${ }^{\mathrm{b}} 23.18 \pm 2.07$ & ${ }^{\mathrm{a}} 2.40 \pm 0.01$ \\
\hline PHBV8+3\%BCNW & ${ }^{\mathrm{b}} 0.99 \pm 0.15$ & ${ }^{\mathrm{b}} 24.22 \pm 1.49$ & ${ }^{\mathrm{a}} 3.87 \pm 0.93$ \\
\hline PHBV44 & ${ }^{\mathrm{a}} 0.40 \pm 0.05$ & ${ }^{\mathrm{a}} 14.57 \pm 1.23$ & ${ }^{\mathrm{c}} 44.00 \pm 5.66$ \\
\hline PHBV44+1\%BCNW & ${ }^{\mathrm{a}} 0.42 \pm 0.06$ & ${ }^{\mathrm{a}} 13.75 \pm 0.63$ & ${ }^{\mathrm{c}} 51.00 \pm 7.93$ \\
\hline PHBV44+3\%BCNW & ${ }^{\mathrm{a}} 0.42 \pm 0.01$ & ${ }^{\mathrm{a}} 13.70 \pm 0.44$ & ${ }^{\mathrm{b}} 22.67 \pm 3.79$ \\
\hline
\end{tabular}

The a, b and c superscripts indicate that with a $95 \%$ confidence level, the values are significantly different, according to the ANOVA statistical analysis and Tukey test of the data.

\subsubsection{Water and oxygen barrier properties}

Several works reported on the incorporation of plant-derived cellulose nanowhiskers into PHA matrices (Jiang et al., 2008b; Ten et al., 2010; Yu et al., 2012), however to the best of our knowledge the effect of this nanofiller on the transport properties of PHAs has not been previously investigated. Table 5 gathers the barrier properties of pure PHAs and their nanocomposite films. The first clear observation is that by increasing the valerate content, PHA films present significantly lower barrier to both water and oxygen. As previously commented, both ATR-FTIR and DSC analyses, suggested that the lower valerate content PHA exhibited greater crystallinity than the high valerate content film. This is in agreement with previous studies which also corroborated that the decreased 
crystallinity of higher valerate PHA films led to increased water permeability (Modi et al., 2011; Shogren, 1997).

The effect of $\mathrm{BCNW}$ incorporation on the barrier properties was slightly different depending on the PHA grade. In general, 1 wt.- $\%$ BCNW was the optimum loading in terms of oxygen and water permeability. This observation may be related to the higher dispersion achieved for lower loadings, as well as to the highly hydrophilic character of BCNW, which may cause an increase in the water permeability and in the oxygen permeability at high relative humidity conditions.

In particular, for PHBV8 the water permeability increased with the nanofiller addition, whereas for PHBV44 a water permeability drop of ca. $28 \%$ was observed for the sample loaded with $1 \mathrm{wt} .-\% \mathrm{BCNW}$. In both cases, the barrier decreased as the nanofiller concentration increased. A previous work, in which PHBV12 films loaded with purified cellulose microfibres were produced by casting, also reported optimum barrier properties for a loading of $1 \mathrm{wt} .-\%$ cellulose microfibres, showing a water permeability decrease of $71 \%$ (Sanchez-Garcia et al., 2008). However, the PHBV grade used in that case was plasticized and showed a water permeability value one order of magnitude higher than that of the PHAs used throughout the present work. The plasticizer may enhance the compatibility between the PHA and the cellulose, although the value for the film loaded with 1 wt.- $\%$ cellulose microfibres was $3.8 \cdot 10^{-15} \mathrm{Kg} \cdot \mathrm{m} / \mathrm{s} \cdot \mathrm{m}^{2} \cdot \mathrm{Pa}$, which is close to the values here reported for the films containing $1 \mathrm{wt} .-\%$ BCNW. Other works on PHAs reinforced with cellulose nanowhiskers claimed a good nanofiller dispersion for loadings up to 2.3 wt.-\% CNW (Ten et al., 2012) and 10 wt.-\% CNW (Yu et al., 2012), nevertheless the barrier properties of the nanocomposite films were not reported in either case. 
Regarding the oxygen permeability, the low valerate PHA presented a higher barrier at both low and high relative humidity. It is interesting to note that whereas the permeability of PHBV8 slightly decreased when increasing the relative humidity, the opposite effect was observed for PHBV44, just as deduced from Table 5. The oxygen permeability decrease observed for PHBV8 has already been reported for hydrophobic polymers such as PET and PLA and it was attributed to a decrease in the oxygen solubility caused by the occupancy of the free volume by water molecules at higher water activity (Auras et al., 2004; Martínez-Sanz et al., 2012). The different behaviour for PHBV44 might be related to the non-continuous structure of this material, which was evidenced by the high amount of voids observed in the SEM micrographs and to the higher mobility of the polymeric chains promoted by the higher amount of hydroxyvalerate units, thus creating preferential diffusion paths.

As observed in Table 5, the effect of BCNW addition was strongly dependent on the moisture conditions. At $0 \% \mathrm{RH}$ the incorporation of $\mathrm{BCNW}$ resulted in a permeability drop for both PHA grades. Furthermore, despite the fact that some agglomerates were detected for $3 \mathrm{wt} .-\% \mathrm{BCNW}$, the oxygen permeability drop was higher when increasing the nanofiller loading (ca. 68\% permeability drop for PHBV8 and ca. 20\% permeability drop for PHBV44), hence demonstrating the blocking capacity of the highly crystalline BCNW. A previous study in which BCNW were incorporated into PLA by melt compounding also showed a great permeability decrease at $0 \% \mathrm{RH}$ with the addition of nanocrystals, even for those nanocomposites in which the dispersion was not optimized (Martínez-Sanz et al., 2012). In contrast, at $80 \% \mathrm{RH}$ the oxygen barrier was slightly improved only for low nanofiller loadings, i.e. 1 wt.-\% BCNW, whereas increasing the loading was detrimental for oxygen barrier properties. This seems to be a consequence of the increased moisture sensitivity of the nanocomposites when increasing the amount 
of BCNW The same behaviour was observed for PLA-BCNW melt compounded nanocomposites (Martínez-Sanz et al., 2012). In that case, it was suggested that $\mathrm{BCNW}$ promoted PLA plasticization as water molecules may distort hydrogen bonds established between the polymeric matrix and $\mathrm{BCNW}$, hence resulting in increased mobility of the polymeric chains for diffusion. Therefore, low BCNW loadings are required in order to maximize PHAs oxygen barrier within a wide range of relative humidities.

Table 5. Water permeability measured at $100 \% \mathrm{RH}$ and oxygen permeability measured at $0 \% \mathrm{RH}$ and $80 \% \mathrm{RH}$.

\begin{tabular}{|c|c|c|c|}
\cline { 2 - 4 } \multicolumn{1}{c|}{} & $\begin{array}{c}\mathrm{PH}_{2} \mathrm{O}\left(\mathrm{Kg} \cdot \mathrm{m} / \mathrm{s} \cdot \mathrm{m}^{2} \cdot \mathrm{Pa}\right) \\
100 \% \mathrm{RH}\end{array}$ & $\begin{array}{c}\mathrm{PO}_{2}\left(\mathrm{~m}^{3} \cdot \mathrm{m} / \mathrm{m}^{2} \cdot \mathrm{s} \cdot \mathrm{Pa}\right) \\
0 \% \mathrm{RH}\end{array}$ & $\begin{array}{c}\mathrm{PO}_{2}\left(\mathrm{~m}^{3} \cdot \mathrm{m} / \mathrm{m}^{2} \cdot \mathrm{s} \cdot \mathrm{Pa}\right) \\
80 \% \mathrm{RH}\end{array}$ \\
\hline PHBV8 & $2.59 \pm 0.38 \mathrm{e}^{-15}$ & $8.16 \pm 0.08 \mathrm{e}^{-19}$ & $5.29 \pm 0.05 \mathrm{e}^{-19}$ \\
\hline PHBV8+1\%BCNW & $4.50 \pm 0.41 \mathrm{e}^{-15}$ & $5.24 \pm 0.10 \mathrm{e}^{-19}$ & $5.28 \pm 0.03 \mathrm{e}^{-19}$ \\
\hline PHBV8+3\%BCNW & $4.57 \pm 1.36 \mathrm{e}^{-15}$ & $2.59 \pm 0.05 \mathrm{e}^{-19}$ & $7.58 \pm 0.07 \mathrm{e}^{-19}$ \\
\hline PHBV44 & $5.14 \pm 0.78 \mathrm{e}^{-15}$ & $10.76 \pm 0.15 \mathrm{e}^{-19}$ & $14.05 \pm 0.24 \mathrm{e}^{-19}$ \\
\hline PHBV44+1\%BCNW & $3.70 \pm 0.44 \mathrm{e}^{-15}$ & $9.45 \pm 0.20 \mathrm{e}^{-19}$ & $11.81 \pm 0.15 \mathrm{e}^{-19}$ \\
\hline PHBV44+3\%BCNW & $7.48 \pm 1.56 \mathrm{e}^{-15}$ & $8.64 \pm 0.08 \mathrm{e}^{-19}$ & $18.84 \pm 0.10 \mathrm{e}^{-19}$ \\
\hline
\end{tabular}

\section{CONCLUSIONS}

In this work, two PHA grades with different valerate contents were synthesized by using microbial mixed cultures. Subsequently, nanobiocomposites were prepared by incorporating different loadings of bacterial cellulose nanowhiskers 
into the produced PHAs by solution casting. The effects of both valerate content and $\mathrm{BCNW}$ incorporation on the morphology, thermal properties, barrier properties and mechanical properties of the generated materials were investigated.

It has been demonstrated that the properties of PHAs may be tuned by varying the valerate content of the polymer. Thus, by increasing the valerate content a material with lower melting point and enthalpy and glass transition temperature was obtained. The presumed crystallinity decrease for the high valerate PHA could be responsible for its increased transparency but on the other hand, it negatively impacted mechanical and barrier properties. The rigidity of the material was strongly reduced for PHBV44, which presented lower elastic modulus and tensile strength and higher elongation at break. In addition, this material displayed higher water and oxygen permeability and it was more sensitive to moisture than PHBV8.

BCNW were incorporated into the PHA matrixes and a high dispersion level was achieved for a low loading of 1 wt.- $\%$, whereas some agglomerates were detected for a loading of $3 \mathrm{wt} .-\%$. The incorporation of BCNW promoted the crystallization of PHAs, resulting in materials with lower cold crystallization temperature and greater melting enthalpy. The nanocomposites also had increased glass transition temperatures due to restricted polymeric chain mobility. These effects were more obvious for the lowest nanofiller loading due to the enhanced dispersion achieved in this case. Furthermore, the addition of low BCNW concentrations resulted in increased thermal stability as a result of the formation of a strong network held by hydrogen bonds between the matrix and the nanofiller. BCNW did not significantly alter the mechanical properties of PHAs, since the formation of the nanocrystals percolation network was not attained due to the agglomeration observed at higher $\mathrm{BCNW}$ loadings. Barrier properties were in general enhanced with the incorporation of $1 \mathrm{wt} .-\% \mathrm{BCNW}$. Hence, only for $1 \mathrm{wt}$-- 
$\%$ BCNW a water permeability drop of ca. $28 \%$ was observed for PHBV44, whereas no improvement was detected for the higher water barrier PHBV8. Oxygen permeability was seen to decrease with the addition of BCNW at $0 \% \mathrm{RH}$, but due to a plasticization effect the permeability of nanocomposites increased when raising the relative humidity. Hence, only for 1 wt.- $\%$ BCNW slight improvements in the oxygen permeability were attained. 


\section{REFERENCES}

Akita, S., Einaga, Y., Miyaki, Y., \& Fujita, H. (1976). Solution properties of poly(D- $\beta$-hydroxybutyrate). $1 . \quad$ Biosynthesis and characterization. Macromolecules, 9(5), 774-780.

Albuquerque, M. G. E., Torres, C. A. V., \& Reis, M. A. M. (2010). Polyhydroxyalkanoate (PHA) production by a mixed microbial culture using sugar molasses: Effect of the influent substrate concentration on culture selection. Water Research, 44(11), 3419-3433.

An, Y., Dong, L., Li, G., Mo, Z., \& Feng, Z. (2000). Miscibility, crystallization kinetics, and morphology of poly( $\beta$-hydroxybutyrate) and poly(methyl acrylate) blends. Journal of Polymer Science, Part B: Polymer Physics, 38(14), 1860-1867.

Arcos-Hernández, M. V., Laycock, B., Donose, B. C., Pratt, S., Halley, P., Al-Luaibi, S., Werker, A., \& Lant, P. A. (2013). Physicochemical and mechanical properties of mixed culture polyhydroxyalkanoate (PHBV). European Polymer Journal, 49(4), 904-913.

Auras, R., Harte, B., \& Selke, S. (2004). An overview of polylactides as packaging materials. Macromolecular Bioscience, 4(9), 835-864.

Azizi Samir, M. A. S., Alloin, F., \& Dufresne, A. (2005). Review of recent research into cellulosic whiskers, their properties and their application in nanocomposite field. Biomacromolecules, 6(2), 612-626.

Barham, P. J., Keller, A., Otun, E. L., \& Holmes, P. A. (1984). Crystallization and morphology of a bacterial thermoplastic: poly-3hydroxybutyrate. Journal of Materials Science, 19(9), 2781-2794.

Bloembergen, S., Holden, D. A., Hamer, G. K., Bluhm, T. L., \& Marchessault, R. H. (1986). Studies of composition and crystallinity of bacterial poly( $\beta$-hydroxybutyrate-co- $\beta$-hydroxyvalerate). Macromolecules, 19(11), 2865-2871. 
Chen, L., Zhu, M., Song, L., Yu, H., Zhang, Y., Chen, Y., \& Adler, H. J. (2004). Crystallization behavior and thermal properties of blends of poly(3hydroxybutyate-co-3-valerate) and poly(1,2-propandiolcarbonate). Macromolecular Symposia, 210, 241-250.

Chen, L. J., \& Wang, M. (2002). Production and evaluation of biodegradable composites based on PHB-PHV copolymer. Biomaterials, 23(13), 2631-2639.

Choi, J. S., \& Park, W. H. (2004). Effect of biodegradable plasticizers on thermal and mechanical properties of poly(3-hydroxybutyrate). Polymer Testing, 23(4), 455-460.

De Souza Lima, M. M., \& Borsali, R. (2004). Rodlike cellulose microcrystals: Structure, properties, and applications. Macromolecular Rapid Communications, 25(7), 771-787.

Drieskens, M., Peeters, R., Mullens, J., Franco, D., Iemstra, P. J., \& Hristova-Bogaerds, D. G. (2009). Structure versus properties relationship of poly(lactic acid). I. effect of crystallinity on barrier properties. Journal of Polymer Science, Part B: Polymer Physics, 47(22), 2247-2258.

Feng, L., Watanabe, T., Wang, Y., Kichise, T., Fukuchi, T., Chen, G. Q., Doi, Y., \& Inoue, Y. (2002). Studies on comonomer compositional distribution of bacterial poly(3-hydroxybutyrate-co-3-hydroxyhexanoate)s and thermal characteristics of their factions. Biomacromolecules, 3(5), 1071-1077.

Gindl, W., \& Keckes, J. (2004). Tensile properties of cellulose acetate butyrate composites reinforced with bacterial cellulose. Composites Science and Technology, 64(15 SPEC. ISS.), 2407-2413.

Graupner, N., \& Müssig, J. (2011). A comparison of the mechanical characteristics of kenaf and lyocell fibre reinforced poly(lactic acid) (PLA) and poly(3-hydroxybutyrate) (PHB) composites. Composites Part A: Applied Science and Manufacturing, 42(12), 2010-2019. 
Hajji, P., Cavaille, J. Y., Favier, V., Gauthier, C., \& Vigier, G. (1996). Tensile behavior of nanocomposites from latex and cellulose whiskers. Polymer Composites, 17(4), 612-619.

Hirai, A., Inui, O., Horii, F., \& Tsuji, M. (2009). Phase separation behavior in aqueous suspensions of bacterial cellulose nanocrystals prepared by sulfuric acid treatment. Langmuir, 25(1), 497-502.

Hossain, K. M. Z., Ahmed, I., Parsons, A. J., Scotchford, C. A., Walker, G. S., Thielemans, W., \& Rudd, C. D. (2012). Physico-chemical and mechanical properties of nanocomposites prepared using cellulose nanowhiskers and poly(lactic acid). Journal of Materials Science, 47(6), 2675-2686.

Jiang, L., Huang, J., Qian, J., Chen, F., Zhang, J., Wolcott, M. P., \& Zhu, Y. (2008a). Study of poly(3-hydroxybutyrate-co-3-hydroxyvalerate) (PHBV)/bamboo pulp fiber composites: Effects of nucleation agent and compatibilizer. Journal of Polymers and the Environment, 16(2), 83-93.

Jiang, L., Morelius, E., Zhang, J., Wolcott, M., \& Holbery, J. (2008b). Study of the poly(3-hydroxybutyrate-co-3-hydroxyvalerate)/cellulose nanowhisker composites prepared by solution casting and melt processing. Journal of Composite Materials, 42(24), 2629-2645.

Kunioka, M., \& Doi, Y. (1990). Thermal degradation of microbial copolyesters poly(3-hydroxybutyrate-co-3-hydroxyvalerate) and poly(3hydroxybutyrate-co-4-hydroxybutyrate) Macromolecules, 23(7), 1933-1936.

Kurata, M., \& Tsunashima, Y. (1988). Molecular Weight Relationships and Unperturbed Dimensions of Linear Chain Molecules. In I. John Wiley and Sons. Polymer Handbook. New York: John Wiley and Sons.

Liu, H., Pancholi, M., Stubbs Iii, J., \& Raghavan, D. (2010). Influence of hydroxyvalerate composition of polyhydroxy butyrate valerate (PHBV) copolymer on bone cell viability and in vitro degradation. Journal of Applied Polymer Science, 116(6), 3225-3231. 
Lundgren, D. G., Alper, R., Schnaitman, C., \& Marchessault, R. H. (1965). Characterization of poly- $\beta$-hydroxybutyrate extracted from different bacteria. J. Bacteriol., 89, 245-251.

Martínez-Sanz, M., Lopez-Rubio, A., \& Lagaron, J. (2011a). Optimization of the nanofabrication by acid hydrolysis of bacterial cellulose nanowhiskers. Carbohydrate Polymers, 85(1), 228-236.

Martínez-Sanz, M., Lopez-Rubio, A., \& Lagaron, J. M. (2012). Optimization of the dispersion of unmodified bacterial cellulose nanowhiskers into polylactide via melt compounding to significantly enhance barrier and mechanical properties. Biomacromolecules, 13(11), 3887-3899.

Martínez-Sanz, M., Olsson, R. T., Lopez-Rubio, A., \& Lagaron, J. M. (2011b). Development of electrospun EVOH fibres reinforced with bacterial cellulose nanowhiskers. Part I: Characterization and method optimization. Cellulose, 18(2), 335-347.

Martínez-Sanz, M. L.-R., A.; Lagaron, J. (2012a). Nanocomposites of ethylene vinyl alcohol copolymer with thermally resistant cellulose nanowhiskers by melt compounding (I): Morphology and thermal properties. Journal of Applied Polymer Science, 128 (5), 2666-2678.

Martínez-Sanz, M. L.-R., A.; Lagaron, J. (2012b). Nanocomposites of ethylene vinyl alcohol copolymer with thermally resistant cellulose nanowhiskers by melt compounding (II): Water barrier and mechanical properties. Journal of Applied Polymer Science, 128 (3), 2197-2207.

Mitomo, H., Takahashi, T., Ito, H., \& Saito, T. (1999). Biosynthesis and characterization of poly(3-hydroxybutyrate-co-3-hydroxyvalerate) produced by Burkholderia cepacia D1. International Journal of Biological Macromolecules, 24(4), 311-318.

Modi, S., Koelling, K., \& Vodovotz, Y. (2011). Assessment of PHB with varying hydroxyvalerate content for potential packaging applications. European Polymer Journal, 47(2), 179-186. 
Moita, R., \& Lemos, P. C. (2012). Biopolymers production from mixed cultures and pyrolysis by-products. Journal of Biotechnology, 157(4), 578583.

Oksman, K., Mathew, A. P., Bondeson, D., \& Kvien, I. (2006). Manufacturing process of cellulose whiskers/polylactic acid nanocomposites. Composites Science and Technology, 66(15), 2776-2784.

Sanchez-Garcia, M. D., Gimenez, E., \& Lagaron, J. M. (2008). Morphology and barrier properties of solvent cast composites of thermoplastic biopolymers and purified cellulose fibers. Carbohydrate Polymers, 71(2), 235-244.

Sanchez-Garcia, M. D., \& Lagaron, J. M. (2010). Novel clay-based nanobiocomposites of biopolyesters with synergistic barrier to UV light, gas, and vapour. Journal of Applied Polymer Science, 118(1), 188-199.

Savenkova, L., Gercberga, Z., Bibers, I., \& Kalnin, M. (2000). Effect of 3hydroxy valerate content on some physical and mechanical properties of polyhydroxyalkanoates produced by Azotobacter chroococcum. Process Biochemistry, 36(5), 445-450.

Scandola, M., Ceccorulli, G., Pizzoli, M., \& Gazzano, M. (1992). Study of the crystal phase and crystallization rate of bacterial poly(3hydroxybutyrate-co-3-hydroxyvalerate). Macromolecules, 25(5), 14051410 .

Serafim, L. S., Lemos, P. C., Torres, C., Reis, M. A. M., \& Ramos, A. M. (2008). The Influence of Process Parameters on the Characteristics of Polyhydroxyalkanoates Produced by Mixed Cultures. Macromolecular Bioscience, 8(4), 355-366.

Shogren, R. (1997). Water vapor permeability of biodegradable polymers. Journal of Environmental Polymer Degradation, 5(2), 91-95.

Siqueira, G., Bras, J., \& Dufresne, A. (2009). Cellulose whiskers versus microfibrils: Influence of the nature of the nanoparticle and its surface 
functionalization on the thermal and mechanical properties of nanocomposites. Biomacromolecules, 10(2), 425-432.

Ten, E., Bahr, D. F., Li, B., Jiang, L., \& Wolcott, M. P. (2012). Effects of cellulose nanowhiskers on mechanical, dielectric, and rheological properties of poly(3-hydroxybutyrate-co-3-hydroxyvalerate)/cellulose nanowhisker composites. Industrial and Engineering Chemistry Research, 51(7), 29412951.

Ten, E., Turtle, J., Bahr, D., Jiang, L., \& Wolcott, M. (2010). Thermal and mechanical properties of poly(3-hydroxybutyrate-co-3hydroxyvalerate)/cellulose nanowhiskers composites. Polymer, 51(12), 2652-2660.

Villano, M., Beccari, M., Dionisi, D., Lampis, S., Miccheli, A., Vallini, G., \& Majone, M. (2010). Effect of $\mathrm{pH}$ on the production of bacterial polyhydroxyalkanoates by mixed cultures enriched under periodic feeding. Process Biochemistry, 45(5), 714-723.

Wang, Y., Yamada, S., Asakawa, N., Yamane, T., Yoshie, N., \& Inoue, Y. (2001). Comonomer compositional distribution and thermal and morphological characteristics of bacterial poly(3-hydroxybutyrate-co-3hydroxyvalerate)s with high 3-hydroxyvalerate content. Biomacromolecules, 2(4), 1315-1323.

Yau, W. W., Kirkland, J. J., \& Bly, D. D. (1979). Modern Size-Exclusion Liquid Chromatography. New York: John Wiley and Sons.

Yoshie, N., Azuma, Y., Sakurai, M., \& Inoue, Y. (1995). Crystallization and compatibility of poly(vinyl alcohol)/poly(3-hydroxybutyrate) blends: influence of blend composition and tacticity of poly(vinyl alcohol). Journal of Applied Polymer Science, 56(1), 17-24.

You, J. W., Chiu, H. J., \& Don, T. M. (2003). Spherulitic morphology and crystallization kinetics of melt-miscible blends of poly(3-hydroxybutyrate) with low molecular weight poly(ethylene oxide). Polymer, 44(15), 43554362 . 
Yu, H. Y., Qin, Z. Y., Liu, Y. N., Chen, L., Liu, N., \& Zhou, Z. (2012). Simultaneous improvement of mechanical properties and thermal stability of bacterial polyester by cellulose nanocrystals. Carbohydrate Polymers, 89(3), 971-978. 

IV . CONCLUSIONS 

The present work investigated on the properties of bacterial cellulose nanowhiskers and their application for the development of nanocomposites with enhanced properties for food packaging applications. Bacterial cellulose nanowhiskers were incorporated into polymeric and biopolymeric materials to improve their properties. Moreover, the production of high barrier films for packaging using bacterial cellulose nanowhiskers as the base material was also investigated

The main conclusions drawn form this work are summarized as follows:

- Highly crystalline, thermally stable $\mathrm{BCNW}$ were produced by the combination of a strong hydrolysis treatment with sulphuric acid followed by neutralization.

- Nanocomposites incorporating BCNW were produced through methods which involve the use of solvents, such as casting, electrospinning or blow spinning by subjecting the $\mathrm{BCNW}$ to a solvent exchange procedure or by chemically modifying their surface.

- The use of pre-incorporation techniques was proven to be an efficient strategy for avoiding BCNW agglomeration in melt compounded nanocomposites. In particular, pre-incorporation through electrospun fibres seemed to be especially effective for improving the dispersion of BCNW in both hydrophilic and hydrophobic polymers, leading also to a better matrix-filler adhesion.

- Hybrid fibres could be synthesized by incorporating BCNW into polymeric materials, such as EVOH and PLA, by means of electrospinning or solution blow 
spinning, provided that suitable solvents and optimum processing parameters were selected.

- The addition of BCNW affected notably the electrospinning or blow spinning solution properties, increasing the viscosity and the surface tension, as well as the conductivity (cf. Electrospinning solutions characterization in Anexes). In the case of electrospinning, the effect of the conductivity prevailed over the effect of the viscosity and therefore, the diameter of electrospun fibres tended to decrease when increasing the loading or dispersion level of BCNW.

- The incorporation of BCNW into electrospun fibres restricted the mobility of the polymeric chains. This effect was more obvious for higher molecular weight polymers and for reduced matrix-filler compatibility. As a result, BCNW promoted the crystallinity of $\mathrm{EVOH}$, whereas for a more hydrophobic matrix such as PLA, the nanocrystals may hinder the crystallization of the polymer depending on its molecular weight. Moreover, in most cases hybrid fibres displayed increased stiffness, which was evidenced by greater glass transition temperatures.

- In general, the incorporation of BCNW in nanocomposite materials increased their rigidity and brittleness. The reduction in the ductility might be limited or even avoided by increasing the dispersion of BCNW or by improving the matrix-filler adhesion. On the other hand, for highly dispersed BCNW optimal mechanical performance was encountered when achieving the percolation threshold, which for the synthesized BCNW corresponded to loadings around 2-3 wt.- $\%$. 
- The water barrier properties of nanocomposites incorporating BCNW were seen to be mainly influenced by the nanofiller loading, dispersion and matrix-filler adhesion.

- The incorporation of freeze-dried BCNW resulted in the creation of preferential diffusion paths through the interphases between the polymer matrix and the filler agglomerates, thus resulting in increased water permeability for both PLA and EVOH.

- In the case of EVOH it was necessary to increase the BCNW concentration to attain water permeability reductions, since for higher loadings the water sorption drop was high enough to counteract the decreased amorphous density, which was responsible for greater diffusion coefficients.

- On the other hand, due to the reduced compatibility between PLA and $\mathrm{BCNW}$, they did not seem to disrupt the polymeric network and the diffusion coefficient decreased by incorporating BCNW.

- The oxygen barrier of nanocomposites containing BCNW was mainly influenced by the nanofiller dispersion and matrix-filler adhesion, as well as by the relative humidity conditions.

- At low relative humidity, all the nanocomposites containing BCNW presented reduced oxygen permeability due to the blocking capacity of the highly crystalline nanofiller. 
- However, lower oxygen permeability reductions were attained at high relative humidity conditions, due to the distortion of the hydrogen bonds established between the cellulose chains and/or with the polymeric matrix.

- Fibres with antimicrobial properties could be synthesized by incorporating additives, such as THC and carvacrol, into PLA, through blow spinning and the antimicrobial effect could be maximized by the addition of a hydrophilic component, such as gelatin. The addition of $\mathrm{BCNW}$ into the fibres further promoted the water sorption.

- Surface modification of BCNW by grafting of poly(glycidyl methacrylate) was seen to enhance the adhesion between BCNW and PLA, leading to increased dispersion of PGMA-grafted BCNW in PLA nanocomposites, increased ductility and reduced detrimental effect of moisture on the oxygen barrier properties at high relative humidity, as compared to unmodified BCNW.

- Fully bio-based nanocomposites synthesized by bacteria were produced by incorporating $\mathrm{BCNW}$ into PHAs by solution casting. PHAs properties could be tuned within a certain window by varying the valerate content and barrier properties could be improved, especially for the low valerate PHA, with low BCNW loadings.

- It was possible to produce high barrier materials based on BCNW films coated with annealed PLA electrospun nanostructured fibres. This novel coating approach guaranteed a good adhesion between the different layers. Thus, the detrimental effect of moisture on the barrier properties of BCNW was strongly limited. 
V. ANNEXES 



\section{ELECTROSPINNING SOLUTIONS CHARACTERIZATION}

Table 1. Viscosity, surface tension and conductivity of electrospinning solutions and average diameter of the corresponding fibres.

\begin{tabular}{|l|c|c|c|c|}
\cline { 2 - 5 } \multicolumn{1}{l|}{} & Viscosity $(\mathrm{cP})$ & $\begin{array}{c}\text { Surface Tension } \\
(\mathrm{mN} / \mathrm{m})\end{array}$ & Conductivity $(\mu \mathrm{S})$ & $\begin{array}{c}\text { Average fibre } \\
\text { diameter }(\mathrm{nm})\end{array}$ \\
\hline EVOH32 & 35.3 & 23.5 & 9.8 & $182.4 \pm 79.0$ \\
\hline EVOH32+15\%BCNW & $>1999$ & 24.8 & 113.8 & $131.9 \pm 53.0$ \\
\hline PLA & 119.8 & 19.4 & 4.9 & $484.0 \pm 189.3$ \\
\hline PLA+15\%BCNW & 579.6 & 27.7 & 9.7 & $90.7 \pm 49.1$ \\
\hline PHBV3 & 481.8 & 19.9 & 16.8 & $319.6 \pm 83.6$ \\
\hline PHBV3+15\%BCNW & $>1999$ & $---{ }^{(*)}$ & 113.0 & $156.5 \pm 65.1$ \\
\hline
\end{tabular}

(*) The material presented a gel-like consistency which impeded a correct measurement.

Description of characterized solutions:

- EVOH32 and EVOH32+15\%BCNW: 5\%w/v solids in 2-propanol/water 70/30 $(\mathrm{v} / \mathrm{v})$.

- PLA: 8 wt.-\% solids in HFP.

- PLA+15\%BCNW: 6 wt.- $\%$ solids in HFP.

- PHBV3 and PHBV3+15\%BCNW: 6 wt.-\% solids in TFE. 


\title{
Development of electrospun EVOH fibres reinforced with bacterial cellulose nanowhiskers. Part I: Characterization and method optimization
}

\author{
Marta Martínez-Sanz · Richard T. Olsson •
}

Amparo Lopez-Rubio $\cdot$ Jose M. Lagaron

\begin{abstract}
In the present study, hybrid electrospun EVOH fibres reinforced with bacterial cellulose nanowhiskers (BCNW) were developed and characterized. The nanowhiskers, obtained by sulphuric acid digestion of native bacterial cellulose mats generated by Gluconacetobacter xylinum, were morphologically characterized by SEM and optical microscopy with polarized light and revealed a highly crystalline structure of nanofibrils aggregates. XRD analyses suggested a crystalline structure corresponding to the cellulose I allomorph. It was also confirmed by means of FT-IR spectroscopy that amorphous regions were preferentially digested by the acid treatment, whereas TGA analyses showed a decrease in the thermal stability of the nanowhiskers most likely due to incorporation of sulphate groups and the inherent acidity remaining in the filler even after extensive washing cycles. A method was developed for improving the incorporation of $\mathrm{BCNW}$ within the EVOH electrospun fibres, consisting on the addition of the BCNW in the form of a centrifuged precipitate, versus the most conventionally employed
\end{abstract}

M. Martínez-Sanz · A. Lopez-Rubio · J. M. Lagaron (ه) Novel Materials and Nanotechnology Group, IATA, CSIC, Apdo. Correos 73, 46100 Burjassot, Spain

e-mail: lagaron @iata.csic.es

R. T. Olsson

Department of Fiber and Polymer Technology,

Royal Institute of Technology, Teknikringen 56,

10044 Stockholm, Sweden freeze-dried nanowhiskers. DSC analyses showed a significant increase in the glass transition temperature of the composites during the second heating run, which may be related to the acidic character of the nanofiller. Finally, sonication was seen to enhance interfacial interaction but to reduce the incorporation of the filler in the matrix in the case of the centrifuged material.

Keywords Bacterial cellulose - Electrospinning . Nanowhiskers - EVOH $\cdot$ Hybrid fibres

\section{Introduction}

Cellulose is the most abundant biopolymer found in nature, as it is the major cell-wall component of plants. Plant-derived cellulose has been widely used as reinforcement in polymeric matrixes (Garcia de Rodríguez et al. 2006; Oksman et al. 2006; Angles and Dufresne 2001; Orts et al. 2005). Besides cellulose from plants, cellulose is also secreted extracellularly as synthesized cellulose fibres by some bacterial species and it is known as bacterial cellulose (BC). Plant cellulose and BC have the same chemical structure although they have different structural organization and mechanical properties. Compared with plant cellulose, $\mathrm{BC}$ possesses higher water holding capacity, higher purity and crystallinity and a finer web-like network (Iguchi et al. 2000; Wan 
Carbohydrate Polymers 85 (2011)228-236

\section{Optimization of the nanofabrication by acid hydrolysis of bacterial cellulose nanowhiskers}

Marta Martínez-Sanz, Amparo Lopez-Rubio, Jose M. Lagaron*

Novel Materials and Nanotechnology Group, IATA, CSIC, Av. Agustin Escardino 7, 46980 Paterna (Valencia), Spain.

\section{A RTICLE INFO}

\section{Article history:}

Received 3 December 2010

Received in revised form 4 February 2011

Available online 16 February 2011

\section{Keywords:}

Bacterial cellulos

Cellulose

Morphology

Nanowhisker

Nanocrystals

\begin{abstract}
A B S T R A C T
This work aims at examining the various factors that affect cellulose nanowhiskers (CNWs) extraction from bacterial cellulose (BC). Specifically, the effect of sulfuric acid hydrolysis time and further treatments such as neutralization and dialysis on the properties of the obtained nanoparticles was studied The morphology of BCNWs was examined by TEM, showing a decrease in the nanowhiskers' length when increasing hydrolysis time as expected. The XRD patterns of the different samples showed a crystalline structure characteristic of the cellulose 1 allomorph. From the calculated crystallinity indexes it was deduced that long hydrolysis times, such as $48 \mathrm{~h}$, are required when intending to digest a significant deduced that lo fraction of amorphous material and thus, obtaining a significant increase in crystallinity by comparison with he acid hydrolysis treatment. the thermal stability of the material is significantly decreased, making it unsuitable for most meltcompoundable polymer-based nanocomposites applications. On the other hand, neutralization produced a slight increase in the crystallinity index, and, most importantly, it led to a remarkable increase on the BCNWs thermal stability, as determined by TGA. Furthermore, it was found out that dialysis applied after neutralization did not present any additional improvement on the BCNWs' properties.

O 2011 Elsevier Ltd. All rights reserved.
\end{abstract}

\section{Introduction}

Cellulose is one of the most abundant biopolymers on earth. Vegetal resources such as wood, cotton and linter are the most commonly raw materials employed to extract cellulose. Nevertheless, cellulose can be also synthesized by some bacterial species, such as Gluconacetobacter xylinum. In a static culture medium rich in polysaccharides, this bacterial species is able to produce a layer of bacterial cellulose (BC) in the liquid/air interface. This highly hydrated pellicle consists of a random assembly of ribbon-shaped fibrils, less than $100 \mathrm{~nm}$ wide, which are composed of a bundle of nanofibrils (Yamanaka et al., 1989). Although plant-derived cellulose $(\mathrm{PC})$ and $\mathrm{BC}$ have the same chemical structure, they have different structural organization and mechanical properties. BC shows a finer web-like network structure, higher water holding capacity and higher crystallinity (Iguchi, Yamanaka, \& Budhiono, 2000; Wan et al., 2007). Furthermore, while PC is naturally associated with other kinds of biopolymers such as hemicelluloses and lignin, BC is practically pure cellulose. Due to its outstanding properties, i.e. high purity, high crystallinity, high mechanical strength, low density and biocompatibility, bacterial cellulose has

\footnotetext{
* Corresponding author. Tel: +34 963900022; fax: +34 963636301. E-mail address: lagaroniara csices (JM. Lagaronj.

become an interesting material with applications in biomedicine (Czaja, Krystynowicz, Bielecki, \& Brown, 2006; Klemm, Schumann, Udhardt, \& Marsch, 2001: Svensson et al., 2005), paper industry and, more recently, as a reinforcement agent for polymeric matrixes (Gindl \& Keckes, 2004; Millon \& Wan, 2006; Park, Kang, Kim, \& Jin, 2007: Wan et al., 2009).

For their application as nanofillers, cellulosic materials are usually subjected to hydrolysis with strong acids such as sulfuric acid or hydrochloric acid, which produce a preferential digestion of the amorphous domains of the material and cleavage of the nanofibril bundles (Rànby, 1949), therefore breaking down the hierarchical structure of the material into crystalline nanofibres or nanocrystals usually referred to as cellulose nanowhiskers (CNWs). The morphology of the obtained CNWs depends on the cellulose source and the hydrolysis conditions. While CNWs extracted from vegetal resources such as cotton or wood typically have a length of $100-300 \mathrm{~nm}$ and width of 5-20 nm (Araki, Wada, Kuga, \& Okano 1998; Favier, Chanzy, \& Cavaille, 1995; Siaueira, Bras, \& Dufresne. 2009). CNWs obtained from tunicin and bacterial cellulose may have several micrometres in length and a width of $5-50 \mathrm{~nm}$ (Araki \& Kuga, 2001; De Souza Lima, Wong, Paillet, Borsali, \& Pecora, 2003 Hirai, Inui, Horii, \& Tsuji, 2009). Regarding the hydrolysis conditions, the acid concentration, cellulose/ acid ratio, temperature and hydrolysis time are factors which determine the CNWs' morphology. The CNWs' aspect ratio $(L / D)$ is a crucial parameter which has 


\title{
Development of Bacterial Cellulose Nanowhiskers Reinforced EVOH Composites by Electrospinning
}

\author{
Marta Martínez-Sanz, ${ }^{1}$ Richard T. Olsson, ${ }^{2}$ Amparo Lopez-Rubio, ${ }^{1}$ Jose M. Lagaron $^{1}$ \\ ${ }^{1}$ Novel Materials and Nanotechnology Group, LATA, CSIC, 46980 Paterna (Valencia), Spain \\ ${ }^{2}$ Department of Fiber and Polymer Technology, Royal Institute of Technology, Teknikringen 56, \\ 10044 Stockholm, Sweden \\ Received 13 March 2011; accepted 6 June 2011 \\ DOI 10.1002/app.35052 \\ Published online 18 October 2011 in Wiley Online Library (wileyonlinelibrary.com).
}

ABSTRACT: In the current study, hybrid electrospun ethylene vinyl alcohol (EVOH) fibers reinforced with bacterial cellulose nanowhiskers (BCNW) were developed and characterized. Additionally, electrospinning was suggested as a method for the incorporation of well-dispersed $\mathrm{BCNW}$ into an EVOH matrix by melt compounding. With the aim of maximizing the BCNW's loading in the electrospun fibers, an optimized method was applied for generating fibers from solutions containing up to $40 \mathrm{wt} \%$ BCNW. As demonstrated by FTIR spectroscopy, it was possible to incorporate $\mathrm{BCNW}$ concentrations up to $\sim 24$ wt $\%$, although a complete incorporation of the nanofiller into the fibers was only achieved with solutions containing up to $20 \mathrm{wt} \%$ of the filler, DSC analyses suggested that the incorporation of the nanofiller reduced the crystallinity of the as-obtained EVOH fibers and produced an increase in the glass transition temperature of these during the second heating run. Thermogravimetric analyses showed that even though EVOH protects the nanowhiskers from thermal degradation, the electrospun hybrid fibers present a relatively lower thermal stability than the pure EVOH fibers. FTIR analyses of the samples subjected to different thermal treatments confirmed that the stiffening effect observed by DSC only occurs after melting of the EVOH phase and is cooperative with a partial acid chemical development in the $\mathrm{BCNW}$, which promotes strong chemical interactions between the polymeric matrix and the nanofiller. Finally, the hybrid electrospun fibers were incorporated into pure EVOH by melt compounding to produce composite films. This methodology showed higher stability and dispersion of the BCNW than direct addition of the freeze-dried nanofiller to EVOH. 92011 Wiley Periodicals, Inc. J Appl Polym Sci 124: 1398-1408, 2012

Key words: bacterial cellulose; electrospinning; nanocomposites; $\mathrm{EVOH}$; melt compounding

\section{INTRODUCTION}

The electrospinning technique has recently attracted considerable interest since it is a versatile method to produce continuous polymer fibers with diameters in the submicron range with applicability as textiles, ${ }^{1}$ wound dressings, ${ }^{2}$ tissue engineering scaf folds, ${ }^{3}$ electronic devices, ${ }^{4}$ and, more recently, in the nanocomposites field. ${ }^{5-7}$ Since recently, great efforts are being focused on the use of nanofillers from renew able resources and, specifically, cellulose nanowhiskers (CNW) have gained great interest for their use as nanoreinforcement in electrospun fibers. Electrospinning has recently been applied to obtain

Correspondence to: J. M. Lagaron (lagaron@iata.csic.es). Contract grant sponsor: Spanish Ministry of Education contract grant number. FPU grant 1484 .

Contract grant sponsor: Spanish Ministry of Science and Innovation.

Contract grant sponsor: MICINN; contract grant number: MAT2009-14533-C02-01 project.

Contract grant sponsor: EU FP7 ECOBIOCAP project.

Journal of Applied Polymer Science, Vol. 124, 1398-1408 (2012) ๑ 2011 Wiley Periodicals, Inc. cellulose fibers $^{8,9}$ as well as hybrid fibers reinforced by cellulose whiskers.

Cellulose is one of the most abundant biopolymers found in nature and it is commonly extracted from vegetal resources such as wood, cotton, and linter However, it can also be synthesized by some bacterial species, which in a culture medium rich in polysaccharides are able to produce a layer of bacterial cellulose (BC). With the aim of removing amorphous regions, cellulosic materials are usually subjected to acid hydrolysis, breaking down the hierarchical structure of the material into crystalline nanocrystals, commonly known as CNW. As a result of their remarkable mechanical properties, as well as their fully degradable and renewable character, $\mathrm{CNW}$ have been widely used as reinforcing filler for polymeric matrices such as poly(lactic acid) (PLA), ${ }^{10,11}$ poly(hydroxybutyratevalerate) (PHBV), ${ }^{1213}$ starch, ${ }^{14}$ and polyvinyl acetate. ${ }^{15}$

$\mathrm{CNW}$ have been used to reinforce electrospun polystyrene nanofibres. ${ }^{16}$ The material was added as a freeze-dried product and the dispersion of the nanoreinforcement in tetrahydrofuran (THF) w as improved by adding a nonionic surfactant. Cellulose nanocrystals were successfully incorporated from aqueous suspensions into electrospun poly(vinyl alcohol) fibers 


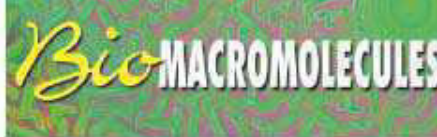

\section{Optimization of the Dispersion of Unmodified Bacterial Cellulose Nanowhiskers into Polylactide via Melt Compounding to Significantly Enhance Barrier and Mechanical Properties}

Marta Martinez-Sanz, Amparo Lopez-Rubio, and Jose M. Lagaron*

Novel Materials and Nanotechnology Group, IATA, CSIC, Avda. Agustín Escardino, 7, 46980 Paterna, Valencia, Spain

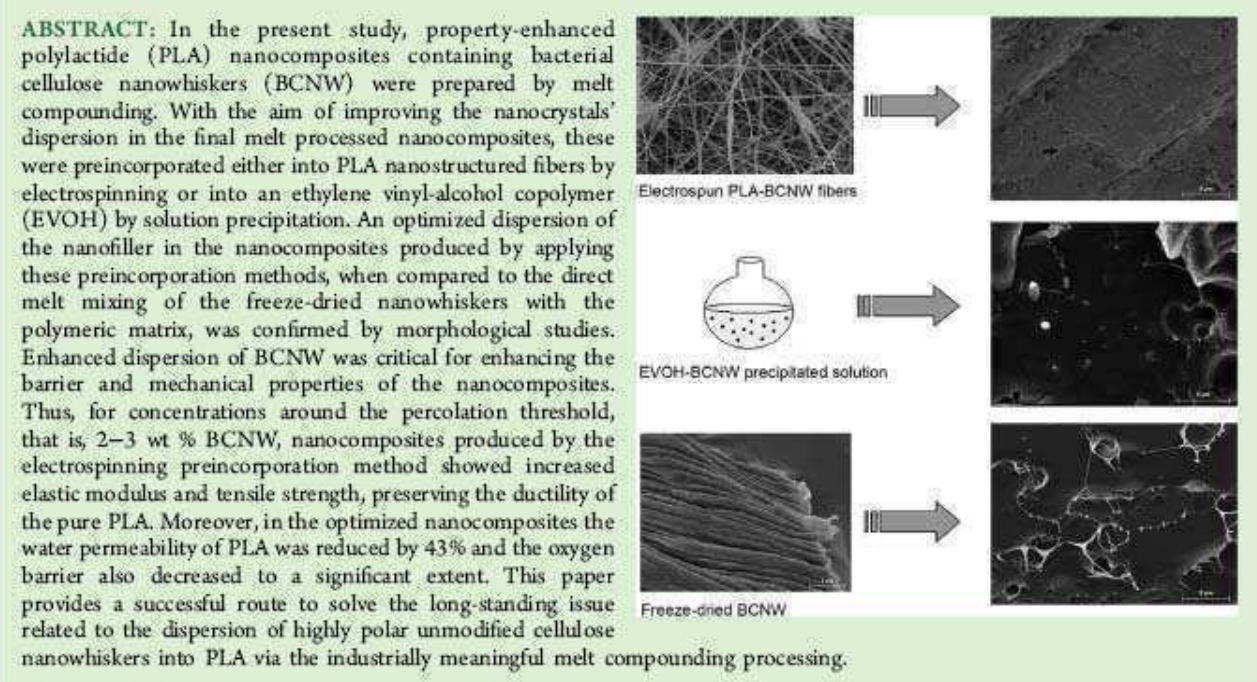

\section{INTRODUCTION}

PLA is a biodegradable, aliphatic biopolyester produced from $\mathrm{t}$. and D-lactic acid, which can be derived from fermentation of corn starch. ${ }^{1}$ As a result of the growing interest in the development of biodegradable materials for applications such as packaging and medicine, PLA bas been extensively studied during the last years and it is already commercially available. Among the available biopolymers, PLA is one of the most attractive materials due to its high transparency and relatively easy processability. Furthermore, it is suitable for electrospinning and several works have previously reported the successful production of submicrometer PLA fibers. ${ }^{2.3}$ Nevertheless, this biopolyester still presents some drawbacks such as low thermal resistance, excessive brittleness, and relatively low barrier to oxygen and water vapor as compared to other packaging materials such as polyethylene terephthalate (PET). The incorporation of nanopartides such as nanoclays and cellulose nanocrystals has been proposed as a strategy for enhancing the properties of PLA and many works have reported on the production of hybrid PLA materials. ${ }^{4-9}$
Bacterial cellulose nanowhiskers (BCNW) represent an interesting alternative for the production of PLA nanobiocomposites with improved properties. Cellulose is typically extracted from vegetal resources, but it can also be synthesized by some bacterial species, such as Giuconactobacter xylinus, which in a culture medium rich in polysaccharides is able to produce a layer of nearly pure bacterial cellulose (BC). By subjecting $B C$ to acid hydrolysis, it is possible to obtain cellulose nanowhiskers (BCNW) presenting a highly crystalline structure, ${ }^{10}$ with several micrometres in length and a width of $5-50 \mathrm{~nm}^{11,12}$ One of the main difficulties associated with the use of unmodified cellulose nanowhiskers as reinforcing agents is their high hydrophilicity, which makes it difficult to disperse them in nonpolar media. To overcome this issue and allow for the dispersion of cellulose nanowhiskers in organic media, the most common alternatives are the use of surfactants, ${ }^{13}$ which are able to coat the whiskers, or by surface chemical

Received: September 12, 2012

Revised: September 14, 2012

Published: September 17, 2012 


\title{
Applied Polymer
}

\section{Nanocomposites of Ethylene Vinyl Alcohol Copolymer with Thermally Resistant Cellulose Nanowhiskers by Melt Compounding (I): Morphology and Thermal Properties}

\author{
Marta Martínez-Sanz, Amparo Lopez-Rubio, Jose M. Lagaron \\ Novel Materials and Nanotechnology Group, IATA, CSIC, 46980 Paterna (Valencia), Spain \\ Correspondence to: J. M. Lagaron (E-mail: lagaron@iata.csic.es)
}

ABSTRACT: In this study, ethylene-vinyl alcohol copolymer (EVOH) nanocomposites were prepared by melt compounding both plan cellulose nanowhiskers (CNW) and bacterial cellulose nanowhiskers (BCNW) as nanofillers. Electrospinning and a "dissolution precipitation" method were used as strategies for the incorporation of CNW in EVOH before melt compounding with the aim of enhancing the degree of dispersion of the nanocrystals when compared with direct melt-mixing of the freeze-dried product with the polymer. As revealed by morphological characterization, the proposed preincorporation methods led to a significant improvement in the dispersion of the nanofiller in the final nanocomposite films. Furthermore, it was possible to incorporate concentrations as high as $4 \mathrm{wt} \%$ BCNW without causing significant agglomeration of the nanofiller, whereas increasing the CNW concentration up to 3 wt \%o induced agglomeration. Finally. DSC studies indicated that the crystalline content was significantly reduced when the incorporation method led to a poor dispersion of the nanocrystals, whereas high-nanofiller dispersion resulted in thermal properties similar to those of the neat EVOH. $\odot 2012$ Wiley Periodicals Inc. I. Appl. Polym. Sci. 128: 2666-2678, 2013

KEYWORDS: biodegradable; biopolymers and renewable polymers; cellulose and other wood products

Received 14 June 2012; accepted 3 August 2012; published online 23 August 2012

DOl: $10.1002 / a p p .38433$

\section{INTRODUCTION}

The great interest of using materials obtained from renewable sources, on which currently many efforts are being focused, is one of the reasons why the use of cellulosic materials as reinforcement agents in nanocomposites has recently gained so much attention. Cellulose is one of the most abundant biopolymers found in nature, and it is commonly extracted from vegetal resouroes such as wood, cotton, and linter. However, it can also be synthesized by some bacterial species, such as Gluconacetobacter xylinus, which, in a culture medium rich in polysaccharides, are able to produce a layer of bacterial cellulose (BC). Compared to plant-derived cellulose (PC), BC shows a finer web-like network structure, higher water holding capacity, and higher crystallinity. ${ }^{1,2}$

For their application in nanocomposites, cellulosic materials are commonly subjected to acid hydrolysis, breaking down the hierardhical structure of the material into crystalline nanofibers or nanocrystals, usually known as cellulose nanowhiskers (CNW). The hydrolysis conditions strongly influence the morphology of the extracted $C N W$ and their aspect ratio $(L D)$, which has a remarkable influence on the reinforcing capacity when incorporating the nanofiller into a polymeric matrix. ${ }^{3}$ In addition to the hydrolysis conditions, the cellulose source has an important effect on the morphology of the obtained nanowhiskers. Although CNW extracted from vegetal resources typically have length of $100-300 \mathrm{~nm}$ and a width of $5-20 \mathrm{~nm}^{4,5}$ those obtained from bacterial cellulose ( $\mathrm{BCNW}$ ) may have several micrometers in length and a width of $5-50 \mathrm{~nm}^{6.7}$

Because of their fully degradable and renewable character and good mechanical properties, the use of $\mathrm{CNW}$ as reinforcing fillers for polymeric matrixes has grown considerably. Plant-derived CNW have been incotporated into a wide variety of materials specifically biopolymers such as poly(lactic acid) (PLA), poly(3-hydroxybutyrate-co-3-hydroxyvalerate), ${ }^{10}$ starch, ${ }^{11}$ and cellulose acetate butyrate. ${ }^{12}$ Solution casting has been the most widely used technique for the incorporation of CNW. Neverthe less, very few reports exist on the production of nanocomposite reinforced with $\mathrm{CNW}$ via conventional industrial thermoplastic processing techniques, such as melt-compounding methods. When aiming at the development of nanocomposite materials through melt compounding, one of the main issues is to achieve a good dispersion of the nanofiller within the matrix An attempt to prepare nanocomposites of PLA reinforced with CNW by pumping a suspension of $\mathrm{CNW}$ in DMAClLiCl into the polymer melt during the extrusion process was reported. ${ }^{13}$ Nevertheless. 


\section{Applied Polymer}

\section{Nanocomposites of Ethylene Vinyl Alcohol Copolymer with Thermally Resistant Cellulose Nanowhiskers by Melt Compounding (II): Water Barrier and Mechanical Properties}

Marta Martínez-Sanz, Amparo Lopez-Rubio, Jose M. Lagaron

Novel Materials and Nanotechnology Group, IATA, CSIC, Av. Agustín Escardino 7, 46980 Paterna (Valencia), Spain

Correspondence to: J. M. Lagaron (E-mail: lagaron@iata.csic.es)

ABSTRACT: In the present work, the crystallinity and crystalline morphology, thermal stability, water barrier, and mechanical properties of ethylene vinyl alcohol copolymer (EVOH) nanocomposites prepared by melt compounding and incorporating both plant (CNW) and bacterial cellulose nanowhiskers (BCNW) are reported. An improvement in the water barrier performance was observed, that is, $67 \%$ permeability drop, only for the microcomposite sample incorporating $2 \mathrm{wt} \%$ of bacterial cellulose fibrils. No significant differences in the water-barrier properties of the nanocomposites generated through the two studied preincorporation methods were observed despite the fact that an excellent dispersion was observed in the previous study. On the other hand, direct melt-mixing of the freeze-dried nanofiller with EVOH resulted in increased water permeation. The aggregation of the filler in the latter nanocomposite was also ascribed to the detrimental effect on the mechanical properties. Interestingly, by using the precipitation method, an increase in the elastic modulus and tensile strength of $\sim 36$ and $22 \%$, respectively, was observed for a $3 \mathrm{wt} 9 \%$ BCNW loading, which was thought to coincide with the percolation threshold, O 2012 Wiley Periodicals Inc, J. Appl. Palym. Sci. 128: 2197-2207, 2013

KEYWORDS: biomaterials; cellulose and other wood products; biopolymers and renewable polymers

Received 14 June 2012; accepted 3 August 2012; published online 21 August 2012 DOI: $10.1002 /$ app.38432

\section{INTRODUCTION}

Ethylene vinyl alcohol copolymers (EVOH) are random semicrystalline materials with excellent gas-barrier properties to oxy gen and organic compounds, considerable chemical resistance and high transparency. ${ }^{1}$ An important application of these materials is as barrier layer in multilayer structures to be used in various packaging designs for foodstuffs. The presence of EVOH in the packaging structure is key to food quality and safety, because it reduces the ingress of oxygen and the loss of aroma components during extended packaging shelf-life. However, in high-relative humidity conditions, the EVOH gas barrier and mechanical properties are significantly deteriorated. ${ }^{2,3}$ This deterioration is thought to derive from the fact that the interand intramolecular hydrogen bonding (so-called self-association) provided by the hydroxyl groups is intercepted by water molecules. This interaction strongly reduces interchain cohesion and mechanical integrity and increments the fractional free volume of the polymer (plasticization effect) for the permeants to travel across polymer packages. Therefore, EVOH is commonly found as an intermediate layer in co-extruded multilayer structures protected by, at least, two layers of hydrophobic materials such as polyolefins.
An alternative for enhancing EVOH water-barrier performance has been the development of EVOH nanocomposites incorporating low amounts of different nanoclays such as modified montmorillonite ${ }^{4,5}$ and kaolin ${ }^{6}$ by using the melt-compounding technique. The incorporation of microfibrillated cellulose (MFC) into $\mathrm{EVOH}$ by the solution-casting technique has also been investigated. ${ }^{7}$ In this latter case, a decrease in the waterbarrier properties of the films was observed when incorporating MFC. This detrimental effect was ascribed to decreased crystallinity of the matrix and probably also to the hydrophilic character of MFC.

Cellulose nanowhiskers: (CNW) have proven to efficiently enhance the barrier properties of polymeric matrixes such as polylactic acid (PLA) ${ }^{8}$ and carrageenan ${ }^{9}$ when incorporated by means of solution casting. In the case of PLA, improvements of $\sim 82$ and $90 \%$ in the water and oxygen permeability, respectively, were reported for 3 wt $\%$ CNW loadings. For the same CNW loading, a water permeability drop of $\sim 70 \%$ was observed in the carrageenan nanocomposites. In both cases, a high-dispersion level of the CNW across the matrix was a crucial factor for obtaining such outstanding improvements on the barrier properties. Unfortunately, achieving such a good 


\author{
Date: Apr 29, 2013 \\ To: "Syed Imam" imamsh@msn.com,syed.imam@ars.usda.gov \\ From: "European Polymer Journal" europol@elsevier.com \\ Subject: Your Submission
}

Ms. Ref. No.: EUROPOL-D-13-00093R1

Title: Incorporation of poly(glycidylmethacrylate) grafted bacterial cellulose nanowhiskers in poly(lactic acid) nanocomposites: improved barrier and mechanical properties

European Polymer Journal

Dear Dr. Imam,

I am pleased to confirm that your paper "Incorporation of poly(glycidylmethacrylate) grafted bacterial cellulose nanowhiskers in poly(lactic acid) nanocomposites: improved barrier and mechanical properties" has been accepted for publication in European Polymer Journal.

Thank you for submitting your work to this journal.

With kind regards,

Julius G. Vancso, Ph.D.

Editor

European Polymer Journal 